International Perspectives on Aging 19

Series Editors: Jason L. Powell, Sheying Chen

Liat Ayalon · Clemens Tesch-Römer

Editors

Contemporary

Perspectives on

Ageism

Springer Open 


\title{
International Perspectives on Aging
}

\author{
Volume 19
}

\section{Series editors}

Jason L. Powell

University of Lancashire, Preston, Lancashire, UK

Sheying Chen

Pace University, New York, New York, USA 
The study of aging is continuing to increase rapidly across multiple disciplines. This wide-ranging series on International Perspectives on Aging provides readers with much-needed comprehensive texts and critical perspectives on the latest research, policy, and practical developments. Both aging and globalization have become a reality of our times, yet a systematic effort of a global magnitude to address aging is yet to be seen. The series bridges the gaps in the literature and provides cuttingedge debate on new and traditional areas of comparative aging, all from an international perspective. More specifically, this book series on International Perspectives on Aging puts the spotlight on international and comparative studies of aging.

More information about this series at http://www.springer.com/series/8818 
Liat Ayalon - Clemens Tesch-Römer Editors

\section{Contemporary Perspectives on Ageism}

照 Springer Open 


\section{Editors}

Liat Ayalon

Louis and Gabi Weisfeld

School of Social Work

Bar Ilan University

Ramat Gan, Israel

\author{
Clemens Tesch-Römer \\ German Centre of Gerontology \\ Berlin, Germany
}

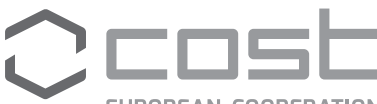 EUROPEAN COOPERATION IN SCIENCE \& TECHNOLOGY

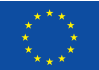 \\ Funded by the Horizon 2020 Framework Programme of the European Union}

This publication is based upon work from COST Action IS1402, supported by COST (European Cooperation in Science and Technology).

COST is a funding agency for research and innovation networks. Our Actions help connect research initiatives across Europe and enable scientists to grow their ideas by sharing them with their peers. This boosts their research, career and innovation. www.cost.eu

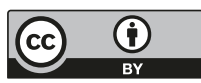

ISSN 2197-5841 International Perspectives on Aging ISBN 978-3-319-73819-2 https://doi.org/10.1007/978-3-319-73820-8

ISSN 2197-585X (electronic)

Library of Congress Control Number: 2018935295

(C) The Editor(s) (if applicable) and The Author(s) 2018, corrected publication 2018. This book is published open access.

Open Access This book is licensed under the terms of the Creative Commons Attribution 4.0 International License (http://creativecommons.org/licenses/by/4.0/), which permits use, sharing, adaptation, distribution and reproduction in any medium or format, as long as you give appropriate credit to the original author(s) and the source, provide a link to the Creative Commons license and indicate if changes were made.

The images or other third party material in this book are included in the book's Creative Commons license, unless indicated otherwise in a credit line to the material. If material is not included in the book's Creative Commons license and your intended use is not permitted by statutory regulation or exceeds the permitted use, you will need to obtain permission directly from the copyright holder.

The use of general descriptive names, registered names, trademarks, service marks, etc. in this publication does not imply, even in the absence of a specific statement, that such names are exempt from the relevant protective laws and regulations and therefore free for general use.

The publisher, the authors and the editors are safe to assume that the advice and information in this book are believed to be true and accurate at the date of publication. Neither the publisher nor the authors or the editors give a warranty, express or implied, with respect to the material contained herein or for any errors or omissions that may have been made. The publisher remains neutral with regard to jurisdictional claims in published maps and institutional affiliations.

Printed on acid-free paper

This Springer imprint is published by the registered company Springer International Publishing AG part of Springer Nature.

The registered company address is: Gewerbestrasse 11, 6330 Cham, Switzerland 


\section{Acknowledgements}

Ageism is a social construct of old age that portrays ageing and older people in a stereotypical, often negative, way. We are convinced that ageism is harmful both to the individuals affected and to society as a whole. Hence, this book provides a thorough overview of insights into the origins of ageism and descriptions of the manifestations and consequences of ageism in different domains and also presents interventions which might curtail and reduce ageism.

This book is the collaborative result of a COST Action entitled "Ageism: A Multinational, Interdisciplinary Perspective" (IS1402). COST is an EU-funded programme that enables researchers like us to set up interdisciplinary research networks in Europe and beyond. We were lucky enough to secure funding for a 4-year research network on the topic of ageism. Among the stated goals of our network was the creation of a common language to allow researchers from various countries, disciplines and sectors to work together in the field of ageism. We aimed for the enhancement of knowledge, the integration of different disciplines and the development of a new generation of researchers in the field of ageism.

The researchers in our network come from 35 countries and represent a highly diverse group of established and early-stage researchers as well as policymakers. As a result, this book is a multidisciplinary, cross-national product of researchers in the fields of psychology, sociology, social work, health, nursing, law, policy, economy, demography, pharmacy, occupational therapy, communication studies, gender studies and labour studies - all working on the topic of ageism.

We are grateful that COST has given us the opportunity to collaborate with excellent colleagues from all over the world. We have learned a lot in this process, and we hope readers will find this book both useful and inspiring.

Tel Aviv, Israel

Liat Ayalon

Berlin, Germany

Clemens Tesch-Römer

August 2017 


\section{Contents}

1 Introduction to the Section: Ageism-Concept and Origins Liat Ayalon and Clemens Tesch-Römer

2 Ageism: The Relationship between Age Stereotypes and Age Discrimination

Peggy Voss, Ehud Bodner, and Klaus Rothermund

3 Multiple Marginalizations Based on Age: Gendered

Ageism and Beyond....

Clary Krekula, Pirjo Nikander, and Monika Wilińska

4 Origins of Ageism at the Individual Level

Sagit Lev, Susanne Wurm, and Liat Ayalon

5 Work Environment and the Origin of Ageism

Laura Naegele, Wouter De Tavernier, and Moritz Hess

6 Ageism and Age Discrimination in the Labour Market:

A Macrostructural Perspective

Justyna Stypińska and Pirjo Nikander

7 Introduction to the Section: On the Manifestations and Consequences of Ageism

Liat Ayalon and Clemens Tesch-Römer

8 Ageism in the Third Age

Angela Kydd, Anne Fleming, Sue Gardner, and Trish Hafford-Letchfield

9 Pathways from Ageism to Loneliness.

Sharon Shiovitz-Ezra, Jonathan Shemesh, and Mary McDonnell/Naughton 
10 Ageism and Sexuality ............................................................... 149

Ateret Gewirtz-Meydan, Trish Hafford-Letchfield, Yael Benyamini, Amanda Phelan, Jeanne Jackson, and Liat Ayalon

11 Visual Ageism in the Media

Eugène Loos and Loredana Ivan

12 Ageism and Older Immigrants

Pnina Dolberg, Sigurveig H. Sigurðardóttir, and Ursula Trummer

13 Ageism in the Health Care System: Providers, Patients, and Systems

Mary F. Wyman, Sharon Shiovitz-Ezra, and Jürgen Bengel

14 Ageism in Medication Use in Older Patients

Daniela Fialová, Ingrid Kummer, Margita Držaić,

and Marcel Leppée

15 Ageism in Mental Health Assessment and Treatment

of Older Adults

Ehud Bodner, Yuval Palgi, and Mary F. Wyman

16 Ageism and Dementia.

Simon Chester Evans

17 Ageism and Neuropsychological Tests

Boaz M. Ben-David, Gali Malkin, and Hadas Erel

18 Introduction to the Section: Against Ageism 299

Liat Ayalon and Clemens Tesch-Römer

19 Ageism and Anti-Ageism in the Legal System:

A Review of Key Themes

Israel (Issi) Doron, Ann Numhauser-Henning, Benny Spanier,

Nena Georgantzi, and Eugenio Mantovani

20 The Council of Europe's Approach towards Ageism

Barbara Mikołajczyk

21 The European Union's Approach towards Ageism

Nena Georgantzi

22 Ageism and the Rights of Older People

Annika Taghizadeh Larsson and Håkan Jönson

23 Educational Methods Using Intergenerational

Interaction to Fight Ageism.

María del Carmen Requena, Hannah J. Swift, Laura Naegele,

Marc Zwamborn, Susan Metz, Wilco P. H. Bosems,

and Joost van Hoof 
24 Introduction to the Section: Researching Ageism ........................ 403 Liat Ayalon and Clemens Tesch-Römer

25 Normative, Empiricist, and Interpretive Considerations in the Ageism Research Process Fredrik Snellman

26 Ageism in a Cross-Cultural Perspective: Reflections from the Research Field

Monika Wilińska, Astrid de Hontheim, and Els-Marie Anbäcken

27 Agisem in the European Region: Finding from the European Social Survey Hannah J. Swift, Dominic Abrams, Sibila Marques, ChristinMelanie Vauclair, Christopher Bratt, and Maria-Luisa Lima

28 Measures of Ageism in the Labour Market in International Social Studies

Liili Abuladze and Jolanta Perek-Białas

29 Researching Ageism in Health-Care and Long Term Care 493 Sandra C. Buttigieg, Stefania Ilinca, José M. S. de Sao Jose, and Annika Taghizadeh Larsson

30 Children's Attitudes toward Older People: Current and Future Directions

Joana Mendonça, Sibila Marques, and Dominic Abrams

31 Researching Ageism through Discourse Amanda Phelan 


\section{About the Authors}

Dominic Abrams PhD, is professor of social psychology and director of the Centre for the Study of Group Processes at the University of Kent. His research focuses on the psychological dynamics of social exclusion and inclusion within and between groups. He is codirector and founder of the European Research Group on Attitudes to Age, which designed the European Social Survey Round 4 module on experiences and expressions of ageism, (http://www.eurage.com). He is coeditor with Michael A. Hogg of the journal Group Processes \& Intergroup Relations and (with Melanie Killen) of the Journal of Social Issues (2014) special issue on social exclusion and children. He is a past president of SPSSI, fellow of the Academy of Social Sciences and vice president of the British Academy.

Liili Abuladze MSc, is a $\mathrm{PhD}$ researcher in demography and a project manager at the Estonian Institute for Population Studies, Tallinn University. Her PhD research focuses on population ageing and its consequences in Estonia and other European countries. She is a national representative at the Academic Network of Experts on Disability (ANED). She has previously attended a research master programme in population studies at the University of Groningen, the Netherlands, and the European Doctoral School of Demography.

Els-Marie Anbäcken has been an associate professor in social work at Mälardalen University (Sweden) since 2014. She was born and brought up in Japan, which continuously influences her life and research. After the PhD thesis (1997), "an ethnography focusing on filial duty and eldercare in the Japanese society", she has continued with research on later life, in both explicitly and implicitly comparative studies. From 2000 to 2008 and 2012 to 2014, she belonged to the Faculty of Social and Welfare Studies at Linköping University. In 2006 (-2011), she became the coordinator of the Swedish-Japanese research network on ageing and care. In 2008 she moved to Japan for a full-time professorship at Kwansei Gakuin University, School of Human Welfare Studies, where she did 4 years of teaching and researching in gerontology, end-of-life care and international social work. She continued to deepen these research profiles, focusing on existential needs in later life as well as 
transnational issues. In a globalising world, the ageing experience in many ways transcends national borders, which is crucial to gerontological social work.

Liat Ayalon received her $\mathrm{PhD}$ in clinical psychology from the Illinois Institute of Technology. She did her internship and postdoctoral training at the University of California, San Francisco. She is currently a full professor in the School of Social Work at Bar-Ilan University. She is currently focused on three major lines of research: ageism, discrimination based on age; the intersection between formal and informal care; and social networks of older adults. Her work has been funded by the German Israel Foundation, the Israel Science Foundation, the National Insurance Institute of Israel, the Israel National Institute for Health Policy Research and the Israel Ministry of Health. She is currently the chair of a COST Action on ageism (IS1402) and the chair of a Marie Curie Innovative Training Network on ageism (EuroAgeism), both funded by the EU. She is also a member of the WHO core group to combat ageism.

Boaz M. Ben-David PhD, is an assistant professor at the Baruch Ivcher School of Psychology in the Interdisciplinary Center (IDC) Herzliya, where he heads the Communication, Aging and Neuropsychology lab (CANlab). Dr. Ben-David completed his $\mathrm{PhD}$ in cognitive psychology at Tel Aviv University. He was a postdoctoral fellow at the University of Toronto and later a scientist at the Toronto Rehabilitation Institute. He currently holds adjunct faculty positions at the University of Toronto (Department of Speech-Language Pathology) and at the Toronto Rehabilitation Institute (University Health Networks). His research interests include the premise that reductions in the quality of the sensory input in older age will result in less efficient cognitive functioning, specifically when communicating in adverse environments (such as a noisy restaurant or a badly lit room); the complex interplay that governs the perception of emotions in spoken language in unique populations; speech perception in adverse conditions in ageing and for second language speakers; and promoting better and more valid ways to test cognitive abilities in older age and other special populations.

Jürgen Bengel is professor and chair of rehabilitation psychology and psychotherapy at the University of Freiburg, Germany. He received his doctoral degree in psychology in 1986 and in medicine in 1987. Dr. Bengel's research focuses on psychological distress in patients with chronic somatic diseases, and he conducts health services research in psychotherapy, psychiatric diagnosis, coping, rehabilitation psychology and health psychology. He is head of the Rehabilitation Multidisciplinary Research Network, head of the Center for Methodology Support and head of the Psychotherapy Outpatient Treatment Center in the Department of Psychology.

Yael Benyamini $\mathrm{PhD}$, attained her bachelor's degree in psychology and biology and her master's degree in social psychology at Hebrew University in Jerusalem and her $\mathrm{PhD}$ in health and social psychology at Rutgers University. She is currently a 
professor at the Bob Shapell School of Social Work, Tel Aviv University. She is an elected honorary fellow of the European Health Psychology Society. She has published numerous articles and chapters and has recently coedited the book Assessment in Health Psychology. Her research focuses on self-regulation in chronic diseases and ageing, women's health issues and health promotion. Her main focus is on subjective perceptions of health, ageing and illness and their effects on coping with health threats and ultimately on the psychological and physical outcomes. Her studies provided evidence for the intricate ways in which one's subjective perceptions of health, age and ageing are interrelated.

Ehud Bodner $\mathrm{PhD}$, received his bachelor's degree in psychology and criminology as well as his PhD in psychology at Bar-Ilan University in Ramat Gan and his master's degree in clinical psychology at Tel Aviv University. He served as the head of the research branch in the Mental Health Department of the Israel Defense Forces. $\mathrm{He}$ is currently an associate professor at the Interdisciplinary Department of Social Sciences and the Music Department at Bar-Ilan University and an active clinical and medical psychologist. His research is currently focused on ageism and ageing and dying perceptions and on emotional complexity and emotion recognition and regulation through music in adulthood and in old age. His studies in the field of gerontology provide evidence for the intricate connections between age, ageing and death perceptions, emotion regulation and mental health aspects.

Wilco P. H. Bosems earned his MSc in psychology and bachelor in applied gerontology at Fontys University of Applied Sciences in Eindhoven. He works as a lecturer at the same university and coordinates the project "Seniors in Class" that facilitates several departments in participation of older people in relevant bachelor programmes and the minor "Healthcare and Technology".

Christopher Bratt Ph.D., is Honorary Research Fellow at the School of Psychology, University of Kent. His research focuses on various aspects of intergroup relations, with a particular interest for predictors of social discrimination and mental health in an intergroup context.

Sandra C. Buttigieg MD (University of Malta), PhD (Aston University, Birmingham, UK), FFPH (UK), MSc (University of Malta), MBA (University of Malta), is associate professor and head of the Department of Health Services Management, Faculty of Health Sciences at the University of Malta. She is also a consultant in public health medicine at Mater Dei Hospital, Malta. Prior to this post, Prof. Buttigieg also held the position of medical superintendent of a 1000-bed geriatric hospital in Malta. She lectures in health services management, public health, family medicine and management. Her research is mainly in health management in the areas of performance management, organisational behaviour, operations management and research and public health. She is currently on the Editorial Boards of Frontiers in Public Health, the International Journal of Human Resource Management, Journal of Health Organization and Management and the Journal of 
Geriatrics and Gerontology Research. She is currently a national delegate for Malta in a COST Action on ageism (IS1402).

José M. S. de Sao Jose has PhD in sociology. He is currently an assistant professor in the Faculty of Economics at the University of Algarve (Portugal) and a researcher in the Research Centre for Spatial and Organizational Dynamics (University of Algarve). He has researched on social care for older people, exploring themes such as reconciliation between work and care and experiences of providing family care and preserving dignity in later life. His research has been funded by the Portuguese Foundation for Science and Technology and by the European Commission. He is currently interested in the following research topics: ageism, active and healthy ageing and sexuality in later life. He is currently a national delegate in a COST Action on ageism (IS1402) and a member of the Iberoamerican Research Network on Ageing and Society (Red Iberoamericana Interdisciplinar de Investigación en Envejecimiento y Sociedad). He is also a member of the Observatory of Families and Family Policies (Institute of Social Sciences, University of Lisbon).

Wouter De Tavernier $\mathrm{PhD}$, is a postdoctoral researcher at the Centre for Comparative Welfare Studies, Aalborg University. He works on issues of social policy and social gerontology, particularly on issues of older workers, retirement, pensions and eldercare. His $\mathrm{PhD}$, awarded by Aalborg University, particularly focused on the role of the family in social policy for older individuals. Before, he was a research assistant at the Centre for Sociological Research, University of Leuven, researching pension protection in Belgium. He also holds an MA in sociology and an MSc in social policy analysis from the University of Leuven.

Pnina Dolberg $\mathrm{PhD}$, is a researcher in the fields of immigration and older age. She obtained her PhD in social work at Ben-Gurion University of the Negev and was a postdoctoral fellow at Louis and Gabi Weisfeld School of Social Work at Bar-Ilan University. Her published work concerns phenomenology of middle-aged and older immigrants, mental health among immigrants, policy concerning older immigrants and phenomenology of middle age.

Israel (Issi) Doron LLB (Hebrew University of Jerusalem, Israel), LLM (Washington College of Law, Washington DC, USA), PhD (Osgoode Hall Law School, Toronto, ON., Canada), is the head of the Center for Research and Study of Aging at the University of Haifa and the past president of the Israeli Gerontological Society. He specialises in the fields of law and ageing, social policy and ageing, human rights and ageism. Professor Doron has written extensively on topics such as law and ageing and human rights of older persons (e.g. Doron, I. \& Apter, I. (2010): The Debate Around the Need for an International Convention on the Rights of Older Persons. The Gerontologist, 50(5), 586-593) and is the editor of key books in the field such as Theories on Law and Ageing: The Jurisprudence of Elder Law (Springer, 2009) and Beyond Elder Law: New Directions in Law and Aging (Springer, 2012; with Ann Soden). Finally, Prof. Doron is also the founder of an 
Israeli NGO, "The Law in the Service of the Elderly", which was involved in key strategic litigation regarding rights of older persons in Israel.

Margita Držaić MPharm, univ. mag. phar. of clinical pharmacy, attained her master's degree in pharmacy at the Faculty of Pharmacy and Biochemistry, University of Zagreb, Croatia. In 2017 she has finished postgraduate specialist study in clinical pharmacy at the same faculty. Currently, she is working as a community pharmacist at Zagreb City Pharmacies, Zagreb, Croatia. She is a member of Croatian Chamber of Pharmacists and an active member of Croatian Pharmaceutical Society (Executive Committee member of Section for Community Pharmacy). Also, she is mentor for trainees and students accredited by the Croatian Chamber of Pharmacists. She cooperates with the Centre for Applied Pharmacy at the Faculty of Pharmacy and Biochemistry, University of Zagreb, on the project "Development of Community Pharmacists' Competencies". Her professional and scientific interests are in the field of clinical pharmacy, development of pharmacists' competencies and medication use safety, especially in the use of potentially inappropriate medication (PIM) in older adults.

Hadas Erel $\mathrm{PhD}$, is a research associate at the Communication, Aging and Neuropsychology lab (CANlab) at the Baruch Ivcher School of Psychology in the Interdisciplinary Center (IDC) Herzliya. Dr. Erel completed her PhD in cognitive psychology at Ben-Gurion University. Her research interests include the influence of the quality of sensory information on cognitive performance, fluid intelligence training in ageing and visual attention and ageing.

Simon Chester Evans $\mathrm{PhD}$, is a principal research fellow and head of research with the Association for Dementia Studies at the University of Worcester, UK. Simon has developed a substantial portfolio of research projects and publications that span a wide range of topics including housing, health, social care, the arts, assistive technology, care homes and communities. His role includes applying for research funding, managing a team of researchers and ensuring that research findings are disseminated to key audiences. Recent research projects include an international evaluation of the Meeting Centres Support Programme for people with dementia and family carers and an exploration of the ability of extra care housing to respond to changing care needs. Simon is part of TanDEm, a Doctoral Training Centre run in partnership with the Centre for Dementia, University of Nottingham, and funded by the Alzheimer's Society. He is a fellow of the National Institute for Health Research School for Social Care Research and a member of the British Society of Gerontology and the ESRC Peer Review College.

Daniela Fialová received her PharmD and $\mathrm{PhD}$ degrees from Charles University in Prague, Faculty of Pharmacy (2006), and the Ward Certification in Clinical Pharmacy at the Institute for Postgraduate Training in Healthcare, Prague, Czech Republic (2001). She has been the head of the University Educational Centre in Clinical Pharmacy, Charles University (since 2014), and researcher and 
academician at the Department of Geriatrics and Gerontology, First Faculty of Medicine and Department of Social and Clinical Pharmacy, Faculty of Pharmacy, Charles University (since 2003). As an expert in medication safety and inappropriate prescribing in older patients, she participated in EU projects, ADHOC (AgeD in Home Care, 5th FP, 2001-2005) and SHELTER (Services and Health in the Elderly in Long-Term Care, 7th FP, 2009-2014), and now is involved in the EU project EUROAGEISM (2017-2021, MCSF-INT, Horizon 2020). She is an invited fellow of the interRAI research corporation; chair of the scientific subgroup "Aging and Changes in the Therapeutic Value of Medications in the Aged" that develops research works in inappropriate prescribing in older patients in Eastern and Central Europe; chair of the WG1b subgroup "Healthy Clinical Strategies for Healthy Ageing" of the EU COST Action IS1402; board member of the Section of Clinical Pharmacy, Czech Pharmaceutical Society and Czech Medical Association J.E. Purkyně; and board member of the European Society of Clinical Pharmacy Research Committee. Her professional interests include clinical pharmacy in geriatrics, evaluation of the medication efficacy and safety in older patients, changes (pharmacological, physiological) accompanying ageing, risk management in pharmacotherapy and analyses of polypharmacy and inappropriate prescribing in the old age. She received several awards for her professional work, e.g. French Award in Pharmacy, Scientific Award of the Czech Medical Society J.E. Purkyně and Scientific Award of Dr. Paul Janssen for Pharmacoeconomics and Drug Policy.

Anne Fleming has $\mathrm{PhD}$ in nursing and was qualified as an occupational therapist in 1983 from Queen Margaret College, Edinburgh. While working in the NHS, she completed her master's degree in inclusive environments at the University of Reading. Her doctoral dissertation explored stakeholder perceptions of homeliness in care homes for older people at the University of the West of Scotland. She is interested in two strands of research: project work in which the end user of services or products is involved in the creation, evaluation or redesign of the service or product and projects designed to improve practice and service delivery.

Sue Gardner has MPhil in clinical psychology and undertook a first degree in psychology in London and completed her clinical training in Glasgow. She has worked, taught and supervised in clinical services for 40 years as a practitioner psychologist and as a service manager. She held various positions in the British Psychological Society from 1985 to 2011 including chairing the Division of Clinical Psychology, the Professional Practice Board and the Ethics Committee and was president in 2009/2010. She worked as clinical manager for Specialist Psychological Services for Adults and Older Adults in Oxfordshire prior to her retirement. Her clinical specialisms as a consultant clinical psychologist were addictions, complex needs, the impact of organisational change on service users and staff and the provision of care. She now works as an independent consultant and lecturer. 
Nena Georgantzi has MA in human rights and European social protection. She is a trained lawyer specialising in human rights (Université de Strasbourg, France) and social protection (KU Leuven, Belgium). Nena Georgantzi has been working since 2010 for AGE Platform Europe (AGE), the European network of organisations that represent over 40 million older people in the continent. Since 2014, Nena has been also doing a PhD on human rights of older persons at the National University of Ireland in Galway. Her professional experience includes policy analysis, project coordination and strategic implementation in the NGO sector. She is currently in charge of the organisation's policy and advocacy work in relation to non-discrimination and human rights of older persons. She has previously been involved in a large number of EU research projects in the field of ageing and contributed with legal expertise to various EU dossiers. She participated in the Council of Europe drafting group, which finalised in 2013 a recommendation on older people's rights. She has spoken on various occasions on the rights of older people, including in the frame of the UN Open-Ended Working Group on Ageing. She has represented AGE in the Fundamental Rights Platform, the Global Alliance for the Rights of Older People and various expert groups on the rights of older people.

Ateret Gewirtz-Meydan MSW, is a PhD candidate in the School of Social Work, Bar-Ilan University, and was awarded a Full Presidential Scholarship for excellence for her dissertation. Her dissertation focused on sexual and relationship satisfaction among community couples. Currently, Ateret is a member of The Aging Research Lab (headed by Prof. Liat Ayalon) where she is involved in research projects regarding sexuality and romantic relationships in later life. In clinical practice, Ateret specialises as a sex therapist in the Sex and Couples Therapy Unit in Meir Medical Center.

Trish Hafford-Letchfield EdD, MA, is professor of social care at the School of Health and Education, Middlesex University, London, UK. Trish is a qualified nurse and social worker and had a long career in social work (1985-2003) including 10 years of managing statutory social care and supported housing for older people. Her research interests are very diverse. She has a long history of pedagogical research in interprofessional learning where she has led many local and national initiatives which co-produce learning with older people and students. Trish engages with the arts and humanities to enrich her teaching, practice and research. Her main research interests are in educational gerontology and the quality of social care, leadership and management and organisational development and LGBTQI issues in ageing and social work. Trish is co-chair and founder member of an international network of professionals interested in sexuality and social work. Recent research includes a national study on mental health hate crime, transgender students in higher education, the experiences of care workers in relation to older people's self-harm and suicide and organisational responses to disabled employees in the National Health Service. 
Moritz Hess has $\mathrm{PhD}$ in sociology. He is a researcher and project coordinator at the Institute of Gerontology at the TU Dortmund University. He received his $\mathrm{PhD}$ at Mannheim University and his MA in sociology from the Free University Berlin. He furthermore holds an MSc in gerontology from the Free University Amsterdam. His research foci are comparative welfare state analysis, the generational conflict and pension policies. His work has been published in several journal articles and book chapters. In addition, he edited a book on the policy shift towards active ageing. He has won research awards from the German Society of Gerontology and Geriatrics, the UN and the Intergenerational Foundation.

Astrid de Hontheim Ph.D. in Anthropology (2007), was at fieldworks in West Papua, remote Oceania, SE Asia, and central Africa. She is currently lecturing in Belgium, formerly in Canada (UOttawa). Her research is focused on traditional healers (Papua, Uganda, Belgium), missionaries strategies among forest people, invisible content of the Oceanic artifact, rituals related to disasters and misfortune, and Western chamanism (drum, ayahuasca) with self-involvement. She is also a yoga instructor focused on energy (prânâ) channeling.

Stefania Ilinca $\mathrm{PhD}$, is researcher and policy analyst in the Health and Care Unit of the European Centre for Social Welfare Policy and Research (UN affiliated) where she is primarily working on projects related to chronic diseases, long-term care and equity in access to care. She holds a PhD in health economics, with a specialisation in frailty and multimorbidity in older age and care integration in developed health systems. She has extensive experience working in large international research projects with comparative and interdisciplinary focus as well as with both quantitative and qualitative research methods. Her publications include numerous peer-reviewed book sections and policy-oriented contributions on topics in the fields of health economics, health and long-term care policy and public health.

Loredana Ivan has $\mathrm{PhD}$ in sociology. She is associate professor at the National University of Political Studies and Public Administration (SNSPA), Communication Department, Bucharest, Romania. She is teaching topics related to interpersonal communication and interpersonal communication mediated by technologies. She is part of the Ageing Communication Technologies project (http://actproject.ca/) based in Canada and co-applicant of ACT project research grant. She is also part of the COST Action IS1402 "Ageism: A Multinational, Interdisciplinary Perspective". Loredana Ivan was a Marie Curie scholar (2003-2004) at the University of Groningen, Interuniversity Center for Methodology (ICS), and a visiting researcher at Humboldt University from Berlin, Department of Social and Organizational Psychology (2012-2013). She is the author of Cele mai importante 20 de secunde (The Most Important 20 Seconds, 2009) and coeditor of two other books in nonverbal communication area. 
Jeanne Jackson has $\mathrm{PhD}$ in occupational science. She is professor at University College Cork where she holds the positions of head of the School of Clinical Therapies and head of the Department of Occupational Science and Occupational Therapy. Previously, she was an associate professor at the University of Southern California where she co-authored the Well Elderly Lifestyle Redesign ${ }^{\circledR}$ Program and was involved in various nationally funded research studies addressing health and wellness among older adults. Her current research interests include understanding how diverse groups of people or individuals who may not fit within the particular social, historical and political constraints of their communities create meaningful lives. Specifically, she focuses on the challenges that heterosexism, disablism and ageism play in people's daily lives. She is a fellow of the American Occupational Therapy Association and on the editorial board of Journal of Occupational Science.

Håkan Jönson $\mathrm{PhD}$, is professor at the School of Social Work, Lund University, where he is also the director of studies at the PhD programme. He heads the Lundbased research group "Care for Older People: Conditions and Everyday Realities" and the "The National Network for Social Science Research on Ageing and Eldercare". His research has focused on images of ageing and older people, pensioners' organisations, crime and abuse as social problems for older people and nursing home scandals. He has published extensively on different aspects of ageism and has during later years devoted his main interest to different aspects of eldercare. He is currently responsible for the research project "Improving Everyday Conditions by Reconceptualising Elder Care Through the Lens of Disability Policies" that is funded by the Swedish Research Council for Health, Working Life and Welfare.

Clary Krekula has $\mathrm{PhD}$ in sociology. She is an associate professor in sociology at Karlstad University. Krekula's thesis from 2006 problematised embodied perspectives on women's ageing. In her subsequent research, she has looked at gendered ageing, age and gender in work organisations, age discrimination and dance among older adults, which has resulted in a number of books, chapters and articles. In several nationally and internationally funded research projects, she has emphasised issues of extended working life, and work and entrepreneurship in later life, and has shed light upon temporal sociological perspectives on age and ageing. She runs AgeS, the Swedish research network on age, where she focuses on developing critical age studies. She is a board member of COST Action 1409 on extended working life.

Ingrid Kummer univ. mag. phar. of clinical pharmacy, works as a community pharmacist at Zagreb City Pharmacies, Zagreb, Croatia. She received her degree in 2016. She is a member of Croatian Pharmaceutical Society, Executive Committee of Section for Community Pharmacy. She cooperates with the Centre for Applied Pharmacy at the Faculty of Pharmacy and Biochemistry, University of Zagreb, on the project "Development of Pharmacist' Competencies that Are Necessary in Daily Work in Public and Hospital Pharmacy", research in progress. Her interest focuses on potentially inappropriate medication use in older adults, pharmacy competencies and improving pharmacy services in community pharmacy. 
Angela Kydd has PhD in nursing. She is an associate professor in gerontology. Her clinical background involved nursing older people in acute care and working as a care home manager. Her interest is the oldest old. Her PhD was focused on the experiences of older people living in a care setting. She has written and taught on gerontology and dementia courses from workshops to leading a nurse specialist programme in gerontological nursing and a master's course in later life. She also teaches internationally and has led and partnered several Erasmus Intensive Programmes. She has led several funded projects, one of which involved the creation of bespoke philosophies of care underpinning practice development with staff in nursing homes, one on a seven-country project on attitudes to nurses who work with older people and one on teaching student nurses to interview older people on their experiences of health and social care. She has coedited a gerontology textbook and has over 50 publications. She is co-founder of the Ageing Research Network at Edinburgh Napier University.

Annika Taghizadeh Larsson $\mathrm{PhD}$, is a senior lecturer at the Division Ageing and Social Change at Linkoping University, Sweden. She received her doctorate in ageing and later life in 2009, with a dissertation on the meanings of "becoming old" for people who have lived with physical disabilities for all or most of their lives. Since then her research has mainly focused on questions and issues at the intersection of disability studies and social gerontology. Theoretically, her main interest concerns age norms and how such ideas about what is appropriate and normal at a certain age are applied in different contexts and by different actors. Between 2011 and 2016, she was linked to CDR (Center for Dementia Research), which was a large 6-year programme, led by Prof. L-C Hydén, with the ambition to conduct social scientific and humanistic research around persons living with dementia diseases. On 1 January 2015, she was part of the project "Improving Everyday Conditions by Reconceptualising Elder Care Through the Lense of Disability Policies", led by Prof. Håkan Jönson. She is actively involved as a MC member in the COST Action on ageism (IS1402).

Marcel Leppée $\mathrm{PhD}$, was born on 30 September 1951 in Zagreb, where he attended elementary school and high school. He graduated from the School of Medicine, University of Zagreb, in 1975. He finished postgraduate study in public health and epidemiology and also study in healthcare and information systems. In 1982 he passed the specialistic exam from social medicine and healthcare organisation. $\mathrm{He}$ completed his internship in Dom Zdravlja Željeznčara in Zagreb. He worked in a primary health centre in Rovinj in 1978, in the Croatian Institute of Public Health from 1979 to 1984 and in the Andrija Stampar Teaching Institute of Public Health in Zagreb in 1984. In 2002 he acquired a master of science from the Zagreb University Medical School and in 2003 became primarius. In 2009 he acquired a doctorate academic degree from the Faculty of Medicine University of Osijek. He is a member of Croatian Medical Chamber and Croatian Public Health Association. $\mathrm{He}$ is author of about 300 professional and scientific papers. 
Sagit Lev $\mathrm{PhD}$, is a researcher in the fields of old age, ethics and social work. Her studies deal with the ethical dilemmas and conflicts experienced by social workers that work in long-term care facilities for older adults, as well as the emotional ramifications of these experiences on the social workers. These studies have been conducted both qualitatively, by examining the social workers' conflicting obligations between the residents and organisations, and quantitatively, by exploring moral distress among social workers in long-term care facilities. As a part of the quantitative study, a unique questionnaire was developed and validated in order to assess moral distress among this population. In addition, cluster analysis was conducted in order to identify a typology of long-term care facility social workers, based on environmental and personal features and the association of these clusters with moral distress. Her fields of research also include ageism, deinstitutionalisation processes in services for older adults and the maltreatment of older adults in long-term care facilities.

Eugène Loos received his $\mathrm{PhD}$ in social sciences from Utrecht University in the Netherlands. He is a professor of "Old and New Media in an Ageing Society" in the Department of Communication Science at the University of Amsterdam and an associate professor of communication, policy and management studies at the Utrecht University School of Governance in the Netherlands. He is a member of ASCoR (Amsterdam School of Communication Research) [http://ascor.uva.nl/] and the Netherlands Institute of Government (NIG) [https://www.utwente.nl/en/nig/]. As a linguist, he has conducted research and written several books, book chapters and journal articles in the field of organisational (intercultural) communication and the use of new media. Currently, his research focuses on the role of old and new media related to accessible information for senior citizens, in order to guarantee their inclusion in our society. He investigates the (ir)relevance of age for (1) senior citizens' digital information search behaviour; (2) the impact of textual and visual signs in health information on their cognition, affection and behaviour; and (3) the use of digital (sport) games for their physical and social well-being. He is currently the co-chair of the WG Media of a COST Action on ageism (IS1402).

Maria Luisa Lima Ph.D., is Professor of social psychology at ISCTE University Institute of Lisbon. Her research focuses on the application of social psychological processes to health and environmental issues, in particular on the importance of social bonds and identities. She was President of the Portuguese Association of Psychology and is Honorary Professor at the University of Bath.

Gali Malkin PhD, is a postdoctoral fellow at the Baruch Ivcher School of Psychology in the Interdisciplinary Center (IDC) Herzliya. She received her PhD in social-organisational psychology from Bar-Ilan University. Prior to her PhD studies, she completed her BA degree at Ben-Gurion University and MA degree at BarIlan University. Her dissertation focused on the interactive role of social identity and threat, in predicting gender harassment behaviours. She is currently the research manager on the "SINAI" (Social Interaction in Aging Immigrants) research team, 
focusing on the study of ageing, health and well-being from a multidisciplinary perspective. She is also investigating the social outcomes of the intersection of age and migration.

Eugenio Mantovani LLM, works at the multidisciplinary Research Group on Law, Science, Technology \& Society (LSTS) at the Vrije Universiteit Brussel (VUB), where he is active in pursuing a number of research interests, including in areas such as data protection, privacy issues, and problems related to aging and human rights law. On one hand, his research focuses on privacy and data protection law, in particular in the area of health care delivery. In this area, Eugenio is interested in the use of patient data, in the applications of eHealth and mhealth technologies, and in the impact of technologies on vulnerable groups or groups with special needs. In this connection, Eugenio has developed specific expertise in e-aging and in other human body related questions raised by technology. On the other hand, Eugenio has been active in research into issues associated with aging and in particular about the human rights status of older persons. His Ph.D. research brings together these two research paths in an investigation of privacy and data protection law from the point of view of older persons in the digital age.

Sibila Marques $\mathrm{PhD}$, is an assistant professor in psychology at ISCTE - University Institute of Lisbon, Portugal. She is a member of the EURAGE research group, an international project investigating attitudes to age across Europe and in charge of the design of the ageism module in the European Social Survey. She has participated in several projects related with ageing (e.g. "Aging of People with Mental Disabilities", "Technology Experience Cafés", "imAGES: Intervention Program to Fight Ageism in Children") and supervised several master thesis related with this field. She has published a number of papers related with ageing in high-impact scientific journals since 2005. She is the author of the essay "Discrimination of older people" and a regular presence in the media regarding issues of ageing and ageism. She has participated in EQUAL initiative projects "FE-FORMEMPREGO" and "RUMO À QUALIDADE", and in 2011 she was a contributor to the FUTURAGE road map. From 2012 to 2016, she was the scientific coordinator in ISCTE-IUL of the FP7 European Project SIforAGE - Social Innovation for Active and Healthy Ageing.

Mary McDonnell/Naughton is a registered nurse and midwife and lecturer in the Department of Nursing and Health Care, Athlone Institute of Technology, Ireland. She received her doctorate from the College of Medicine, University College, Dublin, in 2007, with a thesis on the "Epidemiological Profile of Child Health in Ireland". Since 2010, she has been involved in research studies with the older person in collaboration with different disciplines, such as dementia and nutritional status, an examination of "social capital" and the older person in Ireland. Presently, she is involved in a review of rural transport and its importance for the older person in collaboration with a Local Link programme and the factors which have influenced the health and well-being of centenarians living in Ireland. She is also actively 
involved in developing educational programmes and supervises research in the area of disability. She is also a member of two COST actions, namely, ageism (IS1402) and "Reducing Old-Age Social Exclusion: Collaborations in Research and Policy, ROSEnet" (CA15122). As part of her work in socioeconomic engagement and external stakeholder partnership, she encourages a collaboration with the older person both in a voluntary and educational capacity. She is also actively involved in getting AIT recognised as an Age-Friendly University and is a member of Roscommon County Council Age-Friendly Alliance developing a strategy to enhance the quality of life for the older person in the region. Within AIT, she chairs the Research Ethics Committee and is a member of the National Ethics Committee on the National Forum for the Enhancement of Teaching and Learning in Higher Education.

Joana Mendonça holds a master's in social and organisational psychology from ISCTE - Lisbon University Institute. She was a member of the ISCTE team as partner of the European Project SIforAGE - Social Innovation for Active and Healthy Ageing - and has developed reports about ageing programmes and intervention programmes to fight ageism among children/adolescents and policies at national level and across several European countries. She is presently doing her $\mathrm{PhD}$ in the field of ageism aiming to further understand how ageism develops among children and how we can assess it in a proper and effective way.

Susan Metz MSc, holds a master's degree in health sciences. She works as a project manager with Summa Health Care of Summa College, a school for vocational education in Eindhoven, the Netherlands. She is the coordinator of the "Seniors in Class" project that supports the participation of older people in relevant programmes for vocational students of various departments.

Barbara Mikołajczyk is a professor at the Faculty of Law and Administration of the University of Silesia in Katowice, Poland, and the head of the Department of International Public Law and European Law. She has been involved in the COST Action on ageism (IS1402) and in works of the Polish Commissioner for Human Rights' Group of Experts on Older Persons. She is a member of the Odysseus Academic Network for Studies on Immigration Asylum in Europe. She was also appointed as the ad hoc judge in the European Court of Human Rights (2012-2014). She has authored books and articles dedicated to human rights of various categories of vulnerable persons, as migrant workers, asylum seekers, children, ethnic minorities, sexual minorities and older persons.

Laura Naegele MA, is a researcher, project manager and graduate student with the Department of "Ageing and Work" at the Institute for Gerontology at the University of Vechta, Germany. She holds a BA in media science and sociology from RuhrUniversität Bochum and an MA in sociology from the Free University of Berlin. Since receiving her degree in 2012, she has worked in multiple research and project management positions in Germany and Belgium. Her research focuses primarily on 
ageing workforces, extending working lives, competence development in smalland medium-sized enterprises and ageism at the workplace. Her work has been accepted for various conferences, workshops and summer schools at national, European and international levels and published in several scientific and applied journals and books.

Pirjo Nikander has $\mathrm{PhD}$ in social science. She is a research director of the Doctoral School and a member the Gerontology Research Centerin the University of Tampere, Finland. After completing her master's (in Finland) and her $\mathrm{PhD}$ in social science (as a member of the Discourse and Rhetoric Group in Loughborough University, UK), her academic experience and expertise comprise research in the areas of ageing, the workforce, interprofessional decision-making, meeting interaction and the baby-boom generation. She has always had a keen interest in qualitative research methodology, research ethics and evidence and research design. Nikander is the author of numerous articles and handbook chapters on discourse analysis, social constructionist epistemology and qualitative methodology, as well as the editor of books on women and ageing and interview research. Currently, she is PI for a research project engaged in utilising and developing qualitative longitudinal research methodology.

Ann Numhauser-Henning is professor at the Faculty of Law at Lund University, Sweden, and the former pro-vice-chancellor of the said university. She has been the head of the Norma Research Programme since 1996 and initiated the Norma Elder Law Research Environment in 2012. She has written widely on labour law, especially employment law and non-discrimination law. A more recent field of research is social security law in a European integration perspective.

Yuval Palgi $\mathrm{PhD}$, is a clinical psychologist, the head of the Department of Gerontology and past head of the Center for Research and Study of Aging in the University of Haifa, Israel. His research focuses on psychological aspects of ageing (as manifested by well-being, optimism and subjective perceptions of age or distance to death). He examines how psychological aspects of ageing enhance favourable psychological environment that regulates the effect of life adversities, posttraumatic reactions and ageing processes. He has published more than 100 papers and chapters in peer-reviewed journals and books.

Jolanta Perek-Bialas has PhD in economics. Since 2016 she has been adjunct professor at Jagiellonian University in Cracow (full time) and in the Warsaw School of Economics, Poland, as well. She is currently focused in her research on ageism and age discrimination in the labour market, reconciliation care and work and use of indicators in ageing research like active ageing index. She received the Leslie Kish Scholarship and participated in the Survey Sampling Programme at the University of Ann Arbor, in Michigan, USA. She coordinated and participated in many national and international projects funded by the Polish institutions, the European Commission, the Norwegian Research Council, the OECD, the UNECE and the 
World Bank and as well has been author/co-author of many publications on ageing, active ageing and ageism. She is the chair of Working Group on Ageism in the Labour Market of a COST Action on ageism (IS1402) and a Polish representative in the COST Action Reducing Old-Age Social Exclusion (CA15122). She is also a member of the Expert Group on Active Ageing Index (UNECE/EC) and the Evaluation Board on AAI Seminars $(2015,2018)$.

Amanda Phelan RGN, RM, RPHN, RNT, BNS, MSc, PhD, is an associate professor in the School of Nursing, Midwifery and Health Systems. She also holds the position of associate dean for Global Engagement, codirector of the National Centre for the Protection of Older People and subject head of Older People's Nursing. Amanda's research and publications focus on elder abuse, abuse of vulnerable adults, person-centred coordinated care, missed care in nursing, ageism and resilience in caregivers of people with dementia. Amanda serves on the AIGNA Committee, the Policy and Procedures and National Advisory Committees of Sage Advocacy and Support for Older People, the Board of Directors of Third Age and the Fitness to Practice Committee of the Nursing and Midwifery Board of Ireland. Amanda was also appointed to the Expert Advisory Group for the Citizens' Assembly on Ageing and is a visiting professor in Norwegian University of Science and Technology (NUTU) and an international research project advisor in NUTU and the University of Toronto (Canada).

María del Carmen Requena $\mathrm{PhD}$, attained her bachelor's degrees in psychology and education and obtained her $\mathrm{PhD}$ in neuroscience at the Complutense University in Madrid. She was postdoctoral research fellow at the Spanish Magnetoencephalography Center and intern clinical psychologist (PIR). Currently, she is assistant professor of psychology at the University of Leon. She has designed and developed the "Memoria Mejor" (Better Memory) Program for older persons and directs the "Aging at All Ages Scholarship" giving scientific support to public and private projects and programmes related to ageing. She also directs the EEG Laboratory for the Study of Human Development at the interuniversity E3 campus. She has published several articles related to ageing, both in the field of neuroscience and in the field of psychology and gerontology. Her main focus is on long-term memory and embedding emotional-cognitive programmes in daily life. Her current research grants include a project on adult reasoning. She develops joint research with Prof. G. Rebok on paradigm change in psychostimulation programmes for older persons at the Johns Hopkins Center of Aging and Health. She also works on intergenerational educative methodologies applied in the realm of higher education.

Klaus Rothermund has PhD in psychology (University of Trier, Germany, 1998) and venia legendi in psychology (University of Trier, Germany, 2002). Since 2004, he has been full professor and chair of psychology at the Friedrich-SchillerUniversity of Jena, Germany. He is a member of the Scientific Advisory Board of the German Ageing Survey (DEAS) and a member of the Board of Directors of the Center for Ageing Research Jena (ZAJ, Zentrum für Alternsforschung Jena). His 
current research interests include quality of life and well-being in old age, volunteering and civic engagement, health and health behaviour, social relations and social integration of older persons and comparative ageing research. He has served as a principal investigator of the COST Action IS1402 "Ageism" (since 2014, work group chair) and Ageing as Future (VolkswagenStiftung, since 2009, speaker and chair). He has published 10 monographs, edited books and special issues and has more than 170 publications in scholarly journals and books. He is currently editorin-chief for Cognition \& Emotion.

Jonathan Shemesh is a graduate student of cognitive science at Ben-Gurion University of the Negev and a research assistant at the Israel Gerontological Data Center. His interests focus on the intersection between cognition and society. At present, he is conducting research on the links between personality, morality and economic attitudes. At the Israel Gerontological Data Center, he is involved in research on the psychological and biological determinants of healthy ageing.

Sharon Shiovitz-Ezra PhD, is a senior lecturer at the Paul Baerwald School of Social Work and Social Welfare at Hebrew University, where she received her doctorate in 2005. In 2008 she served as a postdoctoral scholar in the Center on Demography and Economics of Aging, at the University of Chicago. Her theoretical and research agenda focuses on loneliness experienced in the second half of life. Her studies on loneliness have pursued two main directions: identifying risk and protective factors for loneliness and addressing the harmful consequences of loneliness. In 2015 she initiated a large multidisciplinary research proposal that was funded by the Israeli Ministry of Science, Technology and Space, entitled "Do Interpersonal Relationships 'Get Under Your Skin?': Bio-physiological Mechanisms by which the Quality of the Interpersonal Social Milieu Affects the Health of Older Adults". Another research topic of Dr. Shiovitz-Ezra is the phenomenon of "Ageism". Following her scientific work in this field, she served as a principal investigator of a large research project on ageism in the healthcare system in Israel. Since 2015, she has been actively involved in the COST Action on ageism (IS1402). Since 2016 she has served as the head of the MSW programme at the Paul Baerwald School of Social Work and Social Welfare at Hebrew University.

Sigurveig H. Sigurðardóttir $\mathrm{PhD}, \mathrm{MPH}, \mathrm{SW}$, is an associate professor and the head of the Faculty of Social Work, University of Iceland. Her PhD awarded from the School of Health and Welfare, Jönköping University, Sweden, focused on the situation of community-living older people, 65 years of age and older, in Iceland. Her research focuses mainly on formal and informal care of older people, social networks of older adults and social policy. She was a social worker at the Geriatric Department of the University Hospital in Iceland for several years and the administrative officer of the Red Cross Reykjavik Division and participated in implementing different resources for older people such as group living facilities, day-care centres and a nursing home. She is a national delegate in the Cost Action on ageism (IS1402) and in the Cost Action on reducing old-age social exclusion (CA15122). 
She has participated in different Nordic research projects such as REASSESS (The Nordic Centre of Excellence: Reassessing the Nordic Welfare Model) and SIA (Social Inequalities in Ageing; the challenge for the Nordic Welfare Model). Sigurveig is responsible for the Icelandic part of the Nordic Master's Degree Programme in Gerontology (NordMaG), a multidisciplinary and jointly implemented degree programme taught in collaboration of four Nordic universities. She is a board member of the Icelandic Gerontological Research Center.

Fredrik Snellman has PhD in social work and licentiate's degree in social policy. He is a university lecturer and researcher at the Department of Social Work at Umeå University in Sweden. Some of his recent work has appeared in the Journal of Interpersonal Violence (2017), Nordic Psychology (2016) and the International Journal of Sociology and Social Policy (2014). He is currently involved in the interdisciplinary GERDA (Gerontological Regional Database) research initiative, aiming to investigate a wide range of topics affecting people in older (65+) ages. He is actively involved in the COST Action IS1402 on ageism and is a committed spokesperson for raising societal awareness of ageism (e.g. management education for leaders in geriatric nursing in Sweden, pensioner organisation's annual meetings).

Benny Spanier has BA in history and Jewish studies (Hebrew University, Jerusalem), MA in religious studies (Tel Aviv University), LLB (Interdisciplinary Center, Herzliya), LLM (University of Haifa) and PhD (University of Haifa). His research focuses on ageism and the rights of older persons in the international arena. Currently, he is an associate researcher in the Center for Research and Study of Aging at the Department of Gerontology, University of Haifa. He published a number of articles regarding the rights of older persons (e.g. Spanier Benny, Doron Israel (Issi), "From wellbeing to rights: Creating an international older persons' rights index (IOPRI)", 24(2) The Elder Law Journal 245 (2016); Spanier Benny, Doron Israel (Issi), Milman-Sivan Faina, "In course of change? Soft law, elder rights, and the European court of human rights", 34(1) JLI 55 (2016). He has also been involved in the establishment of IOPHRI, the International Older Persons' Human Rights Index, and has studied key European institutions such as the European Court of Human Rights and the European Social Commission.

Justyna Stypińska $\mathrm{PhD}$, is a researcher at the Freie Universität Berlin in Germany. She studied sociology and law at the Jagiellonian University in Kraków, Poland, where she defended her thesis (in sociology) on the topic of age discrimination in labour market in Poland. Her major research focus includes the issues of work in later life and the life course analysis. Currently, she coordinates an international research project on older entrepreneurs in Poland and Germany (in cooperation with researchers in Sweden) financed by the German. In previous research project, she studied topics related to reconciliation of work and elderly care, age discrimination in work, healthcare and education, the transformations of life courses in post-communist countries and wage inequalities in German labour market from the perspective of age, gender and migration. She is a board member of the European 
Sociological Association Research Network on Ageing. She held fellowships from the University of Washington in Seattle, USA, and the German Centre for Gerontology in Berlin.

Hannah J. Swift PhD, is a research fellow at the School of Psychology, University of Kent, from where she also completed her PhD (2012) as an ESRC-CASE grant holder in conjunction with Age UK. Her research focuses on ageism, attitudes to age, active ageing and the consequences of age stereotypes. Aside from contributing to several reports for the UK Government, the European Social Survey, Age UK and the Gerontological Society of America's policy briefings, her research has been published in journals including Journal of Gerontology: Psychological and Social Sciences, Psychology and Aging, Journal of Social Issues, BMJ Open, Journal of Applied Social Psychology and Social Issues and Policy Review. Her research thus far has been supported by funding from research councils, the government and NGOs from UK, EU and the USA. She is a core member of EURAGE, which contributed to the design and analysis of the "Ageism" module in European Social Survey and the UK's Age Action Alliance's working group on attitudes to age.

Clemens Tesch-Römer has $\mathrm{PhD}$ in psychology. He has been a director of the German Centre of Gerontology in Berlin since 1998 and an adjunct professor at the Free University of Berlin since 2003. He has been a member of the Expert Committees for the German Government Reports on Older People in Germany since 1998. His current research interests include quality of life and well-being in old age, volunteering and civic engagement, health and health behaviour, social relations and social integration of older persons and comparative ageing research. He has served as a principal investigator of COST Action IS1402 "Ageism" (since 2014), German Ageing Survey (DEAS, since 2001), German Volunteering Survey (FWS, since 2012) and Old Age and Autonomy: The Role of Service Systems and Intergenerational Family Solidarity (OASIS, 2000-2003). He has published 20 monographs and edited books and has more than 100 publications in scholarly journals and book chapters. From 2008 to 2010, he was president of the German Society for Gerontology and Geriatrics. And since 2015, he has been president of the International Association of Gerontology and Geriatrics, European Region (IAGG-ER).

Ursula Trummer $\mathrm{PhD}, \mathrm{MSc}$, MA, obtained her $\mathrm{PhD}$ in sociology and master's degree in socioeconomic sciences at the University of Vienna, Austria, and an MSc in organisational development and counselling at the Sigmund Freud University Vienna. She is co-founder and head of the Center for Health and Migration (www.chm.com). Her main research interests are social determinants of health, access to healthcare for vulnerable groups, diversity management and methodological challenges of trans- and interdisciplinary research. A recent focus of her work is on ageing in immigrant populations and intergenerational family solidarity among migrant families. She is national delegate to the COST Actions on ageism (IS1402) and on Intergenerational Family Solidarity (IS1311). Ursula Trummer acts as 
project director of European and international projects and lectures at various universities, e.g. the Medical University of Vienna (Diversity and Medicine, Gender Medicine) and the Medical University of Graz (Public Health). She is an independent expert to the European Commission, the European Union Agency for Fundamental Rights and the Norwegian Research Council.

Joost van Hoof $\mathrm{PhD}$, MSc, Eur Ing, works as a research leader and associate professor in the field of design for healthcare with the School of Allied Health Professions of Fontys University of Applied Sciences in the Netherlands. Van Hoof attained his doctoral degree in 2010 from Eindhoven University of Technology with a dissertation on ageing in place for people with dementia (awarded the certificate for best dissertation of the Department of Architecture, Building and Planning) and an MSc degree in building physics and services in 2004. He also studied environmental engineering (mechanical engineering) at the Czech Technical University in Prague. He attained his Eur Ing qualification from the European Federation of National Engineering Associations (FEANI) in 2007. Key to his work are inclusive and participatory design for older people, designing technologies and housing that stress the needs and abilities of people, not their limitations. For his work, Dr. van Hoof won various (inter)national awards, including the best education innovation award by the Netherlands Association for Medical Education, the REHVA Young Scientist Award 2011 by the Federation of European Heating and Air-Conditioning Associations and the 2010 BJ Max Prize. He is a board member of various ISI journals on building, technology and healthcare. Moreover, he is board member of the Herman Bouma Fund for Gerontechnology Foundation and holds two membership positions of the board of directors within the domain of healthcare real estate.

Christin-Melanie Vauclair is a Researcher at the university ISCTE-IUL, Centre for Psychological Research and Social Intervention in Lisbon, Portugal. She holds a Ph.D. in Cross-Cultural Psychology and her research focuses on identifying similarities and differences across different countries and cultures in regard to attitudes to age and the experience of ageism. She is a member of the European Research Group on Attitudes to Age (www.eurage.com; www.melanie-vauclair.com).

Peggy Voss has MSc in psychology. She is a doctoral student at the Department of Psychology of the Friedrich-Schiller-University Jena in Germany. She is part of the international and interdisciplinary research project "Ageing as Future" (funded by the VolkswagenStiftung). Her research interests are images of ageing and their developmental outcomes as well as age stereotypes and (perceived) age discrimination.

Monika Wilińska $\mathrm{PhD}$, works as a senior lecturer at the School of Health and Welfare, Jönköping University, Sweden. Her research focuses on the practices and processes of inequality (re)production across the life course and in various sociocultural contexts. She has extensive research experiences from countries, such as Japan, Poland, Sweden and the UK. Monika's specific research interest is in the ways in 
which age and gender orders are being established, sustained and revised in everyday interactions, including encounters between clients and institutional health and welfare actors. She is a qualitative researcher, with a strong background in discourse and narrative studies.

Susanne Wurm $\mathrm{PhD}$, received her $\mathrm{PhD}$ in psychology at the Freie Universität Berlin and is currently a professor of psychogerontology at the Friedrich-AlexanderUniversity (FAU) in Nuremberg, Germany. Her research areas are health and health changes in later life and the role of psychosocial resources therein. In particular, her research focuses on the impact of different views on ageing for health and health behaviour, adaptation processes after health events and the promotion of effective health behaviour via interventions. She is editorial board member of the European Journal of Ageing and Journal of Gerontopsychology and Geriatric Psychiatry. She is deputy president of the "Health Reporting and Health Monitoring" Committee of the Robert Koch Institute, member of a research network on images of ageing funded by the German Research Foundation (DFG), member of the European Cooperation in Science and Technology (COST) Network and co-chair of COST Workgroup 5 on "internalised age stereotypes".

Mary F. Wyman PhD, received her doctorate in clinical psychology and neuroscience from Indiana University, Bloomington, USA, and received further training at the University of California-San Francisco. In 2015-2016, she was a visiting scientist at the University of Freiburg, Germany. Dr. Wyman's research seeks to achieve a better understanding of the relationship between psychological and physical health in older adults, with a focus on depression and dementia, and to address older adult-specific challenges within the healthcare system. She is a geriatric researcher with the US Department of Veterans' Affairs and an adjunct associate professor at the University of Wisconsin School of Medicine and Public Health.

Marc Zwamborn MSc, holds an engineering degree in molecular sciences. He works as a project manager with Summa Health Care of Summa College, a school for vocational education in Eindhoven, the Netherlands. He is the coordinator of various projects related to transitions in healthcare and the consequences to vocational education.

The original version of this book was revised.

An erratum to this book can be found at DOI https://doi.org/10.1007/978-3-319-73820-8_32 


\title{
Chapter 1 \\ Introduction to the Section: Ageism- Concept and Origins
}

\author{
Liat Ayalon and Clemens Tesch-Römer
}

Human ageing is not solely the biological process of senescence-the gradual deterioration of bodily functions that increases the risk for morbidity and mortality after maturation. Human ageing is embedded in social contexts and is shaped by social factors. We grow old within a social network of partners, family members, and friends. In many countries, we count on old age pensions as well as health and social care services. And we have explicit and implicit assumptions about older people (as a social group), growing old (as a developmental process), and being old (as part of the life course). These assumptions, expectations, and beliefs shape human ageing, as well. We often speak about older people in general (and not about different individuals), about "the" process of ageing (and not about the multiple, unique courses which exist), and about old age as a uniform stage at the end of life (and not about the diverse and heterogeneous living situations of older people). As soon as we neglect the differences between individuals, we over-generalise and treat older people, ageing, and old age in a stereotypical manner. This stereotypical construction of older people, ageing, and old age is called "ageism."

Ageism is ubiquitous: It is in our perception of older people and in our actions towards older people. We even look at ourselves as ageing persons through the lens of ageism. Most often, we are not aware of our ageist perceptions and behaviours. Ageism is prevalent in different domains of life: at work, in public spaces, in shops, and in doctors' offices. Elements of ageism can be found in individuals' behaviour, in organizational regulations, and in cultural values. Ageism is often negative and it

\footnotetext{
L. Ayalon $(\bowtie)$

Louis and Gabi Weisfeld School of Social Work, Bar Ilan University,

Ramat Gan 52900, Israel

e-mail: liat.ayalon@biu.ac.il

C. Tesch-Römer

German Centre of Gerontology, Berlin, Germany

e-mail: clemens.tesch-roemer@dza.de

L. Ayalon, C. Tesch-Römer (eds.), Contemporary Perspectives on Ageism, International Perspectives on Aging 19, https://doi.org/10.1007/978-3-319-73820-8_1
} 
can harm older people because stereotyping ageist beliefs may lead the older person to act as she or he is expected to behave: as a stereotypical older person. Hence, ageism may become a self-fulfilling prophecy.

As scientists, we want to look into the origins of ageism (e.g., how does ageism come about?) and we want to describe the manifestations and consequences of ageism (e.g., what does ageism look like and what follows from ageism?). We are also in need of practical tools with which to study ageism and to adequately monitor its occurrence. This is not enough, however. As scientists, we are also interested in interventions against ageism (e.g., what works best?). Consequently, this book is composed of different sections. The first section contains five chapters on the concept and aetiology of ageism. These chapters provide a review of potential ways to conceptualise and explain the occurrence of ageism. The second section is focused on the manifestations and consequences of ageism. This section is the largest in the book and contains ten chapters, which range in scope from the micro- to the macrolevel, including different settings and groups exposed to ageism. The third section includes five chapters dedicated to interventions to fight ageism. Four of the chapters discuss legal and policy interventions, whereas the latter chapter is on interventions in the field of education. Finally, a section on researching ageism is devoted to knowledge gained by quantitative and qualitative researchers with regard to research in the field of ageism. This section contains seven chapters which address philosophical, methodological, and cultural issues concerning research in the field of ageism.

In this introductory chapter, we discuss definitions of the concept of ageism and give an overview of the most important theories used to explain ageism on different levels. We also introduce the chapters of the first section of this book.

\subsection{Ageism: Concept}

Definitions and concepts of ageism have changed over the years. The term was first defined by Robert Butler, one of the pioneers in ageing research. Butler used the word ageism to describe "prejudice by one age group against another age group" (Butler 1969, p. 243). Butler argued that ageism represents discrimination by the middle-aged group against the younger and older groups in society, because the middle-aged group is responsible for the welfare of the younger and older age groups, which are seen as dependent. He compared the effects of ageism to the negative effects of racism or discrimination based on social class and discussed the intersections between ageism and other forms of discrimination and disempowerment (Butler 1969). In subsequent work, Butler (1980) continued to compare ageism to sexism and racism (the other two well-known "isms"), arguing that ageism is manifested as attitudes, behaviours, and institutional practices and policies directed towards older adults. Ageism can be either positive or negative, yet it tends to carry negative consequences by creating self-fulfilling prophecies (Butler 1980). 
Erdman Palmore, another eminent ageing researcher, has argued that older adults should be seen as a minority group in society (Palmore 1978). Palmore (2000) has argued that normal ageing is seen as a loss of functioning and abilities. Hence, it carries a negative connotation. Accordingly, terms such as "old" or "elderly" have negative connotations and thus should be avoided (Palmore 2000). This corresponds with the notion of language as shaping reality and constructing the meaning of old age (Nuessel 1982).

A clear acknowledgement of the presence of ageism not only in the way one group treats another but also as the "enemy within" was introduced in a paper by Levy (2001). According to Levy, ageism is often directed at one's self and can be implicit. It occurs with very little awareness or intention and literally impacts the social interactions and life of each and every one of us. This definition considers ageism as having behavioural, attitudinal, and emotional components based on chronological age. It can be positive or negative and is thought to shape most interactions with older adults. It has been argued that older adults have internalised negative ageist messages throughout their lives. This, in turn, impacts their view of themselves as well as their view of others in their surroundings (Levy 2001; Levy and Banaji 2002). Every person who grows old is likely to be the target of ageism at some point in life. This is very different from other types of discrimination, which are not likely to impact all people in society (Palmore 2001). Hence, the scope and breadth of ageism are massive (Ayalon 2014).

A more general definition of ageism equates it with discrimination based on age. Because age-related stereotypes are embedded in our lives, we disregard them and hardly notice their effects. It has been suggested that ageism is broadly defined as prejudice or discrimination against or in favour of any age group. While both young and old are affected by ageism, as both age groups are commonly defined as being dependent, rather than as productive members of society (Angus and Reeve 2006), also individuals in middle adulthood may suffer from ageism. Additional attempts at a comprehensive definition of ageism address its emotional, behavioural, and cognitive aspects; its implicit and explicit nature; its positive and negative impacts; and its possible manifestations at the micro-, meso-, and macro-levels (Iversen et al. 2009).

Although both stereotypes and discrimination are discussed with regard to ageism, it is largely accepted that age stereotypes precede age discrimination. Chapter 2 by Voss, Bodner, and Rothermund (2018) in this section suggests that a reverse direction should also be considered. The authors argue that expectations and behaviours reinforce each other. This occurs both at the actor and the perceiver levels and has a domain-specific nature. Hence, this chapter provides a fresh look at the concept and its occurrence.

In this book, we define ageism as the complex, often negative construction of old age, which takes place at the individual and the societal levels. Despite the fact that ageism is regarded as affecting the lives of people of all ages, the entire book is primarily devoted to ageism towards older adults. 


\subsection{Ageism: Aetiology}

Over the past few decades, multiple theories have attempted to explain the occurrence of ageism. We look at three levels of ageism: the micro-level, which is concerned with the individual (thoughts, emotions, actions); the meso-level, which is concerned with groups, organizations, and other social entities (e.g., in the domain of work or health care services); and the macro-level, which relates to cultural or societal values as a whole (e.g., political regulations). A division of theories according to micro-, meso-, or macro-level explanations for the occurrence of ageism is somewhat arbitrary as theories can relate to several levels at the same time. Obviously, other categorizations are also possible.

\subsubsection{Micro-level Theories to Explain the Origins of Ageism}

Theoretical approaches to ageism on the micro-level of the individual come from two traditions of psychological research: social psychology (terror management theory, social identity theory, and the stereotype content model, among others) and developmental psychology (theories based on the social-developmental perspective, stereotype embodiment theory, and others).

Terror Management Theory provides a prominent explanation for the occurrence of ageism. According to terror management theory, older adults serve as a constant reminder of one's mortality and vulnerability. In order to manage the anxiety that their presence produces, individuals unconsciously sustain faith in cultural worldviews that offer literal or symbolic immortality. By adhering to these cultural worldviews, individuals attempt to increase their self-esteem which in turn provides for the person a buffer against death-related anxiety. These efforts, allow the person to maintain relative equanimity despite awareness of one's vulnerability and mortality (Greenberg et al. 1986, 1997).

Social Identity Theory proposes that individuals do not act just on the basis of their personal characteristics or interpersonal relationships, but as members of their reference groups. Group memberships are the basis for the individual identity of group members and, moreover, determine an individual's relationships with members of other groups (Tajfel and Turner 1979). Social identity theory posits that people want to have a positive self-identity. They achieve this goal by demonstrating biases which create positive distinctions between their group (in-group) and other groups (out-groups), and by elevating their in-group status above that of other groups (Kite et al. 2002; Tajfel and Turner 1979). Because age can be one criterion for group identification, the theory can be used to explain ageism, as proposed in the Chap. 4 by Lev, Wurm, \& Ayalon in this section. 
The Stereotype Content Model suggests that groups of people are commonly classified by varying levels of warmth and competence. Older adults, for example, are commonly perceived as being warm but incompetent. These perceptions lead to feelings of pity and sympathy and less so to feelings of envy (Cuddy and Fiske 2002; Fiske et al. 2002).

Theoretical approaches from the perspective of human development emphasise changes over time. According to this group of theories, ageism has origins in childhood and its focus and outcomes may change over the life course. A social development perspective suggests that ageism develops throughout the life course. Perceptual, affective, and sociocultural mechanisms are responsible for the development of ageism. Age-based categories are thought to be universal. For instance, children might perceive older adults negatively with regard to dimensions of activity and potency and positively with regard to social goodness. Negative attitudes towards ageing might also be universal, but seem to vary with children's age, social class, and older adults' gender (Montepare and Zebrowitz 2002).

Stereotype Embodiment Theory proposes that lifetime exposure to negative stereotypes of older adults leads to the internalization of ageism. Over the course of their lives, older adults have internalised negative attitudes towards their own age group, often implicitly. In support of these claims, longitudinal studies have shown that negative age stereotypes and self-perceptions of ageing among older adults have an adverse influence on health, longevity, and cognitive performance (e.g., Levy et al. 2002a, b, 2012; Wurm and Benyamini 2014; Wurm et al. 2007).

Efforts to separate the ageing body from the "young spirit" are seen as attempts to accept old age and mortality. These attempts are equated with the concepts of successful ageing or active ageing, which aim to differentiate between pathological processes that occur in old age, normal aspects of ageing (like decline in cognitive and motor speed), and "exceptional" (successful) aging (aging with low illness burden, good functioning, and high social engagement). These concepts can be seen as combatting certain negative stereotypes of ageing; however, they can also be seen as ageist, because they place the responsibility for failure to "age successfully," which includes a large portion of the population of older adults, on the individual (Liang and Luo 2012).

Chapter 4 by Lev et al. (2018) in the first section of the book attempts to explain the origins of ageism at the individual level. According to the proposed model, terror management theory offers reasonable explanations for the origins of ageism among younger age groups, but not among the oldest-old, who are less concerned with impending death. Stereotype embodiment theory, on the other hand, argues that ageism and its manifestation as discrimination against one's own age group in old age is internalised over the life course. The authors conclude that whereas successful ageing, healthy ageing, and active ageing models can be effective for some older adults, the acknowledgement of decline and losses should be a viable option as well. 


\subsubsection{Meso-level Theories to Explain the Origins of Ageism}

Ageism does not always start at the individual level. Groups, organizations, and other social entities might be the precipitators of ageism, as well. An important example concerns the rules governing entry to and exit from an organization. In the labour market, age can be decisive for entry into a company ("too old to be hired") or for exit from a company ("pension age").

Evolutionary Theories on Group Membership have argued that people are programmed to be part of a group and that they learn that their own wellbeing is interdependent on that of other members of the group. A living arrangement that consists of small groups results in social transactions, cooperation, and reciprocity among members, and the criteria for determining the exchange of assistance are usually implicit, rather than explicit. In this theory, a person's age, wealth, reputation, and health play a role in determining whether or not assistance will be provided, because individuals who are perceived to have greater reproductive potential are more likely to be helped. The degree of threat posed by a situation is also an important factor in determining people's willingness to help. When life is in danger, people are more likely to assist relatives and those who are younger, healthy, and wealthy. Nevertheless, when there is no risk to one's life, people are more likely to assist the very young or old, the sick, and the poor (Burnstein et al. 1994).

Age Segregation is a prominent explanation at the meso-level. In most modern Western societies, there is a clear segregation between the young and the old, based on pre-planned life scripts, which include: (a) education, (b) family creation and work, and (c) retirement (Riley and Riley 1994). When the younger and older generations do not socially engage, ageism is likely to flourish (Hagestad and Uhlenberg 2005).

Intergroup Threat Theory suggests that individuals react in hostile ways towards outgroups, particularly when outgroups are perceived as potentially harmful. The theory identifies two major threats - realistic threats and symbolic threats-which serve to enhance intergroup hostility and conflict. Realistic threats refer to threats to the group's power, resources, and welfare; symbolic threats are threats to one's world view, belief system, and values (Stephan and Mealy 2011). Although the theory was not developed specifically to explain ageism, it can be used to account for age divisions in society.

Intergenerational Conflict Theory proposes three bases for intergenerational conflict, which are exacerbated by the expectations that younger generations have of older generations. These include expectations for the succession of resources from the older to the younger generations; minimal consumption of shared resources by older generations; and age-appropriate symbolic identity maintenance, which means that the older generation should not attempt to "cross the line" and become 
indistinguishable from the younger generation (North and Fiske 2013). When these expectations are not met, ageism might flourish.

Chapter 5 by Naegele, De Tavernier, and Hess (2018) in this section addresses ageism at the meso-level as it manifests in the workplace. The authors identify organizational and contextual factors at the meso-level, which contribute to the occurrence of ageism in the organization. This adds to a broader understanding of ageism in the workplace as well as to a theoretical understanding of meso-level explanations that account for ageism.

\subsubsection{Macro-level Theories to Explain the Origins of Ageism}

Ageism can also be located at the macro-level, in cultural values that depreciate older people, and in societal institutions, such as age-related retirement regulations.

Modernization Theory postulates that through the process of societal modernization, which includes advancements in technology and medicine, older adults have lost their social status in modern times (as compared to pre-modern eras). For one, advancements in technology and medicine have resulted in a larger number of older adults. As a result, old age is no longer the exception, representing a "survival of the fittest," but rather a common occurrence generally associated with frailty, morbidity, and disability. In more modern societies, the accumulated knowledge of older adults is often considered obsolete as a result of advancements in technology. The fact that younger generations tend to have higher levels of education than older generations is yet another contributor to the low status of older adults in modern society. In addition, with increasing urbanization, younger people tend to move to the city, leaving their older parents behind, so that the degree of contact between the generations declines (Cowgill and Holmes 1972). Finally, increased secularization has a role to play in reduced levels of familism and the embracement of individualism (Burgess 1960). In essence, even though this theory is primarily concerned with the declining status of older people, it also predicts an increase in power and status of the younger generations, who are seen as holding the knowledge and skills valued by modern society (Cowgill and Holmes 1972).

Chapter 6 by Stypińska and Nikander (2018) in this section uses the modernization theory to account for ageism in the workforce. The authors also discuss the roles of anti-discrimination policies and macro-level structural, political processes with regard to ageism. This chapter provides context-specific examples for the occurrence of ageism due to macro-level processes.

Ageism may be considered to be one mechanism creating societal inequality, similar to inequalities stemming from gender, race, poverty, and sexual orientation. A more nuanced picture of ageism can be achieved by looking at several mechanisms together, rather than only looking at one mechanism and neglecting the 
others. Hence, it is important to look at ageism from an intersectionality perspective. Intersectionality theory suggests that it is not age per se, but the intersection of age and gender, race, socioeconomic level, sexual orientation, and/or other factors which results in discrimination (Boggs et al. 2014; Krekula 2007; Marcus and Fritzsche 2015; McMullin and Berger 2006?/2013?). Chapter 3 by Krekula, Nikander, and Wilińska (2018) in this section views ageism within a wider context of multiple marignalizations. It is argued that discrimination is never solely based on age alone, but rather, on a multiplicity of characteristics, such as gender, appearance, financial status, and socioeconomic status.

\subsection{Conclusions}

Clearly, there is no consensus regarding the concept of ageism or its causes. Ageism as a concept has gone through various changes, and although it is currently acknowledged that ageism can be directed towards any age group, ageism against older adults has thus far received the most attention. In addition, although positive ageism is well-defined, it has hardly been examined in the literature. Hence, ageism directed at younger age groups and the positive aspects of ageism are potential subjects for future research.

\section{References}

Angus, J., \& Reeve, P. (2006). Ageism: A threat to "aging well" in the 21st century. Journal of Applied Gerontology, 25(2), 137-152.

Ayalon, L. (2014). Perceived age, gender, and racial/ethnic discrimination in Europe: Results from the European social survey. Educational Gerontology, 40(7), 499-517.

Boggs, J., Portz, J. D., Wright, L., King, D., Grimm, C., Retrum, J., \& Gozansky, W. (2014). D3-4: The intersection of ageism and heterosexism: LGBT older adults' perspectives on aging-inplace. Clinical Medicine \& Research, 12(1-2), 101.

Burgess, E. W. (1960). Ageing in Western societies. Chicago: University of Chicago Press.

Burnstein, E., Crandall, C., \& Kitayama, S. (1994). Some neo-Darwinian decision rules for altruism: Weighing cues for inclusive fitness as a function of the biological importance of the decision. Journal of Personality and Social Psychology, 67(5), 773-789.

Butler, R. N. (1969). Age-ism: Another form of bigotry. The Gerontologist, 9(4), 243-246.

Butler, R. N. (1980). Ageism: A foreword. Journal of Social Issues, 36(2), 8-11.

Cowgill, D. O., \& Holmes, L. (1972). Aging and modernization. New York: AppletonCentury-Crofts.

Cuddy, A. J., \& Fiske, S. T. (2002). Doddering but dear: Process, content, and function in stereotyping of older persons. In T. Nelson (Ed.), Ageism: Stereotyping and prejudice against older persons (pp. 3-26). Cambridge, MA: The MIT Press.

Fiske, S. T., Cuddy, A. J., Glick, P., \& Xu, J. (2002). A model of (often mixed) stereotype content: Competence and warmth respectively follow from perceived status and competition. Journal of Personality and Social Psychology, 82(6), 878-902. 
Greenberg, J., Pyszczynski, T., \& Solomon, S. (1986). The causes and consequences of a need for self-esteem: A terror management theory. In R. Baumeister (Ed.), Public self and private self (pp. 189-212). New York: Springer.

Greenberg, J., Solomon, S., \& Pyszczynski, T. (1997). Terror management theory of self-esteem and cultural worldviews: Empirical assessments and conceptual refinements. Advances in Experimental Social Psychology, 29, 61-139.

Hagestad, G. O., \& Uhlenberg, P. (2005). The social separation of old and young: A root of ageism. Journal of Social Issues, 61(2), 343-360.

Iversen, T. N., Larsen, L., \& Solem, P. E. (2009). A conceptual analysis of ageism. Nordic Psychology, 61(3), 4.

Kite, M. E., Wagner, L. S., \& Nelson, T. (2002). Attitudes toward older adults. In T. Nelson (Ed.), Ageism: Stereotyping and prejudice against older persons (pp. 129-161). Cambridge, MA: The MIT Press.

Krekula, C. (2007). The intersection of age and gender: Reworking gender theory and social gerontology. Current Sociology, 55(2), 155-171.

Krekula, C., Nikander, P., \& Wilińska, M. (2018). Multiple marginalizations based on age: gendered ageism and beyond. In L. Ayalon \& C. Tesch-Römer (Eds.), Contemporary perspectives on ageism: Vol. 19. International perspectives on aging (pp. 33-50). Berlin: Springer.

Lev, S., Wurm, S., \& Ayalon, L. (2018). Origins of ageism at the individual level. In L. Ayalon \& C. Tesch-Römer (Eds.), Contemporary perspectives on ageism: Vol. 19. International perspectives on aging (pp. 51-72). Berlin: Springer.

Levy, B. R. (2001). Eradication of ageism requires addressing the enemy within. The Gerontologist, 41(5), 578-579.

Levy, B. R., \& Banaji, M. R. (2002). Implicit ageism. In T. Nelson (Ed.), Ageism: Stereotyping and prejudice against older persons (pp. 49-75). Cambridge, MA: The MIT Press.

Levy, B. R., Slade, M. D., \& Kasl, S. V. (2002a). Longitudinal benefit of positive self-perceptions of aging on functional health. The Journals of Gerontology Series B: Psychological Sciences and Social Sciences, 57(5), P409-P417.

Levy, B. R., Slade, M. D., Kunkel, S. R., \& Kasl, S. V. (2002b). Longevity increased by positive self-perceptions of aging. Journal of Personality and Social Psychology, 83(2), 261-270.

Levy, B. R., Zonderman, A. B., Slade, M. D., \& Ferrucci, L. (2012). Memory shaped by age stereotypes over time. The Journals of Gerontology Series B: Psychological Sciences and Social Sciences, 67(4), 432-436.

Liang, J., \& Luo, B. (2012). Toward a discourse shift in social gerontology: From successful aging to harmonious aging. Journal of Aging Studies, 26(3), 327-334.

Marcus, J., \& Fritzsche, B. A. (2015). One size doesn't fit all: Toward a theory on the intersectional salience of ageism at work. Organizational Psychology Review, 5(2), 168-188.

McMullin, I. A., \& Berger, E. D. (2006/2013). Gendered ageism/age. In K. F. Slevin \& T. M. Calasanti (Eds.), Age matters: Re-aligning feminist thinking (pp. 201-224). New York: Routledge.

Montepare, J. M., \& Zebrowitz, L. A. (2002). A social-developmental view of ageism. In T. Nelson (Ed.), Ageism: Stereotyping and prejudice against older persons (pp. 77-125). Cambridge, MA: The MIT Press.

Naegele, L., De Tavernier, W., \& Hess, M. (2018). Work environment and the origin of ageism. In L. Ayalon \& C. Tesch-Römer (Eds.), Contemporary perspectives on ageism: Vol. 19. International perspectives on aging (pp. 73-90). Berlin: Springer.

North, M. S., \& Fiske, S. T. (2013). A prescriptive intergenerational-tension ageism scale: Succession, identity, and consumption (SIC). Psychological Assessment, 25(3), 706-713.

Nuessel, F. H. (1982). The language of ageism. The Gerontologist, 22(3), 273-276.

Palmore, E. (1978). Are the aged a minority group? Journal of the American Geriatrics Society, 26(5), 214-217.

Palmore, E. (2000). Guest editorial: Ageism in gerontological language. The Gerontologist, 40(6), 645-645. 
Palmore, E. (2001). The ageism survey first findings. The Gerontologist, 41(5), 572-575.

Riley, M. W., \& Riley, J. W., Jr. (1994). Structural lag: Past and future. In M. W. Riley, R. L. Kahn, \& A. Foner (Eds.), Age and structural lag: Society's failure to provide a meaningful opportunities in work, family, and leisure (pp. 15-36). New York: Wiley.

Stephan, W. G., \& Mealy, M. D. (2011). Intergroup threat theory. In D. J. Christie (Ed.), The encyclopedia of peace psychology. Malden: Wiley-Blackwell.

Stypińska, J., \& Nikander, P. (2018). Ageism and age discrimination in the labour market: A macrostructural perspective. In L. Ayalon \& C. Tesch- Römer (Eds.), Contemporary perspectives on ageism: Vol. 19. International perspectives on aging (pp. 73-90). Berlin: Springer.

Tajfel, H., \& Turner, J. C. (1979). An integrative theory of intergroup conflict. In W. G. Austin \& S. Worchel (Eds.), The social psychology of intergroup relations (pp. 33-47). Monterey, CA: Brooks Cole.

Voss, P., Bodner, E., \& Rothermund, K. (2018). Ageism: The relationship between age stereotypes and age discrimination. In L. Ayalon \& C. Tesch- Römer (Eds.), Contemporary perspectives on ageism: Vol. 19. International perspectives on aging (pp. 11-32). Berlin: Springer.

Wurm, S., \& Benyamini, Y. (2014). Optimism buffers the detrimental effect of negative selfperceptions of ageing on physical and mental health. Psychology \& Health, 29(7), 832-848.

Wurm, S., Tesch-Römer, C., \& Tomasik, M. J. (2007). Longitudinal findings on aging-related cognitions, control beliefs, and health in later life. The Journals of Gerontology Series B: Psychological Sciences and Social Sciences, 62(3), P156-P164.

Open Access This chapter is licensed under the terms of the Creative Commons Attribution 4.0 International License (http://creativecommons.org/licenses/by/4.0/), which permits use, sharing, adaptation, distribution and reproduction in any medium or format, as long as you give appropriate credit to the original author(s) and the source, provide a link to the Creative Commons license and indicate if changes were made.

The images or other third party material in this chapter are included in the chapter's Creative Commons license, unless indicated otherwise in a credit line to the material. If material is not included in the chapter's Creative Commons license and your intended use is not permitted by statutory regulation or exceeds the permitted use, you will need to obtain permission directly from the copyright holder. 


\title{
Chapter 2
}

\section{Ageism: The Relationship between Age Stereotypes and Age Discrimination}

\author{
Peggy Voss, Ehud Bodner, and Klaus Rothermund
}

\subsection{Introduction}

[...] everything matched with my occupational profile. But nevertheless I received a rejection because of my age. Born 1943, not stout and fat, not lazy and sluggish but instead still energetic and fit. [...] On the one hand people talk about skilled worker shortage and on the other hand being $65+$ years old one has no chance. (K. H. 2014)

Several explanations can be suggested for this rejection experience: From the person's perspective, which of course might reflect the truth, there is no doubt that he was discriminated against based on his age because it is generally assumed that people of his age are not fit anymore as workers. However, independently of whether or not the recruiter held negative stereotypes about older adults, it is also possible that there was simply someone who was better qualified for the job among the other applicants. In yet another version, the event that led to the rejection could be explained by his interview results that might have been worse compared to those of other applicants, which then again might have been for example caused by what is referred to as "stereotype threat" in the literature (Hess et al. 2003). This was defined as a situation-based fear that one's behaviour is going to be judged based on stereotypes or that one might act in way that confirms a stereotype (Steele et al. 2002) and it might especially occur during an interview with a younger interviewer. This example demonstrates at least two important things: On the one hand, it shows how

\footnotetext{
P. Voss $\cdot$ K. Rothermund $(\bowtie)$

Fakultät für Sozial- und Verhaltenswissenschaften, Allgemeine Psychologie II, Friedrich-

Schiller-University Jena, Jena, Germany

e-mail: peggy.voss@uni-jena.de; klaus.rothermund@uni-jena.de

E. Bodner

Interdisciplinary Department of Social Sciences and Department of Music, Bar Ilan

University, Ramat Gan, Israel

e-mail: ehud.bodner@biu.ac.il
} 
difficult it can be to determine whether a negative outcome or behaviour constitutes a case of age discrimination and if so whether it was caused by age stereotypes at all. Furthermore, even if this is taken for granted, it is important to know whose stereotypes were activated and led to a case of (perceived) discrimination. Taking on different perspectives on a seemingly age discriminatory event can lead to very different conclusions regarding the role that discrimination and age stereotypes played in the event. Age discrimination and the perception of age discrimination are complex phenomena which, at least on a micro-level, most likely emerge from social interactions (see Sect. 2.5). Accordingly, in order to make informed decisions about new research on age stereotypes and age discrimination, to conduct interventions targeting age discrimination, or to initiate policies directed at reducing age discrimination based on age stereotypes, it is of upmost importance to understand the complex relationship between age stereotypes and age discrimination.

Following the introductory quote, and in order to start the inquiry of the relations between age stereotypes and age discrimination, we first have to discuss one of the most widespread and persistent beliefs about the occurrence of age discrimination, that is the idea that age stereotypes and age discrimination are closely intertwined. This idea is already reflected in an early definition of ageism. According to Butler (1980) who first introduced the term, "ageism" is a complex phenomenon subsuming three different aspects: (1). Prejudice against older adults, old age and ageing (i.e., attitudes towards older adults), (2). Discrimination against older adults (i.e., behavioural acts targeting older adults), and (3). Institutional norms and strategies supporting stereotypes and reducing the opportunities of older adults. Thus, from the very beginning it was assumed that age discrimination and age stereotypes as well as prejudice against older adults represent related constructs that are "mutually reinforcing to one another" (Butler 1980, p. 1).

Although empirical evidence for the existence of age stereotypes and age discrimination related to various life domains is abundant (e.g., Brockmann 2002; Hummert et al. 1994; for more examples and reviews on age stereotypes and age discrimination, e.g., in the domains health care, mental health, and work, see Wyman and Shiovitz-Ezra; Bodner, Palgi and Wyman; De Tavernier, Naegele and Hess in this book), their assumed causal relations are difficult to prove and might be more complex than expected (Dovidio et al. 1996; Voss and Rothermund in press). In this chapter, we draw a differentiated picture of this relationship by (a) disentangling conceptual and empirical relations between age stereotypes and age discrimination and (b) focusing not only on the role of age stereotypes held by those who show ageist behaviours, but additionally considering the perspective of older adults themselves as they also hold stereotypes about (their own) age and ageing that are related to perceived age discrimination (Voss et al. 2017). Figure 2.1 gives an overview of the complex mutual relations between age stereotypes and age discrimination, simultaneously taking into account both the perspective of actor and perceiver whereby actor refers to people interacting with older adults (potentially behaving towards them in a discriminatory way) and perceiver refers to older adults (potentially perceiving age discrimination). 


\subsection{Ageist Behaviour and Perceived Age Discrimination: Different Sides of the Same Coin?}

Over the last decades, laws that aim at protecting people from age discrimination have been established in legal systems of countries all over the world (e.g. Age Discrimination in Employment Act in the USA 1967; Allgemeines Gleichbehandlungsgesetz in Germany 2006; for a review of EU law and ageism see Doron, Numhauser-Henning, Spanier, Georgantzi, and Mantovani in this book). The incorporated definitions of age discrimination attempt to provide a clear and objective reference standard of what constitutes age discrimination in different areas of life (e.g., age-dependent selection and recruitment of employees). However, how people interpret behaviour and what they perceive as age discrimination does not necessarily meet these criteria (Rothermund and Mayer 2009). In everyday life, behaviour is often ambiguous and inconclusive with regard to its intentions and underlying causes (Major and Sawyer 2009), and the very same behaviour can have multiple meanings. Therefore, actual age discrimination might remain unnoticed (e.g., if it is widely accepted; Australian Human Rights Commission 2010), but older adults might also feel discriminated against although the way they were treated constitutes no instance of ageist behaviour (e.g., the behaviour was unrelated to their age or did not conflict with any rightful claims or prescriptions). In Fig. 2.1, this is captured by the dotted shape linking perceived age discrimination by the perceiver with non-discriminatory and with discriminatory behaviour produced by the actor as both can be interpreted as age discrimination. Accordingly, to acknowledge the subjective nature of an individual's perception of age discrimination, it is important to differentiate between perceived age discrimination and actual "objective" age

Macro- and meso-level (stereotypes, norms, values, laws, organizational climate...)

Situation (life domain, salience of age, situational framing...)

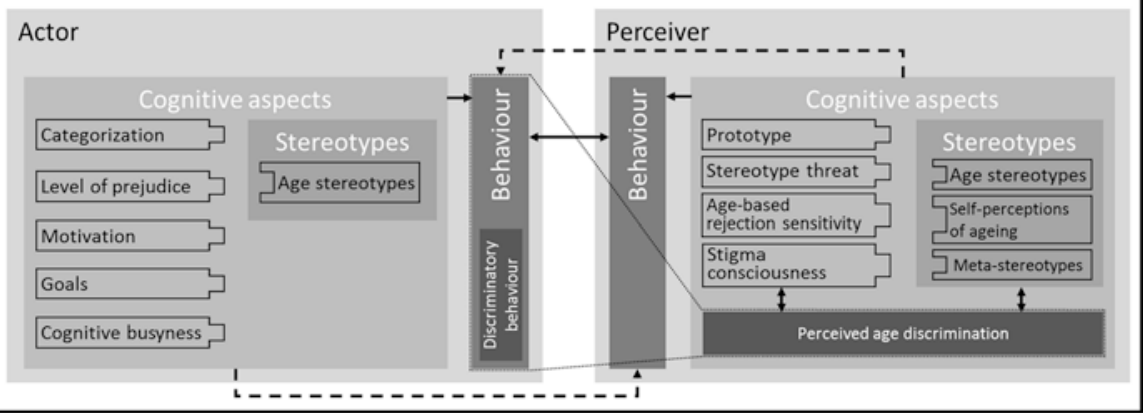

Fig. 2.1 Illustration of the relations between age stereotypes and (perceived) discriminatory behaviour considering the actor's and the perceiver's perspective as well as situational, macro-, and meso-level influences 
discrimination. Considering the subjective nature of perceived age discrimination, we neither intend to deny that "objective" age discrimination exists nor do we consider (falsely) perceiving age discrimination to be less harmful than noticing actual age discrimination. This perspective can, however, help to identify individuals or situations for whom or which the probability of perceiving discrimination is particularly high (Voss et al. 2017), and it also elucidates possible relations between (perceived) age discrimination and an actor's (as well as a perceiver's) behaviour.

Although perceived and "objective" age discrimination are conceptually different, they are somehow empirically linked. For example, in the work domain, the prevalence pattern of perceived age discrimination across adulthood matches with known age preferences for workers (Gee et al. 2007). This points to the possibility that perceived age discrimination is a valid indicator or symptom of actual "objective" age discrimination, at least in some cases. Nevertheless, although perceived age discrimination shows a relation to objective indicators, age discrimination often remains under-reported, potentially due to the strong internalization of age stereotypes (European Commission 2011).

\subsection{Age Stereotypes and Age Discrimination from the Actor's and the Perceiver's Perspective: Distinguishing Between Conceptual and Empirical Relations}

Focusing on the mere definition of age discrimination, a conceptual dependency among age stereotypes and age discrimination becomes apparent. Discrimination can be defined as "inappropriate and potentially unfair treatment" (Dovidio et al. 2010, p. 8) that is based on people's group membership (e.g., belonging to a certain age group), with age being one of the three basic dimensions of automatic social categorization (besides ethnicity, social class, and sex; Fiske and Neuberg 1990). This process of categorization is assumed to be accompanied by the automatic activation of associated stereotypes (Allport 1958; Devine 1989), which in turn shapes the behaviour towards the target person. A closer look reveals that a reference to age alone is not sufficient for behaviours to be classified as age discrimination. What is needed for a categorization as ageist behaviour is a description of the behaviour in terms of a characteristic associated with age (e.g., based on age stereotypes or prejudice). Without such a reference to age stereotypes and age-related prejudice, the age categorization and the resulting behaviour would still be unconnected. Age stereotypes are thus inherent in the mere concept of age discrimination: Age-related stereotypes and prejudice represent a necessary condition for describing a behaviour as discriminatory, thereby providing a possible link between categorization and age discrimination.

Similarly, feeling discriminated against due to one's age also implies that behaviour in a situation that highlights the group membership as old is perceived or interpreted in a certain way (Major et al. 2002). Essentially, perceiving age discrimi- 
nation requires that people have an idea of what it means to be treated in a discriminatory way that is "based on age". Such an idea is inherent in a prototype of a situation where discrimination is likely to occur (Baron et al. 1991; Major and Sawyer 2009; Rodin et al. 1990). This prototype is assumed to work like a template: It can be compared against actual situations and the closer they match the more likely it is that discrimination is perceived (Major and Sawyer 2009). Among other factors, this prototype is informed by the negativity of stereotypes ascribed to older people compared to younger people (i.e. stereotype-asymmetry which could for example be the case in situations that test cognitive abilities, as negative stereotypes about older adults are very prominent in that domain; Major and Sawyer 2009; O'Brien et al. 2008). Accordingly, individually held age stereotypes and perceived age discrimination are conceptually related, although stereotypes are assumed to be only one aspect of many possible contextual and individual characteristics influencing the attribution of behaviour to discrimination (for an overview see, Major et al. 2002; Major and Sawyer 2009).

In sum, age stereotypes are involved in actual as well as in perceived age discrimination for purely conceptual reasons. A reference to age-stereotypical attributes provides the specific link between the age of the target person and the respective discriminating behaviour by explaining or describing it in terms of age stereotypes or age-related prejudice. Importantly, however, reference to age is only a necessary, not a sufficient condition for the emergence (or interpretation) of agediscriminating behaviour. This leaves ample room for empirical analyses of the causal role of age stereotypes and of the sufficient conditions for their activation in explaining and predicting (perceived) age discrimination.

Processes of Age Stereotype Activation Early empirical research regarding processes and conditions of stereotype activation seemed to suggest that mere categorization is associated with the activation of stereotypes, even if these stereotypes were only known and not personally endorsed (Devine 1989). Although this study was later criticized for a number of methodological shortcomings (e.g., stereotyperelated primes were used instead of mere category primes), it still makes an important point in showing that subtly increasing the accessibility of stereotype-related content has a marked influence on subsequent processes of perceiving, evaluating, and behaving towards others. Later research addressing this issue revealed that individual levels of prejudice of the actor had an impact on subsequent impression formation (Lepore and Brown 1997), which attests to the importance of considering individual differences in prejudice when explaining actual and perceived age discrimination.

Other variables affecting whether or not stereotypes are activated are, for example, the availability of cognitive resources (with a lack of resources preventing stereotype activation; Gilbert and Hixon 1991), mind set (priming creativity reduces stereotypic thinking; Sassenberg and Moskowitz 2005), and goals (chronic egalitarian goals are associated with stereotype inhibition; Moskowitz et al. 1999). Similarly, Rahhal et al. (2001) showed that the framing of a cognitive task as being unrelated to memory (e.g., by framing it as a learning task) can prevent the detrimental effect 
on memory performance, which according to the authors might be explained by the lack of activation of corresponding negative age stereotypes. These results demonstrate that the mere categorization of someone as old does not automatically imply the activation of (negative) age stereotypes, indicating that the relation between categorization and an activation of old age stereotypes is more complex and indirect than is often assumed, and does not hold for everyone or in every situation.

Activation of Different Sub-Stereotypes of Aging Images of older people are heterogeneous and encompass a broad mixture of negative and positive stereotypes (e.g. Hummert et al. 1994) differing in their content and in the contexts to which they refer (e.g., Casper et al. 2011; Kornadt and Rothermund 2011). The valence and content of activated stereotypes should not be neglected in discussing their effects, especially as effects of (self- and other-) stereotypes on behaviour were shown to be mostly assimilation effects (i.e., behaviour and stereotypes are consistent, Wheeler and Petty 2001). Which of the multiple stereotypes is predominant in a situation depends for example on contextual information (Casper et al. 2011; Kornadt and Rothermund 2011) and the age of the target person (young-old vs. oldold; Hummert et al. 1997). Not every stereotype possibly activated in a certain situation would be associated with discrimination.

Furthermore, domain-specificity as well as the differential effects of positive and negative stereotypes were also shown with regard to the effects of age stereotype activation among older adults. Specific activated stereotypes unfold their impact most strongly in those domains to which they apply (Levy and Leifheit-Limson 2009). In particular, individually held views on ageing in a specific domain (e.g., physical losses) were only predictive of perceived age discrimination in a matching domain (e.g., medical care; Voss et al. 2017; inner black frame in Fig. 2.1). In line with the importance of stereotype valence it was shown that besides detrimental effects of negative stereotypes, the implicit activation of positive age stereotypes in older adults has positive effects (e.g., Levy 1996). Accordingly, stereotype activation depends on multiple influences and contextual information and is not necessarily detrimental for older adults.

Translation of Stereotypes into Behaviour Most importantly, although several studies show an association between stereotypes and judgements, perceptions, as well as stereotype-consistent behaviour towards older adults (e.g., Hummert et al. 1998; Krings et al. 2011) the mere stereotype activation does not imply that people inevitably act according to them (e.g. Gilbert and Hixon 1991; for a theoretical framework see Kunda and Spencer 2003), also not in an age discriminatory way. Whether or not stereotypes are applied depends for example on cognitive busyness (Gilbert and Hixon 1991) and time pressure (Gordon and Anderson 1995). Similarly, two meta-analyses on the effects of age stereotypes on different performance measures and behaviours in older adults revealed that their association depends on several variables (i.e. moderators; Lamont et al. 2015; Meisner 2012). Investigating stereotype threat Lamont and colleagues found that under certain conditions, for example, when performance in a cognitive domain was measured, the effects were 
more pronounced. Meisner showed that stereotype priming effects were more pronounced when negative stereotypes are primed.

In sum, we have argued that age stereotypes and age discrimination are conceptually related, whereby age-related stereotypes and prejudice provide a possible link between categorization and age discrimination. Such a categorization may be particularly likely in situations where a conflict of interest between groups is salient (e.g., young and old persons competing for jobs, and when older adults are perceived as consuming shared resources; North and Fiske 2012). Going beyond these general conceptual connections, empirical research has contributed important insights regarding the processes underlying the activation of stereotypes and their translation into age discriminating behaviour, and has identified important moderators of this association (see "cognitive aspects" on the actor's side in Fig. 2.1; see above and Sect. 2.3.2). Age stereotypes are not inevitably negative, but differ strongly in content and valence between contexts and individuals (e.g., Kornadt and Rothermund 2011). Even holding negative stereotypes about older adults does not necessarily imply that these negative stereotypes are activated (see above "Processes of age stereotype activation"). Most importantly, however, it does not imply that they are applied and cause discriminatory behaviour (see above and Sect. 2.3). We will address these complexities in more detail in the subsequent paragraphs.

\subsection{Ageism from the Actor's Perspective: Age Stereotypes as Predictors of Age Discrimination}

The fact that age stereotypes are a reason for age discrimination is firmly established in research and in law. However, Allport pointed out as early as 1958 (p.14) that how people actually behave towards members of a group does not necessarily match what they think about these group members.

\subsubsection{Review of Existing Evidence for Age Stereotypes as Predictors of Age Discriminatory Behaviours}

A large body of research demonstrates that negative stereotypes about older adults are widespread in different areas of life whereby their content and valence depend on the specific life domain (e.g., lower performance in the domain work, Bal et al. 2011; perfect grandparent in the domain family, Hummert et al. 1994). Similarly, age discrimination takes on different forms depending on the life domain in which it occurs (e.g., fewer chances for job interviews, Bendick et al. 1999; less expensive treatments in the health care sector, Brockmann 2002). Nevertheless, most of the research conducted so far regarding age stereotypes as predictors of age discrimination focused on the work domain. Although it is assumed that age stereotypes 
predict discriminatory behaviour, this is rarely tested. Often proxies of age discrimination are investigated as dependent variables like stereotype-consistent behaviour or intentions to act in a discriminatory way.

Age Stereotypes and Intentions for Age Discriminatory Behaviours A variety of studies demonstrated that negative age stereotypes predict intentions for discriminatory behaviour using experimental and correlative designs (e.g., Chiu et al. 2001; Krings et al. 2011; Rupp et al. 2006). In a vignette study with students, Rupp et al. (2006) showed that participants made more severe suggestions regarding consequences (e.g., demotion, transfer) in case that an older employee makes a mistake which was especially the case for participants with more negative age stereotypes. Additionally, the association between employee age and consequences was found to be based on the assumption that the cause of errors among older employees as compared to younger employees is more likely to be stable. Similarly, Krings et al. (2011) showed that competence- and warmth-related stereotypes mediate the association between the job applicant's age and interview intentions in a sample of business students. Most importantly, besides testing their mediation model using data from students, the authors also presented the same materials to people working in human resources departments of organizations and again found the same effect. In a study comparing age stereotypes and discriminatory attitudes across Hong Kong and the UK in a sample of part-time students some of which worked in personnel management, Chiu et al. (2001) found that negative stereotypes are related to ageist intentions regarding outcomes like training, promotion, and retention. To further test the role of stereotypes about older adults beyond information about the actual age Abrams et al. (2016) omitted age from their vignettes and instead presented two applicants which either were described using typical old skills (e.g. settling arguments, using a library) or typical young skills (e.g. learning new skills, using social media). The authors found that the participants would rather hire the candidate with the young profile. However, other studies failed to demonstrate an effect of stereotypes on discrimination within the domain of work (Leisink and Knies 2011).

Besides the inconsistency of the results within this area of research, the informative value of many studies regarding the question how age stereotypes are related to discriminatory behaviour is limited due to their design and participants relying mostly on student samples and artificial employment contexts. Regarding participants, it was shown that students and actual managers differ in their performance evaluations and hiring decision (Singer and Sewell 1989). In a meta-analytic review it was found that supervisors as compared to students evaluate older workers more positively (Gordon and Arvey 2004). Regarding the study design, Morgeson et al. (2008) found in their literature review on age discrimination in the work domain that there are fewer discrimination effects in field studies as compared to laboratory studies.

To complicate matters further, studies using a correlative design face an additional problem: The opposite direction of the causal relation between stereotypes and discrimination was proposed as well, whereby stereotypes are considered as an outcome of discrimination (Dovidio et al. 1996; Talaska et al. 2008). This hypoth- 
esis is related to the justification function of stereotypes (Allport 1958) suggesting that if members of a group are rejected, cognitions are formed to justify this behaviour. A consensus might be reached in the idea that the interrelation among stereotypes and discrimination is reciprocal (Dovidio et al. 2010).

Age Stereotypes and Stereotype-Consistent Behaviour As proposed within the behaviours from intergroup affect and stereotypes framework (Cuddy et al. 2007) different behaviours towards members of groups (e.g, older adults) are based on different stereotypes about them, as well as corresponding emotions. As an example for stereotype-consistent behaviour, it was assumed that older adults are confronted with the communication predicament of ageing (e.g., Ryan et al. 1986) "as a consequence of lower expectations for performance". It was shown that people would adjust their communication with older adults for example by reducing their speaking rate depending on the context and characteristics of the older person (Hummert et al. 1998). In this study participants assumed that they would speak to an older adult described as "despondent" in a way that might reflect their age stereotypes like a lower memory performance. However, stereotype consistent or age-differentiated behaviours and judgements do not necessarily equal age discrimination.

In sum, evidence for a simple relation between explicit age stereotypes and age discrimination is sparse, especially considering how wide-spread the idea is. There are two main problems in this regard: The definitions of age discrimination are heterogeneous and in most cases indicators of actual discrimination are used as dependent variables. Accordingly, the relation of age stereotypes and age discrimination was hardly ever investigated. Additionally, studies in this field face a variety of methodological challenges which complicate the interpretation of the results. However, even without those limitations, a small association between age stereotypes and overt discriminatory behaviour against older adults would not be surprising, looking at research from a related area. As was already shown for attitude-behaviour relations in general, correlations between (stereotypical) general beliefs or attitudes and actual specific behaviour in a certain context are relatively small (Ajzen and Fishbein 2005; Schütz and Six 1996). Similarly, studies investigating age stereotypes as predictors of age discrimination show mixed results.

\subsubsection{Moderators of the Relation Between Age Stereotypes and Ageist Behaviour}

There is a variety of potential reasons for the mixed results with regard to the stereotype-discrimination relation. A wide-spread critique that was proposed comparatively early within this line of research is the neglect of situational and contextual influences on the relation between stereotypes and discrimination (e.g., Dovidio et al. 1996; inner black frame of Fig. 2.1). In a review on age stereotypes and their outcomes in the work domain, Posthuma and Campion (2009) identified the match 
between perceived appropriate age in a job and actual age as a moderator of the effect of age stereotypes on age discrimination. It is assumed that besides information that can be derived from a person himself/herself (e.g., by making inferences based on someone's age) there is also information that can be inferred from the specific situation. In a selection context these different sources of information can be compared and the outcome (e.g., a hiring decision, promotion) depends on a match between target age and job age prototype (e.g., Perry et al. 1996). The authors found that young applicants are more positively evaluated for a prototypical "young-typed job" than older applicants. However, there is no difference for the typical "old-typed job". Similar propositions were made by role congruity theory that assumes that discrimination emerges from the interplay of contextual information and stereotypes about the target (Eagly and Diekman 2005). In line with role congruity theory it was shown that in contrast to younger applicants where no difference was found, the hireability of older applicants is higher for a stable company than for a dynamic company (Diekman and Hirnisey 2007). Most importantly the authors also found that this relation was further mediated by perceived adaptability.

In a meta-framework proposed by Posthuma et al. (2012) the authors acknowledge that moderators can exist on different levels whereby some of them are related to an individual level affecting mostly the association between age and stereotypes whereas others are related to the meso-level, and are more likely to affect the stereotype-discrimination association. As discussed in more detail by De Tavernier and colleagues in this book on a meso-level structural as well as softer characteristics of organizations are among the factors associated with age discrimination in the work context. Organizational climate as well as organizational structure like the average or typical age of job holders are related to targeting older applicants whereby the latter indicates that in an organization with an older workforce older applicants appear less non-traditional and less likely to violate expectations regarding typical job holders (Goldberg et al. 2013).

Although discrimination at an institutional level can be associated with stereotypes that are held by individuals and individual actions, it is part of its specific characteristics that it does not depend on them (Dovidio et al. 2010). However, an institution can reinforce the use of age stereotypes in decision making thereby strengthening the link between stereotypes and age discrimination. In the context of medical care, aspects of curricula used during the medical education can entail case studies with "typical "medical conditions of older adults (Higashi et al. 2012). In combination with institutional requirements (e.g. time pressure; Hinton et al. 2007) these circumstances create an environment that could reinforce stereotype-based decisions potentially to the disadvantage of older patients (outer black frame in Fig. 2.1). Going beyond organizational moderators, on a macro-level social norms and laws that prohibit ageist behaviour (Rothermund and Mayer 2009, p. 80) and the cultural background (Chiu et al. 2001) are also assumed to affect the stereotypebehaviour relation (outer black frame in Fig. 2.1). Accordingly, several factors on different levels have been proposed to modulate the relation between explicit age stereotypes and overt age discrimination, indicating that the relation is more complex than was initially presumed (Voss and Rothermund, in press). 


\subsection{Ageism from the Perceiver's Perspective: Individually Held Age Stereotypes as Predictors of Perceived Age Discrimination}

A very interesting aspect of stereotypes about older adults which sets them apart from stereotypes based on other characteristics like gender and race is that eventually everyone gets older. At the same time, age stereotypes become internalized into perceptions older adults have about themselves and their own ageing (Kornadt et al. 2015a; Levy 2009; Rothermund and Brandtstädter 2003), so-called (future) selfviews or self-perceptions of ageing. Accordingly, age stereotypes do not only affect people's behaviour towards other people (i.e., older adults) but also older adults themselves.

\subsubsection{Review of Existing Evidence for Age Stereotypes as Predictors of Perceived Age Discrimination}

A major factor that explains who interprets others' behaviour in terms of discrimination are inter-individual differences (e.g., stigma consciousness, Pinel 1999; sensitivity to befallen injustice, Schmitt et al. 1995). Some of these concepts also relate stereotypes to perceived age discrimination. Within the framework of stigma, which manifests itself in stereotypes and prejudice (for a review see, Chasteen and Cary 2015), the so-called stigma consciousness describes the extent to which people expect that their behaviour is interpreted based on group membership and that they are stereotyped or discriminated against (Pinel 1999). Stigma consciousness was shown to be associated with perceived discrimination (Pinel 1999). Similarly, agebased rejection sensitivity describes older adults' expectation or perceptions of agebased rejection which was also shown to be related to awareness of ageism (Kang and Chasteen 2009; see "cognitive aspects" on the perceiver's side in Fig. 2.1).

Both concepts, stigma consciousness and age-based rejection sensitivity imply that older adults have an idea of which stereotypes members of an out-group hold about them (i.e. they hold meta-stereotypes, Vorauer et al. 1998) based on which they assume to be rejected or discriminated against just as in the introductory example. These meta-stereotypes were demonstrated to be related to perceived discrimination (Owuamalam and Zagefka 2013). Additionally, their own negative self-perceptions of ageing might provide a basis for the expectation of being stereotyped and discriminated as indicated by the fact that perceived stigma (e.g., being rejected, social isolation) is negatively related to different dimensions of self-perception (Fife and Wright 2000; see "cognitive aspects" on the perceiver's side in Fig. 2.1). However, the causal direction remains unclear. A process of mutual influence is conceivable whereby negative self-perceptions of ageing are related to more perceived age discrimination, which in turn reinforces negative self-perceptions of ageing. Therefore Voss et al. (2017) examined the association among self-perceptions of ageing and 
perceived age discrimination across two measurement occasions that were separated by a three-year interval. Their results point to a stronger effect of self-perceptions of ageing on subsequent changes in perceived age discrimination.

Contrary to what was discussed so far, it was also shown that positive expectations can be related to perceived discrimination (Inman 2001) and can have negative effects on social interactions (Son and Shelton 2011). Inman concluded that people who were surprised by a negative evaluation because they had a more positive self-perception were more likely to perceive discrimination. This would indicate that those who have negative as well as those with positive views on ageing should both report higher levels of perceived age discrimination. These seemingly contradictory results might be reconciled by identifying moderators that highlight either positive or negative views on aging as a risk factor for perceiving age discrimination. A likely candidate is the reference object of views on aging, with positive self-views of aging and negative views on aging purportedly held by others pose risk factors for feeling undervalued due to one's age, rendering experiences of exclusion or rejection as examples of age discrimination.

Generally, it is assumed that whether discrimination is perceived or not does not only depend on characteristics of the individual but also on features of the situation and specific event (Major and Sawyer 2009; inner black frame in Fig. 2.1). According to stereotype-asymmetry assumption, people are more likely to perceive discrimination in a situation that is characterized by negative stereotypes about the perceiver than by positive stereotypes (O'Brien et al. 2008). Furthermore, macro-level aspects like societal norms and regulations are assumed to affect age stereotypes and selfperceptions of ageing (e.g., Kornadt and Rothermund 2015; outer black frame in Fig. 2.1). Processes like the internalization of stereotypes (e.g., Kornadt et al. 2015a; Levy 2009) point to the role of the macro- and meso-level influences that have an indirect impact on perceived age discrimination.

\subsubsection{Mediators of the Relations Between Age Stereotypes and Perceived Age Discrimination}

The studies and concepts discussed so far reveal that perceived age discrimination is related to age stereotypes and self-perceptions of ageing. In the current section, we address the question of how these relations can be explained, that is, we focus on the underlying mechanisms that link views on aging with perceived age discrimination. In a model from research on stigma it was assumed that stereotypes not only affect the behaviour of others, but also the way people with a stigma (e.g., old age) interpret the behaviour of others (Rüsch et al. 2005; lower dashed arrow in Fig. 2.1). In an ambiguous situation, members of stigmatized groups are more likely to 
attribute negative feedback to prejudice, compared to those without a stigma (Crocker et al. 1991). Accordingly, the relations between self-perceptions of ageing as well as meta-stereotypes and perceived age discrimination could be based on an attributional bias. However, considering that perceived discrimination and "objective" discrimination are not always independent (see Sect. 2.1) it seems likely that other (additional) processes are at work.

Research on the developmental implications of views on aging has produced ample evidence that age stereotypes held by older adults are related to their own behaviour (e.g., Levy and Myers 2004; Kornadt et al. 2015b). This relation provides another potential pathway through which age stereotypes and perceived age discrimination may be linked (Voss et al. 2017). The basic idea behind this explanation is that by behaving in a stereotype-consistent manner themselves, older adults invite others to behave towards them in a stereotype-consistent fashion, which then gives rise to perceptions of age discrimination. Processes that potentially mediate the relations between age stereotypes and stereotype-consistent behaviour of older adults are internalization of age stereotypes, self-stereotyping, and stereotype threat, all of which were shown to have performance-related behavioural consequences for older adults (e.g., Hess et al. 2003; Levy 1996, 2009; Lamont et al. 2015; for more information on stereotype threat and internalization of age stereotypes see Swift, Abrams, Marques, Vauclair and Bratt in this book). A meta-analysis on the effects of priming with age stereotypes on behaviour of older adults showed the detrimental effects of the activation of negative age stereotypes on different behavioural and performance related outcomes (Meisner 2012). In a related vein, in their study on stereotype threat Hess et al. (2003) reported that older adults' memory performance decreased depending on the degree to which negative stereotypes of ageing were activated. The authors concluded that those mechanisms could also be at work in many situations in everyday life, because subtle characteristic of the environment can trigger the activation of negative age stereotypes, and thereby affect the everyday functioning and behaviour of older adults.

Interestingly, it is furthermore assumed that rejection sensitivity might act as a self-fulfilling prophecy creating a situation that confirms the expectation (Levy et al. 2001). In ambiguous situations expectations of rejection or discrimination (e.g., triggered by the assumed attitude someone has about in-group members) were shown to evoke maladaptive behaviours in terms of a reduced performance (Mendoza-Denton et al. 2009). This might increase the likelihood of a (perceived) rejection. Similarly, the effects of stereotypes on interpretation and behaviour might not represent two different mediating mechanisms but could also reinforce each other (e.g., if the interpretation of behaviour as discriminatory leads to reactance, or if an older adult's behaviour elicits behaviour in an interaction partner that is easily perceived as discriminatory). 


\subsection{Interrelations Between the Perceiver's and the Actor's Perspectives}

Although so far we discussed the perspective of an older person feeling discriminated against separately from the perspective of another person behaving in a discriminatory way, it is important to note that they are most likely interrelated, as in everyday life situations behaviours and expectations of actors and perceivers reinforce each other (Snyder 2001). Consider for example that stereotypes held by older adults also affect their behaviour (see Sect. 2.4.2). The detrimental effects of stereotype threat (e.g., Hess et al. 2003) or self-stereotyping (Levy 1996) on performance could reinforce negative age stereotypes about older adults held by someone else and thus potentially evoke a corresponding reaction. These mutual effects are the central elements of Fig. 2.1: On the backdrop of social and situational constraints and cues the expectations and corresponding behaviours of interaction partners mutually reinforce each other. From studies regarding racial and gender discrimination we know that stereotypes and expectations about a target person can elicit anticipatory behaviour in the interaction partner, which again causes the target person to behave in a way that confirms the stereotype (for review see Snyder 2001; Word et al. 1974). Chen and Bargh (1997) labelled this the expectancy-driven model of behavioural confirmation effects. They demonstrated that this effect even applies to situations where stereotypes are activated unconsciously.

Based on findings demonstrating that stereotypes can elicit stereotype-confirming behaviour in the target person, one might assume that those processes can result in perceived discrimination. If for example, an older applicant in a job interview confirms negative stereotypes about older adults (e.g. because of stereotype threat or stereotype-consistent behaviour of the interviewer) this might entail a rejection. A similar effect was shown in the context of interracial bias. White interviewers created a more negative interview environment for black as compared to white participants which was, as shown in a second experiment, associated with a worse performance (Word et al. 1974). Within the context of employment, Maurer (2001) proposed a model of worker age and self-efficacy for development of career-relevant skills. According to the model, worker's age is related to the confrontation with negative age stereotypes, which results in a decrease in self-efficacy for development and career-relevant learning and eventually in a lesser degree of voluntary training activities. These behavioural outcomes would in turn confirm stereotypes about older workers being resistant to change (Weiss and Maurer 2004) and less interested in training ( $\mathrm{Ng}$ and Feldman 2012), which then again might result in fewer training opportunities offered to older employees.

As proposed by Rüsch et al. (2005), stereotypes affect both the behaviour of actors as well as the behaviour and interpretation of stigmatized people. In interactions, this can result in a self-sustaining chain reaction whereby stereotypes not only shape expectations and interpretations but also elicit corresponding behaviours. Accordingly, in order to fully understand the interrelations among age stereotypes and discrimination from both, the perspective of older adults and potential actors, 
they should be investigated in interactive situations, allowing to disentangle the mutually reinforcing contributions of both pathways.

\subsection{Conclusion and Implications}

A reference to age stereotypes and/or age-related prejudice is a constitutive element of both actual and perceived age discrimination. Importantly, this connection is necessary but not sufficient, allowing for situations in which age stereotypes are activated but do not result in age discrimination. Despite this close conceptual linkage, empirical evidence for a simple empirical association of age stereotypes and overt discriminatory behaviour is scarce. Partly, this can be traced back to the lack of studies actually examining stereotypes as predictors of overt discrimination, but also to difficulties in assessing overt "objective" discrimination and, relatedly, to the large variation of what is considered an instance of age discrimination. Considering the relatively small predictive value of stereotypes for discrimination some authors completely dismiss the idea of stereotypes as predictors of age discrimination and propose prejudice or emotions as a more promising predictor of intergroup behaviour and discrimination (e.g., Cuddy et al. 2007; Talaska et al. 2008). It was proposed that "stereotypes, beliefs, and emotional prejudices all closely relate to what people say they did or will do toward outgroup members, but emotional prejudices are more closely related to what people actually do" (Talaska et al. 2008, p. 284). Amodio and Devine (2006) showed that implicit stereotypes and prejudice distinctively predict different types of inter-group behaviours like judgements and social distance respectively. Accordingly, age stereotypes might be better predictors of perceived age discrimination than they are for "objective" discrimination. The current review of the scarce and limited literature on this important topic clearly suggests, however, that it is much too early for sweeping conclusions regarding the influence of age stereotypes on age discrimination. Additional evidence is needed, in particular, along the lines that have been suggested by recent promising studies that have extended the boundaries of the stereotype-discrimination relations by using, for example, implicit stereotype measures (Sekaquaptewa et al. 2003), by considering additional variables (e.g., Cuddy et al. 2007), or by focussing on moderators (see Sect. 2.3.2). Implicit attitude measures were shown to predict behaviours that could not be predicted by explicit measures or had predictive value above those (Dovidio et al. 2002; Vargas et al. 2004).

Future research on the relations between age stereotypes and age discrimination is urgently needed that (a) is based on an adequate definition and assessment of age discrimination, (b) combines field studies (typically using a correlative design) with more controlled experiments in the lab, and (c) takes into consideration moderating variables in order to investigate for whom and in which situations the relation holds or does not hold.

A second upshot of our review is that taking into account not only the actor, but also the perceiver's perspective provides us with a much broader and more 
comprehensive understanding of the stereotype-discrimination relations, and also implies a new starting point for interventions targeting age discrimination. Both perspectives can inform each other, and considering influences of age stereotypes on the behaviours and perceptions of both sides in interactive situations seems to be a promising avenue for further research. This conclusion is much in line with a suggestion that was put forward by King and Hebl (2013) who claimed that stereotyping is best investigated in real life contexts and interactions. This would also counteract the concerns regarding ecological validity (e.g., a meta-analysis on age bias in laboratory and field settings identified negative relations between generalizability and effect size, Gordon and Arvey 2004).

In sum, although conceptually an involvement of age stereotypes in age discrimination is inevitable, the mere activation of age stereotypes is by no means a sufficient condition for the occurrence of age discrimination. A full understanding of the complexities of these relations requires frameworks that incorporate additional personal and contextual constraints and also consider the domain-specificity of age stereotypes and age discrimination.

\section{References}

Abrams, D., Swift, H. J., \& Drury, L. (2016). Old and unemployable? How age-based stereotypes affect willingness to hire job candidates. Journal of Social Issues, 72, 105-121. https://doi. org/10.1111/josi.12158

Age Discrimination in Employment Act (ADEA) of 1967. (1967). 29 U.S.C. § 621, 81 Stat. 602.

Ajzen, I., \& Fishbein, M. (2005). The influence of attitudes on behavior. In D. Albarracín, B. T. Johnson, \& M. P. Zanna (Eds.), The handbook of attitudes (pp. 173-221). Mahwah: Lawrence Erlbaum Associates Publishers.

Allgemeines Gleichbehandlungsgesetz (AGG) [General Act on Equal Treatment]. (2006). BGBl. I S. 1897.

Allport, G. W. (1958). The nature of prejudice. Garden City: Doubleday.

Amodio, D. M., \& Devine, P. G. (2006). Stereotyping and evaluation in implicit race bias: Evidence for independent constructs and unique effects on behavior. Journal of Personality and Social Psychology, 91, 652-661. https://doi.org/10.1037/0022-3514.91.4.652

Australien Human Rights Commission. (2010). Age discrimination - Exposing the hidden barrier for mature age workers. https://www.humanrights.gov.au/our-work/age-discrimination/ publications/age-discrimination-exposing-hidden-barrier-mature-age. Accessed 10 Mar 2016.

Bal, A. C., Reiss, A. E. B., Rudolph, C. W., \& Baltes, B. B. (2011). Examining positive and negative perceptions of older workers: A meta-analysis. The Journal of Gerontology, Series B: Psychological Sciences an Social Sciences, 66, 687-698. https://doi.org/10.1093/geronb/ gbr056

Baron, R. S., Burgess, M. L., \& Kao, C. F. (1991). Detecting and labeling prejudice: Do female perpetrators go undetected? Personality and Social Psychology Bulletin, 17, 115-123. https:// doi.org/10.1177/014616729101700201

Bendick, M., Brown, L. E., \& Wall, K. (1999). No foot in the door: An experimental study of employment discrimination against older workers. Journal of Aging \& Social Policy, 10, 5-23.

Brockmann, H. (2002). Why is less money spent on health care for the elderly than for the rest of the population? Health care rationing in German hospitals. Social Science \& Medicine, 55, 593-608. 
Butler, R. N. (1980). Ageism: A foreword. Journal of Social Issues, 36, 8-11. https://doi. org/10.1111/j.1540-4560.1980.tb02018.x

Casper, C., Rothermund, K., \& Wentura, D. (2011). The activation of specific facets of age stereotypes depends on individuating information. Social Cognition, 29, 393-414.

Chasteen, A. L., \& Cary, L. A. (2015). Age stereotypes and age stigma: Connections to research on subjective aging. In M. Diehl \& H. Wahl (Eds.), Annual review of gerontology and geriatrics, vol. 35, 2015: Subjective aging: New developments and future directions (pp. 99-119). New York: Springer.

Chen, M., \& Bargh, J. A. (1997). Nonconscious behavioral confirmation processes: The selffulfilling consequences of automatic stereotype activation. Journal of Experimental Social Psychology, 33, 541-560. https://doi.org/10.1006/jesp.1997.1329

Chiu, W. K., Chan, A. W., Snape, E., \& Redman, T. (2001). Age stereotypes and discriminatory attitudes towards older workers: An East-West comparison. Human Relations, 54(5), 629-661. https://doi.org/10.1177/0018726701545004

Crocker, J., Voelkl, K., Testa, M., \& Major, B. (1991). Social stigma: The affective consequences of attributional ambiguity. Journal of Personality and Social Psychology, 60, 218-228. https:// doi.org/10.1037/0022-3514.60.2.218

Cuddy, A. C., Fiske, S. T., \& Glick, P. (2007). The BIAS map: Behaviors from intergroup affect and stereotypes. Journal of Personality and Social Psychology, 92, 631-648. https://doi. org/10.1037/0022-3514.92.4.631

Devine, P. G. (1989). Stereotypes and prejudice: Their automatic and controlled components. Journal of Personality and Social Psychology, 56, 5-18. https://doi.org/10.1037/0022-3514.56.1.5

Diekman, A. B., \& Hirnisey, L. (2007). The effect of context on the silver ceiling: A role congruity perspective on prejudiced responses. Personality \& Social Psychology Bulletin, 33, 13531366. https://doi.org/10.1177/0146167207303019

Dovidio, J. F., Brigham, J. C., Johnson, B. T., \& Gaertner, S. L. (1996). Stereotyping, prejudice, and discrimination: Another look. In N. C. Mcrae, C. Stangor, \& M. Hewstone (Eds.), Stereotypes and stereotyping (pp. 276-322). New York: Guilford Press.

Dovidio, J. F., Kawakami, K., \& Gaertner, S. L. (2002). Implicit and explicit prejudice and interracial interaction. Journal of Personality and Social Psychology, 82, 62-68. https://doi. org/10.1037/0022-3514.82.1.62

Dovidio, J. F., Hewstone, M., Glick, P., \& Esses, V. M. (2010). Prejudice, stereotyping and discrimination: Theoretical and empirical overview. In J. F. Dovidio, M. Hewstone, P. Glick, \& V. M. Esses (Eds.), The SAGE handbook of prejudice, stereotyping and discrimination (pp. 3-28). London: Sage.

Eagly, A. H., \& Diekman, A. B. (2005). What is the problem? Prejudice as an attitude-in-context. In J. F. Dovidio, P. Glick, \& L. A. Rudman (Eds.), On the nature of prejudice: Fifty years after Allport (pp. 19-35). Malden: Blackwell Publishing.

European Commission. (2011). Synthesis report I - 2011. Older workers, discrimination, and employment. http://ec.europa.eu/justice/discrimination/files/sen_synthesisreport2011_en.pdf. Accessed 12 Apr 2016.

Fife, B. L., \& Wright, E. R. (2000). The dimensionality of stigma: A comparison of its impact on the self of persons with HIV/AIDS and cancer. Journal of Health and Social Behavior, 41, 50-67. https://doi.org/10.2307/2676360

Fiske, S. T., \& Neuberg, S. L. (1990). A continuum of impression formation, from category-based to individuating processes: Influences of information and motivation on attention and interpretation. In M. P. Zanna (Ed.), Advances in experimental social psychology (Vol. 23, pp. 1-74). San Diego: Academic.

Gee, G. C., Pavalko, E. K., \& Long, J. S. (2007). Age, cohort and perceived age discrimination: Using the life course to assess self-reported age discrimination. Social Forces, 86, 265-290.

Gilbert, D. T., \& Hixon, J. G. (1991). The trouble of thinking: Activation and application of stereotypic beliefs. Journal of Personality and Social Psychology, 60, 509-517. https://doi. org/10.1037/0022-3514.60.4.509 
Goldberg, C. B., Perry, E. L., Finkelstein, L. M., \& Shull, A. (2013). Antecedents and outcomes of targeting older applicants in recruitment. European Journal of Work and Organizational Psychology, 22, 265-278. https://doi.org/10.1080/1359432X.2012.746315

Gordon, R. A., \& Anderson, K. S. (1995). Perceptions of race-stereotypic and race-nonstereotypic crimes: The impact of response-time instructions on attributions and judgments. Basic and Applied Social Psychology, 16, 455-470. https://doi.org/10.1207/s15324834basp1604_4

Gordon, R. A., \& Arvey, R. D. (2004). Age bias in laboratory and field settings: A metaanalytic investigation. Journal of Applied Social Psychology, 34, 468-492. https://doi. org/10.1111/j.1559-1816.2004.tb02557.x

Hess, T. M., Auman, C., Colcombe, S. J., \& Rahhal, T. A. (2003). The impact of stereotype threat on age differences in memory performance. The Journals of Gerontology: Series B: Psychological Sciences and Social Sciences, 58, 3-11. https://doi.org/10.1093/geronb/58.1.P3

Higashi, R. T., Tillack, A. A., Steinman, M., Harper, M., \& Johnston, C. B. (2012). Elder care as 'frustrating' and 'boring': Understanding the persistence of negative attitudes toward older patients among physicians-in-training. Journal of Aging Studies, 26, 476-483. https://doi. org/10.1016/j.jaging.2012.06.007

Hinton, L., Franz, C. E., Reddy, G., Flores, Y., Kravitz, R. L., \& Barker, J. C. (2007). Practice constraints, behavioral problems, and dementia care: Primary care physicians' perspectives. Journal of General Internal Medicine, 22, 1487-1492. https://doi.org/10.1007/s11606-007-0317-y

Hummert, M. L., Garstka, T. A., Shaner, J. L., \& Strahm, S. (1994). Stereotypes of the elderly held by young, middle-aged, and elderly adults. Journal of Gerontology, 49, 240-249.

Hummert, M. L., Garstka, T. A., \& Shaner, J. L. (1997). Stereotyping of older adults: The role of target facial cues and perceiver characteristics. Psychology and Aging, 12, 107-114. https://doi. org/10.1037/0882-7974.12.1.107

Hummert, M. L., Shaner, J. L., Garstka, T. A., \& Henry, C. (1998). Communication with older adults: The influence of age stereotypes, context and communicator age. Human Communication Research, 25, 124-151. https://doi.org/10.1111/j.1468-2958.1998.tb00439.x

Inman, M. L. (2001). Do you see what I see? Similarities and differences in victims' and observers' perceptions of discrimination. Social Cognition, 19, 521-546. https://doi.org/10.1521/ soco.19.5.521.19912

K. H. (2014). http://www.altersdiskriminierung.de/themen/artikel.php?id=6289

Kang, S. K., \& Chasteen, A. L. (2009). The development and validation of the age-based rejection sensitivity questionnaire. The Gerontologist, 49, 303-316. https://doi.org/10.1093/geront/ gnp035

King, E., \& Hebl, M. (2013). Oh the places we should go!: Stereotyping and prejudice in (real) mixed interactions. In C. Stangor \& C. S. Crandall (Eds.), Stereotyping and prejudice. New York: Psychology Press.

Kornadt, A. E., \& Rothermund, K. (2011). Contexts of aging: Assessing evaluative age stereotypes in different life domains. The Journals of Gerontology: Series B: Psychological Sciences and Social Sciences, 66, 547-556. https://doi.org/10.1093/geronb/gbr036

Kornadt, A. E., \& Rothermund, K. (2015). Views on aging: Domain-specific approaches and implications for developmental regulation. In M. Diehl \& H. Wahl (Eds.), Annual review of gerontology and geriatrics, vol. 35, 2015: Subjective aging: New developments and future directions (pp. 121-144). New York: Springer Publishing.

Kornadt, A. E., Voss, P., \& Rothermund, K. (2015a). Age stereotypes and self-views revisited: Patterns of internalization and projection processes across the life span. The Journals of Gerontology: Series B: Psychological Sciences and Social Sciences. Advance online publication. doi:https://doi.org/10.1093/geronb/gbv099

Kornadt, A. E., Voss, P., \& Rothermund, K. (2015b). Hope for the best, prepare for the worst? Future self-views and preparation for age-related changes. Psychology and Aging, 30, 967976. https://doi.org/10.1037/pag0000048 
Krings, F., Sczesny, S., \& Kluge, A. (2011). Stereotypical inferences as mediators of age discrimination: The role of competence and warmth. British Journal of Management, 22, 187-201. https://doi.org/10.1111/j.1467-8551.2010.00721.x

Kunda, Z., \& Spencer, S. J. (2003). When do stereotypes come to mind and when do they color judgment? A goal-based theoretical framework for stereotype activation and application. Psychological Bulletin, 129, 522-544. https://doi.org/10.1037/0033-2909.129.4.522

Lamont, R. A., Swift, H. J., \& Abrams, D. (2015). A review and meta-analysis of age-based stereotype threat: Negative stereotypes, not facts, do the damage. Psychology and Aging, 30, 180-193. https://doi.org/10.1037/a0038586

Leisink, P. M., \& Knies, E. (2011). Line managers' support for older workers. The International Journal of Human Resource Management, 22, 1902-1917. https://doi.org/10.1080/09585192 .2011 .573969

Lepore, L., \& Brown, R. (1997). Category and stereotype activation: Is prejudice inevitable? Journal of Personality and Social Psychology, 72, 275-287. https://doi.org/10.1037/0022-3514.72.2.275

Levy, B. (1996). Improving memory in old age through implicit self-stereotyping. Journal of PersonalityandSocialPsychology,71,1092-1107.https://doi.org/10.1037/0022-3514.71.6.1092

Levy, B. (2009). Stereotype embodiment: A psychosocial approach to aging. Current Directions in Psychological Science, 18, 332-336. https://doi.org/10.1111/j.1467-8721.2009.01662.x

Levy, B. R., \& Leifheit-Limson, E. (2009). The stereotype-matching effect: Greater influence on functioning when age stereotypes correspond to outcomes. Psychology and Aging, 24, 230 233. https://doi.org/10.1037/a0014563

Levy, B. R., \& Myers, L. M. (2004). Preventive health behaviors influenced by self-perceptions of aging. Preventive Medicine: An International Journal Devoted to Practice and Theory, 39, 625-629. https://doi.org/10.1016/j.ypmed.2004.02.029

Levy, S. R., Ayduk, O., \& Downey, G. (2001). The role of rejection sensitivity in people's relationships with significant others and valued social groups. In M. R. Leary (Ed.), Interpersonal rejection (pp. 251-289). New York: Oxford University Press.

Major, B., \& Sawyer, P. J. (2009). Attributions to discrimination: Antecedents and consequences. In T. D. Nelson (Ed.), Handbook of prejudice, stereotyping, and discrimination (pp. 89-110). New York: Psychology Press.

Major, B., Quinton, W. J., \& McCoy, S. K. (2002). Antecedents and consequences of attributions to discrimination: Theoretical and empirical advances. In M. P. Zanna (Ed.), Advances in experimental social psychology (Vol. 34, pp. 251-330). San Diego: Academic. https://doi. org/10.1016/S0065-2601(02)80007-7

Maurer, T. J. (2001). Career-relevant learning and development, worker age, and beliefs about self-efficacy for development. Journal of Management, 27, 123-140. https://doi.org/10.1016/ S0149-2063(00)00092-1

Meisner, B. A. (2012). A meta-analysis of positive and negative age stereotype priming effects on behavior among older adults. The Journals of Gerontology: Series B: Psychological Sciences and Social Sciences, 67, 13-17. https://doi.org/10.1093/geronb/gbr062

Mendoza-Denton, R., Shaw-Taylor, L., Chen, S., \& Chang, E. (2009). Ironic effects of explicit gender prejudice on women's test performance. Journal of Experimental Social Psychology, 45, 275-278. https://doi.org/10.1016/j.jesp.2008.08.017

Morgeson, F. P., Reider, M. H., Campion, M. A., \& Bull, R. A. (2008). Review of research on age discrimination in the employment interview. Journal of Business and Psychology, 22, 223-232. https://doi.org/10.1007/s10869-008-9066-0

Moskowitz, G. B., Gollwitzer, P. M., Wasel, W., \& Schaal, B. (1999). Preconscious control of stereotype activation through chronic egalitarian goals. Journal of Personality and Social Psychology, 77, 167-184. https://doi.org/10.1037/0022-3514.77.1.167

Ng, T. H., \& Feldman, D. C. (2012). Evaluating six common stereotypes about older workers with meta-analytical data. Personnel Psychology, 65, 821-858. https://doi.org/10.1111/peps. 12003

North, M. S., \& Fiske, S. T. (2012). An inconvenienced youth? Ageism and its potential intergenerational roots. Psychological Bulletin, 138, 982-997. https://doi.org/10.1037/a0027843 
O’Brien, L. T., Kinias, Z., \& Major, B. (2008). How status and stereotypes impact attributions to discrimination: The stereotype-asymmetry hypothesis. Journal of Experimental Social Psychology, 44, 405-412. https://doi.org/10.1016/j.jesp.2006.12.003

Owuamalam, C., \& Zagefka, H. (2013). We'll never get past the glass ceiling! Meta-stereotyping, world-views and perceived relative group-worth. British Journal of Psychology, 104, 543-562.

Perry, E. L., Kulik, C. T., \& Bourhis, A. C. (1996). Moderating effects of personal and contextual factors in age discrimination. Journal of Applied Psychology, 81, 628-647.

Pinel, E. C. (1999). Stigma consciousness: The psychological legacy of social stereotypes. Journal of Personality and Social Psychology, 76, 114-128. https://doi.org/10.1037/0022-3514.76.1.114

Posthuma, R. A., \& Campion, M. A. (2009). Age stereotypes in the workplace: Common stereotypes, moderators, and future research directions. Journal of Management, 35, 158-188. https://doi.org/10.1177/0149206308318617

Posthuma, R. A., Wagstaff, M. F., \& Campion, M. A. (2012). Age stereotypes and workplace age discrimination: A framework for future research. In J. W. Hedge \& W. C. Borman (Eds.), The Oxford handbook of work and aging (pp. 298-312). New York: Oxford University Press. https://doi.org/10.1093/oxfordhb/9780195385052.013.0104

Rahhal, T. A., Hasher, L., \& Colcombe, S. J. (2001). Instructional manipulations and age differences in memory: Now you see them, now you don't. Psychology and Aging, 16, 697-706. https://doi.org/10.1037/0882-7974.16.4.697

Rodin, M. J., Price, J. M., Bryson, J. B., \& Sanchez, F. J. (1990). Asymmetry in prejudice attribution. Journal of Experimental Social Psychology, 26, 481-504. https://doi. org/10.1016/0022-1031(90)90052-NPress.

Rothermund, K., \& Brandtstädter, J. (2003). Age stereotypes and self-views in later life: Evaluating rival assumptions. International Journal of Behavioral Development, 27, 549-554. https://doi. org/10.1080/01650250344000208

Rothermund, K., \& Mayer, A.-K. (2009). Altersdiskriminierung: Erscheinungsformen, Erklärungen und Interventionsansätze. Stuttgart: Kohlhammer.

Rupp, D. E., Vodanovich, S. J., \& Credé, M. (2006). Age bias in the workplace: The impact of ageism and causal attributions. Journal of Applied Psychology, 36, 1337-1364.

Rüsch, N., Angermeyer, M. C., \& Corrigan, P. W. (2005). Mental illness stigma: Concepts, consequences, and initiatives to reduce stigma. European Psychiatry, 20, 529-539. https://doi. org/10.1016/j.eurpsy.2005.04.004

Ryan, E. B., Giles, H., Bartolucci, G., \& Henwood, K. (1986). Psycholinguistic and social psychological components of communication by and with the elderly. Language \& Communication, 6, 1-24. https://doi.org/10.1016/0271-5309(86)90002-9

Sassenberg, K., \& Moskowitz, G. B. (2005). Don't stereotype, think different! Overcoming automatic stereotype activation by mindset priming. Journal of Experimental Social Psychology, 41(5), 506-514. https://doi.org/10.1016/j.jesp.2004.10.002

Schmitt, M. J., Neumann, R., \& Montada, L. (1995). Dispositional sensitivity to befallen injustice. Social Justice Research, 8, 385-407.

Schütz, H., \& Six, B. (1996). How strong is the relationship between prejudice and discrimination? A meta-analytic answer. International Journal of Intercultural Relations, 20, 441-462. https:// doi.org/10.1016/0147-1767(96)00028-4

Sekaquaptewa, D., Espinoza, P., Thompson, M., Vargas, P., \& von Hippel, W. (2003). Stereotypic explanatory bias: Implicit stereotyping as a predictor of discrimination. Journal of Experimental Social Psychology, 39, 75-82. https://doi.org/10.1016/S0022-1031(02)00512-7

Singer, M. S., \& Sewell, C. (1989). Applicant age and selection interview decisions: Effect of information exposure on age discrimination in personnel selection. Personnel Psychology, 42, 135-154. https://doi.org/10.1111/j.1744-6570.1989.tb01554.x

Snyder, M. (2001). Self-fulfilling stereotypes. In A. Branaman (Ed.), Self and society (pp. 30-35). Malden: Blackwell Publishing. 
Son, D., \& Shelton, J. N. (2011). Stigma consciousness among Asian Americans: Impact of positive stereotypes in interracial roommate relationships. Asian American Journal of Psychology, 2, 51-60. https://doi.org/10.1037/a0022651

Steele, C. M., Spencer, S. J., \& Aronson, J. (2002). Contending with group image: The psychology of stereotype and social identity threat. In M. P. Zanna (Ed.), Advances in experimental social psychology (Vol. 34, pp. 379-440). San Diego: Academic. https://doi.org/10.1016/ S0065-2601(02)80009-0

Talaska, C. A., Fiske, S. T., \& Chaiken, S. (2008). Legitimating racial discrimination: Emotions, not beliefs, best predict discrimination in a meta-analysis. Social Justice Research, 21, 263 296. https://doi.org/10.1007/s11211-008-0071-2

Vargas, P. T., von Hippel, W., \& Petty, R. E. (2004). Using partially structured attitude measures to enhance the attitude-behavior relationship. Personality and Social Psychology Bulletin, 30, 197-211. https://doi.org/10.1177/0146167203259931

Vorauer, J. D., Main, K. J., \& O’Connell, G. B. (1998). How do individuals expect to be viewed by members of lower status groups? Content and implications of meta-stereotypes. Journal of Personality and Social Psychology, 75, 917-937. https://doi.org/10.1037/0022-3514.75.4.917

Voss, P., \& Rothermund, K. (in press). Altersdiskriminierung in institutionellen Kontexten [Age discrimination in institutional contexts]. In B. Kracke \& P. Noack (Eds.), Handbuch Entwicklungs- und Erziehungspsychologie. Heidelberg: Springer.

Voss, P., Wolff, J. K., \& Rothermund, K. (2017). Relations between views on ageing and perceived age discrimination: A domain-specific perspective. European Journal of Ageing, 14, 5-15. https://doi.org/10.1007/s10433-016-0381-4

Weiss, E. M., \& Maurer, T. J. (2004). Age discrimination in personnel decisions: A reexamination. Journal of Applied Social Psychology, 34, 1551-1562. https://doi.org/10.1111/ j.1559-1816.2004.tb02786.x

Wheeler, S. C., \& Petty, R. E. (2001). The effects of stereotype activation on behavior: A review of possible mechanisms. Psychological Bulletin, 127, 797-826. https://doi. org/10.1037/0033-2909.127.6.797

Word, C. O., Zanna, M. P., \& Cooper, J. (1974). The nonverbal mediation of self-fulfilling prophecies in interracial interaction. Journal of Experimental Social Psychology, 10, 109-120. https:// doi.org/10.1016/0022-1031(74)90059-6

Open Access This chapter is licensed under the terms of the Creative Commons Attribution 4.0 International License (http://creativecommons.org/licenses/by/4.0/), which permits use, sharing, adaptation, distribution and reproduction in any medium or format, as long as you give appropriate credit to the original author(s) and the source, provide a link to the Creative Commons license and indicate if changes were made.

The images or other third party material in this chapter are included in the chapter's Creative Commons license, unless indicated otherwise in a credit line to the material. If material is not included in the chapter's Creative Commons license and your intended use is not permitted by statutory regulation or exceeds the permitted use, you will need to obtain permission directly from the copyright holder.

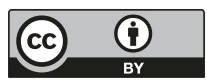




\title{
Chapter 3 \\ Multiple Marginalizations Based on Age: Gendered Ageism and Beyond
}

\author{
Clary Krekula, Pirjo Nikander, and Monika Wilińska
}

\subsection{Introduction}

When Butler introduced the concept of ageism in 1969, it primarily aimed to highlight forms of marginalization and discrimination that older people are exposed to. This was in line with the wider scientific discourse of the time that focused on revealing categorical inequalities as experienced by different social groups based on age, gender, race/ethnicity, and so on. Rooted in social movements, the debate revolved around identity politics with an ambition to expose unique forms of discrimination faced by diverse social groups that were, however, approached from the perspective of a homogeneous collective (Addelson and Potter 1991; Mirza 1997).

As presented in the Chap. 25 by Snellman in this volume (2018), ageism has made a conceptual journey since its inception in the 1960s. One of the hallmarks of that journey was a gradual move from understanding ageism in terms of attitudes only to conceptualizing it as a form of oppression deeply embedded in social structures. In parallel, age is increasingly seen as a socially constructed category that is by no means equivalent to a personal characteristic (Calasanti 2003; Laz 1998; Krekula 2009; Nikander 2009). Age has steadily become recognized as a producer of social division, with a role as a social and identity marker, but also underlining its power in defining social relations, giving rise to institutions and creating inequalities

\footnotetext{
C. Krekula $(\bowtie)$

Karlstad University, Karlstad, Sweden

e-mail: clary.krekula@kau.se

P. Nikander

University of Tampere, Tampere, Finland

e-mail: Pirjo.Nikander@uta.fi

M. Wilińska

Jönköping University, Jönköping, Sweden

e-mail: monika.wilinska@ju.se
}

L. Ayalon, C. Tesch-Römer (eds.), Contemporary Perspectives on Ageism, 
(Gullette 2004; Hockey and James 1993; Krekula 2007; Krekula and Johansson 2016; Nikander 2009). Essentially, this posits age as one of many dimensions of social differentiation processes that cannot be understood in isolation. The understanding of age is therefore becoming further enriched as it is recognized as socially constructed in interaction with other categorizations, such as gender, class, race, and ethnicity (Hockey and James 1993; Krekula 2007; Nikander 2002).

One of the first categories used to complicate the understanding of ageism was gender. The term "gendered ageism" was introduced by Itzin and Phillipson (1993, 1995) in their study of age barriers at work where they focused particularly on gender in both the private and public sector. Since then, gendered ageism has been defined in a range of ways. One recurrent definition describes it as a double jeopardy, where two interacting power systems lead to an increased vulnerability (cf. Barrett and Naiman-Sessions 2016; Handy and Davy 2007; Walker 1998). In gendered ageism, the perspective of double jeopardy emphasizes the dominance of patriarchal norms combined with a preoccupation with youth that results in a faster deterioration of older women's status compared to that of men (Barrett and NaimanSessions 2016).

Any definition of gendered ageism as a phenomenon directed solely against older women is built on delimited categorizations that ascribe them with a presupposed subordinated position. The same is true for definitions of ageism that see it as directed against older people only (see for example Butler 1980; Kalish 1979; Palmore 2001). Both perspectives differ from later research that has shown ageism also as targeting younger people (Duncan and Loretto 2004), and from theoretical work which emphasizes gender as a relational process, and as something which cannot be reduced to women only. Further theoretical problematization of the concept is therefore needed to understand the processes of multiple marginalizations based on age and to see how these affect both men and women of various ages.

In this chapter, we discuss multiple marginalizations based on age by focusing specifically on age and gender as an intersection of power relations. We centre our attention on the concept of gendered ageism that was introduced to spotlight the context-specific dynamics of ageism that women and men alike can be exposed to. The concept is thus placed in a wider context to further problematize the processes which create multiple marginalizations. In this, we draw attention to underlying theoretical assumptions of age-based marginalization and the concept of gendered ageism; we problematize how ageism relates to the current debate on age as socially construed, as a power relation and as marginalization; and we argue that gendered ageism can be understood as a form of doing age. We offer an outline of a research approach that develops the understanding of the processes that can create multiple marginalizations based on age and encourage innovative routes that yield further insight into the complexity of social and gendered inequalities in later life. 


\subsection{From Ageism to Gendered Ageism and Multiple Marginalizations}

In their seminar studies of age barriers at work in the public and private sectors, Itzin and Phillipson $(1993,1995)$ managed to show that ageism does not operate in isolation from other categories, and, alongside others, claimed that the sexualization of women's value in youth was a clear proof of this. They concluded that "gender on its own is an insufficient explanation of the discrimination experienced by women in organisations" (Itzin and Phillipson 1995, p. 91) and claimed that "gendered ageism" formed a central part of organizational cultures. They discovered discrimination in relation to recruitment, career, and pension, and noted that women were defined as ageing at an earlier chronological age, reaching their peak at age 35, while men were considered to reach their peak much later. Their argument indicated that gendered ageism also meant age- and gender-based glass ceilings for women regarding both employment and promotion.

The definition of gendered ageism as a double jeopardy has, with some modification, been applied by other researchers, not least some feminist researchers (e.g., Arber and Ginn 1991; Duncan and Loretto 2004). Researchers have shown that women of all ages, more so than men, experience ageism based on appearance and sexuality in the labour market, among other contexts (Clarke and Griffin 2008; Duncan and Loretto 2004; Granleese and Sayer 2006). Research has also shown, for example, that doctors ask fewer questions and prescribe less medication for coronary heart disease to middle-aged women, which in turn can contribute to inequality in relation to health (Arber et al. 2006), and that female older workers were made invisible in a public inquiry into the older unemployed, due to a discursive struggle for recognition of older male workers as a disadvantaged group in the labour market (Ainsworth 2002).

The concept of gendered ageism as a double jeopardy is also used when pointing to the dynamics of gendered ageism and other categorizations and dimensions, like physical beauty and looks. Here, a so-called triple jeopardy occurs, as appearance has been posited as a further interactive dimension of ageism against women (cf. Granleese and Sayer 2006; Handy and Davy 2007; Jyrkinen 2013; Jyrkinen and McKie 2012). However, in societies that favour health, vitality, and appearance, such requirements might affect older men as well (Hearn 1995). The combined normative forces of healthism (Crawford 1980), lookism, and fitnessism, further supported by ideals of consumerism, means that our future understanding and the scope of gendered ageism continues to unfold.

Despite numerous definitions and continuous discussions on the combined effect of age and gender, the terms double/triple jeopardy remain theoretically underdeveloped and somewhat poorly explored (for a criticism of the concept, see Krekula 2007). For instance, while the dual effect of gender and age is often evidenced by examples concerning women, no substantial data or ambitious theorizing to date exists on whether and how such combined jeopardies affect men, and, if they do, how the dynamics, contexts, and experiences of such ageism might change. Duncan 
and Loretto's (2004) study on ageism in working life showed that a larger number of men than women experienced age discrimination, particularly among the age group 25-44. Consequently, they argued that it would actually be more appropriate to apply the slogan "Never the right age" to men rather than to women. In a similar vein, Thompson (1994) argued that later-life masculinities have been subordinated to the effort to understand middle-aged and younger men's lives, which contribute to gerontophobic masculinity ideals. More recently, work on gendered ageism has mapped the contextual variations and the gender-specific dynamics of people's daily lives to see how interactional contexts shape men's perceptions of ageism in ways that work to provide them with immunity from it (Ojala et al. 2016).

Based on an analysis of an employment tribunal court's final judgment of an accusation of discrimination on the basis of both age and gender, Spedale et al. (2014) argued that ageism has a base in the social construction of an ideology of youthfulness. This ideology is described as having been reproduced through discourses on "brand refreshment and rejuvenation" (p. 1586) and, in that way, obscuring the agency of the more powerful organizational actors while at the same time marginalizing the weaker ones (cf. Clarke and Griffin 2008 and Handy and Davy 2007 on ageism and youthfulness). However, the ideology of youthfulness as a starting point does not suffice to explain marginalization based on age, as it affects younger age groups as well. An increasing number of studies demonstrate that ageism is also directed against children and youth, often discussed through the concepts of adultism (Bell 1995; Ceaser 2014; Flasher 1978; Kennedy 2006) and childism (Pierce and Allen 1975; Young-Bruehl 2012). For instance, entry as well as exit from the labour market can be affected by ageism, the former to a large extent especially targeting youth.

Later shifts in the problematization of both age and ageism resulted not only from changing social realities but also from theoretical developments in understanding inequalities more broadly. Where a focus on homogeneous categories used to exist, contemporary research emphasizes differences within categorizations like age, revealing also their relational nature. For instance, a growing number of studies explore the interaction between age, gender, and class (see McMullin and Cairney 2004; Zajicek et al. 2007), age, gender, and race (Mair 2010), age, gender, and sexuality (Ambjörnsson and Jönsson 2010), and age and masculinity (Bartholomaeus and Tarrant 2016). Reviewing dominant ways of approaching intersectionality and reflecting upon their shortcomings, Walby et al. (2012) proposed that an intersectional perspective encourages a language of inequalities and systems of inequalities. From this perspective, intersectionality stresses the need to understand the powerful alongside the powerless and opens a discourse of mutual shaping while recognizing the flexibility and the unfinished projects of creating differences.

Transferred to debates on ageism, these developments demonstrate that the main problem with the concept, or any other social inequality for that matter, is not oppression organized along the lines of age. Rather, analytic and theoretical work increasingly zoom in on the coexistence of various intersecting forms of oppression that are recreated to produce differencing outcomes and conditions for various groups of people. These challenges are yet to be taken up in the discussions regarding 
ageism. First, as Gullette (2004) vehemently advocated, there needs to be a greater understanding of the prominence of age in the lives and institutions that relate not only to older people but to people of all ages. Second, the relations between people and institutions need to be seen as an interactive whole rather than as flows between static entities (Hancock 2007). Third, instead of presuming a priori defined categories, any intersectional perspective on ageism needs to employ a more empirically driven approach to discover rather than just to test assumptions that are taken for granted (Hancock 2007).

\subsection{The Perspective of Age as Doing}

The perspective of age as doing is grounded in an understanding of age as a socially and culturally constructed category. As such, age does not constitute a role, an identity, or an individual attribute, but is rather an expression of the social context. Researchers have used different concepts to discuss the active and interactional dynamics of age, for example, age-as-accomplishment (Laz 1998), generationing (Alanen 1992), as doing age (Nikander 2002, 2009; Utrata 2011), age relations (Calasanti 2003), and age coding (Krekula 2009). Such interactional perspectives of age offer a move beyond simple understandings of marginalization or ageism as things that are done to one group by members of another. What we begin to see instead is a collaborative social process that involves everyone. This means that ageism, similar to other inequalities, is situationally and interactionally accomplished rather than a natural category (Schwalbe 2008).

Furthermore, to conceive of ageism as actively created in social encounters and processes is to recognize that no one has a predefined role of a victim or an offender. This immediately challenges the widely spread discourse on old age and ageism in which older people are mere victims of ageism. To date, the literature on ageing and inequality typically focusses on things that are perpetrated against old people, while less attention is given to ageist actions by older people themselves. Minichiello et al. (2000) discussed, for example, the concept of interactive ageism to emphasize the diverse ways in which people of different ages respond to and reproduce ageism. Likewise, older people with different life experiences and histories respond to similar oppressive structures differently. What is more, on many occasions, older people themselves are found to convey and maintain ageist attitudes, and to partake in selfinflicted ageism (e.g., Andrews 1999; Hurd 1999; Lund and Engelsrud 2008; Öberg and Tornstam 2001; Wilińska 2012).

Age as formed in and through interaction, negotiation, and on-going discursive processes involves everyone at different levels. Fineman (2011) described this with the metaphor "the social game we play with age" and argued that age as an organizing principle is powerful because it is seen as a neutral affiliation and because the organization thus receives an objective character. In a similar vein, Nikander (2002) claimed that "the theoretical and analytic myopia of much lifespan and ageing research has, in practice, meant overlooking the interactional processes whereby 
age and its meanings are accomplished" (p. 29). The study of age from an interactional perspective thus means examining the nuances and situationally or institutionally processual dynamics of age rather than the category itself. How does age become relevant? How is it done, by whom, and to what ends? When analysing the persistence of the hierarchical gender system, Ridgeway and Correll (2004) proposed that in addition to considering gender norms and beliefs, it is crucial to consider social relational contexts, which they define as "the arenas where these beliefs or rules are in play" (p. 511). This framework can be applied to age to disentangle the variety of ways in which age enters or is actively brought into people's everyday thinking and discourse and institutional contexts, and the ways it produces age orders that organize societies (Twigg 2004).

Observing the encounters between art gallery workers and visitors at the ticket office, Llewellyn (2015) demonstrated the creative ways in which the parties collaboratively do age while engaging in the process of purchasing and selling agegrouped and age-priced entry tickets. Here, the organizational encounter was structured according to the age of the visitors. Some visitors voluntarily announced membership in an age category to receive an age concession. At other times, gallery workers stepped in and actively offered the concession based on their professional ability to interpret visual age cues. An opposite relation was observed in a study of a non-governmental organization working with social programmess addressing older people (Wilińska and Henning 2011). The organization first used socially available images of age to construct an intervention program, and then looked for people who would fit into a very precise definition of an older person. The organizational objectives were therefore reliant on the process of fitting real people into age categories; age was used as resource enabling the organization to govern the participants.

Age as a cultural and social construct comes with an easily accessible and readyto-use arsenal of culture-specific beliefs and norms (see also Tilly 1998, 2003). These are construed around opposing poles: "young," the desired age characterized by beauty, vitality, and strength; and "old," the feared age associated with decline, disease, and weakness. In this construct, age is a cultural resource that, like any other category, helps us make sense of reality, but also limits our way of thinking (Juhila 2004; Ojala et al. 2016). For example, when 55+ members of the University of the Third Age (U3A) reject the idea of old age, they reject the socio-cultural construct that has also very strong moral underpinnings (Wilińska 2012). The rejection becomes an act of protecting one's sense of self-esteem and self-identity.

The same goals of protecting one's sense of self-esteem and self-identity can also be achieved via bodily practices. For instance, a study by Ward and Holland (2011) following older women and their hairdressing practices demonstrated that older women who dyed their hair were not interested in just any type of beauty. Instead, they were interested in non-old standards of beauty. Similarly, when Twigg (2012) discussed the dressing practices of older women, she demonstrated the negotiations and struggles that go into deciding not only what to wear but also where to purchase the clothes. As Krekula (2009) pointed out, different outfits and shopping spots are age coded to indicate those that are more or less appropriate for certain groups of 
women. Regardless of the outcome of such negations, age stands out as a cultural and actively (re)produced resource that facilitates the process of even mundane decision making.

As a chronologically ordered category, age, in other words, clearly allows us to situationally mark and index cultural lifespan norms, preferences, and activities (Nikander 2002). Krekula and Johansson (2016) have noted that there are different aspects of the meaning-creating contexts where age is done. They argue that, even though these are not separate from each other, it can be fruitful to distinguish between, for example, age as a norm, age as a (discursive) resource, and age as marginalization. These different types of doing relate to ageism in different ways, and the doing of age is intimately connected with age as a power relation.

Regardless of the concepts applied, age is thus understood as a kind of political and discursive location. Thus, the perspective of age as doing is only one of several steps that need to be taken in order to have a broader and more dynamic understanding of ageism. Each act of doing, negotiating, and interacting is deeply situated in power structures that are constantly recreated. Age must therefore be understood as an important power structure that has a key role in organizing society, informing groups' identities and their access to power, and intersecting with other power relations (Calasanti and Slevin 2006; Calasanti et al. 2006; Fineman 2011; Krekula 2009). It is only via such conceptualization of age that we come closer to understanding the diversity and complexity of ageing, and by extension, ageism (McMullin 2000).

\subsection{The Perspective of Age as a Power Relation}

Power is not something that one has while others do not; power is a productive capacity emerging in and producing social relations (Foucault 1997). Taking into account the diverse theoretical definitions of power, we take it to refer to the "capacity to make things happen, but exactly what can be made to happen always depends on the context in which resources we possess are or are not usable" (Schwalbe 2008, p. 201). To re-emphasize, it is the situational context that makes some resources more usable than others, and that determines the ways in which those resources can be used.

Three dimensions of power are particularly relevant when seeking to understand ageism: categorical inequality, the normality which appears in (un)marked age, and the structuring via temporality which exists for example in institutionalized life courses and various temporal codes (Krekula and Johansson 2016).

Using the concept "categorical inequality," Tilly (1998, 2003) discusses how "durable inequalities" arise in categorical pairs that are transferred across interactions and contexts, thus (re)producing the system of inequalities organized along the lines of age, gender, race, religion, sexuality, and (dis)ability. In this, the meaning of age to the system of inequality cannot be fully comprehended without understanding the dynamic existing between "old" and "young" age. These two opposing 
categories not only delineate the discursive possibilities, but also indicate the system of values, activities, and norms. To be young is to be active and full of life; to be old is to be passive and void of life. The categorization is, thus, held as the fundamental cause behind inequality and marginalization (see also Bodily 1994), or as expressed with the concept of age coding: these are practices of distinction that are based on and preserve representations of actions, phenomena, and characteristics as associated with and applicable to demarcated ages (Krekula 2009).

The strength in these processes is that they facilitate the transfer of joint notions, practices, and interpersonal relations between different contexts and, by doing so, enable the reproduction of old routines in new contexts. All in all, this perspective points to the fact that inequality is not something done by some people to others, but rather it is a process involving various actors, who do not necessarily reproduce inequality in order to perpetuate harm, but rather to accomplish different goals and objectives. Marginalization based on age is, thus, created in the practices where age is done; it is a form of age doing. In the words of Tilly $(1998,2003)$, inequality is created when people try to solve other organizational problems by applying categorical inequality to divide valued resources. The availability of existing categorization scripts makes the whole process very easy and accessible to everyone who shares the same socio-cultural context. This is also what makes the process very durable and dangerous.

Through categorization, we do perpetuate marginalization. As Schwalbe (2008) contends, the power of small things contributing to the process of inequality is underestimated. This is particularly the case when those small things we do are conceived of as natural or when categorical notions are discussed in terms of normality. Krekula and Johansson (2016) use the the concept pair marked/unmarked age to problematize this type of normality based on age. They argue that marginalization of demarcating age groups is created in the processes where some ages are construed as an unproblematized-“unmarked"-norm, by means of, for example, prefixes and derogatory names which construct one side of a binary categorization as epistemologically unproblematic. When age is done as an age hierarchy, discursively and materially, the unmarked age is both the basis for the doing and the main beneficiary of it. The unmarked age makes up the norm to which other ages relate (Brekhus 1998).

The way normality is shaped and which age groups appear as an unproblematized norm and which are seen as divergent varies in different contexts and situations. For example, Krekula's studies on discrimination and age relations in work organizations show how age normality varies among different work organizations. While employees just under the age of 40 are considered to be too old by the telemarketing industry, they can also be seen as too young to gain status and prestigious assignments within parts of the academic world (Krekula 2011) or regarded as being of the best age to be a firefighter (Krekula 2012). It is therefore essential to precisely focus on the unspoken norm organizing a given context. Importantly, the unspoken/the norm is context-bound, meaning that, once revealed, the same unmarked category cannot be simply applied to different contexts. For example, 
while being 50 is often considered to be "far too old" to become a parent, the same age is regarded as "far too young" to retire (Wilińska and Cedersund 2010).

A third relevant power approach puts emphasis on normativity in relation to temporality: the complex and dynamic relations between the past, the present, and the future (West-Pavlov 2013). This type of power-norma-/temporality (Krekula and Johansson 2016) - is practised through notions of how life ought to be lived and through norms of what is considered a natural consequence and time for different phases in life such as education, long-term relationships, having a family, and retirement. Even though this power perspective has been lifted within several different disciplines in recent years, for example in social and cultural studies (see Ahmed 2007) and queer studies (see Freeman 2010; Halberstam 2005; Riach et al. 2014), the life course perspective has been the most prominent perspective so far.

In his seminal definition of the life course, Elder (1994) describes it as "pathways through the age-differentiated life span, to social patterns in the timing, duration, spacing and order of events" (p. 21). Life course as socially constructed is seen as a dynamic process in which structured pathways interrelate with individual life trajectories. Those structural pathways are bounded by institutions that create a frame for our lives.

One of the most influential theories concerning the patterning of the life course as movement through a sequence of positions is a model of the institutionalization of the life course (Kohli 1986, 1988). This widely used and accepted theory emphasizes life-time temporalization as one of the core structural features of the life course. It sees chronological age as having become the basic criterion for a standardized "normative life course," and focusses on the institutional patterns that shape life course movement through a temporal tripartite order of periods of preparation, activity, and retirement (Kohli 1986, p. 272). The institutionalized life course model provides a general macrosociological frame for understanding how specific patterns of rules constituting the life course operate and process people through social structure, and how collective institutional transitions and expectations shape individual actions and people's biographical perspectives. It can therefore be seen as a power structure - a temporal regime-both in terms of division of resources and opportunities, and as a type of disciplinary element to enforce norm compliance.

The degree to which a unified model of the historical institutionalization of the life course still captures the increasing complexity, heterogeneity, and social differentiation across life can easily be thrown into question. Indeed, both class and gender (Formosa and Higgs 2013; O'Rand and Henretta 1999) as major potential sources of social inequality and marginalization clearly challenge life course patterns and typical (male) trajectories. Bringing gender and gender specific economic life course dynamics and pluralities into the picture clearly complicates any formerly clear-cut view on life course inequality and ageism. 


\subsection{Gendered Ageism as Doing}

Understanding age as doing, and thus also as a power relation, sheds new light on the concept of ageism. Not only does it illustrate the complexity of ageism, but also emphasizes the need to approach marginalization based on age from the perspective of multiplicity. This brings us back to the discussion on gendered ageism and the need to further problematize it theoretically.

We argue that gendered ageism can be understood as a dynamic social positioning practice. This is in contrast to the common approach to gendered ageism that conceives it in terms of stereotypes, prejudices, and discrimination. We draw on contemporary research on age and other social positions that put emphasis on categorizations and the relations between them as created through practices, processes, and everyday interactional doings where one applies notions of difference between age groups. Jyrkinen (2013) gives an example of the elements of such an approach to gendered ageism. Starting from a position that ageism is a question of discriminating practices (for an overview of this perspective, see, e.g., Heikkinen and Krekula 2008; Wilkinson and Ferraro 2002), Jyrkinen argued that gendered ageism refers to discriminatory actions, whether intentional or non-intentional, that are based on the intersection of gender and age. She also contends that gendered ageism is not limited to relations between men and women, but also manifests among women as well as among men.

In a similar vein, we propose that gendered ageism is not only based on notions that age and gender groups are different, but also on notions that phenomena, situations, and spaces are gendered and age coded (Krekula 2009). Importantly, such coding takes place within the context of other structures (e.g., class, ethnicity) that actively delineate the possible repertoire of resources and practices used to define certain situations and their actors. For example, the idea of Marks and Spencer (a company that sells clothing among other things) as a store for older women (Twigg 2012) is also intertwined with structures of social class and ethnicity.

We understand gendered ageism as consisting of differentiating practices which put demarcated age and gender groups in a marginalized position, or, expressed differently, practices which give age-based meaning to bodies. In other words, specific age and gender codings result in the subordination of and in unequal division of resources for the demarcated group. Implied in this is the fact that the perspective of power has not so far been explicitly applied in work on the concept of gendered ageism. However, the presence of power relations in assumptions about gendered ageism appears in studies which emphasize counter-power, or strategies against ageism. One example is Barrett and Naiman-Sessions' (2016) focus on how the simulation of girlhood by the so-called Red Hat Society, in the forms of adopting children's social roles, dressing up, and playing, constitutes a performative act that resists gendered ageism by increasing ageing women's visibility and asserting their right to leisure. At the same time, they argue, it can be seen as resonance with a dominant cultural metaphor for old age as a "second childhood" and therefore not 
only provides opportunities for resistance to gendered ageism but also contributes to its entrenchment.

Similar strategies and counter-power can be seen in Clarke and Griffin's (2008) study on how women up to the age of 70 used beauty work to respond to gendered ageism. The practices they discussed-dressing and beauty—can be seen as an attempt to broaden the room for manoeuvring by challenging perceived age coding (Krekula 2009; Nikander 2008), and therefore can be interpreted as strategies against categorical inequality. This is further exemplified by a study of active, female members of the University of the Third Age. At the outset of ageist structures that exclude older people from social and public life, older women actively turn to different images of womanhood to create a more positive environment for themselves. Effectively, they repress oppressive age identities to fully embrace their various gender identities, such as wife, mother, or girlfriend (Wilińska 2016). Turning to the feminine appears to be an enabling strategy among older women that reduces the impact of ageism that is innately gendered.

Gendered ageism as a practice of inequality is deeply embedded in institutions. Age as a category that defines social relations gives rise to various age-based institutions. One of these is retirement and the pension system. The extant literature examining these two major age-based institutions provides a wealth of examples of how the institutionalized life course contributes to the marginalization and discrimination that, engaging with age, engages also with gender. For example, recent developments within the pension system schemes that promote individualization and privatization of pensions are found to exacerbate gender inequality (Leitner 2001), where the diverse life courses and work histories of men and women have their immediate result in a considerable gender pension gap (Foster and Smetherham 2013; Frericks et al. 2007, 2009; Price 2006). Therefore, not without a reason, Hartmann and English (2009) stated that financial security while on pension is of particular importance to women. The institution of retirement as we know it is a men's concept (Calasanti 1993, 2002) and within that context it is not surprising that unquestioned heteropatriarchal norms (Grady 2015) are overlooked in social policies as a gender-neutral approach.

We also emphasize the relational character of gendered ageism, meaning that its constitutive practices and outcomes vary from situation to situation. This may refer to a range of language and bodily practices that only when put in context gain their ageist meaning. For example, the perception of hair dying as a potentially ageist practice changes its meaning not only depending on how old the person doing it is (compare a 20-year-old woman with a 60-year-old woman), but also what the purpose of doing it is (e.g., covering grey hair versus dressing up for a Halloween party). Similarly, it is within the limits of certain situations that we observe the ways in which gendered ageism affects various groups. This interactive approach to gendered ageism means that we need to remain open to the empirical results revealing concrete forms of marginalization as directed towards different groups of men and women (Ojala et al. 2016). 
Further, approaching gendered ageism through the perspective of ongoing dynamics and processes means recognizing that the construction and reproduction of various age and gender categories takes place in a range of contexts serving different purposes and involving discursive and bodily practices. The doing of age as a power relation is an embodied practice in a sense that age and ageist practices always refer to concrete bodies that are assessed via the perspective of age (Laws 1995). Laz (2003) adds to that, emphasizing the mutually constitutive relation between age and embodiment that cannot be separated. In this, bodies are often the key markers of age at large. Gendered ageism as a concept cannot therefore be reserved for certain groups of people, and the understanding of embodied age opens new ways for examining this phenomenon. For example, a reflection upon media representations of successful ageing images (Calasanti and King 2005) reveals the ways in which bodies of older men are highly sexualized and described based on gendered age norms. Thus, men are not immune to ageism (Duncan and Loretto 2004; Ojala et al. 2016), but the outcomes of gendered ageism on the lives of older men and women are different, as Sandberg's (2013) study on intimate relationships demonstrates.

\subsection{Conclusions}

Starting out from a discussion about the concept of gendered ageism, this chapter problematizes and further develops the phenomenon of multiple marginalizations based on age. Our discussion is inspired by critical age research, a field which emphasizes age as organizing, doing, and as a power relation, and which argues for analyses based on wide age spans, that is, those that do not simply focus on demarcating age categorizations (Krekula and Johansson 2016). This proposition echoes an understanding of different social divisions as having varying organizing logics (e.g., Phoenix and Pattenama 2006; Yuval-Davis 2006).

In this chapter, we placed gendered ageism in a wider context and subsequently examined two interconnected practices: age as doing and age as a power relation. We introduced the concept as a socially constructed relational and differentiating practice, which places specific age groups in marginalized positions with unequal division of resources. From the social constructionist perspective, meanings of age are upheld and/or challenged in everyday interactions, and gender, like other intersectional categorizations, becomes enmeshed with age in everyday encounters. From this perspective, gender as an interactionally constructed facet of ageism can be understood as something which sheds light on age, and, in a similar vein, on practices that construe age as a position of marginalization. This understanding can also, as we have discussed here, be generally applied to multiple marginalization based on age. Below we outline the key starting points for further research on gendered ageism and multiple marginalization. 
One of the most important insights following from our definition of gendered ageism is that research into this phenomenon (and other marginalizations based on age) cannot easily be related to chronological age only. For example, studies highlighting appearance as central to the discrimination of older women (Clarke and Griffin 2008; Handy and Davy 2007) indicate that problematizations of gendered ageism cannot only be based on chronological age, but also need to include how these markers are used and how they create ageism. This brings us to the importance of ideas such as lifetime chronological order and temporal schemes, norms, and imperatives as key conditions affecting the organizational lives of both men and women. The concept of gendered ageism clearly calls for studies that take to heart the temporal processual aspects that may help to further dismantle typical life course patterns. These temporal aspects and dynamics, taken together and explored as mutually intertwined, may open up new venues for the theorizing of multiple, intersectional marginalizations. Viewed in this manner, age, gender, sexuality, and class as temporal practices (see Ahmed 2007) may be approached in ways that go beyond simple understandings built on additive or mutually reinforcing relationships characterized by former notions of double or triple jeopardy.

Methodologically, this draws us towards everyday life and interactional approaches to the study of social life, or as Sztompka (2008) calls it, the sociology of existence that aims to capture social life as it unfolds. By aiming to grasp "the happening of the social world" (Lury and Wakeford 2012, p. 2; see also Pink 2012), we propose to focus on the processes and practices that in turn are contingent upon the engagement with the concepts of time and place.

\section{References}

Addelson, K. P., \& Potter, E. (1991). Making knowledge. In J. E. Hartman \& E. Messer-Davidow (Eds.), (En)gendering knowledge. Feminists in academe (pp. 259-277). Knoxville: The University of Tennessee Press.

Ahmed, S. (2007). A phenomenology of whiteness. Feminist Theory, 8(2), 149-168. https://doi. org/10.1177/1464700107078139

Ainsworth, S. (2002). The 'feminine advantage': A discursive analysis of the invisibility of older women workers. Gender, Work \& Organization, 9(5), 579-601. https://doi. org/10.1111/1468-0432.00176

Alanen, L. (1992). Modern childhood? Exploring the 'child question' in sociology. Institute for educational research. (Publication series A. Research reports 50). Jyväskylä: University of Jyväskylä.

Ambjornsson, F., \& Jönsson, M. (2010). Inledning [Introduction]. In F. Ambjornsson \& M. Jönsson (Eds.), Livslinjer. Berättelser om ålder, genus och sexualitet [Lifelines. Stories about age, gender and sexuality] (pp. 7-21). Gothenburg: Makadam.

Andrews, M. (1999). The seductiveness of agelessness. Ageing and Society, 19, 301. https://doi. org/10.1017/S0144686X99007369-318

Arber, S., \& Ginn, J. (1991). Gender and later life: A sociological analysis of resources and constraints. London: Sage Publications. 
Arber, S., McKinlay, J., Adams, A., Marceau, L., Link, C., \& O'Donnell, A. (2006). Patient characteristics and inequalities in Doctors' diagnostic and management strategies relating to CHD: A video-simulation experiment. Social Science \& Medicine, 62(1), 103-115.

Barrett, A. E., \& Naiman-Sessions, M. (2016). 'It's our turn to play': Performance of girlhood as a collective response to gendered ageism. Ageing and Society, 36(4), 764-784. https://doi. org/10.1017/S0144686X15000021

Bartholomaeus, C., \& Tarrant, A. (2016). Masculinities at the margins of "middle adulthood": What a consideration of young age and old age offers masculinities theorizing. Men and Masculinities, 19(4), 351-369. https://doi.org/10.1177/1097184X15588592

Bell, J. (1995). Understanding adultism: A major obstacle to developing positive youth-adult relationships. Somerville: YouthBuild.

Bodily, C. L. (1994). Ageism and the deployments of 'age'. In T. R. Sarbin \& J. I. Kitsuse (Eds.), Constructing the social (pp. 174-194). London: Sage.

Brekhus, W. (1998). A sociology of the unmarked: Redirecting our focus. Sociological Theory, 16(1), 34-51.

Butler, R. N. (1980). Ageism: A foreword. Journal of Social Issues, 36(2), 8-11.

Calasanti, T. M. (1993). Bringing in diversity: Toward an inclusive theory of retirement. Journal of Aging Studies, 7(2), 133-150. https://doi.org/10.1016/0890-4065(93)90030-N

Calasanti, T. (2002). Work and retirement in the 21 st century: Integrating issues of diversity and globalization. Ageing International, 27(3), 3-20. https://doi.org/10.1007/s12126-003-1000-1

Calasanti, T. (2003). Theorizing age relations. In S. Biggs, A. Lowenstein, \& J. Hendricks (Eds.), The need for theory: Critical approaches to social gerontology (pp. 199-218). Amityville: Baywood.

Calasanti, T. M., \& King, N. (2005). Firming the floppy penis. Age, class and gender relations in the lives of old men. Men and Masculinities, 8(1), 3-23. https://doi.org/10.1177/10971 $84 X 04268799$

Calasanti, T. M., \& Slevin, K. F. (2006). Introduction. Age matters. In T. M. Calasanti \& K. F. Slevin (Eds.), Age matters. Realigning feminist thinking (pp. 1-17). London: Routledge.

Calasanti, T. M., Slevin, K., \& King, N. (2006). Ageism and feminism: From "et cetera" to center. NWSA Journal, 18(1), 13-30. https://doi.org/10.2979/NWS.2006.18.1.13

Ceaser, D. (2014). Unlearning adultism at green shoots: A reflexive ethnographic analysis of age inequality within an environmental education programme. Ethnography and Education, 9, 167-181. https://doi.org/10.1080/17457823.2013.841083

Clarke, L. H., \& Griffin, M. (2008). Visible and invisible ageing: Beauty work as a response to ageism. Ageing and Society, 28(05), 653-674. https://doi.org/10.1017/S0144686X07007003

Crawford, R. (1980). Healthism and the medicalization of everyday life. International Journal of Health Services, 10(3), 356-388. https://doi.org/10.2190/3H2H-3XJN-3KAY-G9NY

Duncan, C., \& Loretto, W. (2004). Never the right age? Gender and age-based discrimination in employment. Gender, Work \& Organization, 11(1), 95-115. https://doi. org/10.1111/j.1468-0432.2004.00222.x

Elder, G. H. (1994). Time, human agency, and social change: Perspectives on the life course. Social Psychology Quarterly, 57(1), 4-15.

Fineman, S. (2011). Organizing age. Oxford: Oxford University Press.

Flasher, J. (1978). Adultism. Adolescence, 13(51), 517-523.

Formosa, M., \& Higgs, P. (2013). Social class in later life. In Power, identity and lifestyle. Bristol: Policy Press.

Foster, L., \& Smetherham, J. (2013). Gender and pensions: An analysis of factors affecting Women's private pension scheme membership in the United Kingdom. Journal of Aging \& Social Policy, 25(3), 197-217. https://doi.org/10.1080/08959420.2013.791783

Foucault, M. (1997). "Society must be defended." Lectures at the Collège de France 1975-76. New York: Picador. 
Freeman, E. (2010). Time binds: Queer temporalities, queer histories. Durham: Duke University Press.

Frericks, P., Maier, R., \& De Graaf, W. (2007). European pension reforms: Individualization, privatization and gender pension gaps. Social Politics: International Studies in Gender, State \& Society, 14(2), 212-237. https://doi.org/10.1093/sp/jxm008

Frericks, P., Knijn, T., \& Maier, R. (2009). Pension reforms, working patterns and gender pension gaps in Europe. Gender, Work \& Organization, 16(6), 710-730. https://doi. org/10.1111/j.1468-0432.2009.00457.x

Grady, J. (2015). Gendering Pensions: Making Women Visible. Gender, Work \& Organization, 22(5), 445-458. https://doi.org/10.1111/gwao.12096

Granleese, J., \& Sayer, G. (2006). Gendered ageism and "lookism": A triple jeopardy for female academics. Women in Management Review, 21(6), 500-517. https://doi. org/10.1108/09649420610683480

Gullette, M. M. (2004). Aged by culture. Chicago: The University of Chicago Press.

Halberstam, J. (2005). In a queer time and place. Transgender bodies, subcultural lives. New York: New York University Press.

Hancock, A. M. (2007). When multiplication doesn't equal quick addition: Examining intersectionality as a research paradigm. Perspectives on Politics, 5(01), 63-79. https://doi.org/10.1017/ S1537592707070065

Handy, J., \& Davy, D. D. (2007). Gendered ageism: Older women's experiences of employment agency practices. Asia Pacific Journal of Human Resources, 1, 85-99. https://doi. org/10.1177/1038411107073606

Hartmann, H., \& English, A. (2009). Older Women's retirement security: A primer. Journal of Women, Politics \& Policy, 30(2-3), 109-140. https://doi.org/10.1080/15544770902901932

Hearn, J. (1995). Imaging the aging of men. In M. Featherstone \& A. Wernick (Eds.), Images of aging: Cultural representations of later life (pp. 97-115). London: Routledge.

Heikkinen, S., \& Krekula, C. (2008). Ålderism—ett fruktbart begrepp?/Ageism-A useful concept? Sociologisk Forskning, 45, 18-34.

Hockey, J., \& James, A. (1993). Growing up and growing old. Ageing and dependency in the life course. London: Sage.

Hurd, L. C. (1999). We're not old!': Older Women's negotiation of aging and oldness. Journal of Aging Studies, 13(4), 419-439. https://doi.org/10.1016/S0890-065(99)00019-5

Itzin, C., \& Phillipson, C. (1993). Age barriers at work. London: METRA.

Itzin, C., \& Phillipson, C. (1995). Gendered ageism: A double jeopardy for women in organisations. In C. Itzin \& C. Phillipson (Eds.), Gender, culture and organisational change. Putting theory into practice (pp. 84-94). London: Routledge.

Juhila, K. (2004). Talking back to stigmatised identities: Negotiation of culturally dominant categories in the interviews with shelter residents. Qualitative Social Work, 3(3), 259-275. https:// doi.org/10.1177/1473325004045665

Jyrkinen, M. (2013). Women managers, careers and gendered ageism. Scandinavian Journal of Management, 30(2), 175-185. https://doi.org/10.1016/j.scaman.2013.07.002

Jyrkinen, M., \& McKie, L. (2012). Gender, age and ageism: Experiences of women managers in Finland and Scotland. Work, Employment and Society, 26(1), 61-77. https://doi. org/10.1177/0950017011426313

Kalish, R. A. (1979). The new ageism and the failure models: A polemic. The Gerontologist, 19(4), 398-402. https://doi.org/10.1093/geront/19.4.398

Kennedy, D. (2006). The well of being: Childhood, subjectivity, and education. New York: State University of New York.

Kohli, M. (1986). The world we forgot: A historical review of the life course. In W. Marshall (Ed.), Later life: The social psychology of ageing (pp. 271-303). Beverly Hills: Sage.

Kohli, M. (1988). Ageing as a challenge for sociological theory. Ageing and Society, 8, 367-394. https://doi.org/10.1017/S0144686X00007169 
Krekula, C. (2007). The intersection of age and gender: Reworking gender theory and social gerontology. Current Sociology, 55(2), 155-171. https://doi.org/10.1177/0011392107073299

Krekula, C. (2009). Age coding: On age-based practices of distinction. International Journal of Ageing and Later Life, 4(2), 7-31. https://doi.org/10.3384/ijal.1652-8670.09427

Krekula, C. (2011). Åldersdiskriminering $i$ svenskt arbetsliv. Om ålderskodningar och myter som skapar ojämlikhet [Age discrimination in Swedish working life. On age codings and myths that create inequality]. Official report from the Equality Ombudsman. http://www.do.se/ Documents/rapporter/aldersdiskriminering\%20i\%20arbetslivet.pdf

Krekula, C. (2012). Attityder till fysisk styrka: Om kvinnor, äldre brandmän och självupplevda begränsningar [Attitudes to physical strength: On women, older firefighters and self-experienced limitations]. In L.-G. Engström, L. Jakobsen, \& C. Krekula (Eds.), Jämställdhet, mångfald och svenska räddningstjänster. Om föreställningar och förändringsviljor [Gender equality, diversity and Swedish rescue services. On notions and willingness to change] (pp. 71-80). Karlstad: Karlstad University Press.

Krekula, C. \& Johansson, B. (Eds.). (2016). Inledning [Introduction]. In C. Krekula \& B. Johansson (Eds.), Introduktion till kritiska åldersstudier [Introduction to critical age studies]. Malmö: Studentlitteratur.

Laws, G. (1995). Understanding ageism: Lessons from feminism and postmodernism. The Gerontologist, 35(1), 112-118. https://doi.org/10.1093/geront/35.1.112

Laz, C. (1998). Act your age. Sociological Forum, 13(1), 85-113.

Laz, C. (2003). Age embodied. Journal of Aging Studies, 17, 503-519. https://doi.org/10.1016/ S0890-4065(03)00066-5

Leitner, S. (2001). Sex and gender discrimination within EU pension systems. Journal of European Social Policy, 11(2), 99-115. https://doi.org/10.1177/095892870101100201

Llewellyn, N. (2015). 'He probably thought we were students': Age norms and the exercise of visual judgement in service work. Organization Studies, 36(2), 153-173. https://doi. org/10.1177/0170840614546151

Lund, A., \& Engelsrud, G. H. (2008). 'I am not that old': Inter-personal experiences of thriving and threats at a senior centre. Ageing and Society, 28(05), 675-692. https://doi.org/10.1017/ S0144686X07006988

Lury, C., \& Wakeford, N. (2012). Introduction: A perpetual inventory. In C. Lury \& N. Wakeford (Eds.), Inventive methods: The happening of the social (pp. 1-24). London: Routledge.

Mair, C. A. (2010). Social ties and depression: An intersectional examination of black and white community-dwelling older adults. Journal of Applied Gerontology, 29(6), 667-696. https://doi. org/10.1177/0733464809350167

McMullin, J. A. (2000). Diversity and the state of sociological aging theory. The Gerontologist, 40(5), 517-530. https://doi.org/10.1093/geront/40.5.517

McMullin, J. A., \& Cairney, J. (2004). Self-esteem and the intersection of age, class, and gender. Journal of Aging Studies, 18, 75-90. https://doi.org/10.1016/j.jaging.2003.09.006

Minichiello, V., Browne, J., \& Kendig, H. (2000). Perceptions and consequences of ageism: Views of older people. Ageing \& Society, 20, 253-278. https://doi.org/10.1017/S0144686X99007710

Mirza, H. S. (1997). Mapping a genealogy of Black British feminism. In H. S. Mirza (Ed.), Black British feminism. A reader (pp. 1-28). London: Routledge.

Nikander, P. (2002). Age in action: Membership work and stage of life categories in talk. Helsinki: Finnish Academy of Science and Letters.

Nikander, P. (2008). Constructionism and discourse analysis. In J. A. Holstein \& J. F. Gubrium (Eds.), Handbook of constructionist research (pp. 413-428). New York: Guilford Press.

Nikander, P. (2009). Doing change and continuity. Age identity and the micro-macro divide. Ageing \& Society, 29, 863-881. https://doi.org/10.1017/S0144686X09008873

O'Rand, A. M., \& Henretta, J. C. (1999). Age and inequality. Diverse pathways through later life. Boulder: Westview Press. 
Öberg, P., \& Tornstam, L. (2001). Youthfulness and fitness. Identity ideas for all ages? Journal of Aging and Identity, 6(1), 15-29.

Ojala, H., Pietilä, I., \& Nikander, P. (2016). Immune to ageism? Men's perceptions of age-based discrimination in everyday contexts. Journal of Aging Studies, 39, 44-53.

Palmore, E. B. (2001). The ageism survey: First findings. The Gerontologist, 41(5), 572-575. https://doi.org/10.1093/geront/41.5.572

Phoenix, A., \& Pattemana, P. (2006). Intersectionality. Editorial. European Journal of Women's Studies, 13(3), 187-192.

Pierce, C. M., \& Allen, G. B. (1975). Childism. Psychiatric Annals, 5(7), 15-24.

Pink, S. (2012). Situating everyday life: Practices and places. London: SAGE.

Price, D. (2006). Gender and generational continuity breadwinners, caregivers and pension provision in the UK. International Journal of Ageing and Later Life, 1(2), 31-66. https://doi. org/10.3384/ijal.1652-8670.061231

Riach, K., Rumens, N., \& Tyler, M. (2014). Un/doing chrononormativity: Negotiating ageing, gender and sexuality in organizational life. Organization Studies, 35(11), 1677-1698. https:// doi.org/10.1177/0170840614550731

Ridgeway, C. L., \& Correll, S. J. (2004). Unpacking the gender system: A theoretical perspective on gender beliefs and social relations. Gender \& Society, 18(4), 510-531. https://doi. org $/ 10.1177 / 0891243204265269$

Sandberg, L. (2013). Just feeling a naked body close to you: Men, sexuality and intimacy in later life. Sexualities, 16(3-4), 261-282.

Schwalbe, M. (2008). Rigging the game. How inequality is reproduced in everyday life. New York: Oxford University Press.

Snellman, F. (2018). Normative, empiricist, and interpretive considerations in the ageism research process. In L. Ayalon \& C. Tesch-Römer (Eds.), Contemporary perspectives on ageism: Vol. 19. International perspectives on aging (pp. 407-422). Berlin: Springer.

Spedale, S., Coupland, C., \& Tempest, S. (2014). Gendered ageism and organizational routines at work: The case of day-parting in television broadcasting. Organization Studies, 35(11), 15851604. https://doi.org/10.1177/0170840614550733

Sztompka, P. (2008). The focus on everyday life: A new turn in sociology. European Review, 16(1), 23-37. https://doi.org/10.1017/S1062798708000045

Thompson, E. H. (1994). Older men as invisible men. In E. Thompson (Ed.), Older men's lives (pp. 1-21). Thousand Oaks: Sage.

Tilly, C. (1998). Durable inequality. Berkely/Los Angeles: University of California Press.

Tilly, C. (2003). Changing forms of inequality. Sociological Theory, 21(1), 31-36. https://doi. org/10.1111/1467-9558.00173

Twigg, J. (2004). The body, gender, and age: Feminist insights in social gerontology. Journal of Aging Studies, 18(1), 59-73. https://doi.org/10.1016/j.jaging.2003.09.001

Twigg, J. (2012). Fashion and age: Dress, the body later life. London: Bloomsbury.

Utrata, J. (2011). Youth privilege doing age and gender in Russia's single-mother families. Gender \& Society, 25(5), 616-641.

Walby, S., Armstrong, J., \& Strid, S. (2012). Intersectionality: Multiple inequalities in social theory. Sociology, 46(2), 224-240. https://doi.org/10.1177/0038038511416164

Walker, A. (1998). Age and employment. Australasian Journal on Ageing, 17(1), 99-103. https:// doi.org/10.1111/j.1741-6612.1998.tb00876.x

Ward, R., \& Holland, C. (2011). 'If I look old, I will be treated old': Hair and later-life image dilemmas. Ageing \& Society, 21, 288-307. https://doi.org/10.1017/S0144686X10000863

West-Pavlov, R. (2013). Temporalities. New York: Routledge.

Wilińska, M. (2012). Is there a place for an ageing subject? Stories of ageing at the University of the Third Age in Poland. Sociology, 46(2), 290-305. https://doi.org/10.1177/0038038511419179

Wilińska, M. (2016). Proud to be a woman: Old age, womanhood and emotions. Journal of Women and Aging. https://doi.org/10.1080/08952841.2015.1017431 
Wilińska, M., \& Cedersund, E. (2010). "Brutal economy"? - Old age and older people in the Polish media. Journal of Aging Studies, 24(4), 335-343.

Wilińska, M., \& Henning, C. (2011). Old age identity in social welfare practices. Qualitative Social Work, 10(3), 346-363. https://doi.org/10.1177/1473325011409477

Wilkinson, J. A., \& Ferraro, K. F. (2002). Thirty years of ageism research. In T. D. Nelson (Ed.), Ageism: Stereotyping and prejudice against older persons (pp. 339-358). Cambridge, MA: MIT Press.

Young-Bruehl, E. (2012). Childism. Confronting prejudice against children. New Haven/London: Yale University Press.

Yuval-Davis, N. (2006). Intersectionality and feminist politics. European Journal of Women's Studies, 13(3), 193-209. https://doi.org/10.1177/1350506806065752

Zajicek, A. M., Calasanti, T. M., \& Zajicek, E. K. (2007). Pension reforms and old people in Poland: An age, class and gender lens. Journal of Aging Studies, 21(1), 55-68. https://doi. org/10.1016/j.jaging.2006.03.002

Open Access This chapter is licensed under the terms of the Creative Commons Attribution 4.0 International License (http://creativecommons.org/licenses/by/4.0/), which permits use, sharing, adaptation, distribution and reproduction in any medium or format, as long as you give appropriate credit to the original author(s) and the source, provide a link to the Creative Commons license and indicate if changes were made.

The images or other third party material in this chapter are included in the chapter's Creative Commons license, unless indicated otherwise in a credit line to the material. If material is not included in the chapter's Creative Commons license and your intended use is not permitted by statutory regulation or exceeds the permitted use, you will need to obtain permission directly from the copyright holder. 


\title{
Chapter 4 \\ Origins of Ageism at the Individual Level
}

\author{
Sagit Lev, Susanne Wurm, and Liat Ayalon
}

\subsection{Introduction}

The term ageism was first coined by Butler in 1969. According to his early definition, ageism is an age discrimination which is reflected in the prejudice of one age group toward other age groups (Butler 1969). Although ageism can be aimed at younger age groups (Snape and Redman 2003), most of the theoretical and empirical research on ageism has focused on the old age group (Iversen et al. 2009). Butler himself refined his definition of ageism in 1975 as "a process of systematic stereotyping and discrimination against people because they are old" (Butler 1975). Following Butler's later definition, the current chapter focuses on ageism toward the old age group.

Although Butler focused on negative stereotypes, current perceptions of ageism include both positive and negative stereotypes towards older adults (Iversen et al. 2009; Palmore 1999). According to the stereotype content model, older adults are perceived as incompetent but warm. These perceptions lead to emotions of pity and sympathy and less so to emotions of envy (Cuddy and Fiske 2002; Fiske et al. 2002). Consistent with this claim, a large body of research has indicated that ageism is manifested in both negative and positive age stereotypes

\footnotetext{
S. Lev $(\bowtie)$

Department of Social Work, Ariel University, Ariel, Israel

Louis and Gabi Weisfeld School of Social Work, Bar Ilan University,

Ramat Gan 52900, Israel

S. Wurm

Friedrich-Alexander-Universität Erlangen-Nürnberg, Nürnberg, Deutschland e-mail: susanne.wurm@fau.de

L. Ayalon

Louis and Gabi Weisfeld School of Social Work, Bar Ilan University,

Ramat Gan 52900, Israel

e-mail: liat.ayalon@biu.ac.il

L. Ayalon, C. Tesch-Römer (eds.), Contemporary Perspectives on Ageism, International Perspectives on Aging 19, https://doi.org/10.1007/978-3-319-73820-8_4
} 
and affective attitudes (e.g., Kite et al. 2005; Meisner 2012). In addition to cognitive and emotional aspects of ageism, studies have also identified behavioural implications of ageism, reflected in avoidance (Bodner et al. 2012) and patronizing language towards older adults (Nelson 2005).

Negative stereotypes as well as discriminatory behaviours toward older adults are spread over diverse areas of society, such as in the labour market (e.g., Posthuma and Campion 2009) and the healthcare system (e.g., Bowling 2007) (for further details see section introduction of this book: "On the Manifestation and Consequences of Ageism;" Ayalon \& Tesch-Römer 2018). Diverse social and psychological theories, operating at a variety of levels (individual, interpersonal, evolutionary, and socio-cultural), shed light on the roots and dynamics of ageism, and by doing so, provide a robust understanding of the topic (North and Fiske 2012).

In this chapter, we present three theories to provide a comprehensive understanding of the psychological and sociological processes that constitute the basis of ageism at the individual level: terror management theory (Greenberg et al. 1986); stereotype embodiment theory (Levy 2009); and social identity theory (Tajfel and Turner 1979). These three theories were chosen because they provide a wide and comprehensive theoretical understanding concerning the causes as well as the expressions of ageism. Additionally, these theories have served as the basis for numerous studies that examine various aspects of ageism and provide evidence for the relevance of these theories to explain ageism at the individual level.

It is important to note that other theories, such as social affordances theory (Montepare and Zebrowitz 2002), which provides an explanation of the roots and dynamics of ageism at the interpersonal level, or social role perspective theory (Kite et al. 2002), which provides an explanation at the socio-cultural level, could also have served as potential explanatory models for the development of ageism (North and Fiske 2012).

Each of the theories sheds light on different roots of and reasons for ageism, and on different reflections of ageism among various age groups. Capitalizing on these three theories, we present a model that suggests possible interactions and relationships between ageism as it is manifested in various age groups across the life span.

We suggest that terror management theory provides an explanation for the roots and motives of ageism towards old age groups among young and middle aged groups as well as among the young-old age group, and that stereotype embodiment theory provides an explanation for ageism among the young-old and old-old age group. Social identity theory, in contrast, provides an overview of the manifestation of ageism among different age groups (see Fig. 4.1).

The definition of ageism is fraught with an assumption that society tends to view the old age group as a distinct and separate group with unique features. Although in the definition lies a criticism of this separation and of the attribution of specific features to the old age group, this separation forms the basis for the theoretical understanding of the dynamic nature of ageism, as well as a methodological basis for the empirical examination of ageism. Hence, the three theories that are presented are based on the assumption that age groups can be captured and defined as social groups with unique features that separate and distinguish them from other age groups.

The following section first provides an overview of the theoretical and empirical basis of the division of individuals into age groups. The subsequent three sections 


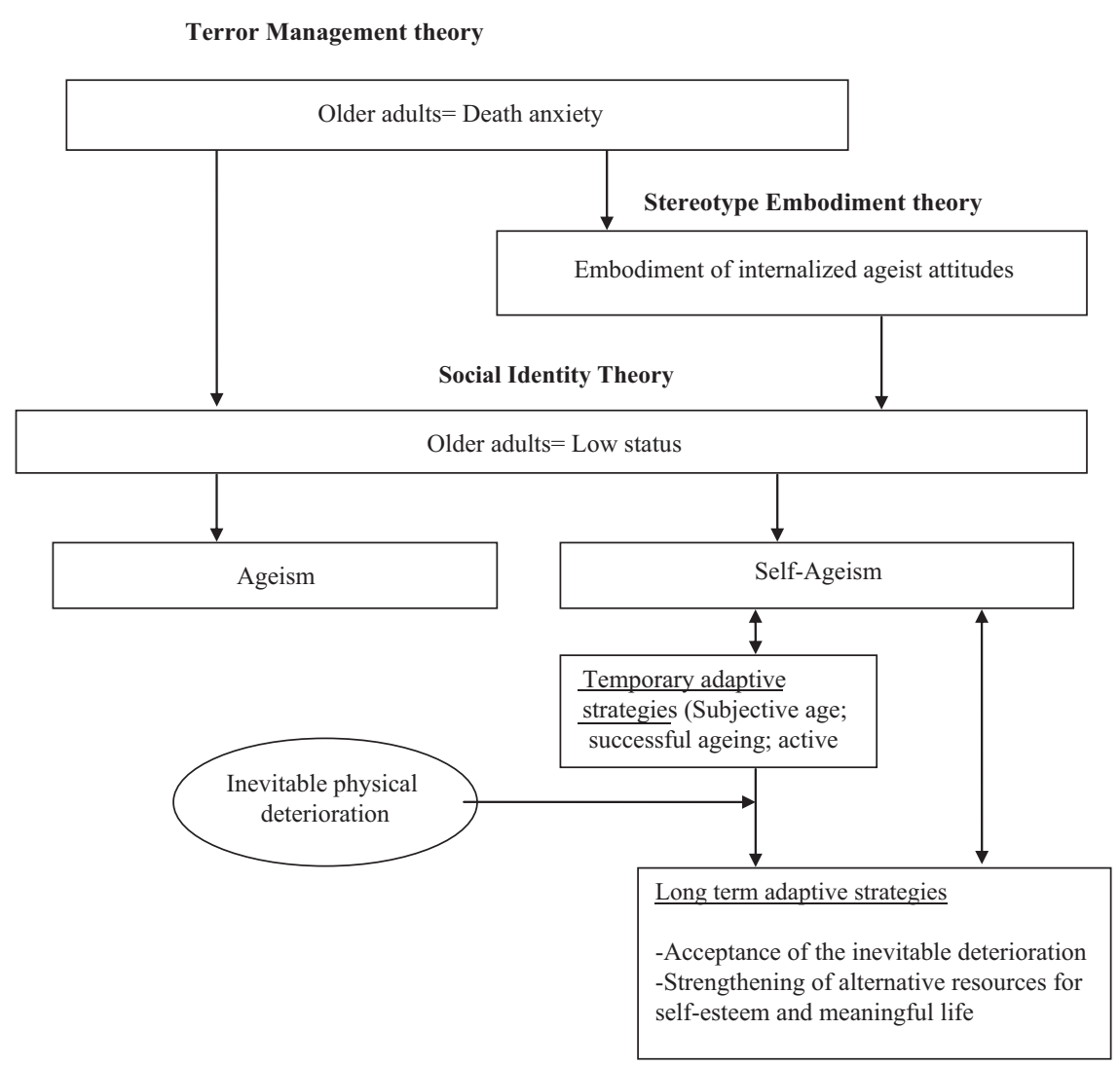

Fig. 4.1 An integrated model of ageism in younger and older adult

present the three theories and their possible contribution to the understanding of the roots and maintenance of ageism at the individual level. Finally, we present a comprehensive model, based on the three theories, to better conceptualize the roots and maintenance of ageism across the life span. The model we present expands on Bodner's (2009) etiological model for ageism among younger and older adults.

\subsubsection{A Rationale for Examining the Etiology of Ageism in Different Age Groups}

Various studies have shown that chronological age is an important marker of objective and subjective transformations that unfold during one's lifespan. According to these studies, older age is associated with deterioration of physical abilities such as sensory and motor performance and gait speed (Chodzko-Zajko and Ringel 1987; 
Reinders et al. 2015) or cognitive ability (e.g., Craik and McDowd 1987; Old and Naveh-Benjamin 2008; Rönnlund et al. 2015). Recent studies that have examined psychological and sociological features, such as wellbeing, emotional experience, and social power, have indicated that these features tend to increase during the first period of life. However, from midlife on, these features tend to decline (Blanchflower and Oswald 2004; Carstensen et al. 2000; Eaton et al. 2008).

The attribution of unique features to different age groups is also reflected in fundamental theories concerning the life course, when different periods are characterized by certain types of psychological crises (Erikson 1950) or by various psychological tasks (Havighurst 1956). Others, however, have noted that there is a wide heterogeneity within age groups. This heterogeneity tends to be particularly pronounced in old age, as older adults are highly affected by their diverse life experiences (Baltes and Baltes 1990).

Although changes during the lifespan are gradual and continuous, in the theoretical and empirical literature it is common to divide the adult population into three main age groups: young adults (from 18 to 34-39 years), middle-aged adults (from 35-40 to 59-65 years), and older adults (aged 60-68+) (e.g., Bodner et al. 2012; Cherry and Palmore 2008; Laditka et al. 2004).

In recent years, due to longevity and improvements in the quality of life, there is a tendency to divide the old age group into two distinct groups: the young-old, which is called the third age (65 to 80-85) and the old-old, which is called the fourth age (80 or 85+) (e.g., Alterovitz and Mendelsohn 2013; Baltes and Smith 2003). Due to increasing longevity, some authors have suggested an even more detailed division into three distinct groups in the fourth age: old (75-84), old-old (85-95), and oldest-old (95+) (Cohen-Mansfield et al. 2013).

Unlike other social characteristics, such as gender or nationality, where membership tends to be permanent during the lifespan, the boundaries between different age groups are permeable and temporary. Thus, although middle-aged adults may perceive themselves as an in-group, and older adults as an out-group, these distinctions are temporary. The instability of the boundaries between age groups is reflected by the fact that the old age group used to be part of the younger groups, and the younger age groups are expected to become part of the old age group, if they survive (Greenberg et al. 2002).

This somewhat arbitrary division into different age groups, and especially the primary division that perceives old age as a distinct category, forms the basis of the theories presented in this chapter. Despite its limitations, this division has been used in studies that examine ageism, and can be a useful tool in understanding of the roots and dynamics of ageism during the life span among different age groups. 


\subsection{Terror Management Theory}

Terror management theory claims that humans possess cognitive abilities that allow them to be self-conscious, and that this self-consciousness is reflected in humans' awareness of their vulnerability and mortality, which creates the potential for a paralysing terror. According to terror management theory, in order to manage the anxiety brought about by the awareness of mortality, humans unconsciously sustain faith in cultural worldviews, which enable them to portray human life as meaningful, important, and enduring. The adoption of social and cultural rules allows humans to believe that they are valuable and deserving within their culture. Perceived social approval leads humans to feel self-esteem, which is reflected in the belief that they are significant human beings in a meaningful world. These perceptions allow humans to buffer anxiety and to maintain relative equanimity despite their awareness of their vulnerability and mortality (Greenberg et al. 1997; Greenberg et al. 1986). Unlike proximal and conscious defences, such as active suppression and cognitive distortion of death-related thoughts, self-esteem and worldview are not based on a logical or rational approach to death, but provide symbolic and ongoing defences which allow humans to construe themselves as valuable participants in a meaningful universe (Greenberg et al. 1994, 1997; Pyszczynski et al. 1999).

There is a large body of research on terror management theory. These studies follow the assumption that self-esteem and faith in one's cultural worldview are two important psychological structures that provide protection against death anxiety. Based on this main assumption, studies have generated two hypotheses. The anxiety buffer hypothesis states that strengthening either self-esteem or faith in one's cultural view reduces anxiety. The mortality salience hypothesis states that reminding people of their mortality activates the need for validating their self-esteem and their faith in their cultural view (Greenberg et al. 1997). Studies that have tested these hypotheses for over 30 years, relying on more than 500 experiments in over 30 different countries, have yielded support for the theory and its core propositions (Darrell and Pyszczynski 2016).

\subsubsection{Social Groups and Stereotypes in Light of Terror Management Theory}

Social relations and group identification constitute significant elements in terror management theory. According to the theory, being part of a social group and having significant social relations with others allows people to feel as though they are integral parts of the cultural world and forms the basis for attaining self-esteem. Yet the wish to be part of a group varies; people may wish to belong to certain groups or to avoid others, according to their pertinent worldviews and their perceived 
self-worth (Solomon et al. 2004). Thus, out-group members who subscribe to different worldviews might threaten explicitly or implicitly the validation of the ingroup's worldview. This psychological threat is one of the main causes of prejudice and discrimination (Greenberg et al. 2002).

To conclude, according to terror management theory, identification with the ingroup is derived from the need to approve one's worldview, to attain self-esteem, and thus to buffer death anxiety. Conversely, discrimination towards out-groups is derived from the anxiety that is evoked as a result of different worldviews that can seem to threaten the worldview of in-group members (Greenberg et al. 2002; Solomon et al. 2004).

These assumptions have formed the basis of various experimental studies that have examined in-group bias as a reaction to mortality salience. Studies have indicated that mortality salience leads to a more positive evaluation of in-group members and a more negative evaluation of out-group members (e.g., Greenberg et al. 1990; Harmon-Jones et al. 1996). Studies have also shed light on the mechanisms that lead from mortality salience to in-group bias, indicating the mediating role of in-group identification and perceived collective continuity (Castano et al. 2002; Herrera and Sani 2013) as well as control motivation (Agroskin and Jonas 2013). In addition, studies have found that mortality salience increased the use of stereotypes based on nationality, race, gender, sexual orientation, and age (e.g., Castano 2004; Martens et al. 2004; Schimel et al. 1999). The use of negative stereotypes further increased when a competitive or threatening out-group member was present (Renkema et al. 2008).

\subsubsection{Ageism Among Young and Middle-Aged Adults in Light of Terror Management Theory}

Following Greenberg et al. (2002), Martens et al. (2005) have suggested that terror management theory could be used as a theoretical and empirical framework for understanding the psychological and sociological processes that underlie ageism. They have identified three psychological threats, derived from terror management theory, to explain negative reactions toward older adults. These three threats include: the threat of death, the threat of animality, and the threat of insignificance (Martens et al. 2005). In the following sections, we discuss these threats and review some studies that have examined ageism in relation to these threats.

\subsubsection{The Threat of Death}

Older adults serve as a direct reminder of our inevitable mortality. A sense of threat is embedded in the human awareness that ageing leads to death. The encounter with ageing, especially in its final stages, reminds us that even if we are able to avoid accidents, diseases, and disasters, we will eventually die (Greenberg et al. 2002; 
Martens et al. 2005). In an experimental study that examined this hypothesis, Martens et al. (2004) found that mortal salience caused participants from the young age group to rate the attributes of older adults as considerably different from their own, thus increasing their distance from older adults. Furthermore, participants who were exposed to mortality salience viewed older adults less positively than in the control group. Another study demonstrated that distancing from and derogating older adults in response to mortal salience occurs primarily among participants who rated their personalities as similar to those of older adults. However, mortal salience did not affect the level of distance from teenagers (Martens et al. 2004). This implies that when participants perceive similarities between themselves and older adults, they might feel more threatened by the prospect of their ageing and inevitable death (Martens et al. 2004).

Additional support for this hypothesis is provided by a study that found a positive correlation between ageism and fear of death among young age groups (Bodner and Cohen-Fridel 2014). A similar pattern has also been found among middle- and old age groups, where death anxiety was correlated with ageism (Bodner et al. 2015) as well as with negative stereotypes of old age (Depaola et al. 2003).

These findings stress the uniqueness of the relationship between social versus age groups and discrimination in different age groups. Whereas among social groups discrimination towards out-groups emerges from holding a different worldview, which can be perceived as a threat to the worldview of in-group members (Greenberg et al. 2002; Solomon et al. 2004), among age groups the threat emerges from the possible similarity between members of the groups. This distinction emphasizes the unique nature of ageism, which is different from other forms of prejudice and discrimination and points to the necessity for generating unique hypotheses concerning its roots (Martens et al. 2004).

\subsubsection{The Threat of Animality}

A less direct association of older adults and death is embedded in the deterioration of the physical body that is reflected in older adults' physical appearance (e.g., wrinkles), as well as in the physical and cognitive decline that is often seen in older age, and in the diminishing control over bodily functions that older adults often experience. These characteristics of old age remind us that, like all animals, we are flesh and blood creatures who are vulnerable to death (Martens et al. 2005). According to Isaksen (2002) the fear of encountering the deteriorating bodies of older adults might be particularly high in Western society. This fear might be explained by the prevailing perception in Western society, influenced by Judeo-Christian beliefs, that view human beings as composed of body, mind, and soul. According to this belief, as regards bodies, all humans are alike. In contrast, soul and mind are perceived as unique features that define us on a social and cultural level and make us different and separate from one another. Thus, physical decline and diminishment of physical control among older adults creates an emphasis on the physical self over the spiritual self and can symbolize the inability to impose mind over matter (Isaksen 2002). 
This hypothesis can be included as part of a wider hypothesis that suggests that physical aspects of the body remind us of our mortal nature. According to this hypothesis, the efforts of human beings to buffer their death anxiety by adopting cultural beliefs and standards are threatened by their awareness of the physical aspects of the human body. Humans might feel uneasiness and even disgust toward physical aspects of their body, because they remind them of their animal nature, their vulnerability, and their inevitable death (Goldenberg 2005).

This hypothesis is supported by studies that found that when mortality was salient, participants expressed negative reactions and disgust towards different aspects of the physical body, such as body products (Goldenberg et al. 2001) and breast feeding (Cox et al. 2007a, b). In addition, the presence of stressing stimuli related to physical aspects of the body were found to lead to higher death-thought accessibility compared with neutral pictures (Cox et al. 2007a, b). However, other studies found that the effect of mortality salience on physical aspects of the body, such as exercise and sexual activity, was limited for participants high in neuroticism ( Goldenberg et al. 1999, 2008).

\subsubsection{The Threat of Insignificance}

Finally, ageism might evoke perceptions concerning the difficulty of preserving positive self-esteem in old age (Martens et al. 2005). According to terror management theory, self-esteem is a vital resource in human life, because it buffers the potential for death-related anxiety (Greenberg et al. 1986). Social perceptions and stereotypes often associate old age with ongoing loss of abilities and resources (Bowd 2003; Cuddy and Fiske 2002; Ellis and Morrison 2005). It is these abilities and resources that are perceived as crucial to acquiring and preserving self-esteem in youth and middle-aged individuals. As a result, these age groups might perceive the older adults as a threat, since they serve as potent reminders of the transitory nature of these attributes. Thus, the threat of loss of these attributes might trigger death anxiety (Martens et al. 2005).

One study that examined this hypothesis found that participants viewed teenagers more favourably than older adults when they were primed with the importance of engaging in physical activity, an attribute that usually declines with age. However, when participants were primed with the importance of wisdom, an attribute that is predicted to increase with age, there was no significant preference of teenagers (Martens et al. 2005).

\subsubsection{Ageism Among Older Adults in Light of Terror Management Theory}

Terror management theory is based on the assumption that death anxiety is a main motive in human life, and that cultural worldview and self-esteem serve as unconscious mechanisms to buffer the threat of death (Greenberg et al. 1997). According to Martens et al. (2005), the encounter with older adults might evoke anxiety 
because they represent inevitable mortality, physical deterioration, and loss of resources perceived as essential to our self-esteem. This anxiety might be manifest in ageism (Martens et al. 2005). However, this theory is focused on the perceptions of young and middle-aged groups towards the old age group and does not describe the way older adults perceive their own ageing process.

McCoy et al. (2000) claim that the protection of one's cultural worldview and self-esteem against the threat of mortality becomes less effective in old age. The ongoing loss of abilities and resources might threaten older adults' self-esteem. In addition, the constantly changing values and rapid technological advancements that characterize the Western world might threaten both the self-esteem and the worldview of older adults. As a result of feeling "left behind" by these advancements, older adults might perceive their abilities and roles as less relevant even before they experience a loss of physical abilities. Moreover, they might perceive their worldview as being threatened by newly emerging worldviews in society. Not only are the mechanisms of self-esteem and the worldview less effective among older adults, but the salience of death is also heightened in this age group through their physical deterioration and the loss of their loved ones (McCoy et al. 2000).

According to McCoy et al. (2000), the increase in mortality salience and the decrease in the effectiveness of protective mechanisms might provide an impetus for psychological reorganization that ultimately functions to help older adults cope with their nearness to death, which is an inherent and inevitable part of late-life. This psychological reorganization, which can be derived from the accumulated wisdom of older adults, may assist older adults in shielding themselves from the terror of death (McCoy et al. 2000).

Support for this hypothesis can be found in studies that have shown that fear of death is diminished in old age (e.g.,(Gesser et al. 1988; Fortner and Neimeyer 1999). Furthermore, experimental studies have found that under a mortality salience condition, old-old adults and young-old adults low in neuroticism perceived their subjective age as significantly lower than young-old adults high in neuroticism (McCoy et al. 2000). Furthermore, unlike other age groups, mortality reminders did not significantly affect the life expectancy of old-old adults (Maxfield et al. 2010). These studies indicate that older adults, especially in the last stage of life, tend to achieve greater acceptance of the inevitability of their own death. The different reactions of older and younger adults to mortality salience is also reflected in studies that have found that young adults respond to mortality salience induction as predicted according to terror management theory, that is, by holding a harsher judgment of moral transgressions and by engaging in health-promoting behaviours, whereas older adults do not (Bozo et al. 2009; Maxfield et al. 2007).

Thus, empirical evidence suggests that death anxiety diminishes in old age, and that older adults respond unlike other age groups to mortality salience. These findings notwithstanding, two studies that examined the relationship between ageist attitudes and death anxiety among older adults showed a positive correlation between them (Bodner et al. 2015; Depaola et al. 2003). However, a careful examination of the age of the participants in these two studies might imply that most of them belonged to the young-old age group, as the mean age ranged between 58.15 and 69.4 (Bodner et al. 2015; Depaola et al. 2003). 
To summarize, the hypothesis of McCoy et al. (2000) that death anxiety diminishes in old age and that, therefore, terror management theory might be less relevant to this age group, is partially supported by empirical studies. According to these studies, terror management theory might be relevant to some extent in the youngold age group and might explain self-ageism in this age group. However, in the last stages of life, the decrease in death anxiety makes terror management theory less relevant as a source of self-ageism.

\subsection{Stereotype Embodiment Theory}

The internalization of negative attitudes towards the self among older adults could be explained by the unique features of different age groups. Unlike other social groups, which tend to be a part of the individual identity for a prolonged period, individuals pass through different age groups during their life course. Thus, negative attitudes and stereotypes of older adults, which the individual has internalized during the lifespan, are often unconsciously embodied in old age (Kite et al. 2002; Levy 2009).

Studies examining explicit attitudes of older adults toward their age group found a positive self-identity (Cherry and Palmore 2008; Laditka et al. 2004). Studies exploring implicit attitudes, however, found a tendency towards internalization and embodiment of negative attitudes among older adults (e.g., Levy and Schlesinger 2005; Meisner 2012).

The embodiment of negative attitudes among older adults towards their own age group is reflected in a study that found that older participants were more likely than younger participants to oppose increased funding to programs that benefitted their age group. This opposition was predicted by age stereotypes (Levy and Schlesinger 2005).

The embodiment of negative stereotypes among older adults has also been shown in experimental studies. These studies found that underperformance in cognitive and physical tasks among older adults was influenced by age group identification (Haslam et al. 2012; Kang and Chasteen 2009) as well as by priming with age stereotypes (Lamont et al. 2015). Additionally, negative age stereotyping had a stronger effect on important behavioural outcomes compared with positive age stereotyping (Meisner 2012). Similarly, longitudinal studies have shown that negative age stereotypes and self-perceptions of ageing among older adults have an adverse influence on health, longevity, and cognitive performance (e.g., Levy et al. 2002a, b, 2012; ; Wurm and Benyamini 2014; Wurm et al. 2007).

\subsection{Social Identity Theory}

According to social identity theory, social behaviour is characterized by two typical behaviours: interpersonal and intergroup behaviours. Interpersonal behaviour is determined by individual characteristics and interpersonal relationships whereas 
intergroup behaviour is determined by respective membership in various social groups or categories. The social behaviour of individuals combines these two aspects. Accordingly, individuals do not act just on the basis of their personal characteristics or their interpersonal relationships, but as members of their reference groups. These memberships reflect on the identities of the individuals as well as on their relationships with members of other groups (Tajfel and Turner 1979).

According to social identity theory, the identification of an individual with a certain group is relational and comparative and can be based on minimal criteria. This determination was based on several studies that indicated that the mere perception of belonging to two distinct groups is sufficient to provoke intergroup competitive or discriminatory responses on the part of the in-group (e.g., Billig and Tajfel 1973; Turner 1975).

Social identity theory posits that people want to have a positive self-identity. They achieve this goal by demonstrating biases which create a positive distinction between their group (in-group) and other groups (out-groups), and by elevating their in-group status above that of other groups (Kite et al. 2002; Tajfel and Turner 1979). However, Tajfel and Turner (1979) claimed that, contrary to the tendency to prefer the in-group over the out-group, subordinate groups often internalize a negative evaluation of themselves and are positively oriented towards out-groups (Tajfel and Turner 1979).

\subsubsection{Ageism Among Young and Middle-Aged Adults in Light of Social Identity Theory}

By examining different age groups in relation to social identity theory, we can infer that young and middle-aged adults might create a positive unique identity, which consists of their age group, by differentiating themselves from and elevating themselves above the old age group. This tendency might increase due to society's negative view of older adults (Kite et al. 2002). An empirical support for this phenomenon can be found in various studies documenting negative attitudes of young adults toward older adults (e.g., Bergman and Bodner 2015; Rupp et al. 2005).

Among middle-aged adults, the need for a positive distinctiveness of their age group might increase due to the recognition that they are closer to becoming members of a devalued group (Kite et al. 2002). This assumption is supported by studies that found that participants in middle-aged groups were more ageist than younger and older groups (Bodner et al. 2012; Laditka et al. 2004). However, other studies did not find significant differences between young and middle-aged groups (Cherry and Palmore 2008) or found conversely that the young group was more ageist than the middle-aged group (Rupp et al. 2005).

According to social identity theory, positive self-identity of the young group could be achieved not only by derogating the old age group, but also by relative positive distinctiveness of both age groups based on personally relevant traits 
(Harwood et al. 1995). The positive distinctiveness of the young age group from the old age group is supported by studies that stressed the mixed nature of older adults' stereotypes, with young adults attributing positive stereotypes to older adults (e.g., warmth and experience) alongside negative ones (e.g., inflexibility and incompetence) (e.g., Chasteen et al. 2002; Cuddy et al. 2005).

\subsubsection{Ageism Among Older Adults in Light of Social Identity Theory}

According to social identity theory, subordinate and minority groups in society often internalize a social evaluation of themselves as "inferior" or "second class" (Tajfel and Turner 1979). Thus, the low status of older adults in society could affect their self-perceptions as members of this age group by internalizing the negative representations of old age that are prevalent in society (Kite et al. 2002). This can be reflected in self-ageism (Bodner et al. 2015).

Along with the assumption of social identity theory that subordinate groups tend to internalize the socially prevalent view of themselves as inferior, an additional and contrary assumption of this theory claims that social groups have a motivation to have a positive self-identity (Tajfel and Turner 1979). This complexity, in the case of older adults, is reflected in studies that examined perceptions and attitudes of older adults towards their own age group (e.g., Levy and Schlesinger 2005; Meisner 2012).

A few studies have explored explicitly ageist attitudes and behaviours of older adults toward their own age group. Research has indicated that older adults have more positive views about older adults than young and middle-aged groups do (Laditka et al. 2004). A different study that examined positive and negative ageist behaviours did not find significant differences between the older and the younger age groups (Cherry and Palmore 2008). However, studies that examined these attitudes as they are implicitly manifested, found a tendency towards internalization and embodiment of ageist attitudes among older adults (e.g., Levy and Schlesinger 2005; Meisner 2012).

\subsubsection{Strategies to Maintain Positive Self-Identity According to Social Identity Theory}

In order to maintain a positive self-identity among minority and subordinate groups (e.g., older adults), Tajfel and Turner (1979) indicated three strategies that members of these groups could adopt. First, older adults can use social mobility by avoiding identification with the old age group. They can achieve this goal by maintaining a youthful appearance and by avoiding behaviours associated with the old age group. 
Second, older adults can use social creativity by focusing on the positive attributes of ageing or by comparing themselves with other less well-off older adults (e.g., a social downward comparison). Finally, older adults can act towards social change by stimulating social action in favour of changing the status of older people in society (Harwood et al. 1995; Kite et al. 2002; Tajfel and Turner 1979).

Evidence for the use of social mobility strategy among older adults can be found in experimental studies that have shown that older adults who were exposed to negative age stereotypes displayed a lower group identification and a stronger subjective age bias, while they tended to feel younger than their actual age (Weiss and Freund 2012; Weiss and Lang 2012). Similarly, the impact of negative age-related information on older adults' explicit and implicit self-esteem was moderated by selfdifferentiation from their age group (Weiss et al. 2013). Furthermore, the tendency of individuals in middle and later adulthood to report younger age identities (Montepare and Lachman 1989) can be interpreted as a desire of these individuals to relate themselves to the young age group and to differentiate themselves from the old age group.

Other studies have found, however, that perceived age discrimination among older adults was positively associated with age group identification (Garstka et al. 2004) and older subjective age (Stephan et al. 2015). Finally, an experimental study found a complex view concerning the activation of negative age stereotypes on three measures of subjective age: felt age ("How old do you feel?"), desired age ("If you could choose your age, how old would you want to be?"), and perceived age ("How old would you say you look?"). Whereas, older adults in good health felt older than their chronological age, older adults in bad health reported older perceived age and younger desired age (Kotter-Grühn and Hess 2012).

Support for the use of social creativity strategies can be found in theories on "successful ageing" (Rowe and Kahn 1997) and "active ageing" (WHO 2002), which stress the positive attributes of ageing. Additional support for these strategies can be found in arguments that call for the separation of the "third age" from the "fourth age." This separation allows young older adults to preserve their status by comparing themselves to the "fourth age," which represents "real old age" and is characterized by frailty, abjection and the "othering" of the self. This results in the defining of older adults by their alienation and vulnerability as well as their exclusion from society (Gilleard and Higgs 2011; Higgs and Gilleard 2014).

\subsection{Synthesis of the Three Theories from a Life Span Perspective}

Although these theories can be seen to provide three different explanations for the origins of ageism at the individual level, a careful examination indicates that they provide a complementary and coherent overview of the origins and processes of ageism over the life course. A sociological and psychological explanation of the 
roots of ageism can be found in terror management theory. According to this theory, the unconscious threats that are embodied in old age undermine our confidence in our cultural worldview and self-esteem (Martens et al. 2005). Ageism is seen as an unconscious defense against death anxiety, which might arise as a result of the encounter with the old age group (Martens et al. 2005). However, studies indicate that this mechanism is relevant mostly among young and middle-aged groups (Bodner and Cohen-Fridel 2014; Martens et al. 2004) and to some extent among old-young adults (Maxfield et al. 2010; McCoy et al. 2000). It becomes less relevant among the old-old age group (Maxfield et al. 2010; McCoy et al. 2000), suggesting a gradual reduction of death anxiety in this age group (e.g., Fortner and Neimeyer 1999) and a greater acceptance of the inevitability of death.

Whereas terror management theory provides an explanation for the roots of ageism among the young, middle- and young-old age groups, stereotype embodiment theory provides a complementary explanation for self-ageism among the young-old and old-old age groups. According to this theory, processes of assimilation of the negative representation of old age from the surrounding culture and the internalization of these representations over one's life span might lead to an embodiment of stereotypes in old age (Levy 2009). Thus, older adults might perceive their status as low, not as a direct response to death anxiety, but due to the internalization of these negative attitudes.

Finally, social identity theory focuses on the diverse expressions of ageism among different age groups. According to this theory, ageism is derived from the desire of the young and middle-aged groups to distinguish themselves from and elevate themselves above the old age group in order to create a positive unique identity based on their own age group. The low status of the old age group, which is reflected in negative attitudes and stereotypes toward older adults in society (and can be explained by the two previous theories) might increase this tendency among different age groups, including older adults themselves (Kite et al. 2002) (see Fig. 4.1).

\subsubsection{Short-Term and Long-Term Strategies for Coping with Self-Ageism}

A unique feature of ageism that emerges from the three presented theories is the inherent threat embedded in it. Unlike other kinds of prejudice and discrimination, which are directed toward distinct out-groups and pose an external threat, ageism is directed toward our future selves by symbolizing our fear of death and the accompanying deterioration of the self (Martens et al. 2005).

Although studies have shown that stereotypes toward older adults in society consist of both negative and positive aspects (e.g., Fiske et al. 2002), the thoughts of inevitable deterioration and death that are associated with old age pose a significant threat to the wellbeing and confidence of the older adults, as they overshadow the positive representations of old age. Moreover, even when old age representations 
are positive, they tend to be devalued in society, relative to the stereotypes of youth. Thus, although people might have a nuanced view of old age as having both positive and negative attributes, they act consciously and unconsciously to differentiate themselves from this age group due to the threats embedded in it.

The conscious and unconscious desire of different age groups to differentiate themselves from the old age group is reflected in their relating themselves to younger age groups or by reporting younger age identities (Montepare and Lachman 1989; Weiss and Freund 2012; Weiss and Lang 2012). Although it may be claimed that this tendency can emerge from the internalization of negative age stereotypes, a growing body of research indicates that a younger subjective age is positively associated with diverse subjective and objective outcomes such as improved physical and cognitive functioning, health, psychological wellbeing, and longevity (e.g., Gana et al. 2004; Kotter-Grühn et al. 2009; Stephan et al. 2014; Stephan et al. 2013). Hence, this strategy has positive outcomes and is highly desirable.

The desire of the middle-age and the young-old age groups to differentiate themselves from the old age group is also reflected in theories such as successful ageing (Rowe and Kahn 1997) and active ageing (WHO 2002), that focus on positive aspects of ageing. These theories undermine the prevailing assumptions that ageing is necessarily characterized by physical and cognitive deterioration, disease, and social isolation and emphasize the potential for maintaining physical, social, and mental wellbeing throughout the life course. According to these theories, successful or active ageing can be achieved by reducing risks for disease and disabilities, maximizing cognitive and physical function, maintaining interpersonal relations, continuing one's engagement in productive activities, and participating in social, economic, cultural, spiritual, and civic affairs (Rowe and Kahn 1997; WHO 2002).

Despite the dominance of these theories, there have been calls over the years that have questioned their legitimacy. These calls have argued that the distinction between successful and unsuccessful agers follows an ageist worldview, as "successful" old age is seen as a continuation of middle age and avoidance of all illness and deterioration (Calasanti 2015; Dillaway and Byrnes 2009; Liang and Luo 2012). Furthermore, the paradigm in these theories reflects Western values of independence and productivity and fails to address values of intergenerational solidarity or harmonization that may be of greater relevance for defining desirable old age for some groups of older adults (Lamb 2014; Liang and Luo 2012). A similar criticism is directed toward the distinction between the third (e.g., successful ageing) and the fourth age (e.g., failed old age), as the fourth age is perceived as the "real old age" and includes all negative attitudes of society toward this age group (Higgs and Gilleard 2014). We suggest that due to the significant threats of death and deterioration that are embedded in old age, the perception of a subjective young age identity ingrained in theories such as successful ageing and active ageing, which emphasize the importance of maintaining physical, social, and mental wellbeing in old age, are essential and have positive outcomes (Montepare and Lachman 1989; Rowe and Kahn 1997; WHO 2002). 
However, these strategies are temporary. Even if an older adult uses all of his or her efforts to maintain good health and good physical and cognitive functioning, he or she would not be able to ignore the deterioration which is almost inevitable in the later stages of life. Therefore, we suggest that a young subjective age identity and theories like successful ageing and active ageing can serve as short-term strategies that are mostly relevant to the middle-age and young-old age groups, but that they gradually become less relevant in the later stages of life, especially in the old-old age group. The encounter with the gradual reduction of physical, cognitive, and social resources in the later stages of life requires the adoption of long-term strategies that do not ignore and repress the inevitable deterioration and death that are embedded in the life course.

These strategies include first a recognition of meaningful decline as a valid dimension of ageing and personhood (Lamb 2014). Second, they pose an alternative to values that emphasize functionality by emphasizing such resources as tradition, wisdom, memory, narrative, change, generation, and leadership (Katz and Marshall 2003). These long-term strategies are reflected in several theories which pose alternatives to the successful ageing and active ageing theories. According to the "conscious ageing" theory, old age is characterized by processes of decrement and compensation. These processes promote a creative response to disability whereby losses are balanced by gains and the decline is compensated for by spiritual insight. According to this theory, old age can be an opportunity for spiritual growth (Moody 2005). Similarly, the "harmonious ageing" theory, which is inspired by Eastern philosophy, possesses a dialectic and holistic ageing approach that allows for crosscultural, liberal, inclusive, and open discourses that emphasize the complementary coexistence of body and mind. The theory defines "harmonious ageing" as a balanced outlook towards the ageing process, which follows the natural laws of the human body and promotes cultivating a sense of harmony with oneself and one's surroundings. This balanced and harmonious outlook promotes handling challenges and thus making adaptations accordingly (Liang and Luo 2012).

\subsection{Conclusions}

To summarize, ageism among young, middle-, and young-old age groups derives from the unconscious threats of death and deterioration that are embedded in old age (Greenberg et al. 1986). Self-ageism among older adults can also derive from the internalization of ageist stereotypes during the life span (Levy 2009). Even when the threat of death declines, especially in the last stages of life (McCoy et al. 2000), self-ageism is often preserved due to these internalization processes (Levy 2009).

In order to protect themselves from the negative consequences of the threat of death and deterioration that are embedded in old age, members of the young-old group might use various strategies. They might perceive their subjective age as 
younger (Montepare and Lachman 1989), identify old age with the "fourth age" (Higgs and Gilleard 2014), or adopt theories such as successful or active ageing, which focus on the positive aspects of old age (Rowe and Kahn 1997; WHO 2002).

However, the positive effects of these strategies are limited, especially among the old-old group, when deterioration and death can no longer be ignored. In order to preserve self-esteem, the old-old might better adopt worldviews that emphasize alternative resources for self-esteem and meaning in old age, alongside the acceptance of the inevitable deterioration in old age (Cosco et al. 2013; Kahana et al. 2012) (see Fig. 4.1).

\section{References}

Agroskin, D., \& Jonas, E. (2013). Controlling death by defending ingroups-Mediational insights into terror management and control restoration. Journal of Experimental Social Psychology, 49(6), 1144-1158.

Alterovitz, S. S., \& Mendelsohn, G. A. (2013). Relationship goals of middle-aged, young-old, and old-old internet daters: An analysis of online personal ads. Journal of Aging Studies, 27(2), $159-165$.

Ayalon, L., \& Tesch-Römer, C. (2018). Introduction to the section: On the manifestations and concequences of ageism. In L. Ayalon \& C. Tesch- Römer (Eds.), Contemporary perspectives on ageism: Vol. 19. International perspectives on aging (pp. 109-113). Berlin: Springer.

Baltes, P. B., \& Baltes, M. M. (1990). Psychological perspectives on successful aging: The model of selective optimization with compensation. Successful Aging: Perspectives from the Behavioral Sciences, 1(1), 1-34.

Baltes, P. B., \& Smith, J. (2003). New frontiers in the future of aging: From successful aging of the young old to the dilemmas of the fourth age. Gerontology, 49(2), 123-135.

Bergman, Y. S., \& Bodner, E. (2015). Ageist attitudes block young adults' ability for compassion toward incapacitated older adults. International Psychogeriatrics, 27(09), 1541-1550.

Billig, M., \& Tajfel, H. (1973). Social categorization and similarity in intergroup behaviour. European Journal of Social Psychology, 3(1), 27-52.

Blanchflower, D. G., \& Oswald, A. J. (2004). Well-being over time in Britain and the USA. Journal of Public Economics, 88(7), 1359-1386.

Bodner, E. (2009). On the origins of ageism among older and younger adults. International Psychogeriatrics, 21(06), 1003-1014.

Bodner, E., \& Cohen-Fridel, S. (2014). The paths leading from attachment to ageism: A structural equation model approach. Death Studies, 38(7), 423-429.

Bodner, E., Bergman, Y. S., \& Cohen-Fridel, S. (2012). Different dimensions of ageist attitudes among men and women: A multigenerational perspective. International Psychogeriatrics, 24(06), 895-901.

Bodner, E., Shrira, A., Bergman, Y. S., Cohen-Fridel, S., \& Grossman, E. S. (2015). The interaction between aging and death anxieties predicts ageism. Personality and Individual Differences, 86, $15-19$.

Bowd, A. D. (2003). Stereotypes of elderly persons in narrative jokes. Research on Aging, 25(1), 3-21.

Bowling, A. (2007). Honour your father and mother: Ageism in medicine. British Journal of General Practice, 57(538), 347-348.

Bozo, Ö., Tunca, A., \& Šimšek, Y. (2009). The effect of death anxiety and age on health-promoting behaviors: A terror-management theory perspective. The Journal of Psychology, 143(4), 377-389. 
Butler, R. N. (1969). Age-ism: Another form of bigotry. The Gerontologist, 9(4 Part 1), 243-246.

Butler, R. N. (1975). Why survive? Being old in America. New York: Harper and Row.

Calasanti, T. (2015). Combating ageism: How successful is successful aging? The Gerontologist, 56(6), 1093-1101.

Carstensen, L. L., Pasupathi, M., Mayr, U., \& Nesselroade, J. R. (2000). Emotional experience in everyday life across the adult life span. Journal of Personality and Social Psychology, 79(4), 644.

Castano, E. (2004). In case of death, cling to the ingroup. European Journal of Social Psychology, 34(4), 375-384.

Castano, E., Yzerbyt, V., Paladino, M. P., \& Sacchi, S. (2002). I belong, therefore, I exist: Ingroup identification, ingroup entitativity, and ingroup bias. Personality and Social Psychology Bulletin, 28(2), 135-143.

Chasteen, A. L., Schwarz, N., \& Park, D. C. (2002). The activation of aging stereotypes in younger and older adults. The Journals of Gerontology Series B: Psychological Sciences and Social Sciences, 57(6), P540-P547.

Cherry, K. E., \& Palmore, E. (2008). Relating to older people evaluation (ROPE): A measure of self-reported ageism. Educational Gerontology, 34(10), 849-861.

Chodzko-Zajko, W. J., \& Ringel, R. L. (1987). Physiological fitness measures and sensory and motor performance in aging. Experimental Gerontology, 22(5), 317-328.

Cohen-Mansfield, J., Shmotkin, D., Blumstein, Z., Shorek, A., Eyal, N., \& Hazan, H. (2013). The old, old-old, and the oldest old: Continuation or distinct categories? An examination of the relationship between age and changes in health, function, and wellbeing. The International Journal of Aging and Human Development, 77(1), 37-57.

Cosco, T. D., Prina, A. M., Perales, J., Stephan, B. C., \& Brayne, C. (2013). Lay perspectives of successful ageing: A systematic review and meta-ethnography. BMJ Open, 3(6), e002710.

Cox, C. R., Goldenberg, J. L., Arndt, J., \& Pyszczynski, T. (2007a). Mother's milk: An existential perspective on negative reactions to breast-feeding. Personality and Social Psychology Bulletin, 33(1), 110-122.

Cox, C. R., Goldenberg, J. L., Pyszczynski, T., \& Weise, D. (2007b). Disgust, creatureliness and the accessibility of death-related thoughts. European Journal of Social Psychology, 37(3), 494-507.

Craik, F. I., \& McDowd, J. M. (1987). Age differences in recall and recognition. Journal of Experimental Psychology: Learning, Memory, and Cognition, 13(3), 474.

Cuddy, A. J., \& Fiske, S. T. (2002). Doddering but dear: Process, content, and function in stereotyping of older persons. In T. D. Nelson (Ed.), Ageism: Stereotyping and prejudice against older persons (pp. 3-26). Cambridge, MA: MIT Press.

Cuddy, A. J., Norton, M. I., \& Fiske, S. T. (2005). This old stereotype: The pervasiveness and persistence of the elderly stereotype. Journal of Social Issues, 61(2), 267-285.

Darrell, A., \& Pyszczynski, T. (2016). Terror management theory: Exploring the role of death in life. In L. A. Harvell \& G. S. Nisbett (Eds.), Denying death: An interdisciplinary approach to terror management theory (pp. 1-15). New York: Routledge.

Depaola, S. J., Griffin, M., Young, J. R., \& Neimeyer, R. A. (2003). Death anxiety and attitudes toward the elderly among older adults: The role of gender and ethnicity. Death Studies, 27(4), 335-354.

Dillaway, H. E., \& Byrnes, M. (2009). Reconsidering successful aging. Gerontology, 28(6), 702-722.

Eaton, A. A., Majka, E. A., \& Visser, P. S. (2008). Emerging perspectives on the structure and function of attitude strength. European Review of Social Psychology, 19(1), 165-201.

Ellis, S. R., \& Morrison, T. G. (2005). Stereotypes of ageing: Messages promoted by age-specific paper birthday cards available in Canada. The International Journal of Aging and Human Development, 61(1), 57-73.

Erikson, E. H. (1950). Childhood and society. New York: Norton. 
Fiske, S. T., Cuddy, A. J., Glick, P., \& Xu, J. (2002). A model of (often mixed) stereotype content: Competence and warmth respectively follow from perceived status and competition. Journal of Personality and Social Psychology, 82(6), 878.

Fortner, B. V., \& Neimeyer, R. A. (1999). Death anxiety in older adults: A quantitative review. Death Studies, 23(5), 387-411.

Gana, K., Alaphilippe, D., \& Bailly, N. (2004). Positive illusions and mental and physical health in later life. Aging \& Mental Health, 8(1), 58-64.

Garstka, T. A., Schmitt, M. T., Branscombe, N. R., \& Hummert, M. L. (2004). How young and older adults differ in their responses to perceived age discrimination. Psychology and Aging, $19(2), 326$.

Gesser, G., Wong, P. T., \& Reker, G. T. (1988). Death attitudes across the life-span: The development and validation of the Death Attitude Profile (DAP). Omega-Journal of Death and Dying, $18(2), 113-128$.

Gilleard, C., \& Higgs, P. (2011). Ageing abjection and embodiment in the fourth age. Journal of Aging Studies, 25(2), 135-142.

Goldenberg, J. L. (2005). The body stripped down: An existential account of the threat posed by the physical body. Current Directions in Psychological Science, 14(4), 224-228.

Goldenberg, J. L., Pyszczynski, T., McCoy, S. K., Greenberg, J., \& Solomon, S. (1999). Death, sex, love, and neuroticism: Why is sex such a problem? Journal of Personality and Social Psychology, 77(6), 1173.

Goldenberg, J. L., Pyszczynski, T., Greenberg, J., Solomon, S., Kluck, B., \& Cornwell, R. (2001). I am not an animal: Mortality salience, disgust, and the denial of human creatureliness. Journal of Experimental Psychology: General, 130(3), 427.

Goldenberg, J. L., Heflick, N. A., \& Cooper, D. P. (2008). The thrust of the problem: Bodily inhibitions and guilt as a function of mortality salience and neuroticism. Journal of Personality, 76(5), 1055-1080.

Greenberg, J., Pyszczynski, T., \& Solomon, S. (1986). The causes and consequences of a need for self-esteem: A terror management theory. In R. F. Baumeister (Ed.), Public self and private self (pp. 189-212). New York: Springer.

Greenberg, J., Pyszczynski, T., Solomon, S., Rosenblatt, A., Veeder, M., Kirkland, S., \& Lyon, D. (1990). Evidence for terror management theory II: The effects of mortality salience on reactions to those who threaten or bolster the cultural worldview. Journal of Personality and Social Psychology, 58(2), 308.

Greenberg, J., Pyszczynski, T., Solomon, S., Simon, L., \& Breus, M. (1994). Role of consciousness and accessibility of death-related thoughts in mortality salience effects. Journal of Personality and Social Psychology, 67(4), 627.

Greenberg, J., Solomon, S., \& Pyszczynski, T. (1997). Terror management theory of self-esteem and cultural worldviews: Empirical assessments and conceptual refinements. Advances in Experimental Social Psychology, 29, 61-139.

Greenberg, J., Schimel, J., \& Martens, A. (2002). Ageism: Denying the face of the future. In T. Nelson (Ed.), Ageism: Stereotyping and prejudice against older persons (pp. 27-48). Cambridge, MA: MIT Press.

Harmon-Jones, E., Greenberg, J., Solomon, S., \& Simon, L. (1996). The effects of mortality salience on intergroup bias between minimal groups. European Journal of Social Psychology, 26(4), 677-681.

Harwood, J., Giles, H., \& Ryan, E. B. (1995). Aging, communication, and intergroup theory: Social identity and intergenerational communication. In J. F. Nussbaum \& J. Coupland (Eds.), Handbook of communication and aging research (LEA communication series) (pp. 133-159). Mahwah: Lawrence Erlbaum Associates.

Haslam, C., Morton, T. A., Haslam, S. A., Varnes, L., Graham, R., \& Gamaz, L. (2012). "When the age is in, the wit is out": Age-related self-categorization and deficit expectations reduce performance on clinical tests used in dementia assessment. Psychology and Aging, 27(3), 778. 
Havighurst, R. J. (1956). Research on the developmental-task concept. The School Review, 64(5), 215-223.

Herrera, M., \& Sani, F. (2013). Why does ingroup identification shield people from death anxiety? The role of perceived collective continuity and group entitativity. Social Psychology, 44(5), 320.

Higgs, P., \& Gilleard, C. (2014). Frailty, abjection and the 'othering' of the fourth age. Health Sociology Review, 23(1), 10-19.

Isaksen, L. W. (2002). Toward a sociology of (gendered) disgust images of bodily decay and the social organization of care work. Journal of Family Issues, 23(7), 791-811.

Iversen, T. N., Larsen, L., \& Solem, P. E. (2009). A conceptual analysis of ageism. Nordic Psychology, 61(3), 4.

Kahana, E., Kelley-Moore, J., \& Kahana, B. (2012). Proactive aging: A longitudinal study of stress, resources, agency, and well-being in late life. Aging \& Mental Health, 16(4), 438-451.

Kang, S. K., \& Chasteen, A. L. (2009). The moderating role of age-group identification and perceived threat on stereotype threat among older adults. The International Journal of Aging and Human Development, 69(3), 201-220.

Katz, S., \& Marshall, B. (2003). New sex for old: Lifestyle, consumerism, and the ethics of aging well. Journal of Aging Studies, 17(1), 3-16.

Kite, M. E., Wagner, L. S., \& Nelson, T. (2002). Attitudes toward older adults. In T. D. Nelson (Ed.), Ageism: Stereotyping and prejudice against older persons (pp. 129-161). Cambridge, MA: MIT Press.

Kite, M. E., Stockdale, G. D., Whitley, B. E., \& Johnson, B. T. (2005). Attitudes toward younger and older adults: An updated meta-analytic review. Journal of Social Issues, 61(2), 241-266.

Kotter-Grühn, D., \& Hess, T. M. (2012). The impact of age stereotypes on self-perceptions of aging across the adult lifespan. The Journals of Gerontology Series B: Psychological Sciences and Social Sciences, 67(5), 563-571.

Kotter-Grühn, D., Kleinspehn-Ammerlahn, A., Gerstorf, D., \& Smith, J. (2009). Self-perceptions of aging predict mortality and change with approaching death: 16-year longitudinal results from the Berlin Aging Study. Psychology and Aging, 24(3), 654.

Laditka, S. B., Fischer, M., Laditka, J. N., \& Segal, D. R. (2004). Attitudes about aging and gender among young, middle age, and older college-based students. Educational Gerontology, 30(5), 403-421.

Lamb, S. (2014). Permanent personhood or meaningful decline? Toward a critical anthropology of successful aging. Journal of Aging Studies, 29, 41-52.

Lamont, R. A., Swift, H. J., \& Abrams, D. (2015). A review and meta-analysis of age-based stereotype threat: Negative stereotypes, not facts, do the damage. Psychology and Aging, 30(1), 180-193.

Levy, B. (2009). Stereotype embodiment a psychosocial approach to aging. Current Directions in Psychological Science, 18(6), 332-336.

Levy, B. R., \& Schlesinger, M. J. (2005). When self-interest and age stereotypes collide: Elders opposing increased funds for programs benefiting themselves. Journal of Aging \& Social Policy, 17(2), 25-39.

Levy, B. R., Slade, M. D., \& Kasl, S. V. (2002a). Longitudinal benefit of positive self-perceptions of aging on functional health. The Journals of Gerontology Series B: Psychological Sciences and Social Sciences, 57(5), P409-P417.

Levy, B. R., Slade, M. D., Kunkel, S. R., \& Kasl, S. V. (2002b). Longevity increased by positive self-perceptions of aging. Journal of Personality and Social Psychology, 83(2), 261.

Levy, B. R., Zonderman, A. B., Slade, M. D., \& Ferrucci, L. (2012). Memory shaped by age stereotypes over time. The Journals of Gerontology Series B: Psychological Sciences and Social Sciences, 67(4), 432-436.

Liang, J., \& Luo, B. (2012). Toward a discourse shift in social gerontology: From successful aging to harmonious aging. Journal of Aging Studies, 26(3), 327-334. 
Martens, A., Greenberg, J., Schimel, J., \& Landau, M. J. (2004). Ageism and death: Effects of mortality salience and perceived similarity to elders on reactions to elderly people. Personality and Social Psychology Bulletin, 30(12), 1524-1536.

Martens, A., Goldenberg, J. L., \& Greenberg, J. (2005). A terror management perspective on ageism. Journal of Social Issues, 61(2), 223-239.

Maxfield, M., Pyszczynski, T., Kluck, B., Cox, C. R., Greenberg, J., Solomon, S., \& Weise, D. (2007). Age-related differences in responses to thoughts of one's own death: Mortality salience and judgments of moral transgressions. Psychology and Aging, 22(2), 341.

Maxfield, M., Solomon, S., Pyszczynski, T., \& Greenberg, J. (2010). Mortality salience effects on the life expectancy estimates of older adults as a function of neuroticism. Journal of Aging Research, 260123. Retrieved from https://doi.org/10.4061/2010/260123.

McCoy, S. K., Pyszczynski, T., Solomon, S., \& Greenberg, J. (2000). Transcending the self: A terror management perspective on successful aging. In A. Tomer (Ed.), Death attitudes and the older adult: Theories, concepts, and applications (pp. 37-64). Philadelphia: Taylor and Francis.

Meisner, B. A. (2012). A meta-analysis of positive and negative age stereotype priming effects on behavior among older adults. The Journals of Gerontology Series B: Psychological Sciences and Social Sciences, 67((1), 13-17.

Montepare, J. M., \& Lachman, M. E. (1989). "You're only as old as you feel": Self-perceptions of age, fears of aging, and life satisfaction from adolescence to old age. Psychology and Aging, $4(1), 73$.

Montepare, J. M., \& Zebrowitz, L. A. (2002). A social-developmental view of ageism (pp. 77-125). Ageism: Stereotyping and prejudice against older persons.

Moody, H. R. (2005). From successful aging to conscious aging. InSuccessful aging through the life span: Intergenerational issues in health (pp. 55-68). New York: Springer.

Nelson, T. D. (2005). Ageism: Prejudice against our feared future self. Journal of Social Issues, 61(2), 207-221.

North, M. S., \& Fiske, S. T. (2012). An inconvenienced youth? Ageism and its potential intergenerational roots. Psychological Bulletin, 138(5), 982.

Old, S. R., \& Naveh-Benjamin, M. (2008). Differential effects of age on item and associative measures of memory: A meta-analysis. Psychology and Aging, 23(1), 104.

Palmore, E. (1999). Ageism: Negative and positive. New York: Springer Publishing Company.

Posthuma, R. A., \& Campion, M. A. (2009). Age stereotypes in the workplace: Common stereotypes, moderators, and future research directions $\dagger$. Journal of Management, 35(1), 158-188.

Pyszczynski, T., Greenberg, J., \& Solomon, S. (1999). A dual-process model of defense against conscious and unconscious death-related thoughts: An extension of terror management theory. Psychological Review, 106(4), 835.

Reinders, I., Murphy, R. A., Koster, A., Brouwer, I. A., Visser, M., Garcia, M. E., \& Jonsson, P. V. (2015). Muscle quality and muscle fat infiltration in relation to incident mobility disability and gait speed decline: The age, gene/environment susceptibility-Reykjavik study. The Journals of Gerontology Series A: Biological Sciences and Medical Sciences, 70(8), 1030-1036.

Renkema, L. J., Stapel, D. A., Maringer, M., \& van Yperen, N. W. (2008). Terror management and stereotyping: Why do people stereotype when mortality is salient? Personality and Social Psychology Bulletin.

Rönnlund, M., Sundström, A., \& Nilsson, L.-G. (2015). Interindividual differences in general cognitive ability from age 18 to age 65 years are extremely stable and strongly associated with working memory capacity. Intelligence, 53, 59-64.

Rowe, J. W., \& Kahn, R. L. (1997). Successful aging. The Gerontologist, 37(4), 433-440.

Rupp, D. E., Vodanovich, S. J., \& Credé, M. (2005). The multidimensional nature of ageism: Construct validity and group differences. The Journal of Social Psychology, 145(3), 335-362.

Schimel, J., Simon, L., Greenberg, J., Pyszczynski, T., Solomon, S., Waxmonsky, J., \& Arndt, J. (1999). Stereotypes and terror management: Evidence that mortality salience enhances stereotypic thinking and preferences. Journal of Personality and Social Psychology, 77(5), 905. 
Snape, E., \& Redman, T. (2003). Too old or too young? The impact of perceived age discrimination. Human Resource Management Journal, 13(1), 78-89.

Solomon, S., Greenberg, J., \& Pyszczynski, T. (2004). The cultural animal. In J. Greenberg, S. L. Koole, \& T. Pyszczynski (Eds.), Handbook of experimental existential psychology (pp. 13-34). New York: Guilford Press.

Stephan, Y., Chalabaev, A., Kotter-Grühn, D., \& Jaconelli, A. (2013). "Feeling younger, being stronger": An experimental study of subjective age and physical functioning among older adults. The Journals of Gerontology Series B: Psychological Sciences and Social Sciences, 68(1), 1-7.

Stephan, Y., Caudroit, J., Jaconelli, A., \& Terracciano, A. (2014). Subjective age and cognitive functioning: A 10-year prospective study. The American Journal of Geriatric Psychiatry, 22(11), 1180-1187.

Stephan, Y., Sutin, A. R., \& Terracciano, A. (2015). How old do you feel? The role of age discrimination and biological aging in subjective age. PLoS One, 10(3), e0119293.

Tajfel, H., \& Turner, J. C. (1979). An integrative theory of intergroup conflict. The Social Psychology of Intergroup Relations, 33(47), 74.

Turner, J. C. (1975). Social comparison and social identity: Some prospects for intergroup behaviour. European Journal of Social Psychology, 5(1), 1-34.

Weiss, D., \& Freund, A. M. (2012). Still young at heart: Negative age-related information motivates distancing from same-aged people. Psychology and Aging, 27(1), 173.

Weiss, D., \& Lang, F. R. (2012). "They" are old but "I" feel younger: Age-group dissociation as a self-protective strategy in old age. Psychology and Aging, 27(1), 153.

Weiss, D., Sassenberg, K., \& Freund, A. M. (2013). When feeling different pays off: How older adults can counteract negative age-related information. Psychology and Aging, 28(4), 1140.

WHO. (2002). Active ageing: A policy framework. (1561-9125). Geneva: World Health Organization.

Wurm, S., \& Benyamini, Y. (2014). Optimism buffers the detrimental effect of negative selfperceptions of ageing on physical and mental health. Psychology \& Health, 29(7), 832-848.

Wurm, S., Tesch-Römer, C., \& Tomasik, M. J. (2007). Longitudinal findings on aging-related cognitions, control beliefs, and health in later life. The Journals of Gerontology Series B: Psychological Sciences and Social Sciences, 62(3), P156-P164.

Open Access This chapter is licensed under the terms of the Creative Commons Attribution 4.0 International License (http://creativecommons.org/licenses/by/4.0/), which permits use, sharing, adaptation, distribution and reproduction in any medium or format, as long as you give appropriate credit to the original author(s) and the source, provide a link to the Creative Commons license and indicate if changes were made.

The images or other third party material in this chapter are included in the chapter's Creative Commons license, unless indicated otherwise in a credit line to the material. If material is not included in the chapter's Creative Commons license and your intended use is not permitted by statutory regulation or exceeds the permitted use, you will need to obtain permission directly from the copyright holder.

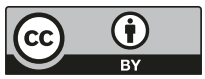




\title{
Chapter 5 \\ Work Environment and the Origin of Ageism
}

\author{
Laura Naegele, Wouter De Tavernier, and Moritz Hess
}

\subsection{Setting the Scene: Ageism at the Workplace}

The ageing of the population and the approaching retirement of the baby boom generation are changing the structure of the workforce all over the industrialised world. The shrinking population of working age and the increased share of older workers within it challenge companies and organizations and call the financial sustainability of welfare states into question (Hedge 2012). While the practice of early retirement of older workers - in order to 'free up' employment opportunities for younger workers-was quite popular in the 1970s and 1980s, governments now recognize the fallacy and the unsustainability of this policy ('lump of labour fallacy'). Older and younger workers are not simply interchangeable e.g. due to their differentiating skill sets, positions within and their contributions to the labour market. Empirical evidence suggests that an increase in employment of older workers is even associated with increasing employment rates of younger cohorts (Kalwij et al. 2010).

Another widely and controversial discussed aspect in this regard is the presumed lower productivity of ageing workforces. Even though the performance or productivity of a worker in itself is rarely viewed as a coherent, analytically easily determinable factor, a negative relationship with age is often almost automatically assumed ( $\mathrm{Ng}$ and Feldman 2012). Instead of acknowledging that workers age

\footnotetext{
L. Naegele $(\bowtie)$

Institute of Gerontology (IfG), University of Vechta, Vechta, Germany

e-mail: laura.naegele@uni-vechta.de

W. De Tavernier

Centre for Comparative Welfare Studies (CCWS), Aalborg University, Aalborg, Denmark

e-mail:wdt@dps.aau.dk
}

M. Hess

Institute for Gerontology at TU Dortmund, Dortmund, Germany

e-mail: mhess@ post.tu-dortmund.de

L. Ayalon, C. Tesch-Römer (eds.), Contemporary Perspectives on Ageism, 
individually and that their productivity is affected by their abilities (physical and cognitive limitations due to age) (Cardoso et al. 2010), education and work experience (outdated or obsolete skills) as well as by work environment related factors such as age-appropriate workplaces and/or career development opportunities (Frerichs et al. 2012), older workers are often seen as less productive than their younger counterparts ( $\mathrm{Ng}$ and Feldman 2008). A closer look at the scientific literature reveals that existing studies do not support this one sided view as they appear to be inconclusive in this regard: Some researchers conclude that ageing populations have a negative effect on labour market productivity, whereas others suggest that at the company level, a higher share of older workers is associated with higher productivity (Van Dalen et al. 2010).

However, the lingering prevalence of prejudices and stereotypes as well as the discrimination of older workers based on age may compromise governments' efforts to extend working lives, which has become a key priority in most of the Western world as well as parts of Asia (Bal et al. 2011). Ageism, defined as discriminatory practices, attitudes and perceptions regarding older workers (Butler 1969), is still pervasive in many companies and organizations in the developed world (Rothenberg and Gardner 2011). In addition previous research has shown that experiencing stereotypes and discrimination at the workplace can influence older employees' productivity (Thorsen et al. 2012), retirement intensions (Schermuly et al. 2014), organizational commitment (Snape and Redman 2006), and work satisfaction (Orpen 1995). The individual perceptions of age discrimination may furthermore be amplified through the interaction with co-workers and supervisors and foster the prevalence of ageism at the organizational level.

Despite efforts to constrain discriminatory behaviour via law-making and employment policies in Europe and elsewhere, ageism is still prevalent in organizations and companies ${ }^{1}$ and affects the careers of older workers in terms of job opportunities, promotions and performance evaluations. As a result—in combination with a shortage of skilled junior personnel—companies might run into difficulties when trying to fill their vacancies, affecting their overall performance and ultimately the growth of the economy (Kunze et al. 2011; Rothenberg and Gardner 2011). Therefore, it is crucial to identify which factors foster or mitigate ageism in the workplace, as it impacts not just older workers' lives, but also organizational performance and the economy and society as a whole.

Understanding the sources of age discrimination at the workplace is the first step in repelling it. Studies explaining ageism and its origins generally fit into three categories. First, there are studies looking at individuals (the micro level), linking ageist attitudes to individual characteristics such as education, gender or income. A

\footnotetext{
${ }^{1}$ For improved readability we use the terms 'company' and 'organizations' synonymously in order to describe the 'places of work' throughout the chapter. We acknowledge that even though all companies can be described as organizations, in a narrow interpretation not all organizations can be described as companies (e.g. in the public sector). The processes discussed in the chapter are relevant for both public and private organizations, as well as non-profit and for-profit ones.
} 
second perspective focuses on the macro level. In this perspective, ageism is attributed to cultural norms and attitudes prevalent in societies (Ayalon 2013). Shared values and norms have been shown to manifest themselves through prejudice and discrimination while shaping individual and organizational behaviour regarding ageism (Shiu et al. 2015). The third perspective relates to the social sphere of work organizations/companies (meso level) which play a key role in age discrimination. They provide the 'places of work' and therefore set the scene for the prevalence of discriminating behaviour towards older workers.

By focusing on the organizational level, this chapter aims to outline how ageism manifests itself in the important arena of work. While acknowledging the importance of other (younger) cohorts within the labour market, as well as the increasing amount of volunteer work done by older people, this chapter aims to primarily focus on ageism at the workplace faced by older workers in paid employment. We present a conclusive overview of theories and findings in the scientific literature regarding the role of organizations or companies in cultivating, preserving or reducing ageism within them. Focusing on studies from the developed world, we first look at the company level where we identify organizational characteristics that affect ageism, namely organizational structure and hierarchy, age structure of the workforce, company size, shared values and aspects of age-friendly human resource management. As organizations and companies never exist within an institutional vacuum, we subsequently identify contextual factors that shape and affect companies and organizational behaviour, and hence ageism within the organization. Here, we consider sectorial affiliation and legal frameworks on the company level. Overall we will discuss seven main determinants of age discrimination at the work place, without any claim for completeness at this point. Rather, these determinants are not set in stone, nor do they exist independently of each other or affect all organizations/companies the same way. In addition, as labour markets, organizations and companies are constantly evolving, it can be expected that in the future new determinants of ageism at the company level might arise.

\subsection{Organizational Characteristics as Sources of Ageism at the Workplace}

\subsubsection{Organizational Structure and Hierarchy}

Even though several studies stipulate the importance of organizational structures for age discrimination within the workforce (e.g. Branine and Glover 1997; Brooke 2010; McGoldrick and Arrowsmith 2001; Riach and Kelly 2015), the structure typically is not the focus of ageism research, but only present as a contextual factor-if at all. McGoldrick and Arrowsmith (2001), for instance, link the organizational structure to stereotypes about and discrimination of older workers, to what it means to be old and to possible solutions to ageism in their conceptual scheme, but this is 
completely overlooked in their analyses. This lack of attention for organizational structures in ageism literature is in stark contrast with the attention it has in other areas of research concerning discrimination. For instance, there is a vast body of research regarding the discrimination of women in the workforce (Gelfand et al. 2007). Other findings suggest that sexual and racial inequalities in an organizational hierarchy tend to reproduce themselves (Gelfand et al. 2005). Bird and Rhoton (2011) develop this idea further in their research on gender and 'professional bureaucracies'. They identify four components elementary to the professional work organization that are vulnerable to discrimination and as such effectively work as a filter guaranteeing that only individuals complying with the logic of the organization reach higher positions in the organizational hierarchy: the organization of work itself (e.g. work hours), decision-making processes (e.g. who makes the decisions), performance evaluation practices (e.g. which criteria are used in the evaluation) and information networks (e.g. largely informal networks through which individuals gather important information for job performance and career advancement). Regarding the latter, Gelfand et al. (2005) also point to the fact that, in line with the similarity-attraction theory (see further below), individuals tend to form informal networks in an organization with other individuals who are similar to them. In a white male dominated organization, for instance, women and ethnic minorities will have less informal access to those higher in the hierarchy than do white men. In the context of ageism, this would mean that workers may benefit from informal networks if individuals higher up in the hierarchy are of the same generation or, as the flip side of the coin, that they receive less opportunities if that is not the case. Interestingly, in their study in the information technology sector in the Anglo-Saxon world, McMullin et al. (2011) find that hierarchy can be beneficial for older workers. Due to the fast evolution in the information technology sector, programming skills can become outdated rather quickly-hence the finding of McMullin and Dryburgh (2011) that programmers are considered 'old' already in their early 40s (note that this implicitly involves the ageist assumption that workers above age 40 are not able to adapt to changes). By climbing higher in the hierarchy into a managerial position, however, different skills become relevant-skills that are more often attributed to older workers.

That brings us to the role of skills: organizational and company structures, like sectors, demand specific skills. In the words of Miles and Snow (1995, p. 5): "Every organizational form-pyramid or pancake, centralized or decentralized-places unique demands on people." These skills can be the subject of ageist ideas, if for example some skills are being mainly attributed to certain age groups and hence they can be a mediator between the organization of work and discrimination based on age. There is a large agreement in the literature that organizational structures have a 'skill bias' (Caroli and Van Reenen 2001).

Much has been written about the knowledge, skills and creativity of workers being important in processes of organizational change and new forms of organization. Whitley (1989) wrote that managerial work is characterized by its unstandardized nature, orientation towards problem-solving and balancing between reproduction and innovation. In a strongly hierarchical system, these skills would 
traditionally be seen as traits of experienced workers in management positions. In new types of organizations with flat hierarchies, where individual workers get more and more tasks and responsibilities (Caroli and Van Reenen 2001), these characteristics are not limited to the management anymore. Such lean organizations redefine and break down established hierarchical models of organizational behaviour and with them the inherent expectations of how age and skill is dispensed within organizations (Ashton 2004; Worley and Doolen 2015). Ashton (2004) argues that such organizations in addition strengthen workers' skills for two reasons: first, to distribute knowledge more widely within the organization, and second, to give workers more opportunities to practice new skills and techniques. Andriopoulos (2001) notes that organizations and companies show an increased focus on creativity and problem-solving, and that flat structures stimulate creativity among their employees. Network organizations, which are flat, flexible and market-oriented, and work with relatively autonomous self-managing teams, require workers who have strong skills ('capabilities') and who are trustworthy (Miles and Snow 1995). Even though none of these studies makes the link with ageism, it is a common finding in studies on ageism that older workers are considered to be less creative though more trustworthy (e.g. Gringart et al. 2005; Taylor and Walker 1998). ${ }^{2}$ Hence, the relationship between these new organizational structures and ageism could be a dual one: on the one hand, the value placed on knowledge and trust may benefit older workers, though the perception of older workers as less creative may be a serious disadvantage for employment of older workers in organizations with flat hierarchies.

\subsubsection{Age Structure}

'Relative age', referring to an individual's age as compared to the average or mean age in a sector, company or profession (McMullin and Duerden Comeau 2011), is a basis for age discrimination in the labour market - the general idea being that the bigger the difference between the individual's age and what is considered 'normal' for a certain function, the higher the risk for discrimination. Individuals working as programmers in the information technology sector, for instance, could be considered 'old' in their early 40s, while a judge may only reach that point 20 years later (McMullin and Dryburgh 2011). Data from the German Institute for Employment Research Establishment Panel show that older workers (50+ years) are perceived more positively regarding their capabilities and performance by management personnel in companies with a higher share of older workers (Bellmann et al. 2003). However, due to the cross-sectional nature of the analysis, it is not possible to make a statement on the causal direction of the relation.

\footnotetext{
${ }^{2}$ According to Binnewies et al. (2008), earlier "[s]tudies reporting relationships between age and creativity most of the times found no relationship (...) or a slightly negative relationship" (p. 442). Their own study suggests that the relation between age and creativity is dependent on the level of job control of the worker.
} 
Kunze et al. (2011) note two general strands in earlier research, linking increased age diversity in an organization to decreasing age discrimination. The first one refers to the contact hypothesis, suggesting that age diversity leads to more contact and familiarity between individuals of different age groups, leading to lower age discrimination. A second strand suggests that increasing age diversity causes workers to believe the organization values diversity, thereby shaping a 'positive diversity climate' (see further below).

However, there are also four prominent hypotheses in the literature expecting the opposite: that ageism will be higher as age diversity in the organization increases. First, the similarity-attraction paradigm suggests people like others they feel are similar to themselves (Kunze et al. 2011, 2013; Shore and Goldberg 2012). Second, according to social identity and self-categorization theory, "individuals tend to classify themselves and others into certain groups on the basis of dimensions that are personally relevant for them" (Kunze et al. 2011, p. 268), and prefer individuals that fall in the same category as themselves (Kunze et al. 2011,2013; Shore and Goldberg 2012). Growing age diversity might then make age as a trait more salient, and hence an element in this categorization process.

The concept of 'career timetables' is a third hypothesis (Kunze et al. 2011, 2013; Shore and Goldberg 2012). It involves expectations of how individuals move up in the organizational hierarchy as they become older and more experienced, and that employees who 'lag behind' on this schedule — and who are hence surrounded by younger individuals in their work unit-are more likely to face discrimination. A fourth theory is related to 'prototype matching', the idea being that certain jobs are considered to be for a specific group of people, for instance because of the skills or knowledge they require (Kunze et al. 2011; Shore and Goldberg 2012). An older person performing a job that would typically be seen as a job for young people has a higher risk of facing discrimination, just like a younger person who has a job higher up in the hierarchy, while workers think the position requires much knowledge and experience-and should hence be executed by an older person.

While Nishii and Mayer (2009) do not find a relation between age structure in the working unit and experiences of age discrimination among older workers in the United States, Kunze et al. $(2011,2013)$ do find that higher age diversity leads to more perceived age discrimination among employees in German companies. Interestingly, Kunze et al. (2013) find that this relation is exacerbated when case managers have ageist attitudes, while the presence of diversity-oriented human resource policies has the opposite effect.

\subsubsection{Age-Diverse Climate, Age-Friendly Corporate Identity and Leadership}

Not only structural characteristics like the size or sector of a company determine the level of ageism at the workplace. 'Soft' factors like company climate, inclusion and diversity policies, and corporate identity are important as well. Four selected factors 
in this context—organizational culture, company climate, corporate identity, and leadership -will be the topic of this section. As human resources measurements that can help fight ageism are also immensely important in this regard, they will be discussed separately in the following section.

When researching discriminative behaviour at the workplace Ciampa and Chernesky (2013) distinguish the important concepts of organizational culture and climate. "Organizational culture refers to the deep structure of organizations, rooted in the values, beliefs, and assumptions of organizational members. It is established through socialization to a variety of identity groups that converge in the workplace [...]. The standards against which behavior is evaluated are that of the majority culture, and reflect the attitude and values of those who hold positions of authority and power" (Ciampa and Chernesky 2013, p. 96). Managers should strive for a culture that does not allow discriminative behavior. Organizational or company climate is the sum of all the members' individual psychological climates. Boehm et al. (2013, p. 671) define a climate that hinders the emergence of ageism " $[\ldots]$ as organizational members' shared perceptions of the fair and non-discriminatory treatment of employees of all age groups with regard to all relevant organizational practices, policies, procedures, and rewards." Hence, an age-friendly or age-diversity climate is based on the workers in the organization agreeing that no one should be discriminated because of age.

Closely linked to these rather abstract conceptions of a positive organizational culture and age-diversity climate is the concept of an age-friendly corporate identity (Kunze et al. 2011, 2013). Companies should free their internal and external communication of ageist language (Fowler et al. 2015) and avoid discriminative behaviour in the hiring and promotion process. They should seek to design and create products that are not ageist, and not be ageist towards their customers (Stroud and Walker 2013). An age-friendly corporate identity will help to form an age-diverse climate. As already mentioned with the concept of organizational culture, one crucial mediator here is the leadership behaviour of managers and supervisors (Liden et al. 2006). They should internalize the idea of an organization or company without ageism, act accordingly, and serve as role models for the other employees (Nishii and Mayer 2009). By doing so, they can positively influence organizational culture and climate.

\subsubsection{Human Resource Measures}

In addition to having an age-friendly corporate identity and trying to create an atmosphere in which older workers feel welcome and that their work is appreciated, companies also have or rather should have a human resources management strategy that aims to fight ageism. Several tools can be identified that human resources mangers can use to create an age-friendly climate at the workplace. In the literature (Boehm et al. 2013; Kooij et al. 2010; Lepak et al. 2006), most scholars agree that human resources measures should be age-inclusive, meaning that no workers should 
be excluded from human resources programs or ignored in the promotion and recruitment process. In addition, the human resources measures should also follow a certain organizational strategy and not consist of single, isolated tools that are not interrelated (Kunze et al. 2013). Instead the human resources tools should be bundled into one consistent and coherent policy. Three examples of tools that help to decrease ageism at the workplace are inclusion of older workers into training courses, age-blind promotion and hiring processes, and special training courses for older workers. Suspending older workers from training measures and programs because of their age is an ageist action and leaves them with outdated and/or obsolete skills. In addition including workers from different age groups into training courses could actively help to decrease ageism (Brownell and Kelly 2013; Chiu et al. 2001). Drawing on classical contact theory (Aronson et al. 2004) which claims that if individuals from different groups get into contact, this will decrease the stereotypes they hold of each other, one could argue that these age-inclusive training programs lead to fewer age stereotypes, and consequently to less ageism at the workplace. A second important human resource tool in the fight against ageism is age-blind promotion (Machado and Portela 2013) and recruitment procedures (Ahmed et al. 2012). They help to ensure that older workers are not discriminated against when applying at a company or for a new job in the same company. Deleting the applicant's age from the curriculum vitae and, thus, having age-blind applications is one practical measure to ensure age-blind promotion and recruiting procedures (Rocco et al. 2014). Besides the age-inclusive general human resources approach and the age-blind promotion and recruiting procedures, companies can also offer specific human resource programs for older workers (Göbel and Zwick 2013). Such specific programs might include part time retirement, support for caring obligations, retirement consultation, and life work-time accounts-the latter allowing older workers to 'save' over-time working hours over several years and use them to work less later on (Burke and $\mathrm{Ng}$ 2006). These help older workers to live up to their potential and be productive employees (Picchio and Van Ours 2013; Göbel and Zwick 2013). This in turn will decrease the occurrence of ageism at the workplace. However, one has to acknowledge that human resources measures aimed at fighting ageism might actually increase it. One unintended consequence of ageblinded promotion and recruitment and special training programs for older workers might be that they are seen as groups that receive undeserved benefits and this might result in ageism (Dipboye and Colella 2013; Lyon et al. 1998).

\subsubsection{Company Size}

Closely linked to the question of the prevalence of age-friendly human resource measurements is the question of company size. Since small and medium sized companies $(<250$ employees) are rather the rule than the exception in a majority of countries, taking a closer look at their relation to ageism might be worthwhile. 
When taking human resource measurements into account, a rather easy assumption would be: Small companies have less means to implement age management measures, which have shown to tackle negative stereotyping of older workers (Kunze et al. 2013; Fuertes et al. 2013), while larger sized companies already widely adapted these measures (Leber et al. 2013). Furthermore, small companies are more likely to not feel the need to change their policies due to changing legislation concerning ageism (Metcalf and Meadows 2010), they do not see older workers as the solution for labour market shortages (Van Dalen et al. 2009) and offer fewer training possibilities for older workers (Taylor 2011), although research in this regard is inconclusive. When for instance asked for less institutionalized, work-integrated measures for older workers, smaller companies have shown to offer these on the same level as companies with more employees (Naegele and Frerichs 2015).

Regarding the perception of older workers, various studies affirm that in smaller companies, older workers are viewed more positively than in companies with larger workforces (Bellmann et al. 2003; Boockmann and Zwick 2004). Similar results have been found when asked about self-perceived stereotyping: Older workers employed by small companies report to be more frequently confronted with positive stereotyping than older employees working in larger companies (Hess 2013). Flat hierarchies and close social embeddedness within the respective workforce, the monopoly held by older workers on company-specific knowledge (Hilzenbecher 2006), or the fact that older workers often hold key positions within small companies, which are unlikely to be filled easily by others such as younger workers (Beck 2013), could be explanatory factors for the relatively positive view on older workers within small and medium sized enterprises. Additionally-even though often not sufficiently recognized - the prevalence of less formal, work-integrated measures focused on older workers in small and medium sized companies could also be a preventive factor for ageist behaviour.

\subsection{Contextual Factors as Sources of Ageism at the Workplace}

\subsubsection{Industrial and Sectorial Affiliation}

Not only the size of a company or the age structure of its labour force influence the perception of older workers in their work environment, the same goes for the sector or industry in which older workers are employed. According to 'age-typed theory' by Oswick and Rosenthal (2001) workers are judged by the fit between the requirement of a particular job and the assumed competences they bring to the table. Negative stereotyping and ageist behaviour towards older workers may result from a perceived 'lack of fit' between a job's requirement and the abilities of a worker. Within certain sectors job requirements 'match up' better with competences 
generally attributed to older workers (such as stability, loyalty or experience) and therefore these sectors may supply more 'fitting places' of work for older employees (Richardson et al. 2013; Turek and Perek-Bialas 2013). An easy example can be drawn by looking at the German craft sector-a work environment which highly depends on knowledge as well as experience of workers, both attributes generally ascribed to older workers (Hilzenbecher 2006). Whereas in small craft businesses, older workers are often highly valued and their retirement day considered a dreaded event, research has shown that in other industries, where the question of productivity of workers is high on the agenda, older workers are more often confronted with negative stereotyping (Van Dalen et al. 2010; Malmberg et al. 2008). Hess (2013) estimated differences between sectors and/or industries in Germany by focusing on the prevalence of stereotyping experienced by workers (49+ years). A more positive stereotyping-'older workers being more reliable than their younger colleagues' - was often found in the retail and health care sectors, whereas negative stereotypes-'older workers being less adaptable' and/or 'less productive'occurred more often in the educational sector, public administration as well as manufacturing. Henkens (2005) finds that amongst Dutch mangers in the public sector, negative stereotypes towards older workers are much stronger than in the private sector. He suggests this might be due to the seniority-based salary system and high job-protection.

The sectorial variations in employment rates of older workers are also found to be influential of a negative age-discrimination climate in industries and ultimately companies (Kunze et al. 2013; Stettes 2012). The cultural and political contexts or more generally speaking the 'institutional surroundings' in which employers operate (e.g. when hiring an older worker) are linked not only to the major changes in national level policies but also to experiences with and normative assumptions about older workers within their respective sectors/industries (Shiu et al. 2015). Employers with a high share of older workers (50+ years) in their respective companies are more likely to report that older workers are less often sick than their younger counterparts, whereas management personnel from 'younger' companies do not share this perception (Stettes 2009). Whereas sectors such as agriculture and fishing are known for employing the oldest workforces (Macinol 2010), in sectors with a predominantly younger workforce such as advertising (Carrigan and Szmigin 2003), older job seekers are often more liable to age discrimination (Richardson et al. 2013). Nevertheless, this behaviour is reported to go both ways. Metcalf and Meadows (2010) concluded from a British survey that close to one fifth of employers viewed certain jobs as more suitable for particular age groups, with a tendency to favour the middle age group (30-50 years old) over not only older but also younger workers (Taylor 2011). 


\subsubsection{Legal Framework for Prohibiting Discrimination Based on Age}

Discriminating behaviour based on age in the field of employment and occupation has been subject to legal controls for several decades (Doron et al. 2013). While acknowledging the wide range of legislations worldwide, due to the level of sophistication, the existing European legal framework presents an especially interesting case in this regard and will be discussed in the following section. ${ }^{3}$

Since the broadening of the scope of anti-discrimination measures beyond sex and nationality with the Amsterdam Treaty (1997), the European Union limits the circumstances under which member states may permit employers a different treatment of workers on the ground of age. Imposed under the European Council directive 2000/78/EC, member states are to be encouraged to combat early resigning as well as to facilitate the hiring, employment, career development and retirement of older workers (Numhauser-Henning 2013; O’Cinneide 2005). By 2006, almost all of the member states had implemented the directive in their national discrimination, employment and labour laws (Spencer 2013).

While prohibiting age discrimination is an important legal mechanism in order to promote the equal treatment of older workers in employment, training and the workplace, it is questionable how successful these non-discrimination laws are in practice. Taking the example of compulsory retirement practices, some authors have argued that legal retirement ages are one of the leading forms of age discrimination, since they exclude people en masse from the workforce, solely due to their age (Walker 1990). Other authors concluded that driven by economic and political interest's mandatory retirement can be interpreted as an institutionalized form of ageism (McDonald 2013; Woolever 2013).

A steady stream of law cases was brought to the Court of Justice of the European Union and while one would expect compulsory retirement age to be contrary to the ban on discriminatory behaviour based on age, so far the Court of Justice of the European Union has accepted age limits if proportionate means of achieving a legitimate aim arise. The court has argued that 'age' is to be set apart from other protected characteristics under the Discrimination Directive because it is shared by everyone and can be seen as a continuum which changes over time: Over the span of a lifetime, almost every worker will benefit from provisions targeting older workers (Vickers and Manfredi 2013). Secondly, according to the Directive a different treatment of workers does not constitute age discrimination if one does not distinguish based on individual factors but based on "legitimate employment policy, labour market and vocational training objectives" (Numhauser-Henning 2013, p. 401).

\footnotetext{
${ }^{3}$ For a more detailed overview on this topic please see Doron et al. (2018; Chap. 19); Mikołajczyk (2018; Chap. 20) and Georgantzi (2018; Chap. 21) as well as Abuladze and Perek-Białas (2018; Chap. 28) in this volume.
} 
Even if such discrimination lawsuits make it to court the 'learning effect' on the employer's side seems to be rather questionable as the review of recent literature addressing age-related cases from the United States of America reveals: It seems that a number of legal firms have established themselves in the lucrative market of assisting human resource managers to avoid lawsuits by terminated older workers. Instead of advising management to adapt more ethical practices towards their older workers, these legal firms specialize in preventing companies to become the target of age-related lawsuits in the first place (Woolever 2013). Furthermore, research has shown that even though legal frameworks are in place individuals are reluctant to acknowledge ageist behaviour (and go to court for it), possibly due to the fact that they do not view themselves as being 'old' and therefore attribute perceived harassment at the workplace as not being related to their age (Blackstone 2013). In addition, in contrast to their younger counterparts, older workers tend to not report harassment at the workplace, while at the same time employers, lawyers as well as other actors within the legal system, tend to treat age discrimination cases as less serious than race or gender based offences (Spencer 2013).

Taking a look at the hiring practice, the existing limitation of laws become obvious: Oblivious to existing legal regulations, ageism can occur in hiring practices when human resource personnel "consciously or subconsciously applies age limits to older applicants" (Spencer 2013, p. 147). Existing stereotypes regarding the productivity or performance of older workers on the employer or human resource side furthermore might lead to older workers taking longer to find new employment or when being reemployed tend to receive a lower salary than in their former employment (Woolever 2013). Although their importance is non-negotiable, laws are often insufficient to guide the personnel actions of human resource managers as a wide range of policies and actions fall outside the domain of the law. Therefore, ethics in general as well as a company's attitude towards their ageing workforce become increasingly important in the daily work of human resource managers.

\subsection{Conclusion: Fighting Ageism at the Workplace}

Against the background of ageing societies in general and an ageing workforce in particular, the subject of old age discrimination at the workplace has moved into the spotlight. Age discrimination or ageism has among others a negative impact on older workers' productivity, quality of work and organizational commitment and, thus, also harms the companies and organizations they are working in. Therefore, fighting ageism must be a priority of policy makers, employers and trade unions. To mitigate the effects of age discrimination, we must know its origins. In this chapter, we focused on the meso-level and the origin of ageism at the workplace. Seven main determinants of ageism were detected: organizational structure and hierarchy; age structure; age-diverse climate; human resources measures; company size; industrial and sectoral affiliation; and the legal framework. 
Regarding a company's organizational structure, four components were identified at which age discrimination is possible: the organization of work itself; decision making process; performance evaluations; and information networks. Moreover, the formal and informal structure of the organization determines the need for certain skills over others, and these skills can be the subject of ageism. Hence, there can be an indirect effect of the organizational structure on ageism through skills. Our literature review reveals a striking lack of research on the relation between age and organizational structure, especially when compared to research on gender and organizations. This could be an interesting path to develop in future research.

A company's age structure can influence the occurrence of ageism in two ways: on the one hand growing age diversity can lead to more contact between workers of different ages and, thus, reduce ageism. On the other hand, it could make age as a category more salient and increase its importance as an element of categorization and potentially lead to discrimination because of age.

Company size is linked with ageism in two ways: Larger companies have institutionalized human resources departments offering age management measures that help to tackle ageism. At the same time, the informal organizational structure of smaller companies might help to create contacts between different generations of workers and, thus, decrease ageism. In addition, less formal work-integrated measures might likewise contribute to a more positive reception of older workers in small and medium sized companies. Further research in this regard could add valuable input to the debate.

A coherent human resources strategy-e.g. age inclusive training programs and an age blind recruitment and promotion procedure-will help to reduce ageism. Closely linked to the human resource strategy, the concept of age friendly climate and corporate identity can play an important role. Creating an atmosphere of ageistfree language, procedures and products is an important step to fight ageism.

Whereas the first five determinants are closely linked to the company level, the last two determinants of ageism at the workplace-industrial and sectorial affiliation and the legal framework - are located between the meso and macro level and therefore policy makers and stakeholders have to put the topic of ageism actively on the political agendas in order to prevent ageist behaviour in the workforce.

What implications can be drawn from this analysis of ageism's sources at the workplace? First, it is important to recognize that older and younger workers are both valuable members of the workforce, and policies should refrain from playing out different labour market groups against each other. Second, employers and trade unions should try to create an ageist-free environment at the workplace. One main tool to do so is the implementation of human resource measures as described above. Third, when trying to fight ageism, companies must seek for tailor fit solutions according to their sizes, sector and the age compositions of their employees. A 'one size fits all' approach will not be sufficient in order to prevent discrimination based on age in the labour market. Fourth, the state should set a legal framework that in alliance with companies' anti-discrimination measures grants workers protection from discrimination based on age. Last, all efforts to combat discrimination because 
of age at the workplace should be synchronized with each other and be embedded into a general strategy of fighting ageism not only at the workplace but also in society in general.

\section{References}

Abuladze, L., \& Perek-Białas, J. (2018). Measures of ageism in the labour market in international social studies. In L. Ayalon \& C. Tesch-Römer (Eds.), Contemporary perspectives on ageism: Vol. 19. International perspectives on aging (pp. 459-489). Berlin: Springer.

Ahmed, A. M., Andersson, L., \& Hammarstedt, M. (2012). Does age matter for employability? A field experiment on ageism in the Swedish labour market. Applied Economics Letters, 19(4), 403-406.

Andriopoulos, C. (2001). Determinants of organisational creativity: A literature review. Management Decision, 39(10), 834-841.

Aronson, E., Wilson, T., \& Akert, R. (2004). Sozialpsychologie. München: Pearson.

Ashton, D. N. (2004). The impact of organisational structure and practices on learning in the workplace. International Journal of Training and Development, 8(1), 43-53.

Ayalon, L. (2013). Feelings towards older vs. younger adults: Results from the European Social Survey. Educational Gerontology, 39(12), 888-901.

Bal, A. C., Reiss, A. E., Rudolph, C. W., \& Baltes, B. B. (2011). Examining positive and negative perceptions of older workers: A meta-analysis. Journal of Gerontology: The Journals of Gerontology, Series B, 66(6), 687-698.

Beck, V. (2013). Employers' use of older workers in the recession. Employee Relations, 35(3), 257-271.

Bellmann, L., Hilpert, M., Kistler, E., \& Wahse, J. (2003). Herausforderungen des demografischen Wandels für den Arbeitsmarkt und die Betriebe. Mitteilungen aus der Arbeitsmarkt- und Berufsforschung, 36(2), 133-149.

Binnewies, C., Ohly, S., \& Niessen, C. (2008). Age and creativity at work. Journal of Managerial Psychology, 23(4), 438-457.

Bird, S. R., \& Rhoton, L. A. (2011). Women professionals' gender strategies: Negotiating gendered organizational barriers. In E. Jeanes, D. Knights, \& P. Y. Martin (Eds.), Handbook of Gender, Work and Organization (pp. 245-262). Hoboken: Wiley-Blackwell.

Blackstone, A. (2013). Harassment of older adults in the workplace. In P. Brownell \& J. J. Kelly (Eds.), Ageism and Mistreatment of Older Workers (pp. 31-49). Dordrecht: Springer.

Boehm, S. A., Kunze, F., \& Bruch, H. (2013). Spotlight on age-diversity climate: The impact of age-inclusive HR practices on firm-level outcomes. Personnel Psychology, 67(3), 667-704.

Boockmann, B., \& Zwick, T. (2004). Betriebliche Determinanten der Beschäftigung älterer Arbeitnehmer. Zeitschrift für Arbeitsmarkt- und Berufsforschung (ZAF), 37(1), 53-63.

Branine, M., \& Glover, I. (1997). Ageism in work and employment: Thinking about connections. Personnel Review, 26(4), 233-244.

Brooke, E. (2010). Employment relations and the wage: How gender and age influence the negotiating power of IT workers. In J. A. McMullin \& V. W. Marshall (Eds.), Aging and working in the new economy: Changing career structures in small IT firms (pp. 88-118). Cheltenham: Edward Elgar.

Brownell, P., \& Kelly, J. J. (Eds.). (2013). Ageism and mistreatment of older workers: Current reality, future solutions. Dordrecht: Springer.

Burke, R., \& Ng, E. (2006). The changing nature of work and organizations: Implications for human resource management. Human Resource Management Review, 16(2), 86-94.

Butler, R. N. (1969). Age-ism: Another form of bigotry. Gerontologist, 9(4), 243-246. 
Cardoso, A. R., Guimarães, P., \& Varejão, J. (2010). Are older workers worthy of their pay? An empirical investigation of age-productivity and age-wage nexuses (IZA discussion paper No. 5121).

Caroli, E., \& Van Reenen, J. (2001). Skill-biased organizational change? Evidence from a panel of British and French establishments. The Quarterly Journal of Economics, 116(4), 1449-1492.

Carrigan, M., \& Szmigin, I. (2003). Regulating ageism in UK advertising: An industry perspective. Marketing Intelligence and Plan, 21(4), 198-204.

Chiu, W., Chan, A. W., Snape, E., \& Redman, T. (2001). Age stereotypes and discriminatory attitudes towards older workers: An East-West comparison. Human Relations, 54(5), 629-661.

Ciampa, E., \& Chernesky, R. (2013). Creating supportive workplace environments for older workers. In P. Brownell \& J. J. Kelly (Eds.), Ageism and mistreatment of older workers (pp. 93-111). Dordrecht: Springer.

Dipboye, R. L., \& Colella, A. (Eds.). (2013). Discrimination at work: The psychological and organizational bases. New York: Psychology Press.

Doron, I., Brown, B., \& Somers, S. B. (2013). International protection for the human rights of older people: History and future prospects. In P. Brownell \& J. J. Kelly (Eds.), Ageism and mistreatment of older workers (pp. 165-181). Dordrecht: Springer.

Doron, I., Numhauser-Henning, A., Spanier, B., Georgantzi, N., \& Mantovani, E. (2018). Ageism and anti-ageism in the legal system: A review of key themes. In L. Ayalon \& C. Tesch-Römer (Eds.), Contemporary perspectives on ageism: Vol. 19. International perspectives on aging (pp. 303-320). Berlin: Springer.

Fowler, C., Gasiorek, J., \& Giles, H. (2015). The role of communication in aging well: Introducing the communicative ecology model of successful aging. Communication Monographs (e-pub ahead of print), 1-27.

Frerichs, F., Lindley, R., Aleksandrowicz, P., Baldauf, B., \& Galloway, S. (2012). Active ageing in organisations: A case study approach. International Journal of Manpower, 33(6), 666-684.

Fuertes, V., Egdell, V., \& McQuaid, R. (2013). Extending working lives: Age management in SMEs. Employee Relations, 35(3), 272-293.

Gelfand, M. J., Raver, J. L., Nishii, L. H., \& Schneider, B. (2005). Discrimination in organizations: An organizational-level systems perspective. In R. L. Dipboye \& A. Colella (Eds.), Discrimination at work: The psychological and organizational bases (pp. 89-116). New York: Psychology Press.

Gelfand, M. J., Nishii, L. H., Raver, J. L., \& Schneider, B. (2007). Discrimination in organizations: An organizational-level systems prespective (CAHRS Working Paper 07-08).

Georgantzi, N. (2018). The European union's approach towards ageism. In L. Ayalon \& C. TeschRömer (Eds.), Contemporary perspectives on ageism: Vol. 19. International perspectives on aging (pp. 341-368). Berlin: Springer.

Göbel, C., \& Zwick, T. (2013). Are personnel measures effective in increasing productivity of old workers? Labour Economics, 22(1), 80-93.

Gringart, E., Helmes, E., \& Speelman, C. P. (2005). Exploring attitudes toward older workers among Australian employers. Journal of Aging \& Social Policy, 17(3), 85-103.

Hedge, J. W. (Ed.). (2012). The Oxford handbook of work and aging. Oxford: Oxford University Press.

Henkens, K. (2005). Stereotyping older workers and retirement: The managers' point of view. Canadian Journal on Aging, 24(4), 353-366.

Hess, M. (2013, September 5-7). Age-stereotypes and their effect on retirement intensions. Paper presented at the 11th annual ESPAnet conference in Poznan.

Hilzenbecher, U. (2006). Wachstumsstrategien für KMUs. In R. Berndt (Ed.), ManagementKonzepte für Kleine und Mittlere Unternehmen (pp. 85-111). Berlin: Springer.

Kalwij, A., Kapteyn, A., \& de Vos, K. (2010). Retirement of older workers and employment of the young. De Economist, 158(4), 341-359. 
Kooij, D. T. A. M., Jansen, P. G. W., Dikkers, J. S. E., \& de Lange, A. H. (2010). The influence of age on the associations between HR practices and both affective commitment and job satisfaction: A meta-analysis. Journal of Organizational Behavior, 31(8), 1111-1136.

Kunze, F., Boehm, S. A., \& Bruch, H. (2011). Age diversity, age discrimination climate and performance consequences - A cross organizational study. Journal of Organizational Behavior, 32(2), 264-290.

Kunze, F., Boehm, S., \& Bruch, H. (2013). Organizational performance consequences of age diversity: Inspecting the role of diversity-friendly HR policies and top managers' negative age stereotypes. Journal of Management Studies, 50(3), 413-442.

Leber, U., Stegmaier, J., \& Tisch, A. (2013). Altersspezifische Personalpolitik: Wie Betriebe auf die Alterung ihrer Belegschaft reagieren (IAB-Kurzbericht No. 13).

Lepak, D. P., Liao, H., Chung, Y., \& Harden, E. H. (2006). A conceptual review of human resource management systems in strategic human resource management research. In J. J. Martocchio (Ed.), Research in personnel and human resources management (Vol. 25, pp. 217-271). Oxford: Elsevier.

Liden, R. C., Erdogan, B., Wayne, S. J., \& Sparrowe, R. T. (2006). Leader-member exchange, differentiation, and task interdependence: Implications for individual and group performance. Journal of Organizational Behavior, 27(6), 723-746.

Lyon, P., Hallier, J., \& Glover, I. (1998). Divestment or investment? The contradictions of HRM in relation to older employees. Human Resource Management Journal, 8(1), 56-66.

Machado, C. S., \& Portela, M. (2013). Age and opportunities for promotion (IZA Discussion Paper No. 7784).

Macinol, J. (2010, August). Ageism and age discrimination: Some analytical issues. ILC-UK think-piece.

Malmberg, B., Lindh, T., \& Halvarsson, M. (2008). Productivity consequences of workforce aging: Stagnation or Horndal effect? In A. Prskawetz, D. E. Bloom, \& W. Lutz (Eds.), Population aging, human capital accumulation, and productivity growth (pp. 238-257). New York: Population Council.

McDonald, L. (2013). The evolution of retirement as systematic ageism. In P. Brownell \& J. J. Kelly (Eds.), Ageism and mistreatment of older workers (pp. 69-93). Dordrecht: Springer.

McGoldrick, A. E., \& Arrowsmith, J. (2001). Discrimination by age: The organizational response. In I. Glover \& M. Branine (Eds.), Ageism in work and employment (pp. 75-95). Aldershot: Ashgate.

McMullin, J., \& Dryburgh, H. (2011). Gender, age, and work in the new economy. In J. A. McMullin (Ed.), Age, gender, and work: Small information technology firms in the new economy (pp. 3-17). Vancouver: UBC Press.

McMullin, J., \& Duerden Comeau, T. (2011). Aging and age discrimination in IT firms. In J. A. McMullin (Ed.), Age, gender, and work: Small information technology firms in the new economy (pp. 133-158). Vancouver: UBC Press.

McMullin, J., Jovic, E., \& Duerden Comeau, T. (2011). Generational and age discourse in IT firms. In J. A. McMullin (Ed.), Age, gender, and work: Small information technology firms in the new economy (pp. 113-132). Vancouver: UBC Press.

Metcalf, H., \& Meadows, P. (2010). Second survey of employers' policies practices and preferences relating to age. London: Department for Business, Innovation and Skills.

Mikołajczyk, B. (2018). The council of europe's approach towards ageism. In L. Ayalon \& C. Tesch-Römer (Eds.), Contemporary perspectives on ageism: Vol. 19. International perspectives on aging (pp. 321-339). Berlin: Springer.

Miles, R. E., \& Snow, C. C. (1995). The network firm: A spherical structure built on a human investment philosophy. Organizational Dynamics, 23(4), 5-18.

Naegele, L., \& Frerichs, F. (2015). Kompetenzentwicklung und Laufbahngestaltung im Handwerk: Die Situation älterer Mitarbeiterinnen und Mitarbeiter (Newsletter Gerontologie No. 6).

Ng, T. W. H., \& Feldman, D. C. (2008). The relationship of age to ten dimensions of job performance. The Journal of applied psychology, 93(2), 392-423. 
Ng, T. W. H., \& Feldman, D. C. (2012). Evaluating six common stereotypes about older workers with meta-analytical data. Personnel Psychology, 65(4), 821-858.

Nishii, L. H., \& Mayer, D. M. (2009). Do inclusive leaders help to reduce turnover in diverse groups? The moderating role of leader-member exchange in the diversity to turnover relationship. Journal of Applied Psychology, 94(6), 1412-1426.

Numhauser-Henning, A. (2013). The EU ban on age-discrimination and elderly workers: Potential and pitfalls. International Journal of Comparative Labour Law and Industrial Relations, 29(4), 391-414.

O'Cinneide, C. (2005). Age discrimination and European Law. Luxembourg: EUR-OP.

Orpen, C. (1995). The effects of perceived age discrimination on employee job satisfaction, organizational commitment and job involvement. Psychology, 32(3-4), 55-56.

Oswick, C., \& Rosenthal, P. (2001). Towards a relevant theory of age discrimination in employment. In M. Noon \& E. Ogbonna (Eds.), Equality, diversity and disadvantage in employment (pp. 156-171). Hampshire: Palgrave.

Picchio, M., \& Van Ours, J. C. (2013). Retaining through training even for older workers. Economics of Education Review, 32(C), 29-48.

Riach, K., \& Kelly, S. (2015). The need for fresh blood: Understanding organizational age inequality through a vampiric lens. Organization, 22(3), 287-305.

Richardson, B., Webb, J., Webber, L., \& Smith, K. (2013). Age discrimination in the evaluation of job applicants. Journal of Applied Social Psychology, 43(1), 35-44.

Rocco, T. S., Thijssen, J. G. L., \& Githens, R. P. (2014). The myths of ageing and decline: Career development and employability of older workers. In J. Walton \& C. Valentin (Eds.), Human resource development: Practices and orthodoxies (pp. 184-201). Basingstoke: Palgrave Macmillan.

Rothenberg, J. Z., \& Gardner, D. S. (2011). Protecting older workers: The failure of the age discrimination in employment act of 1967. Journal of Sociology and Social Welfare, 38(1), 9-30.

Schermuly, C., Deller, J., \& Büsch, V. (2014). A research note on age discrimination and the desire to retire: The mediating effect of psychological empowerment. Research on Aging, 36(3), 382-393.

Shiu, E., Hassan, L. M., \& Parry, S. (2015). The moderating effects of national age stereotyping on the relationships between job satisfaction and its determinants: A study of older workers across 26 countries. British Journal of Management, 26(2), 255-272.

Shore, L. M., \& Goldberg, C. B. (2012). Age discrimination in the workplace. In R. L. Dipboye \& A. Colella (Eds.), Discrimination at work: The psychological and organizational bases (pp. 203-225). New York: Psychology Press.

Snape, E., \& Redman, T. (2006). Too old or too young? The perceived impacts of age discrimination. Human Resource Management Journal, 13(1), 78-89.

Spencer, C. (2013). Legal and legislative issues in protecting older adults in the workplace: An international perspective. In P. Brownell \& J. J. Kelly (Eds.), Ageism and mistreatment of older workers (pp. 145-165). Dordrecht: Springer.

Stettes, O. (2009). Altersbilder in deutschen Industrieunternehmen und Personalpolitik für ältere Beschäftigte. IW-Trends - aus dem Institut der deutschen Wirtschaft Köln, 36. Jahrgang (4).

Stettes, O. (2012). Altersbilder in deutschen Industrieunternehmen und Personalpolitik für ältere Beschäftigte. In F. Berner, J. Rossow, \& K.-P. Schwitzer (Eds.), Altersbilder in der Wirtschaft, im Gesundheitswesen und in der pflegerischen Versorgung (pp. 25-43). Wiesbaden: VS Verlag für Sozialwissenschaften.

Stroud, D., \& Walker, K. (2013). Marketing to the ageing consumer: The secrets to building an age-friendly business (pp. 184-201). Basingstoke: Palgrave Macmillan.

Taylor, P. (2011). Ageism and age discrimination in the labour market and employer responses. In T. Griffin \& F. Beddie (Eds.), Older workers. Research findings (pp. 46-64). NCVER: Adelaide.

Taylor, P., \& Walker, A. (1998). Employers and older workers: Attitudes and employment practices. Ageing and Society, 18(6), 641-658. 
Thorsen, S., Rugulies, R., Longaard, K., Borg, V., Thielen, K., \& Bjomer, J. B. (2012). The association between psychosocial work environment, attitudes towards older workers (ageism) and planned retirement. International Archive of Occupation Environmental Health, 85(4), 437-444.

Turek, K., \& Perek-Bialas, J. (2013). The role of employers opinions about skills and productivity of older workers: Example of Poland. Employee Relations, 35(6), 648-664.

Van Dalen, H. P., Henkens, K., \& Schippers, J. (2009). Dealing with older workers in Europe: A comparative survey of employers' attitudes and actions. Journal of European Social Policy, 19(1), 47-60.

Van Dalen, H. P., Henkens, K., \& Schippers, J. (2010). Productivity of older workers: Perceptions of employers and employees. Population and Development Review, 36(2), 309-333.

Vickers, L., \& Manfredi, S. (2013). Age equality and retirement: Squaring the circle. Industrial Law Journal, 42(1), 61-74.

Walker, A. (1990). The benefits of old age? Age discrimination and social security. In E. McEwen (Ed.), Age: The unrecognised discrimination (pp. 58-70). London: Age Concern.

Whitley, R. (1989). On the nature of managerial tasks and skills: Their distinguishing characteristics and organization. Journal of Management Studies, 26(3), 209-224.

Woolever, J. (2013). Human resource departments and older adults in the workplace. In P. Brownell \& J. J. Kelly (Eds.), Ageism and mistreatment of older workers (pp. 111-135). Dordrecht: Springer.

Worley, J. M., \& Doolen, T. L. (2015). Organizational structure, employee problem solving, and lean implementation. International Journal of Lean Six Sigma, 6(1), 39-58.

Open Access This chapter is licensed under the terms of the Creative Commons Attribution 4.0 International License (http://creativecommons.org/licenses/by/4.0/), which permits use, sharing, adaptation, distribution and reproduction in any medium or format, as long as you give appropriate credit to the original author(s) and the source, provide a link to the Creative Commons license and indicate if changes were made.

The images or other third party material in this chapter are included in the chapter's Creative Commons license, unless indicated otherwise in a credit line to the material. If material is not included in the chapter's Creative Commons license and your intended use is not permitted by statutory regulation or exceeds the permitted use, you will need to obtain permission directly from the copyright holder.

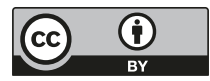




\title{
Chapter 6
}

\section{Ageism and Age Discrimination in the Labour Market: A Macrostructural Perspective}

\author{
Justyna Stypińska and Pirjo Nikander
}

\subsection{Introduction}

Ageism and age discrimination in the labour market have been topics of scholarly interest since the early twentieth century. Today, in markedly different economic conditions, with increasingly globalised labour markets, the victories and failures of workers' movements, and the changing conditions of the European welfare state, the problem of unequal and negative treatment of older workers still prevails. This chapter looks at the phenomenon of age discrimination and ageism in the labour market from a socio-political perspective and draws attention to deciding factors in its emergence. We add to the individualistic and micro accounts adopted by psychological research (see Lev et al. 2018; Chap. 4, in this volume) and the meso level studies of organisation and work environment conditions (see Naegele et al. 2018; Chap. 5 , in this volume) by examining the role of macrostructural processes and transformations to identify their link to the persistence of ageism and age discrimination in contemporary labour markets. First, we provide an overview of the most common conceptual understandings of ageism and age discrimination in employment. Second, we investigate the dynamics between the phenomena of ageism and age discrimination and a range of socio-political contexts, cultural settings, and legal and economic conditions. We then discuss the costs and consequences of age discrimination in employment, and examine various policy responses to these costs and consequences.

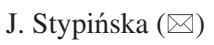

Free University Berlin, Berlin, Germany

e-mail: justyna.stypinska@fu-berlin.de

P. Nikander

University of Tampere, Tampere, Finland

e-mail: Pirjo.Nikander@staff.uta.fi
} 


\subsection{Ageism and Age Discrimination in the Labour Market: Key Theoretical Distinctions}

The concepts of age discrimination and ageism in the labour market have been variously defined and conceptualized in the literature. According to Palmore (1999), "Age discrimination may take the form of refusal to hire or promote older workers, or forcing retirement at a fixed age regardless of the worker's ability to keep working" (p. 119). Macnicol (2006) defined age discrimination as "the use of crude 'age proxies' in personnel decisions" (p. 6), and Carmichael et al. (2011) proposed a definition based on actual experiences of older workers who themselves define workplace age discrimination as "not being allowed to do something you are capable of or willing to do just because of your chronological age" (p. 122). The definition based on subjective perception of age discrimination allows for improved understanding of phenomenological aspects of how ageism operates, casting more light on the individual experiences of older workers.

Another significant distinction was introduced with the tripartite definition of ageism that is in frequent use especially among psychologists (Cuddy and Fiske 2000; Levy and Banaji 2004). This model assumes ageist attitudes as constituted of three mechanisms: prejudice (affective), discrimination (behavioural), and stereotyping (cognitive). Here age discrimination is differentiated from the general concept of ageism as it represents only those elements that have a behavioural and externally manifested character. This partition helped enhance the understanding of ageism and age discrimination and was adopted by McMullin and Marshall (2001), who suggested two further distinct dimensions of ageism: "ageist ideology" and "ageist behaviours." Ageist ideology includes negative stereotypes, beliefs, and attitudes; and ageist behaviours refer to behaviours that exclude certain people and place them in a disadvantaged situation relative to others on the basis of their chronological age (McMullin and Marshall 2001). This distinction is especially useful when referring to the legal prohibition of age discrimination in employment (Macnicol 2010). A key distinction based on empirical research that follows is that biased ageist attitudes may, but do not necessarily, lead to discrimination (Furunes and Mykletun 2010). Thus, ageism can exist without age discrimination.

To better comprehend the behavioural component of ageism (age discrimination), its specific manifestations in the labour market need to be discussed. Studies point to several different types of age discrimination. The first type could be defined as those behaviours which occur in strict relation to the employment status of the worker, i.e. the hiring and firing decisions of employers. Refusing to hire an older person or firing someone because of his or her age form the bluntest type of age discrimination. A plethora of research shows a preference among employers to hire younger workers while placing older ones in a disadvantaged position already in the recruitment process (Malinen and Johnston 2013). The second area where ageism 
manifests is in practices occurring within the workplace. Furunes and Mykletun (2010) identified several such practices: being paid less than younger workers, being left out of promotions, not being accepted to training programmes, and being left out of companies' modernisation processes. Stypińska and Turek (2017) distinguished between two types of age discrimination in the labour market: soft and hard. Hard discrimination refers to the types of discrimination mentioned above, whereas soft discrimination consists of practices that occur in the interpersonal sphere and in the general atmosphere of the workplace; it is also not directly prohibited by law. Examples of these include hearing ageist jokes or remarks; being treated disrespectfully by employers, co-workers or clients; receiving lower evaluation of work outcomes; hearing that "you are too old for something"; or being humiliated or intimidated because of your age (Stypińska and Turek 2017). This is by no means an exhaustive list, but rather examples of possible manifestations of age discrimination on the level of personal experiences.

An important concept in ageism studies is institutional ageism, which refers to a bias against or in favour of (see positive ageism below) actions inherent in the operation of any of society's institutions, including schools, hospitals, police, and the workplace (Wilkinson and Ferraro 2004). Institutional ageism has been explained by Palmore (1999) as a "policy of institutions or organizations, which is discriminatory in a positive or negative way towards older persons" (p. 44). One standard example of institutional ageism in the area of employment is the statutory retirement age that serves as an obligatory condition for leaving the labour market. Institutionalisation of retirement at fixed chronological age boundaries, such as 60 or 65, has, in many industrialised countries, led to an increase of institutional ageism (Breda and Schoenmaekers 2006). Rigid chronological age boundaries support the social conviction that once past a certain age, the economic and social value of an individual suddenly drops, regardless of actual skills and qualifications. Shifting the responsibility for institutional ageism from the individual onto an institution or organisation may lead to its further institutionalisation which, if not contested, might further decrease control over possible consequences (Bytheway 1995).

To introduce the flipside of the predominantly negative term, positive ageism is understood as those stereotypes, attitudes, and practices of individuals and institutions which influence the situation of older adults positively (Palmore 1999). Palmore (1999) recognized eight major positive stereotypes about older adults: kindness, wisdom, dependability, affluence, political power, freedom, eternal youth, and happiness. A number of favourable stereotypes specifically about older employees also exist (Loretto et al. 2007), which can work to their advantage in the labour market, including maturity, experience, responsibility, reliability, stability, loyalty, customer service skills, and patience (Loretto et al. 2000; Malinen and Johnston 2013; Posthuma and Campion 2009). However, studies also show that even when employers display positive attitudes towards older workers, these do not directly translate into positive practices (Loretto and White 2006). 


\subsubsection{Specific Features of Age Discrimination in the Labour Market}

To better understand the dynamics of labour market age discrimination, we need to separate it from ageism in other areas of social life (health care, law, media, access to services, etc.). This distinction boils down to two primary features. First, ageism and age discrimination in the labour market use different chronological ages as benchmarks to define old age than other spheres of life. There is ample evidence of ageist practices being applied to workers and job seekers already in their 30s or 40s (Ghosheh 2008; Stypińska 2015). The contextual character of age that stems from its clearly socially constructed meanings (Aronsson 1997; Hazan 1994; Maier 2009; Nikander 2000) further contributes to the complexity and specificity of the phenomenon of labour force age discrimination. The definition of who is an older worker varies between branches of economy and types of entrepreneurship, as well as among various cultural and local organizational contexts. Certain types of occupations (e.g., programmers, customer service workers, online marketers) and economic branches (e.g., hospitality, new technologies, entertainment, social media, and tech start-ups) are permeated with ageist attitudes, and the "middle age" in these types of companies can be as early as 27 years old (Gaster et al. 2002; Stypińska 2015). To reflect the phenomenon of extreme ageism in modern high tech and start-up working environments, the term Silicon Valley ageism has been coined, which describes the dominant ageist attitudes of most enterprises in this sector (Wickre 2017). It is best manifested in the infamous words of Mark Zuckerberg, CEO and co-founder of Facebook, who stated that "young people are just smarter".

The second important distinction is that age discrimination in the labour market is the only area of social life where legal protection against unequal treatment is deeply institutionalised due to binding regulations, and thus provides a specific context for country-specific analyses. The protection of older workers inscribed in European Union law since the early 2000s, and in the USA since 1967, allows for efficient counteraction to inequalities due to age, be it at the individual or organizational level.

\subsubsection{Intersectional (Multiple) Discrimination}

A further framework for enhancing the understanding of age discrimination in employment, and beyond, is the academic and legal perspective of intersectionality. Crenshaw (1991), who launched the concept within academic research, claimed that the experiences of individuals who hold several disadvantaged statuses are utterly unique, and thus any comparison to single-status disparity is not justified in legal or political terms. Intersectional (or multiple) discrimination is seen to operate between various socio-demographic categories, such as sex, race, age, ethnicity, class, and sexual orientation, and to be structurally carved into societal institutions, creating a 
tangle of multiple oppressions (Baer et al. 2010). The intersectionality framework has also been widely adopted in gerontological research. So far, the most commonly studied aspect of intersectionality in ageing studies has been the combination of age and gender (Calasanti and King 2005; Krekula 2007; Ojala et al. 2016). The literature on the intersection of these two statuses goes back to the work of Simone de Beauvoir's seminal book, The Coming of Age (1970). In this classic work, the common situation of older women was first described as a "double jeopardy" that combines both age and gender, whereas older men were seen to hold only one marginal status (de Beauvoir 1970). The categories of age and gender have also been coupled with minority statuses such as ethnic origin and race when analysing the experiences of older women with different types of discrimination in employment (Moore 2009; van den Heuvel and van Santvoort 2011). In such cases one can talk about "triple jeopardy", where the person suffers from discrimination based on three grounds (Macnicol 2005). These intersecting statuses are also the source of difference in the experiences of various social groups within the labour market. The effects are visible in lower labour force participation rates, lower earnings, and, consequently, lower pension benefits among female populations across Europe. Ample evidence exists of the fact that older women experience barriers to reentering the labour market and that these experiences also vary substantially according to the women's ethnic origin or race. In the area of self-employment, older minority women are similarly precluded from embarking on an entrepreneurial path, as they are constantly confronted with the normative white male ideal type for the entrepreneur (Ainsworth and Hardy 2008).

Intersectional experiences of discrimination often prove challenging for empirical researchers and legal practitioners. Despite the wide theoretical agreement on the fact that intersectional discrimination occurs and that it has detrimental effects on the individual, a lack of agreement prevails as to how to measure this type of discrimination, and moreover, how to address it at the policy level. It is crucial to note, however, that minority statuses as grounds for discrimination and inequality in the labour market are not static functions which operate with the same force throughout the lives of individuals. Work force dynamics and the interplay of sociodemographic characteristics should therefore be analysed from a broader, life-course perspective. The differences between different age groups (cohort effect) as well as the differences between different stages of life (age effect) are certainly valuable and should be incorporated into the intersectional analysis of relatively more static statuses, such as gender, ethnicity, and migration background.

\subsubsection{Ageism and Discrimination Across the Life Course}

Loretto et al. (2000) observed a loosening of the tight association of the term ageism solely with older employees. Instead, ageism is increasingly being recognised as potentially affecting all age categories. Negative stereotypes and discrimination of 
older people are matched by similar stereotypes and discrimination of children or young adults, which is called adultism. Studies of ageism in Europe revealed that across the European Social Survey (ESS) countries, respondents felt more positively towards people aged over 70 than people in their 20s (Abrams et al. 2011). A study of age-related prejudice in the UK showed that younger age groups (below 25 years of age) were more likely to report age discrimination as more serious than older groups (over 64). Moreover, it showed that younger respondents are at least twice as likely to have experienced age prejudice than all other age groups (Swiery and Willitts 2012). Studies also confirm that these attitudes can have a negative effect on the employment opportunities of young adults (Abrams et al. 2011). Similar to challenges faced by older workers, younger employees often come across discriminatory practices, such as lower wages, disadvantaged working conditions, mistrust for their skills and competencies, as well as for their loyalty to the employer (Loretto et al. 2000; Sargeant 2010). What sets experiences of ageism in these age groups apart, however, is their potential outcome. Research shows that younger workers suffer less because of discriminatory practices and have greater opportunities to find alternative employment and to develop new career paths, simply due to the longer span of time available to work ahead of them. Older workers, on the other hand, resort to voluntary resignation much more frequently than younger workers. For older workers this entails a risk, as their options of finding a new job are more limited due to widespread age discrimination in recruitment practices (Sargeant 2010).

The situation of younger workers has also significantly deteriorated in recent years, with the global economic crisis of 2008 bringing an unprecedented rise in unemployment rates among the youngest age cohorts (under the age of 25) (European Commission 2014). The most recent data show a 19.7\% unemployment rate on average in the European Union, with the highest rates found in Greece (48\%), Spain (46\%), Croatia (44\%), and Italy (38\%), and the lowest in Germany (7\%), Denmark (10\%) and the Czech Republic (11\%) (Eurostat 2016). Even though no direct link between the levels of unemployment and age discrimination can be established with certainty, there is evidence that in dire economic situations, younger people tend to be confined to more precarious and insecure jobs with lower levels of workers' protection, including protection from discrimination (Blackham 2015). The harsh effects of the crisis have concentrated on one particular generation, namely those born in the 1980s (Hills et al. 2013). According to Hills et al. (2013), "Despite being better qualified than previous generations, people in their twenties were worst hit by the crisis in terms of unemployment, pay and incomes...The legal cases of age discrimination of younger workers suggest that the phenomenon is relatively widespread and goes underreported when compared with cases from older workers" (p. 6). However, despite its significance, more in-depth study into the experiences of age discrimination in the labour market by younger persons is still largely lacking (Furunes and Mykletun 2010). 


\subsection{Macrostructural Processes and Age Discrimination in the Labour Market}

Three levels of analysis should be used to explain the origins of age discrimination in the workplace: the micro level, where psychological structures of deep-rooted prejudices, stereotypes, and biases are discussed; the meso level, where structures of the enterprise and of the management and interpersonal relations between employees can be studied, and the macro level, where the importance of macrostructural processes and factors on a global scale can be linked to the experiences of older workers with age discrimination. Since the literature on age discrimination pays less attention to the latter, this section digs deeper and discusses the role of macrostructural factors. These will be discussed in three subsections reflecting different macrostructural processes: social and cultural change (in the section on "Modernisation"); mechanisms of capitalist development (in the section on "Globalisation and Economic Crises"); and retirement regulations and antidiscrimination laws (in the section on "The Political Economy of Old Age").

\subsubsection{Modernisation}

Modernisation processes of the last two centuries in industrialised countries have impacted the status of older workers and dramatically changed the structure of the labour market (Hofaecker 2010; Kohli 1985; Palmore and Manton 1974). This change is based on the shift within the economy and society to higher levels of productivity, efficiency, and competitiveness-all core values inscribed in capitalism. Such emphasis has often worked to the disadvantage of older workers, who stereotypically have difficulties keeping up with the strength of younger workers, and with the increasing levels of technological advances and new forms of employment (Macnicol 2006; Palmore 1999).

One of the key theories explaining the decreasing status of older people in societies and the labour market is the modernization theory of Cowgill and Holmes described in 1972 in the book Aging and Modernization. The modernization theory shows that the reduced status of older people occurred because of the transformation from traditional, agrarian societies to modern, urbanised, and industrialised societies. Four major shifts occurred in the social structure throughout the modernising process: (1) improvement of health care resulting in the extension of the lifespan and hence institutionalisation of retirement schemes, but also more competition for jobs; (2) technological advances making older persons' skills obsolete and leading to the emerging pattern of preference for younger workers; (3) urbanisation and the rapid movement of younger people out of traditional housing and family settings which led to the collapse of close ties in extended families and to the loss of status of "wise elders"; (4) the expansion of the public education system and the 
disruption of traditional ways of intergenerational knowledge transfers (Cuddy and Fiske 2000). Although appealing, the modernisation theory has also faced criticism for employing imprecise definitions of social status, overgeneralising the processes of modernisation, and disregarding intervening variables such as ideology and value systems (Morgan and Kunkel 2007). In the process of testing the theory of modernization, Palmore and Manton (1974) concluded that indeed "employment status does decline steadily with the shift from agriculture, but that occupation and education status have a $\mathrm{J}$-shaped ${ }^{1}$ relationship to modernization...It is suggested that as societies move beyond a transitional stage of rapid modernisation, discrepancies between the aged and non-aged decrease, and the relative status of the aged may rise" (p. 205).

\subsubsection{Globalisation and Economic Crises}

Globalisation involved similar processes to those that occurred in modernization period. For this reason, the impact of globalisation on older workers needs careful consideration. Research suggests that globalisation processes have greatly deteriorated the situation of older workers. The loss of status of older workers in globalised economies is seen as a consequence of the demands of a global labour market in which cost-efficiency, flexibility, adaptability, and transferable skills are required (Baars et al. 2006; Hofaecker 2010). Hofaecker (2010) approached the worsening of the situation of older workers with an explanation of profound structural changes that the global economy imposed on labour markets. One such change is the deep restructuring of the traditional industrial sectors of the economy, where older workers were overrepresented. The aftermath of these processes meant increasing unemployment rates for older workers and difficulty in re-entering the labour force, which in turn prompted an intensification of age discrimination. Moreover, replacing older workers with younger ones has sometimes been seen by employers as a cost-saving technique (Roscigno et al. 2007). Age started to turn into a stigma also outside traditional industries, as the competitiveness of new working environments worked to the advantage of younger workers.

Since 2008, the global labour market has been affected by financial crises, the age-specific effects of which are only recently becoming evident (Eurostat/European Commission 2012). The evidence from European social surveys carried out in the first year after the economic crisis of 2008 (European Commission 2009) showed a strong conviction that the economic crisis would negatively influence the position of older workers in job markets through the increase in age discrimination. Analysis from the point of view of employers and companies also revealed that in a situation of economic slowdown and deterioration of market opportunities, the burden shifted towards older employees by cutting their salaries (which are sometimes higher due

\footnotetext{
${ }^{1} \mathrm{~J}$-shaped relationship refers to a variety of J-shaped diagrams where a curve initially falls, then steeply rises above the starting point.
} 
to seniority schemes) or by making them redundant (Cheung et al. 2010). The research evidence from recent years, however, shows that while younger people in many EU countries have faced severe difficulties in finding jobs since the crisis of 2008 , employment rates of prime-age and older workers have remained remarkably stable (Eichhorst et al. 2013).

\subsubsection{The Political Economy of Old Age}

Despite the key role of modernisation and globalisation processes discussed above, the crucial role of state policies can shed light on the way older workers started to be perceived as unattractive and a burden rather than as capital to the economy and welfare systems. The political economy of old age describes the complex and dynamic relationship between the situation of older people and the social and political organisation of labour, retirement, and social assistance. The role of the state is central to the understanding of how the political economy of old age operates and thus the implications of certain state policies need to be analysed separately. According to Alan Walker (1981), the state regulated boundaries of productive economic activity (in the form of fixed retirement age) lead to high levels of dependency of older people in capitalist societies. The evidence for this process comes from theoretical deliberations on structured dependency - a term used to describe how the dependency of older people came to be artificially structured or deepened as an effect of various state policies (Townsend 2006). Among the most significant are policies dating back to the 1960s and 1970s, such as a fixed age for retirement; the minimal subsistence afforded on the state pension; substitution of retirement status for unemployment; near-compulsory admission to residential care of people whose abilities were fairly intact; the dependence of many residents in homes and of patients in hospitals and nursing homes; and the conversion of domiciliary services into commodity services (Townsend 2006). When it concerns age discrimination, however, the early retirement schemes introduced in many industrialised countries impacted the status of older workers the most (Breda and Schoenmaekers 2006; Neumark and Button 2014), and thus will be discussed below in more detail.

Early retirement represents a long-term process, the first attempts of which can be traced back to the 1950s for some industrialised countries. In the economically prosperous period of the 1950s and early 1960s, most societies still practiced a full labour force participation of older workers. It was only in the 1970s that early retirement started to significantly increase in most Western societies (Hofaecker 2010). The reason for early retirement schemes was attributed to the expansion of welfare systems that provided financial security for old age and worked to pull older workers out of active labour participation. Second, higher unemployment rates for older workers in the late twentieth century represented a push factor for early retirement. High unemployment rates were also grounds for the introduction of early retirement 
policies in Eastern European countries in the 1990s, ${ }^{2}$ and also eased the effects of the end of guaranteed employment after the collapse of Communism (Zimmer and McDaniel 2016). The effects of early retirement policies triggered changes in retirement behaviours of older workers, but also influenced the image of older workers in general, as well as employers' attitudes towards them. Employers increasingly started to perceive workers aged 50 and over as redundant and unemployable, and accordingly tended to disadvantage them in recruitment, training, and retirement practices. Moreover, companies became used to early-exit policies as an "easy solution" for personnel management, especially in times of radical change in the global economy (Baars et al. 2006; Bytheway 2007). Workers even in their 40s are often seen as a risky investment and are therefore subjected to age discrimination in the workplace.

The reversal of early retirement options has proven a difficult path for many governments. In recent years, policy makers are increasingly developing strategic goals for raising employment rates among older workers. The most prominent examples of this have been the so-called "Stockholm" and "Barcelona" targets introduced by the European Union, which aim to reach an average employment level of 50\% among older workers aged 55 to 64 years, as well as a 5-year postponement in the typical age of retirement (Hofaecker 2010). From 2002 onwards, the employment rate of people aged 55-64 in the EU has grown steadily to reach 55.3\% in 2016, compared with 38.4\% in 2002 (Eurostat 2017). Any increase in the number of employed older persons does not on its own necessarily indicate that the levels of age discrimination have decreased, but certainly points to a steady direction of greater inclusion of older workers into productive labour.

\subsection{The Consequences and Costs of Ageism in Employment}

The negative consequences and costs of ageism and age discrimination in the labour market can be divided into individual, institutional, economic (pecuniary), and societal (Minichiello et al. 2000; Palmore 2005; Taylor et al. 2012). Each category is discussed below.

\subsubsection{Individual and Institutional Costs and Consequences}

The negative consequences of age discrimination for older workers themselves include barriers to recruitment and hiring, diminished conditions of work and employment, limited career development and, in the absence of legislation, diminished employment protection and rights. Negative effects can be observed not

\footnotetext{
${ }^{2}$ Although some aspects of these policies had been introduced before the 1990s.
} 
only in career paths and occupational opportunities, but also increasingly in family life, wellbeing, health outcomes, with increased stress levels, lower self-esteem, and loss of a sense of control (North and Fiske 2012). These negative consequences can in turn lead to self-inflicted discrimination, as victims of prejudice and discrimination sometimes adopt the dominant group's negative image of the subordinate group, start to behave accordingly, and thus further reduce their chances in the labour market (Palmore 2005). Research also shows that age discrimination reportedly leads older persons to consider changing their occupation or retraining, to give up looking for work altogether, or to consider early retirement (Australian Human Rights Commission 2015).

The institutional cost of age discrimination for employers is also on the rise. Demographic analyses show unequivocally that older workers are the fastest growing labour pool. One in four workers will be over 55 in 2020, versus one in six in 2007 (Hofaecker 2010). Employer- and manager-level prejudice and bias against older workers results in company loss of experienced workers and decreased efficiency in the workplace (Ghosheh 2008; Stypińska 2014). Employers that do not hire on merit, in other words, risk their own survival as they compete among themselves for a shrinking pool of younger workers.

\subsubsection{Social and Economic Costs and Consequences}

The social costs of ageism and age discrimination can be understood as the effects of long-term exclusion from the labour market that result in social, economic, and cultural segregation, which are detrimental for individuals and societies at large (Simms 2004). Social isolation which might result from economic inactivity among older workers can impact the integrity of families and local communities, pose a great threat to their wellbeing, and impose an additional burden on the welfare state.

The costs of an ageist environment can be detrimental to the financial situation of any company. Workplaces that embrace age diversity, and that are perceived as doing so, tend to have higher levels of employee engagement, and motivated employees are more productive, profitable, safe, create better customer relationships, and are more loyal to the company (Parry and Tyson 2011). In contrast, less engaged or motivated workers cost businesses in lost productivity, workers' compensation claims, and wasted time. Assessing the costs of age discrimination to a single company's economic performance is not easy. Some estimates are available, however. According to a Gallup study, in a 10,000-person company, disengagement of the workers due to unequal treatment represents 5000 unexcused days of absence, and about $\$ 600,000$ in lost salary per annum (Wilson 2006). Calculations concerning the Australian labour market suggest that an increase of 5\% in paid employment of Australians over the age of 55 would result in a $\$ 48$ billion impact on the national economy every year (Australian Human Rights Commission 2015). 


\subsection{Policy Responses to Ageism}

The remaining space of this chapter is dedicated to specific policies targeting ageism in employment. Anti-discrimination legislation and active ageing policies are discussed in particular.

\subsubsection{Legal Solutions and Responses}

One policy tool that is receiving growing attention concerns age discrimination legislation. Its main function is to safeguard access of older workers to employment and hiring opportunities under conditions of equality with other age groups. Second, it protects the employment status and training/career development opportunities of those already employed (Ghosheh 2008). In the European context, until only recently, age discrimination did not receive recognition and attention to the same extent as other forms of discrimination based on gender or nationality (Mikołajczyk 2013). This lack of acknowledgement is due to two facts: first, age discrimination has different characteristics from other types of inequality, because it applies to a social group with less clearly identifiable features than women or ethnic minorities, for instance. Age distinctions are more fluid as there is no fixed upper or lower boundary at which the worker can be defined as old. Second, not all age distinctions in employment necessarily constitute age discrimination, which makes recognising them particularly challenging.

Whereas recognition of age discrimination by the European Union is quite a recent fact, the United States started acknowledging, identifying, and tackling the problem much earlier. American anti-discrimination legislation came into force in 1967 with the adoption of the Age Discrimination in Employment Act (ADEA). It was part of an unprecedented turn in the 1960s, when public policy started advancing toward economic and social justice by defending the rights of vulnerable social groups (Rothenberg and Gardner 2011). In the first instance, the law covered workers between 40 and 65 years old. With the abolition of the mandatory retirement age in 1986, the regulatory means gained a new momentum and older workers were also covered (Friedman 2003; Macnicol 2006). The actions prohibited by the law pertained only to the employment field and covered discriminatory job advertisements, discrimination in pay, and discrimination in the use of company facilities (Friedman 2003).

Several authors have suggested that the European legislation was modelled on the American law, but with additional distinctive features (Friedman 2003; Lahey 2010). The approach adopted to combat age discrimination in the European Union labour market is important due to two factors. First, the legal provisions existing in the European law are binding for all member states and must be implemented in national legal systems. This means that employers in all member states can be held accountable for them. The proof that the legislation is not a dead letter law can be seen in the systematically growing number of age discrimination cases in national 
courts, as well as in the European Court of Justice (Rothermund and Temming 2010; Umhauser-Enning 2013). Second, these regulations are crucial, because although ageism and age discrimination may occur in a range of fields, including health care, financial services, housing, and education, it is the labour market which has been given priority in the legal system of the EU (Mikołajczyk 2015).

Discrimination in the labour market can take many forms. EU legislation makes a distinction between direct and indirect discrimination, harassment, and instruction to discriminate (Ghosheh 2008). Direct age discrimination occurs when a person is treated less favourably than another person in an analogous situation due to his or her age. Indirect age discrimination happens when an "apparently neutral provision, criterion or practice would disadvantage people on the grounds of age unless the practice can be objectively justified by a legitimate aim" (Furunes and Mykletun 2010, p. 125). Harassment is defined as "unwanted conduct related to ... age with the purpose or effect of violating the dignity of a person and of creating an intimidating, hostile, degrading, humiliating or offensive environment" (European Commission 2009, p. 29). Instruction to discriminate occurs when, using existing power dependencies, such as employer-employee, a person is told to discriminate against another person (Ghosheh 2008).

The effects of anti-discrimination legislation are difficult to measure (Loretto et al. 2000; Mikołajczyk 2015; Neumark 2009). Existing studies show that legislation could increase employment levels of older workers, but that there is no positive impact on the hiring practices of protected workers as their contracts are more difficult to terminate (Neumark 2009). Other studies have found that a minor number of reported cases of age discrimination go to trial and an even smaller number terminate in compensation. This is due to the difficulties of proving age discrimination in court (Rothenberg and Gardner 2011). Moreover, severe labour market distractions, such as the economic crisis, make it difficult to recognise discrimination and can weaken the effects of stronger state age discrimination legislation (Neumark and Button 2014). It has also been found that anti-discrimination legislation can raise awareness of the problem among older workers and employers (Amiraux and Guiraudon 2010). However, as noted by Amiraux and Guiraudon (2010), the social fluidity of discrimination contrasts with the boundaries of its legal existence, which calls for more interaction between the two spheres to enhance the efficiency of the legislation and to increase its social impact.

\subsubsection{Active and Productive Ageing Policies of the European Union}

The second leg of European policies aiming at reducing age discrimination in the labour market consists of policies in the realm of active ageing, or, as it used to be called, "productive ageing." The history of active ageing policies can be traced back to the 1960s in the United States, where it was argued that the key to successful ageing was the maintenance of the activity patterns and values typical of the middle age. This approach came to be known later as activity theory (Walker 2002). In 
relation to the area of employment, active ageing measures might include age management; lifelong education and continuous training; reconsideration of policies that stimulate early exit; abolishing mandatory retirement age; and introducing flexible options for pre-retirement employment (e.g., half-time contracts). A more recent approach consists of policies targeted at combating age discrimination, age boundaries in the labour market, and motivating employers to recruit and retain older workers. Walker (2002) noted that "age discrimination is the antithesis of active ageing," and thus concerted efforts should be made at work in order to combat it. He claimed that raising pension ages without fighting ageism in the workplace would only result in more social isolation and poverty in old age. On the other hand, policies targeting activity in older age have been systematically criticised since their implementation. Moulaert and Biggs (2012) called such policies "a new orthodoxy of ageing subjectivity" (p. 3), which restricts the social contribution of older adults to work and work-like activities and propagates a one-size-fits-all model for a very heterogeneous population of older adults.

In the EU, the most recent focus of Active Ageing as part of the Europe 2020 strategy is to enable older people to contribute fully both within and outside the labour market. These policies envision older people as empowered to remain active as workers, consumers, carers, volunteers, and citizens (European Commission 2012a). A special policy programme titled "A European Year for Active Ageing and Solidarity Between Generations" was introduced in 2012. It presented tools for improving the situation of older persons and preventing their exclusion, including a new index, the Active Ageing Index, that monitors the situation of older people in society. The index measures the extent to which older individuals can realise their full potential with regard to employment, participation in social and cultural life, and independent living. It also measures the degree to which the environment they live in enables seniors to lead an active life. Attempting to evaluate the impact of the reforms within the Active Ageing programmes is limited because they were introduced relatively recently. As a result, only a few evaluations of their actual impact have been carried out to date. Nevertheless, some countries have observed increased participation of older workers in the period since the reform was introduced (European Commission 2012b).

\subsection{Conclusions}

The aim of this chapter was to give an overview of conceptual distinctions between ageism and age discrimination in the labour market, and to examine the impact of macro-structural processes on the status of older workers in modern economies. Age discrimination in employment is not only an effect of the individual prejudices and stereotypes of the employers, but rather, has a longer history in industrial relations, and is firmly embedded in the structural components of global labour markets. The strong relation between the status of older workers and economic situations and state policies propagated in the past explain the structured nature of ageism and age discrimination in the labour market. The critical question remains, however: can 
ageism and age discrimination decrease let alone disappear from the workplace over time? The overview of policies introduced in the EU during the last decade suggests that a certain improvement in the situation of older workers can be observed, especially with regard to their increasing employment rates. A further chance for improvement comes from the fact that an ever-growing older population will inevitably change the social structure of age. This means that as older people become increasingly difficult to ignore, perceptions of older employees will need to adjust to the same measure and the relationship between work and retirement will need to be reconsidered.

\section{References}

Abrams, D., Russel, P., Vauclair, C.-M., \& Swift, H. (2011). Ageism in Europe. Findings from the European social survey. London: Age UK.

Ainsworth, S., \& Hardy, C. (2008). The enterprising self: An unsuitable job for an older worker. Organization, 15(3), 389-405. https://doi.org/10.1177/1350508408088536

Amiraux, V., \& Guiraudon, V. (2010). Discrimination in comparative perspective: Policies and practices. American Behavioral Scientist, 53(12), 1691-1714. https://doi. org/10.1177/0002764210368092

Aronsson, K. (1997). Age in social interaction. On constructivist epistemologies and the social psychology of language. International Journal of Applied Linguistics, 7(1), 49-56. https://doi. org/10.1111/j.1473-4192.1997.tb00103.x

Australian Human Rights Commission. (2015). National prevalence survey of age discrimination in the workplace. Sydney: Australian Human Rights Commission.

Baars, J., Dannefer, D., Phillipson, C., \& Walker, A. (2006). Aging, globalization, and inequality: The new critical gerontology. New York: Baywood Publishing Company. https://doi. org/10.1177/009430610703600249

Baer, P. S., Bittner, M., \& Göttsche, A. L. (2010). Mehrdimensionale Diskriminierung - Begriffe, Theorien und juristische Analyse. Berlin: Antidiskriminierungsstelle des Bundes.

Blackham, A. (2015). Falling on their feet: Young workers, employment and age. Industrial Law Journal, 44(2), 246-261.

Breda, J., \& Schoenmaekers, D. (2006). Age: A dubious criterion in legislation. Ageing and Society, 26(4), 529-547. https://doi.org/10.1017/S0144686X06004946

Bytheway, B. (1995). Ageism. Virginia: McGraw-Hill.

Bytheway, B. (2007). Choose when you stop? Retirement and age discrimination. Policy and Politics, 35(3), 551-555. https://doi.org/10.1332/030557307781571560

Calasanti, T., \& King, N. (2005). Firming the floppy penis: Age, class, and gender relations in the lives of old men. Men and Masculinities, 8(1), 3-23. https://doi.org/10.1177/10971 84X04268799

Carmichael, F., Claire, H., Porcellato, L., Ingham, B., \& Prashar, A. (2011). Ageism and age discrimination. In E. Parry \& S. Tyson (Eds.), Managing age diverse workforce (pp. 115-129). Basingstoke: Palgrave Macmillan.

Cheung, C., Kam, P., \& Ngan, R. (2010). Age discrimination in the labour market from the perspectives of employers and older workers. International Social Work, 1, 1-20. https://doi. org $/ 10.1177 / 0020872810372368$

Crenshaw, K. (1991). Mapping the margins: Intersectionality, identity politics, and violence against women of color. Stanford Law Review, 43(6), 1241.

Cuddy, A., \& Fiske, S. (2000). Doddering but dear: Process, content, and function in stereotyping of older persons. In T. D. Nelson (Ed.), Ageism: Stereotyping and prejudice against older persons (pp. 3-26). Cambridge, MA: MIT Press.

de Beauvoir, S. (1970). The coming of age. New York: G.P. Putnam. 
Eichhorst, W., Boeri, T., Braga, M., De Coen, A., Galasso, V., Gerard, M., et al. (2013). Combining the entry of young people in the labour market with the retention of older workers (IZA Research Report Series, 53, p. 140). https://doi.org/10.1186/2193-9012-3-19.

European Commission. (2009). Discrimination in the EU in 2009 (Special Eurobarometer 317). Brussels. https://doi.org/10.1093/deafed/enq042.

European Commission. (2012a). The EU contribution to active ageing and solidarity between generations. https://doi.org/10.2767/67267

European Commission. (2012b). EEO review: Employment policies to promote active ageing 2012. Luxembourg: Publications Office of the European Union.

European Commission. (2014). Employment and social developments in Europe. Brussels: European Commission. https://doi.org/10.1017/CBO9781107415324.004

Eurostat. (2016). Youth unemployment rate in EU member states as of December 2015. http:// www.statista.com/statistics/266228/youth-unemployment-rate-in-eu-countries/. Accessed 4 Apr 2016.

Eurostat (2017). Europe 2020 employment indicators. Available online at: http://ec.europa.eu/ eurostat/documents/2995521/7997105/3-25042017-BP-EN.pdf/377b4834-5a19-42f4$8 \mathrm{a} 2 \mathrm{~d}-36 \mathrm{e} 133 \mathrm{ed} 887 \mathrm{~d}$

Eurostat/European Commission. (2012). Active ageing and solidarity between generations. Luxembourg: Publications Office of the European Union. https://doi.org/10.4017/ gt.2011.10.01.014.00

Friedman, L. (2003). Age discrimination law: Some remarks on the American experience. In S. Fredman \& S. Spencer (Eds.), Age as an equality issue (pp. 175-195). Oxford/Portland: Hart Publishing.

Furunes, T., \& Mykletun, R. J. (2010). Age discrimination in the workplace: Validation of the Nordic Age Discrimination Scale (NADS). Scandinavian Journal of Psychology, 51(1), 23-30. https://doi.org/10.1111/j.1467-9450.2009.00738.x

Gaster, L., Ashon, K., \& Bass, M. (2002). Past it at 40? A grassroots view of ageism and discrimination in employment. Bristol: The Policy Press.

Ghosheh, N. (2008). Age discrimination and older workers: Theory and legislation in comparative context (No. 20). Geneva: International Labour Office.

Hazan, H. (1994). Old age: Constructions and deconstructions. Cambridge: Cambridge University Press.

Hills, J., Cunliffe, J., Gambaro, L., \& Obolenskaya, P. (2013, June). Winners and losers in the crisis: The changing anatomy of economic inequality in the UK 2007-2010. Social Policy in a Cold Climate, Research Report, 2, 1-54.

Hofaecker, D. (2010). Older workers in a globalizaing World. Cheltenham/Northampton: Edward Elgar.

Kohli, M. (1985). Die Institutionalisierung des Lebenslaufs. Historische Befunde und theoretische Argumente. Kölner Zeitschrift für Soziologie und Sozialpsychologie, 37(1), 1-29.

Krekula, C. (2007). The intersection of age and gender: Reworking gender theory and social gerontology. Current Sociology, 55(2), 155-171. https://doi.org/10.1177/0011392107073299

Lahey, J. N. (2010). International comparison of age discrimination laws. Research on Aging, 32(6), 679-697. https://doi.org/10.1177/0164027510379348

Lev, S., Wurm, S., \& Ayalon, L. (2018). Origins of ageism at the individual level. In L. Ayalon \& C. Tesch-Römer (Eds.), Contemporary perspectives on ageism: Vol. 19. International perspectives on aging (pp. 51-72). Berlin: Springer.

Levy, B. R., \& Banaji, M. R. (2004). Implicit Ageism. In T. D. Nelson (Ed.), Ageism: Stereotyping and prejudice against older persons (pp. 49-75). Cambridge, MA: MIT Press.

Loretto, W., \& White, P. (2006). Population ageing and older workers: Employers' perceptions, attitudes and policies. Population, Space and Place, 12, 345-361. https://doi.org/10.1002/psp

Loretto, W., Duncan, C., \& White, P. J. (2000). Ageism and employment: Controversies, ambiguities and younger people's perceptions. Ageing and Society, 20(3), 279-302. https://doi. org/10.1017/S0144686X00007741

Loretto, W., Vickerstaff, S., \& White, P. (Eds.). (2007). The future for older workers. Bristol: Policy Press. 
Macnicol, J. (2005). The age discrimination debate in Britain: From the 1930s to the present. Social Policy and Society, 4(3), 295-302. https://doi.org/10.1017/S1474746405002447

Macnicol, J. (2006). Age discrimination: An historical and contemporary analysis. Cambridge: Cambridge University Press.

Macnicol, J. (2010). Ageism and age discrimination: Some analytical issues. London: International Longevity Centre.

Maier, F. (2009). Scrap iron and old stagers. Construction of old age in unemployment. Frankfurt am Main: Peter Lang.

Malinen, S., \& Johnston, L. (2013). Workplace ageism: Discovering hidden bias. Experimental Aging Research, 39(4), 445-465. https://doi.org/10.1080/0361073X.2013.808111

Mcmullin, J. A., \& Marshall, V. W. (2001). Ageism, age relations, and garment industry work in Montreal. The Gerontologist, 41, 111-122.

Mikołajczyk, B. (2013). Is the ECHR ready for global ageing? The International Journal of Human Rights, 17(4), 511-529. https://doi.org/10.1080/13642987.2013.784490

Mikołajczyk, B. (2015, April). International law and ageism. Polish Yearbook of International Law, XXXIV. https://doi.org/10.7420/pyil2015c

Minichiello, V., Browne, J., \& Kendig, H. (2000). Perceptions and consequences of ageism: Views of older people. Ageing and Society, 20(3), 253-278. https://doi.org/10.1017/ S0144686X99007710

Moore, S. (2009). "No matter what I did I would still end up in the same position": Age as a factor defining older women's experience of labour market participation. Work, Employment and Society, 23(4), 655-671. https://doi.org/10.1177/0950017009344871

Morgan, L., \& Kunkel, S. (2007). Aging, society, and the life course (5th ed.). New York: Springer.

Moulaert, T., \& Biggs, S. (2012). International and European policy on work and retirement: Reinventing critical perspectives on active ageing and mature subjectivity. Human Relations, 1-21. https://doi.org/10.1177/0018726711435180

Naegele, L., De Tavernier, W., \& Hess, M. (2018). Work environment and the origin of ageism. In L. Ayalon \& C. Tesch-Römer (Eds.), Contemporary perspectives on ageism: Vol. 19. International perspectives on aging (pp. 73-90). Berlin: Springer.

Neumark, D. (2009). The age discrimination in employment act and the challenge of population aging. Research on Aging, 31(1), 41-68. https://doi.org/10.1177/0164027508324640

Neumark, D., \& Button, P. (2014). Did age discrimination protections help older workers weather the great recession? Journal of Policy Analysis and Management, 33(4), 566-601. https://doi. org/10.1002/pam

Nikander, P. (2000). "Old" versus "little girl" a discursive approach to age categorization and morality. Journal of Aging Studies, 14(4), 335-358.

North, M. S., \& Fiske, S. T. (2012). An inconvenienced youth? Ageism and its potential intergenerational roots. Psychological Bulletin, 138(5), 982-997. https://doi.org/10.1037/a0027843

Ojala, H., Pietila, I., \& Nikander, P. (2016). Immune to ageism? Men's perceptions of agebased discrimination in everyday contexts. Journal of Aging Studies, 39, 44-53. https://doi. org/10.1016/j.jaging.2016.09.003

Palmore, E. (1999). Ageism, negative and positive (2nd ed.). New York: Springer.

Palmore, E. (2005). Costs of ageism. In E. B. Palmore, L. G. Branch, \& D. K. Harris (Eds.), Encyclopedia of ageism (pp. 80-84). New York/London/Oxford: Haworth Press.

Palmore, E., \& Manton, K. (1974). Modernization and status of the aged: International correlations. Journal of Gerontology, 29(2), 205-210. https://doi.org/10.1093/geronj/29.2.205

Parry, E., \& Tyson, S. (Eds.). (2011). Managing age diverse workforce. London/New York: Palgrave Macmillan.

Posthuma, R., \& Campion, M. (2009). Age stereotypes in the workplace: Common stereotypes, moderators, and future research directions. Journal of Management, 35(1), 158-188. https:// doi.org/10.1177/0149206308318617

Roscigno, V. J., Mong, S., Byron, R., \& Tester, G. (2007). Age discrimination, social closure and employment. Social Forces, 86(1), 313-334. https://doi.org/10.1353/sof.2007.0109

Rothenberg, J. Z., \& Gardner, D. S. (2011). Protecting older workers: The failure of the age discrimination in employment act of 1967. Journal of Sociology and Social Welfare, 38(1), 9-30. 
Rothermund, K., \& Temming, F. (2010). Diskriminierung aufgrund des Alters. Expertise. Berlin: Antidiskriminierungsstelle des Bundes.

Sargeant, M. (2010). Young workers and age discrimination. International Journal of Comparative Labour Law and Industrial Relations, 26(4), 467-478.

Simms, M. (2004). A theory of age exclusion through closure: "Chronological age" to "clinical need". Journal of Aging Studies, 18(4), 445-465.

Stypińska, J. (2014). Age discrimination in the labour market in Poland - A socio-legal perspective. Emecon, 1(1), 2014.

Stypińska, J. (2015). Starszy pracownik na rynku pracy w Polsce: 40+?50+? Czy tylko "plus"? Studia Socjologiczne, 2(217), 1-24.

Stypińska, J., \& Turek, K. (2017). Soft and hard age discrimination - dual nature of workplace discrimination. European Journal of Ageing, 14(1), 49-61. https://doi.org/10.1007/ s10433-016-0407-y

Swiery, D., \& Willitts, M. (2012). Attitudes to age in Britain 2010/11. Sheffield: DWP Department for Work and Pensions.

Taylor, P., Mcloughlin, C., Meyer, D., \& Brooke, E. (2012). Everyday discrimination in the workplace, job satisfaction and psychological wellbeing: Age differences and moderating variables. Ageing and Society, 33, 1-34. https://doi.org/10.1017/S0144686X12000438

Townsend, P. (2006). Policies for the aged in the 21st century: More "structured dependency" or the realisation of human rights. Ageing and Society, 26, 161-179.

Umhauser-Enning, A. (2013). The EU ban on age-discrimination and older workers: Potentials and pitfalls. The International Journal of Comparative Labour Law and Industrial Relations, 29(4), 391-414.

van den Heuvel, W. J., \& van Santvoort, M. M. (2011). Experienced discrimination amongst European old citizens. European Journal of Ageing, 8(4), 291-299. https://doi.org/10.1007/ s10433-011-0206-4

Walker, A. (1981). Towards a political economy of old age. Ageing and Society, 1(01), 73-94.

Walker, A. (2002). A strategy for active ageing. International Social Security Review, 55(1), $121-$ 139. https://doi.org/10.1111/1468-246X.00118

Wickre, K. (2017). Surviving as an old in the tech world. Retrieved on 17.05.2017. Available online at: https://www.wired.com/story/surviving-as-an-old-in-the-tech-world/

Wilkinson, J. A., \& Ferraro, K. F. (2004). Thirty years of ageism research. In T. D. Nelson (Ed.), Ageism: Stereotyping and prejudice against older persons (pp. 339-359). Cambridge, MA: MIT Press.

Wilson, D. C. (2006). The price of age discrimination. Business Journal, Available online at: http:// news.gallup.com/businessjournal/23164/price-age-discrimination.aspx.

Zimmer, Z., \& McDaniel, S. A. (2016). Global ageing in the twenty-first century: Challenges, opportunities and implications. Surrey: Ashgate Publishing.

Open Access This chapter is licensed under the terms of the Creative Commons Attribution 4.0 International License (http://creativecommons.org/licenses/by/4.0/), which permits use, sharing, adaptation, distribution and reproduction in any medium or format, as long as you give appropriate credit to the original author(s) and the source, provide a link to the Creative Commons license and indicate if changes were made.

The images or other third party material in this chapter are included in the chapter's Creative Commons license, unless indicated otherwise in a credit line to the material. If material is not included in the chapter's Creative Commons license and your intended use is not permitted by statutory regulation or exceeds the permitted use, you will need to obtain permission directly from the copyright holder.

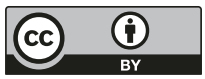




\title{
Chapter 7 \\ Introduction to the Section: \\ On the Manifestations and Consequences of Ageism
}

\author{
Liat Ayalon and Clemens Tesch-Römer
}

The chapters in this section describe in detail the manifestations and consequences of ageism. The diversity of settings and situations described in this section clearly indicates the pervasiveness of the phenomenon. Ageism occurs at the individual level as well as at the societal/structural level, and the interaction between these two levels further perpetuates its occurrence. The negative impact of ageism on the lives of older adults is clearly discussed and demonstrated in the ten chapters presented in this section.

The first chapter in this section, by Kydd, Fleming, Gardner, and HaffordLetchfield (2018; Chap. 8) critically examines ageism in the third age that is directed towards individuals in their fourth age. This chapter follows the definition of ageism as the "enemy within" (Levy 2001) by discussing ways in which older adults attempt to disassociate themselves from old age and decline. This division between the third and the fourth age is clearly articulated by the author John Burroughs (1837-1921): "To me, old age is always ten years older than I am". In the successful or active ageing models, the third age is associated with good health and a high degree of societal participation, whereas the fourth age represents the failure to maintain the functioning of middle age and the surrender into decline and decay. Hence, the fourth age is classified as "old," whereas the third age makes attempts to stay "forever young."

The second chapter in this section, by Shiovitz-Ezra, Shemesh, and McDonnellNaughton (2018; Chap. 9) corresponds to the chapter by Kydd et al. (2018; Chap. 8) by articulating the negative consequences of ageism on older adults' satis-

\footnotetext{
L. Ayalon $(\bowtie)$

Louis and Gabi Weisfeld School of Social Work, Bar Ilan University,

Ramat Gan 52900, Israel

e-mail: liat.ayalon@biu.ac.il

C. Tesch-Römer $(\square)$

German Centre of Gerontology, Berlin, Germany

e-mail: clemens.tesch-roemer@dza.de

L. Ayalon, C. Tesch-Römer (eds.), Contemporary Perspectives on Ageism, International Perspectives on Aging 19, https://doi.org/10.1007/978-3-319-73820-8_7
} 
faction with social life, manifested in high levels of loneliness. In the case of older adults, ageism likely plays a role as an intra-psychic experience that inhibits older adults from developing relationships with other older adults (similar to the case described by Kydd et al. 2018) as well as with people of different age groups. Ageism also serves as a structural barrier in societies that divide young and old, allowing for very little contact between people of different generations. Finally, although loneliness is in part a subjective experience associated with dissatisfaction with one's relationships, it is important to acknowledge that many objective losses in old age also make older adults particularly vulnerable to loneliness. These vulnerabilities are further intensified by the experience of ageism.

Another area where ageism plays a role is sexuality. At the micro-level, the perceptions and beliefs of older adults impact their expectations as well as behaviours regarding sexuality. However, older adults do not operate in isolation. Instead, their experiences, expectations, and behaviours are largely influenced by messages portrayed in the media, and by health care professionals, long-term care providers, and family members, among others. The chapter by Gewirtz-Meydan, HaffordLetchfield, Benyamini, Phelan, Jackson, and Ayalon (2018; Chap. 10) points to the role of ageism in shaping the discourse about sexuality in old age. The view of sexuality as non-existent and invisible in old age, or as a purely bio-medical "problem," serves to deprive older adults of their sexuality and does not allow for the actual diversity of experiences, desires, and beliefs about sexuality among older adults.

The media as a way to portray and also influence reality is discussed in the chapter by Loos and Ivan in this section (2018; Chap. 11). The chapter demonstrates how the visual presentation of older adults has changed over the years. Whereas early representations of older adults were minimal and tended to focus on the negative, current representations of older adults follow the spirit of successful and active ageing. Although the latter perspectives represent an attempt to move away from the pathology of old age and ageing, they clearly place on older adults the responsibility for their own decline and eventual mortality and, thus, they can be seen as promoting another form of ageism (Liang and Luo 2012). The unreasonable expectations disseminated by the media likely reinforce ageism and may increase social isolation and loneliness among older adults who "fail" to age successfully (e.g., the fourth age in Kydd's chapter (2018; Chap. 8)).

In this section, Dolberg, Sigurðardóttir, and Trummer (2018; Chap. 12) discuss an unexplored yet highly topical issue that has made the headlines recently, namely, immigrants and immigration policies. Although ageism is not the first topic that comes to mind when considering immigration, there is no doubt, after reading this chapter, that ageism plays a substantial role in the life of older immigrants. As illustrated in the chapter, older immigrants are exposed to double or even triple jeopardy by policies that privilege younger immigrants and by cumulative stresses and disadvantages associated with the deleterious effects of immigration status and old age combined.

The chapter by Wyman, Shiovitz-Ezra, and Bengel (2018; Chap. 13) on ageism in the health care system and the chapter by Fialová, Leppee, Kummer, and Držaić (2018; Chap. 14) on ageism and medication in older adults are highly important 
given the fact that older adults have to rely on adequate health care services and are at a high risk for taking a large number of medications. This reliance on medical services in later life has even led some philosophers to ask whether older adults have a duty to die (Hardwig 1997). The chapter by Wyman, Shiovitz-Ezra, and Bengel (2018) provides a comprehensive overview of the role of ageism in the health care system by demonstrating how ageism operates at the individual level, at the mesolevel, and at the macro-level to impact the quality of health care provided to older adults. This chapter is complemented by the chapter on ageism and medication use, which outlines the negative consequences of ageism on the prescription of medication for older adults. This chapter also contains recommendations for strategies to reduce inappropriate prescribing, risky polypharmacy, and medication non-adherence in older patients.

Bodner, Palgi, and Wyman (2018; Chap. 15) offer a fresh perspective on ageism in mental health care. They vividly illustrate how both the assessment and the treatment of mental illness are impacted by ageism. The role of countertransference has received substantial attention in the mental health literature, but, in this chapter, it is viewed in the context of ageism, as the psychologist's feelings and attitudes about age. Given the stigma of old age, many symptoms of mental illness are seen as signs of ageing and vice versa. This often hampers the quality of treatment provided to older adults with mental illness.

Like mental illness, dementia is a highly stigmatized condition. Hence, the chapter by Evans in this section (2018; Chap. 16) explores the role of double stigma in the life of older adults who suffer from dementia, and describes how this double stigma impacts the care provided to them. Evans illustrates how older adults and having dementia become synonymous at times. In addition to other chapters in this section (Wyman, Shiovitz-Ezra, and Bengel 2018; Fialová et al. 2018; Bodner et al. 2018; and Ben-David, Malkin, and Erel 2018), this chapter stresses the pervasive and debilitating presence of ageism in the health care system. Clearly, ageism impacts older adults' access to health care services, as well as the quality and availability of services.

The concluding chapter in this section is by Ben-David et al. (2018; Chap. 17) This chapter provides a brave attempt to dispute a priori assumptions about the relationship between old age and cognitive decline and deterioration. The authors argue for a sensory decline, rather than "the usual suspect" of cognitive decline, as a barrier to adequate performance on neuropsychological tests. Moreover, another major obstacle faced by older adults who encounter neuropsychological assessments is the threatening and unfamiliar testing situation, which often puts them at a disadvantage compared with younger adults. Self-fulfilling prophecies and the internalization of negative stigma regarding the relationship between old age and cognitive impairments are also substantial obstacles to adequate performance of older adults on neuropsychological tests.

These highly diverse chapters have several aspects in common. First, they address multiple levels of manifestations of ageism. All of the chapters in this section show that ageism is manifested in social interactions involving older adults (see, for example, Kydd et al. 2018). Moreover, ageism is well-internalized and impacts older adults through their belief systems and expectations, influencing social integration 
and their relations to other people (Shiovitz-Ezra et al. 2018; Gewirtz-Meydan et al. 2018). Ageism is also present at the meso-level, and manifests in interactions with professionals (Wyman, Shiovitz-Ezra, and Bengel 2018; Bodner et al. 2018; BenDavid et al. 2018). These may include a variety of health or mental health care professionals (Wyman, Shiovitz-Ezra, and Bengel 2018; Fialová et al. 2018; Bodner et al. 2018; Evans, Ben-David et al. 2018) or long-term care workers (GewirtzMeydan et al. 2018). Finally, ageism also occurs at the macro-level, as clearly illustrated in policies which discriminate against older immigrants (Dolberg, Sigurðardóttir, and Trummer 2018), older adults with dementia (Evans), or older adults with other health conditions (Wyman, Shiovitz-Ezra, and Bengel 2018).

Another common feature of these chapters is the emphasis on multiple jeopardies that older adults experience. The chapters demonstrate that ageism increases vulnerability in old age, which is often further amplified by impaired health status (Gewirtz-Meydan et al. 2018; Wyman, Shiovitz-Ezra, and Bengel 2018; Fialová et al. 2018), immigration status (Dolberg, Sigurðardóttir, and Trummer 2018), mental illness (Bodner et al. 2018), dementia status (Evans), or a sensory decline (BenDavid et al. 2018). These multiple vulnerabilities correspond with the chapter by Krekula et al. (2018; Chap. 3) in the previous section, and support the need to view ageism in context, as part of other potential sources of discrimination. Healthism, disablism, lookism, and sexism represent discrimination based on qualities other than age. The ten chapters presented in this section clearly demonstrate the interaction of ageism with these other bases for discrimination. Hence, it is often not age per se, but age in combination with other qualities that promotes discrimination.

One question raised by this section is "What would be considered a non-ageist approach?" The chapter on ageism in the visual media by Loos and Ivan (2018; Chap. 11) attempts to answer this question by arguing for the importance of diversity in older adults' representations and experiences. They support a transition from the portrayal of older adults in the visual media as invisible, weak, or frail to other, more nuanced portrayals of ageing and old age. However, they argue that the current successful ageing and active ageing models do not fit the ageing process of all older adults, and, thus, they must be diversified. This is similar to the arguments made by Gewirtz-Meydan et al. (2018) in this section regarding sexuality in the age of Viagra. Providing older adults with diverse models of ageing is a necessary next step in creating a non-ageist society. This claim is also supported in the previous section by Lev et al., who see a long continuum that includes impairment, failure, and disability as well as successful or active ageing, which should be acknowledged and respected. The chapters by Wyman, Shiovitz-Ezra, and Bengel (2018) and Fialová et al. (2018) in this section, on the other hand, argue that a non-ageist approach must be individually tailored. Although age can be one characteristic to take into account in medical diagnosis or treatment, it is by no means the only criterion. An individualized approach to care takes into account a variety of factors, not just chronological age. Such an approach is non-ageist and highly appropriate for both young and old.

Other chapters, such as the chapter by Bodner et al. (2018; Chap. 15) on ageism in the mental health system, the chapter by Evans (2018; Chap. 16) on ageism and dementia, and the chapter by Ben-David et al. (2018; Chap. 17) on ageism and neuropsychological assessment, argue for increased knowledge and awareness as a 
means to address ageism. These authors, as well as others in this section, demonstrate the role of the beliefs and attitudes of health and mental health professionals in shaping reality. Greater awareness of ageist attitudes can help overcome some of the ageist practices currently in use.

This section on the manifestations and consequences of ageism is important because it demonstrates the pervasiveness of ageism and its negative contribution to the life and care of older adults. Ageism can be subtle and hardly noticed or explicit and well-acknowledged. Regardless of its form, it shapes the views of older adults about their abilities and needs as well as the views of the people surrounding them. Although the chapters do not aim to provide solutions to combat ageism, they do point to future directions which could improve the wellbeing and quality of life of older adults. These can be at the policy level (detailed in the next section), as well as at the individual level, for example in the form of educational interventions to promote individualized approaches and increase awareness of ageist attitudes.

\section{References}

Ben-David, B. M., Malkin, G., \& Erel, H. (2018). Ageism and neuropsychological tests. In L. Ayalon \& C. Tesch-Römer (Eds.), Contemporary perspectives on ageism: Vol. 19. International perspectives on aging (pp. 277-297). Berlin: Springer.

Bodner, E., Palgi, Y., \& Wyman, F. (2018). Ageism in mental health assessment and treatment of older adults. In L. Ayalon \& C. Tesch-Römer (Eds.), Contemporary perspectives on ageism: Vol. 19. International perspectives on aging (pp. 241-262). Berlin: Springer.

Dolberg, P. H., Sigurðardóttir, S., \& Trummer, U. (2018). Ageism and older immigrants. In L. Ayalon \& C. Tesch-Römer (Eds.), Contemporary perspectives on ageism: Vol. 19. International perspectives on aging (pp. 177-191). Berlin, Germany: Springer.

Evans, S. C. (2018). Ageism and dementia. In L. Ayalon \& C. Tesch-Römer (Eds.), Contemporary perspectives on ageism: Vol. 19. International perspectives on aging (pp. 263-275). Berlin: Springer.

Fialová, D., Kummer, I., Držaić, M., \& Leppee, M. (2018). Ageism in medication use in older patients. In L. Ayalon \& C. Tesch-Römer (Eds.), Contemporary perspectives on ageism: Vol. 19. International perspectives on aging (pp. 214-240). Berlin: Springer.

Gewirtz-Meydan, A., Hafford-Letchfield, T., Benyamini, Y., Phelan, A., Jackson, J., \& Ayalon, L. (2018). Ageism and sexuality. In L. Ayalon \& C. Tesch-Römer (Eds.), Contemporary perspectives on ageism: Vol. 19. International perspectives on aging (pp. 149-162). Berlin: Springer.

Krekula, C., Nikander, P., \& Wilińska, M. (2018). Multiple marginalizations based on age: gendered ageism and beyond. In L. Ayalon \& C. Tesch-Römer (Eds.), Contemporary perspectives on ageism: Vol. 19. International perspectives on aging (pp. 33-50). Berlin: Springer.

Kydd, A., Fleming, A., Gardner, S., \& Hafford-Letchfield, P. (2018). Ageism in the third age. In L. Ayalon \& C. Tesch-Römer (Eds.), Contemporary perspectives on ageism: Vol. 19. International perspectives on aging (pp. 115-130). Berlin: Springer.

Hardwig, J. (1997). Is there a duty to die? Hastings Center Report, 27(2), 34-42.

Levy, B. R. (2001). Eradication of ageism requires addressing the enemy within. The Gerontologist, $41(5), 578-579$.

Liang, J., \& Luo, B. (2012). Toward a discourse shift in social gerontology: From successful aging to harmonious aging. Journal of Aging Studies, 26(3), 327-334. 
Loos, E., \& Ivan, L. (2018). Visual ageism in the media. In L. Ayalon \& C. Tesch-Römer (Eds.), Contemporary perspectives on ageism: Vol. 19. International perspectives on aging (pp. 163176). Berlin: Springer.

Shiovitz-Ezra, S., Shemesh, J., Gardner, S., \& McDonnell- Naughton, M. (2018). Pathways from ageism to loneliness. In L. Ayalon \& C. Tesch- Römer (Eds.), Contemporary perspectives on ageism: Vol. 19. International perspectives on aging (pp. 131-147). Berlin: Springer.

Wyman, M. F., Shiovitz-Ezra, S., \& Bengel, J. (2018). Ageism in the health care system: Providers, patients, and systems. In L. Ayalon \& C. Tesch-Römer (Eds.), Contemporary perspectives on ageism: Vol. 19. International perspectives on aging (pp. 193-213). Berlin: Springer.

Open Access This chapter is licensed under the terms of the Creative Commons Attribution 4.0 International License (http://creativecommons.org/licenses/by/4.0/), which permits use, sharing, adaptation, distribution and reproduction in any medium or format, as long as you give appropriate credit to the original author(s) and the source, provide a link to the Creative Commons license and indicate if changes were made.

The images or other third party material in this chapter are included in the chapter's Creative Commons license, unless indicated otherwise in a credit line to the material. If material is not included in the chapter's Creative Commons license and your intended use is not permitted by statutory regulation or exceeds the permitted use, you will need to obtain permission directly from the copyright holder.

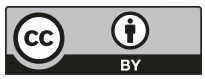




\title{
Chapter 8 \\ Ageism in the Third Age
}

\author{
Angela Kydd, Anne Fleming, Sue Gardner, and Trish Hafford-Letchfield
}

\subsection{Introduction}

Older people are the largest group accessing and using care services within Europe (Eurostat 2015) and are often referred to as a "burden" (Beard and Bloom 2015). Improvements in public health, medical screening, timely treatments, and improved health and social care services in industrialized countries have all contributed to people living longer and healthier lives (Carr and Komp 2011). Average life expectancy is now estimated to be 78 years in developed countries and 68 years in less developed countries, with the gap continually narrowing every year. By 2045-2050, life expectancy is projected to reach 83 years in more developed countries and 75 years in less developed countries (Department of Economic and Social Affairs Population Division 2013).

Whilst a defining characteristic of the ageing process may involve increased vulnerability to a decline in health and wellbeing (Kirkwood 2014), novel approaches to wellbeing alongside complex biological, medical, psychosocial, political, and economic factors can influence both individual and group trajectories in later life. Ageing remains an extremely complex field in terms of understanding the relationships between these contributory factors and the transitions that connect them.

\footnotetext{
A. Kydd ( $\triangle)$

Edinburgh Napier University, Edinburgh, Scotland, UK

e-mail: a.kydd@napier.ac.uk
}

\author{
A. Fleming \\ Independent Researcher, Edinburgh, Scotland, UK \\ S. Gardner \\ Independent Researcher, Thame, UK \\ T. Hafford-Letchfield \\ Social Care, Middlesex University, London, UK \\ (C) The Author(s) 2018 \\ L. Ayalon, C. Tesch-Römer (eds.), Contemporary Perspectives on Ageism, \\ International Perspectives on Aging 19, \\ https://doi.org/10.1007/978-3-319-73820-8_8
}


Simultaneously, there has been a reorganization of health and social care services, caused in part by the universal adoption of economic rationalism, managerialism, and fiscal restraint (Hafford-Letchfield 2014). Not least, there has been a notable change in the retreat of government from its traditional role as a provider of institutional care, which has led to greater promotion of individualization while at the same time reducing eligibility for services (Scourfield 2010). These expectations and developments pose enormous challenges, tensions, and ambiguities for how the ageing trajectory and the multiple factors affecting it over the life course are understood.

The increasingly older population is accompanied by a new discourse about "active and successful ageing" (Foster and Walker 2014). However, the "good" and "successful" versus "bad" and "burdensome" dichotomy that is set up by this discourse may especially impact active older people who are averse to viewing their future older selves as a burden (Nelson 2005). Both "good" and "bad" ageing discourses differentiate between those who are "successfully" ageing and those people for whom successful ageing is not possible. This may contribute to tensions between third and fourth agers.

Discourses associated with ageing, and interactions between these two cohorts, may indeed contribute to intergenerational ageism. Although there are few empirical studies of these tensions, this chapter capitalizes on the timeliness of exploring such discourses by synthesizing some of the relevant literature and the possible themes to increase our understanding. We address previous classifications of ageing; demography; key concepts of the third and fourth ages; evidence of distancing between these two cohorts; and implications for health and wellbeing. We conclude with recommendations for further research.

\subsection{Classifications of Ageing}

Gerontology has always engaged with critical theory to question normative theories about ageing, wellbeing and the significance of deconstructing these theories to promote self-determination and human rights (Cocker and Hafford-Letchfield 2014). Age-related prejudice and discrimination is commonly seen as a social construction based on classification systems. Yet the classification of old age is ill defined. Morrow-Howell (2012, p. 379), writing her paper at the age of 60, asked, "Will we continue to use 60 or 65 years old to define the older population, even when the majority of people in that category will be there for 20 or 30 more years?"

To classify people from the age of 55 to over 100 as "old" implies that there have to be overwhelming commonalities in this period of life. Serra et al. (2011) believed that age classifications would serve to dispel the image of the "burdensome old" and suggested chronological age categories, such as octogenarians (80-89); nonagenarians (90-99); centenarians (100-104); semi-supercentenarians (105-109), and supercentenarians $(110+)$. However, from the studies reviewed in this chapter, there are no references to sexagenarians (age 60-69) or septuagenarians (age 70-79), and there is 
no apparent consistency in defining age groups. Using such categories would remove the words "young" and "old" from common parlance and would serve to describe cohorts over the life course. Further life-course categorizations would include denarian (age 10-19); vicenarian (20-29); tricenarian (30-39); quadragenarian (40-49); and quinquagenarian (50-59). These conventions, however, consider each category as homogeneous and based solely on chronology, and such theorizing denies the complex intersectionality of ageing and the importance of recognizing and responding to extremely divergent life experiences (Hafford-Letchfield 2013).

Older people's experiences are not shaped by only one aspect of their identity, but by a combination of factors, such as gender, age, religion, disability, health, location, sexual identity, migration history, socioeconomic status, and ethnicity. Key processes that shape outcomes for older people may include the texture of dayto-day life, the decisions and assumptions that people make as individuals, and the interactions between people (Hafford-Letchfield 2013). One example is the impact of economic vulnerability on insecurity and sensitivity in the wellbeing of older individual households and communities (Victor 2013). External factors may also be mediated by internal factors such as an older person's responsiveness and resilience to risks they face in later life. These critiques draw attention to the inadequate nature of normative life-course theories.

\subsection{Perceptions of One's Own Old Age}

Heikkinnen (2000) searched for a narrative of ageing in a study of Finns $(n=20)$ aged 80 in 1990, with a follow-up 5 years later $(n=17)$. The participants were all born in the same year and all lived in the same city in Finland. In her group, she found that experiences of ageing were expressed according to the positive and negative meanings that individuals attached to these experiences. In other words, she found that their experiences of ageing were heterogeneous, together with the social, physical, and cultural environments in which they occurred. At the baseline, her participants did not consider themselves to be old, as they were not experiencing problems with everyday life, thus placing her 80 -year-old participants firmly in the third age. At follow-up, when they were 85 years old, most of her participants felt that they were now old, due to deterioration in health, loss of human relationships, and an increase in frailty and/or pain. The participants had to change the way they perceived themselves and the way they organized their days to match with their abilities.

Nicholson et al. (2012) interviewed 17 older people, aged 86-102 years and living at home, to gain an understanding of the experience of living and dying with frailty in old age. Their data analysis revealed three main themes: the dynamics of physical and psychosocial frailty, sustaining connections within the home, and connecting with death and dying. The first theme was concerned with increasing uncertainty and loss as a result of physical and psychosocial deterioration, which changed how the individual perceived themselves and how they were perceived by others. The second theme was concerned with the work and adaptations participants made 
to compensate for increasing frailty in order to maintain satisfactory routines and sustain a feeling of being at home. The third theme focused on the participants' recognition that they were approaching the end of life, which the authors describe as "inhabiting the space between living and dying".

In exploring self-perceptions of ageing with those who had outlived the average age of their birth cohorts, both Nicholson et al. (2012) and Heikkinnen (2000) highlighted resilience and capacity for change in contrast to traditional negative stereotyping. They showed the ability of much older people to change their perceptions of self and the rate at which they felt becoming old happened to them and the strategies they used to achieve this. According to Johnson and Barer (1997), older adults' re-conceptualization of their self-perception is thought to occur in the following four domains. In the first, one accepts the temporality of life and places oneself towards the end of it. In the second, the self-concept belies the reality of the situation; for example, although physically and/or mentally less competent than they used to be, they describe themselves as being in good health. In the third, they detached voluntarily from some aspects of the world surrounding them, such as unwanted roles and responsibilities. And the fourth involved living in the presenta "one day at a time" approach.

Comparing oneself to others is a widely reported positive strategy in developing or refining self-perception in old age: positive comparisons such as "I am much fitter than others are" or "I can still get around without a wheelchair, unlike my friend" are used to construct a more positive identity (Johnson and Barer 1997). However, these positive messages can also be said to emphasize loss of function: "I can still get around without a wheelchair" or "I can get around without a wheelchair ... but only around the house". Another strategy that is commonly used is to separate the mind from the body: for example, "It's just my knees that are old; my mind is still sharp".

The most common strategy in older age is to maintain a sense of control over both health and lifestyle, perhaps because ageing is a process over which people feel they have no control (Johnson and Barer 1997). Betts Adams et al. (2010) explored changes in activity and interest in the third and fourth ages (in their study this referred to ages 64-79 and 80+, respectively). They referred to the concept of selectivity introduced by Baltes and Baltes (1993), in which older people decided themselves where to focus their energies to best advantage. They found that both the younger cohort $(n=50)$ and older cohort $(n=128)$ demonstrated a pattern of disengagement from active pursuits in favour of more passive social and spiritual pursuits in the fourth age. Heikkinnen (2000) suggested that individuals organize their daily life in a way that is consistent with their abilities. The participants in her study who described themselves as feeling old reported that they structured their days around their physical needs and had replaced earlier activities with more simple tasks. Nicholson et al. (2012) suggested that these daily routines not only provide a sense of control, or pass the time, but that they also serve to connect individuals to the past as well as the present through the provision of a pattern of work and rest. Routine, they suggest, can also be helpful in distracting the mind from unwanted thoughts of dependency or decline. 
How older people view themselves and their peers has an impact on how they make choices and whether or how they engage with services. Sarkisian et al. (2002) found that having low expectations of ageing not only had a negative impact on preventative health behaviours, but also indicated a low engagement with healthcare services for conditions such as depression and urinary incontinence. Half of the participants in their study expected ageing to lead to depression, dependency, decreased ability to have sex, more aches and pains, trouble sleeping, less energy, and becoming less attractive. Those with low expectations were less likely to seek healthcare for age-associated conditions. Levy and Myers (2004) measured the attitudes of older people aged $50-80$ years $(n=241)$ towards their own ageing to explore how age beliefs predicted a variety of preventative health behaviours and the impact of these over a 20-year period. Older people with a positive selfperception of ageing reported engagement in more preventative health behaviours over the course of the study, with significantly higher self-rated health than those with a negative self-perception of ageing. This predictive value of ageing selfperceptions may therefore be valuable to those researching or practising preventative health behaviours. In contrast, Jopp et al. (2008) found that both young-old and old-old people showed high levels of valuation of life (VOL), which reduced from the third to the fourth age. Nonetheless, this study supported earlier work in demonstrating that, despite high levels of health impairment, the oldest-old can still hold high levels of VOL through a complex process of balancing the positive and negative aspects of life. The young-old group in this study placed a higher value on health factors, while the old-old placed more value on social factors.

Litwin and Stoeckel (2013) examined the associations between social networks, life satisfaction and feelings of wellbeing in a young-old cohort (6079 years) and an old-old cohort ( 80 years and over) from the second wave of the Survey of Health, Ageing and Retirement in Europe study ( $\mathrm{n}=14,728$ ). They found that social networks were greatly valued in very old age, but not in the same way as in younger-old adults: for example the older cohort living with one or more adult children reported this as having a positive impact on wellbeing, while the younger cohort demonstrated a negative association between living with adult children and quality of life. Other opposite findings between the cohorts studied by Litwin and Stoeckel (2013) included living with a spouse; this related to better quality of life in the younger group, and was negatively associated with quality of life by the older participants. Similarly, being in receipt of personal or practical assistance from someone outside the household had a negative impact on wellbeing for the younger cohort, but a positive impact on wellbeing for the older cohort. Associations between social networks and life satisfaction were also found to be opposing between the two cohorts; for example, having a greater number of grandchildren was associated positively by the younger cohort and negatively by the older cohort.

Exploring the potential for isolation and loneliness in old-old age was a key part of a study by Fischer et al. (2008). In interviews with people aged 85 years $(n=15)$, 
they encouraged participants to reflect on their various perspectives on life. These included important life events, the experience of growing old, experiences of loneliness, difficult life events, positive life events, and experiences of comfort and consolation. Four themes emerged: embracing weakness and strength; embracing slowness and swiftness of time; embracing reconciliation and regret; and embracing connectedness and loneliness (Fischer et al. 2008). Their findings suggest the importance of embracing the contradictions and challenges that come with longevity, and echo Erikson's stages of psychosocial development. This comprehensive psychoanalytic theory identifies eight stages of life, which occur in healthy developing individuals from infancy through to late adulthood. The stages unfold as an individual advances through the life course and each stage is characterized by a psychosocial crisis of two conflicting forces, those in later adulthood being integrity versus despair (Erikson 1968). The theory was updated in the late nineties to include a ninth stage, allowing for the increased ageing of the population (those over 80); the conflicting forces being dystonic versus syntonic, illustrating a negative or positive approach to facing the challenges of ageing (Erikson 1997).

\subsection{The Creation of the Third and Fourth Age}

Distinctions between the third and the fourth age have generally been determined by the average life expectancy in a population/demography-based or a person-based equation (Baltes and Smith 2003). In developed countries, a population-based equation would put the transition from third to fourth age at 80-85, whereas a personbased equation depends on the estimated maximum lifespan of the individual. The transition from third to fourth age could be at 60 years for some and at 90 years for others.

The original concept of the third age is associated with Neugarten (1968) and the fourth age with Laslett (1994), who both sought to dispel the marginalization of the old. Neugarten (1968) stated that in social organizations, the relations between individuals and between groups are organized by age differences, but little attention had been placed on age grading to show relationships between generations. Similarly, with reference to age grading, Laslett (1994) argued that after retirement the "old" were a consumer group of growing importance, with the potential for achieving personal fulfilment and active participation in the economy, politics, and policy making, making the newly retired a different group of older people from the oldest old. This development in ideas about later life served to emphasize autonomy, agency and self-actualization. It also served to distinguish the concept of the fourth age, with dependency as a key marker in the transition.

Narratives that describe the third age as an opportunity and the fourth age as a threat point to a discursive "othering" wherein the fourth age functions as social imagery of a fear of incapacity, poverty, and decrepitude, rather than age per se (Higgs and Gilleard 2014). "Within this social imagery, old age is represented less 
as a status and more as a state of being, one that is typically envisioned through discourses about the costliness, the frailties and the indignities of old age" (Higgs and Gilleard 2014, p. 10).

George (2011) suggested that creating distinctions between a third and fourth age only serves to postpone the onset of what seems to be old age and creates a more severe form of ageism for those in the fourth age. She wrote, "Just as the image of the third age is socially desirable because it is not old age, the image of a fourth age is socially undesirable because it reinforces negative stereotypes of later life. Fourth agers will be viewed as frail, dependent, lonely, sick and as coping with impending death" (George 2011, p. 253).

So how does this creation of a distinction between the active and the dependent old impact those making the transition from the third to the fourth age?

\subsection{The Third Age Distancing Itself from the Fourth Age}

Leaving paid employment to pursue hobbies and engage in activities that the time constraints of work would normally not allow makes retirement, once seen as the end of one's life, now attractive (Kuh 2007). Retired active people can partake of successful active ageing strategies which generally exclude the old-old, the frail old, and the disabled, who are less likely to be able to pursue these activities (Betts Adams et al. 2010). Gilleard and Higgs (2011a) suggested that members of the third age can reject old age as a collective voice through lifestyle choices, but this can only come with economic stability and health. Where people in the third age are not conceptualized as being really old, it is argued that this group wish to distance themselves from the ageist stereotypes seemingly afforded to those in the fourth age. This is demonstrated by George (2011, p. 253) who wrote, "The eagerness of many to proclaim the third age strikes me first and foremost as a desire to avoid or postpone being labelled as old and suffering the negative social stereotypes that accompany that label. The image of the third age appears to reflect the same desire to view oneself and have others view one as not being old." However, Higgs and Gilleard (2014) suggested that such distancing, in order to avoid being classed as one of the oldest old, is potentially damaging to individuals in both age groups.

\subsection{Evidence of Distancing}

There is very little robust evidence to help understand the concept of distancing between the third age and the fourth age, especially due to methodological inconsistencies in determining what is meant by "old" and "oldest old". Characteristics, personal appearance, identifying traits, and practices that might link a person to the 
fourth age are actively forestalled by some. This might be related to how people seek to maintain their appearance through cosmetic means in the quest to avoid being seen as one of the "real" old. As Hazan (2009, p. 98) put it, "The liminal geography of the third age stretches between the face-lifted edges of a dream of middle age and the murky terrains of lived in and feared old age."

Avoiding the use of aids and equipment or living in environments that might put them (in their own and other people's eyes) in the oldest old category is another way some older people distance themselves from the fourth age. Distancing is not purely physical, but can also be demonstrated in attitudes and behaviours. An Israeli study $(\mathrm{n}=955$ ) by Bodner et al. (2012), using the Fraboni Scale of Ageism (Fraboni et al. 1990), found that in cohorts of young (18-39), middle-aged (40-67), and old (6898) participants, middle-aged participants were significantly more ageist than younger and older participants. In all age groups, men showed more avoidance and stereotypical attitudes toward older adults than women. The authors then subdivided the old age group and found participants aged 81-98 held more ageist attitudes than those aged 68-73. The authors concluded that ageism changes across the lifespan and it is necessary to explore the reasons why ageist attitudes change in different stages of life. One reason has been suggested by Iecovich and Lev-Ran (2006) in their examination of the attitudes held by well older people towards disabled older people living in the same facility $(n=140$ : age $>64)$. Well older people tended to hold more negative attitudes towards frail older people when they lived in an integrated facility, with the more able voicing a preference for segregated facilities. Iecovitch and Lev-Ran suggested that holding these negative attitudes may ameliorate the frightening thoughts of one's own mortality, and recommended that further gerontological studies examine intergenerational prejudices.

Similarly, Gilleard and Higgs (2011a) reported that some older people avoid exposure to forms of assessment that may put them in a category for health and social care services, thereby avoiding "objectification" as a "needy" older person. Such assessments may result in recommending aids or equipment to the individual because of physical problems. This may not be acceptable to some who feel this would then make them look old. However, the consequences of refusing aids and adaptations can be damaging to the individual, their families, and other people they are close to. For example, if individuals seek to compensate for and actively hide disabilities, such as memory loss or hearing loss, they may isolate themselves for fear of being "found out". Such avoidance of help was found by Costley (2008) to be the result of an effort by the old (defined by Costley as ages 69-91) to resist the social stigma of old age. However, an earlier US study by Hackstaff et al. (2004) found that some older people refused services for a myriad of personal reasons, including cost or fear of new people.

Despite the dearth of evidence, there is a clear message that some older people do not want to be seen as the "burdensome" oldest-old, and that this ageist distancing of the third age from the fourth age can be detrimental to an individual's health and wellbeing. 


\subsection{The Fourth Age}

The lifespan is finite and with added years come the losses and illnesses of old age (Cohen-Mansfield et al. 2013). Whilst these may come at earlier or later stages in one's older years, if people live long enough they will experience them, and they will have to adapt to the changes forced upon them. Lloyd et al. $(2014$, p. 2) wrote of the "event horizon" that puts one into the fourth age, which is seen as a point of no return: "It is within the power of others-professionals and carers-to determine when an individual has lost the capacity for self-care and management of everyday life and thus makes the transition over the event horizon into the fourth age." In making such a transition, Holstein (2011) suggests that individuals have to reinterpret their lives, as some identities they have will disappear and new identities will appear. However, Chang et al. (2013), in agreeing that frailty, comorbidity, and disability are common major health problems affecting the oldest old, suggested that health promotion strategies, careful management of comorbidities, and targeted strategies to prevent further disability can and should be provided by integrated knowledgeable teams.

In his seminal text, Why Survive?, Butler (1975) saw the potential in people considered the oldest old (Achenbaum 2013): "We must ask ourselves if we are willing to settle for mere survival when so much more is possible" (Butler 1975, p. xiii). Butler advocated for interdisciplinary care together with enhancement of older people's resources and resilience whilst attending to the health issues that frequently come with advancing years. He stated that the gains of ageing need to be celebrated because old people are survivors.

Coleman and O'Hanlon (2004) called for more positive meanings to be associated with later life, particularly to overcome cultural failures in supporting people's end of life needs. Jopp et al. (2008) concurred with Butler (1975) in the findings from their study of valuation of life in very old age. The participants in this study were $65-94$ years of age $(n=356)$ and this sample was stratified by gender and age (5-year age groups). They found that despite increasingly negative conditions such as physical and social loss, community dwelling older adults maintain a high attachment to, and value of, life. Jopp et al. (2008) suggested the need for professionals to develop interventions that enhance the positive features of old age and temper the negative, in order that older people may live a satisfying and valuable life, even if not always a healthy one.

Developing the work of Butler (1975), Jopp et al. (2008) and Nicholson et al. (2012) sought to capture the dimensions of social, psychological, and physical frailty among people aged 86-102 $(n=17)$, but found that participants did not describe themselves as frail and gave examples of resilience and capacity in the face of old declining or failing health status. Nicholson et al. (2012) conceptualized the social identities of the third and fourth age as liminal-passing from one culturally 
defined state or status to another. They considered the transition between ages to involve three distinct stages: the preliminal, liminal, and postliminal. Liminality is described as a threshold space, a space between social structures that is fluid and allows for the potential redefinition of self-identity. Nicholson et al. (2012) suggested that as their participants simultaneously seemed to be living across the third and fourth ages, then the attributes of people in this space are necessarily ambiguous both in terms of their inner conflicts and also in relation to the provision of services by the welfare state. They concluded that frailty is a persistent liminal state, as there is no movement from one stage to another. Therefore frail older people are continually modifying their identities through the construction of personal habits, routines and stories. In order to allow these individuals to lead long and valuable lives, Nicholson et al. (2012) identified a need for older people and health and social care professionals to find shared meanings and understandings of the continual and shifting state of frailty.

A study by Koch et al. (2007) found that ageism was rife in acute hospital settings and that people in the fourth age were most at risk of losing their dignity, identity, and independence when in contact with health and welfare services. Lloyd et al. (2014) explored the perseverance, adaptation, and maintenance of dignity and identity more generally in the fourth age. They found that the way people dealt with ageing and changed health status was dependent upon their views of themselves, how they could or should present themselves in public places, how others behaved towards them, and how accessible the built environment was. The majority of participants $(n=34)$ felt negative about ageing, that it was something that happened to them and for which they could not prepare. In contrast to these participants, other studies (Kornadt and Rothermund 2014; Koss and Ekerdt 2016) found that planning and preparatory activities for age-related changes helped and were organized by life domains. These domains differed between preparing for the third age (activities peaking around age 65, focusing on leisure, work, and fitness activities, and appearance) and in preparing for the fourth age (activities continued linearly up to age 80, focusing on independence, housing, and financial issues). These preparatory activities also involved accepting, rather than preventing age-related changes. Koss and Ekerdt (2016) focused specifically on how anticipation of the fourth age influences third age decisions about housing in later life. These authors suggest that given the strong association between the fourth age and residential or nursing home care, that where one lives becomes not only a question of accommodation but also a visible marker of one's location in relation to the third and fourth ages. A study by Ayalon (2014) examining older people's attitudes on admission to living in Community Care Retirement Communities (CCRC) in Israel revealed that these communities were viewed either positively as luxurious hotels, or negatively as the "last stop". 


\subsection{Age and Disability}

The stress of coping with disability can have a detrimental effect on physiological wellbeing and quality of life, such as increased falls and their association with increased morbidities. In relation to the arbitrary differentiation between the third and fourth age, promoting health becomes even more important when chronic conditions begin to appear and interventions need to be in place to prevent further loss of function (Levy and Myers 2004; Wells 1992). Yet age does not mean disability. In an analysis of the health of centenarians, Hitt et al. (1999) observed that health span equals lifespan. In a later study of American centenarians, Rau and Vaupel (2014) noted a marked delay in disability towards the end of the centenarians' long lives and identified centenarians as models of ageing well. The study concluded that as one approaches the limits of lifespan; diseases (morbidity) must have been delayed (or escaped) towards the end of these longest lived lives. This study illustrated that instead of the aging myth that "the older you get, the sicker you get", it is much more the case that "the older you get, the healthier you've been". These concepts are important when examining ageing discourses and research findings for third and fourth age interventions, and how transition points throughout the life course might be recognized as appropriate mediators in promoting positivity and wellbeing.

\subsection{Discussion}

But what does the evidence reveal? A census of the characteristics of fourth agers in England and Wales in 2011 (Office for National Statistics 2013) showed an increase of almost $25 \%$ in people aged 85 or over since 2001 . The number of centenarians living in the UK has risen by $65 \%$ over the last decade, to 14,570 in 2015 . In this group, 850 people were 105 years old or older-double that of 2005 (Office for National Statistics 2013). Given that frailty is a defining attribute of the fourth age (Gilleard and Higgs 2011b), it is important to note that in 2010, only $25 \%$ of the 85-89 year olds in the UK are classed as frail (Clegg and Young 2011). Later statistics show that in England, for example, $37 \%$ of people over 80 are providing $20 \mathrm{~h}$ or more of care a week, while $34 \%$ per cent are providing $35 \mathrm{~h}$ or more (Age UK 2017). This overlap of third and fourth age characteristics blurs traditionally prescribed transitional boundaries. Kydd and Fleming (2015) suggested that it is an individual's periodic vulnerability at any given time that needs to be managed rather than their age. The fourth age can be seen as a celebration. For example, Tornstam (2005, 1989) introduced the concept of "gerotranscendence", which sees ageing as part of a person's life-long development and recognizes how individuals embrace the age they are in at whatever age they are. Koch et al. (2007), recording centenarians' stories, found an alternative to negative stereotyping in these people's strong and resilient sense of self, a finding outlined in earlier work by Kaufman (1986). 
The respondents were matter of fact about their difficulties and losses, which they considered to be a part of life. The overarching finding was that these centenarians had a sense of self that was strong and resilient (Koch et al. 2007). Similarly, Jopp et al. (2008) highlighted the resilience of the oldest old, and the gratitude and celebration of having lived a long life. Experience of losses and deficits were not a focus for these survivors, but were events in their long lives and in no way extraordinary. This reinforces work by Serra et al. (2011), who referred to this group as the most celebrated and least understood cohort.

An additional consideration of age and disability is the ageing of the younger generation. After the 2008 recession, retirement ages have become more flexible, final salary payments have become rare, and a long paid retirement is not guaranteed. The western world is experiencing changes due to digital technology, reduced unskilled labour, greater consumption of high-calorie, low-nutrient fast foods, higher unemployment, and sedentary lifestyles. Many of these factors have been shown to be contributing to a global rise in obesity and accompanying long-term conditions such as type 2 diabetes, coronary heart disease, and cancer (OECD 2017). As a result, the ageing of this generation is not predicted to be as healthy, long, and well-funded as the ageing of the "baby boomers" (Age UK 2017).

\subsection{Conclusions}

Since its definition in the 1960s, ageism has been seen as an uncontested phenomenon. It is both universal and individual, and deleterious, but it is also unpredictable and unique. Age-related changes may be inevitable, but they depend on a range of physical, social, economic, political, and global factors. At any stage in life, health promotion and illness prevention strategies will serve to ameliorate certain conditions, and self-care at any age is necessary for physical, psychological, and spiritual wellbeing.

Although ageing is a natural process, how societies view their older citizens and how old age is viewed by individuals will colour both the way older people are treated and the way they view themselves. Chronological ageing is no longer viewed as an illness, with many older people living well into their fourth age and beyond. However, the ageing trajectory is unpredictable and the insecurities that come from not knowing how one will age can manifest itself in a form of ageism-that of not wanting to belong, or to be seen to belong - to the fourth age. This chapter has explored the concept of old age and discussed the age stratifications of those classed as old. The positive aspects of ageing have been seen in the third agers, who are active, engaged, and pursuing their own interests. This in turn has created the fourth agers - those (erroneously) classed as the dependent old. At some point in a third ager's life, they will reach a point where they need help with their everyday living. This point may be associated with increased loss of physical function, and may be labelled as the point, or the event horizon, at which they enter the fourth age. For this reason, some third agers may strive to avoid entering into this fourth age. For 
many this is seen as the point of "no return" and signals the end of life. However, when reviewing the literature on centenarians, it would appear that this much feared transition to the fourth age can become a celebration as individuals reach their 100th year. In fact in many societies, the 100th year is seen as a triumph, as it celebrates survival and resilience.

At the heart of this discourse is the fear of the unknown. Many people fear dependency, loss of agency, loss of dignity and death. The experience of very old age is unpredictable and many services are not geared to the needs of the frail old. Perhaps if people felt more supported within their societies, with health and social care services geared to the oldest old, then the fourth age would not be so feared. This is clearly an area for future research.

\section{References}

Achenbaum, W. (2013). Robert N. Butler, MD (January 21, 1927-July 4, 2010): Visionary leader. The Gerontologist, 54(1), 6-12.

Age UK. (2017). Briefing: Health and care of older people in England 2017. Retrieved from http:// www.ageuk.org.uk/Documents/EN-GB/For-professionals/Research/The_Health_and_Care_ of_Older_People_in_England_2016.pdf?dtrk=true

Ayalon, L. (2014). Perceptions of old age and aging in the continuing care retirement community. International Psychogeriatrics: International Psychogeriatric Association 2014. doi: https:// doi.org/10.1017/s1041610214002415.

Baltes, P., \& Baltes, M. (1993). Successful aging: Perspectives from the behavioural sciences. Cambridge: Cambridge University Press.

Baltes, P., \& Smith, J. (2003). New frontiers in the future of ageing: From successful ageing of the young old to the dilemmas of the fourth age. Gerontology, 49, 123-135.

Beard, J., \& Bloom, D. (2015). Towards a comprehensive public health response to population ageing. The Lancet, 385(9968), 658-661.

Betts Adams, K., Roberts, A. R., \& Cole, M. (2010). Changes in activity and interest in the third and fourth age: Associations with health, functioning and depressive symptoms. Occupational Therapy International, 18(1), 4-17. https://doi.org/10.1002/oti.304

Bodner, E., Bergman, Y., \& Cohen-Fridel, S. (2012). Different dimensions of ageist attitudes among men and women: A multigenerational perspective. International Psychogeriatrics, 24(6), 895-901.

Butler, R. (1975). Why survive? Being old in America. New York: Harper and Row.

Carr, D., \& Komp, K. (2011). Gerontology in the era of the third age. New York: Springer.

Chang, W., Lu, F., Lan, T., \& Wu, S. (2013). Multidimensional health-transition patterns among a middle-aged and older population. Geriatrics \& Gerontology International, 13(3), 571-579. https://doi.org/10.1111/j.1447-0594.2012.00937

Clegg, A., \& Young, M. (2011). The frailty syndrome. Clinical Medicine, 11(1), 72-75.

Cocker, C., \& Hafford-Letchfield, T. (Eds.). (2014). Rethinking anti-discriminatory and antioppressive theories for social work practice. Basingstoke: Palgrave Macmillan.

Cohen-Mansfield, J., Shmotkin, D., Blumstein, Z., Shorek, A., Eyal, N., \& Hazan, H. (2013). The old, old-old, and the oldest old: Continuation or distinct categories? An examination of the relationship between age and changes in health, function, and wellbeing. International Journal of Aging \& Human Development, 77(1), 37-57. Retrieved from https://login.ezproxy.napier. ac.uk/login?url=http://search.ebscohost.com/login.aspx?direct=true \&db=cmedm\&AN=23986 979\&site=ehost-live 
Coleman, P., \& O'Hanlon, A. (2004). Ageing and development: Theories and research. London: Arnold.

Costley, A. (2008). "I can manage": The measure and the meaning of daily life among the elderly of Washington heights in New York City'. Dissertation Abstracts International Section A, 68(11-A), 4753.

Department of Economic and Social Affairs Population Division. (2013). World population ageing. New York: United Nations.

Erikson, J. M. (1968). Identity, youth and crisis. Cited in: Goebel, B. L., \& Brown, D. R. (1981). Age differences in motivation related to Maslow's need hierarchy. Developmental Psychology 17(6), 809-815.

Erikson, J. M. (1997). The life cycle completed. Extended version with new chapters on the ninth stage of development. New York: W. W. Norton and Company.

Eurostat. (2015). Online database: Source EHSIS in population by sex, age and disability statusLife expectancy by age and sex. Retrieved from: http://ec.europa.eu/eurostat/data/database

Fischer, R. S., Norberg, A., \& Lundman, B. (2008). Embracing opposites: Meanings of growing old as narrated by people aged 85. International Journal of Aging \& Human Development, 67(3), 259-271. Retrieved from: https://login.ezproxy.napier.ac.uk/login?url=http://search. ebscohost.com/login.aspx?direct=true $\& \mathrm{db}=\mathrm{cmedm} \& \mathrm{AN}=19049246 \&$ site=ehost-live

Foster, L., \& Walker, A. (2014). Active and successful ageing: A European policy perspective. The Gerontologist, 55(1), 83-90. Retrieved from: https://academic.oup.com/gerontologist/ article/55/1/83/570558/Active-and-Successful-Aging-A-European-Policy

Fraboni, M., Saltstone, R., \& Hughes, S. (1990). The Fraboni Scale of Ageism (FSA): An attempt at a more precise measure of ageism. Canadian Journal on Aging, 9, 55-56.

George, L. (2011). The third age: Fact or fiction-And does it matter? In S. Funk, E. Tornquist, M. Champagne, \& R. Wiese (Eds.), Key aspects of elder care. New York: Springer.

Gilleard, C., \& Higgs, P. (2011a). Ageing abjection and embodiment in the fourth age. Journal of Aging Studies, 25(2), 135-142. https://doi.org/10.1016/j.jaging.2010.08.018

Gilleard, C., \& Higgs, P. (2011b). Frailty, disability and old age: A re-appraisal. Health, 15(5), 475-490. https://doi.org/10.1177/1363459310383595

Hackstaff, L., Davis, C., \& Katz, L. (2004). The case for integrating behavior change, clientcentered practice and other evidence-based models into geriatric care management. Social Work In Health Care, 38(3), 1-19.

Hafford-Letchfield, T. (2013). Social work, class and later life. In M. Formosa \& P. Higgs (Eds.), Social class in later life: Power, identity and lifestyle. Bristol: The Policy Press.

Hafford-Letchfield, T. (2014). Critical educational gerontology: What has it got to offer social work with older people? European Journal of Social Work. ISSN 1369-1457

Hazan, H. (2009). Beyond dialogue: Entering the fourth space in old age. In R. Edmondson \& H. J. von Kondratowitz (Eds.), Valuing older people: A humanist approach to ageing. Bristol: Policy Press.

Heikkinnen, R. (2000). Ageing in an autobiographical context. Ageing and Society, 20(4), 467-483.

Higgs, P., \& Gilleard, C. (2014). Frailty, abjection and the 'othering' of the fourth age. Health Sociology Review., 23(1), 10-19.

Hitt, R., Young-Xu, Y., Silver, M., \& Perls, T. (1999). Centenarians: The older you get, the healthier you have been. Lancet, 354(9179), 652.

Holstein, M. (2011). Cultural ideals, ethics, and agelessness: A critical perspective on the third age. In S. Funk, E. Tornquist, M. Champagne, \& R. Wiese (Eds.), Key aspects of elder care. New York: Springer.

Iecovich, E., \& Lev-Ran, O. (2006). Attitudes of functionally independent residents toward residents who were disabled in old age homes: The role of separation versus integration. Journal of Applied Gerontology, 25(3), 252-268.

Johnson, C., \& Barer, B. (1997). Life beyond 85 years: The aura of survivorship. New York: Springer. 
Jopp, D., Rott, C., \& Oswald, F. (2008). Valuation of life in old and very old age: The role of sociodemographic, social, and health resources for positive adaptation. The Gerontologist, 48(5), 646-658. https://doi.org/10.1093/geront/48.5.646

Kaufman, S. (1986). The ageless self: Sources of meaning in late life. Madison: University of Wisconsin Press.

Kirkwood, T. (2014). Biological determinants and malleability of ageing. In T. B. L. Kirkwood \& G. Cooper (Eds.), Wellbeing in later life (pp. 31-52). West Sussex: Wiley Blackwell. https:// doi.org/10.1002/9781118539415.wbwell080

Koch, T., Power, C., \& Kralik, D. (2007). Researching with centenarians. International Journal of Older People Nursing, 2, 52-61.

Kornadt, A. E., \& Rothermund, K. (2014). Preparation for old age in different life domains: Dimensions and age differences. International Journal of Behavioural Development, 38(3), 228-238. https://doi.org/10.1177/0165025413512065

Koss, C., \& Ekerdt, D. (2016). Residential reasoning and the tug of the fourth age. The Gerontologist. Retrieved from: https://academic.oup.com/gerontologist/article-lookup/doi/10.1093/geront/ gnw010\#47447415

Kuh, D. (2007). New dynamics of ageing (NDA) preparatory network. A life course approach to healthy aging, frailty, and capability. Journal of Gerontology: Medical Sciences, 62A(7), $717-721$.

Kydd, A., \& Fleming, A. (2015). Ageism and age discrimination in health care: Fact or fiction? A narrative review of the literature. Maturitas, 81, 432-438.

Laslett, P. (1994). The third age, the fourth age and the future. Ageing and Society, 14(3), 436-447. https://doi.org/10.1017/S0144686X00001677

Levy, B., \& Myers, L. (2004). Preventive health behaviours influenced by self-perceptions of aging. Preventive Medicine, 39(3), 625-629. https://doi.org/10.1016/j.ypmed.2004.02.029

Litwin, H., \& Stoeckel, K. J. (2013). Social networks and subjective wellbeing among older Europeans: Does age make a difference? Ageing and Society, 33(7), 1263-1281. https://doi. org/10.1017/S0144686X12000645

Lloyd, L., Calnan, M., Cameron, A., Seymour, J., \& Smith, R. (2014). Identity in the fourth age: Perseverance, adaptation and maintaining dignity. Ageing and Society, 34(1), 1-19. Retrieved from: https://login.ezproxy.napier.ac.uk/login?url=http://search.ebscohost.com/login. aspx?direct $=$ true $\& \mathrm{db}=$ psyh $\& A N=2013-44782-001 \&$ site $=$ ehost-live

Morrow-Howell, N. (2012). Toward a more accurate view of 'the elderly'. Journal of Gerontological Social Work, 55(5), 379-381. https://doi.org/10.1080/01634372.2012.691421

Nelson, T. (2005). Ageism: Prejudice against our future selves. Journal of Social Issues, 61(2), 207-221.

Neugarten, B. (1968). Middle age and aging. Chicago/London: The University of Chicago Press.

Nicholson, C., Meyer, J., Flatley, M., Holman, C., \& Lowton, K. (2012). Living on the margin: Understanding the experience of living and dying with frailty in old age. Social Science and Medicine, 75(8), 1426-1432. https://doi.org/10.1016/j.socscimed.2012.06.011

OECD. (2017). Obesity update 2017. Retrieved from http://www.oecd.org/els/health-systems/ Obesity-Update-2017.pdf

Office for National Statistics. (2013). What does the 2011 census tell us about the "oldest old" living in England and Wales? London: ONS.

Rau, R., \& Vaupel, J. (2014). The changing demographic context of aging. Vol 4 Wellbeing in later life; Part 1 longevity and wellbeing. Retrieved from http://onlinelibrary.wiley.com/ doi/10.1002/9781118539415. wbwell079/abstract;jsessionid=6F544844F0A1AA9FC2B4C69 8258F3D81.f01t04

Sarkisian, C., Hays, R., \& Mangione, C. (2002). Do older adults expect to age successfully? The association between expectations regarding aging and beliefs regarding healthcare seeking among older adults. Journal of the American Geriatrics Society, 50(11), 1837-1843. 
Scourfield, P. (2010). Going for brokerage: A task of 'independent support' or social work? British Journal of Social Work, 40(3), 858-877.

Serra, V., Watson, J., Sinclair, D., \& Kneale, D. (2011). Living beyond 100: A report on centenarians. London: International Longevity Centre.

Tornstam, L. (1989). Gerotranscendence: A reformulation of the disengagement theory. Aging Clinical and Experimental Research, 1(1), 55-63.

Tornstam, L. (2005). Gerotranscendence-A developmental theory of positive aging. New York: Springer.

Victor, C. (2013). Old age in modern society: A textbook of social gerontology. New York: Springer. Retrieved from: https://doi.org/10.1007/978-1-4899-3075-0

Wells, T. (1992). Managing falls, incontinence, and cognitive impairment: Nursing research. In S. Funk, E. Tornquist, M. Champagne, \& R. Wiese (Eds.), Key aspects of elder care. New York: Springer.

Open Access This chapter is licensed under the terms of the Creative Commons Attribution 4.0 International License (http://creativecommons.org/licenses/by/4.0/), which permits use, sharing, adaptation, distribution and reproduction in any medium or format, as long as you give appropriate credit to the original author(s) and the source, provide a link to the Creative Commons license and indicate if changes were made.

The images or other third party material in this chapter are included in the chapter's Creative Commons license, unless indicated otherwise in a credit line to the material. If material is not included in the chapter's Creative Commons license and your intended use is not permitted by statutory regulation or exceeds the permitted use, you will need to obtain permission directly from the copyright holder. 


\title{
Chapter 9 \\ Pathways from Ageism to Loneliness
}

\author{
Sharon Shiovitz-Ezra, Jonathan Shemesh, and Mary McDonnell/Naughton
}

\subsection{Introduction}

Europe is seeing unprecedented growth in the ageing population. The World Health Organization projects that from 2000 to 2050, the ageing population over 60 years will triple in size from 600 million to two billion (World Health Organization 2015). As this trend progresses, governments are faced with the ethical and moral imperative to ensure that older persons maintain a high quality of life as they age.

One of the major hazards to older people's well-being is loneliness (de Jong Gierveld et al. 2016). Loneliness is the subjective, unwelcome feeling of lack or loss of companionship (De Jong Gierveld 1998). It is distinguished from social isolation; While the latter reflects an objective social situation characterized by lack of relationships with others (Dykstra 2009), loneliness is a marker of the quality of a person's social interactions. As such, loneliness develops when one's social relationships are not accompanied by the desired degree of intimacy (De Jong Gierveld 1998).

In recent years, interest in ageing and loneliness has grown for two primary reasons. First, loneliness is a socially prevalent phenomenon among old people. In a representative sample of British community-dwelling older adults, almost $40 \%$

\footnotetext{
S. Shiovitz-Ezra $(\bowtie)$

The Paul Baerwald School of Social Work and Social Welfare, The Hebrew University of Jerusalem, Jerusalem, Israel

The Israeli Gerontological Data Center (IGDC), the Hebrew University of Jerusalem, Jerusalem, Israel

e-mail: sharon.shiovitz@mail.huji.ac.il

J. Shemesh

The Israeli Gerontological Data Center (IGDC), the Hebrew University of Jerusalem, Jerusalem, Israel

M. McDonnell/Naughton

Department of Nursing and Health Care, Athlone Institute of Technology, Athlone, Ireland

(C) The Author(s) 2018

L. Ayalon, C. Tesch-Römer (eds.), Contemporary Perspectives on Ageism, International Perspectives on Aging 19, https://doi.org/10.1007/978-3-319-73820-8_9
} 
reported experiencing some degree of loneliness (Victor et al. 2005). Similar prevalence rates were found in Finland among a random sample of people aged 75 and over (Savikko et al. 2005). In the United States, Theeke (2007) reports that approximately $17 \%$ of the people aged 50 and above reported feeling lonely. Chronic loneliness, afflicting individuals over prolonged periods of time, affects approximately $10 \%$ of older people (Harvey and Walsh 2016).

A second reason for the rising interest in late-life loneliness has to do with its detrimental effects to physical and mental health which have been recorded in numerous studies. In a population-based study (CHASRS), loneliness was found to be associated with elevated systolic blood pressure (Hawkley et al. 2006). Moreover, the researchers found loneliness to be a unique predictor of age-related increases in systolic blood pressure (Hawkley et al. 2006). Loneliness was also found to compromise cardiovascular health (Hawkley et al. 2003), and was identified as a significant risk factor for coronary heart conditions (Sorkin et al. 2002; Thurston and Kubzansky 2009). Furthermore, in a study carried out in the Netherlands among 2788 community-dwelling individuals aged between 55 and 85 years, peripheral vascular disease, lung disease, and arthritis were found to be associated with greater loneliness after adjusting for demographic variables and other diseases, such as stroke and cancer (Penninx et al. 1999). A prospective association between loneliness and mortality years later has been repeatedly reported in the literature (HoltLunstad et al. 2015; Luo et al. 2012; Shiovitz-Ezra and Ayalon 2010).

Along with its adverse effects on physical health, loneliness is also associated with poor mental health. In both cross-sectional and longitudinal studies, greater loneliness has been associated with higher levels of depression even after taking into account central demographic and psychosocial factors (Cacioppo et al. 2006). Feelings of loneliness are positively associated with psychological distress (Constanca et al. 2006), hopelessness (Barg et al. 2006), serious thoughts of suicide and parasuicide (Stravynski and Boyer 2001), passive death wishes (Ayalon and Shiovitz-Ezra 2011), and negatively associated with emotional well-being (Lee and Ishii-Kuntz 1987).

Several studies, too, have noted the negative association between loneliness and cognition in later life. In a cross-sectional community based study, loneliness was found to be associated with impaired global cognition after adjusting for depression, social network and demographic characteristics (O'Luanaigh et al. 2012). In a longitudinal study conducted in Finland, loneliness at baseline predicted cognitive decline 10 years later (Tilvis et al. 2004). In accordance with these findings, in a prospective study conducted in the U.S., loneliness was found to be a robust risk factor for developing clinical Alzheimer's disease, net of the effect of potential confounders including social isolation (Wilson et al. 2007). More recently, in the English Longitudinal Study of Ageing, loneliness at baseline was found to be associated with poorer cognitive functioning, measured by immediate and delayed recall over a 4-year follow-up (Shankar et al. 2013).

The bio-physiological mechanisms whereby loneliness affects health are not yet well-understood, but growing evidence links loneliness to inflammation and metabolic deregulation. Loneliness was found to be associated with pro-inflammatory 
cytokine responses. In one study, lonelier participants showed elevated stimulated pro-inflammatory cytokine production in the presence of acute laboratory stress (Jaremka et al. 2013). In another study, loneliness was positively associated with IL-6 responses to acute laboratory psychological stress in an adjusted model that controlled for socioeconomic background and health behaviors among older women (Hackett et al. 2012). Loneliness was also independently associated with elevated HbA1c levels, a bio-marker of metabolic dysregulation (O'Luanaigh et al. 2012).

Considering the high prevalence of late-life loneliness and its deleterious effect on physical, mental and cognitive health, it is critical that we identify the risk factors associated with loneliness earlier in the trajectory of ageing so that appropriate public policy may be put in place to address the issue. One significant, albeit understudied, risk factor for late-life loneliness is ageism - stereotypes, prejudice, and discrimination against older persons. Below, we review loneliness and ageism separately. Following, we outline the pathways whereby ageism may contribute to late life loneliness, and bring initial evidence supporting the claims.

\subsection{Loneliness}

Loneliness is a subjective marker for deficits in one's social relationships and interactions. These social deficits manifest in terms of both quantity (i.e., limited social interactions or absence of social interactions), and more importantly, quality (i.e., lack of intimacy, reliable alliance, and attachment; De Jong Gierveld 1998; Perlman 2004). Loneliness is characterized as a painful, distressing, and unpleasant experience (Peplau and Perlman 1982) deriving from a perceived discrepancy between desired and actual social connections. According to the cognitive discrepancy model, feelings of loneliness arise when there is a mismatch between what individuals want, need, or desire on the one hand, and their actual social relations on the other hand. Predisposing factors include cultural norms as well as precipitating events such as chronic conditions and widowhood, which become more prevalent in old age and potentially contribute to a gap between one's desired and existing social environment. However, a perceived mismatch does not necessarily entail loneliness. Several cognitive processes of evaluation mediate between the perceived mismatch and feelings of loneliness. These processes include causal attributions, social comparisons, and perceived control. Past experience and the experience of other people in the social environment shape this evaluation process. Therefore, people vary in the way they interpret and react to their social circumstances.

Contrary to other theoretical views of loneliness, such as the social needs approach (represented by Weiss 1973, 1987), the cognitive discrepancy model of loneliness suggests an indirect relationship between objective deficits in one's social network and feelings of loneliness, which is mediated by cognitive processes of perception and evaluation (De Jong Gierveld 1998; Perlman and Peplau 1998; Peplau and Perlman 1982). Therefore, loneliness is only associated with deficits in one's objective social situation, but is not synonymous with the circumstances of 
that situation. For example, people can feel lonely in the company of many others ("lonely in the crowd"), or they can be alone for long periods of time without feeling lonely. Objective isolation does not lead to loneliness when the desired level of social relations is low; being alone is voluntary, or when the social situation is attributed to external factors beyond one's control (Perlman 2004).

Similarly, the evolutionary theory of loneliness (Cacioppo et al. 2015a) views loneliness as an aversive signal deriving from a discrepancy between desired and actual social relationships, which motivates people to socially engage and reconnect. According to this perspective, loneliness plays a key role in the evolution of humanity, because reconnection with others is crucial for survival and reproduction (Goossens et al. 2015). The evolutionary theory argues that loneliness is similar to other biological needs such as hunger, in that it creates significant feelings of discomfort that motivate individuals to take action and extricate themselves from the painful and distressing experience.

Recently, a review of the ontogeny of loneliness has differentiated between environmental triggers of loneliness across the life span (Qualter et al. 2015). It was suggested that as of adolescence, romantic relationships become increasingly important, and that compromised quality of that type of relationship is mostly related to loneliness. This relationship is also evident throughout adulthood, including early adulthood and mid-life, when poor quality of marriage has been found to explain loneliness. Similarly, marital quality and life partnership fulfill needs for belonging in old age. However, at this stage of life these needs are challenged as widowhood, illness, and reduced social activities become sources of loneliness (Qualter et al. 2015).

Previous studies have mostly attempted to attribute late life loneliness to individual (micro) and social network (meso)-level characteristics (Ayalon et al. 2016; Kahn et al. 2003; Shiovitz-Ezra 2013). However, restricted opportunities for meaningful social participation in old age may bring about feelings of loneliness. The following section explores how ageism, including stereotypes, prejudice and discrimination against older persons may lead to late-life loneliness.

\subsection{Ageism}

We live in a society that glorifies youth and dreads old age. We are deeply disturbed by the appearance of a new wrinkle adorning our face; we balk at the sight of our ever-expanding forehead gnawing higher and higher at our hairline. Both are reminders of the incontrovertible truth that we are getting older. A 140.3 billiondollar anti-ageing industry capitalizes on these anxieties, selling the public the products - and promise - to hold off wrinkling, blur pigmentation, eliminate excess fat, and restore the growth of youthful hair (Zion Market Research 2016).

But people's concerns about ageing go beyond the cosmetic. The imminent threats of sickness, disability, cognitive deterioration, loss of independence, and death, hang over the prospect of old age. Tremendous efforts on the side of scientists 
and pharmaceutical companies are made to discover new means to influence the physiological pathways leading to biological ageing, hoping to set back the clock, or at least slow it down. Our relentless efforts to hold off ageing and the sentiments they feed on speak volumes about how we, as a society, regard ageing (one famous gerontologist characterized these sentiments as "dread, discomfort, and denial", Butler 1980, p. 10).

Not only are we disgruntled with our own ageing process, we also harbor ambivalent attitudes towards older people at large. Changes in societal structure over the past few centuries have rendered older adults "marginalized, institutionalized, and stripped of responsibility [and] power" (Nelson 2005, p. 208). The industrial revolution, which brought about increased mobility for workers, also in so doing contributed to the disintegration of the extended family structure. As a result, grandparents no longer lived with their families. In the light of technological advances, older people's work experience became outdated, and their work obviated. Simultaneous advances in medicine extended people's lives, and as the older population grew in size, they came to be regarded as non-contributing burdens on society (Nelson 2005).

A recent large-scale linguistic analysis encompassing two centuries of written American English has found that stereotypes of older adults have grown increasingly negative over the years (having started out slightly positive in the $1800 \mathrm{~s} ; \mathrm{Ng}$ et al. 2015). The study found that negativity towards older adults has grown in step with their relative share within society, presumably due to concerns of the younger generation that older adults act as a drain on economic resources ( $\mathrm{Ng}$ et al. 2015). Complicating matters still, these concerns are not completely unfounded; with fertility rates falling and lifespans extending in recent years, the retired population is growing larger and larger in proportion to the employed sector, and it is expected that care for older adults - formal and informal - will impose a heavy cost on society (Suzman and Beard 2011).

Negative attitudes towards older adults, including stereotypes, prejudices, and de facto discrimination based on age, have been termed Ageism. Butler (1980, p. 10) identified three societal problems posed by ageism: “(1) Prejudicial attitudes toward the aged, toward old age, and toward the aging process, including attitudes held by the elderly themselves; (2) discriminatory practices against the elderly, particularly in employment, but in other social roles as well; and (3) institutional practices and policies which, often without malice, perpetuate stereotypic beliefs about the elderly, reduce their opportunities for a satisfactory life and undermine their personal dignity." (p. 8).

\subsubsection{The Stereotypes of Ageing}

What are the major stereotypes that people harbor about ageing? To answer this question, researchers have asked participants to note the typical traits that came to their minds when they thought about old people (regardless of whether they believed 
them to be accurate or not). Collectively, these studies have yielded seven general stereotypes, four negative and three positive, shared by people of all ages about older adults: Severely Impaired; Despondent; Shrew/Curmudgeon; Recluse; Golden Ager; Perfect Grandparent; and John Wayne Conservative (Hummert 2011).

A complementary approach to age stereotyping relates the stereotypes of older adults to their perceived status within society. According to the Stereotype Content Model (Cuddy and Fiske 2002; Cuddy et al. 2005) two core dimensions jointly determine the content of stereotypes applied to groups within society: those of "competence (e.g., independent, skillful, confident, able)" and "warmth (e.g., goodnatured, trustworthy, sincere, friendly)" (Cuddy and Fiske 2002, p. 8). Of the possible constellations of the two dimensions, older adults occupy a quadrant defined by low competence and high warmth, or as Cuddy and Fiske (2002) put it, 'doddering, but dear'. Other groups that fall in this cluster include retarded and disabled people (Fiske et al. 2002). The prejudices most commonly elicited by people in this quadrant include pity and sympathy (Fiske et al. 2002). The structural relationships within society that antecede the competence and warmth dimensions are status and competition; perceptions of a group as high status indicate its competence, while its perceived competitiveness designates it as cold (Fiske et al. 2002). Accordingly, people tend to see older adults as lower-status and relatively uncompetitive (Fiske et al. 2002). A meta-analysis encompassing decades of research on attitudes towards older adults confirms that old people are generally perceived more stereotypically, as less attractive and as less competent than younger adults (Kite et al. 2005). What is more, it was found that people tended to behave less favorably towards older, as compared to younger adults (ibid). In sum, evaluations towards older people are somewhat ambivalent, with a negative predominance.

\subsubsection{Neglect and Social Exclusion}

What kind of behaviors derive from the stereotypes (doddering, but dear) and prejudices (pity and sympathy) towards older adults? Cuddy et al. (2007) found that perceived warmth of a group correlated with behavioral tendencies of helping, presumably mediated by pity, while perceived incompetence correlated with tendencies to neglect. This observation, once again, highlights the ambivalent nature of attitudes towards older adults. Older people are targets for help and sympathy, and at the same time are often neglected and socially excluded. Two major arenas where ageist practices are widespread are the health-care system (Ben-Harush et al. 2016) and the labor market (Pasupathi and Löckenhoff 2002). In both fields ageist beliefs and attitudes can join and become institutionalized forms of discriminatory norms and practices that intensify social exclusion of older adults. One prominent example from the labor market is mandatory retirement that occurs at a certain age without any consideration of whether the older worker prefers to continue working and contribute in the professional domain. Ending the working phase has many adverse consequences, including the narrowing of social network 
size (greater details about the retirement-social exclusion-loneliness relation will be provided later in this chapter).

Studies show that age-based discrimination is widespread. In the United States, $29.1 \%$ of adults 52 years and older in a sample of 4818 individuals reported being discriminated against on a range of interpersonal and medical issues, including being treated with disrespect, being threatened, and receiving worse medical services, based on their age (Rippon et al. 2015). In the UK, 34.8\% of a sample of 7478 respondents reported being discriminated against (Rippon et al. 2015). Across 28 European countries, about a quarter of adults 62 years and older reported being discriminated against based on their age, treated with prejudice, with disrespect or treated badly because of their advanced age (van den Heuvel and van Santvoort 2011).

\subsection{Pathways from Ageism to Loneliness}

So far we have examined the phenomenon of ageism, as well as the content of ageing stereotypes and their societal roots. We have also seen some ways in which older people are discriminated against, presumably as a result of widespread ageism. As mentioned earlier, nowadays, one of the major difficulties faced by older adults is social exclusion and loneliness. The following section will sketch out how negativity towards older adults may contribute to social exclusion and loneliness.

\subsubsection{Social Rejection}

One psychological theory accounts for how discrimination against older adults could result in their progressive withdrawal from social participation and growing feelings of loneliness. Smart Richman and Leary (2009) propose a model for how humans, in general, respond to discrimination and stigmatization. While the model has yet to be applied to older adults, its relevance will briefly become apparent.

"[T]he psychological core of all instances in which people receive negative reactions from other people is that they represent, to varying degrees, threats to the goal of being valued and accepted by other people." (Smart Richman and Leary 2009, p. 373) According to the theory, the primary emotion evoked by feeling socially devalued, unwanted and rejected is hurt. Smart Richman and Leary report on a study of emotional word associations (Storm and Storm 1987) which found that feelings of hurt are most strongly associated the terms neglected, rejected, unwanted, unwelcome, betrayal, misunderstood, different and isolated.

Following a rejection episode, people typically feel three sets of motives which may promote competing behaviors: (1) a desire for social connection; (2) antisocial aggressive or defensive urges, and (3) a drive to withdraw in order to avoid further rejection. What determines which motive will win out is the affected person's construal of the rejection event. According to the theory, rejection that is experienced 
chronically over a prolonged period of time will increase the likelihood of withdrawal and avoidance behaviors.

To the extent that elderly people experience discrimination often and for prolonged periods of time (as indeed has been found, see the sections above), they would be expected to respond with behavioral avoidance, and to forego social participation opportunities. The hypothesis has yet to be directly tested. However, two studies give initial credence to the logic of discrimination-induced withdrawal in older adults.

Coudin and Alexopoulos (2010) asked older adults to read a text passage, ostensibly in order to gauge their language comprehension. The text was said to be taken from a speech in a gerontology conference, and its content was manipulated so as to include either positive, negative, or neutral portrayals of older adults. Subsequently the participants completed a questionnaire measuring their social and emotional loneliness (adapted from the UCLA Loneliness Scale, a well-known loneliness scale, Russel 1996). The authors found that the older adults who read the negative text subsequently reported feeling lonelier than those who had read the positive or neutral passages. Thus an experience of being negatively stereotyped can immediately lead a person to feel lonelier.

Sutin et al. (2015) explored the longitudinal relationship between perceived discrimination and subsequent loneliness in a nationally representative sample of adults 50 years and older in the American Health and Retirement Survey. The study followed 7622 participants (average age 67.5) over a 5 year period, measuring their baseline levels of everyday perceived discrimination and subsequent reports of loneliness. It was found that perceptions of discrimination based on age significantly predicted feelings of loneliness 5 years later (other types of discrimination had a similar effect). Age discrimination, like other forms of discrimination, can lead to feelings of loneliness that build up over time.

How do the experiences of ageism translate into feelings of loneliness? Vitman et al. (2014) demonstrate how ageism could lead to social exclusion of older adults in their neighborhood. In the study, younger adults in three neighborhoods in Tel Aviv, Israel completed questionnaires regarding attitudes towards older people. As a measure of social integration, older adults in the same neighborhoods indicated how often they participated in neighborhood activities, how familiar they are with neighbors, and to what degree they feel a 'sense of neighborhood'. Regression analysis revealed that higher ageism in the neighborhood predicted reduced social integration. Encountering ageist attitudes in one's neighborhood may lead to behavioral withdrawal and avoidance, in line with Smart Richman and Leary's (2009) theory.

\subsubsection{Stereotype Embodiment}

Another pathway whereby ageism may affect loneliness is stereotype embodiment. Stereotype embodiment theory (Levy 2009) proposes that individuals absorb stereotypes present in their surrounding culture, giving rise to self-definitions that, in turn, affect functioning and health. 
Various longitudinal studies have found that the endorsement of elderly stereotypes by ageing people themselves (called self-perceptions of ageing) foretell significant adverse effects to physical and mental functioning, sometimes decades down the line (Levy 2009). For example, one study, based on the Ohio Longitudinal Study of Aging and Retirement (utilizing data from 660 individuals) found that positive self-perceptions of ageing at baseline predicted survival rates more than 20 years later (Levy et al. 2002b). Self-perceptions of ageing were measured using items such as "Things keep getting worse as I get older" and "As you get older, you are less useful". The effect of positive self-perceptions on survival remained significant even after controlling for baseline age, socioeconomic status, functional health, and loneliness. Another study (Levy et al. 2002a) based on a similar dataset found that positive self-perceptions of ageing at baseline were related to better functional health more than two decades later, adjusting for baseline functional health, selfrated health, age, gender, race, and socioeconomic status.

Experimental studies have found that exposing older adults to ageing stereotypes affects their performance in a stereotype-consistent manner (Levy and LeifheitLimson 2009). For example, priming older adults with negative stereotypes of physical functioning was found to degrade motor performance, while priming them with negative stereotypes of cognitive function led to decrements in memory performance. In other words, the stereotypes people assimilate from the surrounding culture and identify with may act as self-fulfilling prophecies.

Pikhartova et al. (2016) sought to explore whether late-life loneliness stereotypes can, too, become self-fulfilling prophecies. The study utilized data from the English Longitudinal Study of Ageing. First, the authors identified participants who reported no feelings of loneliness at baseline. Subsequently, these participants' endorsement of statements expressing (1) their expectation to become lonelier as they age, and (2) the stereotype that old age is a time of loneliness, were analyzed and related to levels of reported feelings of loneliness several years later. It was found that approximately a third of participants expected to become lonelier as they aged, and about a quarter of the sample endorsed the stereotype that old age is a time of loneliness. In addition, it was found that both expectations and stereotypes of loneliness in old age predicted feelings of loneliness several years ahead, even after controlling for measures of social inclusion and a host of other demographic variables. In other words, this study found that harboring expectations and stereotypes of old-age loneliness - even when one is presently not feeling lonely - could act as self-fulfilling prophecies.

And yet, evidence that loneliness stereotypes operate as self-fulfilling prophecies is equivocal. One longitudinal study investigated the link between expectations of loneliness on the one hand and loneliness, new friendships, and perceived social support on the other (Menkin et al. 2016). The data were taken from the Baltimore Experience Corps Trial, a longitudinal volunteer intervention for older adults. The participants, 424 Baltimore residents age 60 and older, were randomly assigned either to an intervention group, who was to provide academic support to elementary school students, or to a control group that received information on other volunteer opportunities. At baseline, the participants answered a questionnaire measuring 
expectations regarding ageing. One and two years later, the participants completed measures of new friendships forged, perceived and desired social support, and loneliness. The expectations about ageing measure included subscales pertaining to physical health, mental health, and cognitive function. One of the mental health included items regarding expectations of loneliness, such as "Being lonely is just something that happens when people get old".

The researchers found that positive expectations about ageing at baseline predicted more new friends 2 years later, including close friendships. In addition, it was found that baseline positive expectations predicted less desire for additional social support 12 months later. However, expectations regarding loneliness at baseline did not predict feelings of loneliness at follow-up.

\subsubsection{Social Exclusion}

Widely held ageist beliefs and attitudes can coalesce and become institutionalized forms of discriminatory norms and practices. Society-wide ageist norms and practices can, in turn, act as barriers to older adults' active participation in social activities. Here we briefly discuss three domains in which stereotypes, prejudices, and discrimination against older adults may result in reduced social participation, predisposing adults to late-life loneliness.

One prominent form of social exclusion is mandatory retirement. At a certain age, people are expected - sometimes pressured, or even forced - to retire (Pasupathi and Löckenhoff 2002). While some workers welcome retirement, retiring effectively cuts off a wellspring of social connections, opportunities, and meaning available on a day-to-day basis. Early retirement - which can be catalyzed by the experience of ageism at the workplace (Thorsen et al. 2012; von Hippel et al. 2013) - can be particularly pernicious to older adults' cognition and mental health (Börsch-Supan and Schuth 2014). Börsch-Supan and Schuth (2014) found that retirement in general, and early retirement in particular, are associated with reductions in overall social network size, and that this reduction is mostly owing to the presence of fewer friends, colleagues, and other non-family contacts in one's social network.

Early retirement is sometimes imposed on older adults, since finding a job and rejoining the workforce over a certain age is much more difficult. Several field studies have found that companies grossly under-respond to work applications made by older adults compared to equally capable younger peers (Neumark et al. 2017; Pasupathi and Löckenhoff 2002). Older workers are perceived to be reliable and loyal, but at the same time, as less productive, less energetic, technologically savvy, or trainable than younger workers (reviewed in Swift et al. 2017, p. 206). Further impediments to hiring older workers include perceptions that older adults demand higher salaries and incur increased training and health care costs (ibid).

Finally, retirement - whether voluntary or forced - is accompanied by a reduction in income, which can compromise older people's ability to afford participating in activities they enjoy (World Health Organization 2007, p.38). Indeed, low income 
has been pinpointed as a strong predictor of loneliness in old age (Luhmann and Hawkley 2016).

Another domain in which older people regularly experience prejudice and discrimination is healthcare. A review of the literature on age-differentiated behavior in the medical sphere has found that doctors often misdiagnose and disregard health complaints made by older adults, as well as emphasize disease management over disease prevention (Pasupathi and Löckenhoff 2002). These practices may stem from the underlying assumption that older adults' health complaints are the inevitable result of advanced age, leading health professionals to overlook potential treatable causes for those complaints. As an example, cognitive deficits in older adults can be attributed - at least to some extent - to underlying depression. Attributing cognitive decline to aging alone may lead to older adults' depression going unnoticed (ibid).

Neglect, misdiagnosis, and mistreatment of older adults may lead to deterioration in physical and mental health, as well as in mobility, thereby impeding social participation. Hawkley et al. (2008) have found that ill health, an inability to satisfy the desire to engage in social activity, and a small social network (among other risk factors) jointly contribute to older adults' risk of late-life loneliness.

Finally, an inconspicuous feature of society that covertly discriminates against older adults and impedes social participation has to do with the design of the living environment. A survey conducted among older city dwellers around the world by the World Health Organization found some of the following features as barriers to social participation: inaccessibility to social activities due to distance and lack of or inconvenient transportation, inaccessibility of buildings, and lack of facilities such as toilets and rest areas (World Health Organization 2007). Some of the respondents in the survey voiced the belief that the living environment was not designed with older people's needs in mind. Such inconspicuous features of the living environment, such as narrow or cracked sidewalks, lack of resting areas, insufficient lighting, and unclear bus route signs, can severely diminish older adults' ability to remain physically and socially active.

\subsection{Conclusions}

Cumulative evidence attests to the negative consequences of loneliness. Its high prevalence among the older adult population alongside the deleterious effects on physical, emotional and cognitive health have urged an extensive exploration of its robust risk factors. Such studies, however, predominately have explored factors at the micro and meso levels. At the micro level, background factors such as gender, marital status, socio-economic status and health state are frequently being addressed as well as experiencing life-time traumatic events (Palgi et al. 2012). Examples for potential risk factors at the meso level are characteristics of one's social network (Shiovitz-Ezra 2013). The quantitative domain but mainly the qualitative nature of one's close social relationships have been found to predict late-life loneliness. Much 
less attention, however, has been given to the macro-cultural level, i.e. the way older people are being negatively perceived and the restricted social opportunities that are available for them to act socially.

The current chapter highlights the macro-cultural level by addressing the potential pathways from ageism to later-life loneliness and social exclusion. We overview two theoretical perspectives by which age negative perceptions and age discrimination potentially lead to feelings of loneliness. The "social rejection" model points to the negative feelings of being undesired, unwanted, betrayed and socially rejected that could lead to social withdrawal. The "stereotype embodiment" theory focused on self-fulfilling prophecies. Older people internalize the prevalent age related negative stereotypes and act accordingly. For example, when one's expect to be lonely at old age and when old age is perceived as a lonely time it seems to become a reality. Another mechanism stresses how ageist practices restrict social opportunities for older adults, leading to reduced social engagement, and increased late-life loneliness. Studies have provided some support for these theoretical assumptions but this territory is yet insufficiently explored. Future research, for instance, should address ageism as a significant risk factor for late-life loneliness in a multi-level analysis where the Micro, Meso and Macro levels are taken into account. The unique contribution of each of these levels to loneliness experienced in old age is highly important in formulating causal process of developing loneliness.

A thorough exploration of risk factors is not merely important in the theoretical sense of gathering a better understanding of the loneliness phenomenon. It is also crucial in order to combat deleterious phenomena such as loneliness. The literature on interventions aimed at preventing and coping with loneliness lays out four strategies: (a) improving social skills; (b) enhancing social support; (c) increasing opportunities for social contact; and (d) addressing maladaptive social cognition. Among these the latter was found to be the most successful intervention strategy (Masi et al. 2011). Most recently, it has been proposed that integrated interventions which combine (social) cognitive behavioral therapy with short-term adjunctive pharmacological treatments are most effective in combating loneliness (Cacioppo et al. 2015b).

We would like to challenge the notion that puts heavy weight on the individual level when trying to minimize late-life loneliness. Three of the above mentioned strategies deal with compromised social skills, maladaptive social cognition and medical treatment for individuals who suffer from loneliness. Therefore, all three locate the risk factors in the individual. Another strategy looked at the meso level by addressing lack of social support. Only one strategy of dealing with loneliness looked at the social opportunities available for older adults and called for increasing the opportunity for social interactions. This is, however, only one step in taking into account the Macro-cultural level and in addressing ageism as one of the prime predictors of late-life loneliness. Increasing social opportunities does not deal with social rejection that might jeopardize any social contact. It also is not addressing the negative age-related stereotypes that might create a reality where stereotypes of weakness, incompetence and sickness become a fact and actively narrow older people's social sphere. 
Ageism is not easy to combat. It has profound psychological and sociological origins that shape the way people get older in a society that admires youth and antiageing. The deleterious effects of loneliness might give a significant incentive for policy makers and clinicians to develop and construct social plans that take into account the complexity of ageism. These "anti-ageism" plans should approach different arenas such as the education system (at all levels starting from kindergartens; see Requena et al. 2018; Chap. 23, in this volume) and the legal system (Doron et al. 2018; Chap. 19; Mikołajczyk 2018; Chap. 20; Georgantzi 2018; Chap. 21, in this volume). Decisive policy against ageism will potentially advance socially engaged older people and the perception of old age as a social and meaningful time.

\section{References}

Ayalon, L., \& Shiovitz-Ezra, S. (2011). The relationship between loneliness and passive death wishes in the second half of life. International Psychogeriatrics, 23(10), 1677-1685.

Ayalon, L., Shiovitz-Ezra, S., \& Roziner, I. (2016). A cross-lagged model of the reciprocal associations of loneliness and memory functioning. Psychology and Aging, 31(3), 255-261.

Barg, F. K., Huss-Ashmore, R., Wittink, M. N., Murray, G. F., Bogner, H. R., \& Gallo, J. J. (2006). A mixed-methods approach to understanding loneliness and depression in older adults. The Journals of Gerontology Series B: Psychological Sciences and Social Sciences, 61(6), S329-S339.

Ben-Harush, A., Shiovitz-Ezra, S., Doron, I., Alon, S., Golander, H., Lebovitsh, A., Haron, Y., \& Ayalon, L. (2016). Ageism among physicians, nurses and social workers: Findings from a qualitative research. European Journal of Ageing. https://doi.org/10.1007/s10433-016-0389-9

Börsch-Supan, A., \& Schuth, M. (2014). Early retirement, mental health, and social networks. In D. A. Wise (Ed.), Discoveries in the Economics of Aging (pp. 225-255). Chicago: Chicago Press.

Butler, R. N. (1980). Ageism: A foreword. Journal of Social Issues, 36(2), 8-11.

Cacioppo, J. T., Hughes, M. E., Waite, L. J., Hawkley, L. C., \& Thisted, R. A. (2006). Loneliness as a specific risk factor for depressive symptoms: Cross-sectional and longitudinal analyses. Psychology and Aging, 21(1), 140-151.

Cacioppo, J. T., Cacioppo, S., Cole, S. W., Capitanio, J. P., Goossens, L., \& Boomsma, D. I. (2015a). Loneliness across phylogeny and a call for comparative studies and animal models. Perspectives on Psychological Science, 10(2), 202-212.

Cacioppo, J. T., Grippo, L., Goossens, L., \& Cacciopo, S. (2015b). Loneliness clinical import and interventions. Perspectives on Psychological Science, 10(2), 238-249.

Constanca, P., Salma, A., \& Shah, E. (2006). Psychological distress, loneliness and disability in old age. Psychology, Health \& Medicine, 11(2), 221-232.

Coudin, G., \& Alexopoulos, T. (2010). "Help me! I"m old!' How negative aging stereotypes create dependency among older adults. Aging \& Mental Health, 14(5), 516-523. https://doi. org $/ 10.1080 / 13607861003713182$

Cuddy, A. J., \& Fiske, S. T. (2002). Doddering but dear: Process, content, and function in stereotyping of older persons. InAgeism: Stereotyping and prejudice against older persons (pp. 3-26). Cambridge: MIT Press.

Cuddy, A. J., Norton, M. I., \& Fiske, S. (2005). This old stereotype: The perveasiveness and persistence of older adults stereotype. Journal of Social Issues, 61(2), 267-285.

Cuddy, A. J., Fiske, S. T., \& Glick, P. (2007). The BIAS map: Behaviors from intergroup affect and stereotypes. Journal of Personality and Social Psychology, 92(4), 631. 
De Jong Gierveld, J. (1998). A review of loneliness: Concept and definitions, determinants and consequences. Reviews in Clinical Gerontology, 8, 73-80.

de Jong Gierveld, J, van Tilburg, T. G, \& Dykstra, P. A. (2016). Loneliness and social isolation. In A. Vangelisti \& D. Perlman (Eds.), The Cambridge handbook of personal relationships (2nd ed., pp. 1-30). Cambridge University Press (forthcoming).

Doron, I., Numhauser-Henning, A., Spanier, B., Georgantzi, N., \& Mantovani, E. (2018). Ageism and anti-ageism in the legal system: A review of key themes. In L. Ayalon \& C. Tesch-Römer (Eds.), Contemporary perspectives on ageism: Vol. 19. International perspectives on aging (pp. 303-320). Berlin: Springer.

Dykstra, P. A. (2009). Older adult loneliness: Myths and realities. European Journal of Ageing, 6(2), 91.

Fiske, S. T., Cuddy, A. J. C., Glick, P., \& Xu, J. (2002). A model of (often mixed) stereotype content: Competence and warmth respectively follow from perceived status and competition. Journal of Personality and Social Psychology, 82(6), 878-902. https://doi. org/10.1037/0022-3514.82.6.878

Georgantzi, N. (2018). The European union's approach towards ageism. In L. Ayalon \& C. TeschRömer (Eds.), Contemporary perspectives on ageism: Vol. 19. International perspectives on aging (pp. 341-368). Berlin: Springer.

Goossens, L., Van Roekel, E., Verhagen, M., Cacioppo, J. T., Cacioppo, S., Maes, M., \& Boomsma, D. I. (2015). The genetics of loneliness: Linking evolutionary theory to genome-wide genetics, epigenetics, and social science. Perspectives on Psychological Science, 10(2), 213-226.

Hackett, R. A., Hamer, M., Endrighi, R., Brydon, L., \& Steptoe, A. (2012). Loneliness and stress-related inflammatory and neuroendocrine responses in older men and women. Psychoneuroendocrinology, 37(11), 1801-1809.

Harvey, B., \& Walsh, C. (2016). Loneliness and ageing: Ireland. North and South Dublin: Institute of Public Health.

Hawkley, L. C., Burleson, M. H., Berntson, G. G., \& Cacioppo, J. T. (2003). Loneliness in everyday life: Cardiovascular activity, psychosocial context, and health behaviors. Journal of Personality and Social Psychology, 85(1), 105-120.

Hawkley, L. C., Masi, C. M., Berry, J. D., \& Cacioppo, J. T. (2006). Loneliness is a unique predictor of age-related differences in systolic blood pressure. Psychology and Aging, 21(1), 152-164.

Hawkley, L. C., Hughes, M. E., Waite, L. J., Masi, C. M., Thisted, R. A., \& Cacioppo, J. T. (2008). From social structural factors to perceptions of relationship quality and loneliness: The Chicago health, aging, and social relations study. The Journals of Gerontology Series B: Psychological Sciences and Social Sciences, 63(6), S375-S384.

Holt-Lunstad, J., Smith, T. B., Baker, M., Harris, T., \& Stephenson, D. (2015). Loneliness and social isolation as risk factors for mortality: A meta-analytic review. Perspectives on Psychological Science, 10(2), 227-237. https://doi.org/10.1177/1745691614568352

Hummert, M. L. (2011). Age stereotypes and aging. In K. Warner Schaie \& S. L. Willis (Eds.), Handbook of the psychology of aging (pp. 249-262). San Diego: Academic.

Jaremka, L. M., Fagundes, C. P., Peng, J., Bennett, J. M., Glaser, R., Malarkey, W. B., \& KiecoltGlaser, J. K. (2013). Loneliness promotes inflammation during acute stress. Psychological Science, 24(7), 1089-1097.

Kahn, J. H., Hessling, R. M., \& Russell, D. W. (2003). Social support, health, and well-being amongolder adults: What is the role of negative affectivity? Personality and Individual Differences, $35,5-17$.

Kite, M. E., Stockdale, G. D., Whitley, B. E., \& Johnson, B. T. (2005). Attitudes toward younger and older adults: An updated meta-analytic review. Journal of Social Issues, 61(2), 241-266.

Lee, G. R., \& Ishii-Kuntz, M. (1987). Social interaction, loneliness, and emotional well-being among older adults. Research on Aging, 9(4), 459-482.

Levy, B. (2009). Stereotype embodiment: A psychosocial approach to aging. Current Directions in Psychological Science, 18(6), 332-336. 
Levy, B. R., \& Leifheit-Limson, E. (2009). The stereotype-matching effect: Greater influence on functioning when age stereotypes correspond to outcomes. Psychology and Aging, 24(1), 230.

Levy, B. R., Slade, M. D., Kunkel, S. R., \& Kasl, S. V. (2002a). Longevity increased by positive self-perceptions of aging. Journal of Personality and Social Psychology, 83(2), 261-270. https://doi.org/10.1037/0022-3514.83.2.261

Levy, B. R., Slade, M. D., \& Kasl, S. V. (2002b). Longitudinal benefit of positive self-perceptions of aging on functional health. The Journals of Gerontology. Series B, Psychological Sciences and Social Sciences, 57(5), P409-P417. https://doi.org/10.1093/geronb/57.5.P409

Luhmann, M., \& Hawkley, L. C. (2016). Age differences in loneliness from late adolescence to oldest old age. Developmental Psychology, 52(6), 943.

Luo, Y., Hawkley, L. C., Waite, L. J., \& Cacioppo, J. T. (2012). Loneliness, health, and mortality in old age: A national longitudinal study. Social Science \& Medicine, 74(6), 907-914. https://doi. org/10.1016/j.socscimed.2011.11.028

Masi, C. M., Chen, H. Y., Hawkley, L. C., \& Cacioppo, J. T. (2011). A meta-analysis of interventions to reduce loneliness. Personality and Social Psychology Review, 15(3), 219-266.

Menkin, J. A., Robles, T. F., Gruenewald, T. L., Tanner, E. K., \& Seeman, T. E. (2016). Positive expectations regarding aging linked to more new friends in later life. The Journals of Gerontology. Series B, Psychological Sciences and Social Sciences, 0(0), 1-11. https://doi. org/10.1093/geronb/gbv118

Mikołajczyk, B. (2018). The council of europe's approach towards ageism. In L. Ayalon \& C. Tesch-Römer (Eds.), Contemporary perspectives on ageism: Vol. 19. International perspectives on aging (pp. 321-339). Berlin: Springer.

Nelson, T. D. (2005). Ageism: Prejudice against our feared future self. Journal of Social Issues, 61(2), 207-221. https://doi.org/10.1111/j.1540-4560.2005.00402.x

Neumark, D., Burn, I., \& Button, P. (2017). Age discrimination and hiring of older workers. Age, $2017,06$.

Ng, R., Allore, H. G., Trentalange, M., Monin, J. K., \& Levy, B. R. (2015). Increasing negativity of age stereotypes across 200 years: Evidence from a database of 400 million words. PLoS One, 10(2). https://doi.org/10.1371/journal.pone.0117086

O’Luanaigh, C., O’Connell, H., Chin, A. V., Hamilton, F., Coen, R., Walsh, C., et al. (2012). Loneliness and vascular biomarkers: The Dublin healthy ageing study. International Journal of Geriatric Psychiatry, 27(1), 83-88.

Palgi, Y., Shrira, A., Ben Ezra, M., Shiovitz Ezra, S., \& Ayalon, L. (2012). Self- and other-oriented potential lifetime traumatic events as predictors of loneliness in the second half of life. Aging \& Mental Health, 16(4), 423-430.

Pasupathi, M., \& Löckenhoff, C. E. (2002). Ageist behavior. In Nelson (Ed.), Ageism: Stereotyping and prejudice against older persons (pp. 201-246). Cambridge, MA: MIT Press.

Penninx, B. W., van Tilburg, T., Kriegsman, D. M., Boeke, A. J., Deeg, D. J., \& van Eijk, J. T. (1999). Social network, social support, and loneliness in older persons with different chronic diseases. Journal of Aging and Health, 11(2), 151-168.

Peplau, L. A., \& Perlman, D. (1982). Perspectives on loneliness. In L. A. Peplau \& D. Perlman (Eds.), Loneliness: A sourcebook of current theory, research and therapy (pp. 1-20). New York: Wiley.

Perlman, D. (2004). European and Canadian studies of loneliness among seniors. Canadian Journal on Aging/La Revue canadienne du vieillissement, 23(02), 181-188.

Perlman, D., \& Peplau, L. A. (1998). Loneliness. Encyclopedia of Mental Health, 2, 571-581.

Pikhartova, J., Bowling, A., \& Victor, C. (2016). Is loneliness in later life a self-fulfilling prophecy? Aging \& Mental Health, 20(5), 543-549. https://doi.org/10.1080/13607863.2015.10237 67

Qualter, P., Vanhalst, J., Harris, R., Van Roekel, E., Lodder, G., Bangee, M., et al. (2015). Loneliness across the life span. Perspectives on Psychological Science, 10(2), 250-264. 
Requena, M. J., Swift, H., Naegele, L., Zwamborn, M., Metz, S., Bosems, W. P. H., \& Hoof, J. (2018). Educational methods using intergenerational interaction to fight ageism. In L. Ayalon \& C. Tesch-Römer (Eds.), Contemporary perspectives on ageism: Vol. 19. International perspectives on aging (pp. 383-402). Berlin, Germany: Springer.

Rippon, I., Zaninotto, P., \& Steptoe, A. (2015). Greater perceived age discrimination in England than the United States: Results from HRS and ELSA. The Journals of Gerontology Series B: Psychological Sciences and Social Sciences, 70(6), 925-933. https://doi.org/10.1093/geronb/ gbv040

Russel, D. (1996). UCLA loneliness scale (Version 3): Reliability, validity, and factor structure. Journal of Personality Assessment, 66(1), 20-40.

Savikko, N., Routasalo, P., Tilvis, R., Strandberg, T., \& Pitkala, K. (2005). Predictors and subjective causes of loneliness in an aged population. Gerontology \& Geriatrics, 41(3), 223-233.

Shankar, A., Hamer, M., McMunn, A., \& Steptoe, A. (2013). Social isolation and loneliness: Relationships with cognitive function during 4 years of follow-up in the English longitudinal study of ageing. Psychosomatic Medicine, 75(2), 161-170.

Shiovitz-Ezra, S. (2013). Confidant networks and loneliness. In A. Borsch-Supan, M. Brandt, H. Litwin, \& W. Guglielmo (Eds.), Active ageing and solidarity between generations in Europe: First results from SHARE after the economic crisis (pp. 349-358). Berlin: DeGruyter.

Shiovitz-Ezra, S., \& Ayalon, L. (2010). Situational versus chronic loneliness as risk factors for all-cause mortality. International Psychogeriatrics, 22, 455-462.

Smart Richman, L., \& Leary, M. R. (2009). Reactions to discrimination, stigmatization, ostracism, and other forms of interpersonal rejection: A multimotive model. Psychological Review, 116(2), 365-383. https://doi.org/10.1037/a0015250

Sorkin, D., Rook, K. S., \& Lu, J. L. (2002). Loneliness, lack of emotional support, lack of companionship, and the likelihood of having a heart condition in an elderly sample. Annual of Behavioral Medicine, 24(4), 290-298.

Storm, C., \& Storm, T. (1987). A taxonomic study of the vocabulary of emotions. Journal of Personality and Social Psychology, 53(4), 805.

Stravynski, A., \& Boyer, R. (2001). Loneliness in relation to suicide ideation and parasuicide: A population -wide study. Suicide and Life-threatening Behavior, 31(1), 32-40.

Sutin, A. R., Stephan, Y., Carretta, H., \& Terracciano, A. (2015). Perceived discrimination and physical, cognitive, and emotional health in older adulthood. The American Journal of Geriatric Psychiatry, 23(2), 171-179. https://doi.org/10.1016/j.jagp.2014.03.007

Suzman, R., \& Beard, J. (2011). Global health and aging (pp. 1-32). US Department of State.

Swift, H. J., Abrams, D., Lamont, R. A., \& Drury, L. (2017). The risks of ageism model: how ageism and negative attitudes toward age can be a barrier to active aging. Social Issues and Policy Review, 11(1), 195-231.

Theeke, L. A. (2007). Socidemographic and health-related risks for loneliness and outcome differences by loneliness status in a sample of older U.S. adults. Doctoral dissertation, Morgantown, West Virginia University.

Thorsen, S., Rugulies, R., Løngaard, K., Borg, V., Thielen, K., \& Bjorner, J. B. (2012). The association between psychosocial work environment, attitudes towards older workers (ageism) and planned retirement. International Archives of Occupational and Environmental Health, 85(4), 437-445.

Thurston, R. C., \& Kubzansky, L. D. (2009). Women, loneliness, and incident coronary heart disease. Psychosomatic Medicine, 71(8), 836-842.

Tilvis, R. S., Kähönen-Väre, M. H., Jolkkonen, J., Valvanne, J., Pitkala, K. H., \& Strandberg, T. E. (2004). Predictors of cognitive decline and mortality of aged people over a 10-year period. The Journals of Gerontology Series A: Biological Sciences and Medical Sciences, 59(3), M268-M274.

van den Heuvel, W. J., \& van Santvoort, M. M. (2011). Experienced discrimination amongst European old citizens. European Journal of Ageing, 8(4), 291-299. 
Victor, C. R., Scambler, S. J., Bowling, A., \& Bond, J. (2005). The prevalence of, and risk factors for, loneliness in later life: A survey of older people in Great Britain. Ageing and Society, 25, $357-375$.

Vitman, A., Iecovich, E., \& Alfasi, N. (2014). Ageism and social integration of older adults in their neighborhoods in Israel. The Gerontologist, 54(2), 177-189.

von Hippel, C., Kalokerinos, E. K., \& Henry, J. D. (2013). Stereotype threat among older employees: Relationship with job attitudes and turnover intentions. Psychology and Aging, 28(1), 17-27.

Weiss, R. S. (1973). Loneliness: The experience of emotional and social isolation. Cambridge, MA: MIT Press.

Weiss, R. S. (1987). Reflections on the present state of loneliness research. Journal of Social Behavior and Personality, 2(2), 1.

Wilson, R. S., Krueger, K. R., Arnold, S. E., Schneider, J. A., Kelly, J. F., Barnes, L. L., et al. (2007). Loneliness and risk of Alzheimer disease. Archives of General Psychiatry, 64(2), 234-240.

World Health Organization. (2007). Global age-friendly cities: A guide. Geneva: World Health Organization.

World Health Organization. (2015). World report on ageing and health. Geneva: World Health Organization.

Zion Market Research. (2016, July). Global anti-aging market set for rapid growth to reach around USD 216.52 Billion in 2021. Retrieved from: https://www.zionmarketresearch.com/ news/global-anti-aging-market

Open Access This chapter is licensed under the terms of the Creative Commons Attribution 4.0 International License (http://creativecommons.org/licenses/by/4.0/), which permits use, sharing, adaptation, distribution and reproduction in any medium or format, as long as you give appropriate credit to the original author(s) and the source, provide a link to the Creative Commons license and indicate if changes were made.

The images or other third party material in this chapter are included in the chapter's Creative Commons license, unless indicated otherwise in a credit line to the material. If material is not included in the chapter's Creative Commons license and your intended use is not permitted by statutory regulation or exceeds the permitted use, you will need to obtain permission directly from the copyright holder.

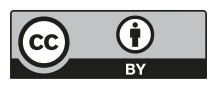




\title{
Chapter 10 \\ Ageism and Sexuality
}

\author{
Ateret Gewirtz-Meydan, Trish Hafford-Letchfield, Yael Benyamini, \\ Amanda Phelan, Jeanne Jackson, and Liat Ayalon
}

\subsection{Introduction}

In contemporary society, sexuality, intimacy, and sexual identities are considered central to a meaningful personal life, and on a fundamental level, constitute one of our basic human needs and rights. Until relatively recently however, much of the literature and discussion on these issues tended not to acknowledge older people and the topic remained taboo. These silences are further enshrined in many areas of social policy and practice in relation to ageing support and mirror older people's invisibility in other areas of society. This chapter explores some of the dominant

A. Gewirtz-Meydan ( $₫)$

School of Social Work, Bar Ilan University, Ramat-Gan 592000, Israel

The Sex and Couple Therapy Unit, Meir Medical Center, Kfar Saba, Israel

T. Hafford-Letchfield

Department of Mental Health, Social Work, Interprofessional Learning and Integrative

Medicine School of Health and Education, Middlesex University, London, UK

Y. Benyamini

Bob Shapell School of Social Work, Tel Aviv University, Tel Aviv, Israel

A. Phelan

School of Nursing, Midwifery \& Health Systems, University College Dublin, Dublin, Ireland e-mail: amanda.phelan@ucd.ie

J. Jackson

School of Clinical Therapies and Department of Occupational Science \& Occupational

Therapy, University College Cork, Cork, Ireland

L. Ayalon

Louis and Gabi Weisfeld School of Social Work, Bar Ilan University,

Ramat Gan 52900, Israel

e-mail: Liat.ayalon@biu.ac.il

(C) The Author(s) 2018

L. Ayalon, C. Tesch-Römer (eds.), Contemporary Perspectives on Ageism,

International Perspectives on Aging 19,

https://doi.org/10.1007/978-3-319-73820-8_10 
discourses about sexuality, intimacy, and sexual identities in later life. By drawing on a range of secondary literature, it examines the different positions and contexts that situate the 'practice' (Foucault 1981) of sexuality in later life.

In relation to older people, preoccupation with sexuality and beliefs about 'normal' or 'appropriate' sexual behavior remains firmly entrenched in society, despite popular exposure. Sexuality in later life is mainly addressed from the biomedical perspective (DeLamater and Koepsel 2015), assuming there is a natural decline in the individual's sexual functioning in later life (Gewirtz-Meydan and Ayalon 2017), which needs to be treated with medication (Gledhill and Schweitzer 2014). Some other main issues and key myths that have been conceptualized in relation to older people's sexuality include: a lack of sexual desire that accompanies ageing; the physical unattractiveness and undesirability of older people, which is particularly evident in relation to gender; the idea that it is shameful and perverse for older people to engage in sexual activity; the invisibility of the older Lesbian, Gay, Bisexual, Transgender, Queer and Intersex (LGBTQ\&I) community, and individuals who may need to return to the 'closet' in later life (Hafford-Letchfield 2008).

In the current chapter, we explore how ageism is constructed through the influences of attitudes promoted by the media, attitudes by younger people towards sexuality in later life, older people's attitudes towards their own sexuality and attitudes of those who provide care services.

Sexuality is defined by the World Health Organization as the integration of "somatic, emotional, intellectual and social aspects of sexual being, in ways that are positive, enriching and that enhance personality, community and love" (WHO, 2006). This holistic definition articulates sexuality as a state of being beyond sexual activity or sexual relationships. It includes notions of intimacy where there is close association, familiarity and shared personal knowledge between people, suggesting a degree of caring, sympathy or emotional understanding. The notion of sexual identity or sexual orientation adds complex dimensions, which may include political and community elements of how people relate to one another. Researchers are also beginning to note greater fluidity in sexuality over the life span, further complicating our definitions of sexual identities, including gender identities, which may not coincide with sexual orientation (Willis et al. 2016).

\subsection{Attitudes and Perceptions of the Media}

The media has an important role in shaping the public image of later life and sexuality.

(DeLamater and Koepsel 2015). In the media "ageing" and "sexuality" are portrayed and understood as unrelated concepts. The voices presented in the media frequently contradict. There is a repeated assertion that sexuality continues to play an important role as people age (Scherrer 2009). Notions such as 'sexy senior' or 'sexy oldie' are partly replacing stereotypical notions such as 'dried up old woman', 'nasty/dirty old man’ or 'asexual oldies' (Marshall 2011; Steinke 1994; Vares 2009). Yet, older people who remain sexually active are stereotyped by the popular media, as well. Heterosexist concepts such as cougar or MILF (Acronym for 'Mother, I'd 
like to fuck') are introduced by the popular media and represent stereotypical, ageist approaches towards older people's sexuality and toward older women in particular (Alarie and Carmichael 2015). Thus, while these labels acknowledge sexual desire in older persons, they portray negative aspects and reinforce the concept of most older persons as asexual (Montemurro and Siefken 2014).

Due to the emphasis on youthfulness by mass media, older men and women are underrepresented in advertisements. Moreover, when they do appear, they are typically peripheral, grouped with others or in a specific context such as insurance plans (Hurd Clarke et al. 2014; Low and Dupuis-Blanchard 2013). Images of older people relating to specific advertisements, such as pensions or health care products are associated with notions of burden frailty, loneliness or vulnerability (Media and diversity in an ageing society, 2002-2004), which reflect stereotypical expectations about later life (Prieler 2012; Williams et al. 2010) and convey them to society. A discourse analysis of how Canadian newspapers and magazines portray and construct older people's sexuality is a good example (Wada et al. 2015). The dominant, idealized notion of remaining young-looking, physically attractive and sexually active was highlighted, which marginalized older people who chose not to conform to that ideal or were unable to do so. This dominant ideal alongside with the successful ageing paradigm that encourages older people to stay sexually active, have led to a reconstruction of sexuality in later life.

Engaging in sexual activities has become an indicator of success or failure of the ageing process (Gott 2005; Katz 2002; Katz and Marshall 2003), which vacillates between 'normal' or 'pathological' and successful or unsuccessful ageing. Whereas a more positive image of older people's sexuality is certainly welcome, these kinds of advertisements and implicit messages to remain sexually active in older age create a division in which those who chose a different way may be defined as nonfunctional or as failing to age successfully. The representations of older people in print media established and reinforced the paradox that while sexuality is crucial to remaining youthful and aging successfully, youth and beauty are essential requisites for active sexual engagement. (Wada et al. 2015). Older people are expected to use pharmaceutical and medical interventions to sustain and enhance sexual functioning (Wada et al. 2015; Wentzell 2013) and intercourse is still presented as the "gold standard of sexuality" in later life (Gott 2005, p.14).

Emphasizing heterosexual ideals (e.g., penetration, orgasm, younger-looking) enhances ageism and the anti-ageing consumer culture (Hurd Clarke 2010; Katz and Marshall 2003). In-depth interviews with 44 women, ages 50-70 years, revealed that women respond to ageism and social obsession with youthfulness and discrimination against older people by engaging in beauty work such as hair dye, make-up, cosmetic surgery, and non-surgical cosmetic procedures, in order to fight social invisibility (Clarke and Griffin 2008). Advertisements for creams that 'will make you look 10 years younger' and the growth of cosmetic surgery are usually aimed towards the third-age, which is characterized by active sexual engagement. This creates an artificial distinction between the third age and the fourth age, when older people are seen as becoming non-sexual (Wada et al. 2015). The consequence of the divergence between the third and the fourth ages is growing stigmatization and ageism towards people as they grow older. The subtext underlying this type of advertis- 
ing portrays older people as unattractive. While anti-ageing and pharmaceutical interventions are portrayed as enabling older people to restore their sexual functioning and youthfulness, they shape public perceptions of ageing as a pathological, rather than a normal, natural process (González 2007; Gott 2005; Katz and Marshall 2003).

It seems that despite the increasing recognition by mass media of older people as sexual human beings, ageing is still presented in a very narrow and one-dimensional mode. The gaps between the idealized images of ageing and the subjective experience can harm older people's self-image. As a result, sexual desire and enjoyment, achieving orgasm and frequency of sexual activity might diminish (Koch et al. 2005).

\subsection{Attitudes and Perceptions of the Young Towards Older People's Sexuality}

Studies have indicated that younger adults have accepting, tolerant, open-minded and positive attitudes towards sexuality in later life (Allen and Roberto 2009; Freeman et al. 2014). A survey of college students regarding their sexual attitudes and behaviors, both currently and projecting into later life, found that although younger adults were optimistic about continued sexual enjoyment in later life, they also believed many of the current myths about ageing. They expected considerably diminished sexual activity, along with increased sexual problems. Their expectations regarding sexual activity in later life were more conservative than their current attitudes were (Floyd and Weiss 2001).

Nonetheless, explicitly ageist attitudes toward sexuality might be difficult to detect (Thompson et al. 2014) and the implicit and explicit attitudes reported might diverge (Mahieu et al. 2011; Thompson et al. 2014). Acceptance of sexuality in older people by younger individuals seems to be a more 'politically correct' approach, whereas negative perceptions are portrayed as 'old-fashioned' and primitive. Evidence for this was found in a study that used an implicit attitudes test, which operates beyond conscious awareness (Lai and Hynie 2011). The study was conducted among 305 young adult university students who rated men and women's likely interest in a range of sexual activities. Their responses regarding younger (their own age) and older (65 years or older) individuals were compared. Participants perceived older people to be significantly less interested in sexual activities than were younger generations. However, both older men and older women were rated as varying between 'somewhat' to 'very interested' in both traditional and experimental forms of sexual activity. Another study (Thompson et al. 2014) examined young adults' explicit and implicit attitudes regarding the sexuality of older people. The authors reported that, consistent with other contemporary research (Lai and Hynie 2011), when asked, young adults explicitly reported positive views about the sexu- 
ality of older people; however, implicit attitudes towards sexuality and ageing were negative.

Most of the discussion about sex assumes heterogeneity and lacks awareness of LGBTQ\&I issues. These assumptions sustain a language for discussing relationships and life in a heteronormative way (Hafford-Letchfield 2008). Within the LGBTQ\&I community, ageing issues may not be prioritized, resulting in the lack of a valued role for older lesbians and gay men. Such experiences, combined with a history of stigmatization, can subject older LGBTQ\&I people to increased risk of depression, substance misuse, unnecessary institutionalization and premature death. Similar to misperceptions about older heterosexual people and their sexual lives, the majority of older LGBTQ\&I people continue to have sexual desires and needs. A Gay and Gray Project study (2006) found that just over three-quarters of respondents said that they had active sexual lives and over half felt that their sexuality had an important positive impact on their lives. Therefore, adjustment to ageing is significantly related to satisfaction with one's sexual identity and the role society plays in shaping an individual's acceptance and sense of fulfillment from life experiences.

Being lesbian, gay or bisexual is about more than defining your sex life. It shapes the way you experience life, your interests, likes, dislikes, humor, friendship, and attitudes. A care plan that neglects to include this huge part of a person's individuality is clearly incomplete and is likely to fall short of meeting that person's needs (Gay and Gray Project 2006).

The LGBTQ\&I community, like any other, has some tension between generations related to sexuality. For example, within the LGBTQ\&I community accusations of ageism are common - older men in particular often report feeling alienated from younger groups whom they perceive focus too much on appearance (body fascism). Meanwhile, younger LGBTQ\&I people have reported that they are wary that older LGBTQ\&I people only see them through a sexual lens (ILC 2011). Little intergenerational work has been done to explore the potential for increasing understanding in the context of the LGBTQ\&I community, even though the old and young LGBTQ\&I live side by side (ILC 2011).

In summary, attitudes held by the younger generations towards older people are important, as they potentially impact their behavior toward older people, as well as the beliefs and attitudes of older people towards sexuality.

\subsection{Attitudes of Older People Towards Their Own Sexuality}

Studies examining sexual behavior and attitudes of older people towards their own sexuality, reported that most engage in partner or other intimate relationships and view sexuality as an important part of life (Lindau et al. 2007). Findings from a study conducted in Nigeria, revealed that older people portray sexuality as an important aspect of later life, with heterosexual intercourse construed as having physical and spiritual consequences (Agunbiade and Ayotunde 2015). Yet, 
research has consistently found that older people often internalize stereotypes and myths regarding late-life sex/sexuality and often are hesitant to express their sexuality.

A particularly significant indication of internalizing ageism is the reluctance of older people to discuss sexual issues with their primary care physician, due to fear that sex in later life does not meet with societal expectations and therefore, might be disapproved of by healthcare providers (Gott and Hinchliff 2003). Implicit in many stories was the perception that older people are not or should not be sexual beings. According to Vares (2009), older women internalize societal norms of beauty and ageism, view themselves as unattractive and perceive their bodies in negative ways such as 'wilting', getting 'rolls', 'sags' and 'flabby'.

In an attempt to combat ageism, older people undergo many beauty and antiageing treatments (Vares 2009) and consume pharmaceuticals aimed to enhance sexual performance (Gledhill and Schweitzer 2014; Katz and Marshall 2003; Wentzell 2013). Unfortunately, beauty and anti-ageing treatments and pharmaceuticals to enhance sexual performance do not always lead to satisfaction. Older people reported pharmaceuticals were often prescribed without assessment of the factors involved and without warning of side effects. They found pharmaceuticals aimed to enhance sexual performance ineffective and costly (Gledhill and Schweitzer 2014). Similarly, older women, who knew about vaginal lubricants, said that they felt that sex was still physically uncomfortable even when using lubrication (Shea 2011). In addition, while men were concerned about erectile function, women agreed that in older age, a companion is more important than sex and that they engage in sex as part of an obligation to sexually satisfy their partner (Baldissera et al. 2012). Shea (2011) opined that expanding the notion of sexuality beyond sexual intercourse is necessary. Absence of sexual activity may reflect a desire for liberation from sexual obligations, an acceptance of changing circumstances or the informed choice of other social priorities. There are also grey areas in relation to these issues, for example, the misunderstood orientation of asexuality, where one's identity is not aligned with sexual attraction or activity.

Specific, narrow societal norms and expectations were found to be main barriers to expressing sexual needs and sexuality, and to raising or discussing sexuallyrelated issues with professionals. Internalizing societal norms and ageism caused sexual problems that were attributed to ageing, to be viewed as normal and irreversible or untreatable (Gott and Hinchliff 2003). Other barriers to discussing sexuallyrelated issues with physicians were personal embarrassment, lack of knowledge and awareness, fear of wasting the doctor's time, or indirect presentation of sexual dysfunction hidden by other symptoms (Gott and Hinchliff 2003; Humphery and Nazareth 2001). Contextual/structural barriers, such as lack of time, lack of availability of secondary psychosexual services, lack of doctors' freedom to prescribe (Humphery and Nazareth 2001), setting and privacy (Sarkadi and Rosenqvist 2001) were noted, as well. 


\subsection{Attitudes and Perceptions of Primary Care Providers and Long-Term Care Staff}

Sexual activity in later life is closely linked to physical health, diseases and functional decline (Dennerstein et al. 2002; Kontula and Haavio-Mannila 2009; Lindau et al. 2007; Mulligan et al. 2006). Therefore it is expected to be addressed by primary care providers who tend to serve as the primary 'gatekeepers' (Hughes and Wittmann 2015).

However, it is unclear, how well primary care providers' formal education has prepared them to address sexual health concerns among older people. Primary care physicians' knowledge of sexuality in later life was found to vary across studies. Whereas some studies reported adequate (Hughes and Wittmann 2015) or average/ moderate (Mahieu et al. 2016) knowledge regarding sexual health issues in older people, others indicated limited and insufficient knowledge (Dogan et al. 2008; Mahieu et al. 2011; Snyder and Zweig 2010) among physicians. A recent review found that healthcare professionals often consider older people's sexuality as outside their scope of practice and lack knowledge and confidence in this area (Haesler et al. 2016). Obtaining relevant knowledge regarding sexuality in later life is especially important for adequately addressing older patients' sexual health concerns, for diagnosing problems, for recommending adequate treatment (Gewirtz-Meydan and Ayalon 2017) and for assisting older people to overcome barriers to sexual expression (Rheaume and Mitty 2008). Yet, physicians report they receive inadequate and insufficient education about sexuality in later life (Dogan et al. 2008; Gott et al. 2004). As a result, sexual issues are not raised during routine healthcare visits or interactions with older people and physicians' awareness of sexual issues in later life is very low (Gott et al. 2004).

Maes and Louis (2011) found that only $2 \%$ of a random sample of 500 American Academy of Nurse Practitioners members indicated they always conduct a sexual history with their patients aged 50 and older, whereas $23.4 \%$ never or seldom do such an assessment. Similarly, a study conducted among 144 psychiatrists in the US (Bouman and Arcelus 2001) found that sexual history is often omitted in the psychiatric assessment of older men. This often results in inappropriate referral and treatment procedures.

Knowledge and attitudes towards sexuality in later life were positively linked in many studies (Mahieu et al. 2016), making it difficult to determine causality. Ageist attitudes are not uncommon among health care providers (Dogan et al. 2008; Langer-Most and Langer 2010) and they have a great effect on the legitimacy of expressing sexuality in later life. A qualitative study conducted among general practitioners (Gott et al. 2004) revealed clear ageist attitudes toward sexuality of older people, as discussing sexual health issues seemed more relevant to younger patients, then older patients. In addition, sex was not recognized as an appropriate topic for discussion with older people. Nonetheless, no matter what the reasons for differential attitudes towards older people, it is clear that physicians exhibit strong biases in their approach to them. A recent study (Gewirtz-Meydan and Ayalon 2017) used 
two similar case vignettes, describing young $(\mathrm{N}=110)$ vs. older $(\mathrm{N}=126)$ adults who presented the same indication for sexual performance anxiety. The treating physicians revealed an obvious age bias, as adults in the "older" vignette were more likely to be diagnosed with erectile dysfunction, whereas those in the "younger" vignette were more likely to be correctly diagnosed with sexual performance anxiety. Moreover, older people's dysfunction was more likely to be attributed to hormonal changes, health problems and decreased sexual desire rather than to psychological factors. Lastly, physicians were more likely to recommend testosterone replacement therapy and products which contain PDE5 inhibitors (such as Viagra $^{\mathrm{TM}}$, Levitra ${ }^{\mathrm{TM}}$ or Cialis ${ }^{\mathrm{TM}}$ ), as well as referral to urology for the "older" vignette, whereas the "younger" vignette was more often referred to a sexologist and received a more positive prognosis. These results clearly demonstrate that older people's sexual issues are more likely to be addressed through medical technology, whereas younger adults are more likely to be offered interventions in line with the biopsychosocial model, which is currently advocated for sexual issues.

Attitudes towards sexuality in later life, among staff in long-term care (LTC) facilities, are very relevant to the level of sexual expression among residents (Elias and Ryan 2011; McAuliffe et al. 2007). Staff attitudes define the institutional stance on this issue, which can range from restricting sexual expression to being responsive to or even promoting residents' sexual needs (Roach 2004). Although most studies indicate that LTC staff have positive attitudes of (Bouman et al. 2007; Mahieu et al. 2011), they are far from perfect. Staff knowledge regarding sexuality in later life is limited (Mahieu et al. 2011, 2016), personal comfort discussing sexually-related issues is low (Gilmer et al. 2010), trivial circumstances required for sexual expression (as privacy) are not facilitated (Gilmer et al. 2010) and a clear policy regarding the issue is generally lacking, leaving each institution to formalize policy regarding this issue independently, if at all (Bauer et al. 2009).

Prior to entering care facilities, prospective residents are not provided with information about how their sexual and intimacy needs will be respected (Bauer et al. 2009), nor do nurses routinely enquire about sexual practices and conduct sexual health assessments among older residents (McAuliffe et al. 2007). In addition, even though the majority of LTC staff believe residents have sexual needs that should be acknowledged and supported, the need was not regularly assessed due to discomfort about the topic among the staff, negative attitudes among the staff towards older people, as well as a lack of privacy and unclear institutional policy regarding the issue (Gilmer et al. 2010). Lastly, it should be noted, not all explicit, positive attitudes truly represent inner-thoughts or feelings (Thompson et al. 2014). In a study conducted among LTC staff, respondents acknowledged the existence of negative reactions towards masturbation only among other colleagues. When asked for their own opinion, they stated they viewed masturbation as normal and acceptable behavior (Villar and Serrat 2016). Sexual expression among LGBTQ\&I people can be even more difficult in LTC facilities where any kind of sexual expression is censored or where judgments are made about those who are not in long-term relationships or have multiple sexual partners. This can be particularly stressful when the person finds him- or herself in a care environment where they will inevitably have 
less personal freedom. When the person also has dementia, sexual disinhibition might lead to more openly sexual behavior, which might be more quickly labeled as deviant (Knocker 2012).

Staff perceptions and responses to residents' sexual behavior were found to be associated with personal level of comfort related to sexuality issues, the ethos within the employing organization (Roach 2004) and experience and age of the LTC staff. Older care staff reflected more positive attitudes towards later life sexuality, as they have more years of work experience in their field (Bouman et al. 2007). Knowledge and attitudes proved to be positively related, indicating that greater knowledge of sexuality among older people is associated with more positive attitudes toward sexuality in later life (Mahieu et al. 2016). Attitudes and beliefs towards older people expressing their sexuality in LTC facilities, including same sex couples and people with dementia, became more permissive after staff education (Bauer et al. 2013). Education is an important factor in dispelling commonly held, negative views of residential care staff about older people expressing their sexuality. Thus, it is very important to provide this information to LTC and nursing home staff (Bauer et al. 2013; Mahieu et al. 2016).

\subsection{Conclusions and Recommendations}

Sexuality in later life remains a largely unexplored and taboo topic. It is characterized by a dual nature and dominated by social constructivism. Despite recognition that sexuality is important to the quality of life of older people, this chapter identifies ageist perceptions regarding sexuality in later life among the media, young people, healthcare service providers and among older people. Any discussion needs to deconstruct the myths and stereotypes that deny older people their own unique sense of sexual being and the right to express it (McAuliffe et al. 2007). Rooted in and compounding ageism, are irrational fears, stereotypical thinking and lack of knowledge, resulting in attitudes and behaviors that constitute significant barriers to sexual expression, the enjoyment of sexuality and achieving a sense of self in later life (Snyder and Zweig 2010). Surveys conducted in several countries consistently found that older people indicated the importance of remaining sexually active as a major component of their quality of life and well-being (Kontula and HaavioMannila 2009). Research has shown that older people continue to engage in various sexual activities, such as penetrative sex, oral sex, and masturbation even in the eighth and ninth decades of life (Lindau et al. 2007). Hence, the expressed desire to remain sexually active is often accompanied by corresponding behaviors. Similarly, researchers have failed to challenge age-related stereotyping by placing older people outside the remit of national, population-based surveys on sexuality and sexual health issues, reinforcing the notion that these are not relevant to this sector of the community. When studies were conducted, they tended to focus on the more problematic aspects of sex, such as dysfunction in sexual performance or challenging behavior associated with cognitive, psychological or biological changes (for 
example, disinhibition associated with conditions such as dementia). All of these serve to promote a medical model of older people's sexuality (Hafford-Letchfield 2008).

Not least, most research has neglected the voices of older people themselves, which are essential to capturing the diversity of experiences of sexuality and to challenging dominant discourses. This requires examination of how older people's experiences are incorporated into the discourse of people working with and relating to them. Sexuality is fundamental to social organization and is an important focus of power and resilience. Placing it at the center of an analysis of ageing and later life can provide insights into the possibilities of reworking the stereotypes and social practices that shape attitudes and subsequent actions when providing services and support.

Finally, until relatively recently, the research literature has tended not to acknowledge ethnic or cultural diversity. Many studies were framed from a white, middleclass, male, heterosexual perspective, suggesting a need for more cross-cultural studies. Fewer studies utilized representative samples exploring the sexual histories of older LGBTQ\&I people and none collected information on gender identity. Due to a lack of representative, population-based samples, older LGBTQ\&I people, and others with a history of same-sex sexual desire, behavior or identity, remain invisible (Brown and Grossman 2014).

Concurrently, paradigms for active and successful ageing reinforce high expectations concerning sexual behaviors, activities and desire, which are often inconsistent with the reality of many older people (Woloski-Wruble et al. 2010). Encouraging older people to stay sexually active in a way that is inconsistent with their reality, is another form of ageism (DeLamater and Koepsel 2015; Marshall 2012). Although it is agreed that some sexual changes and dysfunctions can be due to hormonal and other physical changes or long-term conditions related to ageing (Dennerstein et al. 2002; Mulligan et al. 2006), focusing on biological aspects alone might facilitate a narrow, counter-productive perspective (Hillman 2008). A biopsychosocial model is a multidisciplinary approach to the diagnosis and treatment of sexual problems, as it considers psychological and social factors such as stereotypes, gender socialization, partner availability, socioeconomic status, ethnicity, religious beliefs, and sexual orientation, in addition to biological influences (DeLamater and Sill 2005; Hillman 2008). Professional care providers including medical practitioners, nurses, social workers, psychologists and physical therapists are required to understand physiological and psychological factors that may impede the expression of sexuality in order to help older people manage sexual issues (Hillman 2008). Older adults can incorporate negative perceptions towards older people, which might hinder sexual expression in later life. Promoting realistic attitudes, alongside overthrowing ageist perceptions are required in order to enable older people to express their sexuality and sexual identity freely and fully. Open and legitimate discussions regarding sexuality in later life are needed to enable the expression of older adults' sexuality and to promote their sexual health. More robust explorations of ageist myths regarding sexuality in later life including qualitative, implicit and explicit research 
perspectives are required to reach a comprehensive understanding of ageism torowards older adult's sexuality.

\section{References}

Agunbiade, O. M., \& Ayotunde, T. (2015). Ageing, sexuality and enhancement among Yoruba people in south western Nigeria, 1058(November). https://doi.org/10.1080/13691058.2012.6 77861

Alarie, M., \& Carmichael, J. T. (2015). The "cougar" phenomenon: An examination of the factors that influence age-hypogamous sexual relationships among middle-aged women. Journal of Marriage and Family, 77(2005), n/a-n/a. https://doi.org/10.1111/jomf.12213

Allen, K. R., \& Roberto, K. A. (2009). From sexism to sexy: Challenging young adults' ageism about older women's sexuality. Sexuality Research \& Social Policy: A Journal of the NSRC, 6(4), 13-24. https://doi.org/10.1525/srsp.2009.6.4.13

Baldissera, V. D. A., Bueno, S. M. V., \& Hoga, L. A. K. (2012). Improvement of older women's sexuality through emancipatory education. Health Care for Women International, 33(10), 956972. https://doi.org/10.1080/07399332.2012.684986

Bauer, M., Nay, R., \& McAuliffe, L. (2009). Catering to love, sex and intimacy in residential aged care: What information is provided to consumers? Sexuality and Disability, 27(1), 3-9. https:// doi.org/10.1007/s11195-008-9106-8

Bauer, M., McAuliffe, L., Nay, R., \& Chenco, C. (2013). Sexuality in older adults: Effect of an education intervention on attitudes and beliefs of residential aged care staff. Educational Gerontology, 39(2), 82-91. https://doi.org/10.1080/03601277.2012.682953

Bouman, W. P., \& Arcelus, J. (2001). Are psychiatrists guilty of "ageism" when it comes to taking a sexual history? International Journal of Geriatric Psychiatry, 16(1), 27-31. https://doi. org/10.1002/1099-1166(200101)16:1

Bouman, W. P., Arcelus, J., \& Benbow, S. M. (2007). Nottingham study of sexuality and ageing (NoSSA II). Attitudes of care staff regarding sexuality and residents: A study in residential and nursing homes. Sexual and Relationship Therapy, 22(1), 45-61. https://doi. org/10.1080/14681990600637630

Brown, M. T. \& Grossman, B. R. (2014). Same-Sex sexual relationships in the national social life, health and aging project: Making a case for data collection. Journal of Gerontological Social Work, 57(2-4), 108-129.

Clarke, L. H., \& Griffin, M. (2008). Visible and invisible ageing: Beauty work as a response to ageism. Ageing \& Society, 28(5), 653-674. https://doi.org/10.1017/S0144686X07007003

DeLamater, J., \& Koepsel, E. (2015). Relationships and sexual expression in later life: A biopsychosocial perspective. Sexual and Relationship Therapy, 30(1), 37-59. https://doi.org/10.1080 /14681994.2014.939506

DeLamater, J. D., \& Sill, M. (2005). Sexual desire in later life. Journal of Sex Research, 42(2), 138-149. https://doi.org/10.1080/00224490509552267

Dennerstein, L., Randolph, J., Taffe, J., Dudley, E., Burger, H., Dennerstein, L., et al. (2002). Hormones, mood, sexuality, and the menopausal transition. Fertility and Sterility, 77(Suppl 4(4)), S42-S48. https://doi.org/10.1016/S0015-0282(02)03001-7

Dogan, S., Demir, B., Eker, E., \& Karim, S. (2008). Knowledge and attitudes of doctors toward the sexuality of older people in Turkey. International Psychogeriatrics/IPA, 20(5), 1019-1027. https://doi.org/10.1017/S1041610208007229

Elias, J., \& Ryan, A. (2011). A review and commentary on the factors that influence expressions of sexuality by older people in care homes. Journal of Clinical Nursing, 20(11-12), 1668-1676. https://doi.org/10.1111/j.1365-2702.2010.03409.x 
Floyd, M., \& Weiss, L. (2001). Sex and aging: A survey of young adults. Journal of Sex Education and Therapy, 26(2), 133-139. https://doi.org/10.1080/01614576.2001.11074393

Foucault, M. (1981). The history of sexuality, Volume 1: An introduction, (Penguin). Harmondsworth.

Freeman, S., Sousa, S., \& Neufeld, E. (2014). Sexuality in later life: Examining beliefs and perceptions of undergraduate students. Gerontology \& Geriatrics Education, 35(2), 200-213. https:// doi.org/10.1080/02701960.2013.830114

Gay and Gray Project. (2006). Lifting the lid on sexuality and ageing: Report of a research project into the needs, wants, fears and aspirations of older lesbians and gay men. Bournemouth/ Dorset: Help and care development Ltd.

Gewirtz-Meydan, A., \& Ayalon, L. (2017). Physicians' response to sexual dysfunction presented by a younger vs. an older adult. International Journal of Geriatric Psychiatry, 32(12), 1476-1483.

Gilmer, M. J., Meyer, A., Davidson, J., \& Koziol-McLain, J. (2010). Staff beliefs about sexuality in aged residantial care. Nursing Praxis in New Zealand, 26(3), 17-24.

Gledhill, S., \& Schweitzer, R. D. (2014). Sexual desire, erectile dysfunction and the biomedicalization of sex in older heterosexual men. Journal of Advanced Nursing, 70(4), 894-903. https:// doi.org/10.1111/jan.12256

González, C. (2007). Age-graded sexualities: The struggles of our ageing body. Sexuality and Culture, 11(4), 31-47. https://doi.org/10.1007/s12119-007-9011-9

Gott, M. (2005). Sexuality, sexual health and ageing. Berkshire: Open University Press.

Gott, M., \& Hinchliff, S. (2003). Barriers to seeking treatment for sexual problems in primary care: A qualitative study with older people. Family Practice, 20(6), 690-695. https://doi. org/10.1093/fampra/cmg612

Gott, M., Hinchliff, S., \& Galena, E. (2004). General practitioner attitudes to discussing sexual health issues with older people. Social Science and Medicine, 58(11), 2093-2103. https://doi. org/10.1016/j.socscimed.2003.08.025

Haesler, E., Bauer, M., \& Fetherstonhaugh, D. (2016). Sexuality, sexual health and older people: A systematic review of research on the knowledge and attitudes of health professionals. Nurse Education Today, 40, 57-71. https://doi.org/10.1016/j.nedt.2016.02.012

Hafford-Letchfield, T. (2008). What's love got to do with it? Developing supportive practices for the expression of sexuality, sexual identity and the intimacy needs of older people. Journal of Care Services Management, 2(4), 389-405.

Hillman, J. (2008). Sexual issues and aging within the context of work with older adult patients. Professional Psychology: Research and Practice, 39(3), 290-297. https://doi. org/10.1037/0735-7028.39.3.290

Hughes, A. K., \& Wittmann, D. (2015). Aging sexuality: Knowledge and perceptions of preparation among U.S. primary care providers. Journal of Sex \& Marital Therapy, 41(3), 304-313. https://doi.org/10.1080/0092623X.2014.889056

Humphery, S., \& Nazareth, I. (2001). GPs' views on their management of sexual dysfunction. Family Practice, 18(5), 516-518. https://doi.org/10.1093/fampra/18.5.516

Hurd Clarke, L. (2010). Facing age: Women growing older in anti-aging culture. Lanham: Rowman \& Littlefield Publishers.

Hurd Clarke, L., Bennett, E. V., \& Liu, C. (2014). Aging and masculinity: Portrayals in men's magazines. Journal of Aging Studies, 31, 26-33. https://doi.org/10.1016/j.jaging.2014.08.002

International Longevity Centre (2011) Celebrating intergenerational diversity nn evaluation of three projects working with younger and older Lesbian, Gay, Bisexual and Transgender people. http://www.ilcuk.org.uk/files/Report_1.pdf

Katz, S. (2002). Growing older without aging? Positive aging, antiageism, and anti-aging. Generations, 25(4), 27-32.

Katz, S., \& Marshall, B. (2003). New sex for old: Lifestyle, consumerism, and the ethics of aging well. Journal of Aging Studies, 17(1), 3-16. https://doi.org/10.1016/S0890-4065(02)00086-5

Knocker, S. (2012). Perspectives on ageing: Lesbians, gay men and bisexuals. York: Joseph Rowntree Foundation. 
Koch, P. B., Mansfield, P. K., Thurau, D., \& Carey, M. (2005). "Feeling frumpy": The relationships between body image and sexual response changes in midlife women. Journal of Sex Research, 42(3), 215-223. https://doi.org/10.1080/00224490509552276

Kontula, O., \& Haavio-Mannila, E. (2009). The impact of aging on human sexual activity and sexual desire. Journal of Sex Research, 46(1), 46-56. https://doi.org/10.1080/00224490802624414

Lai, Y., \& Hynie, M. (2011). A tale of two standards: An examination of young adults' endorsement of gendered and ageist sexual double standards. Sex Roles, 64(5-6), 360-371. https://doi. org/10.1007/s11199-010-9896-x

Langer-Most, O., \& Langer, N. (2010). Aging and sexuality: How much do gynecologists know and care? Journal of Women \& Aging, 22(4), 283-289. https://doi.org/10.1080/08952841.201 0.518882

Lindau, S. T., Schumm, L. P., Laumann, E. O., Levinson, W., O’Muircheartaigh, C. a., \& Waite, L. J. (2007). A study of sexuality and health among older adults in the united states. New England Journal of Medicine, 357(8), 762-774. https://doi.org/10.1056/NEJMoa067423

Low, J., \& Dupuis-Blanchard, S. (2013). From zoomers to geezerade: Representations of the aging body in ageist and consumerist society. Societies, 3(1), 52-65. https://doi.org/10.3390/ $\operatorname{soc} 3010052$

Maes, C. A., \& Louis, M. (2011). Nurse practitioners' sexual history-taking practices with adults 50 and older. Journal for Nurse Practitioners, 7(3), 216-222. https://doi.org/10.1016/j. nurpra.2010.06.003

Mahieu, L., Van Elssen, K., \& Gastmans, C. (2011). Nurses' perceptions of sexuality in institutionalized elderly: A literature review. International Journal of Nursing Studies, 48(9), 1140-1154. https://doi.org/10.1016/j.ijnurstu.2011.05.013

Mahieu, L., de Casterlé, B. D., Acke, J., Vandermarliere, H., Van Elssen, K., Fieuws, S., \& Gastmans, C. (2016). Nurses' knowledge and attitudes toward aged sexuality in Flemish nursing homes. Nursing Ethics, 23(6), 605-623. https://doi.org/10.1177/0969733015580813

Marshall, B. L. (2011). The graying of "sexual health": A critical research agenda. Canadian Review of Sociology = Revue Canadienne de Sociologie, 48(4), 390-413. https://doi. org/10.1111/j.1755-618X.2011.01270.x

Marshall, B. L. (2012). Medicalization and the refashioning of age-related limits on sexuality. Journal of Sex Research. Marshall, Barbara L.: Department of Sociology, Trent University, 1600 West Bank Drive, Peterborough, ON, Canada, K9J 7B8, bmarshall@ trentu.ca: Taylor \& Francis. https://doi.org/10.1080/00224499.2011.644597

McAuliffe, L., Bauer, M., \& Nay, R. (2007). Barriers to the expression of sexuality in the older person: The role of the health professional. International Journal of Older People Nursing, 2(1), 69-75. https://doi.org/10.1111/j.1748-3743.2007.00050.x

Montemurro, B., \& Siefken, J. M. (2014). Cougars on the prowl? New perceptions of older women's sexuality. Journal of Aging Studies, 28, 35-43. https://doi.org/10.1016/j.jaging.2013.11.004

Mulligan, T., Frick, M. F., Zuraw, Q. C., Stemhagen, A., \& McWhirter, C. (2006). Prevalence of hypogonadism in males aged at least 45 years: The HIM study. International Journal of Clinical Practice, 60(7), 762-769. https://doi.org/10.1111/j.1742-1241.2006.00992.x

Prieler, M. (2012). Gender representation in a Confucian society: South Korean television advertisements. Asian Women, 28(2), 1-26.

Rheaume, C., \& Mitty, E. (2008). Sexuality and intimacy in older adults. Geriatric Nursing, 29(5), 342-349. https://doi.org/10.1016/j.gerinurse.2008.08.004

Roach, S. M. (2004). Sexual behaviour of nursing home residents: Staff perceptions and responses. Journal of Advanced Nursing, 48(4), 371-379. https://doi. org/10.1111/j.1365-2648.2004.03206.x

Sarkadi, A., \& Rosenqvist, U. (2001). Contradictions in the medical encounter: Female sexual dysfunction in primary care contacts. Family Practice, 18(2), 161-166. https://doi.org/10.1093/ fampra/18.2.161

Scherrer, K. S. (2009). Images of sexuality and aging in gerontological literature. Sexuality Research and Social Policy, 6(4), 5-12. https://doi.org/10.1525/srsp.2009.6.4.5 
Shea, J. L. (2011). Older women, marital relationships, and sexuality in China. Ageing International, 36(3), 361-377. https://doi.org/10.1007/s12126-011-9114-3

Snyder, R. J., \& Zweig, R. a. (2010). Medical and psychology students' knowledge and attitudes regarding aging and sexuality. Gerontology \& Geriatrics Education, 31(3), 235-255. https:// doi.org/10.1080/02701960.2010.503132

Steinke, E. E. (1994). Knowledge and attitudes of older adults about sexuality in ageing: A comparison of two studies. Journal of Advanced Nursing, 19(3), 477-485. Retrieved from http:// www.ncbi.nlm.nih.gov/pubmed/8014308

Thompson, A. E., O’Sullivan, L. F., Byers, E. S., \& Shaughnessy, K. (2014). Young adults' implicit and explicit attitudes towards the sexuality of older adults. Canadian Journal on Aging, 33(3), 259-270. https://doi.org/10.1017/S0714980814000208

Vares, T. (2009). Reading the "sexy oldie": Gender, age(ing) and embodiment. Sexualities, 12(4), 503-524. https://doi.org/10.1177/1363460709105716

Villar, F., \& Serrat, R. (2016). Staff attitudes and reactions towards residents' masturbation in Spanish long-term care facilities. Journal of Clinical Nursing, 25, 819-828. https://doi. org/10.1111/jocn.13105

Wada, M., Hurd Clarke, L., \& Rozanova, J. (2015). Constructions of sexuality in later life: Analyses of Canadian magazine and newspaper portrayals of online dating. Journal of Aging Studies, 32, 40-49. https://doi.org/10.1016/j.jaging.2014.12.002

Wentzell, E. (2013). Aging respectably by rejecting medicalization: Mexican men's reasons for not using erectile dysfunction drugs. Medical Anthropology Quarterly, 27(1), 3-22. https://doi. org/10.1111/maq.12013

World Health Organization. (2006). Defining sexual health: Report of a technical consultation on sexual health 28-31 January 2002. Geneva: World Health Organization.

Williams, A., Wadleigh, P. M., \& Ylänne, V. (2010). Images of older people in UK magazine advertising: Toward a typology. International Journal of Aging \& Human Development, 71(2), 83-114. https://doi.org/10.2190/AG.71.2.a

Willis, P., Hafford-Letchfield, P., \& Smith, A. (2016). In the margins or the mainstream? Future directions and innovations in providing inclusive accommodation and support for older LGBTI adults. Quality in Ageing and Older Adults, 17(1), 1-5.

Woloski-Wruble, A. C., Oliel, Y., Leefsma, M., \& Hochner-Celnikier, D. (2010). Sexual activities, sexual and life satisfaction, and successful aging in women. Journal of Sexual Medicine, 7, 2401-2410. https://doi.org/10.1111/j.1743-6109.2010.01747.x

Open Access This chapter is licensed under the terms of the Creative Commons Attribution 4.0 International License (http://creativecommons.org/licenses/by/4.0/), which permits use, sharing, adaptation, distribution and reproduction in any medium or format, as long as you give appropriate credit to the original author(s) and the source, provide a link to the Creative Commons license and indicate if changes were made.

The images or other third party material in this chapter are included in the chapter's Creative Commons license, unless indicated otherwise in a credit line to the material. If material is not included in the chapter's Creative Commons license and your intended use is not permitted by statutory regulation or exceeds the permitted use, you will need to obtain permission directly from the copyright holder.

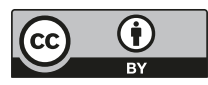




\title{
Chapter 11 \\ Visual Ageism in the Media
}

\author{
Eugène Loos and Loredana Ivan
}

\subsection{Introduction}

Since the introduction of the term "ageism" in the literature by Butler (1969), the number of studies documenting the process of systematic stereotyping and discrimination against people because they are old, and analysing the way these stereotypes are shared in the population and how they persist over time (Nelson 2004; Palmore 2001), has continued to expand. In this chapter, we analyse representations of older people in the visual media-print advertisements, television advertisements, and television programs. We examine whether older people are represented as third agers, who are active, enjoy life, and who maintain a healthy life style, which are all part of the successful ageing discourse (Rowe and Kahn 2015), or as fourth agers, who are inactive and unable to live independently. We assess empirical evidence that suggests a shift away from negative representations of older adults in visual media towards more positive representations, and illustrate the way in which this change has occurred in advertisements and television programs.

Previous media studies research has mainly focused on the frequency with which women and various minority groups are characterized in television content and advertisements. In media research, ageism, like other forms of stereotype, is seen as "a coherent set of shared ideas and beliefs that constitutes a particular justification of the interests of dominant groups: the state, employers, hospitals, media" (Bytheway 1994, p. 130). Albeit not explicitly, media studies have approached ageism as an asymmetric power structure based on age, a constructed justification of

\footnotetext{
E. Loos $(\bowtie)$

Utrecht School of Governance, Utrecht University, Utrecht, The Netherlands

e-mail: e.f.loos@uu.nl
}

L. Ivan

National University of Political Studies and Public Administration, Bucharest, Romania

e-mail: loredana.ivan@communicare.ro

L. Ayalon, C. Tesch-Römer (eds.), Contemporary Perspectives on Ageism, 
inequalities between age groups (Angus and Reeve 2006), by focusing on groups that are systematically under- or misrepresented in the media. They criticize the negative representation of older adults in the media, including the fact that they are often only given minor or peripheral roles and that they are portrayed with no positive attributes, and argue in favour of more positive, more realistic and nuanced representation, in which the portrayals of older adults more accurately reflect the characteristics of the audience.

Media content, including visual media, is a continuous reflection of societal practices. It influences everyday interactions, including the way we relate to older people, as well as the way we see ourselves as "being old." Media representations offer a means to examine the logic according to which the social construction of ageing is made and maintained (Minichiello et al. 2000). However, media studies are often criticized for the overuse of content analysis as a method, the lack of theoretical discussion (Seiter 1986), and the fact that they focus on the sender and neglect the receiver in the communication process. To address some of these issues, ageism researchers have started to document the frequency of stereotypic representations from a communicative perspective, regarding aging as an interactive process between society and the individual (Nussbaum and Coupland 2004).

We coined the term "visual ageism" to describe the social practice of visually underrepresenting older people or misrepresenting them in a prejudiced way. We believe that this concept could be useful in researching the way older people are presented in visual media content (see also Nelson 2004). Visual ageism includes older adults being depicted in peripheral or minor roles without positive attributes; non-realistic, exaggerated, or distorted portraits of older people; and over-homogenized characterizations of older adults. At the end of this chapter, we discuss an alternative to reduce visual ageism: the "design for diversity" approach.

\subsection{Why Visual Ageism in the Media Matters}

Empirical studies conducted by Roy and Harwood (1997) and Walker (2012) showed that in print advertisements, television advertisements, and television programs, older adults are sometimes depicted as posing a financial burden on society. Atkins et al. (1990), Roy and Harwood (1997), Simcock and Lynn (2006), and Van Selm et al. (2007) showed that older people were often underrepresented in television programs, relative to the percentage of older people in the population. According to Ylänne (2015, p. 370), "under-representation has been found to be particularly pertinent in relation to people over 65." An explanation could be that companies feared that the image of their products and services would suffer if they were associated with the idea of being old. The portrayals of certain social groups in society, as well as the type of characteristics depicted in those portrayals, matter in societies that value social justice and power balance. These representations, visual and otherwise, can reinforce stereotypes and play a role in stereotype formation. Encountering such stereotypes in the media can negatively impact the self-esteem, health status, 
physical wellbeing, and cognitive performance of older people (Levy et al. 2002a, b). As Williams et al. (2009) found, "groups that appear more often in the media are more 'vital' and enjoy better status and power in daily life" (p. 818). Taking this into account, we agree with Lester and Ross (2003) that "pictures can injure." The act of visually underrepresenting older people in the media or representing them in a stigmatized way is not harmless, as it not only reflects societal practices, but also produces meaning about these practices (Hall et al. 2013).

\subsection{Changes of Visual Ageism in the Media}

To gain insight into the under- and misrepresentation of older people in our society, we reviewed empirical studies that focused on images of older people in print and television advertisements and television programs. Some authors, such as Ylänne (2015), have found a steady increase in visibility of older people in the media and a switch towards more positive portrayals. As Cole (1992) noted, "during the 1970s, an emerging consensus among health professionals, social workers, and researchers insisted on a view that was the mirror opposite of ageism: Older people are (or should be) healthy, sexually active, engaged, productive and self-reliant" (p. 229). We examined studies conducted in Europe and North America since 1950 to explore empirical support for this change in visual ageism in print and television advertisements and television programs.

In order to explore changes in visual ageism in the media in detail, we asked the following research questions:

1. Do changes in the visual representation of older adults in the media relate only to younger-old (third age) adults, or are older-old (fourth age) adults also represented?

2. Are changes in the representation of older adults evident only in the attributes of depictions of older adults, or are they also evident in the roles in which older adults are depicted?

3. Are these changes in visual ageism consistent with successful aging discourse?

To answer these research questions, we present a narrative literature review (see Green 2006) of empirical studies that analysed the visual representations of older people in print and television advertisements and in television programs. We took the systematic review of television advertising by Zhang et al. (2006) and a study by Ylänne (2015) on representations of ageing in the media as starting points, using key references to lead to other empirical studies (see Ridley 2012). We selected only empirical studies conducted in Europe and North America because (a) most empirical studies of the representation of older people in the visual media in the past 40 years have been conducted in these socio-cultural contexts; (b) the abovementioned changes over time in the way older people are represented in the media refer specifically to Europe and North America; and (c) successful ageing discourse is particularly dominant in the West (Kendig 2004). 
Table 11.1 illustrates the literature on changes in visual ageism over time. We looked at the presence of negative versus positive visual representations over time in terms of roles (peripheral, incidental, or minor roles; major/leading roles; other roles, such as advisory roles) and in terms of attributes (positive, negative, exaggerated). Table 11.1 also shows whether each study differentiated between the youngerold and older-old, and whether the characteristics used to portray older people match the successful ageing discourse, in which older people are active, enjoy life, and maintain a healthy lifestyle (third age: younger old), or whether they are depicted as passive, dependent, and withdrawn from personal responsibility (fourth age: older old).

Table 11.1 shows that older people were underrepresented in television and print advertisements until the 1990s, when older people started to become more visible, first in television and print advertisements and around 2001 also in television programs.

These findings are in line with Vickers (2007) and Ylänne (2015). One possible explanation for this trend could be that at a certain point older people were spotted by marketing strategists as potential consumers (Loos and Ekström 2014), which is part of the successful ageing discourse we explore below.

Since the 1990s, older people, particularly the younger-old, have increasingly been depicted as having positive attributes (see Table 11.1). The older-old age group has continued to be underrepresented in programs and advertisements and to be portrayed with fewer positive attributes than younger people. In the last 15 years, there has been a shift toward another kind of representation, that of younger older people having the positive attributes-consonant with successful ageing discourse - of being active, enjoying life, and maintaining a healthy life style. The data presented in Table 11.1 show that the change in the way older people are represented relates solely to their attributes and not to their social roles, as they continue to be depicted in minor, peripheral, and incidental roles. We found only one empirical study (Kessler et al. 2010) in which the proportion of older people portrayed in major roles was higher than in other age groups, and these findings only described the younger-old group. Kessler et al. (2010) also noted the underrepresentation of the older-old in the television programs they analysed.

The literature shows that the changes in visual ageism are consistent with successful ageing discourse, in which especially the younger-old are depicted positively as being active, healthy, and independent. In an appeal to our pursuit of everlasting youth, the advertising industry uses images invoking eternal youth, with marketers depicting older adults as a wealthy and healthy target group (Loos and Ekström 2014). The problem of our mortality is "solved" by the concept of the third age, a long period of wellbeing, which precedes the fourth age, a short, painful descent into decay (Laslett 1991; Loos 2013). It comes as no surprise that our desire to remain forever young should be commercially exploited; the narrative of eternal youth has deep historical roots and taps into the universal yearning to live a long and healthy life (Loos 2013). 
Table 11.1 Changes in visual ageism by media type and time period

\begin{tabular}{|c|c|c|c|c|c|c|}
\hline $\begin{array}{l}\text { Author/ } \\
\text { Year }\end{array}$ & $\begin{array}{l}\text { Media } \\
\text { type }^{\mathrm{a}}\end{array}$ & Country & $\begin{array}{l}\text { Time } \\
\text { period }\end{array}$ & $\begin{array}{l}\text { Representations of } \\
\text { older people }\end{array}$ & $\begin{array}{l}\text { Age } \\
\text { of the } \\
\text { sample }\end{array}$ & $\begin{array}{l}\text { Differences } \\
\text { between younger- } \\
\text { old and older-old }^{\text {b }}\end{array}$ \\
\hline \multicolumn{7}{|c|}{ Television advertisements } \\
\hline $\begin{array}{l}\text { Miller } \\
\text { et al. } \\
(2002)\end{array}$ & TA & USA & $\begin{array}{l}1950- \\
1990\end{array}$ & $\begin{array}{l}\text { Increasing trend in } \\
\text { positive attributes } \\
\text { from 1950-1990 }\end{array}$ & $\begin{array}{l}60-74 \\
75+\end{array}$ & $\begin{array}{l}\text { Older-old } \\
\text { represented in a } \\
\text { less positive way } \\
\text { than younger-old }\end{array}$ \\
\hline $\begin{array}{l}\text { Hiemstra } \\
\text { et al. } \\
(1983)\end{array}$ & TA & USA & 1981 & $\begin{array}{l}\text { Underrepresented; } \\
\text { peripheral roles }\end{array}$ & $\begin{array}{l}50-59 \\
60+\end{array}$ & $\begin{array}{l}\text { Older-old } \\
\text { underrepresented } \\
\text { for some categories } \\
\text { of products (food, } \\
\text { health, recreation, } \\
\text { services) }\end{array}$ \\
\hline $\begin{array}{l}\text { Swayne } \\
\text { and } \\
\text { Greco } \\
(1987)\end{array}$ & TA & USA & 1987 & $\begin{array}{l}\text { Underrepresented; } \\
\text { peripheral roles; } \\
\text { advisor roles }\end{array}$ & $65+$ & $\begin{array}{l}\text { Older-old } \\
\text { underrepresented } \\
\text { for some categories } \\
\text { of products (food, } \\
\text { services) }\end{array}$ \\
\hline $\begin{array}{l}\text { Atkins } \\
\text { et al. } \\
(1990)\end{array}$ & TA & USA & 1990 & $\begin{array}{l}\text { Underrepresented; } \\
\text { peripheral roles }\end{array}$ & $50+$ & NS \\
\hline $\begin{array}{l}\text { Peterson } \\
\text { and Ross } \\
(1997)\end{array}$ & TA & USA & 1991 & $\begin{array}{l}\text { Underrepresented; } \\
\text { less favourably } \\
\text { portrayed (fewer } \\
\text { positive attributes } \\
\text { than younger } \\
\text { people) }\end{array}$ & $\begin{array}{l}45-64 \\
65+\end{array}$ & $\begin{array}{l}\text { Older-old } \\
\text { underrepresented; } \\
\text { less favourable } \\
\text { attributes } \\
\text { (significant } \\
\text { differences) } \\
\end{array}$ \\
\hline $\begin{array}{l}\text { Roy and } \\
\text { Harwood } \\
(1997)\end{array}$ & TA & USA & 1994 & $\begin{array}{l}\text { Positive attributes } \\
\text { (3rd age) - food, } \\
\text { retail and health/ } \\
\text { beauty }\end{array}$ & $50+$ & $\begin{array}{l}\text { Older-old } \\
\text { underrepresented } \\
\text { (food, retail and } \\
\text { health/beauty) }\end{array}$ \\
\hline $\begin{array}{l}\text { Van Selm } \\
\text { et al. } \\
(2007)\end{array}$ & TA & Netherlands & $\begin{array}{l}2003 \\
\text { compared } \\
\text { to } \\
1990- \\
1994\end{array}$ & $\begin{array}{l}\text { More positive } \\
\text { attributes (3rd age); } \\
\text { more diverse } \\
\text { attributes; } \\
\text { underrepresented }\end{array}$ & NS & NS \\
\hline $\begin{array}{l}\text { Lee et al. } \\
(2007)\end{array}$ & TA & USA & 2003 & $\begin{array}{l}\text { Positive attributes } \\
\text { (3rd age); minor } \\
\text { roles }\end{array}$ & $55+$ & NS \\
\hline $\begin{array}{l}\text { Simcock } \\
\text { and Lynn } \\
(2006)\end{array}$ & TA & UK & $2004 / 2005$ & $\begin{array}{l}\text { Positive attributes } \\
\text { (3rd age); } \\
\text { underrepresented in } \\
\text { major roles }\end{array}$ & $50+$ & $\begin{array}{l}\text { Older-old } \\
\text { underrepresented } \\
\text { (food, retail, } \\
\text { holiday/leisure, } \\
\text { insurance/ } \\
\text { financial) }\end{array}$ \\
\hline
\end{tabular}


Table 11.1 (continued)

\begin{tabular}{l|l|l|l|l|l|l}
\hline $\begin{array}{l}\text { Author/ } \\
\text { Year }\end{array}$ & $\begin{array}{l}\text { Media } \\
\text { type }\end{array}$ & Country & $\begin{array}{l}\text { Time } \\
\text { period }\end{array}$ & $\begin{array}{l}\text { Representations of } \\
\text { older people }\end{array}$ & $\begin{array}{l}\text { Age } \\
\text { of the } \\
\text { sample }\end{array}$ & $\begin{array}{l}\text { Differences } \\
\text { between younger- } \\
\text { old and older-old }\end{array}$ \\
\hline $\begin{array}{l}\text { Kessler } \\
\text { et al. } \\
(2010)\end{array}$ & TA & Germany & 2005 & $\begin{array}{l}\text { Positive attributes } \\
\text { (3rd age); more } \\
\text { present in major } \\
\text { roles }\end{array}$ & $60+$ & $\begin{array}{l}\text { Older-old } \\
\text { underrepresented }\end{array}$ \\
\hline
\end{tabular}

Print advertisements

\begin{tabular}{|c|c|c|c|c|c|c|}
\hline $\begin{array}{l}\text { Ursic } \\
\text { et al. } \\
(1986)\end{array}$ & PA & USA & $\begin{array}{l}1950- \\
1980\end{array}$ & $\begin{array}{l}\text { Overall increase in } \\
\text { frequency of } \\
\text { representations, but } \\
\text { non-significant } \\
\text { roles }\end{array}$ & NS & NS \\
\hline $\begin{array}{l}\text { Miller } \\
\text { et al. } \\
1999\end{array}$ & PA & USA & $\begin{array}{l}1956- \\
1996\end{array}$ & Negative attributes & $\begin{array}{l}55-64 \\
65-74 \\
75+\end{array}$ & $\begin{array}{l}\text { Older-old; fewer } \\
\text { positive attributes } \\
\text { (significant } \\
\text { differences) }\end{array}$ \\
\hline $\begin{array}{l}\text { Lohmann } \\
\text { (1997) }\end{array}$ & $\mathrm{PA}^{\mathrm{c}}$ & Germany & $\begin{array}{l}1989- \\
1991\end{array}$ & Negative attributes & NS & NS \\
\hline $\begin{array}{l}\text { Lohmann } \\
\text { (1997) }\end{array}$ & $\mathrm{PA}^{\mathrm{d}}$ & Germany & 1990 & $\begin{array}{l}\text { Underrepresented; } \\
\text { unrealistic portraits } \\
\text { (exaggeration) }\end{array}$ & NS & NS \\
\hline $\begin{array}{l}\text { Lohmann } \\
\text { (1997) }\end{array}$ & PA & USA & $\begin{array}{l}1989- \\
1991\end{array}$ & Positive attributes & NS & NS \\
\hline $\begin{array}{l}\text { Williams } \\
\text { et al. } \\
(2007) \\
\end{array}$ & PA & UK & $\begin{array}{l}1996- \\
2003\end{array}$ & $\begin{array}{l}\text { More positive } \\
\text { attributes as time } \\
\text { progresses }\end{array}$ & NS & NS \\
\hline $\begin{array}{l}\text { Williams } \\
\text { et al. } \\
\text { (2010) }\end{array}$ & PA & UK & $\begin{array}{l}1999- \\
2004\end{array}$ & $\begin{array}{l}\text { Positive attributes } \\
\text { (3rd age) }\end{array}$ & $60+$ & NS \\
\hline $\begin{array}{l}\text { Ylänne } \\
\text { et al. } \\
(2009) \\
\end{array}$ & PA & UK & $\begin{array}{l}1999- \\
2004\end{array}$ & $\begin{array}{l}\text { Positive attributes } \\
\text { (3rd age) }\end{array}$ & $60+$ & NS \\
\hline $\begin{array}{l}\text { Coupland } \\
\text { (2007) }\end{array}$ & $\mathrm{PA}^{\mathrm{e}}$ & UK & $\begin{array}{l}2004- \\
2005\end{array}$ & $\begin{array}{l}\text { Positive attributes } \\
\text { (3rd age) }\end{array}$ & $50+$ & NS \\
\hline
\end{tabular}

\begin{tabular}{l|l|l|l|l|l|l}
\hline \multicolumn{2}{l}{ Television programs } & & NS \\
\hline $\begin{array}{l}\text { Aronoff } \\
(1974)\end{array}$ & TP & USA & $\begin{array}{l}1969- \\
1971\end{array}$ & Negative attributes & NS & NS \\
\hline $\begin{array}{l}\text { Bosch } \\
(1990)\end{array}$ & TP & Germany & 1982 & $\begin{array}{l}\text { Underrepresented; } \\
\text { peripheral roles; } \\
\text { when present- } \\
\text { active, healthy }\end{array}$ & NS & NS \\
\hline $\begin{array}{l}\text { Vernon } \\
\text { et al. } \\
(1990)\end{array}$ & TP & USA & $1987 / 1988$ & $\begin{array}{l}\text { Underrepresented: } \\
\text { ather positive } \\
\text { attributes }\end{array}$ & & \\
\hline
\end{tabular}


Table 11.1 (continued)

\begin{tabular}{l|l|l|l|l|l|l}
\hline $\begin{array}{l}\text { Author/ } \\
\text { Year }\end{array}$ & $\begin{array}{l}\text { Media } \\
\text { type }\end{array}$ & Country & $\begin{array}{l}\text { Time } \\
\text { period }\end{array}$ & $\begin{array}{l}\text { Representations of } \\
\text { older people }\end{array}$ & $\begin{array}{l}\text { Age } \\
\text { of the } \\
\text { sample }\end{array}$ & $\begin{array}{l}\text { Differences } \\
\text { between younger- } \\
\text { old and older-old }\end{array}$ \\
\hline $\begin{array}{l}\text { Harwood } \\
\text { and } \\
\begin{array}{l}\text { Anderson } \\
(2002)\end{array}\end{array}$ & TP & USA & 1999 & $\begin{array}{l}\text { Negative attributes; } \\
\text { peripheral roles }\end{array}$ & $60+$ & NS \\
\hline $\begin{array}{l}\text { Kessler } \\
\text { et al. } \\
(2004)\end{array}$ & TP & Germany & 2001 & $\begin{array}{l}\text { Positive attributes } \\
\text { (3rd age) }\end{array}$ & $60+$ & $\begin{array}{l}\text { Older-old } \\
\text { underrepresented }\end{array}$ \\
\hline
\end{tabular}

${ }^{\mathrm{a}} T A$ Television Advertisements, $P A$ Print Advertisements, $T P$ Television Programs; ${ }^{\mathrm{b}} N S$ not specified; 'Magazines; ${ }^{\mathrm{d} P o p u l a r}$ illustrated magazines; ${ }^{\mathrm{e}}$ Study includes print advertisements and magazines

\subsection{New Visual Ageism in the Media: The Trend Towards a Positive Representation of Older People}

The trend towards a positive representation of older people in visual media is embedded in a larger discourse of successful ageing (e.g., Rowe and Kahn 1997; Ylänne 2015) and active ageing (e.g., WHO 2014). This discourse empowers older people to live as healthily as possible, and focuses on the quality of the ageing experience, described by Rowe and Kahn (1997) as "the avoidance of disease and disability, the maintenance of high physical and cognitive function, and sustained engagement in social and productive activities" (p. 433). The positive consequences of this discourse could include adopting an active lifestyle, maintaining functional health, and enhancing capacities, such as individual responsibility and civic engagement, which could lead to a reduction of older people's dependability on public system provision (Neilson 2006). On the other hand, the possible negative consequences of this discourse, including the marginalization of the ageing process and the societal exclusion of the older-old, especially those who are no longer able to enjoy so-called successful ageing, are also being debated in the literature today (e.g., Cole 1992; Neilson 2006; Rozanova 2010; Ylänne 2012).

Katz and Calasanti (2015) state that the dominant successful ageing discourse poses at least two negative consequences for the ageing process, which are reflected in the imagery used in the media. Successful ageing is associated with individual choices in terms of lifestyle and the level of empowerment: success or failure is seen as the responsibility of the individual and something which an individual is able to control. In fact, the lifestyle of an individual is rarely a matter of volition, but an issue of economic opportunities and constraints, of power and inequalities in access to resources (Rozanova 2010). Once we categorize older people as "winners" or "losers", the social and structural factors involved in people's "choices" to age successfully are ignored. Older people in the so-called fourth age in particular are not able to meet the obligations imposed on them by the dominant successful ageing 
discourse (Loos 2013). As Rozanova (2010) argues, successful ageing is problematic "in prescribing how older adults should age, rather than seeking to understand and to describe how different people make meaning of their lives as they age" (p. 213).

Successful ageing discourse can be seen as having been produced by a consumerist approach, a marketing manoeuvre to make senior consumers treat ageing as a controllable disease, rather than as a natural, universal process (Vincent et al. 2008). Trying to eliminate the signs of ageing and to deny the natural process of ageing can be seen to stem from a fear of the signs of the ageing process, because these signs act as reminders of our mortality (Martens et al. 2004, 2005). Consumers have only two options: to continually attempt to control age-related "problems" or to refuse to incorporate consumerist choices in their life as part of their wellbeing (Ylänne et al. 2009). The anti-ageing trend can be seen as the expression of a marketing discourse to consumers to take responsibility for their wellbeing, for control of their bodies, and to avoid social exclusion (Vincent et al. 2008).

Our review of empirical studies showed that although the past decades have seen a gradual increase in the presence of older people in the visual media, ageism is still prevalent. In the past, ageism in the visual media was characterized by negative attributes Aronoff 1974), such as being "ineffective, unattractive and unhappy" (Vickers 2007, p. 101), "senile, stupid, ugly, unskilled, unproductive, unhealthy, badly dressed, sedentary, and inactive" (Rozanova 2010, p. 214), and "frail, lonely, dependent and technologically illiterate" (Joyce et al. 2015). Visual ageism has changed and older people in today's society are depicted as having positive attributes, such as being "healthy, sexually active, engaged, productive and self-reliant" (Cole 1992, p. 229); or "healthy, vigorous, productive, attractive and smart" (Rozanova 2010, p. 214). Still, as our empirical work shows, not much has changed in the roles assigned to older people-they still tend to be visually represented in minor, peripheral, or incidental roles - or in the way older-old adults are visually represented, namely, as possessing fewer positive attributes than the younger-old group.

It is also important to remember that what might be considered "positive" attributes in the depiction of old age could in fact be a normative construction which has nothing to do with the real experience of older people in everyday life (e.g., Katz and Calasanti 2015). As Ylänne (2015) states: "In particular, what might be considered 'positive' portrayals can turn out to be more ambiguous in their construction of older age than might at first appear to be the case" (p. 369).

The point we would like to make is that this portrayal of positive attributes of older people in our society could also have an ageist dimension. As Giddens (1984) states: "The structural properties of social systems are both medium and outcome of the practices they recursively organize" (p. 25). New visual ageism in the media means that, on the one hand, positive attributes associated with older people as part of the successful ageing discourse encourage them to live as healthily as possible. On the other hand, this can act as an enabling constraint, suggesting that good health in later life is fully the choice and responsibility of the individual, and that older people who fail to age successfully are somehow themselves to blame (Katz 2009). 
We are facing a shift from visual ageism characterized by underrepresentation and the negative representation of older people to a representation of older age characterized by images of stereotypically third age older adults, in incidental roles, enjoying life and living their golden years, while older adults in their fourth age remain invisible.

\subsection{Designing for Dynamic Diversity: An Alternative to Visual Ageism}

One could ask whether it is possible to visually represent older people in a nonageist way. In our opinion, pictures are never neutral, as signifying practices cause each of us to consume them in our own way (Hodge and Kress 1988; Hall et al. 2013). The prejudicial effects of stereotyped visual imagery injure and exclude, and should therefore be avoided (Lester and Ross 2003). Several recommendations for reducing visual ageism have been formulated since the 1980s. For example, Hiemstra et al. (1983) suggested that educators play a role as social interventionists and agents of change by teaching people to correct misleading and exaggerated images, both on the side of the marketers and of the consumers. As our review of empirical studies revealed, though, visual ageism is still prevalent today. Richards et al. (2012) referred to the Madrid International Plan of Action on Ageing, which "identified as one of its objectives the need to facilitate contributions of older women and men to the presentation by the media of their activities and concerns" (United Nations 2002, p. 45) and underlined how important it is to create expectations in both younger and older people about ageing and old age. They pointed to the New Dynamics of Ageing initiative, "Representing Self—Representing Ageing", ${ }^{1}$ which argues that "new sets of images need to be presented to the media" that counteract current ageist preoccupations and instead reflect the "contributions, strengths, and resourcefulness" of older women (United Nations 2002, p. 44). ${ }^{2}$

Vickers (2007) suggested that an increase in the visibility of older people in society would foster more respect and a better understanding of old age. She expressed the hope that visibility advocacy groups succeed in changing our attitudes towards aging: "Perhaps one day we will turn on the television and see a commercial for an aging cream that brings out the best in your wrinkles rather than trying to hide them, while sending a message that older people are alive, active, and living well" (p. 104). In 2007, personal care products brand Dove did just that, by launching Pro Age as part of their Campaign for Real Beauty. ${ }^{3}$ It featured several women

\footnotetext{
${ }^{1}$ http://www.representing-ageing.com/

${ }^{2} \mathrm{http} / / / \mathrm{www} . u n . o r g / e n /$ development/devagenda/ageing.shtml

${ }^{3}$ See https://www.google.nl/search?q=dove+campaign+older+people\&rls=com.microsoft:enUS:IE-Address\&tbm $=i s c h \&$ tbo $=u \&$ source $=$ univ $\& s a=X \& v e d=0$ ahUKEwjYk8bi2p3MAhVCD 8 AKHaNnCW0QsAQIHw\&biw=1920\&bih=986
} 
in their 50s and 60s. The campaign captured the imagination of baby boomer women around the world. The campaign presented images of women who were not professional models, literally laying bare their age spots, grey hair, and curves, and demonstrating that women are beautiful at all ages. ${ }^{4,5}$ Despite critical remarks from Johnston and Taylor (2008, p. 962), who said that "although broadly accessible, Dove's critique of beauty ideology is diluted by its contradictory imperative to promote self-acceptance and at the same time increase sales by promoting women's consumption of products that encourage conformity to feminine beauty ideology" (p. 962), in our opinion, this is one of the rare efforts to visually depict older people in a non-ageist way (see also Brossoie 2010 on the societal resonance and success of this campaign).

Other campaigns, such as those of Specsavers in $2013^{6}$ and Swiss Life in 2016, have tried to do the same. In the Specsavers advertisement an older couple thankfully sinks down onto what they think is a bench in a park, but which turns out to be the seat of a roller coaster. The commercial concludes with a voice-over saying, "Should've gone to Specsavers". The Swiss Life campaign also makes use of humour to sell insurance and provide financial advice to older people. In one commercial, an older man is ably competing with a much younger man at the gym. Unlike the Dove Pro Age Campaign, however, the Specsavers campaign pokes fun at older people (their poor eyesight causes them to sit on the wrong bench) and the Swiss Life campaign humorously exaggerates the older person's ability to perform as well as his younger counterpart.

Both the Specsavers campaign and the Swiss Life campaign reinforce positive characteristics, in the sense that they depict older people as active, but their depictions are more in keeping with what we consider to be ageist third age representations. Our review of empirical studies clearly revealed that visual ageism remains a challenge. These days, visual ageism in the media tends to come wrapped in the guise of the positive attributes of third age representations of older people, while adults in their fourth age continue to be underrepresented. One possible explanation for this is that healthy third agers might prefer not to be associated with fourth agers, as they remind them too starkly of what lies ahead in their own near future. Although this discomfort or even fear about mortality is undeniably common, from a societal point of view this kind of (self-)ageism is hurtful to fourth agers as a group and in a sense to third agers as well, as they risk to become fourth agers themselves one day.

Based on the insights of this chapter, we suggest that one way to address visual ageism is to "design for dynamic diversity", an approach originally developed by Gregor et al. (2002) as a method to create interface designs for older people having "significantly different and dynamically changing needs". Applied to the visual representation of older people in the media, this implies the use of a multiplicity of images and more nuanced imagery to combat the over-homogeneity of

\footnotetext{
${ }^{4}$ See http://advertisingforadults.com/2007/02/dove-pro-age-women/

${ }^{5}$ See https://www.youtube.com/watch?v=vilUhBhNnQc

${ }^{6}$ See https://www.youtube.com/watch?v=K_nM0y9Hryw

${ }^{7}$ See http://creativity-online.com/work/swiss-life-retirement-trainees/45228
} 
representations of older adults (see also Loos 2013). The Dove Pro Age campaign is a good illustration of this approach that could be a fruitful way to reduce visual ageism in an ever more ageing society.

\section{References}

Andrews, M. (2009). The narrative complexity of successful aging. International Journal of Sociology and Social Policy - Special Issue on Theorising Aging Studies, 29(1-2), 73-83. https://doi.org/10.1108/01443330910934736

Angus, J., \& Reeve, P. (2006). Ageism: A threat to "aging well" in the 21st century. Journal of Applied Gerontology, 25(2), 137-152. https://doi.org/10.1177/0733464805285745

Aronoff, C. (1974). Old age in prime time. Journal of Communication, 24(4), 86-87. https://doi. org/10.1111/j.1460-2466.1974.tb00412.x

Atkins, T., Jenkins, M. C., \& Perkins, M. H. (1990). Portrayal of persons in television commercials age 50 and older. Psychology: A Journal of Human Behaviour, 27(4), 30-37.

Bergman, Y. S., \& Bodner, E. (2015). Ageist attitudes block young adults' ability for compassion toward incapacitated older adults. International Psychogeriatrics, 27(9), 1541-1550. https:// doi.org/10.1017/S1041610215000198

Bosch, E.-M. (1990). Altersbilder in den Bundesdeutschen Medien. In G. A. Straka, T. Fabian, \& J. Will (Eds.), Aktiver Mediennutzung im Alter. Modelle und Erfahrungen aus der Medienarbeit mit älteren Menschen (pp. 77-91). Heidelberg: Asanger.

Brossoie, N. (2010). Social Gerontology. In R. H. Robnett \& W. C. Chop (Eds.), Gerontology for the health care professional (pp. 19-51). New York: Jones \& Bartlett Publishers.

Butler, R. (1969). Age-ism: Another form of bigotry. The Gerontologist, 9, 243-246. https://doi. org/10.1093/geront/9.4_Part_1.243

Bytheway, B. (1994). Ageism. London: McGraw-Hill Education.

Calasanti, T., Sorensen, A., \& King, N. (2012). Anti-ageing advertisements and perceptions of ageing. In V. Ylänne (Ed.), Representing Ageing (pp. 19-35). London: Palgrave Macmillan.

Cole, T. R. (1992). The journey of life: A cultural history of aging in America. Cambridge: CUP.

Coupland, J. (2007). Gendered discourses on the 'problem'of ageing: Consumerized solutions. Discourse \& Communication, 1(1), 37-61.

Giddens, A. (1984). The constitution of society: Outline of the theory of structuration. Cambridge: Polity Press.

Green, B. N. (2006). Writing narrative literature reviews for peer-reviewed journals: Secrets of the trade. Journal of Chiropractic medicine, 5(3), 101-117.

Gregor, P., Newell, A. F., \& Zajicek, M. (2002, July). Designing for dynamic diversity: Interfaces for older people. In Proceedings of the fifth international ACM conference on assistive technologies (pp. 151-156). New York: ACM.

Gullette, M. M. (2004). Aged by culture. Chicago: University of Chicago Press.

Hall, S., Evans, H., \& Nixon, S. (Eds.). (2013). Representation: Cultural representations and signifying practices. Thousand Oaks: Sage.

Harwood, J., \& Anderson, K. (2002). The presence and portrayal of social groups on prime-time television. Communication Reports, 15(2), 81-89. https://doi.org/10.1080/08934210209367756

Hiemstra, R., Goodman, M., Middlemiss, M. A., Vosco, R., \& Ziegler, N. (1983). How older persons are portrayed in television advertising: Implications for educators. Educational Gerontology: An International Quarterly, 9(2-3), 111-122. https://doi.org/10.1080/0380127830090202

Hodge, R., \& Kress, G. (1988). Social semiotics. Ithaca/New York: Cornell University Press.

Johnston, J., \& Taylor, J. (2008). Feminist consumerism and fat activists: A comparative study of grassroots activism and the Dove real beauty campaign. Signs, 33(4), 941-966. https://doi. org/10.1086/528849 
Joyce, K., Loe, M., \& Diamond-Brown, L. (2015). Science, technology an ageing. In J. Twigg \& W. Martin (Eds.), Routledge handbook of cultural gerontology (pp. 157-164). London: Routledge.

Katz, S. (2009). Cultural aging: Life course, lifestyle, and senior worlds. Toronto: University of Toronto Press.

Katz, S., \& Calasanti, T. (2015). Critical perspectives on successful aging: Does it "appeal more than it illuminates"? The Gerontologist - Special Issue: Successful Ageing, 55(1), 2-8. https:// doi.org/10.1093/geront/gnu027

Kendig, H. (2004). The social sciences and successful aging: Issues for Asia-Oceania. Geriatrics \& Gerontology International, 4, s1-s6.

Kessler, E. M., Rakoczy, K., \& Staudinger, U. M. (2004). The portrayal of older people in prime time television series: The match with gerontological evidence. Ageing and Society, 24(04), 531-552.

Kessler, E. M., Schwender, C., \& Bowen, C. E. (2010). The portrayal of older people's social participation on German prime-time TV advertisements. The Journals of Gerontology Series B: Psychological Sciences and Social Sciences, 65B(1), 97-106. https://doi.org/10.1093/geronb/ gbp084

Laslett, P. (1991). A fresh map of life. The emergence of the third age. Cambridge, MA: Harvard University Press.

Lee, M. M., Carpenter, B., \& Meyers, L. S. (2007). Representations of older adults in television advertisements. Journal of Aging Studies, 21(1), 23-30. https://doi.org/10.1016/j. jaging.2006.04.001

Lester, P. M., \& Ross, S. D. (Eds.). (2003). Pictures that injure. Pictorial stereotypes in the media. Westport: Praeger Publishers.

Levy, B. R., Slade, M. D., Kunkel, S. R., \& Kasl, S. V. (2002a). Longevity increased by positive self-perceptions of aging. Journal of Personality and Social Psychology, 83(2), 261-270.

Levy, B. R., Slade, M. D., \& Kasl, S. V. (2002b). Longitudinal benefit of positive self-perceptions of aging on functional health. The Journals of Gerontology Series B: Psychological Sciences and Social Sciences, 57(5), P409-P417.

Lohmann, R. H. (1997). Images of old age in German and American print media: Empirical investigations into defining principles and patterns of visual representation. Aachen: Alano.

Loos, E. F. (2013). Designing for dynamic diversity: Representing various senior citizens in digital information sources. Observatorio (OBS*) Journal, 7(1), 21-45.

Loos, E. F., \& Ekström, M. (2014). Visually representing the generation of older consumers as a diverse audience: Towards a multidimensional market segmentation typology. Participations, $11(2), 258-273$.

Martens, A., Greenberg, J., Schimel, J., \& Landau, M. J. (2004). Ageism and death: Effects of mortality salience and perceived similarity to elders on reactions to elderly people. Personality and Social Psychology Bulletin, 30(12), 1524-1536. https://doi.org/10.1177/0146167204271185

Martens, A., Goldenberg, J. L., \& Greenberg, J. (2005). A terror management perspective on ageism. Journal of Social Issues, 61(2), 223-239. https://doi.org/10.1111/j.1540-4560.2005.00403

Miller, P. N., Miller, D. W., McKibbin, E. M., \& Pettys, G. L. (1999). Stereotypes of the elderly in magazine advertisements 1956-1996. The International Journal of Aging and Human Development, 49(4), 319-337. https://doi.org/10.2190/A078-FRJE-NQ1P-C3KY

Miller, D. W., Leyell, T. S., \& Mazachek, J. (2002). Stereotypes of the elderly in US television commercials from the 1950s to the 1990s. The International Journal of Aging and Human Development, 58(4), 315-340. https://doi.org/10.2190/N1R6-7Q5Y-2N7Q-8NM1

Minichiello, V., Browne, J., \& Kendig, H. (2000). Perceptions and consequences of ageism: Views of older people. Ageing and Society, 20(3), 253-278.

Neilson, B. (2006). Anti-ageing cultures, bio-politics and globalisation. Cultural Studies Review, 12(2), 149-164.

Nelson, T. D. (Ed.). (2004). Ageism: Stereotyping and Prejudice against Older Persons. Cambridge, MA/London: MIT Press. 
Nussbaum, J. F., \& Coupland, J. (Eds.). (2004). Handbook of communication and aging research. London: Routledge.

Palmore, E. (2001). The ageism survey first findings. The Gerontologist, 41(5), 572-575. https:// doi.org/10.1093/geront/41.5.572

Peterson, R. T., \& Ross, D. T. (1997). A content analysis of the portrayal of mature individuals in television commercials. Journal of Business Ethics, 16(4), 425-433.

Richards, N., Warren, L., \& Gott, M. (2012). The challenge of creating 'alternative' images of ageing: Lessons from a project with older women. Journal of Aging Studies, 26(1), 65-78. https:// doi.org/10.1016/j.jaging.2011.08.001

Ridley, D. (2012). The literature review: A step-by-step guide for students. Los Angeles: Sage.

Rowe, J. W., \& Kahn, R. L. (1997). Successful aging. The Gerontologist, 37(4), 433-440. https:// doi.org/10.1093/geront/37.4.433

Rowe, J. W., \& Kahn, R. L. (2015). Successful aging 2.0: Conceptual expansions for the 21st century. The Journals of Gerontology Series B: Psychological Sciences and Social Sciences, 70(4), 593-596.

Roy, A., \& Harwood, J. (1997). Underrepresented, positively portrayed: Older adults in television commercials. Journal of Applied Communication Research, 25(1), 39-56. https://doi. org/10.1080/00909889709365464

Rozanova, J. (2010). Discourse of successful aging in The Globe \& Mail: Insights from critical gerontology. Journal of Aging Studies, 24(4), 213-222. https://doi.org/10.1016/j. jaging.2010.05.001

Seiter, E. (1986). Stereotypes and the media: A re-evaluation. Journal of Communication, 36(2), 14-26. https://doi.org/10.1111/j.1460-2466.1986.tb01420.x.

Simcock, P., \& Lynn, S. (2006). The invisible majority? Older models in UK television advertising. International Journal of Advertising, 25(1), 87-106. https://doi.org/10.1080/02650487.2 006.11072953

Swayne, L. E., \& Greco, A. J. (1987). The portrayal of older Americans in television commercials. Journal of Advertising, 16(1), 47-54. https://doi.org/10.1080/00913367.1987.10673060

United Nations. (2002). Second world assembly on ageing. Madrid international plan of action on ageing. New York: UN.

Ursic, A. C., Ursic, M. L., \& Ursic, V. L. (1986). A longitudinal study of the use of the elderly in magazine advertising. Journal of Consumer Research, 13, 131-133. https://doi. org/10.1086/209054

van Selm, M., Westerhof, G. J., \& de Vos, B. (2007). Competent en veelzijdig. Tijdschrift voor Gerontologie en Geriatrie, 38(2), 51-58.

Vernon, J. A., Williams, J. A., Jr., Phillips, T., \& Wilson, J. (1990). Media stereotyping: A comparison of the way elderly women and men are portrayed on prime-time television. Journal of Women \& Aging, 2(4), 55-68. https://doi.org/10.1300/J074v02n04_05.

Vickers, K. (2007). Aging and the media: Yesterday, today, and tomorrow. Californian Journal of Health Promotion, 5(3), 100-105.

Vincent, J. A., Tulle, E., \& Bond, J. (2008). The anti-ageing enterprise: Science, knowledge, expertise and values. Journal of Aging Studies, 22, 291-294. https://doi.org/10.1016/j. jaging.2008.05.001

Walker, A. (2012). The new ageism. The Political Quarterly, 83(4), 812-819. https://doi. org/10.1111/j.1467-923X.2012.02360.x.

WHO (2014). "Ageing well” must be a global priority. http://www.who.int/mediacentre/news/ releases/2014/lancet-ageing-series/en/

Williams, A., Ylänne, V., \& Wadleigh, P. M. (2007). Selling the 'elixir of life': Images of the elderly in an Olivio advertising campaign. Journal of Aging Studies, 21(1), 1-21. https://doi. org/10.1016/j.jaging.2006.09.001

Williams, D., Martins, N., Consalvo, M., \& Ivory, J. D. (2009). The virtual census: Representations of gender, race and age in video games. New Media \& Society, 11(5), 815-834. https://doi. org/10.1177/1461444809105354 
Williams, A., Wadleigh, P. M., \& Ylänne, V. (2010). Images of older people in UK magazine advertising: Toward a typology. The International Journal of Aging and Human Development, 71(2), 83-114. https://doi.org/10.2190/AG.71.2.a

Ylänne, D. V. (Ed.). (2012). Representing ageing. New York: Palgrave Macmillan.

Ylänne, V. (2015). Representations of ageing in the media. In J. Twigg \& W. Martin (Eds.), Routledge handbook of cultural gerontology (pp. 369-375). London: Routledge.

Ylänne, V., Williams, A., \& Wadleigh, P. M. (2009). Ageing well? Older people's health and wellbeing as portrayed in UK magazine advertisements. International Journal of Ageing and Later Life, 4(2), 33-62.

Zhang, Y. B., Harwood, J., Williams, A., Ylänne-McEwen, V., Wadleigh, P. M., \& Thimm, C. (2006). The portrayal of older adults in advertising: A cross-national review. Journal of Language and Social Psychology, 25(3), 264-282. https://doi.org/10.1177/02619 27X06289479

Open Access This chapter is licensed under the terms of the Creative Commons Attribution 4.0 International License (http://creativecommons.org/licenses/by/4.0/), which permits use, sharing, adaptation, distribution and reproduction in any medium or format, as long as you give appropriate credit to the original author(s) and the source, provide a link to the Creative Commons license and indicate if changes were made.

The images or other third party material in this chapter are included in the chapter's Creative Commons license, unless indicated otherwise in a credit line to the material. If material is not included in the chapter's Creative Commons license and your intended use is not permitted by statutory regulation or exceeds the permitted use, you will need to obtain permission directly from the copyright holder.

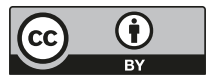




\title{
Chapter 12 \\ Ageism and Older Immigrants
}

\author{
Pnina Dolberg, Sigurveig H. Sigurðardóttir, and Ursula Trummer
}

\subsection{Introduction}

Since the 1950s, the global economy has been characterized by transnational movements of people in search of better lives and employment opportunities in developed countries (Castles and Miller 1993; ILO 2011; Sasken 1999). In the past few decades, the population of older immigrants in Europe has also significantly increased (Torres 2015; White 2006). This population consists of two main groups: individuals who migrated as labour migrants during the mass-migration flows, who then aged in the host country, and individuals who migrated in older age for either family, amenity, or other reasons (Warnes et al. 2004; Warnes and Williams 2006; White 2006). The current chapter examines ageism towards these two populations.

Immigration policies are usually designed to meet the host country's labour market needs, as well as demographic trends and objectives. There are several immigration types. Permanent migration, which characterizes countries such as Australia and Canada, means a long-term stay of immigrants in their host countries, which requires their adaptation to local society and culture. In recent decades, these countries' policies have become more selective to meet the local economic and labour market needs. Temporary migration is sought for a limited period of time, and is

\footnotetext{
P. Dolberg $(\bowtie)$

Ruppin Academice Center, Emek Hefer, Israel

e-mail:pninad@ruppin.ac.il

\section{S. H. Sigurðardóttir}

Faculty of Social Work, University of Iceland, Reykjavík, Iceland

e-mail: sighsig@hi.is

U. Trummer

Center for Health and Migration, Vienna, Austria

e-mail: ursula.trummer@c-hm.com
} 
aimed at meeting labour force shortages, such as in the fields of domestic care, construction, and agriculture. A third type is family reunification migration. This type mostly entails the migration of family members who are considered dependents, usually the spouse and minor children. Family reunification is not recognized as a universal right, but rather relies on individual nations' migration objectives. A fourth migration type is highly skilled migration. These migrants are usually granted preferential treatment compared with less skilled migrants (United Nations 2013).

The literature describes older immigrants in a variety of terms, such as "older immigrants" (e.g., Leach 2008; Terrazas 2009), "elderly immigrants" (e.g., Torres 2006), "older migrants" (e.g., Attias-Donfut 2016; Torres 2015; Van der Geest et al. 2004; Warnes et al. 2004; Warnes and Williams 2006), "immigrant seniors" (e.g., Koehn et al. 2010), "elderly migrants" (e.g., Bolzman et al. 2006; Ruspini 2010; Zahlen 2016), "older ethnic minorities" (e.g., Lievesley 2010), and "ethnic minority elders" (Victor et al. 2012). Other terms emphasize these people's past as workers, such as "post-retirement migrants" (e.g., Ackers and Dwyer 2004) and "older labour migrants" (e.g., Bolzman et al. 2004). The ambiguity caused by such a variety of terms might partially be due to the neglect of the topic of older immigrants by both migration and gerontology researchers (Torres and Karl 2016) and also to the limited public and political discourse regarding older immigrants. The current chapter uses the term "older immigrants" in order to focus on the important fact of their having moved to a different country, and to emphasize the immigration's permanence (in contrast to the focus on movement that is embedded in the term "migration").

At the beginning of 2015, there were nearly 53 million persons living in EU member states who had been born outside their current countries of residence. The age structure of this population was younger than the EU countries' national age structure (Eurostat 2016). The exact number of older immigrants in Europe is difficult to calculate, because of the group's heterogeneity (Ruspini 2010; Torres 2006) and because data are only sporadically available. Not all countries and regions have data on their older immigrant population, and the different measurement tools they use make the existing data not readily comparable (White 2006). According to one estimate, as of 2006, there were more than 2.5 million older non-nationals aged 55 and older resident in EU member states, with approximately $30 \%$ of this group aged 65 or older (Dwyer and Papadimitriou 2006). Later estimations suggest an increase in numbers of older immigrants in Europe from 7 million in 2008 to 15 million in 2015 (Ruspini 2010). Different estimates suggest that the current number of older immigrants is increasing and will continue to grow substantially during the coming years (Eurostat 2016; Lievesley 2010; Warnes et al. 2004; White 2006).

Because being an older adult and an immigrant might place an individual at risk of experiencing a double jeopardy of marginalization and social exclusion, the presence of this population raises specific questions regarding ageing, welfare needs, and policy responses (Torres and Lawrence 2012). In this chapter, we examine older immigrants' characteristics and policies regarding older immigrants, and discuss these characteristics and policies within the context of ageism. We examine the existence and weight of the age factor in immigration policies as well as policies 
concerning age-related issues such as health and retirement that affect immigrants. We examine whether a migrant status constitutes a situation of increased vulnerability to ageism. First we discuss the association between ageism, ageing destination countries, and immigration policies. Then we outline the disadvantages of older immigrants who have aged in the host country and the countries' immigrant age limitation policies, and discuss these within the context of ageism. The chapter concludes with recommendations and implications given current immigration waves.

\subsection{Ageism, Ageing Destination Countries, and Immigration Policies}

Ageism has been defined as a complex and often negative socially constructed perception of old age (Bytheway 1995; Palmore 1999) that takes place at the institutional and cultural level (macro-level), in social networks (meso-level), and on the individual level (micro-level) (Iversen et al. 2009). Ageism may be expressed in both positive and negative forms (Cuddy and Fiske 2002; Levy and Banaji 2002). Ageism includes behavioural (e.g., discriminating), cognitive (e.g., stereotyping), and affective components (e.g., positive or negative feelings) (Iversen et al. 2009).

Ageism can be either implicit or explicit; in other words, even without intention or awareness, people might discriminate against older people (Iversen et al. 2009). Explicit ageism can be direct (and therefore not "politically correct") or indirect, hidden in various practices (e.g., employers' justification of ageism based on unrelated grounds) (Cheung et al. 2011; McVittie et al. 2003).

Ageism may frequently form as a double jeopardy, because it is easier to use ageist attitudes and behaviours against socially disadvantaged groups (Dowd and Bengtson 1978). The literature reveals older immigrants' vulnerabilities to poverty (e.g., Terrazas 2009), health problems (e.g., Beiser 2005; Jass and Massey 2004), mental health problems (e.g., Bhugra 2004; Pumariega et al. 2005), and social isolation (e.g., Victor et al. 2012); yet most immigration studies have failed to examine ageism towards older immigrants.

The association between ageing, ageism, and migration is reflected in various ways. Classic modernization theory (Cowgill and Holmes 1972) suggests that as societies become more industrialized and modernized, younger people tend to leave their extended families and establish their households in modern cities. According to this theory, Zimmermann (1995) argued that stagnating and aging populations tend to attract migrants, while young and large populations generate more mobile individuals. The migration targets tend to be industrialized countries with a high demand for workers (Castles and Miller 1993; ILO 2011; Sasken 1999). Consequently, in the sending countries, older people might be left behind, without their children to look after them (Van der Geest et al. 2004; Warnes et al. 2004), and the economic and social vitality of the countries of origin might therefore be threatened (Warnes et al. 2004). 
Recent data regarding asylum seekers in Europe shows that in 2016, more than 1,200,000 people applied for asylum for the first time in the EU-28 member states. Among them, more than $83 \%$ were younger than 35 years old (Eurostat 2017). This is not a unique situation; the history of immigration to Europe since 1945 shows that asylum seekers are usually young (and usually men). Young men were also the first labour migrants who immigrated to Europe during the period of "blooming economies" in the 1950s and 1960s. Many were later followed by their family members (Hansen 2003).

Industrialized countries that demand workers are usually ageing countries (United Nations 2013). The case of Austria may serve as an example: similar to other European countries, Austria has an ageing and shrinking population, with positive net immigration being the only demographic driver of population growth. The total fertility rate was 1.44 children per woman in 2013 , measured by the "net reproduction rate" such that the generation currently at reproductive ages will numerically reproduce itself by only 69\%. Population forecasts based on 2013 data foresee a share of $28 \%$ being 65 and older in 2050 (Statistik Austria 2014). If so, contemporary Austria (like other industrialized countries) is a country that depends on immigration to compensate for an ageing and shrinking population.

Immigration policies usually assume that immigration is an option which is intended and appropriate for young people (Harper 2011; Van der Geest et al. 2004; Vullnetari and King 2008). Younger people are perceived as replacements of the ageing labour force, assuming that higher immigration and higher economic activity might slow the economic consequences of structural ageing (Aydemir 2013; Harper 2011). For instance, migration is a valid policy approach in the context of worker deficit in the UK; immigrant workers fill both the demand for highly skilled workers and the gap in unskilled employment (Harper 2011). Furthermore, immigrants are often perceived by host countries as having larger families than the local population have, and therefore as a potential means to raise the number of births in the country. This perception is associated with the view of immigrants as a potential means to delay population ageing and to maintain the support ratio (Aydemir 2013; Harper 2011). Hence, age and ageing are significant parts of the current migration processes (Van der Geest et al. 2004).

\subsection{Disadvantages of Older Immigrants Who Aged in Their Immigration Countries}

This section describes the multiple disadvantages of older immigrants who aged in their immigration countries. This population consists largely of older labour migrants and their family members. 
Economic Difficulties Older immigrants are over-represented among the vulnerable, marginalized, and disadvantaged sections of the population (Bolzman et al. 2004). Because older immigrants are often employed in poorly paid jobs, with limited job security and poor pension rights, they depend on state pensions in retirement (Ahmed 2016; Nazroo 2006). If they have an occupational pension, it is typically low, due to unemployment or early retirement (Bolzman et al. 2004). One particular disadvantaged group in Europe is that of older non-European immigrants. This is because EU immigrants are able to transfer some pension rights, but nonEuropean immigrants usually cannot. In addition, non-Europeans are characterized by higher rates of unemployment, and their concentration in low-skilled or unskilled sectors is associated with lower levels of occupational pension (Dywer and Papadimitriou 2006).

Inferior Health Evidence from different countries demonstrates the inferior health state of older immigrants. According to Nazroo (2006), ethnic inequalities in health increase markedly with age, and are largely driven by economic inequalities. Moreover, Nazroo (2003) showed evidence of the significance of racism and discrimination to the life chances of older immigrants who migrated to the UK in the 1950s and 1960s. In Switzerland, a high proportion of older immigrants was forced to retire early because of health problems. For example, half of the older immigrants in Switzerland who had worked in construction left the labour market before the official retirement age and received a disability allowance (Bolzman et al. 2004). This syndrome has been referred to as the "exhausted migrant effect" (Bollini and Siem 1995, cited in Bolzman et al. 2004): immigrants who arrived in their host countries in good health and after years of hard manual work, problematic living conditions, and an insecure legal status, developed health problems.

Limited Welfare and Health Entitlements As workers, immigrants contribute to public welfare funds: immigrants' age structure usually denotes little demand on public sector finances (Harper 2011). However, immigrants' welfare rights eligibilities are linked to their location within a particular state (Dywer and Papadimitriou 2006). For instance, according to Bolzman et al. (2004), Swiss cantons and communes pay supplementary benefits to those whose old-age pensions are insufficient to cover their basic needs. In the case of immigrants, access to supplementary benefits depends on nationality and the existence of bilateral social agreements with Switzerland, and on the duration of residence in both Switzerland and the canton. Immigrants must have an unbroken 10-year residence to qualify for supplementary benefits. Older immigrants are less likely to have supplementary health insurance than locals. The Swiss case exemplifies the high cost of supplementary health insurance, as well as the low probability that older immigrants, even if they have worked in Switzerland for years, are eligible for supplementary benefits (Bolzman et al. 2004). 
Limited Access to Services Older immigrants' access to various governmental services and entitlements is limited. Various reasons have been suggested to explain this disadvantage: inadequate language ability, lack of education and cultural capital, lack of information, poor local social networks, and low ability to deal with bureaucracy. As a result, older immigrants in need usually turn to their families or communities (Bolzman et al. 2004; Warnes and Williams 2006; White 2006). Professionals and planners who work with older immigrants tend to attribute the under-use of services to the characteristics of the immigrants and not to the nature of the organization or the services provided (Patel 2004, as cited in Ruspini 2010). However, according to Bolzman et al. (2004), services tend not to be accessible for older immigrants because of the absence of policies to ensure the inclusion of this population in society, including insufficient attention to older immigrants on the part of many mainstream institutions, and insufficient training in multicultural approaches to health and social work. Ahmed (2016) discusses older immigrants in the UK as a group that social care services have traditionally disregarded.

Lack of Policy or Insufficient Policy Despite the fact that the regulation of migration is prominent in contemporary European social policy discourse, the discourse on migration policy has habitually focused on immediate and short-term economic issues. A failure to look ahead at the consequences of ageing among immigrants is manifested through the neglect of many issues concerning ageing and immigration: long-term socio-cultural issues as well as health and welfare issues (Warnes and Williams 2006). Failing to plan for the specific needs of a population subgroup can constitute a form of social exclusion (White 2006). This maintains their perception as "birds of passage" rather than as accepted elements of society (Bolzman et al. 2004).

Some countries have a statutory policy concerning one of the immigrant groups (e.g., immigrants who aged in the host country) but not for the other (e.g., people who immigrated in older age). Israel, for example, regards its Jewish immigrants as a returning diaspora and is committed to their integration (Semyonov et al. 2015). Israel's Law of Return does not impose any age limits on Jewish immigrants and their descendants (Israeli Ministry of Foreign Affairs n.d.). Moreover, Israel holds a statutory supporting policy concerning immigrants who have immigrated to Israel in older age: in Israel, older people are entitled to older-age state pension if they have accumulated seniority through their old-age insurance. However, older immigrants who have not accumulated the required seniority receive a special benefit from the National Insurance Institute, funded by the Ministry of Finance (National Insurance Institute of Israel n.d.). In addition, special grants and benefits are given to this group of older immigrants by the Ministry of Immigrant Absorption and the Ministry of Social Affairs and Services. Services such as nursing homes, older adults' clubs, and counselling, are available in many immigrants' languages. However, this policy usually does not include immigrants who moved to Israel earlier in life and aged in Israel, as they are not entitled to special support (Dolberg 2013).

Another example comes from Iceland, a country that has experienced a significant increase in immigration in the last decade (Vinnumalastofnun n.d.). In 2007, 
the Icelandic government released the first Icelandic state policy of integration of immigrants, which emphasized that immigrants should have access to health care and municipal resources as non-residents (Iceland's Ministry of Social Affairs 2007). Older immigrants are subject to the same rules as other older persons in the social security system: in order to be entitled to an old age state pension, the person must have resided in Iceland for at least three calendar years between 16-67 years of age. Old age state pensions are paid as a proportion of the period of residence between the ages of 16 and 67. Over the past 4 years, there has been a substantial increase in the population of older foreign citizens receiving financial assistance. The numbers have increased from $2.7 \%$ to $5.2 \%$. The reason for this increase is that they are not entitled to full social security benefits because of their short time of residence (Municipality of Reykjavik 2016). In a policy plan on care of older people in Iceland for the period 2003-2015, the special needs of older people with a foreign background were emphasized (Iceland's Ministry of Healthcare and Social Security 2003). However, a specific policy regarding older immigrants has not yet been formulated.

Risk of Being Portrayed as a Social Problem Holding a statutory policy regarding older immigrants might also be associated with exclusion and marginalization, as the Swedish case demonstrates. In the late 1990s, the Swedish government appointed a committee to develop elderly care policies. The purpose was to "take into consideration the growing number of elders with foreign backgrounds and the problems that they might pose" (Statens Offentliga Utredningar 1997, 2002, p. 413, as cited in Torres 2006, pp. 1341-1342). According to Torres (2006), at the core of the equation "elderly immigrants = special needs" lies the assumption that older immigrants are disadvantaged. One of the reasons for this assumption is that almost all research on older immigrants in Sweden (until 2006) focused on immigrants who came outside Europe, and were usually less privileged in terms of continuity of social rights. In fact, older immigrants in Sweden are an extremely heterogeneous group. These previous studies might be partially responsible for perpetuating a potentially damaging stereotype, as new generations of Swedish care planners and providers have learned to regard these elders as "problematic others" (Torres 2006).

\subsection{Immigrant Age Limitation Policies}

Individuals who aim to migrate in older age for family, amenity, or other reasons, might be subject to age discrimination in the form of nations' age limitation policies (Warnes et al. 2004; Warnes and Williams 2006; White 2006). Two main forms of discrimination are presented as examples: discrimination against skilled older workers and discrimination against older family members.

Discrimination Against Skilled Older Workers A substantial number of western countries impose age limitations on potential immigrant workers by relying on points-based assessments to obtain skilled immigrants. Points-based systems 
attempt to capture a multi-dimensional notion of human capital. In most pointsbased systems, age is one dimension according to which points are allocated. Other dimensions are education level, professional experience (or previous earnings), factors that might influence integration costs (such as language ability or previous in-country work experience), and current national demand for particular skills (Parsons et al. 2014).

Although points-based systems vary across countries and the age criterion has a different weight in each, age usually has a high weight in the total multi-dimensional score (Parsons et al. 2014) and might be a barrier for applying for an immigration visa. For instance, applicants for Australian skill stream visas must be under 50 years old (this age threshold was changed from 45 to 50 in July 2011) (Van de Ven et al. 2014). Moreover, age has the heaviest weight of all factors in the Australian skilled migration system, as it may provide the applicant with the maximum number of points - 30 out of a minimum of 60 points required as a threshold (Facchini and Lodigiani 2014). However, only 25-32-year-old applicants can receive 30 points for age; 33-39-year-old applicants receive 25 points, 40-44-year-old applicants receive 15 points, and 45-49-year-old applicants do not receive any points for age (Australian Visa Bureau n.d.), and therefore, their chance of passing the 60-point threshold might be low.

Another example is that of Austria's recent "Red-White-Red Card" criteriabased immigration scheme, introduced in 2011. The program was introduced in order to regulate immigration of qualified third-country workers and their families with a goal of permanent settlement in Austria. In order to receive a Red-White-Red Card, the applicant has to achieve a sufficient number of points (e.g., for education, professional experience, age, language skills). Again, the prioritization of young migrants is demonstrated by the points given for age when applying for the Card: 20 points for an age up to 35, 15 points for ages 35-40, and 10 points for ages 40-45. No points are given after the age of 45 . The minimal pass mark point score is 70 , out of a possible 100 (Migration.gv.at n.d.).

The award of points for age represents an attempt to reward experience along with selecting younger migrants, who could potentially contribute to the work force of host countries for a longer time than older migrants. Following this rationale, people in their late 20s to early 30s are awarded the most points (Parsons et al. 2014). However, these policies might represent a type of institutional ageism. Under this system, older people who wish to immigrate might not be able to, and therefore might be excluded from being part of society merely due to their age.

Discrimination Against Older Family Members Older people who wish to immigrate for family reasons sometimes face another form of direct ageism. Research has shown that these older people might face more discrimination than younger people who wish to immigrate on the same basis. One example comes from Canada, where Family Class immigrants account for almost $80 \%$ of the immigrants who arrive in Canada after the age of 60. In British Columbia, older Family Class immigrants are dependent on their family sponsors, who are expected to support 
them financially for 10 years, a considerably longer period than for other family class groups (the period for a sponsored spouse, for example, is 3 years). During that period, older immigrants are usually not eligible for public benefits (Koehn et al. 2010; Koehn and Kobayashi 2011).

In the past two decades, several governments have been changing their policies regarding older immigrants who apply for family reunification. For instance, in 1997, Sweden introduced restrictive rules for family reunification. The age limit for family reunification was lowered to children under 18 years old. The ability of older parents, especially widows and widowers, to unite with their adult children in Sweden was restricted (Migrationsverket n.d.-a, b) solely to cases in which the following can be shown: (a) a relationship of dependence between relatives such that it is difficult for them to live apart; (b) the older parent and the sponsor (the adult child in Sweden) lived in the same household immediately before the adult child moved to Sweden; (c) the older parent's application was submitted soon after the adult child settled in Sweden. However, even under these restrictive limitations, this regulation includes a warning concerning the "difficulties of applying for reunification directly after the sponsor settled in Sweden" (Government Bill 1996/97:25, p. 113, as cited in Riekkola and Nilsson 2011).

A more recent change occurred in the UK in 2012, with the new Adult Dependent Relatives rules. Previously, UK permanent residents' parents or grandparents over the age of 65 (or under 65 in exceptional circumstances), who had no other family abroad and were financially dependent on their UK relatives, were able to apply for settlement in the UK. The UK sponsor was required to commit to a 5-year sponsorship without recourse to public funds (UK Visas and Immigration (n.d.), Immigration Directorate Instructions 2012, as cited in JCWI 2014). Under the new rules, older parents and grandparents asking to reunite with an adult child or grandchild in the UK should prove that, due to age, illness, or disability, they require long-term personal care to perform everyday tasks and are unable to obtain the required level of care in their country of origin, even with the financial and practical support of their UK sponsor (Immigration Directorate Instructions 2012, as cited in JCWI 2014). The likelihood of the older parents or grandparents of a UK permanent resident receiving a settlement visa of this category is practically negligible (JCWI 2014).

These changes to the Adult Dependent Relatives rules in the UK prompted reactions from NGOs as well as from Parliament members. According to the Joint Council for the Welfare of Immigrants report (JCWI 2014), the Adult Dependent Relatives rules prior to the changes were not a significant burden on the taxpayer. This is because parents and grandparents of UK citizens and settled residents consistently represent less than $1 \%$ of the overall net migration and less than $3 \%$ of grants of settlement in the category "Family Formation and Reunion" since 2005. According to the report, the cost-benefit analysis in the government's impact assessment is primarily focused on partners coming to the UK. Therefore, the report suggests that the UK government's proposed policy objectives of "reducing the burden on taxpayers, promoting integration, preventing abuse and contributing to reducing 
net migration" are not met by the new rules, and that "there is a complete rationale disconnect between the harshness of the rules and the aims they are meant to achieve" (JCWI 2014, p. 43).

Hence, governments' objectives to reduce net migration and to reduce the burden on taxpayers by disadvantaging older immigrants might appear as discriminative. The next section discusses whether this practice might be considered ageist.

\subsection{Summary and Conclusions}

Europe is ageing, and so is its immigrant population. Moreover, the older immigrant population in Europe is expected to grow substantially in the coming years. This chapter examined policies concerning older immigrants and the disadvantages that characterize this group within the context of ageism. This was done in order to examine whether migration status and old age increase vulnerability to ageism.

Two types of discrimination against older immigrants were presented. The first type of discrimination against older immigrants consists of the various disadvantages that older migrant workers often face. These disadvantages include inferior health, economic difficulties, limited welfare and health services, limited access to services, a lack of policy or insufficient policy, and the risk of being portrayed as a social "problem". The second type of discrimination consists of age constraints in immigration policies. This category includes discrimination against skilled older workers and discrimination against older family members. The question that arises is whether these discriminatory practices and disadvantages could be referred to as ageist.

We will start this discussion with regard to the various disadvantages older migrants are exposed to. Short-term policies concerning immigrants represent a failure to look ahead at the consequences of immigrants' ageing (Warnes and Williams 2006; White 2006). Turning a blind eye on the later phases of immigrants' lives in this way can be interpreted as passive ageism: a lack of policies that meet the needs of older adults (Bugental and Hehman 2007; North and Fiske 2013; Rosen and Persky 1997). Here we wish to emphasize that older immigrants are one segment of the wider ageing community, which should be equally treated, yet might be an easier target for discrimination or neglect.

The host country should consider the entire life course of immigrants' lives and the lives of their relatives. Stereotypical generalizations about older adults and failure to take into account the later phase of immigrants' lives represent an exclusion of older immigrants and therefore, in our opinion, might be referred to as ageist.

Attempts to address the needs of this heterogeneous population without "othering" them - that is, without assuming that they are "problematic others" who might have "special needs" (Torres 2006) — is a multifaceted task. This mission requires a careful study of each cultural group, and thorough research concerning the charac- 
teristics and needs of older adults within each cultural group. The different issues and needs of immigrants who aged in the host country and people who immigrated as older adults should be examined. Because countries differ in policies, each cultural group should be studied in its own context in order to better understand the intersection between the infrastructure of the country and older immigrants' needs. Caution should be exercised regarding stereotyping older immigrants and "othering" them; the heterogeneity of the older immigrant population must be taken into consideration (Torres 2006).

To address the multiple disadvantages of older immigrants, we recommend allowing older immigrants efficient access to services. Moreover, we recommend implementing services that target older immigrants, such as translators, cultural brokers, and older adult care services. Because the care of older immigrants often lies with their families, beyond the relief of the older immigrants themselves, these services could assist the families and further strengthen their bond with the local community and the country.

The other type of discrimination against older immigrants consists of age constraints in immigration policies. Because older immigrants have the right to apply for public funds in their countries of immigration in some of the cases, policies that discriminate against older immigrants on the grounds of age might rely on the idea that public resources are limited. Because immigration policies are usually designed to meet the country's labour market needs, as well as demographic trends and objectives (United Nations 2013), the decision to restrict immigration by age could be regarded as being simply due to economic efficiency. Hence, age constraints on immigration may not unequivocally be seen as discriminatory.

However, when people are banned from immigration because of their age, and are therefore excluded from being part of a society due to their age, we see it as age discrimination, which might involve both explicit and implicit ageist policies. Furtheremore, placing age limits on immigrants sends a clearly age-discriminatory message not only to potential immigrants but also to the country's native born people. Though protective laws against age discrimination have come into force in various countries (Kapp 2013), many older adults who wish to be part of these countries are being discriminated against.

Social identity theory (Tajfel and Turner 1979; presented by Lev et al. in this volume) includes the idea that foreigners become an easy target for discriminatory responses. One possible grounds for discrimination is age. Following this line, as foreigners, immigrants might be subject to age discrimination more than nonimmigrants. Therefore, countries that hold protective laws against age discrimination might still discriminate against older immigrants.

In summary, the older immigrant population in Europe has grown in recent decades and is expected to continue to grow. This chapter aims to raise awareness about older immigrants and their unique characteristics, as well as the restrictive policies and disadvantages they might face. We argue that these experiences of older immigrants can be viewed within the context of ageism. 


\section{References}

Ackers, L., \& Dwyer, P. (2004). Fixed laws, fluid lives: The citizenship status of post-retirement migrants in the European Union. Ageing and Society, 24(3), 451-475.

Ahmed, A. (2016). UK's elderly care and migration regimes. In S. Torres \& U. Karl (Eds.), Ageing in contexts of migration (pp. 56-66). New York: Routledge.

Attias-Donfut, C. (2016). Older migrants ageing and dying. In S. Torres \& U. Karl (Eds.), Ageing in contexts of migration (pp. 83-95). New York: Routledge.

Australian visa bureau. (n.d.). Immigration points tests. Retrieved from http://www.visabureau. com/australia/immigration-points-test.aspx\#age

Aydemir, A. (2013). Skill-based immigrant selection and labor market outcomes by visa category. In A. F. Constant \& K. F. Zimmermann (Eds.), International handbook on the economics of migration (pp. 432-452). Cheltenham: Edward Elgar publishing.

Beiser, M. (2005). The health of immigrants and refugees in Canada. Canadian Journal of Public Health/Revue Canadienne de Sante'e Publique, 96, S30-S44.

Bhugra, D. (2004). Migration and mental health. Acta Psychiatrica Scandinavica, 109(4), 243-258.

Bolzman, C., Poncioni-Derigo, R., Vial, M., \& Fibbi, R. (2004). Older labour migrants' well being in Europe: The case of Switzerland. Ageing and Society, 24(3), 411-429.

Bolzman, C., Fibbi, R., \& Vial, M. (2006). What to do after retirement? Elderly migrants and the question of return. Journal of Ethnic and Migration Studies, 32(8), 1359-1375.

Bugental, D. B., \& Hehman, J. A. (2007). Ageism: A review of research and policy implications. Social Issues and Policy Review, 1(1), 173-216.

Bytheway, B. (1995). Ageism. Virginia: McGraw-Hill.

Castles, S., \& Miller, M. (1993). The age of migration: International population movements in the modern world. New York: Guilford.

Cheung, C. K., Kam, P. K., \& Man-hung Ngan, R. (2011). Age discrimination in the labour market from the perspectives of employers and older workers. International Social Work, 54(1), $118-136$.

Cowgill, D. O., \& Holmes, L. D. (1972). Aging and modernization. New York: Appleton-Century-Crofts.

Cuddy, A. J., \& Fiske, S. T. (2002). Doddering but dear: Process, content, and function in stereotyping of older persons. In T. D. Nelson (Ed.), Ageism: Stereotyping and prejudice against older persons (pp. 3-26). Cambridge, MA: MIT Press.

Dolberg, P. (2013). Experiences of age among elder migrants. Gerontology \& Geriatrics, 40(2-3), 79-108. (In Hebrew).

Dowd, J. J., \& Bengtson, V. L. (1978). Aging in minority populations an examination of the double jeopardy hypothesis. Journal of Gerontology, 33(3), 427-436.

Dwyer, P., \& Papadimitriou, D. (2006). The social security rights of older international migrants in the European Union. Journal of Ethnic and Migration Studies, 32(8), 1301-1319.

Eurostat. (2016). Migration and migrant population statistics. Retrieved from http://ec.europa.eu/ eurostat/statistics-explained/index.php/Migration_and_migrant_population_statistics

Eurostat. (2017). Asylum statistics. Retrieved from http://ec.europa.eu/eurostat/statisticsexplained/index.php/Asylum_statistics

Facchini, G., \& Lodigiani, E. (2014). Attracting skilled immigrants: An overview of recent policy developments in advanced countries. National Institute Economic Review, 229(1), R3-R21.

Hansen, R. (2003). Migration to Europe since 1945: Its history and its lessons. The Political Quarterly, 74(s1), 25-38.

Harper, S. (2011). Migration and global environmental change. PD7: Environment, migration and the demographic deficit. Oxford Institute of Population Ageing, University of Oxford. Retrieved from http://dev.ageing.ox.ac.uk/files/11-1145-pd7-environment-migration-anddemographic-deficit.pdf

Iceland's Ministry of Healthcare and Social Security. (2003). Skýrsla stýrihóps um stefnumótun i málefnum aldraðra til ársins 2015 (A Steering Committee policy report on interests of the 
elderly from 2003-2015). Retrieved from https://www.velferdarraduneyti.is/media/Skyrslur/ stefnum-aldradir.pdf

Iceland's Ministry of Social Affairs. (2007). Stefna ríkisstjórnarinnar um aðlögun innflytjenda (Government Policy on Integration of Immigrants). Retrieved from https://www.velferdarraduneyti.is/media/acrobat-skjol/Stefna_um_adlogun_innflytjenda.pdf

ILO. (2011). A changing world: Adapting to an ageing population in the workplace. Retrieved from http://www.ilo.org/global/publications/magazines-and-journals/world-of-work-magazine/articles/WCMS_170533/lang--en/index.htm Accessed 1 April 2017

Israeli Ministry of Foreign Affairs. (n.d.). Law of return. Retrieved from http://www.mfa.gov.il/ $\mathrm{mfa} / \mathrm{mfa}$-archive/1950-1959/pages/law\%20of\%20return\%205710-1950.aspx

Iversen, T. N., Larsen, L., \& Solem, P. E. (2009). A conceptual analysis of ageism. Nordic Psychology, 61(3), 4-22.

Jass, G. \& Massey, D. S. (2004). Immigrant health: selectivity and acculturation (No. 04/23). IFS Working Papers, Institute for Fiscal Studies (IFS).

Joint Council for the Welfare of Immigrants (JCWI). (2014). Harsh, unjust, unnecessary: Report on the impact of the adult dependent relative rules on families \& children. Retrieved from https://www.jcwi.org.uk/sites/default/files/documets/adr\%20report.pdf

Leach, M. A. (2008). America's older immigrants: A profile. Generations, 32(4), 34-39.

Levy, B. R., \& Banaji, M. R. (2002). Implicit ageism. In T. D. Nelson (Ed.), Ageism: Stereotyping and prejudice against older persons (pp. 49-75). Cambridge, MA: MIT Press.

Lievesley, N. (2010). The future ageing of the ethnic minority population of England and Wales. London: Runnymede and the Centre for Policy on Ageing. Retrieved from http://www.runnymedetrust.org/uploads/publications/pdfs/TheFutureAgeingOfTheEthnicMinorityPopulat ion-ForWebJuly2010.pdf

McVittie, C., McKinlay, A., \& Widdicombe, S. (2003). Committed to (un) equal opportunities?: 'New ageism' and the older worker. British Journal of Social Psychology, 42(4), 595-612.

Migration.gv.at. (n.d.). Points calculator. http://www.migration.gv.at/en/service-and-links/pointscalculator.html

Migrationsverket. (n.d.-a). Facts on migration. Retrieved from http://www.migrationsverket.se/ Om-Migrationsverket/Fakta-om-migration/Historik.html

Migrationsverket. (n.d.-b) Moving to someone in Sweden. Retrieved from http://www.migrationsverket.se/English/Private-individuals/Moving-to-someone-in-Sweden/Close-relative.html

Municipality of Reykjavik. (2016). Analysis of foreign nationalities using welfare services. Department of quality and Research. Retrieved from http://reykjavik.is/sites/default/files/ notendur_af_erlendum_uppruna_30.03.2016.pdf

National Insurance Institute of Israel. (n.d). Special old age benefits. Retrieved from https:// www.btl.gov.il/English\%20Homepage/Benefits/Old\%20Age\%20Insurance/Pages/Specialoldagebenefit.aspx

Nazroo, J. Y. (2003). The structuring of ethnic inequalities in health: Economic position, racial discrimination, and racism. American Journal of Public Health, 93(2), 277-284.

Nazroo, J. (2006). Ethnicity and old age. In J. A. Vincent, C. Phillipson, \& M. Downs (Eds.), The futures of old age (pp. 62-72). London: Sage.

North, M. S., \& Fiske, S. T. (2013). Subtyping ageism: Policy issues in succession and consumption. Social Issues and Policy Review, 7(1), 36-57.

Kapp, M. (2013). Looking at age discrimination laws through a global lens. Generations, 37(1), 70-75.

Koehn, S., \& Kobayashi, K. (2011). Age and ethnicity. In M. Sargeant (Ed.), Age discrimination and diversity: Multiple discrimination from an age perspective (pp. 132-159). Cambridge, MA: Cambridge University Press.

Koehn, S., Spencer, C., \& Hwang, E. (2010). Promises, promises: Cultural and legal dimensions of sponsorship for immigrant seniors. In D. Durst \& M. MacLean (Eds.), Diversity and aging among immigrant seniors in Canada: Changing faces and greying temples (pp. 79-102). Calgary: Detselig Enterprises Ltd.. 
Palmore, E. (1999). Ageism, negative and positive (2nd ed.). New York: Springer.

Parsons, C. R., Rojon, S., Samanani, F., \& Wettach, L. (2014). Conceptualising international highskilled migration (IMI working paper, No. 104).

Pumariega, A. J., Rothe, E., \& Pumariega, J. B. (2005). Mental health of immigrants and refugees. Community Mental Health Journal, 41(5), 581-597.

Riekkola, S., \& Nilsson, E. (2011). Conditions for family reunification in the European Union: Sweden. National Report to the European Policy Centre on the Family Reunification Project 2011. Retrieved from http://umu.diva-portal.org/smash/get/diva2:471872/FULLTEXT03.pdf

Rosen, A. L., \& Persky, T. (1997). Meeting mental health needs of older people: Policy and practice issues for social work. Journal of Gerontological Social Work, 27(3), 45-54.

Ruspini, P. (2010). Elderly migrants in Europe: An overview of trends, policies and practices, preliminary report. Prepared in 2009 for the European Committee on Migration of the Council of Europe (CDMG) and first published as Occasional Paper, Sofia: CERMES - Centre for European Refugees, Migration and Ethnic Studies, New Bulgarian University. Retrieved from http://www.cermes.info/upload/docs/Elderly_migrants_in_Europe_paolo_ruspini_14_07_10. pdf

Sasken, S. (1999). Guests and aliens. New York: New York Press.

Semyonov, M., Raijman, R., \& Maskileyson, D. (2015). Ethnicity and labor market incorporation of post-1990 immigrants in Israel. Population Research and Policy Review, 34(3), 331-359.

Statistik Austria. (2014). Migration \& integration. Zahlen. Daten. Indikatoren 2014. Wien: Statistik Austria.

Tajfel, H., \& Turner, J. C. (1979). An integrative theory of intergroup conflict. The social psychology of intergroup relations, 33(47), 74.

Terrazas, A. (2009). Older immigrants in the United States (Migration information source). Retrieved from http://globalaging.org/elderrights/us/2009/immigrants.pdf

Torres, S. (2006). Elderly immigrants in Sweden: 'Otherness' under construction. Journal of Ethnic and Migration Studies, 32(8), 1341-1358.

Torres, S., \& Lawrence, S. (2012). An introduction to 'the age of migration' and its consequences for the field of gerontological social work. European Journal of Social Work, 15(1), 1-7.

Torres, S. (2015). Ethnicity, culture and migration. In J. Twigg \& W. Martin (Eds.), Handbook of cultural gerontology (pp. 277-284). London: Routledge.

Torres, S., \& Karl, U. (2016). A migration lens on inquiries into ageing, old age and elderly care. In S. Torres \& U. Karl (Eds.), Ageing in contexts of migration (pp. 1-12). New-York: Routledge.

UK Visas and Immigration. (n.d.). Maintenance and accommodation. Retrieved from https://www.gov.uk/government/publications/maintenance-and-accommodation-maa/ maintenance-and-accommodation-maa--2

United Nations. (2013). International migration policies: Government views and priorities. New York: Department of economic and social affairs, Population Division.

Van der Geest, S., Mul, A., \& Vermeulen, H. (2004). Linkages between migration and the care of frail older people: Observations from Greece, Ghana and The Netherlands. Ageing and Society, 24(3), 431-450.

Van de Ven, J., Voitchovsky, S., \& Buddelmeyer, H. (2014). When general skills are not enough: The influence of recent shifts in Australian skilled migration policy on migrant employment outcomes (Melbourne Institute Working Paper No. 21/14). Melbourne Institute of Applied Economic and Social Research, the University of Melbourne.

Victor, C. R., Burholt, V., \& Martin, W. (2012). Loneliness and ethnic minority elders in great Britain: An exploratory study. Journal of Cross-Cultural Gerontology, 27(1), 65-78.

Vinnumalastofnun. (n.d.) Multicultural and information center. Retrieved from https://www.vinnumalastofnun.is/en

Vullnetari, J., \& King, R. (2008). 'Does your granny eat grass?' On mass migration, care drain and the fate of older people in rural Albania. Global Networks, 8(2), 139-171.

Warnes, A. M., Friedrich, K., Kellaher, L., \& Torres, S. (2004). The diversity and welfare of older migrants in Europe. Ageing and Society, 24(03), 307-326. 
Warnes, A. M., \& Williams, A. (2006). Older migrants in Europe: A new focus for migration studies. Journal of Ethnic and Migration Studies, 32(8), 1257-1281.

White, P. (2006). Migrant populations approaching old age: Prospects in Europe. Journal of Ethnic and Migration Studies, 32(8), 1283-1300.

Zahlen, P. (2016). Elderly migrants in Luxembourg. In S. Torres \& U. Karl (Eds.), Ageing in contexts of migration (pp. 39-55). New York: Routledge.

Zimmermann, K. F. (1995). Tackling the European migration problem. The Journal of Economic Perspectives, 9(2), 45-62.

Open Access This chapter is licensed under the terms of the Creative Commons Attribution 4.0 International License (http://creativecommons.org/licenses/by/4.0/), which permits use, sharing, adaptation, distribution and reproduction in any medium or format, as long as you give appropriate credit to the original author(s) and the source, provide a link to the Creative Commons license and indicate if changes were made.

The images or other third party material in this chapter are included in the chapter's Creative Commons license, unless indicated otherwise in a credit line to the material. If material is not included in the chapter's Creative Commons license and your intended use is not permitted by statutory regulation or exceeds the permitted use, you will need to obtain permission directly from the copyright holder. 


\title{
Chapter 13 \\ Ageism in the Health Care System: \\ Providers, Patients, and Systems
}

\author{
Mary F. Wyman, Sharon Shiovitz-Ezra, and Jürgen Bengel
}

\subsection{Introduction}

According to the World Health Organization, 23.1\% of the global burden of disease (measured in disability-adjusted life years, or DALYs) can be attributed to illness in persons aged 60 years and older (World Health Organization 2008). Throughout much of the world, the ongoing demographic shifts in the population has resulted in the steady growth of the older adult patient group in the health care system (Thiem et al. 2011). Further, despite general agreement that older adults do not access medical care as frequently as needed (European Commission 2008), per-person health care spending is much higher for older adults than for younger adults. In the USA, for example, those over 65 years make up less than $15 \%$ of the population but account for over $36 \%$ of total health care costs (Jecker 2013). In Germany, older citizens with multiple medical conditions comprise the $5 \%$ of health care users responsible for over $30 \%$ of prescription drug costs (Kuhlmey et al. 2003). Within

M. F. Wyman $(\bowtie)$

W. S. Middleton Memorial Veterans Hospital and University of Wisconsin School of

Medicine \& Public Health, Madison, WI, USA

University of Freiburg, Freiburg im Breisgau, Germany

e-mail:mfwyman@wisc.edu

S. Shiovitz-Ezra

The Paul Baerwald School of Social Work and Social Welfare, The Hebrew University of Jerusalem, Jerusalem, Israel

The Israeli Gerontological Data Center (IGDC), the Hebrew University of Jerusalem, Jerusalem, Israel

e-mail: sharon.shiovitz@mail.huji.ac.il

J. Bengel

University of Freiburg, Freiburg im Breisgau, Germany

e-mail: bengel@psychologie.uni-freiburg.de

L. Ayalon, C. Tesch-Römer (eds.), Contemporary Perspectives on Ageism, International Perspectives on Aging 19,

https://doi.org/10.1007/978-3-319-73820-8_13 
the National Health Service in the United Kingdom, older persons make up twothirds of all care consumers (United Kingdom Department of Health 2001). The growing group of "old-old" patients (those aged 85+) with complex medical needs accounts for an over-proportionate amount of health care spending in Europe (Konig et al. 2013; Kuhlmey et al. 2003; Lehnert et al. 2011).

Thus, older adults represent a highly significant group of users of the health care system, and their care has a major impact on health care costs. Additionally, being a regular consumer of medical services is a significant part of daily life for many older adults around the globe. As the "third age" has been extended through longer average lifespans, so too are older persons living with more chronic and acute health problems and relying on care through the health system to maintain functioning and prolong life.

Despite their importance as health care consumers, a recent report issued by the Institute of Medicine (Institute of Medicine 2008) argues that negative attitudes towards older adults persist in the health care community, across professional disciplines, and across care settings. Ageist stereotypes, prejudice, and discrimination are potential barriers for health equality, in terms of the quantity and quality of care provided to older patients and their health-related outcomes (Courtney et al. 2000; Robb et al. 2002). Ageism is similar to other known forms of discrimination such as gender-based discrimination (sexism) and ethnicity-based discrimination (racism). Whereas sexism and racism rely on biological attributes which are life-long and usually cannot be changed, however, the bias against older persons will affect all of us who live long enough (Levy and Banaji 2002; Palmore 2001). In the words of Robert Butler (1975), who coined the term, ageism results in older persons being "categorized as senile, rigid, and old-fashioned in morality and skills. Ageism allows those of us who are younger to see old people as 'different.' We subtly cease to identify with them as human beings, which enables us to feel more comfortable about our neglect and dislike of them" (p. 894). More recently, Iversen and colleagues proposed a comprehensive description of ageism with the goal of further refining the operationalization and conceptualization of the construct in research (Iversen et al. 2009). This definition encompasses dimensional concepts already well-established in social psychology: (1) cognitive dimension (stereotypes); (2) emotional dimension (prejudice); and (3) behavioral dimension (discrimination). This dimensional approach reflects the fact that, on the basis of age-based categorizations or stereotyping, people can have biased thoughts or feelings about older people and/or engage in discriminating behavior toward older people. These authors go on to state that ageism can be conscious (explicit) or unconscious (implicit), and can be expressed at three levels: interpersonally, among individuals (the micro level); intra-group, that is, within social networks (the meso level); and through institutional policies or cultural traditions (the macro level).

There are a number of theories which attempt to explain the origin of ageism. Two theories in particular are highly relevant to healthcare providers and have received considerable attention (Nelson 2005). The functional approach theory (Snyder and Miene 1994) views stereotyping as serving an important function in the cognitive realm (e.g., using rapid categorization to enhance efficiency) and social realm (e.g., identifying oneself with the social in-group). Categorization may serve 
an important function for clinical decision making. This theory, along with the Terror Management Theory (Greenberg et al. 2002), also emphasizes that a negative bias against older persons acts as an ego-protective mechanism, used to deny and distance ourselves from the negative aspects of old age. According to the Terror Management Theory, ageism is closely associated with a human desire to dissociate one's self from reminders of one's own inevitable death, leading to attitudes and behaviors that reinforce separation from individuals or groups that arouse fear of death, such as older persons (Greenberg et al. 2002). As old age is also closely associated with deteriorating health, diminishing functional abilities, and lower social status, which leads to low self-esteem (Martens et al. 2005), the adoption of ageist attitudes and behavior serves to enhance our identification with our social in-group, and to help us dissociate ourselves from reminders of our own future decline.

One can understand intuitively that anxiety regarding severe illness or death may be highly relevant within the health care setting. Health care professionals often have prolonged exposure to the most infirm, ill, and senile older adults, which may bias their perspective and intensify their willingness to disassociate from the older population through ageist practices (Kearney et al. 2000; Lookinland and Anson 1995; Palmore 1990). There is some empirical support for the association of more negative attitudes with higher anxiety about ageing among health care workers (Liu et al. 2015).

This chapter presents a focused look at age bias as it is manifested in the health care setting. Of note, in this chapter we concentrate on the medical care setting, whereas the chapter by Bodner and colleagues (2018; Chap. 15) in this volume explores ageism within the mental health care system, and the chapter by Fialova and colleagues (2018; Chap. 14) is focused on pharmacological treatments and ageism. We leave a detailed critique of research methodology in this area to Buttigieg and colleagues (2018; Chap. 29) in this volume. Within the micro level (provider to patient), we review research examining attitudes toward, beliefs about, and clinical practices with older patients. On the macro (policy and cultural) level, we examine geriatric care and reimbursement policy across countries, and look at the very limited presence of older patients in the development of new therapies and within health care training curricula. We briefly consider the challenge of distinguishing between discrimination based on age and reasoned, conservative care provided by clinicians to their older patients. Finally, we offer conclusions and recommendations for the future.

\subsection{Providers and Patients: Ageism at the Micro Level}

\subsubsection{Ageist Attitudes and Practices Among Health Care Professionals}

There is an ample body of literature documenting negative attitudes towards older patients among health care providers, though conclusions are limited due to the use of a wide range of measurement approaches (for example, a number of different instruments have been used to assess "ageist" attitudes). Lookinland and Anson 
(1995) reported that registered nurses, as well as high school students interested in becoming nurses, exhibited negative attitudes and stereotypical beliefs related to ageing and older adults, with the latter exhibiting the least favorable attitudes and views. One study found that nurses tend to assign a lower status to geriatric nursing compared to other practice areas (Wells et al. 2004) and in another study, nursing trainees indicated a general lack of interest in working with older adults (Hayes et al. 2006). However, a recent survey study (Boswell 2012) among health care students in an undergraduate course on ageing found no clear tendency toward more negative or positive attitudes.

Several review articles have focused on attitudes toward older adults among health care providers. Attitudes among physicians are complex and mixed (Meisner 2012), with some studies of this population demonstrating clearly negative evaluations of older adults and others more neutral or positive evaluations. This also appears to be true of studies of attitudes toward ageing among nurses (Liu et al. 2013). There may be shifts in attitudes among health care professionals over time: results of a recent systematic review suggested an improvement in medical students and physician attitudes since 2000, but a decrease from positive to more neutral attitudes towards older people among nurses and nurse trainees (Liu et al. 2012). A review of studies examining nurses working in the acute health care setting revealed primarily positive attitudes toward ageing, though some studies reported negative attitudes, mainly reflecting a negative emotional evaluation of patients (Courtney et al. 2000). Most concerning, these authors found evidence in their review for an association between negative attitudes and clinical practice decisions.

Discrimination based on age may be reflected in clinical practice and decisionmaking among health care providers. Studies using both hypothetical decisionmaking scenarios and patient record review have demonstrated age-based disparities in diagnostic procedures as well as in the types of treatment offered to patients. These reports emerge from various fields of medicine including cardiology (Bowling 1999), oncology (Kagan 2008), and stroke treatment (Hadbavna and O'Neill 2013). For example, a study conducted in England revealed that though the prevalence of breast cancer is considerably higher among older women compared to younger women (40\% of cases are over age 70 ), only $11 \%$ of these older women had received breast cancer screening examinations by their physician. Moreover, only $7 \%$ of the physicians participating in that study conducted breast examinations on older female patients on a routine basis (Haigney et al. 1997). A study conducted among physicians and second-year medical students indicated an age bias in beliefs regarding follow-up treatment for patients undergoing surgery for breast cancer (Madan et al. 2001, 2006). Younger patients described in vignettes were significantly more likely to be recommended for breast-conservation therapy, whereas a higher percentage of older patients were recommended for modified radical mastectomy. This study also found that younger patients were more likely to be recommended for breast reconstruction procedures following mastectomy. Among lung cancer patients in the U.K., the likelihood of being referred for surgery was lower for older people, despite clinical evidence that post-operative recovery outcomes are not dependent on age (Peake et al. 2003). The same trend has been found in cardiology: 
coronary heart disease in older patients, specifically older women, is more likely to be treated pharmacologically rather than surgically (Wenger 1997). A U.S. study found evidence of age-related under-treatment of heart attacks relative to national treatment guidelines, with older patients less likely to receive standard diagnostic procedures and recommended treatments (McLaughlin et al. 1996).

\subsubsection{Ageist Communication by Health Care Professionals}

Another aspect of age discrimination relates to the way health care providers communicate with older adults. A number of studies provide evidence that patronizing and ineffective communication can characterize discourse between providers and older patients (Ambady 2002). Overall, physicians involve older patients in medical decisions less frequently than they involve younger patients. Further, physicians tend to be less patient, less respectful, less involved, and less optimistic with older patients compared to younger patients (Greene et al. 1996). While there is certainly individual variability in patient preferences for the type of communication with a health care provider, there is no evidence that these attributes of interpersonal communication are preferred by older persons. Above and beyond the potentially negative emotional experience for older patients and family members in the face of a provider's "poor bedside manner," provider communication styles may have substantive negative health consequences for the patient (Nussbaum et al. 2005). For example, one research study analyzing videotaped encounters between a physical therapist and an older patient found that distancing and indifferent behaviors (e.g., not smiling; looking away from the client) were related to more negative short- and long-term cognitive and physical health outcomes for the patient (Ambady 2002).

In a study of nurses, the quality of communication with and care provided to older patients was found to be associated with attitudes toward ageing (CarisVerhallen et al. 1999). More negative nurse attitudes were related to shorter, more superficial, and more task-oriented conversations with older patients. The nurses tended to speak to the older patients in a patronizing tone and did not involve them in consultations or decisions. In a similar vein, McLafferty and Morrison (2004) found that nurses' negative attitudes towards older patients were reflected in low expectations for rehabilitation as well as in more detached treatment of the patients. In this study, nurses were less likely to use humor with their older patients, and were less likely to remember the names of older patients compared to younger patients. A recent qualitative study which compared physicians, nurses, and social workers in Israel found that exclusion of older patients from conversations about their own medical care characterized the interactional styles across disciplines. These health care professionals tended to either "bypass" the older patient by approaching younger family members, or to make clinical decisions without any meaningful patient input. In follow-up interviews, health care providers listed several primary reasons for this type of communication style: (1) lack of self-awareness of this pattern; (2) "choosing the way that is easiest" (i.e., it is simpler to have health care 
discussions with a younger family member rather than the older patient); and (3) the provider "not relating to the patient [as a person]" (Ben-Harush et al. 2016).

An operant-observational study conducted in a nursing home revealed yet another detrimental pattern of communication between staff and residents, termed the "dependency-support script" (Baltes et al. 1980). Findings showed that nursing assistants were more positively responsive to dependent behaviors than to expressions of independence, and reacted with a dependence-supporting response (i.e., praising residents for their acceptance of help). The authors asserted that this type of communication reinforces dependency and discourages independent behavior in older adults. This association was identified in the Ben-Harush et al. (2016) study as well, as described clearly in a quote by a social worker:

When an older person enters the hospital, there is a certain approach towards them that makes them more dependent. The patient can be a very independent person... and somehow the attitude of the personnel towards them makes them change...they immediately put a diaper on people who did not need a diaper before... Something about entering a hospital promotes a regression for every person, and for older adults the regression is even harsher. They put a diaper on so fast because they don't want to deal with it. Someone has to help these patients stand and walk them to the bathroom... there is no time... (Ben-Harush et al. 2016).

\subsubsection{Factors Associated with Ageism in the Medical Setting}

Factors Associated with Health Care Personnel A handful of studies have examined predictors of ageist attitudes among health care providers. Among nursing students and registered nurses in Sweden, younger age ( $<25$ years old) and male gender were associated with more negative attitudes toward ageing (Lookinland and Anson 1995; Soderhamn et al. 2001). These associations were confirmed in a study conducted among Greek nursing students; young age and male gender were associated with increased ageism, as measured by more negative attitudes towards older adults and less accurate knowledge about ageing (Lambrinou et al. 2009). Similarly, characteristics of physicians that were associated with more positive attitudes towards older people included being older and being female, as well as having more years of education, previous working experience with the geriatric population, having higher interest in care of older people, and having more frequent social interaction with healthy older people (Leung et al. 2011). A recent systematic review of 25 studies across different countries, however, suggested that age and gender are not reliably associated with nurse's attitudes toward older patients, whereas preference to work with older patients and level of knowledge related to ageing are more consistent predictors (Liu et al. 2013). These same two factors, along with high anxiety about one's own ageing, were the strongest predictors of negative attitudes toward ageing among nurses (Liu et al. 2015). Further, in a sample of junior doctors in Singapore, personal and professional background characteristics such as age, marital status, living arrangements and years in medical practice were not associated with attitudes 
towards older adults (Lui and Wong 2009). Harries and colleagues (Harries et al. 2007) found no effect of medical specialty on attitudes and clinical decision making in response to patient vignettes. However, other researchers report such differences, e.g. that surgeons tend to hold more negative attitudes toward ageing compared to other medical subspecialties (Krain et al. 2007). Taken together, the available evidence on health care provider characteristics which may serve as predictors of age bias is mixed and inconclusive, and further research in this area is warranted.

Factors Associated with the Older Patient Some characteristics of the older patient may increase the likelihood that negative age stereotypes are activated and that age-based discrimination can occur. We will first address how older patients' health and functional status may influence attitudes toward ageing, and then discuss the concept of "self-ageism" and its impact on health and health care.

Past research on patient factors in ageism, which has been primarily conducted among mental health providers, spawned the term "healthism" to describe negative perceptions of others based on poor health status, not purely on age (Gekoski and Knox 1990; James and Haley 1995). Because poor health is strongly associated with old age and older adult identity (Coupland and Coupland 1994; Vauclair et al. 2015), the potential impact of "healthism" on the quality of patient-provider interactions and on care in the health care system is worthy of brief discussion. (Bodner et al. 2018, Chap. 15 provide additional details on this construct in their chapter on ageism in the mental health care setting, in this volume.)

Health care providers may develop attitudes toward older patients based on their medical diagnoses, functional deficits, or symptoms. A bias against older adults who are medically ill was demonstrated in a sample of mental health therapists (James and Haley 1995). Among medical providers, Gunderson and colleagues (Gunderson et al. 2005) found that rurally-based physicians in the U.S. endorsed more negative views of "nursing home patients" compared to typical "older" patients, in terms of patients' ability to change health behaviors and to learn new health-related information, their ability to offer important input during a medical visit, and their personality traits (e.g., "less warm and accepting"). Healthism may be related to the increasing "medicalization" of old age in Western societies identified by some scholars (Ng et al. 2015). Increased focus on the medical aspects of being old - to the exclusion of other dimensions of older age - is reflected at the level of policy and reimbursement in the geriatric health care setting, and has a clear impact on provider choices, service availability, and quality of care (Binney et al. 1990). A recent sociological study of changes in culture-based age stereotypes appearing in print over the past 200 years in the USA found an increasing association over time between the mention of an older adult and references to the medical status of that person, using words such as "sickness" or "stamina" (Ng et al. 2015). This increasing medicalization of old age was associated with increasingly negative age stereotypes, leading the authors to conclude that this increasing negativity toward older adults is systemic and pervasive throughout the culture. 
The construct of healthism may be related to self-ageism (see below). In an effort to distance themselves from stereotypical views of old age and their own aging experience, older adults may tend to deny health problems to order to more easily present as exemplifying "healthy ageing" (Tanner 2003).

\subsubsection{Self-Ageism in the Health Care Setting}

Ageist biases or assumptions held by older adults themselves (i.e. "self-ageism") may also impact their interactions with the medical system and quality of health care. Among older adults, the development of negative attitudes toward ageing or older people can be considerable, and in fact may be inevitable in an ageist society (Levy 2001). These biases may lead to irrational illness perceptions, for example, that pain and suffering are to be expected in old age. One recent qualitative study on back pain - one of the most common medical conditions among older adults around the globe - found that many older patients believe that pain is a "normal" part of old age (Makris et al. 2015). They are less likely to seek treatment for unmet medical needs, due to low expectancies of being helped because of their advanced age (Walters et al. 2001). These self-directed biases can also impact health and healthcare outcomes for the geriatric patient. Over a series of studies, Levy and colleagues have demonstrated a relationship between negative age self-stereotypes and health outcomes (Hausdorff et al. 1999; Levy and Banaji 2002). For example, one longitudinal study found that the endorsement of negative statements about older adults (e.g., "old people are helpless") was related to a higher risk for cardiovascular events over the next 38 years, controlling for cardiovascular risk factors (Levy et al. 2009). A more recent report revealed an association between negative age stereotypes held earlier in life and a later increased risk for Alzheimer's brain pathology (Levy et al. 2016). Moreover, a meta-analysis of 19 longitudinal studies concluded that positive subjective ageing (defined as positive ageing attitudes and youthful identities) contributes to better health and increased longevity in later life (Westerhof et al. 2014). Potential explanations may include that self-ageist ideas or negative views on ageing make it less likely for older adults to embrace positive health behaviors such as physical activity (Wurm et al. 2010), take preventive health measures, or adhere to recommended treatments (Levy and Myers 2004).

In summary, there is evidence of age-based bias at the micro, or interpersonal, level. This is reflected in attitudes and behaviors toward older adults among health care workers, and research suggests that these attitudes affect clinician behavior and clinical decision making. Patient factors, such as self-ageism, also impact the processes and outcomes of health care. Thus far, data regarding specific provider or patient factors which may predict prejudice and discrimination based on age in the health care setting appear to be mixed. In the next section, we examine ageism at the macro-level within this setting. 


\subsection{Structural Factors that Impact Care for Older Persons: Ageism at the Macro Level}

Macro-level ageism refers to age-biased attitudes and practices present at the cultural and institutional levels. This form of ageism has an important impact on health care for older adults. Numerous scholars have acknowledged the impact of age discrimination on continued inequalities in the health care system. Atul Gawande, in his recent popular book "Being Mortal," argues that despite the world-wide demographic changes resulting in an unprecedented number of older adults in the population - due in part to improvements in health care services - "...medicine has been slow to confront the very changes it has been responsible for - or to apply the knowledge we have about how to make old age better" (Gawande 2014, p. 34). He goes on to opine that health care consumers and policy makers "have not insisted on a change in priorities [in the health care system] ... when the prevailing fantasy is that we can be ageless, the geriatrician's uncomfortable demand is that we are not" (p. 46). As Prince et al. (2015) note, "the fitness for purpose of health services and systems for older adults and their complex, interacting, chronic medical and social difficulties is open to question" (p. 557).

There is general agreement that age discrimination is present in the systems and policies of health care services, though conclusive data on health care access for older persons in Europe is generally lacking (European Commission 2008). Highlighting the impact of cultural and institutional tradition on health care practice, a 2001 United Kingdom Department of Health publication noted that "...too often the financial commitment to older people in these core public services has not been translated into a cultural and institutional focus on the needs of older people....Instances of adverse discrimination have usually been inadvertent, a result of the survival of old systems and practices [emphasis added] that have failed to keep pace with changing attitudes or advances in the capacity of professionals to intervene successfully" (United Kingdom Department of Health 2001). This section will briefly review systemic and policy issues which demonstrate the existence of "institutional" or "structural" ageism (AGE Platform Europe 2016; International Longevity Center 2006) within health care.

\subsubsection{Age Discrimination Exists in the Health Care System}

Complaints of age bias in care, beyond the level of provider attitudes or providerlevel behaviors, have been reported within a variety of health care systems (European Commission 2008; International Longevity Center 2006; Jacobsen 2015; Williams 2009). A recent European Union-commissioned study across several EU countries reported that the frail, medically complex older adults comprise one of the populations at risk of "falling through [the] safety net" of public health care coverage programmes, resulting in reduced access to quality health care (European Commission 2008). This study found evidence, across most nations examined, of 
less access to necessary medical care among older adults compared to younger adults. Multiple so-called "supply-side" or system-level barriers to health care access for older adults were identified. These included requirements for patientborne cost sharing of services and medications, which can result in a deleterious interaction between older adults' higher service needs and more limited financial resources; geographic barriers and lack of transportation options, resulting in limited access to care due to mobility restrictions; inadequate numbers of geriatricstrained providers; a shortage of preventive and rehabilitation-focused care options for older patients; and age-discriminatory clinical decision making by providers. "Demand-side" or patient-level factors contributing to health disparities for older EU citizens include lower expectations of health care services, leading to minimal demand for change; more limited health literacy; and heightened challenges in managing their own care within a bureaucratic, fragmented service organization (European Commission 2008). As others have noted (Nies and Berman 2004), despite the fact that care coordination has long been identified as a quintessential pillar of quality geriatric care, current geriatric health care systems in the EU are generally not based on principles of collaborative partnership with social care systems and informal caregivers.

Access to care following a stroke, or cardiovascular accident (CVA), is one example that has been studied by researchers. In general, age-based bias in stroke treatment - referring to differences in care that are not justified by clinical evidence or best-practice guidelines - appears to be quite common, according to a recent systematic review (Luker et al. 2011). One study found a significant impact of age of the patient on the quality and type of immediate care for CVA in several UK countries, with older persons less likely to receive care consistent with current guidelines (Rudd et al. 2007). Another large pan-European study found that while older stroke patients have equal or better access to specialized stroke care, rates of standard diagnostic and therapeutic procedures, as well as rehabilitation services, were lower for older patients compared to their younger counterparts (Bhalla et al. 2004). These results are concerning in light of data that suggest that health outcomes after stroke do not vary by age when guideline-level care is provided (Saposnik et al. 2009). Of note, it is likely that the age-based differences identified in these studies represent the interaction of micro-level age-based attitudes (such as clinician decisions or patient preferences) and institutional or cultural norms in stroke care. However, clear instances of age-related bias in formal policy regarding stroke care can be found in a number of countries. For example, Greece has a policy governing decisions in inpatient stroke care, with patients over 65 sent for admission to a general internal medicine ward rather than a neurology specialty service (Theofanidis 2015). In Finland, a recently revamped policy does not provide coverage for medical rehabilitation - services to address deficits in activities of daily living following an illness - for persons over age 65 (AGE Platform Europe 2016), despite functional rehabilitation being part of standard care for many patients with stroke.

How health care services are reimbursed can differently affect older adults compared to younger patients. Health care reimbursement is a topic of great interest currently, as policy makers in many different countries work to address anticipated 
budget shortfalls due to ageing populations. As others have noted, current payment mechanisms incentivize medical procedures and technology-driven tests, but do not reimburse providers for the often complicated and time-consuming process of geriatric care (Alliance for Aging Research 2002). In addition, in many publicly-funded health care systems, there is an ongoing and heated debate about the rights of older persons to receive any health care benefits, and about how to manage the financial "burden" related to the care of older persons. Surveys within such countries reveal public opinion supporting the idea of an age cut-off for medical services; for example, in Belgium, persons over 85 years old are considered by many citizens as "not worthy of care" (AGE Platform Europe 2016). Within the UK's National Health Service, discussions about rationing of care have frequently pointed to long-standing age-based discrimination at a systemic level (Shaw 1994). For example, until recently, the UK's National Health Service breast cancer screening program offered regular mammography only to women under the age of 65 (the program has recently been extended up to age 70). A performance indicator in the United Kingdom sets the undesirable outcome "premature death" as occurring at or below age 75. Thus, this is a policy which does not differentiate patients based on comorbidities or clinical presentation, but on age alone. The policy also implies that human life after age 75 has less inherent worth compared to life at a younger age (AGE Platform Europe 2016). Vascular disease screening invitations in the UK are also age-based, despite the high prevalence of cardiovascular disease among older adults (Lievesley 2009). These are not isolated examples. Upper age limits on funding for diagnostic tests, screening procedures, and health-related social benefits are part of policy in many European countries (AGE Platform Europe 2016).

In the US, the existence of the federally funded and regulated Medicare health care insurance program for citizens over age 65 has resulted in a health care coverage system for older adults that is effectively separate from coverage programs for other age groups. Medicare policies on reimbursement for medications, equipment, and services have a profound and wide-reaching effect on health care for older adults in the US. One example is Medicare's payment policy for inpatient rehabilitation, usually provided within a long-term care setting. Current Medicare benefits provide for a maximum of 100 days of reimbursement, creating an incentive for facilities to keep patients in the rehabilitation setting for this full time period, whether or not the patient is benefitting from the care or able to participate in rehabilitation treatments such as physical therapy. Medicare reimbursement policies are not structured to provide incentives to delay or prevent entry into a long-term care facility. There was no coverage for preventive care until recently, and preventive services that would benefit a majority of older adults (and reduce health care costs), such as a falls risk screening or home safety assessment, are still excluded. Medicare neither reimburses comprehensive outpatient geriatric care, despite evidence of good outcomes (Boult et al. 2001), nor the relatively low costs of part-time custodial care at home (e.g., assistance with cooking, cleaning, shopping, bathing) to keep frail patients safe and functioning outside of an institution. Of note, until recently, Medicare did not provide reimbursement for care costs incurred during participation in clinical research trials. 
It should be noted that changes in the US public health care programs are gradually occurring as the Patient Protection and Affordable Care Act (ACA) of 2010 continues implementation, and there may be additional positive impacts on health care services for older adults (Goyal et al. 2012). The ACA includes a mandate for the expansion of the scope of routine care to include mental health care and chronic disease self-management, and places an emphasis on a patient-centered care experience and quality of life as measurable outcomes. Financial payment incentives are being realigned, especially for primary care providers who work in geriatrics, and there is increased attention to the development of care coordination and disease management programs for older adults to prevent unnecessary medical interventions and reduce costs. Thus, there may be reduction of age bias at the systemic level as we move toward the future.

\subsubsection{Older Persons Participate Minimally in Clinical Trials}

Another aspect of age bias at the structural level concerns clinical research trial participation. As Topinkova and colleagues note (Topinkova et al. 2012), "the health care industry and regulatory authorities have for a long time negated the age-specific needs of older drug consumers. Only recently the European Medicines Agency has begun recognizing the need for a specific 'geriatric' approach in both drug development and registration" (p. 479). Older patients are typically excluded from the development and testing of new compounds, from ongoing drug efficacy monitoring programs, and from undergoing age-appropriate outcome evaluations. In clinical drug trials for cancer and coronary artery disease, both conditions for which incidence increases with age, persons over the age of 65 are systematically underrepresented (Witham and McMurdo 2007). The same trend can be seen in research on intervention for strokes and on stroke rehabilitation: in both cases, there is global evidence of age bias, as the mean age of participants in clinical trials reported in the stroke literature was a decade younger than the average age of stroke patients (Gaynor et al. 2014; Hadbavna and O'Neill 2013).

A systematic review of recruitment of older cancer patients into clinical trials identified age-related barriers to equal inclusion in four broad domains: trial design, physician factors, patient factors, and trial logistics (Townsley et al. 2005). In the majority of clinical trials, protocol design stipulates exclusion criteria such as impaired functional status, past cancer illnesses, and medical comorbidities. This effectively screens out many older patients. Indeed, in a recent prospective study, not being eligible was the most common reason for lower enrollment of older persons (Javid et al. 2012). Further, a recent study of heart failure trials (Cherubini et al. 2011) found that almost $50 \%$ of the trials included what the authors termed "poorly justified" exclusionary criteria, resulting in lower participation by patients over 65 years old. At least one study has found similar age-based bias in nonpharmacological health behavior clinical research (Levy et al. 2006).

Physician-related barriers to referral of older adults to clinical trials include provider concerns about co-morbidities and potential adverse events related to study 
participation, factors which are evaluated in the context of patient age (Townsley et al. 2005). There is no evidence that provider characteristics impact referral rates. A U.S. study compared rates of physicians offering clinical trial participation to older versus younger breast cancer patients, and found no significant associations with physician demographic or professional experience variables. Patient age and stage of disease were the only significant predictors of referral (Kemeny et al. 2003). In terms of patient-level barriers, both older and younger patients most frequently explained their nonparticipation in trials by a reluctance to experience limitations on their choice of treatment. Some scholars, however, assert that older adults' health literacy and knowledge about participation in clinical trials may be at a lower level compared to younger persons, preventing fully informed decision-making in these situations (Townsley et al. 2005).

Factors related to patient safety and scientific integrity, such as risk of adverse events and ensuring sample homogeneity, are often cited for this age-based exclusion. These are important concerns. However, the nonparticipation of older patients in clinical trials likely has a profound impact on health care for older adults. Lack of older adults' participation prevents the generalization of study results to older patients and therefore may contribute to "double discrimination": without clinical evidence supporting the use of novel treatments in the older population, the chance is reduced that older patients will receive these treatments. This may happen due to age-biased beliefs that continue unchallenged without newly emerging research on older populations, or due to clinicians' uncertainty about safety and benefits for older patients and a resultant reluctance to pursue screening or treatment (Walter et al. 2005). Thus, age-based barriers to access to medical therapy might be partially attributed to the under-representation of the older age population in clinical trials. Further, the treatments that older adults receive should be based on solid clinical evidence relevant to that population, which is not currently the case (Cherubini et al. 2011). Indeed, it can be argued that underrepresentation of the older patient population in clinical trials is not only one of the consequences of ageism in medicine, but may also be one of its major perpetuating factors.

\subsubsection{Training of Health Care Professionals}

Another systemic factor which may sustain the age bias which exists within the health care system is the type of training received by health care professionals. Several scholars have argued that training programs do too little to actively combat existing negative views of older adults and to positively promote geriatrics or gerontology as practice fields. Some years ago, Levenson (1981) asserted that "medical students' attitudes have reflected a prejudice against older persons surpassed only by their racial prejudice" (p. 161). More recent research has demonstrated that medical residents perceive themselves to have a gap in geriatric training and exposure to older patients (Chodosh et al. 1999), and that both US and European nursing students and nurses viewed the care of older people as a topic that currently receives 
too little attention in professional education programs (Kydd et al. 2014). Of note, however, a recent study of US medical schools reported improvements in the past decade in geriatric-specific physician training (Bragg et al. 2012). Thus, while inadequate training in geriatrics remains a problem to solve, it appears that institutions charged with health care education may be progressing in the right direction.

\subsection{Conclusions and Recommendations}

Health care represents a key domain of civilized life, and provides services to all members in a society. Indeed, bioethics scholars debating about the rationing of health care to address rising costs have argued that protecting health is of "special moral importance", also noting that health care systems are not prepared to meet the challenges of the ageing of the global population (Daniels 2013). There is ample research evidence demonstrating that age-based discrimination is common and long-standing among health care providers, within health care systems, and in health care policies. Further, there are systemic forces which have an impact on geriatric health services before the older patient even feels the need to seek care for example, the lengthy process of developing, testing, and monitoring medications, which has excluded older adults to a significant extent. On the positive side, there is increasing recognition of these manifestations of ageism at all levels, and there is increasing support for interventions to change negative attitudes and reduce age discrimination. The landscape of health care is not static. This may be especially true in the area of geriatrics, as countries around the globe scramble to prepare for the ever-increasing numbers of complex older patients.

An important additional point is this: given the complexities of health care, it is sometimes difficult to distinguish between inappropriate and discriminatory agebased bias - "ageism" - and prudent, carefully reasoned decisions by clinicians in their care of older adults. Multiple patient-level and institutional-level factors impact clinical decision-making about screening, diagnostic tests, and treatment (e.g., Breslau et al. 2016). Clinical decision-making for older patients is often a highly complex task which is not made easier with the dearth of clinical evidence regarding appropriate treatments for this population. Clinical practice is guided by familiarity and routine as well as evidence, and some categorizing or stereotyping of patients by risk or potential outcome is sometimes necessary to make treatment decisions. One might ask: how much of "ageism" in clinicians can be attributed to the perpetuation of outdated ideas regarding good clinical care for older adults, rather than purely to age-biased attitudes and behaviors? Is age bias merely reflective of our human affinity for tradition and resistance to change? This begs the question, however, of why health care systems have been so very resistant to change and slow to embrace proven approaches to improve services for this large group of constituents. Older adults comprise the most frequently seen, and costliest, consumer group in health care. Their numbers are increasing. Yet, there is a pronounced lag in the development of widespread implementation of well-accepted clinical guidelines 
for this population, despite adequate evidence documenting the benefits (Boult et al. 2001). Do ageist stereotypes and prejudices - in the provider, in the patient, in the system - play a role? We believe they do. Thus, while we acknowledge that agebased bias may not always be specifically reflective of negative age stereotyping, we believe ageism remains a powerful force within the health care setting. Identifying ageist attitudes and practices is the first step to eliminating this bias and improving health care for persons of all ages.

The task remains to define and describe health care for older adults that is not ageist. What does this look like? We believe that a non-ageist approach to developing health care services for older persons does not mean standardizing assessment and treatment procedures and processes across the age span. We, like other authors (Bodner et al. 2018, Chap. 15, this volume), believe that health care equity for older adults refers to equality in the adequacy and case-appropriateness of diagnosis and treatment, rather than to uniformity in the evaluation and treatment itself. It means creating care that respects the unique needs of the aged, that results in high patient satisfaction, and that achieves success in reaching desired outcomes. High quality medical treatment is always relative to what is required and what is adequate for that particular patient. It requires an individualized, person-centered approach to care (Breslau et al. 2016), and is in keeping with the anti-ageist ideology inherent in the principles of modern geriatric practice (Coupland and Coupland 1994). It supports the potential for the field of geriatric medicine not only to treat health conditions and reduce suffering in older persons, but also to "engage in work either to endorse or to reconstruct patients' [ageist] conceptions of their own ageing and health" (Coupland and Coupland 1994). It is our view that the health care system has an obligation to actively address ageism - in patients, in the professionals working within the system, and in the systems themselves.

In conclusion, the health care system can be improved for patients and health care providers alike through acknowledging and working to eliminate ageism. To this end, continued research in this area is certainly needed. Future research efforts should strive be more theoretically-based, and might focus on further uncovering factors that influence the development and maintenance of age discrimination in this setting. Hagestad and Uhlenberg (2005) argue that micro-level bias results in macro-level bias through the isolation of social sub-groups and subsequent reduced inter-group contact. Social networks - the meso-level at which ageism can be manifested - may be an important area for future research and intervention to address ageism in the health care setting. Certainly, improved education and training of the key players at all levels of geriatric health care is vital to reducing age bias. This includes hospital administrators, physicians, nurses, personal caregivers, and associated health professions. Acknowledging and working to reduce ageist attitudes in patients and their family caregivers cannot be neglected in these efforts, as ample evidence points to the important impact of self-directed ageism on health. We can take a cue from best-practice geriatric health care: these efforts need to be coordinated and collaborative, taking into account all sources and factors of age bias and discrimination, in order to address this problem. As stated quite succinctly by the physician who coined the term "ageism," Robert Butler: "ultimately, such initiatives will benefit all who would grow old" (Butler 2009). That means all of us. 


\section{References}

AGE Platform Europe. (2016). AGE Platform Europe Position on Structural Ageism. http://ageplatform.eu/images/stories/Publications/papers/AGE_IntergenerationalSolidarity_Position_ on_Structural_Ageism.pdf

Alliance for Aging Research. (2002). Medical never-never land: Ten reasons why America isn't ready for the coming age boom. Washington, DC: Alliance for Aging Research.

Ambady, N. (2002). Physical therapists' nonverbal communication predicts geriatric patients' health outcomes. Psychology and Aging, 17(3), 443.

Baltes, M. M., Burgess, R. L., \& Stewart, R. B. (1980). Independence and dependence in self-care behaviors in nursing home residents: An operant-observational study. International Journal of Behavioral Development, 3(4), 489-500.

Ben-Harush, A., Shiovitz-Ezra, S., Doron, I., Alon, S., Leibovitz, A., Golander, H., et al. (2016). Ageism among physicians, nurses, and social workers: Findings from a qualitative study. European Journal of Ageing, 14, 39. https://doi.org/10.1007/s10433-016-0389-9

Bhalla, A., Grieve, R., Tilling, K., Rudd, A. G., \& Wolfe, C. D. (2004). Older stroke patients in Europe: Stroke care and determinants of outcome. Age and Ageing, 33(6), 618-624.

Binney, E. A., Estes, C. L., \& Ingman, S. R. (1990). Medicalization, public policy and the elderly: Social services in jeopardy? Social Science \& Medicine, 30(7), 761-771.

Boswell, S. S. (2012). Predicting trainee ageism using knowledge, anxiety, compassion, and contact with older adults. Educational Gerontology, 38(11), 733-741.

Bodner, E., Palgi, Y., \& Wyman, F. (2018). Ageism in mental health assessment and treatment of older adults. In L. Ayalon \& C. Tesch-Römer (Eds.), Contemporary perspectives on ageism: Vol. 19. International perspectives on aging (pp. 241-262). Berlin: Springer.

Boult, C., Boult, L. B., Morishita, L., Dowd, B., Kane, R. L., \& Urdangarin, C. F. (2001). A randomized clinical trial of outpatient geriatric evaluation and management. Journal of the American Geriatrics Society, 49(4), 351-359.

Bowling, A. (1999). Ageism in cardiology. The BMJ, 319, 1353-1355.

Bragg, E. J., Warshaw, G. A., Meganathan, K., \& Brewer, D. E. (2012). The development of academic geriatric medicine in the United States 2005 to 2010: An essential resource for improving the medical care of older adults. Journal of the American Geriatrics Society, 60(8), 1540-1545.

Breslau, E., Gorin, S., Edwards, H., Schonberg, M., Saiontz, N., \& Walter, L. (2016). An individualized approach to cancer screening decisions in older adults: A multilevel framework. Journal of General Internal Medicine, 31(5), 539-547.

Butler, R. N. (1975). Psychiatry and the elderly: An overview. American Journal of Psychiatry, 132(9), 893-900.

Butler, R. N. (2009). Combating ageism. International Psychogeriatrics, 21, 211.

Buttigieg, S., Ilinca, S., Jose, M. S., \& Larsson, A. T. (2018). Researching ageism in health-care and long term care. In L. Ayalon \& C. Tesch-Römer (Eds.), Contemporary perspectives on ageism: Vol. 19. International perspectives on aging (pp. 491-513). Berlin: Springer.

Caris-Verhallen, W. M., de Gruijter, I. M., Kerkstra, A., \& Bensing, J. M. (1999). Factors related to nurse communication with elderly people. Journal of Advanced Nursing, 30(5), 1106-1117.

Cherubini, A., Oristrell, J., Pla, X., Ruggiero, C., Ferretti, R., Diestre, G., et al. (2011). The persistent exclusion of older patients from ongoing clinical trials regarding heart failure. Archives Internal Medicine, 171(6), 550-556.

Chodosh, J., Tulsky, A., Naumburg, E., Branca, L., Frankel, R. M., McCann, R. M., et al. (1999). What residents want to know about geriatrics: An approach to curriculum development. Gerontology \& Geriatrics Education, 20(2), 19-35.

Coupland, J., \& Coupland, N. (1994). Old age doesn't come alone': Discursive representations of health-in-aging in geriatric medicine. The International Journal of Aging \& Human Development, 39(1), 81-95.

Courtney, M., Tong, S., \& Walsh, A. (2000). Acute-care nurses' attitudes towards older patients: A literature review. International Journal of Nursing Practice, 6(2), 62-69.

Daniels, N. (2013). Global aging and the allocation of health care across the life span. American Journal of Bioethics, 13(8), 1-2. https://doi.org/10.1080/15265161.2013.807187 
European Commission. (2008). Quality in and equality of access to healthcare services. Retrieved from http://ec.europa.eu/social

Fialová, D., Kummer, I., Držaić, M., \& Leppee, M. (2018). Ageism in medication use in older patients. In L. Ayalon \& C. Tesch-Römer (Eds.), Contemporary perspectives on ageism: Vol. 19. International perspectives on aging (pp. 214-240). Berlin: Springer.

Gawande, A. (2014). Being mortal. London: Profile Books, Wellcome Collection.

Gaynor, E. J., Geoghegan, S. E., \& O’Neill, D. (2014). Ageism in stroke rehabilitation studies. Age and Ageing, 43(3), 429-431.

Gekoski, W. L., \& Knox, V. J. (1990). Ageism or healthism? Perceptions based on age and health status. Journal of Aging and Health, 2(1), 15-27.

Goyal, S., Kamel, M., \& Thomas-Hemak, L. (2012). Patient protection and affordable care act: Implications for geriatrics practice. http://www.todaysgeriatricmedicine.com/news/ ex_101912.shtml. Accessed 10 Apr 2016.

Greenberg, J., Schimel, J., \& Martens, A. (2002). Ageism: Denying the face of the future. In T. D. Nelson (Ed.), Ageism: Stereotyping and prejudice against older persons (pp. 27-48). Cambridge, MA: The MIT Press.

Greene, M. D., Adelman, R. D., \& Rizzo, C. (1996). Problems in communication between physicians and older patients. Journal of Geriatric Psychiatry, 29(1), 13-32.

Gunderson, A., Tomkowiak, J., Menachemi, N., \& Brooks, R. (2005). Rural physicians' attitudes toward the elderly: Evidence of ageism? Quality Management in Health Care, 14(3), 167-176.

Hadbavna, A., \& O'Neill, D. (2013). Ageism in interventional stroke studies. Journal of the American Geriatrics Society, 61(11), 2054-2055.

Hagestad, G., \& Uhlenberg, P. (2005). The social separation of old and young: A root of ageism. Journal of Social Issues, 61(2), 343-360.

Haigney, E., Morgan, R., King, D., \& Spencer, B. (1997). Breast examinations in older women: Questionnaire survey of attitudes of patients and doctors. The BMJ, 315(7115), 1058-1059.

Harries, C., Forrest, D., Harvey, N., McClelland, A., \& Bowling, A. (2007). Which doctors are influenced by a patient's age? A multi-method study of angina treatment in general practice, cardiology and gerontology. Quality \& Safety in Health Care, 16(1), 23-27.

Hausdorff, J. M., Levy, B. R., \& Wei, J. Y. (1999). The power of ageism on physical function of older persons: Reversibility of age-related gait changes. Journal of the American Geriatrics Society, 47(11), 1346-1349.

Hayes, L. J., Orchard, C. A., McGillis Hall, L., Nincic, V., O’Brien-Pallas, L., \& Andrews, G. (2006). Career intentions of nursing students and new nurse graduates: A review of the literature. International Journal of Nursing Education Scholarship, 3(1), Article26. https://doi. org/10.2202/1548-923x.1281

Institute of Medicine. (2008). Retooling for an aging America: Building the health care workforce. Washington, DC: National Academies Press.

International Longevity Center. (2006). Ageism in America. New York: International Longevity Center.

Iversen, T. N., Larsen, L., \& Solem, P. E. (2009). A conceptual analysis of ageism. Nordic Psychology, 61(3), 4-22. https://doi.org/10.1027/1901-2276.61.3.4

Jacobsen, F. F. (2015). Understanding public elderly care policy in Norway: A narrative analysis of governmental white papers. Journal of Aging Studies, 34, 199-205.

James, J. W., \& Haley, W. E. (1995). Age and health bias in practicing clinical psychologists. Psychology and Aging, 10(4), 610-616.

Javid, S. H., Unger, J. M., Gralow, J. R., Moinpour, C. M., Wozniak, A. J., Goodwin, J. W., et al. (2012). A prospective analysis of the influence of older age on physician and patient decisionmaking when considering enrollment in breast cancer clinical trials (SWOG S0316). The Oncologist, 17(9), 1180-1190.

Jecker, N. S. (2013). Justice between age groups: An objection to the prudential lifespan approach. American Journal of Bioethics, 13(8), 3-15. https://doi.org/10.1080/15265161.2013.802061

Kagan, S. H. (2008). Ageism in cancer care. Seminars in Oncology Nursing, 24(4), 246-253.

Kearney, N., Miller, M., Paul, J., \& Smith, K. (2000). Oncology healthcare professionals' attitudes toward elderly people. Annals of Oncology, 11(5), 599-601. 
Kemeny, M. M., Peterson, B. L., Kornblith, A. B., Muss, H. B., Wheeler, J., Levine, E., et al. (2003). Barriers to clinical trial participation by older women with breast cancer. Journal of Clinical Oncology, 21(12), 2268-2275.

Konig, H. H., Leicht, H., Bickel, H., Fuchs, A., Gensichen, J., Maier, W., et al. (2013). Effects of multiple chronic conditions on health care costs: An analysis based on an advanced tree-based regression model. BMC Health Services Research, 13, 219. https://doi. org/10.1186/1472-6963-13-219

Krain, L. P., Fitzgerald, J. T., Halter, J. B., \& Williams, B. C. (2007). Geriatrics attitudes and knowledge among surgical and medical subspecialty house officers. Journal of the American Geriatrics Society, 55(12), 2056-2060.

Kuhlmey, A., Winter, M. H., Maaz, A., Hofmann, W., Nordheim, J., \& Borchert, C. (2003). High utilization of health care services by older adults. Zeitschrift für Gerontologie und Geriatrie, 36(3), 233-240.

Kydd, A., Touhy, T., Newman, D., Fagerberg, I., \& Engstrom, G. (2014). Attitudes towards caring for older people in Scotland, Sweden and the United States. Nursing Older People, 26(2), 33-40. https://doi.org/10.7748/nop2014.02.26.2.33.e547

Lambrinou, E., Sourtzi, P., Kalokerinou, A., \& Lemonidou, C. (2009). Attitudes and knowledge of the Greek nursing students towards older people. Nurse Education Today, 29(6), 617-622.

Lehnert, T., Heider, D., Leicht, H., Heinrich, S., Corrieri, S., Luppa, M., et al. (2011). Review: Health care utilization and costs of elderly persons with multiple chronic conditions. Medical Care Research and Review, 68(4), 387-420.

Leung, S., Logiudice, D., Schwarz, J., \& Brand, C. (2011). Hospital doctors' attitudes towards older people. Internal Medicine Journal, 41(4), 308-314.

Levenson, A. J. (1981). Ageism: A major deterrent to the introduction of curricula in aging. Gerontology \& Geriatrics Education, 1(3), 161-162.

Levy, B. R. (2001). Eradication of ageism requires addressing the enemy within. The Gerontologist, $41(5), 578-579$.

Levy, B. R., \& Banaji, M. R. (2002). Implicit ageism. In T. D. Nelson (Ed.), Ageism: Stereotyping and prejudice against older persons (pp. 49-75). Cambridge, MA: The MIT Press.

Levy, B. R., \& Myers, L. M. (2004). Preventive health behaviors influenced by self-perceptions of aging. Preventive Medicine, 39(3), 625-629.

Levy, B. R., Kosteas, J., Slade, M., \& Myers, L. (2006). Exclusion of elderly persons from healthrisk behavior clinical trials. Preventive Medicine, 43(2), 80-85.

Levy, B. R., Zonderman, A. B., Slade, M. D., \& Ferrucci, L. (2009). Age stereotypes held earlier in life predict cardiovascular events in later life. Psychological Science, 20(3), 296-298.

Levy, B. R., Ferrucci, L., Zonderman, A. B., Slade, M. D., Troncoso, J., \& Resnick, S. M. (2016). A culture-brain link: Negative age stereotypes predict Alzheimer's disease biomarkers. Psychology and Aging, 31(1), 82-88.

Lievesley, N. (2009). Ageism and age discrimination in secondary health care in the United Kingdom: A review from the literature. London: Centre for Policy on Aging Department of Health.

Liu, Y. E., While, A. E., Norman, I. J., \& Ye, W. (2012). Health professionals' attitudes toward older people and older patients: A systematic review. Journal of Interprofessional Care, 26(5), 397-409. https://doi.org/10.3109/13561820.2012.702146

Liu, Y. E., Norman, I. J., \& While, A. E. (2013). Nurses' attitudes towards older people: A systematic review. International Journal of Nursing Studies, 50(9), 1271-1282. https://doi. org/10.1016/j.ijnurstu.2012.11.021

Liu, Y. E., Norman, I. J., \& While, A. E. (2015). Nurses' attitudes towards older people and working with older patients: An explanatory model. Journal of Nursing Management, 23(8), 965973. https://doi.org/10.1111/jonm.12242

Lookinland, S., \& Anson, K. (1995). Perpetuation of ageist attitudes among present and future health care personnel: Implications for elder care. Journal of Advanced Nursing, 21(1), 47-56.

Lui, N. L., \& Wong, C. H. (2009). Junior doctors' attitudes towards older adults and its correlates in a tertiary-care public hospital. Annals, Academy of Medicine, Singapore, 38(2), 125-129.

Luker, J. A., Wall, K., Bernhardt, J., Edwards, I., \& Grimmer-Somers, K. A. (2011). Patients' age as a determinant of care received following acute stroke: A systematic review. BMC Health Services Research, 11. https://doi.org/10.1186/1472-6963-11-161 
Madan, A. K., Aliabadi-Wahle, S., \& Beech, D. J. (2001). Ageism in medical students' treatment recommendations: The example of breast-conserving procedures. Academic Medicine, 76(3), 282-284.

Madan, A. K., Cooper, L., Gratzer, A., \& Beech, D. J. (2006). Ageism in breast cancer surgical options by medical students. Tennessee Medicine, 99(5), 37-38. 41.

Makris, U. E., Higashi, R. T., Marks, E. G., Fraenkel, L., Sale, J. E., Gill, T. M., \& Reid, M. C. (2015). Ageism, negative attitudes, and competing co-morbidities--why older adults may not seek care for restricting back pain: A qualitative study. BMC Geriatrics, 15, 39. https://doi. org/10.1186/s12877-015-0042-z

Martens, A., Goldenberg, J. L., \& Greenberg, J. (2005). A terror management perspective on ageism. Journal of Social Issues, 61(2), 223-239.

McLafferty, I., \& Morrison, F. (2004). Attitudes towards hospitalized older adults. Journal of Advanced Nursing, 47(4), 446-453.

McLaughlin, T. J., Soumerai, S. B., Willison, D. J., Gurwitz, J. H., Borbas, C., Guadagnoli, E., et al. (1996). Adherence to national guidelines for drug treatment of suspected acute myocardial infarction: Evidence for undertreatment in women and the elderly. Archives of Internal Medicine, 156(7), 799-805.

Meisner, B. A. (2012). Physicians' attitudes toward aging, the aged, and the provision of geriatric care: A systematic narrative review. Critical Public Health, 22(1), 61-72. https://doi.org/10.1 080/09581596.2010.539592

Nelson, T. D. (2005). Ageism: Prejudice against our feared future self. Journal of Social Issues, 61(2), 207-221.

Ng, R., Allore, H. G., Trentalange, M., Monin, J. K., \& Levy, B. R. (2015). Increasing negativity of age stereotypes across 200 years: Evidence from a database of 400 million words. PLoS One, 10(2), e0117086. https://doi.org/10.1371/journal.pone.0117086

Nies, H., \& Berman, P. (2004). Integrating services for older people: A resource book for managers. Dublin: European Health Management Association.

Nussbaum, J. F., Pitts, M. J., Huber, F. N., Krieger, J. L. R., \& Ohs, J. E. (2005). Ageism and ageist language across the life span: Intimate relationships and non-intimate interactions. Journal of Social Issues, 61(2), 287-305.

Palmore, E. (1990). Ageism: Negative and positive. New York: Springer.

Palmore, E. (2001). The ageism survey: First findings. The Gerontologist, 41(5), 572-575.

Peake, M. D., Thompson, S., Lowe, D., \& Pearson, M. G. (2003). Ageism in the management of lung cancer. Age and Ageing, 32(2), 171-177.

Prince, M. J., Wu, F., Guo, Y., Gutierrez Robledo, L. M., O’Donnell, M., Sullivan, R., \& Yusuf, S. (2015). The burden of disease in older people and implications for health policy and practice. Lancet, 385(9967), 549-562. https://doi.org/10.1016/s0140-6736(14)61347-7

Robb, C., Chen, H., \& Haley, W. E. (2002). Ageism in mental health and health care: A critical review. Journal of Clinical Geropsychology, 8(1), 1-12.

Rudd, A. G., Hoffman, A., Down, C., Pearson, M., \& Lowe, D. (2007). Access to stroke care in England, Wales and Northern Ireland: The effect of age, gender and weekend admission. Age and Ageing, 36(3), 247-255.

Saposnik, G., Kapral, M. K., Coutts, S. B., Fang, J., Demchuk, A. M., \& Hill, M. D. (2009). Do all age groups benefit from organized inpatient stroke care? Stroke, 40(10), 3321-3327.

Shaw, A. B. (1994). In defence of ageism. Journal of Medical Ethics, 20(3), 188-191, 194.

Snyder, M., \& Miene, P. K. (1994). Stereotyping of the elderly: A functional approach. British Journal of Social Psychology, 33(1), 63-82.

Soderhamn, O., Lindencrona, C., \& Gustavsson, S. M. (2001). Attitudes toward older people among nursing students and registered nurses in Sweden. Nurse Education Today, 21(3), 225 229. https://doi.org/10.1054/nedt.2000.0546

Tanner, D. (2003). Older people and access to care. British Journal of Social Work, 33(4), 499-515.

Theofanidis, D. (2015). A qualitative study on discrimination and ethical implications in stroke care in contemporary Greece. Journal of Vascular Nursing, 33(4), 138-142. https://doi. org/10.1016/j.jvn.2015.05.040 
Thiem, U., Hinrichs, T., Muller, C. A., Holt-Noreiks, S., Nagl, A., Bucchi, C., et al. (2011). Prerequisites for a new health care model for elderly people with multiple morbidities: Results and conclusions from 3 years of research in the PRISCUS consortium. Zeitschrift für Gerontologie und Geriatrie, 44(Suppl 2), 101-112. https://doi.org/10.1007/s00391-011-0246-6

Topinkova, E., Baeyens, J. P., Michel, J. P., \& Lang, P. O. (2012). Evidence-based strategies for the optimization of pharmacotherapy in older people. Drugs \& Aging, 29(6), 477-494. https://doi. org/10.2165/11632400-000000000-00000

Townsley, C. A., Selby, R., \& Siu, L. L. (2005). Systematic review of barriers to the recruitment of older patients with cancer onto clinical trials. Journal of Clinical Oncology, 23(13), 31123124. https://doi.org/10.1200/jco.2005.00.141

United Kingdom Department of Health. (2001). National service framework for older people. London: Department of Health.

Vauclair, C. M., Marques, S., Lima, M. L., Abrams, D., Swift, H., \& Bratt, C. (2015). Perceived age discrimination as a mediator of the association between income inequality and older people's self-rated health in the European region. Journals of Gerontology, B: Psychological Sciences and Social Sciences, 70(6), 901-912.

Walter, L., Lewis, C., \& Barton, M. (2005). Screening for colorectal, breast, and cervical cancer in the elderly: A review of the evidence. The American Journal of Medicine, 118(10), 1078-1086.

Walters, K., Iliffe, S., \& Orrell, M. (2001). An exploration of help-seeking behaviour in older people with unmet needs. Family Practice, 18(3), 277-282.

Wells, Y., Foreman, P., Gething, L., \& Petralia, W. (2004). Nurses' attitudes toward aging and older adults--examining attitudes and practices among health services providers in Australia. Journal of Gerontological Nursing, 30(9), 5-13.

Wenger, N. K. (1997). Coronary heart disease: An older woman's major health risk. The BMJ, 315(7115), 1085-1090.

Westerhof, G. J., Miche, M., Brothers, A. F., Barrett, A. E., Diehl, M., Montepare, J. M., et al. (2014). The influence of subjective aging on health and longevity: A meta-analysis of longitudinal data. Psychology and Aging, 29(4), 793-802.

Williams, P. W. (2009). Age discrimination in the delivery of health care services to our elders. Marquette Elder's Advisor, 11(1). http://scholarship.law.marquette.edu/elders/vol11/iss1/3

Witham, M. D., \& McMurdo, M. E. (2007). How to get older people included in clinical studies. Drugs \& Aging, 24(3), 187-196.

World Health Organization. (2008). Global burden of disease: 2004 update. Geneva: World Health Organization.

Wurm, S., Tomasik, M. J., \& Tesch-Römer, C. (2010). On the importance of a positive view on ageing for physical exercise among middle-aged and older adults: Cross-sectional and longitudinal findings. Psychology \& Health, 25(1), 25-42. https://doi.org/10.1080/08870440802311314

Open Access This chapter is licensed under the terms of the Creative Commons Attribution 4.0 International License (http://creativecommons.org/licenses/by/4.0/), which permits use, sharing, adaptation, distribution and reproduction in any medium or format, as long as you give appropriate credit to the original author(s) and the source, provide a link to the Creative Commons license and indicate if changes were made.

The images or other third party material in this chapter are included in the chapter's Creative Commons license, unless indicated otherwise in a credit line to the material. If material is not included in the chapter's Creative Commons license and your intended use is not permitted by statutory regulation or exceeds the permitted use, you will need to obtain permission directly from the copyright holder.

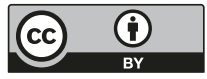




\title{
Chapter 14 \\ Ageism in Medication Use in Older \\ Patients
}

\author{
Daniela Fialová, Ingrid Kummer, Margita Držaić, and Marcel Leppee
}

\subsection{Introduction}

Medications and doses are often similarly prescribed to older and younger adult patients (Somers 2016). This is a problem that must be viewed as ageist, because pharmacological studies have shown for decades that many medications act differently in older and younger people due to the physiological and pathological changes that accompany ageing. Many medications have different efficacy and safety profiles in younger and older age groups (American Geriatrics Society (AGS) 2015; Fialová and Onder 2009; Pazan et al. 2016). For this reason, treating older adults the same as younger adults when prescribing medication, without respecting age-specific needs in terms of such issues as individual dose adjustments, geriatric drug forms, and geriatric medication management, can be seen as a form of ageism. Among older adults, the selection of medication, dosing schedules, and combined drug regimens, as well as appropriate follow-up and management of medication treatment, should always be age-specific and highly individualized. Unfortunately, this is not a common clinical practice (Fialová and Onder 2009; Petrovic et al. 2016).

The appendix for a list of abbreviations used in this chapter is located at the end of the chapter.

D. Fialová $(\bowtie)$

Department of Social and Clinical Pharmacy, Faculty of Pharmacy in Hradec Králové,

Charles University, Prague, Czech Republic

Department of Geriatrics and Gerontology, 1st Faculty of Medicine and General Teaching Hospital, Charles University, Prague, Czech Republic

e-mail: daniela.fialova@faf.cuni.cz

I. Kummer · M. Držaić

Gradska Ljekarna Zagreb, Zagreb, Croatia

M. Leppee

Department of Public Health and Department of Pharmacoepidemiology, Andrija Stampar Institute for Public Health, Zagreb, Croatia

L. Ayalon, C. Tesch-Römer (eds.), Contemporary Perspectives on Ageism, International Perspectives on Aging 19, https://doi.org/10.1007/978-3-319-73820-8_14 
In 1969, Butler defined ageism as "systematic stereotyping and discrimination against older people because of their higher age" (Achenbaum 2014). Based strictly on this definition, non-discrimination of older adults in medication use could be understood as providing the same treatments to older adults as to younger adults. However, this "age-blind" approach has actually translated into some discriminatory practices towards older patients, including not prescribing safer and equally economically available drugs with lower therapeutic risks, not selecting geriatric low-dose drug regimens, prescribing medication with unknown efficacy in older patients with the potential to cause substantial harm, prescribing risky polypharmacy, and so on (Fialová et al. 2005; Fialová and Onder 2009; Petrovic et al. 2016).

This age-blind approach leads to a variety of direct and indirect forms of ageism (Coupland and Coupland 1993, 1998 Ouchida and Lachs 2015). Implicit ageist attitudes may be present as negative thoughts, feelings, and behaviours toward older people that may occur without conscious control and awareness. These can be reduced by self-assessment methods and training techniques aimed at overcoming implicit ageism (Adelman et al. 2000; Levy 2001). Explicit ageist attitudes may be exacerbated by persistent misconceptions that older patients are often demented, incontinent, depressed, and somehow "unsalvageable". Higashi et al. (2012) described some of these ageist attitudes among young medical trainees. For example, one of the trainees said, "It's always a bigger save when you help a 35-year-old woman with kids than it is to bring an altered 89-year-old woman with a urinary tract infection back to her semi-altered state" (Higashi et al. 2012). Direct ageism also occurs when it is considered normal and expected to have side effects from medications because "that's just the way it is when people are old" and when healthcare professionals consider older patients to be just "poor old dears," unable to look after themselves (Brossoie 2013). Becoming aware of these attitudes is one of the first steps in reducing ageism and is the responsibility of every healthcare professional caring for older persons (Brossoie 2013).

"Hidden" forms of ageism may also occur, for example, as a consequence of poorly coordinated, non-appropriately managed geriatric care (Ouchida and Lachs 2015). Moreover, fragmented healthcare systems limit healthcare communication, especially with older people, and reduce older patients' access to adequate care (Adelman et al. 2000). For additional information on ageism in the healthcare system, see Wyman, Shiovitz-Ezra, and Bengel, 2018, Chap. 13 in this volume.

\subsection{Aspects of Ageism and Inappropriate Medication Use in Older Patients}

For many frequently prescribed medications (e.g., some cholinesterase inhibitors, antidepressants, and antivertiginous agents), clinical data from randomized controlled trials (RCTs) on standard dosing, clinically approved indications, and specific risks in geriatric patients are not available (Fialová and Onder 2009). This is 
because, in the past, older patients were explicitly excluded from RCTs due to their higher age and higher probability of drug risks (Crome et al. 2011). During work on the new "Fit fOR the Aged" (FORTA) geriatric recommendations, Wehling and his team (Wehling 2016) reviewed the German Association of Scientific Medical Societies Guideline Register and found that only 2 out of 926 clinical guidelines explicitly addressed geriatric patients. One guideline dealt with nutrition in older patients and the other addressed the treatment of urinary incontinence. Information in other guidelines on specific aspects of drug therapy in older patients was short and vague, not addressing the complexity of clinical needs in older patients (Wehling 2016). However, the majority of current users of medication are geriatric patients. They are often prescribed multiple drug combinations despite a substantial gap in our knowledge about the efficacy and safety of multiple drug regimens in older adults. This gap is a direct product of ageist practices, which excluded older adults from clinical trials. These ethical problems also contribute to ageism in medication use.

Existing studies have described discrimination towards older patients in the provision of drug treatments. For example, sometimes treatable pathologies are dismissed because they are considered just common problems in old age. This phenomenon frequently leads to underdiagnosing and undertreating pain, depression, dementia, and other comorbidities in older adults (Cherubini et al. 2012). Other age-related drug provision problems include indication of a new drug or drugs for wrongly diagnosed drug-related problems (DRPs) and not reducing a dose or not withdrawing harmful medication (Kane et al. 2004; Routledge et al. 2004). Also, unnecessary overuse of some diagnostic tests and failure to provide appropriate geriatric care in poorly coordinated and fragmented healthcare systems are forms of ageism that can result in inadequate drug treatment for older adults (Fialová and Onder 2009; Qaseem et al. 2012).

In addition to an age-specific approach, highly individualized drug therapy is also necessary, particularly when treating older adults with complex conditions. Some older patients suffer from several disorders, disability, and are frail; they may use multiple medications (polypharmacy) and may be exposed to a variety of risk factors, such as memory problems, decreased ability to handle medication, and economic and social problems. Older patients should therefore be specifically protected from adverse drug outcomes by highly individualized medication treatment and highly individualized care that not only includes age-specific approaches, but also considers individual risk factors and individual goals of care (Fialová and Onder 2009; Petrovic et al. 2016). By not providing such highly individualized care, healthcare professionals and sometimes even healthcare managers promote ageist attitudes and approaches which compromise the health and wellbeing of older adults.

This chapter focusses on the association between ageism and three types of inappropriate medication use in older patients: inappropriate prescribing, polypharmacy and/or polyherbacy, and medication nonadherence. Definitions, risk factors, and negative outcomes of these three phenomena are comprehensively described (for an overview of negative outcomes see Table 14.1), as well as future possibilities for improvements. 
Table 14.1 Negative consequences of polypharmacy, suboptimal prescribing and medication nonadherence

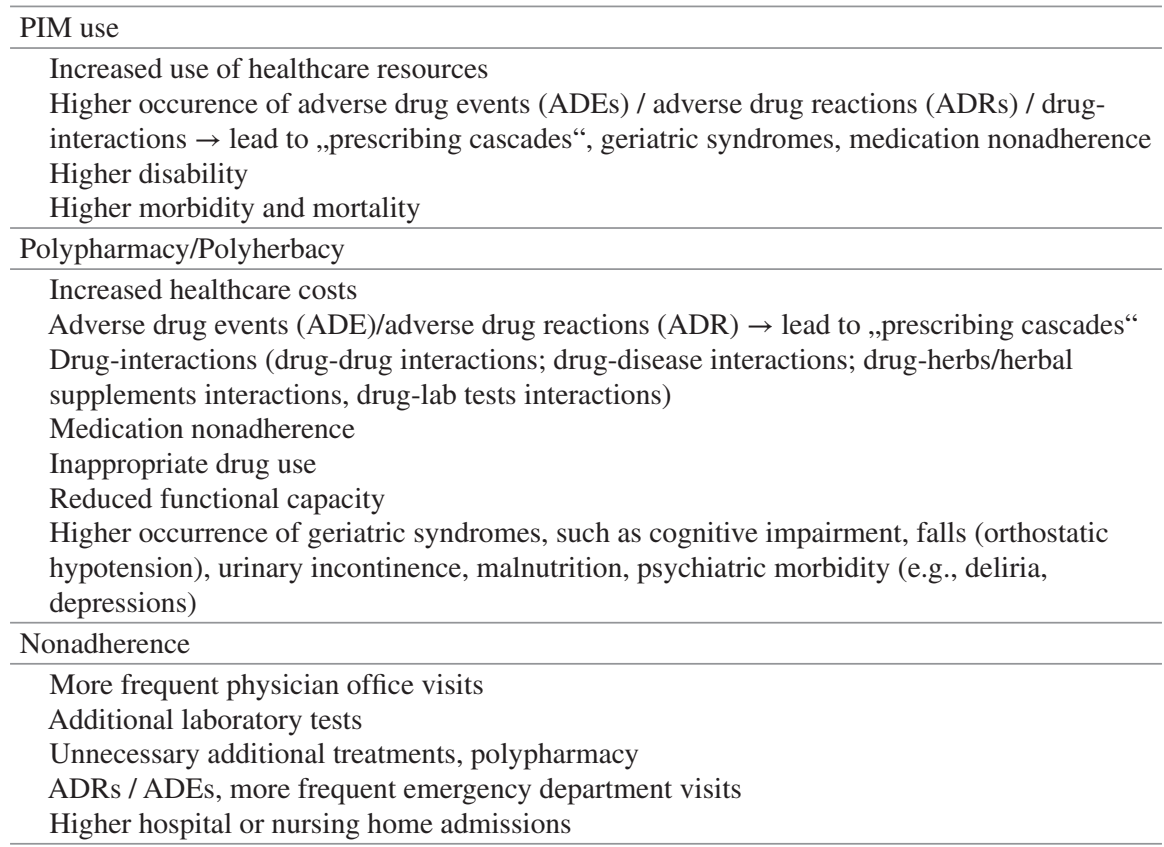

References: Abdulraheem (2013), Akazawa et al. (2010), ASA/ASCPF (2006), Gurwitz et al. (2003), Leendertse et al. (2011), Maher et al. (2014), Sabaté (2003), Scheen and Giet (2010), Spinewine et al. (2012), Strandberg (1984), and Vermiere et al. (2001)

\subsection{Inappropriate Prescribing in Older Patients and Aspects of Ageism}

\subsubsection{Definitions and Epidemiology of Inappropriate Prescribing in Older Adults}

Inappropriate prescribing in older patients is understood in many studies to be the prescribing of medication that is potentially inappropriate in older age. These socalled PIMs (potentially inappropriate medications) have been identified by a consensus of expert panels as medications that carry more risks than benefits for older adults. While safer alternatives exist in the pharmaceutical market, PIMs should not be prescribed to older patients because of their higher risks of drug-therapy problems. The best-known clinical criteria for describing these medications are the Beers Criteria (AGS 2015) and STOPP (Screening Tool of Older People's Prescriptions)/START (Screening Tool to Alert to Right Treatment) criteria (O’Mahony et al. 2015).

Unfortunately, previous studies have documented a high prevalence (14.6-44\%) of PIMs being used in hospitalized older adults (Hajjar et al. 2005; Onder et al. 
2003); $19.3 \%$ in older patients admitted to emergency department units (Chen et al. 2009); up to 48-59.2\% in community-residing older patients (Baldoni et al. 2014); and $43 \%$ in older adults residing in nursing home facilities (measured as overall weighted point prevalence in a systematic review of studies) (Morin et al. 2016).

Prescription of PIMs, however, presents only one piece of suboptimal prescribing in older patients. Hanlon et al. (2001) define suboptimal prescribing in the geriatric population using the following three categories:

- Overprescribing or overuse of medicines: application of higher doses of medicine than is clinically necessary; excessive or inappropriate polypharmacy; longterm use of medication without proved efficacy; use of medication in vague indications

- Underprescribing or underuse of medicines: use of lower than optimal doses; not prescribing medications known to be effective and safe in geriatric patients

- Inappropriate prescribing: prescribing PIMs in geriatric patients; prescribing despite known drug-drug or drug-disease interactions

Inappropriate medication use is a general term describing a range of problems arising from the prescription, administration, and storing of medication, as well as problems with medication nonadherence (Griese and Leikola 2014). According to the Pharmaceutical Care Network of Europe (PCNE), all of these problems are classified as drug related problems (DRPs). A DRP is by definition "an event or circumstance involving drug therapy that actually or potentially interferes with desired health outcomes" (Griese and Leikola 2014; Somers 2016) and can include adverse drug reactions (ADRs), drug-disease interactions, drug-drug interactions (DDI), drug therapy failures, inadequate dosing, drug use without indication, patient nonadherence, and many other DRPs.

\subsubsection{Risks Factors of Inappropriate Prescribing in Older Patients}

Inappropriate prescribing in older patients is usually the result of multiple risk factors, such as:

- Inadequacies in the provision of healthcare, such as ineffective care at the interface between hospital and primary care and inappropriate systems for repeated prescriptions;

- Lack of geriatric knowledge among prescribers or inadequate use of some therapeutics in relation to multimorbidity (e.g., some high-risk medications such as nonsteroidal anti-inflammatory drugs, anticoagulants, diuretics, psychotropics), and inadequate training in recognizing adverse drug interactions and reactions;

- Clinical guidelines aimed at managing single but not multiple conditions;

- Failure to recognize the need to stop inappropriate treatments; 
- Psycho-social reasons on the side of prescriber, such as the desire to please patients, feeling pressured to prescribe medication, and balancing between prescribers' experiences and clinical evidence (Cullinan et al. 2014; Fialová and Onder 2009; Petrovic et al. 2016).

Older patients are often treated by several healthcare professionals, including different prescribing physicians, which may lead to duplicate prescribing and serious problems with inappropriate prescribing. There are also inconsistencies in updates on information about indications, duration of therapy, monitoring of adverse reactions and follow-up of safety and effectiveness of medications prescribed to older patients. Problems also arise from the lack of training in undertaking complex medication reviews among prescribers and the fact that prescribers often do not have time to undertake such reviews in routine clinical practice (Avery et al. 2012).

The risk factors positively associated with prescribing medications that are potentially inappropriate for older adults (see Table 14.2) include the following: polypharmacy; psychotropic drug use; polymorbidity (mostly colinear with polypharmacy); specific health conditions, such as depression and psychoses; sociodemographic factors, such as low socioeconomic status, low income, low education level, illiteracy, and being single. Some risk factors relate to management and quality of healthcare, such as hospital stay of ten or more days; institutional care; longer stay in the nursing home; having more than one prescriber; and frequent physician visits (Baldoni et al. 2014; Chen et al. 2012; Fialová et al. 2005; Haasum et al. 2012; Lin et al. 2011; Niwata et al. 2006; Undela et al. 2014; Vieira de Lima et al. 2013; Zhan et al. 2001). Studies have found that older patients with psychiatric disorders had up to five times higher risk of being prescribed PIMs than other older patients (Vieira de Lima et al. 2013), and that a diagnosis of acute illness increased the risk of PIM prescribing more than eight times (Lin et al. 2011).

Many of the risk factors described above may indicate ageist attitudes and behaviour. When older patients frequently visit the physician's office, require acute care, or stay longer in nursing homes, they run a higher risk of being prescribed PIMs. More frequent use of PIMs has also been documented among older patients already at higher risk of adverse drug events (ADEs) for other reasons, such as in polymorbid older patients using polypharmacy and those using psychotropic drugs (Baldoni et al. 2014; Chen et al. 2012; Fialová et al. 2005; Haasum et al. 2012), even though drug risks should be rigorously reviewed in these groups of patients. Zhan et al. (2001) discussed, based on their findings, that visits at physicians' offices may frequently end with drug prescription in order to satisfy the patient. Some studies also showed that if older patients were more dependent on the prescriber (e.g., when they suffered from psychiatric illness, were in a poor economic situation, or did not have a partner) they were at significantly higher risk of inappropriate prescribing (Baldoni et al. 2014; Fialová et al. 2005; Qato and Trivedi 2013; Vieira de Lima et al. 2013). These examples suggest ageist behaviour, even though ageism has not yet been thoroughly studied in relation to prescribing practices.

PIMs include older medicines that have been available in the pharmaceutical market for decades. They can be cheaper than safer drug alternatives and are usually 
Table 14.2 Risk factors associated with use of potentially inappropriate medications (PIMs)

\begin{tabular}{|c|c|c|}
\hline & Positively associated & Negatively associated \\
\hline \multirow[t]{4}{*}{$\begin{array}{l}\text { Demographic factors/ } \\
\text { socio-economic } \\
\text { factors }\end{array}$} & $\begin{array}{l}\text { Age groups from } 65 \text { to } 80 / 85 \text { years (in the } \\
\text { majority of studies) }(*) \text { female gender (in the } \\
\text { majority of studies, usually collinear with } \\
\text { having more health compliants and using } \\
\text { polypharmacy) } \$(*)\end{array}$ & $\begin{array}{l}\text { Very old patients } 85+\text { (in } \\
\text { the majority of studies) \$ }\end{array}$ \\
\hline & Living alone/not having a partner $(*)$ & $\begin{array}{l}\text { Not visiting a physician } \\
\text { (in some studies collinear } \\
\text { with living along and not } \\
\text { having a caregiver) }\end{array}$ \\
\hline & Poor economic situation, low income $(*)$ & \\
\hline & Illiteracy $(*)$ & \\
\hline \multirow{5}{*}{$\begin{array}{l}\text { Disease- related } \\
\text { factors }\end{array}$} & Psychiatric disorders $(*)$ & Hypertension \\
\hline & $\begin{array}{l}\text { Rarely other disorders (e.g. neurological } \\
\text { disorders, cardiac arrhytmias; congestive } \\
\text { heart failure;et al.) }\end{array}$ & \multirow[t]{4}{*}{$\begin{array}{l}\text { Cognitive impairment / } \\
\text { severe cognitive } \\
\text { impairment, mental illness }\end{array}$} \\
\hline & Impaired physical functioning, disability $(*)$ & \\
\hline & Diagnosis of acute diseases $(*)$ & \\
\hline & Polymorbidity $(*)$ & \\
\hline \multirow{6}{*}{$\begin{array}{l}\text { Medication use and } \\
\text { medication } \\
\text { prescribing-related } \\
\text { factors }\end{array}$} & $\begin{array}{l}\text { Polypharmacy }(5+/ 6+, 9+/ 10+) \text {, number of } \\
\text { drugs }(*)\end{array}$ & \\
\hline & Psychotropic drug use (1 and more) $\left(^{*}\right)$ & \\
\hline & Antianxiety drugs ( 1 and more) $(*)$ & \\
\hline & Higher medication costs $(*)$ & \\
\hline & $\begin{array}{l}\text { More than } 1 \text { prescriber }(*), \text { prescribers' age } \\
>35 \text { years }\end{array}$ & \\
\hline & Frequent physician visits $(*)$ & \\
\hline \multirow{3}{*}{$\begin{array}{l}\text { Healthcare provision- } \\
\text { related factors }\end{array}$} & Hospital admission $(*)$ & \\
\hline & Longer hospital or nursing home stay $(*)$ & \\
\hline & Living in a institution $(*)$ & \\
\hline
\end{tabular}

References: Akazawa et al. (2010), Fialová et al. (2005), Chen et al. (2009), Chen et al. (2012), Lin et al. (2011), Niwata et al. (2006), Onder et al. (2003), Qato and Trivedi (2013), Undela et al. (2014), and Vieira de Lima et al. (2013)

Footnote: Many of above stated risk factors may be directly or indirectly linked to ageism (*) $\$-$ in some studies, positive association of PIM use with male gender and age group of patients $85+$ have been also documented

available without co-payments. For this reason, PIMs are often more economically available to poor older adults than safer drug alternatives (Fialová et al. 2005). This form of ageism occurs at the drug regulatory level, when safer drug alternatives are less available to older patients with economic difficulties due, among other things, to higher co-payments. 


\subsubsection{Negative Consequences of Inappropriate Prescribing in Older Patients}

As emphasized by many previous review studies, older patients suffer more often from drug-related problems and negative outcomes than younger adults (Beard 1992; Spinewine et al. 2012; for an overview of negative consequences see Table 14.1). At least $20-30 \%$ of patients in the 70-79 year old age group suffer from ADEs compared to 3-6\% among the 20-29 year old age group (Beard 1992; Fialová and Onder 2009; Spinewine et al. 2012). ADRs among older patients in acute care setting range between 5.8\% and 46.3\% (Alhawassi et al. 2014), and for older people the risk of ADR-related hospitalization is 4 times higher than for younger adults (16.6\% vs. $4.1 \%$ ) (Beijer and de Blaey 2002). However, in older patients, up to $88 \%$ of the ADR-related hospital admissions may be preventable, while for younger adults it is only 24\% (Beijer and de Blaey 2002). The extensive Hospital Admissions Related to Medication (HARM) study identified several risk factors for adverse drug outcomes due to inappropriate prescribing, namely: being 65 or older, polypharmacy ( $>5$ chronic medications), nonadherence, decreased cognitive function, renal impairment, four or more co-morbidities, and living alone (Leendertse et al. 2008).

Inappropriate prescribing substantially contributes to higher morbidity and mortality among older adults and significantly raises overall medication costs (e.g., cost of more frequent ambulatory office visits, costs associated with drugrelated health complications, and cost of drug-related admissions to acute hospitalization) (Bordet et al. 2001; Johnson and Bootman 1995; Leendertse et al. 2011). These costs are estimated to be 3-4 times higher than direct medication costs, and they substantially contribute to higher total expenditures for drug treatment in the healthcare system (Bordet et al. 2001; Johnson and Bootman 1995; Leendertse et al. 2011).

\subsubsection{Strategies to Reduce Inappropriate Prescribing in Older Patients and Aspects of Ageism}

Several studies have reviewed strategies for reducing inappropriate prescribing in older patients (e.g., Petrovic et al. 2016). Studies aimed at reducing inappropriate prescribing have used a variety of tools: decision-making support aids for prescribers; computer alerts for prescribing errors; medication reviews; training and learning methods; patient reminder systems; and novel methods of service provision (Duerden et al. 2013). In the United Kingdom, the PINCER trial was undertaken to evaluate whether a complex IT-based intervention was more effective than simple feedback in reducing medication error rates in general practices (GPs). At 6 months' follow-up, the GPs that received both computerized feedback and pharmacist 
support had significantly fewer prescribing errors than the GPs that received computerized feedback alone (Avery et al. 2012). Studies have shown that effective interventions improving drug prescribing must combine several methods and that multidisciplinary cooperation and the provision of clinical medication reviews are crucial to successful intervention (Petrovic et al. 2016). One simple strategy would be also to avoid prescribing highly complex drug regimens (polypharmacy) and PIMs.

The number of drugs approved for clinical use has increased exponentially on the US and European pharmaceutical markets. As described in the publication of Bernhardt et al. (2017), global pharmaceutical consumption has increased four times since 1970, with estimations of 760 billion dollars spent annually in 2015 (Bernhardt et al. 2017). Pharmaceutical firms and regulatory agencies have been found to switch more medications to over-the-counter (OTC) status (Francis et al. 2005). Some PIMs for older patients are already available as OTC medications (Francis et al. 2005), such as contact laxatives, loperamide, proton-pump inhibitors, and nonsteroidal anti-inflammatory drugs for systemic use. Increasing the number of registered active substances, brand names, drug forms, and OTCs contributes to more frequent medication errors (e.g., transcription errors during the prescribing process; drug duplication; dispensing errors; and errors in the use of medicines by patients themselves). Controlling drug prescribing and drug use appropriateness has become more and more complicated.

Considering the vulnerability of older adults to ADEs as well as the increase in population ageing, the trends described above can be seen to reflect ageism at the level of regulatory institutions as well as in society in general. Significant discrepancies in providing standard healthcare to older adults already exist, and population ageing and the concomitant lack of adequate numbers of healthcare professionals raise worries that the prevalence of ageist attitudes and inappropriate prescribing in geriatric patients might increase in the future. Solutions to this problem can potentially begin at the regulatory level, by more strictly regulating the availability of risky medications to geriatric patients; by regulating drug advertisements and internet sales; and by stricter regulations on switching more risky medications to OTC status. In many European countries, there is still insufficient support of safer, more geriatric-oriented clinical practice, and insufficient support of clinical pharmacy, and clinical pharmacology services that create important feedback (Fialová et al. 2005; Fialová and Desplenter 2016; Spinewine et al. 2012). In some EU countries, such as the UK, the Netherlands, Belgium, and several other countries, patients already benefit from clinical pharmacy services that significantly help to improve appropriateness of drug prescribing and reduce overall healthcare costs and ADEs in older adults (Fialová and Desplenter 2016). More support of these positive feedback strategies could help to optimize medication treatment in vulnerable populations, including geriatric patients. 


\subsection{Polypharmacy and Polyherbacy in Older Patients and Aspects of Ageism}

\subsubsection{Definitions and Epidemiology of Polypharmacy and Polyherbacy}

The majority of older adults, approximately three quarters of geriatric patients (Anderson 2010), suffer from multiple chronic conditions and are consequently prescribed multiple medications (Lorgunpai et al. 2014). Polypharmacy describes an individual's use of multiple medications; however, a uniform definition for polypharmacy has not yet been set (Votova et al. 2013). "Polypharmacy" is usually defined as the concurrent use of five or more medications (Hoffmann et al. 2011), whereas "excessive polypharmacy" refers to the simultaneous use of more than ten prescribed medications (Jyrkkä et al. 2012). The term polyherbacy (Ness et al. 2003 ) is defined as the use of multiple natural health products, which include dietary supplements, vitamins, minerals, and herbals.

Today, polypharmacy and polyherbacy present important and growing public health problems, as their prevalence among older adults is high and rising and may significantly differ from country to country as well as regionally. In the United States, the concurrent use of five or more prescribed medications among older adults increased from 30.6\% (2005-2006) to 35.8\% (2010-2011) (Qato et al. 2016). Similar trends have been observed in Europe. In Sweden, the increase in excessive polypharmacy was $15.7 \%$ between 2005 and 2008 (Hovstadius et al. 2010). Observed use of dietary supplements in the United States increased from $51.8 \%$ (2005-2006) to 63.7\% (201-2011) (Qato et al. 2016).

\subsubsection{Risk Factors of Polypharmacy and Polyherbacy in Older Patients}

The risk factors of polypharmacy and polyherbacy can be classified into three groups: demographic risk factors; health status-related; and access to healthcarerelated risk factors (see Table 14.3). Demographic characteristics of the older population cannot be influenced; however, interventions can be made to patients' habits and healthcare providers' practices to reduce the risk of polypharmacy.

\subsubsection{Negative Consequences of Polypharmacy and Polyherbacy in Older Adults}

Like inappropriate prescribing and medication nonadherence, polypharmacy and polyherbacy in older patients have numerous negative consequences on both the patient and the healthcare system (see Table 14.1). They are associated with greater 
Table 14.3 Risk factors associated with polypharmacy

\begin{tabular}{|c|c|}
\hline \multirow[t]{4}{*}{ Demographic factors } & Increased age $(*)$ \\
\hline & White race \\
\hline & Education \\
\hline & Female gender \\
\hline \multirow[t]{3}{*}{ Health factors } & Poorer health $(*)$ \\
\hline & $\begin{array}{l}\text { Comorbidities (cardiovascular disease, hypertension, asthma, diabetes } \\
\text { mellitus) }\end{array}$ \\
\hline & Use of $>9$ medications $(*)$ \\
\hline \multirow[t]{3}{*}{ Access to healthcare } & Number of healthcare visits $(*)$ \\
\hline & Supplemental insurance $\left(?^{*}\right)$ \\
\hline & Multiple providers $(*)$ \\
\hline \multirow{8}{*}{$\begin{array}{l}\text { Due to healthcare } \\
\text { providers (*) }\end{array}$} & Presuming that patient expects prescription medication \\
\hline & Prescribing drugs without sufficient investigating of clinical situation \\
\hline & $\begin{array}{l}\text { Providing unclear, complex or incomplete instructions how to take } \\
\text { medicines }\end{array}$ \\
\hline & Not simplifying medication regimens, when it is possible \\
\hline & Not conducting patient's medication review regularly \\
\hline & Ordering automatic refills without adequate follow- up \\
\hline & Lack of knowledge of geriatric clinical pharmacology \\
\hline & Stacking and insisting on using drugs that are no longer necessary \\
\hline \multirow[t]{6}{*}{ Due to patients } & $\begin{array}{l}\text { Inaccurate report to physicians of all medicines that patients are using } \\
\text { simultaneously }\end{array}$ \\
\hline & $\begin{array}{l}\text { Not reporting symptoms patients are experiencing (these can be also } \\
\text { drug-induced) }\end{array}$ \\
\hline & Having duplicate prescriptions \\
\hline & $\begin{array}{l}\text { Using additional drugs to treat symptoms, disorders (also OTC drugs) } \\
\text { or also drug-related symptoms }\end{array}$ \\
\hline & $\begin{array}{l}\text { Using medications for a very long period, without appropriate follow } \\
\text {-up }\end{array}$ \\
\hline & $\begin{array}{l}\text { Influence of patients' daily manners on the action of medications (i.e. } \\
\text { smoking, changes in activity level, food and fluid intake) }\end{array}$ \\
\hline
\end{tabular}

References: Abdulraheem (2013), Hajjar et al. (2007), and Hovstadius et al. (2010)

Footnote: Many of above stated risk factors may be directly or indirectly linked to ageism (*)

healthcare costs and an increased risk of ADRs and other complications, such as drug-interactions, medication nonadherence, reduced functional capacity, and multiple geriatric syndromes (Maher et al. 2014).

Polypharmacy has been found to be associated with a higher risk of outpatient visits, hospitalizations, taking PIMs, and with an approximate $30 \%$ increase in medical costs (Akazawa et al. 2010). The risk of ADRs and other ADEs may be substantially increased by a higher number of prescribed drugs and OTC medication. Polypharmacy and polyherbacy sometimes lead to so-called prescribing cascades that begin when an ADR is misdiagnosed as a new medical condition and, consequently, a new medicine is prescribed. The patient is then exposed to a risk of developing additional adverse effects (Rochon and Gurwitz 1997). The potential for drug interactions increases exponentially with the number of applied medicines. Doan 
et al. (2013) found that a patient taking 5-9 medications had a 50\% probability of a drug-drug interaction (DDI), and a patient taking 20 or more medications had a $100 \%$ probability of developing DDIs.

Studies that analysed the correlation between polypharmacy and underprescribing have had conflicting results. Some researches consider the number of medications to be a risk factor for underuse of highly effective drug treatment strategies (Kuijpers et al. 2008), whereas others did not find an association (Gallagher et al. 2011; Ryan et al. 2009; Ryan et al. 2013; Wright et al. 2009). It is important to identify which pharmacological groups and risk factors are linked with polypharmacy and underprescribing, and to examine this possible relationship (BlancoReina et al. 2015) with an aim to achieve improvements in pharmacotherapy (Franchi et al. 2013). As confirmed by previous studies, the main determinants of underprescribing in older patients are comorbidity, polypharmacy, ageism, lack of or scanty evidence concerning the efficacy and safety of drugs in older patients, fear of ADRs, and economic constraints (Cherubini et al. 2012).

Polypharmacy and polyherbacy are also associated with medication nonadherence. One of the most important negative consequences of polypharmacy/polyherbacy is the higher risk of occurrence of geriatric syndromes. This includes increased risk of cognitive impairment, falls, urinary incontinence, and reduced functional capacity (Maher et al. 2014). Also, a patient's nutritional status can be affected by polypharmacy. Jyrkkä et al. (2011) found that $50 \%$ of patients taking ten or more medications were malnourished or at risk of malnourishment, mostly because of frequent indigestion and other gastrointestinal problems caused also by the mixture of chemical substances interacting in the gastrointestinal tract and consequently decreased food intake.

\subsubsection{Strategies to Reduce Inappropriate Polypharmacy and Polyherbacy in Older Patients}

We argue that the issue of the increasing prevalence of polypharmacy in older patients (and consequently increasing problems of side effects, geriatric syndromes, malnutrition, hospitalizations, higher healthcare costs, and other negative consequences) is strongly linked to ageism. In the current world of "consumer" healthcare, the consumption of medications and the phenomenon of polypharmacy both increase (Bernhardt et al. 2017; Hovstadius et al. 2010). Older patients and their informal caregivers generally cannot judge whether multiple drug prescription is appropriate or not and they are fully dependent in this respect on the decisions, skills, and attitudes of healthcare providers. Because of strong pressure on drug market sales, patients and healthcare providers are (intentionally or unintentionally) pressured to prescribe and consume more medicines, having less time to thoroughly consider their long-term benefits and risks (Bernhardt et al. 2017; Petrovic et al. 2016). Polypharmacy becomes a common practice, particularly in older patients 
with complex disorders (Petrovic et al. 2016). Patients, carers, patient organizations, healthcare providers, and regulatory institutions should jointly support strategies against ageist medication-related practices which may increase in the future because of increased consumption of medicinal products.

When treating patients with complex medical issues and high-risk patient groups, such as older adults, it is particularly important to obtain a balance between different therapeutic goals and the expected efficacy and possible risks of medications for the ageing organism, and to practise more frequent reviews of medication and overall health status than in younger patients (Steinman and Hanlon 2010). The prescribing physician or consulting clinical pharmacist should evaluate the use of appropriate medication; minimize doses of medication without affecting treatment efficacy; readjust inappropriate doses of drugs, such as doses beyond the drug safety margin; and rectify any incorrect or inappropriate use of medication by older patients (Simonson and Feinberg 2005; Steinman and Hanlon 2010). Medication regimens of older patients should be evaluated at least twice a year, ideally monthly, to reduce the incidence and adverse effects of polypharmacy (Rochon 2016). Even for older patients who have been using the same drug regimen for a long time, medication reviews are necessary, because physiological changes associated with ageing can alter drug pharmacokinetics and increase the risk of ADRs (Corsonello et al. 2010; Routledge et al. 2004; Sokol et al. 2007). Treatments should be designed to prioritize improvements in health, functional status, and quality of life (BlancoReina et al. 2015). Some studies have found that physicians already consider medication guidelines to be too rigid, resulting in individuals with multiple disorders receiving an increasing number of different drugs (Hovstadius et al. 2010; Moen et al. 2010). Clinical care is structured and organized mainly to treat a single health problem at a time or to treat the various illnesses a single patient has as if they were independent of each other and isolated from the individual who suffers from them (Starfield 2006). Unfortunately, physicians often add medications without being aware of potential interactions with other medications and/or diseases (BlancoReina et al. 2015). If different specialists are involved in the care of the same patient, a risk of fragmented care occurs, due to frequent failures of communication among healthcare professionals (Green et al. 2007; Hajjar et al. 2007). Poor communication can result in conflicting or poorly coordinated treatment goals, inadequate monitoring of the patient's therapeutic regimen, and inappropriate expectations and definitions of success, which may contribute to patients' overall negative outcomes and negative perceptions of the healthcare system (Makris et al. 2015).

Chronic drug therapy in older patients should generally be started with the lowest possible dose, following the well-known geriatric phrase, "Start low, go slow," and both physicians and patients should be aware of the general rule that "Less is more" (Steinman and Hanlon 2010). At first, more physiological, nonpharmacological strategies should be promoted, if appropriate (e.g., physical exercise, sun exposure, nutritional interventions, and rehabilitation) (Abraha et al. 2015; Naci and Ioannidis 2013; Taylor et al. 2014). It is also important to regularly identify and eliminate unessential drugs and duplicate prescriptions for the same condition or disease (Dagli and Sharma 2014). 
Many existing studies warn that polypharmacy in older patients is becoming more common and is strongly associated with higher mortality, faster functional decline, malnutrition, severe drug therapy problems, and often undertreatment of major disease conditions (Bourgeois et al. 2010; Jyrkkä et al. 2011; Kojima et al. 2012; Shah and Hajjar 2012). Ageism can be seen to be in effect in prescribing polypharmacy and in poor or no monitoring of drug efficacy and safety, and the patient's functional status and quality of life during treatment. A large number of older patients in a variety of care settings are currently prescribed multiple medications. Vulnerable older patients are among the biggest "consumers" of polypharmacy (Chau et al. 2016). As shown in the European project AdHOC (Aged in Home Care, 2001-2005), 22\% of home care older clients used polypharmacy (9+ medications) in 8 European countries, however medication reviews provided on a regular basis at least every 6 months have been documented in only $11 \%$ of older patients in home care (Fialová et al. 2005).

It is essential to continuously create healthcare systems that optimize the use of medication and where older patients can obtain maximum benefits from their medication with the least harm (Duerden et al. 2013). The strategy of identifying and avoiding risky polypharmacy can lead to better outcomes in older patients and can help improve their quality of life (Dagli and Sharma 2014).

\subsection{Medication Nonadherence in Older Patients and Aspects of Ageism}

\subsubsection{Definitions and Epidemiology of Medication Nonadherence}

The scientific literature uses a variety of terms to describe medication-taking behaviours, including medication compliance, adherence, persistence, and concordance (American Society on Aging/American Society of Consultant Pharmacists Foundation (ASA/ASCPF) 2006; Chakrabarti 2014; Krueger et al. 2003; Sabaté 2003). Adherence is the most often used term, defined in the 2003 report of the World Health Organization (WHO) as “the extent to which a person's behaviour taking medication, following a diet, and/or executing lifestyle changes, etc. corresponds with agreed recommendations from a healthcare provider" (Sabaté 2003). The previously used term compliance has come into disfavour because of its connotation of patients passively following doctors' recommendations. Adherence, on the other hand, requires the patient's agreement with the physician's recommendations (Sabaté 2003). Persistence is defined as the ability of a person to continue in medication treatment for the intended course of therapy (whether for months, years, or for the rest of the patient's life). Non-persistence is when the patient does not fill his or her prescription or discontinues therapy too early (ASA/ASCPF 2006; Krueger et al. 2003). A newer term, concordance, takes into account agreement between the clinician and the patient on medication therapy as well as each other's views and 
perspectives about medication-taking. It describes a broad process in which, after education and discussion with the patient, the physician should respect the patient's choice and views on the therapy, even if they are different or conflict with the clinician's views (Chakrabarti 2014). The evolution of the terms compliance, adherence, and concordance indicates a striving towards active patient involvement and a patient-centred approach in the medication treatment process (Chakrabarti 2014).

Medication nonadherence is the most frequently used term in the literature. Taken broadly, it includes different types of nonadherence, noncompliance, and nonpersistence, for example:

- Taking less or more of a medication/medications than prescribed, omitting a dose, taking a dose at the wrong time, taking a dose with prohibited foods, liquids, and other medication

- Improper administration of medication, including also improper use of administration devices, such as inhalers, injections, etc.

- Taking outdated medication or damaged medication, or storing medication improperly

- Taking a medication prescribed for someone else

- Prematurely discontinuing medication, failing to initially fill in a prescription or failing to refill a prescription as directed. (ASA/ASCPF 2006; Krueger et al. 2003)

Nonadherence to medication is a very frequent problem, particularly in community-dwelling older adults, where the prevalence of nonadherence has been reported to be between 43-100\% (Vik et al. 2004).

\subsubsection{Negative Consequences of Medication Nonadherence in Older Patients}

There are various negative consequences of medication nonadherence: less than optimal management and control of the illness, medical and psychosocial complications of the disease, reduced patient quality of life, and increased use of medical resources, such as physician visits, laboratory tests, unnecessary additional treatments, emergency department visits, and hospital or nursing home admissions (see Table 14.1) (Col et al. 1990; Gurwitz et al. 2003; Scheen and Giet 2010; Strandberg 1984; Vermiere et al. 2001).

Problems with medication nonadherence have been documented as a contributing factor in more than $20 \%$ of preventable ADEs in older patients in ambulatory care settings (Gurwitz et al. 2003). Studies have also found that more than $10 \%$ of older adults' admissions to acute care may have been caused by nonadherence to medication regimens (Vermiere et al. 2001). Col et al. (1990) described in his study that one-third of older persons admitted to the hospital had a history of nonadherence, and Strandberg (1984) found that nearly one-fourth of admissions of older adults to nursing homes were due to their inability to self-administer medication. 


\subsubsection{Risk Factors of Medication Nonadherence and Aspects of Ageism}

Medication nonadherence is a multidimensional phenomenon which is determined by the interplay of different sets of risk factors, termed "dimensions" according to WHO (Sabaté 2003). These are namely:

- Socioeconomic risk factors

- Healthcare system and provider-related risk factors

- Condition-related risk factors

- Therapy-related risk factors, and

- Patient-related factors

Some of these risk factors may be directly or indirectly related to ageism (see Table 14.4); however, the relationship between medication nonadherence and ageist attitudes and behaviours has not been yet thoroughly studied.

The common belief that older persons are mostly nonadherent with medication can be seen as an ageist attitude. Published evidence confirms that all age groups are prone to nonadherence and that older persons are not an exception (Cooper et al. 2005; Culig et al. 2011; Topinková et al. 2012). Another common belief is that individuals are solely responsible for taking their medication appropriately, but this belief reflects a misunderstanding of the fact that a range of factors, including nonpersonal patient-related factors can strongly affect medication-taking behaviour (ASA/ASCPF 2006; Sabaté 2003). This misunderstanding may contribute to ageism when no help is provided to older patients with complex disease conditions that require compliance support, or to older adults who are cognitively impaired or otherwise have problems administering or taking drugs. Many older patients are prescribed several medications without any education on how to take and manage them appropriately. In one of the study of the European Commission project, Aged in Home Care (AdHOC) project (2001-2005), more than 2700 home care older patients were assessed in metropolitan areas of $8 \mathrm{EU}$ countries. Of these older patients, $12.4 \%$ reported no help with medication compliance and managing their medications despite an objective need (Fialová et al. 2005).

When older people forget to take medication regularly (on time or in a prescribed dose) they are often viewed as senile, which is ageist attitude, whereas the same behaviour in a younger person is explained without these stereotypes. Culig et al. (2011) found in his study that the majority of subjects cited forgetfulness as the main reason for skipping drug dosing $(60 \%)$, followed by not being at home $(45.4 \%)$, and having run out of the drug (44.4\%). However, with the simple help of pill boxes and adherence reminders, even forgetfulness is a modifiable risk factor of nonadherence that can be easily resolved (Culig et al. 2011). Not providing compliance support tools to geriatric patients should be viewed as a lack of age-specific care, and therefore as ageist behaviour.

Medication adherence depends on patients' comprehension, their attitudes to disease and need to control the disease, reliance on their own capability to manage 
Table 14.4 Risk factors associated with medication nonadherence

\begin{tabular}{|c|c|c|}
\hline Patient- related factors & & \\
\hline \multirow[t]{4}{*}{ Physical factors } & Visual impairment $(*)$ & $\begin{array}{l}\text { Patient sleepiness (e.g. drug-related } \\
\text { sedation) contributing to inability to } \\
\text { take medicine }(*)\end{array}$ \\
\hline & Hearing impairment $(*)$ & Decreased dexterity $(*)$ \\
\hline & Cognitive impairment $(*)$ & Swallowing problems $(*)$ \\
\hline & Impaired mobility (*) & \\
\hline \multirow[t]{5}{*}{$\begin{array}{l}\text { Psychological/ } \\
\text { behavioral factors }\end{array}$} & $\begin{array}{l}\text { Medication knowledge }(*) \text {, } \\
\text { education }(*)\end{array}$ & Motivation $(*)$ \\
\hline & Health literacy $(*)$ & Beliefs about medicines $(*)$ \\
\hline & Forgetfulness $(*)$ & Attitudes to medication treatment $(*)$ \\
\hline & $\begin{array}{l}\text { Decreased self-performance } \\
(*)\end{array}$ & Social support $(*)$ \\
\hline & $\begin{array}{l}\text { Alcohol and substance abuse } \\
(*)\end{array}$ & \\
\hline \multirow[t]{2}{*}{ Other factors } & $\begin{array}{l}\text { Demographic factors: Age } \\
(*) \text {, gender, ethnicity, marital } \\
\text { status }\end{array}$ & Patient-prescriber relationship $(*)$ \\
\hline & History of good adherence & Not at home \\
\hline \multirow{5}{*}{$\begin{array}{l}\text { Therapy-related } \\
\text { factors }\end{array}$} & Treatment complexity $(*)$ & Route of administration $(*)$ \\
\hline & $\begin{array}{l}\text { Duration of the treatment } \\
\text { period }(*)\end{array}$ & Taste of the medication $(*)$ \\
\hline & $\begin{array}{l}\text { Medication side effects or } \\
\text { adverse drug reactions }(*)\end{array}$ & Requirements for drug storage \\
\hline & $\begin{array}{l}\text { Therapies that are } \\
\text { inconvenient or interfere with } \\
\text { a person's lifestyle }(*)\end{array}$ & $\begin{array}{l}\text { Medications with a social stigma } \\
\text { attached to its use (such as } \\
\text { antidepressants, antipsychotics) }(*)\end{array}$ \\
\hline & $\begin{array}{l}\text { Lack of accessibility of } \\
\text { medication }(*)\end{array}$ & $\begin{array}{l}\text { Administration of a medication } \\
\text { requiring the mastery of specific } \\
\text { techniques (injections, inhalers) }(*)\end{array}$ \\
\hline \multirow{4}{*}{$\begin{array}{l}\text { Provider- and } \\
\text { healthcare system- } \\
\text { related factors }\end{array}$} & $\begin{array}{l}\text { Accessibility of healthcare } \\
\text { provider }(*)\end{array}$ & $\begin{array}{l}\text { Difficulty in getting prescriptions } \\
\text { filled }(*)\end{array}$ \\
\hline & $\begin{array}{l}\text { Long waiting time or making } \\
\text { appointments difficult }(*)\end{array}$ & $\begin{array}{l}\text { Lacking continuity of provider care } \\
(*)\end{array}$ \\
\hline & Unhappy clinic visits(*) & $\begin{array}{l}\text { Using restrictive formularies/ } \\
\text { changing formularies }(*)\end{array}$ \\
\hline & $\begin{array}{l}\text { Physician's readiness to } \\
\text { change compliance } \\
\text { assessment method }\end{array}$ & High drug costs, high copayments (*) \\
\hline $\begin{array}{l}\text { Condition/disease } \\
\text { related factors }\end{array}$ & Severity of the disease $\left(?^{*}\right)$ & Disease symptoms $(*)$ \\
\hline \multirow{3}{*}{$\begin{array}{l}\text { Social and economic } \\
\text { factors }\end{array}$} & Cost and income $(*)$ & Inability to take time off work $(*)$ \\
\hline & Poor social support $(*)$ & Lack of health insurance coverage $(*)$ \\
\hline & Homelessness (*) & \\
\hline
\end{tabular}

References: Aggarwal and Mosca (2010), Crowley et al. (2013), Harris et al. (2011), and Munger et al. (2007)

Footnote: Many of above stated risk factors may be directly or indirectly linked to ageism (*) 
the use of medicines, their expectations concerning the drug therapy, and their behavior when the results of therapy are unsatisfactory (Casula et al. 2012). Patients' behaviour is a complex phenomenon significantly influenced by patients' home environments, the healthcare system, and healthcare professionals (ASA/ASCPF 2006). Table 14.4 shows there are many risk factors and groups of risk factors that contribute to lower adherence of patients to their medications. Some of these risk factors are related to ageism, for example, poorly coordinated care, inappropriate expectations of carers from the patient, inadequate education of older adults about medication because of physician's perceived lack of time, and so on (ASA/ASCPF 2006; Sabaté 2003; Scheen and Giet 2010).

\subsubsection{Strategies to Reduce Medication Nonadherence in Older Patients}

For a number of chronic medical conditions, such as diabetes, hypertension, hypercholesterolemia, and congestive heart failure, higher rates of medication adherence have been found to be associated with lower rates of hospitalization. For example, for diabetes and hypercholesterolemia, better compliance to medication was associated with lower disease-related medical costs (Sokol et al. 2005).

Several publications and website sources have summarized the prerequisites for good adherence to medication regimens that require that a person will

- Show interest in his or her health and understand the diagnosis and potential impact of the diagnosis

- Believe that the prescribed treatment will help

- Know exactly how to take the medication and know the duration of therapy (it is possible to assess the patient's understanding of the disease and the treatment regimen and provide information where knowledge gaps exist)

- Find ways to fit the medication regimen into his or her daily routine, use adherence aids, such as medication organizers and charts

- Value the outcome of treatment more than the cost of treatment

- Believe that he or she can carry out the treatment plan and is actively involved in the treatment process.

- Get support from the healthcare team, both professional support (e.g., by simplifying medication regimens) and human support (e.g., by recognizing any difficulties in coping with or recognizing other socio-behavioural issues that may affect the person's ability to follow the treatment regimen)

- Believe that the healthcare practitioners truly care about him/her as a person rather than as a disease to be treated. (ASA/ASCPF 2006; Krueger et al. 2003) 
Studies have shown that single interventions are not usually adequate to improve adherence (Hughes 2004) and almost all effective interventions for improving patient adherence long-term have been complex (including a combination of different intervention strategies, such as patient counselling, patient selfmonitoring, medication use reminders, telephone follow-up, psychological therapy, crisis intervention, supportive care, and so on) (Haynes et al. 2008). In clinical practice, many interventions focus on providing only one strategy (if any): for example, education to increase knowledge; simplifying the medication regimen (e.g., prescribing fixed-dose combination pills and slow-release drug forms for once-daily dosing) (Schroeder et al. 2004), using adherence aids, or using refill reminders. However, simplifying a dosage regimen alone cannot positively influence adherence if a person does not believe that drug treatment will be effective. It has been demonstrated that comprehension of drug therapy alone is insufficient for keeping good medication adherence (ASA/ASCPF 2006; Haynes et al. 2008; Hughes 2004).

Some disease-specific health education programmes (e.g. for diabetes and hypertension) were found to be effective in improving patients' adherence (Balamuguran et al. 2006), but in the absence of such formal programmes, physicians can use other educational resources (e.g., pharmacists' counselling, interactive web-based materials, etc.). The more empowered older patients feel, the more likely they are to be motivated to manage their health and adhere to their medications. Ageist practices contributing to medication nonadherence can be reduced by physicians, carers, and patients being motivated to be actively involved in drug treatments. A comprehensive approach requires team-based care that includes non-physician staff (such as nurses and pharmacists) to perform assessment and management of medication adherence. It might require some of the duties traditionally performed by physicians to be transferred to non-physician staff. This strategy allows physicians more time for diagnostic procedures and interpretation. Recently, motivational interviewing - a counseling technique originally developed to help treat addiction (designed to help patients identify and overcome reasons they may be reluctant to change their behaviour) - is also recommended (Miller 2010).

Healthcare providers can significantly influence patients' healthy behaviour. Atreja et al. (2005) reviewed interventions that helped to improve patients' adherence to medications and summarized them into several simply remembered recommendations under the acronym "SIMPLE":

1. Simplifying regimen characteristics;

2. Imparting knowledge;

3. Modifying patient beliefs;

4. Patient communication;

5. Leaving the bias; and

6. Evaluating adherence. 
In conclusion, the most important measures for improving medication adherence in older patients are: (a) increase training and education of healthcare providers and patients in adherence support, team-based approach, active patient involvement, motivation to use appropriate treatment, and continuous research in specific aspects of aging; (b) empower and educate older patients; and (c) utilize appropriate screening and treatment methods for improving adherence among older patients.

Medication adherence is an important contributor to improved patient health. In order to reduce ageist behaviours stemming from ageist attitudes, healthcare systems must ensure that sufficient time in daily clinical practice is allocated to the appropriate management of adherence in older patients (Abbo et al. 2008).

\subsection{Conclusions}

It is important to take an active, more realistic role in confronting and preparing healthcare systems for the ageing of the population. Selection of age-specific approaches (e.g., the right geriatric drug, dosing schedule, drug combination, and appropriate geriatric recommendations during the drug treatment process) are crucial first steps in the area of appropriate medication use in older patients. Prescribers currently tend to follow mostly nongeriatric recommendations, which are not relevant to potentially frail, polymorbid, and highly complex older adults (Steinmann and Hanlon 2010; Wehling 2016). Part of the problem is due to missing evidence from randomized controlled trials on effective and safe medication and dosing for geriatric patients. Novel evidence from specifically geriatric studies is necessary, ideally for specific groups of geriatric patients. Individualization of drug regimens and adherence support under close clinical surveillance must be also used to improve appropriate medication use in older patients. Further training of physicians, nurses, and pharmacists in these techniques, in patient active involvement, and in teambased care is needed.

Today's healthcare provision and drug use in the geriatric population is clearly not meeting the specific needs of older patients. Older adults are often either untreated in situations where treatment is relevant and necessary, or they suffer inappropriately from adverse drug reactions or unnecessary and aggressive treatments. These extremes represent a significant shortage in the appropriate managing of healthcare needs for older patients in the area of medication use and must be addressed by more individualized, age-specific, integrated care. 


\section{Appendix: List of Abbreviations}

\begin{tabular}{l|l}
\hline ADE(s) & Adverse Drug Event(s) \\
\hline AdHOC & Aged in HOme Care project \\
\hline ADR(s) & Adverse Drug Reaction(s) \\
\hline AGS & American Geriatric Society \\
\hline ASA/ASCPF & $\begin{array}{l}\text { American Society on Aging/American Society of Consultant } \\
\text { Pharmacists Foundation }\end{array}$ \\
\hline DDI(s) & Drug-Drug Interaction(s) \\
\hline DRP(s) & Drug- Related Problem(s) \\
\hline FORTA List (of & Fit fOR the AgeD List (of medications) \\
\hline GP(s) & General Practice(s) \\
\hline HARM study & Hospital Admissions Related to Medications study \\
\hline OTC & Over-the-Counter (Over-the Counter Medications) \\
\hline PCNE & Pharmaceutical Care Network of Europe \\
\hline PIM(s) & Potentially Inappropriate Medication(s) \\
\hline PINCER trial & $\begin{array}{l}\text { A Pharmacist-led information technology intervention for medication } \\
\text { errrors' trial (called PINCER trial) }\end{array}$ \\
\hline RCTs & Randomised Controlled Trials \\
\hline $\begin{array}{l}\text { STOPP/START } \\
\text { criteria }\end{array}$ & $\begin{array}{l}\text { Screening Tool of Older Person's Prescriptions/Screening Tool to Alert } \\
\text { Doctors to Right Treatment Criteria }\end{array}$ \\
\hline
\end{tabular}

\section{References}

Abbo, E. D., Zhang, Q., Zelder, M., \& Huang, E. S. (2008). The increasing number of clinical items addressed during the time of adult primary care visits. Journal of General Internal Medicine, 23(12), 2058-2065. https://doi.org/10.1007/s11606-008-0805-8

Abdulraheem, I. S. (2013). Polypharmacy: A risk factor for geriatric syndrome, morbidity \& mortality. Journal of Aging Science, 1(2), e103. https://doi.org/10.4172/2329-8847.1000e103

Abraha, I., Cruz-Jentoft, A., Soiza, R. L., O’Mahony, D., \& Cherubini, A. (2015). Evidence of and recommendations for non-pharmacological interventions for common geriatric conditions: The SENATOR-ONTOP systematic review protocol. BMJ Open, 5(1). https://doi.org/10.1136/ bmjopen-2014-007488

Achenbaum, W. A. (2014). Robert N. Butler, M.D. (January 21, 1927-July 4, 2010): Visionary leader. The Gerontologist, 54(1), 6-12. https://doi.org/10.1093/geront/gnt015

Adelman, R. D., Greene, M. G., \& Ory, M. G. (2000). Communication between older patients and their physicians. Clinics in Geriatric Medicine, 16(1), 1-24.

Aggarwal, B., \& Mosca, L. (2010). Lifestyle and psychosocial risk factors predict non-adherence to medication. Annals of Behavioral Medicine: A Publication of the Society of Behavioral Medicine, 40(2), 228-233. https://doi.org/10.1007/s12160-010-9212-6

Akazawa, M., Imai, H., Igarashi, A., \& Tsutani, K. (2010). Potentially inappropriate medication use in elderly Japanese patients. The American Journal of Geriatric Pharmacotherapy, 8(2), 146-160. https://doi.org/10.1016/j.amjopharm.2010.03.005 
Alhawassi, T. M., Krass, I., Bajorek, B. V., \& Pont, L. G. (2014). A systematic review of the prevalence and risk factors for adverse drug reactions in the elderly in the acute care setting. Clinical Interventions in Aging, 9, 2079-2086. https://doi.org/10.2147/CIA.S71178

American Geriatrics Society 2015 Beers Criteria Update Expert Panel. (2015). American Geriatrics Society 2015 updated beers criteria for potentially inappropriate medication use in older adults. Journal of the American Geriatrics Society, 63(11), 2227-2246. https://doi. org/10.1111/jgs. 13702

American Society on Aging and American Society of Consultant Pharmacists Foundation (ASA/ ASCPF) (2006). Overview medication adherence-Where are we today? Resource document. http://www.adultmeducation.com/downloads/Adult_Med_Overview.pdf. Accessed 21 July 2017.

Anderson, G. F. (2010). Chronic care: Making the case for ongoing care. Resource document. John Hopkins Bloomberg School of Public Health. http://www.rwjf.org/content/dam/farm/reports/ reports/2010/rwjf54583. Accessed 14 May 2016.

Atreja, A., Bellam, N., Levy, S. R. (2005). Strategies to enhance patient adherence: Making it simple. MedGenMed: Medscape General Medicine, 7(1), 4.

Avery, A. J., Rodgers, S., Cantrill, J. A., Armstrong, S., Cresswell, K., Eden, M., et al. (2012). A pharmacist-led information technology intervention for medication errors (PINCER): A multicentre, cluster randomised, controlled trial and cost-effectiveness analysis. The Lancet, 379(9823), 1310-1319. https://doi.org/10.1016/S0140-6736(11)61817-5

Balamurugan, A., Ohsfeldt, R., Hughes, T., \& Phillips, M. (2006). Diabetes self-management education program for Medicaid recipients: A continuous quality improvement process. The Diabetes Educator, 32(6), 893-900. https://doi.org/10.1177/0145721706294787

Baldoni Ade, O., Ayres, L. R., Martinez, E. Z., Dewulf, N. D. L. S., dos Santos, V., \& Pereira, L. R. L. (2014). Factors associated with potentially inappropriate medication use by the elderly according to Beers criteria 2003 and 2012. International Journal of Clinical Pharmacy, 36(2), 316-324. https://doi.org/10.1007/s11096-013-9880-y.

Beard, K. (1992). Adverse reactions as a cause of hospital admission in the aged. Drugs \& Aging, 2(4), 356-367.

Beijer, H. J., \& de Blaey, C. J. (2002). Hospitalisations caused by adverse drug reactions (ADR): A meta-analysis of observational studies. Pharmacy World \& Science: PWS, 24(2), 46-54.

Bernhardt, E. S., Rosi, E. J., \& Gessner, M. O. (2017). Synthetic chemicals as agents of global change. Frontiers in Ecology and the Environment, 15(2), 84-90. https://doi.org/10.1002/ fee. 1450

Blanco-Reina, E., Ariza-Zafra, G., Ocaña-Riola, R., León-Ortíz, M., \& Bellido-Estévez, I. (2015). Optimizing elderly pharmacotherapy: Polypharmacy vs. undertreatment. Are these two concepts related? European Journal of Clinical Pharmacology, 71(2), 199-207. https://doi. org/10.1007/s00228-014-1780-0

Bordet, R., Gautier, S., Le Louet, H., Dupuis, B., \& Caron, J. (2001). Analysis of the direct cost of adverse drug reactions in hospitalised patients. European Journal of Clinical Pharmacology, 56(12), 935-941.

Bourgeois, F. T., Shannon, M. W., Valim, C., \& Mandl, K. D. (2010). Adverse drug events in the outpatient setting: An 11-year national analysis. Pharmacoepidemiology and Drug Safety, 19(9), 901-910. https://doi.org/10.1002/pds.1984

Brossoie, N. (2013). Social gerontology. In R. H. Robnett \& W. C. Chop (Eds.), Gerontology for the health care professional (pp. 17-42). Burlington: Jones \& Bartlett Publishers.

Casula, M., Tragni, E., \& Catapano, A. L. (2012). Adherence to lipid-lowering treatment: The patient perspective. Patient Preference and Adherence, 6, 805-814. https://doi.org/10.2147/ PPA.S29092

Chakrabarti, S. (2014). What's in a name? Compliance, adherence and concordance in chronic psychiatric disorders. World Journal of Psychiatry, 4(2), 30-36. https://doi.org/10.5498/wjp. v4.i2.30 
Chau, S. H., Jansen, A. P., van de Ven, P. M., Hoogland, P., Elders, P. J., \& Hugtenburg, J. G. (2016). Clinical medication reviews in elderly patients with polypharmacy: A cross-sectional study on drug-related problems in the Netherlands. International Journal of Clinical Pharmacy, 38(1), 46-53. https://doi.org/10.1007/s11096-015-0199-8

Chen, Y. C., Hwang, S. J., Lai, H. Y., Chen, T. J., Lin, M. H., Chen, L. K., et al. (2009). Potentially inappropriate medication for emergency department visits by elderly patients in Taiwan. Pharmacoepidemiology and Drug Safety, 18(1), 53-61. https://doi.org/10.1002/pds.1684

Chen, L. L., Tangiisuran, B., Shafie, A. A., \& Hassali, M. A. (2012). Evaluation of potentially inappropriate medications among older residents of Malaysian nursing homes. International Journal of Clinical Pharmacy, 34(4), 596-603. https://doi.org/10.1007/s11096-012-9651-1

Cherubini, A., Corsonello, A., \& Lattanzio, F. (2012). Underprescription of beneficial medicines in older people: Causes, consequences and prevention. Drugs \& Aging, 29(6), 463-475. https:// doi.org/10.2165/11631750-000000000-00000

Col, N., Fanale, J. E., \& Kronholm, P. (1990). The role of medication noncompliance and adverse drug reactions in hospitalizations of the elderly. Archives of Internal Medicine, 150(4), 841845. https://doi.org/10.1001/archinte.1990.00390160093019

Cooper, C., Carpenter, I., Katona, C., Schroll, M., Wagner, C., Fialova, D., et al. (2005). The AdHOC study of older adults' adherence to medication in 11 countries. The American Journal of Geriatric Psychiatry: Official Journal of the American Association for Geriatric Psychiatry, 13(12), 1067-1076. https://doi.org/10.1176/appi.ajgp.13.12.1067

Corsonello, A., Pedone, C., \& Incalzi, R. A. (2010). Age-related pharmacokinetic and pharmacodynamic changes and related risk of adverse drug reactions. Current Medicinal Chemistry, 17(6), 571-584. https://doi.org/10.2174/092986710790416326

Coupland, N., \& Coupland, J. (1993). Discourses of ageism and anti-ageism. Journal of Aging Studies, 7(3), 279-301.

Coupland, N., \& Coupland, J. (1998). Reshaping lives: Constitutive identity work in geriatric medical consultations. Text-Interdisciplinary Journal for the Study of Discourse, 18(2), 159-189.

Crome, P., Lally, F., Cherubini, A., Oristrell, J., Beswick, A. D., Clarfield, A. M., et al. (2011). Exclusion of older people from clinical trials: Professional views from nine European countries participating in the PREDICT study. Drugs \& Aging, 28(8), 667-677. https://doi. org/10.2165/11591990-000000000-00000

Crowley, M. J., Grubber, J. M., Olsen, M. K., \& Bosworth, H. B. (2013). Factors associated with non-adherence to three hypertension self-management behaviors: Preliminary data for a new instrument. Journal of General Internal Medicine, 28(1), 99-106. https://doi.org/10.1007/ s11606-012-2195-1

Culig, J., Leppée, M., Boskovic, J., \& Eric, M. (2011). Determining the difference in medication compliance between the general patient population and patients receiving antihypertensive therapy: A case study. Archives of Pharmacal Research, 34(7), 1143-1152. https://doi. org/10.1007/s12272-011-0712-0

Cullinan, S., O’Mahony, D., Fleming, A., \& Byrne, S. (2014). A meta-synthesis of potentially inappropriate prescribing in older patients. Drugs \& Aging, 31(8), 631-638. https://doi. org/10.1007/s40266-014-0190-4

Dagli, R. J., \& Sharma, A. (2014). Polypharmacy: A global risk factor for elderly people. Journal of International Oral Health: JIOH, 6(6), i-ii.

Doan, J., Zakrzewski-Jakubiak, H., Roy, J., Turgeon, J., \& Tannenbaum, C. (2013). Prevalence and risk of potential cytochrome P450-mediated drug-drug interactions in older hospitalized patients with polypharmacy. The Annals of Pharmacotherapy, 47(3), 324-332. https://doi. org/10.1345/aph.1R621

Duerden, M., Avery T., Payne R. (2013). Polypharmacy and medicines optimisation: Making it safe and sound. Resource document. The King's Fund. http://www.kingsfund.org.uk/sites/ files/kf/field/field_publication_file/polypharmacy-and-medicines-optimisation-kingsfundnov13.pdf. Accessed 14 May 2016. 
Fialová, D., \& Desplenter, F. (2016). Aging of the population, clinical pharmacy services, and interdisciplinary cooperation in the optimization of pharmacotherapy in older patients. Drugs \& Aging, 33(3), 163-167. https://doi.org/10.1007/s40266-016-0361-6

Fialová, D., \& Onder, G. (2009). Medication errors in elderly people: Contributing factors and future perspectives. British Journal of Clinical Pharmacology, 67(6), 641-645. https://doi.org /10.1111/j.1365-2125.2009.03419

Fialová, D., Topinková, E., Gambassi, G., Finne-Soveri, H., Jónsson, P. V., Carpenter, I., et al. (2005). Potentially inappropriate medication use among elderly home care patients in Europe. JAMA, 293(11), 1348-1358.

Franchi, C., Cartabia, M., Risso, P., Mari, D., Tettamanti, M., Parabiaghi, A., et al. (2013). Geographical differences in the prevalence of chronic polypharmacy in older people: Eleven years of the EPIFARM-Elderly Project. European Journal of Clinical Pharmacology, 69(7), 1477-1483. https://doi.org/10.1007/s00228-013-1495-7

Francis, S. A., Barnett, N., \& Denham, M. (2005). Switching of prescription drugs to over-thecounter status: Is it a good thing for the elderly? Drugs \& Aging, 22(5), 361-370.

Gallagher, P., Lang, P. O., Cherubini, A., Topinková, E., Cruz-Jentoft, A., Montero Errasquín, B., et al. (2011). Prevalence of potentially inappropriate prescribing in an acutely ill population of older patients admitted to six European hospitals. European Journal of Clinical Pharmacology, 67(11), 1175-1188. https://doi.org/10.1007/s00228-011-1061-0

Green, J. L., Hawley, J. N., \& Rask, K. J. (2007). Is the number of prescribing physicians an independent risk factor for adverse drug events in an elderly outpatient population? The American Journal of Geriatric Pharmacotherapy, 5(1), 31-39.

Griese, N., \& Leikola, S. (2014). PCNE working symposium Sliema. Malta: Pharmaceutical Care Network Europe. http://www.pcne.org/upload/files/28_Malta_MR_report.pdf. Accessed 3 Mar 2015.

Gurwitz, J. H., Field, T. S., Harrold, L. R., Rothschild, J., Debellis, K., Seger, A. C., et al. (2003). Incidence and preventability of adverse drug events among older persons in the ambulatory setting. JAMA, 289(9), 1107-1116.

Haasum, Y., Fastbom, J., \& Johnell, K. (2012). Institutionalization as a risk factor for inappropriate drug use in the elderly: A Swedish nationwide register-based study. Annals of Pharmacotherapy, 46(3), 339-346.

Hajjar, E. R., Hanlon, J. T., Sloane, R. J., Lindblad, C. I., Pieper, C. F., Ruby, C. M., et al. (2005). Unnecessary drug use in frail older people at hospital discharge. Journal of the American Geriatrics Society, 53(9), 1518-1523.

Hajjar, E. R., Cafiero, A. C., \& Hanlon, J. T. (2007). Polypharmacy in elderly patients. The American Journal of Geriatric Pharmacotherapy, 5(4), 345-351. https://doi.org/10.1016/j. amjopharm.2007.12.002

Hanlon, J. T., Schmader, K. E., Ruby, C. M., \& Weinberger, M. (2001). Suboptimal prescribing in older inpatients and outpatients. Journal of the American Geriatrics Society, 49(2), 200-209.

Harris, J., Pillinger, M., Fromstein, D., Gomez, B., Garris, I., Kanetsky, P. A., et al. (2011). Risk factors for medication non-adherence in an HIV infected population in the Dominican Republic. AIDS and Behavior, 15(7), 1410-1415. https://doi.org/10.1007/s10461-010-9781-1

Haynes, R. B., Ackloo, E., Sahota, N., McDonald, H. P., \& Yao, X. (2008). Interventions for enhancing medication adherence. The Cochrane Database of Systematic Reviews, 16(2). https://doi.org/10.1002/14651858.CD000011

Higashi, R. T., Tillack, A. A., Steinman, M., Harper, M., \& Johnston, C. B. (2012). Elder care as "frustrating" and "boring": Understanding the persistence of negative attitudes toward older patients among physicians-in-training. Journal of Aging Studies, 26(4), 476-483. https://doi. org/10.1016/j.jaging.2012.06.007

Hoffmann, F., van den Bussche, H., Wiese, B., Schön, G., Koller, D., Eisele, M., et al. (2011). Impact of geriatric comorbidity and polypharmacy on cholinesterase inhibitors prescribing in dementia. BMC Psychiatry, 11. https://doi.org/10.1186/1471-244X-11-190 
Hovstadius, B., Hovstadius, K., Astrand, B., \& Petersson, G. (2010). Increasing polypharmacy - An individual-based study of the Swedish population 2005-2008. BMC Clinical Pharmacology, 10(16). https://doi.org/10.1186/1472-6904-10-16

Hughes, C. M. (2004). Medication non-adherence in the elderly: How big is the problem? Drugs \& Aging, 21(12), 793-811.

Johnson, J. A., \& Bootman, J. L. (1995). Drug-related morbidity and mortality: A cost-of-illness model. Archives of Internal Medicine, 155(18), 1949-1956.

Jyrkkä, J., Enlund, H., Lavikainen, P., Sulkava, R., \& Hartikainen, S. (2011). Association of polypharmacy with nutritional status, functional ability and cognitive capacity over a three-year period in an elderly population. Pharmacoepidemiology and Drug Safety, 20(5), 514-522. https://doi.org/10.1002/pds.2116

Jyrkkä, J., Mursu, J., Enlund, H., \& Lönnroos, E. (2012). Polypharmacy and nutritional status in elderly people. Current Opinion in Clinical Nutrition and Metabolic Care, 15(1), 1-6. https:// doi.org/10.1097/MCO.0b013e32834d155a

Kane, R. L., Ouslander, J. G., \& Abrass, I. B. (2004). Essentials of clinical geriatrics (5th ed.). New York: The McGraw-Hill Companies.

Kojima, T., Akishita, M., Nakamura, T., Nomura, K., Ogawa, S., Iijima, K., et al. (2012). Polypharmacy as a risk for fall occurrence in geriatric outpatients. Geriatrics \& Gerontology International, 12(3), 425-430. https://doi.org/10.1111/j.1447-0594.2011.00783.x

Krueger, K. P., Felkey, B. G., \& Berger, B. A. (2003). Improving adherence and persistence: A review and assessment of interventions and description of steps toward a national adherence initiative. Journal of the American Pharmacists Association : JAPhA, 43(6), 668-678.

Kuijpers, M. A. J., van Marum, R. J., Egberts, A. C. G., \& Jansen, P. A. F. (2008). Relationship between polypharmacy and underprescribing. British Journal of Clinical Pharmacology, 65(1), 130-133. https://doi.org/10.1111/j.1365-2125.2007.02961.x

Leendertse, A. J., Egberts, A. C., Stoker, L. J., \& Van den Bemt, P. M. (2008). Frequency of and risk factors for preventable medication-related hospital admissions in the Netherlands. Archives of Internal Medicine, 168(17), 1890-1896. https://doi.org/10.1001/archinternmed.2008.3

Leendertse, A. J., Van Den Bemt, P. M., Poolman, J. B., Stoker, L. J., Egberts, A. C., \& Postma, M. J. (2011). Preventable hospital admissions related to medication (HARM): Cost analysis of the HARM study. Value in Health, 14(1), 34-40. https://doi.org/10.1016/j.jval.2010.10.024

Levy, B. R. (2001). Eradication of ageism requires addressing the enemy within. The Gerontologist, 41(5), 578-579.

Lin, Y. J., Peng, L. N., Chen, L. K., Lin, M. H., \& Hwang, S. J. (2011). Risk factors of potentially inappropriate medications among older patients visiting the community health center in rural Taiwan. Archives of Gerontology and Geriatrics, 53(2), 225-228. https://doi.org/10.1016/j. archger.2010.11.017

Lorgunpai, S. J., Grammas, M., Lee, D. S., McAvay, G., Charpentier, P., \& Tinetti, M. E. (2014). Potential therapeutic competition in community-living older adults in the U.S.: Use of medications that may adversely affect a coexisting condition. PLoS One, 9(2). https://doi.org/10.1371/ journal.pone. 0089447

Maher, R. L., Hanlon, J., \& Hajjar, E. R. (2014). Clinical consequences of polypharmacy in elderly. Expert Opinion on Drug Safety, 13(1), 57-65. https://doi.org/10.1517/14740338.2013.827660

Makris, U. E., Higashi, R. T., Marks, E. G., Fraenkel, L., Sale, J. E., Gill, T. M., et al. (2015). Ageism, negative attitudes, and competing co-morbidities-why older adults may not seek care for restricting back pain: A qualitative study. BMC Geriatrics, 15(39). https://doi.org/10.1186/ s12877-015-0042-z

Miller, N. H. (2010). Motivational interviewing as a prelude to coaching in healthcare settings. The Journal of Cardiovascular Nursing, 25(3), 247-251. https://doi.org/10.1097/ JCN.0b013e3181cec6e7

Moen, J., Norrgård, S., Antonov, K., Nilsson, J. L., \& Ring, L. (2010). GPs' perceptions of multiple-medicine use in older patients. Journal of Evaluation in Clinical Practice, 16(1), 69-75. https://doi.org/10.1111/j.1365-2753.2008.01116.x 
Morin, L., Laroche, M. L., Texier, G., \& Johnell, K. (2016). Prevalence of potentially inappropriate medication use in older adults living in nursing homes: A systematic review. Journal of the American Medical Directors Association, 17(9), 862.e1-9. https://doi.org/10.1016/j. jamda.2016.06.011

Munger, M. A., Van Tassell, B. W., \& LaFleur, J. (2007). Medication nonadherence: An unrecognized cardiovascular risk factor. MedGenMed: Medscape General Medicine, 9(3), 58.

Naci, H., \& Ioannidis, J. P. (2013). Comparative effectiveness of exercise and drug interventions on mortality outcomes: Metaepidemiological study (p. 347). BMJ: British medical journal / British Medical Association. https://doi.org/10.1136/bmj.f5577

Ness, J., Johnson, D., \& Nisly, N. (2003). Polyherbacy: Herbal supplements as a form of polypharmacy in older adults. The Journals of Gerontology. Series A, Biological Sciences and Medical Sciences, 58(5), 478.

Niwata, S., Yamada, Y., \& Ikegami, N. (2006). Prevalence of inappropriate medication using Beers criteria in Japanese long-term care facilities. BMC Geriatrics, 6(1). https://doi. org/10.1186/1471-2318-6-1

O’Mahony, D., O’Sullivan, D., Byrne, S., O’Connor, M. N., Ryan, C., \& Gallagher, P. (2015). STOPP/START criteria for potentially inappropriate prescribing in older people: Version 2. Age and Ageing, 44(2), 213-218. https://doi.org/10.1093/ageing/afu145

Onder, G., Landi, F., Cesari, M., Gambassi, G., Carbonin, P., \& Bernabei, R. (2003). Inappropriate medication use among hospitalized older adults in Italy: Results from the Italian Group of Pharmacoepidemiology in the Elderly. European Journal of Clinical Pharmacology, 59(2), 157-162.

Ouchida, K. M., \& Lachs, M. S. (2015). Not for doctors only: Ageism in healthcare. Generations, 39(3), 46-57.

Pazan, F., Weiss, C., \& Wehling, M. (2016). The FORTA (Fit fOR The Aged) list 2015: Update of a validated clinical tool for improved pharmacotherapy in the elderly. Drugs \& Aging, 33(6), 447-449. https://doi.org/10.1007/s40266-016-0371-4

Petrovic, M., Somers, A., \& Onder, G. (2016). Optimization of geriatric pharmacotherapy: Role of multifaceted cooperation in the hospital setting. Drugs \& Aging, 33(3), 179-188. https://doi. org/10.1007/s40266-016-0352-7

Qaseem, A., Alguire, P., Dallas, P., Feinberg, L. E., Fitzgerald, F. T., Horwitch, C., et al. (2012). Appropriate use of screening and diagnostic tests to foster high-value, cost-conscious care. Annals of Internal Medicine, 156(2), 147-149. https://doi. org/10.7326/0003-4819-156-2-201201170-00011

Qato, D. M., \& Trivedi, A. N. (2013). Receipt of high risk medications among elderly enrollees in medicare advantage plans. Journal of General Internal Medicine, 28(4), 546-553.

Qato, D. M., Wilder, J., Schumm, L. P., Gillet, V., \& Alexander, G. C. (2016). Changes in prescription and over-the-counter medication and dietary supplement use among older adults in the United States, 2005 vs 2011. JAMA Internal Medicine, 176(4), 473-482. https://doi. org/10.1001/jamainternmed.2015.8581

Rochon, P. (2016). Drug prescribing for older adults. Peer review. Resource document. http:// www.uptodate.com/contents/drug-prescribing-for-older-adults. Accessed 14 May 2016.

Rochon, P. A., \& Gurwitz, J. H. (1997). Optimising drug treatment for elderly people: The prescribing cascade. BMJ: British Medical Journal/British Medical Association, 315(7115), 1096-1099.

Routledge, P. A., O'Mahony, M. S., \& Woodhouse, K. W. (2004). Adverse drug reactions in elderly patients. British Journal of Clinical Pharmacology, 57(2), 121-126. https://doi. org/10.1046/j.1365-2125.2003.01875.x

Ryan, C., O’Mahony, D., Kennedy, J., Weedle, P., \& Byrne, S. (2009). Potentially inappropriate prescribing in an Irish elderly population in primary care. British Journal of Clinical Pharmacology, 68(6), 936-947. https://doi.org/10.1111/j.1365-2125.2009.03531.x

Ryan, C., O’Mahony, D., Kennedy, J., Weedle, P., Cottrell, E., Heffernan, M., et al. (2013). Potentially inappropriate prescribing in older residents in Irish nursing homes. Age and Ageing, 42(1), 116-120. https://doi.org/10.1093/ageing/afs068 
Sabaté, E. (2003). Adherence to long-term therapies - Evidence for action. Resource document. World Health Organization. http://apps.who.int/medicinedocs/en/d/Js4883e/. Accessed 9 Sept 2016.

Scheen, A. J. \& Giet, D. (2010). Non-observance thérapeutique: Causes, conséquences, solutions [Non compliance to medical therapy; causes, consequences, solutions]. Revue Médicale de Liège, 65(5-6), 239-245.

Schroeder, K., Fahey, T., \& Ebrahim, S. (2004). How can we improve adherence to blood pressurelowering medication in ambulatory care? Systematic review of randomized controlled trials. Archives of Internal Medicine, 164(7), 722-732. https://doi.org/10.1001/archinte.164.7.722

Shah, B. M., \& Hajjar, E. R. (2012). Polypharmacy, adverse drug reactions, and geriatric syndromes. Clinics in Geriatric Medicine, 28(2), 173-186. https://doi.org/10.1016/j.cger.2012.01.002

Simonson, W., \& Feinberg, J. L. (2005). Medication-related problems in the elderly: Defining the issues and identifying solutions. Drugs \& Aging, 22(7), 559-569.

Sokol, M. C., McGuigan, K. A., Verbrugge, R. R., \& Epstein, R. S. (2005). Impact of medication adherence on hospitalization risk and healthcare cost. Medical Care, 43(6), 521-530.

Sokol, K. C., Knudsen, J. F., \& Li, M. M. (2007). Polypharmacy in older oncology patients and the need for an interdisciplinary approach to side-effect management. Journal of Clinical Pharmacy and Therapeutics, 32(2), 169-175. https://doi.org/10.1111/j.1365-2710.2007.00815.x

Somers, A. (2016). Hospital care and older patients- inappropriate prescribing, drug related problems and experience with clinical pharmacy services. In: D. Fialová, A. LukačišinováBallóková, L. Ayalon, C. Tesch-Römer (Eds.), EU COST action 1402 training school abstract book "European perspectives in rational and individualized drug therapy and ageism- priorities for next decades" (pp. 16-20). Prague: Prager press.

Spinewine, A., Fialová, D., \& Byrne, S. (2012). The role of the pharmacist in optimizing pharmacotherapy in older people. Drugs \& Aging, 29(6), 495-510. https://doi. org/10.2165/11631720-000000000-00000

Starfield, B. (2006). Threads and yarns: Weaving the tapestry of comorbidity. Annals of Family Medicine, 4(2), 101-103. https://doi.org/10.1370/afm.524

Steinman, M. A., \& Hanlon, J. T. (2010). Managing medication in clinically complex elders: "There's got to be a happy medium". JAMA, 304(14), 1592-1601. https://doi.org/10.1001/ jama.2010.1482

Strandberg, L. R. (1984). Drugs as a reason for nursing home admissions. Journal of the American Health Care Association, 10(4), 20-23.

Taylor, R. S., Sagar, V. A., Davies, E. J., Briscoe, S., Coats, A. J., Dalal, H., et al. (2014). Exercisebased rehabilitation for heart failure. The Cochrane Database of Systematic Reviews. https:// doi.org/10.1002/14651858.CD003331.pub4

Topinková, E., Baeyens, J. P., Michel, J. P., \& Lang, P. O. (2012). Evidence-based strategies for the optimization of pharmacotherapy in older people. Drugs \& Aging, 29(6), 477-494. https://doi. org/10.2165/11632400-000000000-00000

Undela, K., Bansal, D., D’Cruz, S., Sachdev, A., \& Tiwari, P. (2014). Prevalence and determinants of use of potentially inappropriate medications in elderly inpatients: A prospective study in a tertiary healthcare setting. Geriatrics \& Gerontology International, 14(2), 251-258. https://doi. org/10.1111/ggi.12081

Vermeire, E., Hearnshaw, H., Van Royen, P., \& Denekens, J. (2001). Patient adherence to treatment: Three decades of research. A comprehensive review. Journal of Clinical Pharmacy and Therapeutics, 26(5), 331-342.

Vieira de Lima, T. J., Garbin, C. A., Garbin, A. J., Sumida, D. H., \& Saliba, O. (2013). Potentially inappropriate medications used by the elderly: Prevalence and risk factors in Brazilian care homes. BMC Geriatrics, 13. https://doi.org/10.1186/1471-2318-13-52

Vik, S. A., Maxwell, C. J., \& Hogan, D. B. (2004). Measurement, correlates, and health outcomes of medication adherence among seniors. The Annals of Pharmacotherapy, 38(2), 303-312. https://doi.org/10.1345/aph.1D252

Votova, K., Blais, R., Penning, M. J., \& Maclure, M. K. (2013). Polypharmacy meets polyherbacy: Pharmaceutical, over-the-counter, and natural health product use among Canadian adults. Canadian Journal of Public Health, 104(3), e222-e228. 
Wehling, M. (2016). Efficacy and safety of medication in the old age, clinical guidelines and FORTA recommendations. In: D. Fialová, A. Lukačišinová-Ballóková, L. Ayalon, \& C. TeschRömer (Eds.), EU COST action 1402 training school abstract book "European perspectives in rational and individualized drug therapy and ageism- priorities for next decades" ( $\mathrm{pp} 10-13)$. Prague: Prager press.

Wright, R. M., Sloane, R., Pieper, C. F., Ruby-Scelsi, C., Twersky, J., Schmader, K. E., et al. (2009). Underuse of indicated medications among physically frail older US veterans at the time of hospital discharge: Results of a cross-sectional analysis of data from the Geriatric Evaluation and Management Drug Study. The American Journal of Geriatric Pharmacotherapy, 7(5), 271-280. https://doi.org/10.1016/j.amjopharm.2009.11.002

Wyman, M. F., Shiovitz-Ezra, S., \& Bengel, J. (2018). Ageism in the health care system: Providers, patients, and systems. In L. Ayalon \& C. Tesch-Römer (Eds.), Contemporary perspectives on ageism: Vol. 19. International perspectives on aging (pp. 193-213). Berlin: Springer.

Zhan, C., Sangl, J., Bierman, A. S., Miller, M. R., Friedman, B., Wickizer, S. W., et al. (2001). Potentially inappropriate medication use in the community-dwelling elderly: Findings from the 1996 medical expenditure panel survey. JAMA, 286(22), 2823-2829.

Open Access This chapter is licensed under the terms of the Creative Commons Attribution 4.0 International License (http://creativecommons.org/licenses/by/4.0/), which permits use, sharing, adaptation, distribution and reproduction in any medium or format, as long as you give appropriate credit to the original author(s) and the source, provide a link to the Creative Commons license and indicate if changes were made.

The images or other third party material in this chapter are included in the chapter's Creative Commons license, unless indicated otherwise in a credit line to the material. If material is not included in the chapter's Creative Commons license and your intended use is not permitted by statutory regulation or exceeds the permitted use, you will need to obtain permission directly from the copyright holder. 


\title{
Chapter 15 \\ Ageism in Mental Health Assessment and Treatment of Older Adults
}

\author{
Ehud Bodner, Yuval Palgi, and Mary F. Wyman
}

\subsection{Ageism Among Mental Health Clinicians and Patients}

\subsubsection{Ageist Attitudes and Perceptions Among Mental Health Clinicians}

As mental health clinicians, we strive to meet, treat, and be with our patients through their own experiences, tribulations, and personal journeys. However, when a psychotherapist (for example, a social worker, a psychologist, or a psychiatrist) encounters an older patient, he or she may be subject to ageist judgements which stem from a stereotypical view of older adults in general, regardless of how the individual patient presents him or herself. Perhaps the seed of these ageist attitudes among psychotherapists can be located in Freud's view (1905/1953) on the lack of mental flexibility of older adults, which, he argued, impedes their ability to benefit from psychotherapy. Seventy years later, this scepticism among psychotherapists toward the value of both psychotherapy and medical treatment for the aged was characterized by Butler (1975) as "therapeutic nihilism." According to Butler, such an

\footnotetext{
E. Bodner $(\bowtie)$

Interdisciplinary Department of Social Sciences and Department of Music, Bar Ilan University, Ramat Gan, Israel

e-mail: ehud.bodner@biu.ac.il

Y. Palgi

University of Haifa, Haifa, Israel

e-mail: ypalgi@research.haifa.ac.il

M. F. Wyman

W. S. Middleton Memorial Veterans Hospital and University of Wisconsin School of Medicine \& Public Health, Madison, WI, USA

University of Freiburg, Freiburg im Breisgau, Germany

e-mail: mfwyman@wisc.edu

L. Ayalon, C. Tesch-Römer (eds.), Contemporary Perspectives on Ageism, International Perspectives on Aging 19, https://doi.org/10.1007/978-3-319-73820-8_15
} 
attitude represents a self-fulfilling prophecy, generated by ageist behaviors, which prevents clinicians from examining the validity of their views about the aged.

Ageism in the form of age discrimination and age stereotypes is considered a domain-specific phenomenon (see Voss et al.'s Chap. 2). A lot has been written in general about ageism in the domains of health care systems and long term care (see the chapters in this volume by Wyman et al. Chap. 13 and Buttigieg et al. Chap. 29). However, less has been published about ageism in the domain of mental health. Nevertheless, a number of studies over the last three decades have demonstrated the existence of negative attitudes toward older adults among psychotherapists. For example, Dye (1978) found negative views regarding the ageing process, and a preference against working with older patients, in a large sample of clinical and counseling psychologists in the USA. Older persons were described by the psychologists as being rigid, as having difficulties in learning new material, and as lacking the required energy and resilience for therapeutic growth. Two other studies eliciting assessments of standardized case vignettes from 179 psychiatrists (Ford and Sbordone 1980), and from 407 licensed clinical psychologists in the U.S.A (Ray et al. 1987) found that older patients consistently received less favorable prognoses than their younger counterparts and were perceived as less ideal for therapy. Moreover, in Israel, 55\% of a sample of clinical psychologists indicated their reluctance to work with older patients (Shmotkin et al. 1992), and in Great Britain, psychiatrists were less likely to recommend psychotherapy for sexual dysfunction to an older patient compared with a younger patient (Bouman and Arcelus 2001; see Gewirtz-Meydan and colleagues in this volume).

In Australia, Helmes and Gee (2003) presented 414 psychologists and 293 counselors with a vignette describing a fictitious case, and found that an older patient was rated as less able to create proper therapeutic relationship, as having a poorer prognosis, and as being less appropriate for therapy compared with a younger patient with the same symptoms. More recently, a review demonstrated an age bias among psychotherapists, with many expressing the view that depression in late life is a natural consequence of old age and that old age is a phase of life associated with less satisfaction and diminished personal growth (Laidlaw and Pachana 2009). In Portugal, Gonçalves and colleagues (Gonçalves et al. 2011) found that compared with nursing and social work undergraduates, psychology students expressed the most negative attitudes, the lowest level of knowledge, and the lowest level of interest in working with older adults.

An urgent issue which emphasizes the existence of negative attitudes toward older adults among psychotherapists concerns the legitimacy of suicide in older adults. Uncapher and Arean (2000) found that USA physicians were less interested in treating older adults with suicidal tendencies than they were in treating younger patients with identical problems. According to the physicians' view, the existence of suicidal tendencies among older adults was seen as logical and normal. Hence they were less willing to use therapeutic strategies to address suicidal thinking in older patients. In another study (Barnow et al. 2004), German medical professionals (physicians and nurses working in psychiatric institutions), in response to a vignette describing an older client, were less likely to suggest treatment to patients exhibiting 
suicidal tendencies compared to an identical vignette featuring a young client. Here, too, health professionals working in psychiatric institutions expressed less willingness to treat older compared to younger suicidal patients.

These biases against older patients appear to be formed well before mental health clinicians enter the professional world. A survey of clinical psychology trainees (Lee et al. 2003) revealed predominant perceptions of older adults as being people who are resistant to new things, have limited opportunities, demonstrate rigidness and inflexibility, and have a very limited potential to change, as they are too close to the end of their lives. Many of the trainees believed that psychotherapy was problematic in this age group due to cognitive problems, such as difficulties with memory $(74.4 \%)$, concentration $(61.2 \%)$, and mental rigidity $(60.4 \%)$. The psychotherapists also identified other challenges to working with older patients, such as a decline in hearing (60.4\%), apathy $(57.1 \%)$, passivity (46.6\%), difficulties in learning new material (45.3\%), problems in changing habits (44.5\%), and a lack of psychological mindedness (56.9\%).

To sum up, evidence from across the globe over the last 30 years demonstrates that many mental health clinicians are less willing to work with older adults, have negative assumptions about the effectiveness of psychotherapy with older adults, and lack professional knowledge of the geriatric population.

\subsubsection{Training in Geriatric Mental Health and Exposure to Older Patients}

Curriculum content in mental health training programs has traditionally been lacking in material related to geriatric patients and in clinical skills for working with the older population (e.g., Qualls et al. 2002). Subsequent professional work experiences often do not allow for adequate exposure to older patients. For example, data on the current major fields of APA members in 2015 show that only 240 health services providers out of 43,353 , reported Geropsychology as their main area (APA Center for Workforce Studies 2015 reported in American Psychological Association 2015). A survey in Australia also found that only $6 \%$ indicated they were specialists in aged care, and $40 \%$ of the sample reported having no contact at all with older patients (Koder and Helmes 2008). In the UK, similar figures were reported (Bryant and Koder 2015).

As a result, many mental health professionals report a lack of specific knowledge about psychopathology and psychotherapy with older adults. For example, in Britain, trainees in psychotherapy expressed a lack of information about psychotherapy with older adults (Scott and Bhutani 1999), and recruiting psychologists to work with older adults has been challenging (e.g., Britton and Woods 1996). American psychologists reported minimal formal education in geropsychology and endorsed the need for additional training (Qualls et al. 2002). A survey among 200 clinical psychologists in training programs found that many reported having "less to 
offer" to older patients compared to patients from other age groups (Lee et al. 2003). Another study in Britain (Richards et al. 2007) conducted 30 interviews with health and social care practitioners currently working with older people. This study found that the practitioners lacked essential theoretical and research-based knowledge in the field of ageing and old age; rather, they primarily made use of common organizational policies and personal experience with ageing family members to analyze a clinical vignette presented to them.

In summary, the lack of knowledge and training in geriatric care, especially in the field of clinical psychology, presents a global problem, in particular in the context of demographic trends toward an increase in the aged population. Lack of specialized geriatric knowledge was found to be an influential factor in the negative attitudes of psychologists toward older adults (Koder and Helmes 2008). This problem begins at the undergraduate psychology education level, as most courses do not include content on the psychology of old age, and continues through the advanced training of clinical psychologists specializing in geriatric care (Bryant and Koder 2015; Qualls et al. 2002). This lack of knowledge in geriatric mental health and the minimal exposure to older patients among mental health clinicians may be the main reason for their reluctance to work with older adults and a primary contributing factor to stereotyped "ageist" attitudes. Therefore, clinical exposure to the aged has frequently been suggested as a means to mitigate pre-existing negative stereotypes concerning older adults (Bryant and Koder 2015; Koder and Helmes 2008).

Nevertheless, the factors underlying age-based bias in mental health care are numerous. Research suggests that an additional reason for these attitudes among clinicians may be the way elderly patients internalize ageist social stereotypes, and how the patients themselves perceive their psychiatric problems (Laidlaw and Pachana 2009). In the next subsection we will change our perspective from the psychotherapist to the patient, discuss self-ageism among older mental health patients, and elaborate on the effect of self-ageism on the encounter between older mental health patients and clinicians.

\subsubsection{Self-Ageism Among Older Patients with Mental Illness}

One out of five persons above the age of 65 suffers from some form of mental illness (e.g., Karel et al. 2012). The majority of these older adults prefers to consult a primary general practitioner and does not seek out mental health clinicians (Lerner and Levinson 2012). Unfortunately, primary general practitioners encounter barriers to the management of mental illness both at the individual and the system levels (Ayalon et al. 2016). But more importantly, when referrals to mental health practitioners are made, older adults are unlikely to follow through on these referrals, and thus further assessment often does not occur (DiNapoli et al. 2015). Therefore, it is essential to examine the reasons for older adults' reluctance to use mental health services. 
When older adults relate to a social group which may be discriminated against, based on their skin color, race, gender, or being a cultural minority (see Krekula et al.'s Chap. 3 on gendered ageism, and also Dolberg et al.'s Chap. 12 on ageism and older immigrants), they may experience double- jeopardy and stigmatization. This may also be the experience of older adults who suffer from mental health problems. One unique problem that older adults with mental illness face is "double stigmatization," which refers to negative attitudes toward old age combined with negative attitudes toward mental illness (Werner et al. 2009). "Self-double stigmatization" is the internalization of these stigmas by those who are the target of double stigmatization (Rush et al. 2005). Self-double stigmatization may have a negative effect on the ability of older adults with psychiatric conditions to seek help from mental health professionals. Studies have shown that internalized stigma related to mental illness (e.g., schizophrenia) makes it more challenging for the patient to seek therapy (Fung et al. 2007) and to comply with recommendations in psychotherapy (Mackin and Arean 2007).

Several researchers have examined double stigmatization associated with depression in old age. Depression is one of the most prevalent mental illnesses in the population of older adults, with a prevalence estimates in the general elderly population ranging from $1-4 \%$ for major depression, $4-13 \%$ for minor depression (Blazer 2003), and $8-16 \%$ for significant depressive symptoms (Blazer 1989). Depression is a stigmatized illness and may be seen as a sign of personality weakness and as something to hide. Therefore, there are societal negative attitudes toward depressive patients (e.g., Boardman et al. 2011). It has been suggested that negative attitudes towards depressive patients harm self-esteem and can worsen symptoms (Fung et al. 2007).

In addition, negative self-perceptions of ageing are associated with increased depressive symptoms in later life (e.g., Wurm and Benyamini 2014). Two crosssectional studies have pointed to the link between more positive attitudes toward ageing and less depression (Bryant et al. 2012), which has also been found in relation to subsyndromal depressive symptoms (Chachamovich et al. 2008). Moreover, a recent study of over 2000 older military veterans in the U.S. has found that those who had more negative stereotypical perceptions of their own ageing, reported a higher frequency of psychiatric symptoms, in comparison with those who had fewer negative stereotypical perceptions of ageing (Levy et al. 2014). Group differences were found in rates of suicidal ideation (30.1\% vs. $5.0 \%)$, anxiety symptoms (34.9\% vs. 3.6\%) and Post Traumatic Stress Disorder (PTSD) symptoms (18.5\% vs. $2.0 \%$ ), and were maintained after relevant sociodemographic variables were controlled for.

Whereas higher negative self-perceptions of ageing are associated with more severe psychopathology, double stigmatization further impedes the tendency of older mental health patients to seek help from mental health professionals (e.g., Fung et al. 2007). Several researchers have suggested that the underutilization of mental health services by older adults may result from the internalization of ageist attitudes by older patients (Levy 2003). Consequently, the difficulties that older patients experience in mental health treatment likely increase as their mental condition persists or even worsens as a result of their inability to receive help. 
When trying to understand the mechanisms responsible for the association between negative self-perceptions of ageing and proneness to severe psychopathology, ageism can be identified as a stressor in its own right. According to Ingram and Luxton's (2005) stress and vulnerability model, exposure to various environmental stressors is linked with an increased risk for developing psychiatric conditions. Following this line of thought, people who hold negative attitudes toward their ageing may be less willing to take part in positive social activities (Weiss and Lang 2012), and may hold negative images of age-related health problems. This may in turn result in an increased vulnerability to depression, that is, a type of "selffulfilling prophecy" (Kessler and Bowen 2015). In contrast, positive attitudes toward ageing may act as a buffer against mental distress, as older adults with more positive attitudes toward ageing seem to become more involved in healthier ways of living, such as maintaining a nutritious diet (Huy et al. 2010) or engaging in regular physical activity (Levy and Myers 2004).

There is also empirical evidence indicating that ageism is associated with heightened ageing anxiety (Bodner et al. 2015a). These concerns act as stressors that increase sensitivity to physical symptoms (Poon and Knight 2009), and become associated with higher levels of depression during midlife (Barrett and Robbins 2008), as well as with other symptoms of mental distress (Bodner et al. 2015b). Of note, these findings are also consistent with the behavioral model of late life depression (Fiske et al. 2009), which regards negative cognitions about the self and the future as risk factors for depression in late life.

In summary, older adults with mental health problems may hold both ageist negative attitudes toward themselves as well as negative attitudes toward mental illness. This self-double stigmatization may have an impact on their symptoms and their interactions with the mental health care system. Following this line of thought, in the next subsection we will discuss the objective difficulties clinicians face when diagnosing mental health problems in older adults. Then, we will examine how ageist attitudes of both clinicians and patients may impact the accuracy of several mental health diagnoses and subsequent treatment recommendations.

\subsection{Difficulties in the Assessment of Older Persons with Mental Health Problems: The Impact of Ageism}

\subsubsection{Objective Difficulties in Assessing Psychiatric Conditions in Old Age}

For a number of reasons, the assessment of mental health disorders in older adults can be complex and often requires a high level of expertise, effort, and time. In old age, there is an overlap between some psychiatric symptoms and symptoms related to changes in hormone levels (Sternbach 1998), declines in cognition (Petersen 2004), physical disability (Milaneschi and Penninx 2014), and physiological 
processes (McKinney and Sibille 2013). These non-psychiatric symptoms are often part of normal ageing. For example, needing less sleep, changes in diet and digestive functioning (Elsner 2002), reduction in energy, and slowed information processing are considered normal age-related changes (Whitbourne and Krauss 2011). However, these symptoms can also be part of the clinical presentation associated with common disorders such as anxiety or depression (Fiske et al. 2009). Teasing apart the etiology or multiple etiologies of such symptoms can be very challenging when working with an older patient.

Another challenge to accurate diagnosis of mental health problems in older adults lies in the limitations of available psychiatric assessment tools. Mental health symptom questionnaires and interview instruments have been criticized for inadequately discerning between age-related problems and psychiatric symptoms (Eisner et al. 1999) and may not have been validated with older adult samples (Owens et al. 2000). Despite the fact that many scholars have studied this issue and considered potential solutions (e.g., Hendrie et al. 1995), there is, as of yet, no clear consensus on an optimal approach to the assessment of mental health conditions in older adults. Moreover, as noted above, many mental health clinicians have not received adequate basic education in geriatric mental health and thus may experience additional challenges in providing assessment and treatment for complicated older adult cases (Halpain et al. 1999). If we add to this the fact that older adults prefer primary general practitioners, and refrain from seeking out mental health clinicians (Lerner and Levinson 2012), we end up with another almost impossible challenge for the practitioner - to make a psychiatric diagnosis and treat other medical age-related conditions in the brief time allotted to that patient.

A further issue concerns the clinical presentation of mental disorders. Clinicians and researchers have long reported age differences in symptom constellation of some mental disorders, such as depression (see Blazer and Hybels 2005) and PTSD (Palgi 2015; Pietrzak et al. 2012). However, age-based comparisons of symptom presentations have found mixed results (e.g., see Luppa et al. 2012 for evidence suggesting an increase in depression with aging, and a review by Debast et al. 2014, reporting age differences in somatoform disorders). The mixed results in the literature have not helped to decrease clinician bias and confusion in this domain. Adding to this is the mounting evidence that subthreshold mental disorders are more prevalent than diagnosed disorders in late life and are associated with significant disability and comorbidity (e.g., Meeks et al. 2011). Together, these factors make the diagnosis of mental disorders in old age more difficult.

Eliciting older patients' own attributions for their problems, whether physical or emotional, is an important piece of the diagnostic process for the clinician. However, when the etiology of the symptoms is unclear, such attributions may further complicate the clinical picture. Research suggests that older adults with depression may tend to blame themselves and their lifestyle choices for their own medical symptoms, while making different attributions for the same symptoms in others (Benedict 1995). They may attribute physical symptoms (for example, fatigue, concentration problems, and weight loss) to medical diagnoses and not to psychiatric conditions, which may affect responses on self-report mental health measures and in 
interview-based assessments. In addition, older adults may not endorse the "impairment in social or occupational functioning" needed to meet DSM diagnostic criteria for mental disorders. It can be difficult for both patient and clinician to identify impaired functioning when a retired or disabled older adult has few social roles or formal responsibilities (Hendrie et al. 1995). Further, willingness on the part of older adults to admit impairment may be related to ethnicity or cultural values (e.g. Apesoa-Varano et al. 2015).

To sum, the interaction between age-related changes and the clinical phenomenology of psychiatric problems in old age makes it more challenging and timeconsuming for patients and clinicians to accurately perceive and diagnose psychiatric conditions. It can be especially problematic when these objective difficulties in diagnosing psychiatric syndromes in late life are combined with stereotypes based on age, in both patients and clinicians.

\subsubsection{Psychiatric Diagnoses Biases in Late Life: The Role of Ageism}

In this subsection we discuss four specific psychiatric syndromes which can be difficult to diagnose in old age. We raise concerns about the possibility that a lack of knowledge among both older patients and clinicians regarding the ageing process may contribute to age-related biased attributions, which may in turn be associated with typical biases in making these psychiatric diagnoses. Such a lack of knowledge may contribute to the attribution of debilitating clinical symptoms primarily to the ageing process, as if these symptoms are natural and "to be expected" in old age (Laidlaw and Pachana 2009). For some clinicians, this lack of knowledge likely also contributes to the difficulty in differentiating between signs of normal age-related deterioration and symptoms associated with treatable mental health problems. Finally, as later elaborated, paternalistic attitudes toward older adults and a view of these patients as incompetent may partially contribute to the problem of overuse of neuroleptic medications and reluctance to refer them for psychological or psychiatric treatments (Bronskill et al. 2004). Some of these typical biases may be evident in the following diagnoses.

Psychosis Distorted thinking and abnormal perceptual experiences are the hallmark symptoms of a primary psychotic disorder. These symptoms can also be concordant with conditions such as delirium, dementia, medication, and medical illness (Reinhardt and Cohen 2015), all of which can be relatively common in late life. Subsequent therapeutic decisions regarding psychotic symptoms require a high level of psychogeriatric-specific knowledge and a careful process of exclusion of potential causes. At the same time, a lack of psychogeriatric-specific knowledge, which may be reflected in ageist assumptions regarding older adults (e.g., "disturbed thinking in an older person means he or she have dementia"), can lead primary general practitioners to the misdiagnosis of psychotic syndromes by attributing these symptoms to dementia, rather than to a primary psychotic disorder. 
Depression In several past studies, the prevalence of depression in older adults was lower compared to younger adults (Blazer and Hybels 2005). However, a recent meta-analysis suggested that rates of depressive disorders increase dramatically in the oldest old compared to the young-old. For example, rates of depression among those 85 years and older were almost $25 \%$ higher compared with those $75-79$ years old, and 30 to 50\% higher among persons 90 years and over (Luppa et al. 2012). This inconsistency might be accounted for in several ways; one main factor might be problems in the diagnosis of depression in older adults. For example, evidence shows that compared to younger populations, a smaller percentage of older adults suffers from a major depressive disorder but a higher percentage experiences subsyndromal depressive symptoms (Meeks et al. 2011). Furthermore, in many cases, it can be difficult to distinguish between diagnosable depression, subsyndromal depressive states, and normal ageing among older adults (Fiske et al. 2009).

Part of this diagnostic conundrum may be due to differences in clinical presentation. For example, older adults who suffer from depressive symptoms may be less likely than younger adults to endorse sadness or low mood, or they may present primarily with less common symptoms such as apathy, possibly due to neurological changes (Alexopoulos et al. 2013). This phenomenon, known as "depression without sadness" or "masked depression" may lead to misdiagnosis (Covinsky et al. 2014). A lack of consensus on how to classify subsyndromal depressive symptoms or depressive presentations that are atypical may lead to misindentification of these syndromes (Ludvigsson et al. 2014). Furthermore, somatic elements which are prevalent in old age (e.g., physical disability, functional limitations, fatigue, digestive problems, and physical pain) may also cause emotional distress, leading to a clinical picture that, in some ways, resembles a depressive syndrome. We believe that a lack of knowledge about these changes in old age among both clinicians in geriatric mental health and patients may lead in some cases to overdiagnosis (and overtreatment, particularly with medication) of depression (Parmelee et al. 2013).

In addition, cognitive deficits may present as part of a psychiatric syndrome such as depression. Scholars have written extensively on "pseudo-dementia," a clinical presentation of depression distinguished by cognitive decline as the hallmark complaint (Burns and Jolley 2015). This syndrome is more common among older adults compared to younger adults, and assessment may be complicated by the presence of changes in cognition due to normal ageing or medication effects - both frequent among elderly patients (Lamberty and Bieliauskas 1993). In the case of pseudodementia, an emphasis by a clinician solely on the presentation of cognitive deterioration may reflect an ageist assumption that dementia is an unavoidable part of old age. At times this will result in the underdiagnosis of depression.

Anxiety Disorders Schuurmans and Balkom (2011) point to the fact that while there is a high prevalence of anxiety disorders in late life, these disorders are not easily diagnosed in older adults. The authors opine that older adults with anxiety use avoidance behaviors and thus run "under the radar" - resulting in significant underidentification and under-diagnosis. They explain the ability of older adults to avoid certain activities as being supported by the tendency of others to hold stereotypical 
views of older persons as incapable of completing tasks that require physical ability. They further note that family members have a tendency to aid the older adult by replacing him/her in performing these chores. This tendency may result from attitudes which are described by Palmore as "positive ageism", defined as attitudes toward older adults which may seem prosocial, but are, in essence, patronizing (Palmore et al. 2005). Schuurmans and Balkom (2011) also contend that ageism may be linked with a tendency to interpret anxiety and avoidance behaviors in late life (e.g., reluctance to leave the house, or to travel by bus) as adaptive or "realistic" reactions to age-related physical illnesses (e.g., arthritis affecting the person's mobility), or to life events (e.g., a previous fall on the street or on the bus). Moreover, the authors refer to the lack of knowledge about anxiety in late life among general practitioners, which makes it difficult for these clinicians to identify avoidance symptoms). They also note the fact that current diagnostic instruments may not identify the specific age-related factors of late-life anxiety disorders.

Another problem with anxiety disorders lies in the overlapping symptoms between Generalized Anxiety Disorder (GAD) and depression (Roy-Byrne and Wagner 2004). For example, fatigue and other physical symptoms, as well as negative ruminations, can be part of both syndromes. When GAD presents together with depression, primary care physicians tend to devaluate the persistent worries and to over-evaluate the negative mood, ending up with a diagnosis of depression (Calleo et al. 2009). Taken together, the evidence suggests that there is a lack of training in anxiety disorders in late-life and that these disorders are generally underindentified in clinical practice. We further suggest that the misdiagnosis of anxiety is related to a common stereotypical belief that old age is full of stressors and that older adults are "normally" distressed, worried, and avoidant.

Personality Disorders Personality disorders (PDs) were previously believed to be stable and unchanging conditions. However, it is unclear as to whether they are as stable across the life span as they were once assumed to be (Debast et al. 2014). In this respect, it is uncertain whether age-related changes in values and behaviors may be counted inappropriately as diagnostic symptoms of PD, or alternatively, whether these changes might conceal existing symptoms in a way that would disguise the existence of PDs. For example, studies have suggested that PDs may be manifested differently in later life compared to in younger adulthood due to cognitive decline, somatic comorbidities, and increased medication use (van Alphen et al., 2012).

In a recent study, older adults exhibited a higher level of avoidant personality symptoms compared to younger adults, yet showed lower levels of paranoid, schizoid, schizotypal, antisocial, borderline, histrionic, and narcissistic personality symptoms (Debast et al. 2014). This finding does not answer the question of whether current criteria for a PD diagnosis can be applied to older adults with clinical validity, or whether changes in these symptoms reflect a real change in the ways PDs are manifested in old age. In this vein, several items in diagnostic questionnaires have been reported to be less applicable for older adults compared to younger patients. For example, the item "avoids occupational activities", which is one of the 
criteria for avoidant PD, refers to a life domain that may be irrelevant in the assessment of a retired elderly person (Tackett et al. 2009). In a similar manner, the item "neither enjoys nor experiences sexual relations," which is one of the criteria for schizoid PD, may have a different relevance for younger versus older adults. These examples provide a glimpse into the numerous questions and challenges in assigning psychiatric diagnoses to older patients. Unfortunately, there is a dearth of literature in this area, despite the importance of personality in navigating the many changes and stressors of ageing. We suggest that the limited interest to date in studying age-related changes in PD stems from a narrow psychological perspective on human development. This perspective perceives adulthood as the end point of personality development and does not acknowledge late life as a stage in life which has an important effect on the individual's personality (in this respect, see Carstensen et al. 2011).

In summary, overdiagnosis, underdiagnosis, and misdiagnosis of the abovementioned diagnoses is related to the fact that diagnostic criteria and diagnostic tools have generally been normed on younger adults and may not be appropriate for use with older adults. Lack of knowledge and training represent additional factors. Finally, in some cases, ageist, stereotypical perceptions of older adults add to the difficulties in assessing psychiatric conditions in old age.

\subsection{Ageism in Treatment: Providing Psychotherapy to Older Persons}

In this subsection we aim at providing answers to the following questions: what are the adaptations required for psychotherapy with older adults, and what possible impact may negative age-related attitudes have on these adaptations? Are there specific age-related issues concerning the relationship between psychotherapists and older patients, and what is the potential effect of ageist attitudes of both partners on the therapeutic relationship? What is the possible effect of ageist attitudes on the implementation of interventions for mental health problems which are common in old age?

\subsubsection{Attitudes and Adaptations in Psychotherapy with Older Patients}

When working with older patients, certain adaptations can make almost any therapeutic approach more effective in reaching treatment goals. At the same time, agebased prejudice and discrimination can impact the provider-patient relationship and hinder the therapeutic work. When working with an elderly patient, for example, there may be a greater likelihood of encountering difficulties with transportation to 
appointments, medical health symptoms, conflicts with care-giving obligations, and financial constraints. These difficulties may activate stereotyped and ageist attitudes on the part of the psychotherapist. If the psychotherapist follows Freud's view (1905/1953) on therapy in old age, and perceives older adults as passive, rigid, stubborn, unwilling to invest efforts in changing, or as lacking the flexibility required to engage in psychotherapy, he or she may view these barriers not as problems to be solved in order to continue in psychotherapy, but as resistance on the part of the patient. Such a stance by the psychotherapist may be perceived as an insult by a patient who is facing these serious difficulties (Wyman et al. 2011). Ageist attitudes may also impede the flexibility of psychotherapists to consider relevant issues of access to psychotherapy and psychotherapy location, session's length and continuity. Therefore, psychotherapists may fail in adapting the psychotherapy to settings which are more available for older patients (e.g., primary care medicine settings, adult day health centers). When the patient is a frail older adult, ageist attitudes which attribute communication problems only to cognitive impairment (e.g., "all older adults are senile and confused") might hinder psychotherapists in taking steps toward helpful adaptations for working with such patients (e.g., audiotaping therapy sessions for review at home, ensuring good lighting in the therapy room, slowing the pace of speech and lowering the tone of voice, etc. See Wyman et al. 2011).

\subsubsection{Psychotherapists' and Patients'Ageist Attitudes and the Therapeutic Relationship}

Psychotherapists and patients might bring into the therapeutic relationship responses that were learnt in other interpersonal contexts. Knight (2004) suggests that the terms "transference" (the feelings and thoughts the patient has about the psychotherapist) and "countertransference" (the feelings and thoughts the psychotherapist has about the patient) can be used to understand how age-related stigmas affect the psychotherapeutic relationship with older patients. Stereotypes and attitudes related to age can affect the internal representations each party establishes regarding the other, which are not based on real people or on what really happens in therapy (Knight 2004). On both sides of the psychotherapeutic relationship, age-biased attitudes can impact how the other is viewed.

Psychotherapists may adhere to stereotypes pertaining to the age group of older frail adults and fail to acknowledge the strengths and resources of these patients. In some cases, the psychotherapist might interact with the patient as a parent or a grandparent figure. This may lead to overcautious and unassertive approaches by the therapist during the course of psychotherapy. Moreover, when working with an older patient, psychotherapists may overlook erotic transference or react to it negatively, as erotic transference contradicts society's ageist perceptions about sexuality in old age (Wyman et al. 2011). Older patients may stigmatically define their psychotherapist as belonging to an age group of younger and healthy adults, who 
"knows nothing about the experience of being old and frail." They might also relate to a younger psychotherapist as a child or grandchild, and not acknowledge his or her professional abilities (Knight 2004). These transference and counter-transference attitudes are based on negative age-related biases which likely have a negative impact on therapeutic outcome.

\subsubsection{Ageist Attitudes and Specific Psychotherapeutic and Drug Interventions in Old Age}

Geriatric mental health scholars agree that evidence-based psychotherapy approaches (e.g., cognitive-behavioral therapy, interpersonal therapy, problem solving therapy) are appropriate and effective for use with older adult patients, with some adaptations (Wyman et al. 2011). An in-depth review of these approaches is beyond the scope of this chapter. However, a brief discussion of the effects of ageist attitudes on the implementation of therapies for mental disorder with older patients is in order. We will then relate to the possible impact of physicians' ageist attitudes on their tendency for overuse of psychiatric medications in older adults.

Cognitive behavioral therapy (Beck 1995) is effective for older adults suffering from depression (Arean and Cook 2002) and anxiety (Nordhus and Pallesen 2003). However, an ageist approach which perceives older patients as generally frail and incompetent may cause the psychotherapist to assign fewer tasks for patients to complete between therapy sessions, though these "homework assignments" are considered fundamental to treatment success in this modality. In addition, when the psychotherapist's stereotypical, and likely subconscious, beliefs about the elderly (e.g., "older adults who are not working, are a societal burden") correspond to automatic maladaptive thoughts held by the patient (e.g., "As a retired worker, I'm no use anymore"), it is quite challenging for a psychotherapist to identify these maladaptive thoughts and engage the patient in correcting them.

Interpersonal therapy also has a strong evidence base for use with older persons (Arean and Cook 2002) and focuses on symptom relief and on the improvement of interpersonal coping strategies in depression (Klerman et al. 1984). However, it may be difficult for a psychotherapist who perceives older patients as incompetent, disabled, and inflexible to acknowledge the changes that come with age, in their patients' social roles within the family and work environment, to understand the impact of the loss of loved ones, or to be aware of potential intergenerational conflicts that may exist for the patient (Wyman et al. 2011). Such stereotypical attitudes toward ageing can hinder the psychotherapist's insight into these issues and pose a real threat to the effectiveness of interpersonal therapy.

In problem-solving therapy, which views a deficit in problem-solving skills as one of the causes for depression, the psychotherapist and patient work together to identify problems patients are currently facing and solve them in a series of standard steps (Nezu et al. 1988). However, the implementation of this form of therapy with 
older adults requires the understanding that a number of problems which present in later life are not "solvable" in the commonly-understood sense. For example, some illnesses cannot be cured, and the loss of close relatives and friends cannot be reversed. It may be difficult for a psychotherapist who does not accept his or her own ageing to assist patients to effectively accept these inevitabilities and apply the therapeutic tools to problems that can be effectively managed to improve mood. Here too, negative beliefs about old age as a time of resignation, slowed or absent personal growth and passivity might block the psychotherapist's ability to most effectively work with this therapeutic approach.

Psychotherapeutic treatment, or "talk therapy," is not the only mental health treatment approach that is impacted by ageism. The overuse of psychiatric medication in older adults is well documented in the literature and is a rising concern (for a review, see Ruxton et al. 2015; see also Fialova and colleagues in this volume). This tendency is pronounced in long-term care facilities, where a particularly high consumption is reported for benzodiazepines, antipsychotics and antidepressants (Anrys et al. 2016). These trends continue despite clear evidence of the heightened risks of certain medications for the elderly - including accidents and falls, cognitive impairment, and a development of tolerance and addiction to these drugs - and despite the existence of evidence-based guidelines for prescribing (Schuurmans and Balkom 2011).

According to some researchers system-based ageist attitudes (e.g. perceiving older adults as "beyond help", "useless", or perhaps undeserving of equal attention to quality mental health care) plays a role in maintaining the gap between best practice and reality (Kolanowski et al. 2009). For example, one qualitative study on the use of non-pharmacological interventions in nursing homes identified the typical reduced evening and weekend staffing patterns, and the resultant time pressure on personnel, as a significant barrier to using behavioral approaches to address problem behaviors versus medications (Kolanowski et al. 2009). These authors concluded that a culture change related to use of medication in older patients is necessary, noting that successful use of nonpharmacological interventions requires "the right staff with the right education at the right time" (p. 1). Similar concerns have also been demonstrated in primary care settings (Cook et al. 2007) and relate to impatience of primary doctors and nurses, who may quickly opt to use benzodiazepines when faced with agitated behaviors in an older person (Ayalon et al. 2013). Medications require less effort and less time, and are more cost-effective for the medical system, at least in the short term.

A second reason for the frequent use of medications to treat mental disorder is related to the belief that "older patients don't want psychotherapy." This is a widelyheld misconception, despite the evidence for a "positive cohort shift" in the attitudes of healthy older adults to seek help for mental health difficulties (Woodward and Pachana 2009) and evidence to the contrary from large-scale clinical trials (Gum et al. 2006). We argue that age stereotypes play a role in perpetuating this misconception, and that addressing ageism needs to be part of the culture change away from overuse of medications and toward increased use of behavioral interventions for older patients. 


\subsubsection{Recommendations for Mental Health Clinicians}

In summary, the assessment and treatment of older adults within the mental health setting presents many challenges even to seasoned clinicians. These challenges include complicated symptom presentations, inadequate professional training and exposure to geriatric syndromes and psychiatric conditions in late life and a limited set of assessment tools which are appropriate and valid for use with older patients. Psychotherapy with older adults is frequently less straightforward and requires adaptations of commonly used therapeutic approaches to address the unique problems and difficulties faced in the later years in order to maximize the chances of therapeutic success.

Ageism presents another important, though often overlooked, challenge. Ageist attitudes of both patients and psychotherapists present as transference and countertransference phenomena. Ageist attitudes of the psychotherapists can interact in various ways with different methods of therapy which are used for treating older adults. When adapting different methods of therapy to older adults, psychotherapists should strive to identify their own ageist biases which may be at play and to remain flexible in adapting their approach.

In order to neutralize the effect of ageist attitudes, professionals working with older adults should first strive to understand the meaning of "ageing" and "old age" for their older patients as well as for themselves. They should reflect on their own attitudes toward the ageing of loved ones and themselves, and become aware of the ways in which they want to be seen by their older patients (Wyman et al. 2011). Psychotherapists also need to be able to acknowledge not only the weaknesses but also the strengths of older patients. Ageist attitudes may lead psychotherapists to ignore internal and external resources and to focus only on the patients' shortcomings. Such an attitude may cause psychotherapists to perceive their older patients as more helpless than they truly are, and is compatible with the tendency described by Palmore as "positive ageism": an attitude toward older adults which may seem (in this case - to the psychotherapist) as beneficial, but is, in essence, patronizing (Palmore et al. 2005).

Further, we strongly encourage professionals to directly address age-related stigmas, including self-ageism and "self-double stigmatization" and misperceptions with their older patients. For example, a mental health provider might raise ideas related to stigmatization of mental illness and therapy with their patients for discussion (for example, the common concern that "receiving therapy means I'm weak"), as well as age-related stigmas (e.g., "younger psychotherapists will never understand me"; "I'm too old to change"). A mental health clinician can encourage the patient to express these concerns by being proactive and raising frequently asked questions, and can provide written educational materials addressing these issues. Addressing age- and mental illness-related stigmas with patients can increase older patients' attendance and engagement in psychotherapy, regardless of the therapeutic approach (Wyman et al. 2011). 


\subsection{General Conclusions and Recommendations}

In this chapter, we have explored how negative ageist attitudes on the part of both mental health care providers and older patients may contribute to challenges in the diagnosis and psychotherapy of mental disorders in older adults. We note the inherent challenges in diagnosis and therapy of mental disorders in older adults, which are due to complex clinical presentations and comorbidities. We argue that - in general - mental health clinicians continue to be less equipped to work and do psychotherapy with older adults compared with younger adults, hold generally negative assumptions about older adults as psychiatric patients and lack adequate professional knowledge of the geriatric population. In addition, internalized ageism (selfdouble stigmatization) impacts the interactions of older patients with the mental health care system and can contribute to a reluctance to seek mental health care services.

Changing these attitudes and misconceptions requires a combined effort of both governments and mental health clinicians. Governments have to allocate more financial resources for mental health services for older adults and for geriatric training and education for both providers and consumers of mental health care. In this regard, several specific recommendations for mental health clinicians can be made: (1) Providers should be supported in seeking out appropriate training on working with older adults and the developmental changes that occur in late life. Training programs that acknowledge the uniqueness of the older adult population are needed, especially in countries without a presence of the psychogeriatric field (e.g., Israel, as of this writing).

(2) Scientific study is needed to ensure that mental health diagnostic criteria and available assessment instruments are valid for use with older adults. (3) Further scientific investigation is also required for the adaptation of therapies for use with older adults. (4) Mental health clinicians will benefit from self-reflection to increase awareness of ageist attitudes which impact their work with older patients. (5) Improved collaboration and an exchange of knowledge among health professions in the field of gerontology (e.g., occupational therapists, physiotherapists, psychologists, psychiatrists and psychogeriatricians) can improve assessment and therapeutic abilities.

As for the elderly consumers of mental health care services, several steps can be done in order to change their negative views about the ageing process and about mental health services: (1) Patients' education about the benefits of mental health psychotherapy at all ages, and about effective engagement in mental health services might increase the use of psychological and psychiatric therapy for older adults. (2) Psychoeducation for older mental health patients could help to reduce self-ageism among this patient group.

In conclusion, we agree with other authors in this volume (e.g., Wyman et al., Fialova et al., Gweyrtz-Meydan et al., Evans) that addressing ageism within health care is vital in improving services and achieving optimal treatment outcomes. We believe that, while mitigating ageism among mental health clinicians, older mental 
health patients, and their family members and friends may not add years to their lives, it can add lives to their years - which might be even more important.

\section{References}

Alexopoulos, G. S., Hoptman, M. J., Yuen, G., Kanellopoulos, D., Seirup, J. K., Lim, K. O., \& Gunning, F. M. (2013). Functional connectivity in apathy of late-life depression: A preliminary study. Journal of Affective Disorders, 149(1), 398-405. https://doi.org/10.1016/j. jad.2012.11.023

American Psychological Association, Center for Workforce Studies. (2015). 2015: APA member profiles. Retrieved from http://www.apa.org/workforce/publications/15-member/profiles.pdf

Anrys, P., Strauven, G., Boland, B., Dalleur, O., Declercq, A., Degryse, J. M., et al. (2016). Collaborative approach to optimise MEdication use for older people in nursing homes (COME-ON): Study protocol of a cluster controlled trial. Implementation Science, 11(35), 1-11. https://doi.org/10.1186/isrctn66138978

Apesoa-Varano, E. C., Barker, J. C., Unutzer, J., Aguilar-Gaxiola, S., Johnson, M. D., Tran, C., et al. (2015). Idioms of distress among depressed white-non-Mexican and Mexican-origin older men. Journal of Cross-Cultural Gerontology, 30(3), 305-318. https://doi.org/10.1007/ s10823-015-9267-8

Arean, P. A., \& Cook, B. L. (2002). Psychotherapy and combined psychotherapy/pharmacotherapy for late life depression. Biological Psychiatry, 52(3), 293-303. https://doi.org/10.1016/ s0006-3223(02)01371-9

Ayalon, L., Gross, R., Yaari, A., Feldhamer, E., Balicer, R. D., \& Goldfracht, M. (2013). Patients' and physicians' characteristics associated with the purchase of benzodiazepines by older primary care patients in Israel. Administration and Policy in Mental Health and Mental Health Services Research, 40(2), 117-123. https://doi.org/10.1007/s10488-011-0381-9

Ayalon, L., Karkabi, K., Bleichman, I., Fleischmann, S., \& Goldfracht, M. (2016). Barriers to the treatment of mental illness in primary care clinics in Israel. Administration and Policy in Mental Health and Mental Health Services Research, 43(2), 231-240. https://doi.org/10.1007/ s10488-015-0634-0

Barnow, S., Linden, M., Lucht, M., \& Freyberger, H. J. (2004). Influence of age of patients who wish to die on treatment decisions by physicians and nurses. The American Journal of Geriatric Psychiatry, 12(3), 258-264. https://doi.org/10.1176/appi.ajgp.12.3.258

Barrett, A. E., \& Robbins, C. (2008). The multiple sources of women's ageing anxiety and their relationship with psychological distress. Journal of Ageing and Health, 20(1), 32-65. https:// doi.org/10.1177/0898264307309932

Beck, J. S. (1995). Cognitive therapy: Basics and beyond. New York: Guilford. https://doi. org/10.1037/000344

Benedict, A. (1995). Attributions of causes for chronic illness among aged persons. Activities, Adaptation \& Ageing, 19(4), 49-59. https://doi.org/10.1300/j016v19n04_04

Blazer, D. (1989). Depression in the elderly. New England Journal of Medicine, 320(3), 164-166. https://doi.org/10.1056/nejm198901193200306

Blazer, D. G. (2003). Depression in late life: Review and commentary. The Journals of Gerontology Series A: Biological Sciences and Medical Sciences, 58(3), M249-M265. https:// doi.org/10.1176/foc.7.1.foc118

Blazer, D. G., \& Hybels, C. F. (2005). Origins of depression in later life. Psychological Medicine, 35(09), 1241-1252. https://doi.org/10.1017/s0033291705004411

Boardman, F., Griffiths, F., Kokanovic, R., Potiriadis, M., Dowrick, C., \& Gunn, J. (2011). Resilience as a response to the stigma of depression: A mixed methods analysis. Journal of Affective Disorders, 135(1-3), 267-276. https://doi.org/10.1016/j.jad.2011.08.007 
Bodner, E., Shrira, A., Bergman, Y. S., \& Cohen-Fridel, S. (2015a). Anxieties about ageing and death and psychological distress: The protective role of emotional complexity. Personality and Individual Differences, 83, 91-96. https://doi.org/10.1016/j.paid.2015.03.052

Bodner, E., Shrira, A., Bergman, Y. S., Cohen-Fridel, S., \& Grossman, E. S. (2015b). The interaction between ageing and death anxieties predicts ageism. Personality and Individual Differences, 86, 15-19. https://doi.org/10.1016/j.paid.2015.05.022

Bouman, W. P., \& Arcelus, J. (2001). Are psychiatrists guilty of 'ageism'when it comes to taking a sexual history? International Journal of Geriatric Psychiatry, 16(1), 27-31. https://doi. org/10.1002/1099-1166(200101)16:1<27::aid-gps267>3.3.co;2-j

Britton, P. G., \& Woods, R. T. (1996). Introduction. In R. T. Woods (Ed.), Handbook of the clinical psychology of ageing (pp. 1-14). Chichester: Wiley. https://doi.org/10.1002/9780470773185

Bronskill, S. E., Anderson, G. M., Sykora, K., Wodchis, W. P., Gill, S., Shulman, K. I., \& Rochon, P. A. (2004). Neuroleptic drug therapy in older adults newly admitted to nursing homes: Incidence, dose, and specialist contact. Journal of the American Geriatrics Society, 52(5), 749-755. https://doi.org/10.1111/j.1532-5415.2004.52212.x

Bryant, C., \& Koder, D. (2015). Why psychologists do not want to work with older adults-and why they should.... International Psychogeriatrics, 27(03), 351-354. https://doi.org/10.1017/ s1041610214002208

Bryant, C., Bei, B., Gilson, K., Komiti, A., Jackson, H., \& Judd, F. (2012). The relationship between attitudes to ageing and physical and mental health in older adults. International Psychogeriatrics, 24(10), 1674-1683. https://doi.org/10.1017/s1041610212000774

Burns, A., \& Jolley, D. (2015). Pseudodementia: History, mystery and positivity. In D. Bhugra \& G. S. Malhi (Eds.), Troublesome disguises: Manageing challenging disorders in psychiatry (pp. 218-230). West Sussex: Wiley. https://doi.org/10.1002/9781118799574

Butler, R. N. (1975). Psychiatry and the elderly: An overview. The American Journal of Psychiatry, 132(9), 893-900. https://doi.org/10.1176/ajp.132.9.893

Buttigieg, S., Ilinca, S., Jose, M. S., \& Larsson, A. T. (2018). Researching ageism in health-care and long term care. In L. Ayalon \& C. Tesch-Römer (Eds.), Contemporary perspectives on ageism: Vol. 19. International perspectives on aging (pp. 491-513). Berlin: Springer.

Calleo, J., Stanley, M. A., Greisinger, A., Wehmanen, O., Johnson, M., Novy, D., Wilson, N., \& Kunik, M. (2009). Generalized anxiety disorder in older medical patients: Diagnostic recognition, mental health management and service utilization. Journal of Clinical Psychology in Medical Settings, 16(2), 178-185. https://doi.org/10.1007/s10880-008-9144-5

Carstensen, L. L., Turan, B., Scheibe, S., Ram, N., Ersner-Hershfield, H., Samanez-Larkin, G. R., Brooks, K. P., \& Nesselroade, J. R. (2011). Emotional experience improves with age: Evidence based on over 10 years of experience sampling. Psychology and ageing, 26(1), 21-33. https:// doi.org/10.1037/a0021285

Chachamovich, E., Fleck, M., Laidlaw, K., \& Power, M. (2008). Impact of major depression and subsyndromal symptoms on quality of life and attitudes toward ageing in an international sample of older adults. The Gerontologist, 48(5), 593-602. https://doi.org/10.1093/geront/48.5.593

Cook, J. M., Marshall, R., Masci, C., \& Coyne, J. C. (2007). Physicians' perspectives on prescribing benzodiazepines for older adults: A qualitative study. Journal of General Internal Medicine, 22(3), 303-307. https://doi.org/10.1007/s11606-006-0021-3

Covinsky, K. E., Cenzer, I. S., Yaffe, K., O’Brien, S., \& Blazer, D. G. (2014). Dysphoria and anhedonia as risk factors for disability or death in older persons: Implications for the assessment of geriatric depression. The American Journal of Geriatric Psychiatry, 22(6), 606-613. https:// doi.org/10.1016/j.jagp.2012.12.001

Debast, I., van Alphen, S. P., Rossi, G., Tummers, J. H., Bolwerk, N., Derksen, J. J., \& Rosowsky, E. (2014). Personality traits and personality disorders in late middle and old age: Do they remain stable? A literature review. Clinical Gerontologist, 37(3), 253-271. https://doi.org/10. 1080/07317115.2014.885917 
DiNapoli, E. A., Cully, J. A., Mott, J. M., Hundt, N. E., Mignogna, J., Sansgiry, S., Yu, H. J., Trahan, L. H., \& Kunik, M. E. (2015). Mental health utilization among older veterans with coexisting depression and dementia. SAGE Open Medicine, 3, 1-6.

Dye, C. J. (1978). Psychologists' role in the provision of mental health care for the elderly. Professional Psychology, 9(1), 38-49. https://doi.org/10.1177/2050312114566488

Dolberg, P. H., Sigurðardóttir, S., \& Trummer, U. (2018). Ageism and older immigrants. In L. Ayalon \& C. Tesch-Römer (Eds.), Contemporary perspectives on ageism: Vol. 19. International perspectives on aging (pp. 177-191). Berlin: Springer.

Eisner, R. J., Quinn, M. E., Fanning, S. D., Gueldner, S. H., \& Poon, L. W. (1999). Ethical and policy considerations for centenarians-the oldest old. Image: The Journal of Nursing Scholarship, 31(3), 263-267. https://doi.org/10.1111/j.1547-5069.1999.tb00495.x

Elsner, R. J. (2002). Changes in eating behavior during the aging process. Eating Behaviors, 3(1), 15-43. https://doi.org/10.1016/s1471-0153(01)00041-1

Fiske, A., Wetherell, J. L., \& Gatz, M. (2009). Depression in older adults. Annual Review of Clinical Psychology, 5, 363-389. https://doi.org/10.1146/annurev.clinpsy.032408.153621

Ford, C. V., \& Sbordone, R. J. (1980). Attitudes of psychiatrists toward elderly patients. The American Journal of Psychiatry, 137(5), 571-575. https://doi.org/10.1176/ajp.137.5.571

Freud, S. (1953). On psychotherapy. In The complete works of Sigmund Freud (J. Strachey, Trans., Vol. 6, pp. 249-263). London: Hogarth. (Original work published 1905).

Fung, K. M., Tsang, H. W., Corrigan, P. W., Lam, C. S., \& Cheng, W. M. (2007). Measuring selfstigma of mental illness in China and its implications for recovery. International Journal of Social Psychiatry, 53(5), 408-418. https://doi.org/10.1177/0020764007078342

Gonçalves, D. C., Guedes, J., Fonseca, A. M., Pinto, F. C., Martín, I., Byrne, G. J., \& Pachana, N. A. (2011). Attitudes, knowledge, and interest: Preparing university students to work in an ageing world. International Psychogeriatrics, 23(02), 315-321. https://doi.org/10.1017/ s1041610210001638

Gum, A. M., Arean, P. A., Hunkeler, E., Tang, L., Katon, W., Hitchcock, P., et al. (2006). Depression treatment preferences in older primary care patients. Gerontologist, 46(1), 14-22. https://doi. org/10.1176/appi.psy.48.6.482

Halpain, M. C., Harris, M. J., McClure, F. S., \& Jeste, D. V. (1999). Training in geriatric mental health: Needs and strategies. Psychiatric Services, 59(9), 1205-1208. https://doi.org/10.1176/ ps.50.9.1205

Helmes, E., \& Gee, S. (2003). Attitudes of Australian therapists toward older clients: Educational and training imperatives. Educational Gerontology, 29(8), 657-670. https://doi. org/10.1080/03601270390225640

Hendrie, H. C., Callahan, C. M., Levitt, E. E., Hui, S. L., Mustek, B., Austrom, M. G., Numberger, J. I., \& Tierney, W. M. (1995). Prevalence rates of major depressive disorders: The effects of varying the diagnostic criteria in an older primary care population. The American Journal of Geriatric Psychiatry, 3(2), 119-131. https://doi.org/10.1097/00019442-199500320-00004

Huy, C., Schneider, S., \& Thiel, A. (2010). Perceptions of ageing and health behaviour: Determinants of a healthy diet in an older German population. The Journal of Nutrition, Health and Ageing, 14(5), 381-385. https://doi.org/10.1007/s12603-010-0084-z

Ingram, R. E., \& Luxton, D. D. (2005). Vulnerability-stress models. In B. L. Hankin \& J. R. Z. Abela (Eds.), Development of psychopathology: A vulnerability-stress perspective (pp. 32-46). Los Angeles: Sage. https://doi.org/10.4135/9781452231655.n2

Karel, M. J., Gatz, M., \& Smyer, M. A. (2012). Ageing and mental health in the decade ahead: What psychologists need to know. American Psychologist, 67(3), 184-198. https://doi. org/10.1037/a0025393

Kessler, E. M., \& Bowen, C. E. (2015). Resilience. The Encyclopedia of Adulthood and Ageing, 3(1), 1213-1216. https://doi.org/10.1002/9781118521373.wbeaa231

Klerman, G. L., Weissman, M. M., Rounsaville, B., \& Chevron, E. (1984). Interpersonal psychotherapy for depression. New York: Basic Books. 
Knight, B. G. (2004). Transference and counter transference in older adlts. In B. G. Knight (Ed.), Psychotherapy with older adults (pp. 60-77). Los Angeles: Sage Publications. https://doi. org/10.4135/9781452204574

Koder, D. A., \& Helmes, E. (2008). Predictors of interest in working with older adults: A survey of postgraduate trainee psychologists. Gerontology \& Geriatrics Education, 29(2), 158-171. https://doi.org/10.1080/02701960802223233

Kolanowski, A., Fick, D., Frazer, C., \& Penrod, J. (2009). It's about time: Use of nonpharmacological interventions in the nursing home. Journal of Nursing Scholarship, 42(2), 214-222. https://doi.org/10.1111/j.1547-5069.2010.01338.x

Krekula, C., Nikander, P., \& Wilińska, M. (2018). Multiple marginalizations based on age: gendered ageism and beyond. In L. Ayalon \& C. Tesch-Römer (Eds.), Contemporary perspectives on ageism: Vol. 19. International perspectives on aging (pp. 33-50). Berlin: Springer.

Laidlaw, K., \& Pachana, N. A. (2009). Ageing, mental health, and demographic change: Challenges for psychotherapists. Professional Psychology: Research and Practice, 40(6), 601-608. https:// doi.org/10.1037/a0017215

Lamberty, G. J., \& Bieliauskas, L. A. (1993). Distinguishing between depression and dementia in the elderly: A review of neuropsychological findings. Archives of Clinical Neuropsychology, 8(2), 149-170. https://doi.org/10.1016/0887-6177(93)90032-v

Lee, K. M., Volans, P. J., \& Gregory, N. (2003). Attitudes towards psychotherapy with older people among trainee clinical psychologists. Ageing \& Mental Health, 7(2), 133-141. https://doi. org/10.1080/1360786031000072303

Lerner, Y., \& Levinson, D. (2012). Who gets mental health treatment from the GP? Results from the Israel National Epidemiological Mental Health Survey. Family Practice, 29(5), 561-566. https://doi.org/10.1093/fampra/cms017

Levy, B. R. (2003). Mind matters: Cognitive and physical effects of ageing self-stereotypes. The Journals of Gerontology Series B: Psychological Sciences and Social Sciences, 58(4), 203211. https://doi.org/10.1093/geronb/58.4.p203

Levy, B. R., \& Myers, L. M. (2004). Preventive health behaviors influenced by self-perceptions of aging. Preventive Medicine, 39(3), 625-629. https://doi.org/10.1016/j.ypmed.2004.02.029

Levy, B. R., Pilver, C. E., \& Pietrzak, R. H. (2014). Lower prevalence of psychiatric conditions when negative age stereotypes are resisted. Social Science \& Medicine, 119, 170-174. https:// doi.org/10.1016/j.socscimed.2014.06.046

Ludvigsson, M., Milberg, A., Marcusson, J., \& Wressle, E. (2014). Normal ageing or depression? A qualitative study on the differences between subsyndromal depression and depression in very old people. The Gerontologist, 55(5), 760-769. https://doi.org/10.1093/geront/gnt162

Luppa, M., Sikorski, C., Luck, T., Ehreke, L., Konnopka, A., Wiese, B., Weyerer, S., König, H. H., \& Riedel-Heller, S. G. (2012). Age-and gender-specific prevalence of depression in latest-lifesystematic review and meta-analysis. Journal of Affective Disorders, 136(3), 212-221. https:// doi.org/10.1016/j.jad.2010.11.033

Mackin, R. S., \& Areán, P. A. (2007). Cognitive and psychiatric predictors of medical treatment adherence among older adults in primary care clinics. International Journal of Geriatric Psychiatry, 22(1), 55-60. https://doi.org/10.1002/gps.1653

McKinney, B. C., \& Sibille, E. (2013). The age-by-disease interaction hypothesis of late-life depression. The American Journal of Geriatric Psychiatry, 21(5), 418-432. https://doi. org/10.1097/jgp.0b013e31826ce80d

Meeks, T. W., Vahia, I. V., Lavretsky, H., Kulkarni, G., \& Jeste, D. V. (2011). A tune in "a minor" can "b major": A review of epidemiology, illness course, and public health implications of subthreshold depression in older adults. Journal of Affective Disorders, 129(1), 126-142. https:// doi.org/10.1016/j.jad.2010.09.015

Milaneschi, Y., \& Penninx, B. W. J. H. (2014). Depression in older persons with mobility limitations. Current Pharmaceutical Design, 20(19), 3114-3118. https://doi.org/10.2174/13816128 113196660060 
Nezu, A. M., Nezu, C. M., \& Perri, M. G. (1988). Problem solving therapy for depression. New York: Wiley-Interscience.

Nordhus, J. H., \& Pallesen, S. (2003). Psychological treatment of late-life anxiety: And empirical review. Journal of Consulting and Clinical Psychology, 71(4), 643-651. https://doi. org/10.1037/0022-006x.71.4.643

Owens, K. M. B., Hadjistavropoulos, T., \& Asmundson, G. J. G. (2000). Addressing the need for appropriate norms when measuring anxiety in seniors. Aging \& Mental Health, 4(4), 309-314. https://doi.org/10.1080/713649964

Palgi, Y. (2015). Predictors of the new criteria for probable PTSD among older adults. Psychiatry Research, 230, 777-782. https://doi.org/10.1016/j.psychres.2015.11.006

Palmore, E. B., Branch, L., \& Harris, D. (Eds.). (2005). Encyclopedia of ageism. Binghamton: Haworth Press. https://doi.org/10.4324/9781315043975

Parmelee, P. A., Harralson, T. L., McPherron, J. A., \& Schumacher, H. R. (2013). The structure of affective symptomatology in older adults with osteoarthritis. International Journal of Geriatric Psychiatry, 28(4), 393-401. https://doi.org/10.1002/gps.3837

Petersen, R. C. (2004). Mild cognitive impairment as a diagnostic entity. Journal of Internal Medicine, 256(3), 183-194. https://doi.org/10.1111/j.1365-2796.2004.01388.x

Pietrzak, R. H., Goldstein, R. B., Southwick, S. M., \& Grant, B. F. (2012). Physical health conditions associated with posttraumatic stress disorder in US older adults: Results from wave 2 of the National Epidemiologic Survey on alcohol and related conditions. Journal of the American Geriatrics Society, 60(2), 296-303. https://doi.org/10.1111/j.1532-5415.2011.03788.x

Poon, C. Y., \& Knight, B. G. (2009). Influence of sad mood and old age schema on older adults' attention to physical symptoms. The Journals of Gerontology Series B: Psychological Sciences and Social Sciences, 64((1), 41-44. https://doi.org/10.1093/geronb/gbn025

Qualls, S. H., Segal, D. L., Norman, S., Niederehe, G., \& Gallagher-Thompson, D. (2002). Psychologists in practice with older adults: Current patterns, sources of training, and need for continuing education. Professional Psychology: Research and Practice, 33(5), 435-442. https://doi.org/10.1037//0735-7028.33.5.

Ray, D. C., McKinney, K. A., \& Ford, C. V. (1987). Differences in psychologists' ratings of older and younger clients. The Gerontologist, 27(1), 82-86. https://doi.org/10.1093/geront/27.1.82

Reinhardt, M. M., \& Cohen, C. I. (2015). Late-life psychosis: Diagnosis and treatment. Current Psychiatry Reports, 17(2), 1-13. https://doi.org/10.1007/s11920-014-0542-0

Richards, S., Donovan, S., Victor, C., \& Ross, F. (2007). Standing secure amidst a falling world? Practitioner understandings of old age in responses to a case vignette. Journal of Interprofessional Care, 21(3), 335-349. https://doi.org/10.1080/13561820701289352

Roy-Byrne, P. P., \& Wagner, A. (2004). Primary care perspectives on generalized anxiety disorder. The Journal of Clinical Psychiatry, 65(suppl 13), 20-26.

Rush, N., Angermeyer, M. C., \& Corrigan, P. W. (2005). Mental illness stigma: Concepts, consequences, and initiatives to reduce stigma. European Psychiatry, 20(8), 529-539. https://doi. org/10.1016/j.eurpsy.2005.04.004

Ruxton, K., Woodman, R. J., \& Mangoni, A. A. (2015). Drugs with anticholinergic effects and cognitive impairment, falls and all-cause mortality in older adults: A systematic review and metaanalysis. British Journal of Clinical Pharmacology, 80(2), 209-220. https://doi.org/10.1111/ bcp. 12617

Schuurmans, J., \& van Balkom, A. (2011). Late-life anxiety disorders: A review. Current Psychiatry Reports, 13(4), 267-273. https://doi.org/10.1007/s11920-011-0204-4

Scott, A., \& Bhutani, G. (1999). Career choices and attitudes to the older adult specialty. Clinical Psychology Forum, 126, 11-15.

Shmotkin, D., Eyal, N., \& Lomranz, J. (1992). Motivations and attitudes of clinical psychologists regarding treatment of the elderly. Educational Gerontology: An International Quarterly, 18(2), 177-192. https://doi.org/10.1080/0360127920180205

Sternbach, H. (1998). Age-associated testosterone decline in men: Clinical issues for psychiatry. American Journal of Psychiatry, 155(10), 1310-1318. https://doi.org/10.1176/ajp.155.10.1310 
Tackett, J. L., Balsis, S., Oltmanns, T. F., \& Krueger, R. F. (2009). A unifying perspective on personality pathology across the life span: Developmental considerations for the fifth edition of the diagnostic and statistical manual of mental disorders. Development and Psychopathology, 21(03), 687-713. https://doi.org/10.1017/s095457940900039x

Uncapher, H., \& Areán, P. A. (2000). Physicians are less willing to treat suicidal ideation in older patients. Journal of the American Geriatrics Society, 48, 188-192. https://doi. org/10.1111/j.1532-5415.2000.tb03910.x

Van Alphen, S. P. J., Bolwerk, N., Videler, A. C., Tummers, J. H. A., Van Royen, R. J. J., Barendse, H. P. J., et al. (2012). Age-related aspects and clinical implications of diagnosis and treatment of personality disorders in older adults. Clinical Gerontologist, 35(1), 27-41. https://doi.org/1 0.1080/07317115.2011.628368

Voss, P., Bodner, E., \& Rothermund, K. (2018). Ageism: The relationship between age stereotypes and age discrimination. In L. Ayalon \& C. Tesch-Römer (Eds.), Contemporary perspectives on ageism: Vol. 19. International perspectives on aging (pp. 11-32). Berlin: Springer.

Weiss, D., \& Lang, F. R. (2012). "They" are old but "I" feel younger: Age-group dissociation as a self-protective strategy in old age. Psychology and Ageing, 27(1), 153-163. https://doi. org/10.1037/a0024887

Werner, P., Stein-Shvachman, I., \& Heinik, J. (2009). Perceptions of self-stigma and its correlates among older adults with depression: A preliminary study. International Psychogeriatrics, 21(06), 1180-1189. https://doi.org/10.1017/s1041610209990470

Whitbourne, S. K., \& Krauss, S. (2011). Central nervous system. In S. K. Whitbourne (Ed.), The aging body: Physiological changes and psychological consequences (pp. 125-149). New York: Springer.

Woodward, R., \& Pachana, N. A. (2009). Attitudes towards psychological treatment among older Australians. Australian Psychologist, 44(2), 86-93. https://doi. org/10.1080/00050060802583610

Wurm, S., \& Benyamini, Y. (2014). Optimism buffers the detrimental effect of negative selfperceptions of ageing on physical and mental health. Psychology \& Health, 29(7), 832-848. https://doi.org/10.1080/08870446.2014.891737

Wyman, M. F., Gum, A., \& Arean, P. A. (2011). Psychotherapy with older adults. In M. E. Agronin \& G. J. Maletta (Eds.), Principles and practice of geriatric psychiatry (pp. 177-203). Philadelphia: Lippincott Williams \& Wilkins.

Wyman, M. F., Shiovitz-Ezra, S., \& Bengel, J. (2018). Ageism in the health care system: Providers, patients, and systems. In L. Ayalon \& C. Tesch-Römer (Eds.), Contemporary perspectives on ageism: Vol. 19. International perspectives on aging (pp. 193-213). Berlin: Springer.

Open Access This chapter is licensed under the terms of the Creative Commons Attribution 4.0 International License (http://creativecommons.org/licenses/by/4.0/), which permits use, sharing, adaptation, distribution and reproduction in any medium or format, as long as you give appropriate credit to the original author(s) and the source, provide a link to the Creative Commons license and indicate if changes were made.

The images or other third party material in this chapter are included in the chapter's Creative Commons license, unless indicated otherwise in a credit line to the material. If material is not included in the chapter's Creative Commons license and your intended use is not permitted by statutory regulation or exceeds the permitted use, you will need to obtain permission directly from the copyright holder.

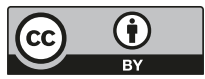




\title{
Chapter 16 \\ Ageism and Dementia
}

\author{
Simon Chester Evans
}

\subsection{Dementia and Its Prevalence As a Function of Age}

The term 'dementia' covers a range of neurological diseases whose most common symptoms include memory loss, disorientation, behavioural changes and difficulties with thinking or problem solving. Dementias are progressive, which means that the structure and chemistry of the brain become increasingly damaged over time. Alzheimer's Disease (AD) accounts for approximately $60 \%$ of dementias but there are many other types including Vascular dementia, dementia with Lewy bodies and Fronto-temporal dementia. Each of these has different neurological characteristics and causes specific symptoms, but it is important to recognise that the experience of dementia, whatever the type, is unique for each individual person.

The number of people affected by dementia worldwide is predicted to rise from 47 million in 2015 to 75 million by 2030 and 130 million by 2050 . This situation has led to calls for dementia to be recognised as a global public health priority from the EU (European Parliament 2010), the World Health Organisation (2015) and many individual countries.

Although dementia is not an unavoidable consequence of ageing, and the phenomenon of early-onset dementia is widely recognised, increasing age is undoubtedly the biggest risk factor. For example, the number of people who develop AD before the age of 65 only represents $5 \%$ of all those with the disease. The prevalence of dementia increases exponentially with age in all parts of the world. Prevalence doubles with every 5.5 years of age in North America, 6.5 years in West and Central Europe, 6.6 years in South Asia, and 10.6 years in Southeast Asia (Prince et al. 2015).

\footnotetext{
S. C. Evans $(\bowtie)$

Association for Dementia Studies, University of Worcester, Worcester, UK

e-mail: simon.evans@worc.ac.uk

L. Ayalon, C. Tesch-Römer (eds.), Contemporary Perspectives on Ageism, International Perspectives on Aging 19, https://doi.org/10.1007/978-3-319-73820-8_16
} 
So, while dementia is not an inevitable part of ageing, the chances of getting dementia increase incrementally with age. As a result, people with dementia are likely to experience the stigma that is specifically associated with the disease as well as the broader stigma of ageism. This has been called the 'double stigma of dementia' (Urbańska et al. 2015).

\subsection{The Impact of Dementia-Related Stigma}

Goffman first used the term 'stigma' in social sciences (Goffman 2005), describing it as the relationship between a particular trait and social stereotypes. Link and Phelan (2001) characterised stigma as a multistage process based on labelling, stereotyping, alienation, loss of social status, discrimination and emotional reactions. At an individual level, stigma has been associated with low self-esteem, feelings of shame, a sense of dehumanisation and experiences of social isolation (Urbanska et al. 2015).

There is currently no cure for dementia and the evidence for the effectiveness of treatments that aim to ameliorate the symptoms is not strong. This, combined with growing awareness of the disease and its effects, such as ailing memory, has led to considerable fears of getting dementia (Corner and Bond 2004). One effect of such fears is that a high level of stigma has become attached to dementia, as witnessed by the growing voice of those living with the disease. Because age is the major risk factor in developing a dementia, those with the condition often experience the effects of dementia stigma in addition to ageist discrimination and the distinction between the two types of stigma often becomes blurred. There is substantial evidence that stigma exists towards dementia worldwide (Moniz-Cook and Manthorpe 2009; Prince et al. 2011). Cultural factors can be important. For example, some Asian traditional spiritual beliefs about the causes of dementia can lead to attempts to conceal it within families. There is now a widespread recognition of an urgent need to reduce the stigma and negative connotations associated with Alzheimer's disease and other dementias more broadly (Batsch and Mittelman 2013; Jolley and Benbow 2000).

A 2014 meta-analysis of 99 research papers (Werner 2014) found substantial evidence of stigma in relation to people living with dementia. The most common negative emotions associated with stigma were shame, humiliation and disgust. Stigma can occur at three levels: self-stigma is the internalisation by individuals of ideas and reactions; public stigma is evident through the reactions of lay persons towards stigmatised individuals or groups; while stigma by association comprises the emotions and beliefs of those surrounding people with dementia, including family members and professionals.

Werner reported that stigma is perceived as pervasive and is associated with negative consequences at four levels. At the individual level it can lead to low selfesteem, feelings of shame and humiliation, and social isolation. For families, stigma can also cause increased burden, depression, concealment, decreased use of services 
and feelings of moral failure. At the professional level it can lead to differential or delayed diagnosis or treatment, while the effects of stigma at the societal level include differential access and use of services and increased institutionalisation.

Anger and fear were found to be the primary emotions contributing to stigmatic behaviours in relation to mental illness, while for Alzheimer's Disease it was feelings of rejection including ridicule, shame and impatience. Lower levels of stigma were associated with AD than other dementias. This review found limited use of operational or conceptual definitions or theoretical background when considering stigma and dementia. Where theories were included they were predominantly modified labelling theory (stigma as a social construct reflecting power relations at a society level) and attribution theory (stigma as a process in which cognitive attributions (stereotypes) are followed by emotional responses (prejudices) and behaviour reactions (discrimination).

It is also important to consider the impact of stigma on the families of people with dementia, who often provide much of the high levels of care and support that are required. This role is crucial to maximising quality of life for people with dementia and delaying moves to institutional care (Brodaty and Donkin 2009). While there are many positive aspects attached to family caring, it can also bring challenges including increased stress, social isolation and economic burden. In the UK there are 670,000 carers of people with dementia, whose caregiving saves the economy an estimated $£ 11$ billion a year.

Providing effective support for carers, including psycho-social interventions, is therefore essential to maintaining quality of life for the person with dementia, but good quality support is not always available when required (Manthorpe et al. 2004). When combined with stereotypes that are associated with ageing more generally across a broad age spectrum from fourth grade school children (Seefeldt 1984) to older adults (Dobbs et al. 2008), this kind of 'stigma by association' can lead to both people with dementia and their family carers experiencing double discrimination. This means that they are likely to be discriminated against as a result of having dementia in addition to the wider discrimination that often occurs against people due to their age.

\subsection{Media Portrayals of Dementia}

In many countries across the world dementia has been recognised as a 'crisis', resulting in a surge in policies and strategies aimed not only at finding a cure but also at helping people to 'live well with dementia' (Department of Health 2009), partly by improving the responses of individuals, organisations and professionals. Public awareness has been identified as a key factor, with the media having a central role in creating and reflecting attitudes and opinions. A UK study (Peel 2014) that drew on 350 national newspaper articles and interviews with family carers found that dementia was frequently portrayed as catastrophic. 'Tsunami', 'a bomb ready to explode', 'Alzheimer's epidemic' 'brain-wasting', 'terrrible affliction' and 
'worse than death' are just a few of the newspaper headlines that are quoted. Reporting of this sort can lead to people with dementia experiencing discrimination because of their condition as well as their age.

There are many similarities between the language that was used in the 1980's in relation to HIV/Aids, despite the fact that dementia is neither contagious nor preventable in any straightforward way. Many of the same terms and assumptions are applied to describe ageing in general, which associates ageing with a range of negative experiences and attributes such as dementia. The author contrasted this to other media discourses around more 'controllable' and treatable chronic conditions. For example, people with cancer tend to be portrayed in a more positive way and are often said to be 'fighting' the disease. The limited presence of people living with dementia themselves in media coverage was also noted, with a much greater focus on the views of representatives from medical and charitable organisations.

Language is an important element in how health related conditions are represented in the media and more generally, as increasingly acknowledged:

A casual misuse of words or the use of words with negative connotations when talking about dementia in everyday conversations can have a profound impact on the person with dementia as well as on their family and friends. It can also influence how others think about dementia and increase the likelihood of a person with dementia experiencing stigma or discrimination. (Alzheimer's Australia)

\subsection{Dementia and Health and Social Care Services}

For many people, health and social care services are the main source of information and support for their dementia. However, rates of diagnosis vary considerably across Europe. Most countries report missing 40-60\% of expected dementia diagnoses and that when a diagnosis is made, the dementia is often already at a moderate or late stage. Rates of diagnosis vary considerably across the world. For example, one study suggests that $90 \%$ of people with dementia remain unidentified in India, while in England the diagnosis rate is 38\% and rising. A European study (Brooker et al. 2014) found that while most countries reported missing $40 \%-60 \%$ of expected dementia diagnoses, some countries reported missing above $60 \%$, and some reported missing only $30 \%$. Most also reported that when a diagnosis is made, the dementia is already at a moderate or late stage. A diagnosis of dementia is often a key criterion for accessing the services that statutory health services offer, which makes the generally low rates of diagnosis a major challenge for many people living with dementia.

The findings from Alzheimer Cooperative Valuation in Europe (ALCOVE), a Joint Action co-financed by the European Commission, suggest that few family doctors have adequate training in recognising symptoms of early dementia which, combined with insufficient understanding or clarity regarding their role, can result in low rates of timely diagnoses (Brooker et al. 2014). 
A growing body of evidence suggests that timely diagnosis and intervention can be important in maintaining quality of life for people living with dementia and their families (Banerjee and Wittenberg 2009; Mittelman et al. 2008). In addition, early intervention can delay cognitive decline, maintain functional abilities and delay admission to institutional care (Waldemar et al. 2007; Banerjee and Wittenberg 2009; Prince et al. 2011), as well as leading to improved outcomes for family members, delayed placement into long-term care and increased carer coping (Mittelman et al. 2006, 2007).

It can be argued that these low rates of diagnosis are at least partly due to the negative images that are associated with dementia as well as to the blurred perception of dementia as being an inevitable consequence of old age (Brooker et al. 2014). Similarly, limited understanding on the part of caregivers and physicians of the difference between memory processes in aging and Alzheimer's Disease can be a barrier to timely diagnosis (Knopman et al. 2000). This provides another example of how those who have dementia, a disease linked to ageing, are likely to experience double discrimination. Stigma can be a major factor in the person's willingness or reluctance to seek diagnosis and subsequently to seek support (Milne 2010; Burgener and Berger 2008). Similarly, the standard of care provided to people with dementia is often lower due to the impact of stigma on the health care profession (Devlin et al. 2007; Benbow and Jolley 2012). A study based on interviews with family doctors in the North of England (Gove et al. 2016) concluded that there is a need to separate personal fears from professional judgements, and called for training and support in addressing patient fears and exploring early symptoms.

Even when a diagnosis is received, the ALCOVE study suggests that the provision of support is sparse, with $61 \%$ of respondents saying that they always' or 'often' provided information about dementia following diagnosis, and $39 \%$ providing education and social support. There is also evidence that some treatments that would benefit people with dementia are not offered because of a belief on behalf of some healthcare professionals that rehabilitation is not possible for people living with dementia, despite evidence to the contrary (Evans 2008).

People with dementia are also likely to have a high prevalence of other comorbid medical conditions, many of which are undiagnosed and preventable, for which they are less likely to receive the same treatment than people without dementia (Scrutton and Brancati 2016). Research suggests that $61 \%$ of people with Alzheimer's disease have three or more comorbid diagnoses, while the rate of comorbid conditions increases with the severity of the dementia (Fillit 2000; Murali Doraiswamy et al. 2002). This can lead to a range of discrepancies in health outcomes for people with dementia including faster deterioration in daily functioning, a reduced quality of life, and earlier death. For example, UK hospital patients with dementia are over three times more likely to die during their first admission for an acute medical condition than those without dementia. Similarly, urinary tract infections are one of the principal cause of hospital admission for people with dementia (Sampson et al. 2009), despite both conditions being avoidable and relatively easy to manage if treated promptly. More than $50 \%$ of patients in America with moderately severe dementia who are admitted to hospital with hip fracture died within 
6 months, a much higher rate than for patients without dementia (Morrison and Siu 2000). An Australian study suggested that dementia patients are more likely than those without dementia to develop preventable comorbidities whilst in acute hospital (Bail 2013).

Poor pain management is another common feature of care for people with dementia, with patients with advanced dementia and a hip fracture in America being prescribed one-third of the analgesia compared with other patients (Morrison and Siu 2000). This has far reaching implications because it can lead to unnecessary suffering as well as the potential inappropriate use of psychiatric medications, particularly towards the end of life (Sampson 2006). Reasons for these inequalities include care systems that focus on the dementia rather than the needs of the individual, a lack of dementia training among health professionals, poor medication management, and mis-interpretation of atypical symptoms. These deficits mean that many people are receiving poorer services due to having dementia in addition to the broader manifestation of ageism in the healthcare system, which can also lead to reduced access to services. Further information on this can be found in the chapter on ageism and the healthcare system (Wyman et al. 2018; Chap. 13)).

\subsection{Social Contact and Engagement}

The value of social interaction and participation in group activities is widely recognised. Enjoying good social relationships with family, friends and neighbours and engaging in a large number of social activities are key elements of quality of life for older people (Bowling 2011). There is also a strong argument that having opportunities for social interaction is a basic human right for every citizen, irrespective of their health condition. In this section, we explore the impact of growing old on levels of social interaction and how this is exacerbated for people who have dementia.

Much of the literature suggests that older adults tend to experience a reduction in the size of their social network in later life, along with a decrease in the frequency of their social contacts (for example, Lang and Hornburg 1998; Okun and Keith 1998). It is often suggested that this is partly due to significant life events, such as reduced mobility and the death of a partner and peers. A meta analysis by Pinquart and Sorenson (2001) concluded that greater social contact is associated with lower levels of loneliness, although other factors such as the emotional quality of contacts are also likely to be influential.

While it is important to note that the experience of loneliness is a subjective matter, so that someone who has little social contact may not feel lonely, while another person might feel lonely despite a very active social life, there is widespread agreement that for many people growing older comes with increased feelings of loneliness. Pinquart and Sorensen (2001) also suggested that between 5\% and $15 \%$ of those aged over 65 frequently feel lonely, although this is likely to be an underestimate, while for those aged 80 or over the figure is closer to $50 \%$. In addition, 
they concluded that loneliness is more widespread in older age groups, largely due to reductions in the frequency of social contact related to the death of peers (including partners), the loss of social roles and physical/sensory limitations. Lower levels of activity and sensory capacity can hinder social contact and are associated with higher levels of loneliness. In the UK, it has been estimated that about $10 \%$ of the general population aged over 65 is lonely all or most of the time (Bolton 2012), which equates to over 900,000 older people. Levels of loneliness among ethnic minority elders are generally higher, with $15 \%$ reporting that they always or often feel lonely. Institutionalisation can also be associated with increased loneliness, partly because people who move to residential settings tend to be those with fewest family members who also lack informal support systems.

There are several theories concerning why social contact is of such value to individuals, as summarised by Bolton (2012). For example, the 'stress regulator' hypothesis suggests that social relationships provide resources that aid adaptation to stressful events, including illness and life transitions, and enable positive behaviours such as healthy eating. Under the 'main effects' model, social relationships have a more direct protective effect on health through cognitive, emotional, behavioural and biological influences. The effects of loneliness are therefore substantial and can include higher cortisol levels, reduced protection against infection, increased risk of heart disease, higher blood pressure, disrupted sleep, greater levels of depression and even higher mortality (Bolton 2012. One study (Holt-Lunstad et al. 2010) has shown that having weak social connections is, in health terms, equivalent to smoking up to 15 cigarettes a day as well as being twice as harmful as obesity.

For people living with dementia, social interaction has specific benefits that can contribute towards a good quality of life, including reductions in agitation and other behavioural symptoms (Cohen-Mansfield and Parpura-Gill 2007). However, maintaining social contact can be particularly challenging for people living with dementia as well as their family carers. In a UK report (Alzheimer's Society 2013), 33\% of those living with dementia said they lost friends following a diagnosis and $39 \%$ said they felt lonely, compared with $24 \%$ of over $55 \mathrm{~s}$ in general. The figure increased to $62 \%$ for people with dementia living on their own. The report called for greater understanding on the part of local government and other commissioners about the needs of people with dementia living within the community, and the provision of services to ensure that they are not socially isolated or lonely. Examples of how to support social interaction include dementia cafés, walking groups, befriending services and accessible transport to allow people with dementia to attend social clubs or other services.

In summary, for a number of reasons, including ageism, older people often experience an increase in loneliness and lose the direct protective effect on health that social relationships. The situation can be accentuated for people with dementia, an age-related condition, because of the frequent loss of friendships due to the stigma associated with the disease. Therefore, it appears that older adults who suffer from dementia are susceptible to loneliness due to the double jeopardy associated with old age and dementia status. 


\subsection{Research Funding}

In the UK, government spending for medical research is increasing year on year, while spending on dementia research was $£ 66$ million in 2015 . That is double the figure for 2009-2010, but it is important to note that much of this is on bio-medical studies that aim to find a cure for dementia. Relatively little is spent on psychosocial research that aims to improve quality of life for those living with dementia, which has potential to be more effective in the short to medium term in the absence of a cure. UK charities also make a substantial financial investment in dementia research, a figure of approximately $£ 20$ million a year. However, the total government and charitable spend on cancer research is almost 7 times greater, despite the fact that similar economic costs are associated with the two conditions.

It is also interesting to note that, in addition to impacting on the receipt of care and support, stigmatisation can be a barrier to participation in research (van der Vorm et al. 2008). This can be exacerbated by barriers imposed by gatekeepers towards people with dementia, often based on stereotypes concerning their communication abilities and their interests (Brooks et al. 2017; Sherratt et al. 2008).

\subsection{Recent Changes and Potential Lessons Learnt}

Recent years have seen a major change in how governments across the world approach dementia, largely driven by recognition of the personal, social and economic costs of the rapidly increasing numbers of people living with the disease. In many countries, this approach is based on a national plan, strategy or framework that aims to improve diagnosis, treatment and support. The majority of these approaches include dementia awareness campaigns, based on a recognition that the stigma that is widely associated with dementia can prevent people from seeking a diagnosis and therefore from having the opportunity to access appropriate care and support. This was captured in one of the recommendations of the ALCOVE project, which stated that 'Decreasing fear and stigma about dementia is a necessary precursor for increasing the numbers of people coming forward for diagnosis' (Brooker et al. 2014). Dementia awareness campaigns were reported by almost all countries provided for both professionals and the general public, but $32 \%$ reported a lack of legislation to protect people with dementia, and nearly $50 \%$ reported no legislation for advance statements/directives. Where legislation existed, it was often inconsistently implemented, supported or promoted particularly in the promotion of advance directives. This suggest that in many countries people experience discrimination in terms of the care and support they receive as a result of having dementia, in addition to any discrimination that occurs as a result of ageism. A total of $43 \%$ countries reported having specific policies in place to improve the quality of diagnosis. Countries that did have policies in place reported diagnosis being made at an earlier stage. 
Attention on dementia has also been focused and coordinated through a range of international initiatives including the Paris Declaration, the G8 dementia summit, the World Dementia Council, the WHO global dementia observatory and a European Parliament declaration, all of which recognised the need to increase awareness and address stigma as part of the 'fight' against dementia. However, there is no evidence for the impact of policy based initiatives such as these.

Another initiative to reduce stigma and discrimination is the 'dementia-friendly communities' movement that has been adopted in in several countries including the UK, India, France, Ireland and Canada (Wiersma and Denton 2013). In the UK, over 120 communities are now registered as dementia-friendly, using an overarching framework to monitor their progress. This covers a range of key areas: the involvement of people with dementia from diverse groups; challenging stigma and building understanding; ensuring an early diagnosis; providing consistent and reliable travel options; developing easy to navigate environments; and promoting respectful and responsive businesses and services. This movement overlaps considerably with the age-friendly cities and communities movement that has been led by the World Health Organisation (WHO 2007) with the aim of improving quality of life for older people and reducing ageism.

The independent sector has also made a significant contribution towards increasing awareness of dementia and tackling stigma. This has taken place at national levels, as demonstrated by the actions of the Alzheimer's Society in England, and internationally through the work of Alzheimer's Europe. Alongside this, in some countries there has been a growth in the dementia rights movement, which has seen the voice of people with dementia and their family carers become a major force for change in social perceptions of people with dementia and how they are treated within society, including by health and other public service providers. In the UK, this has been a key factor in a government commitment to enabling people to 'live well with dementia', particularly through the Dementia Strategy, the Prime Ministers Dementia Challenge, and the Dementia Friends approach. These initiatives appear to have led to a growing awareness of the need to raise awareness of dementia across society, to improve services for people living with dementia and the importance of adopting a truly person-centred approach.

\subsection{Conclusion}

The information presented in this chapter suggests that people living with dementia experience a double stigmatization, due to old age and dementia, which can lead to people feeling excluded from many of the activities that most of us take for granted. However, there are some important differences between general ageism and dementia stigma. For example, discrimination and stigma are based on judgements concerning a person's characteristics and membership of particular 'group'. Therefore, everyday ageism against an individual is often based on the perception that they belong to the group of 'older people'. For dementia the situation is different because 
it is not generally possible to tell that someone has dementia by looking at them. Therefore, the operationalization of stigma against individuals with dementia is usually only possible for those who have access to knowledge of their condition. This tends to be the professionals and organisations that are responsible for delivering health and social care services, but might also include friends, relatives and neighbours. Another important difference is that increasing age is often associated with some positive stereotypes, such as wisdom and high morals, whereas it is difficult to find any positive attributes that are commonly associated with dementia. It is also important to note that, as discussed in other parts of this book, widespread ageist views often lead to an assumption that older people have symptoms of 'senility', such as memory problems and other forms of cognitive impairment.

Swaffer (2014) puts it well when writing about stigma, language and dementia:

In short, social action is needed to ensure that we engage people with dementia, not just the wider community in understanding dementia and in that way reduce the social isolation, discrimination and stigma that people with dementia experience. We want to access services and to participate in the community the way everyone has a right to expect, and to have our disabilities respected with acceptance, support and enablement. (p. 714).

Finally, the study of ageism and dementia is relatively new and there is a need for more specific research in this area. Work of this kind will enable us to develop a more nuanced picture of discrimination and stigma in a range of countries and settings and to explore how it can best be addressed. Reducing stigma is a crucial element in the challenge of supporting people to live well with dementia and reducing the 'double stigma' that they frequently experience in addition to ageism.

\section{References}

Alzheimer's Society. (2013). Dementia 2013: The hidden voice of loneliness. London: Alzheimer's Society.

Bail, K. (2013). Potentially preventable complications of urinary tract infections, pressure areas, pneumonia, and delirium in hospitalised dementia patients: Retrospective cohort study. BMJ Open, 3, e002770. http://bmjopen.bmj.com/content/3/6/e002770.full

Banerjee, S., \& Wittenberg, R. (2009). Clinical and cost effectiveness of services for early diagnosis and intervention in dementia. International Journal of Geriatric Psychiatry, 24(7), 748-754.

Batsch, M. L., \& Mittleman, L. S. (2013). World Alzheimer's report 2012: Overcoming the stigma of dementia. London: Alzheimer's Disease International.

Benbow, S. M., \& Jolley, D. (2012). Dementia: Stigma and its effects. Neurodegenerative Disease Management, 2(2), 165-172.

Bolton, M. (2012). Loneliness - The state we're in. Oxford: Age UK.

Bowling, A. (2011). Good Neighbours: Measuring quality of life in older age. London: ILC-UK. www.ilc.org.uk

Brodaty, H., \& Donkin, M. (2009). Family caregivers of people with dementia. Dialogues Clinical Neuroscience, 11(2), 217-228.

Brooker, D., La Fontaine, J., Evans, S., \& Saad, K. (2014). Public health guidance to facilitate timely diagnosis of dementia: ALzheimer's Cooperative valuation in Europe recommendations. International Journal of Geriatric Psychiatry, 29(7), 682-693. https://doi.org/10.1002/ gps.4066 
Brooks, J., Savitch, N., \& Gridley, K. (2017). Removing the 'gag': Involving people with dementia in research as advisers and participants. Social Research Practice, 3, 3-14.

Burgener, S. C., \& Berger, B. (2008). Measuring perceived stigma in persons with progressive neurological disease. Dementia, 7(1), 31-53.

Cohen-Mansfield, J., \& Parpura-Gill, A. (2007). Loneliness in older persons: A theoretical model and empirical findings. International Psychogeriatrics, 19(02), 279.

Corner, L., \& Bond, J. (2004). Being at risk of dementia: Fears and anxieties of older adults. Journal of Aging Studies, 18(2), 143-155.

Department of Health. (2009). Living well with dementia: A national dementia strategy. Available online at http://www.dh.gov.uk/en/Publicationsandstatistics/Publications/ PublicationsPolicyAndGuidance/DH_094058

Devlin, E., MacAskill, S., \& Stead, M. (2007). 'We're still the same people': Developing a mass media campaign to raise awareness and challenge the stigma of dementia. International Journal of Nonprofit and Voluntary Sector Marketing, 12(1), 47-58.

Dobbs, D., Eckert, J. K., Rubinstein, B., Keimig, L., Clark, L., Frankowski, A. C., \& Zimmerman, S. (2008). An ethnographic study of stigma and ageism in residential care or assisted living. Gerontologist, 48(4), 517-526. https://doi.org/10.1093/geront/48.4.517

European Parliament. (2010). European initiative on Alzheimer's disease and other dementias. 2010. http://www.europarl.europa.eu/oeil/popups/ficheprocedure.do?lang=en\&reference=201 0/2084(INI). Accessed 15 Apr 2016.

Evans, S. (2008). Providing rehabilitation services for people with dementia through intermediate care. Nursing Older People, 20(2), 33-35.

Fillit, H. M. (2000). The pharmacoeconomics of Alzheimer's disease. The American Journal of Managed Care, 6(22), 1139-1144.

Goffman, E. (2005). Stigma. Notes on the management of spoiled identity. New York: Touchstone.

Gove, D., Downs, M., Mernooij-Dassen, M., \& Small, N. (2016). Stigma and GPs' perceptions of dementia. Aging \& Mental Health, 20(4), 391-400. https://doi.org/10.1080/13607863.201 5.1015962

Gunhild Waldemar, K. T. T., Phung, A. B., Georges, J., Hansen, F. R., Iliffe, S., Marking, C., Rikkert, M. O., Selmes, J., Stoppe, G., \& Sartorius, N. (2007). Access to diagnostic evaluation and treatment for dementia in Europe. International Journal of Geriatric Psychiatry, 22(1), $47-54$.

Holt-Lunstad, J., Smith, T. B., \& Layton, J. B. (2010). Social relationships and mortality risk: A meta-analytic review. PLoS Medicine, 7(7), e1000316. https://doi.org/10.1371/journal. pmed.1000316

Jolley, D. J., \& Benbow, S. M. (2000). Stigma and Alzheimer's disease: Causes, consequences and a constructive approach. International Journal of Clinical Practice, 54(2), 117-119.

Knopman, D., Donohue, J. A., \& Gutterman, E. M. (2000). Patterns of Care in the Early Stages of Alzheimer's disease: Impediments to timely diagnosis. Journal of the American Geriatrics Society, 48(3), 300-304.

Lang, R. E., \& Hornburg, S. P. (1998). What is social capital and why is it important to public policy? Housing Policy Debate, 9(1), 1-16.

Link, B. G., \& Phelan, J. C. (2001). Conceptualizing Stigma. Annual Review of Sociology, 27, 363-385.

Manthorpe, J., Iliffe, S., \& Eden, A. (2004). Early recognition of and responses to dementia: Health professionals' views of social services' role and performance. British Journal of Social Work, 34(3), 335-348.

Milne, A. (2010). Dementia screening and early diagnosis: The case for and against. Health, Risk \& Society, 12(1), 65-76.

Mittelman, M. S., Haley, W. E., Clay, O. J., \& Roth, D. L. (2006). Improving caregiver wellbeing delays nursing home placement of patients with Alzheimer disease. Neurology, 67(9), $1592-1599$. 
Mittelman, M. S., Roth, D. L., Clay, O. J., \& Haley, W. E. (2007). Preserving health of alzheimer caregivers: Impact of a spouse caregiver intervention. The American Journal of Geriatric Psychiatry, 15(9), 780-789.

Mittelman, M. S., Brodaty, H., Wallen, A. S., \& Burns, A. (2008). A three-country randomized controlled trial of a psychosocial intervention for caregivers combined with pharmacological treatment for patients with Alzheimer disease: Effects on caregiver depression. The American Journal of Geriatric Psychiatry, 16(11), 893-904.

Moniz-Cook, E., \& Manthorpe, J. (2009). Personalising psychosocial interventions to individual needs and context. In E. Moniz-Cook \& J. Manthorpe (Eds.), Early psychosocial interventions in dementia. London: Jessica Kingsley Publishers.

Morrison, R. S., \& Siu, A. L. (2000). Survival in end-stage dementia following acute illness. JAMA, 284(1), 4752.

Murali Doraiswamy, P., Leon, J., Cummings, J. L., Marin, D., \& Neumann, P. J. (2002). Prevalence and impact of medical comorbidity in Alzheimer's disease. The Journals of Gerontology. Series A, Biological Sciences and Medical Sciences, 57(3), M133-M177.

Okun, M. A., \& Keith, V. M. (1998). Effects of positive and negative social exchanges with various sources on depressive symptoms in younger and older adults. The Journals of Gerontology Series B: Psychological Sciences and Social Sciences, 53B(1), P4-P20.

Peel, L. (2014). 'The living death of Alzheimer's' versus 'take a walk to keep dementia at bay': Representations of dementia in print media and carer discourse. Sociology of Health and Illness, 36(6), 885-901.

Pinquart, M., \& Sorensen, S. (2001). Influences on loneliness in older adults: A meta-analysis. Basic and Applied Social Psychology, 23(4), 245-266.

Prince, M., Wimo, A., Guerhet, M., Ali, G.-C., Wu, Y.-T., \& Prina, M. (2015). World Alzheimer report 2015: The global impact of dementia. London: Alzheimer's Disease International.

Prince, M., Bryce, R., \& Ferri, C. (2011). Alzheimer's disease international-World Alzheimer report 2011: The benefits of early diagnosis and intervention.. Available online at http://www. alz.co.uk/research/WorldAlzheimerReport2011.pdf

Sampson, E. L. (2006). Differences in care received by patients with and without dementia who died during acute hospital admission: A retrospective case note study. Age and Ageing, 35(2), 187-189.

Sampson, E. L., Blanchard, M. R., Jones, L., Tookman, A., \& King, M. (2009). Dementia in the acute hospital: Prospective cohort study of prevalence and mortality. British Journal of Psychiatry, 195(01), 61-66.

Scrutton, J., \& Brancati, C. (2016). Dementia and comorbidities ensuring parity of care. London: ILC.

Seefeldt, C. (1984). Children's attitudes toward the elderly: A crosscultural comparison. International Journal of Aging \& Human Development, 19(4), 319-328.

Sherratt, C., Soteriou, T., \& Evans, S. (2008). Ethical issues in social research involving people with dementia, dementia. The International Journal of Social Research and Practice, 6(4), 463-479.

Swaffer, K. (2014). Dementia: Stigma, language, and dementia-friendly. Dementia, 13(6), $709-716$.

Urbańska, K., Szcześniak, D., \& Rymaszewska, J. (2015). The stigma of dementia. Postępy Psychiatrii i Neurologii, 24(4), 225-230.

van der Vorm, A., Rikkert, M. O., Vernooij-Dassen, M., \& Dekkers, W. (2008). Genetic research into Alzheimer's disease: A European focus group study on ethical issues. International Journal of Geriatric Psychiatry, 23(1), 11-15.

Werner, P. (2014). Stigma and Alzheimer's disease: A systematic review of evidence, theory, and methods. In P. W. Corrigan (Ed.), The stigma of disease and disability: Understanding causes and overcoming injustices (pp. 223-244). Washington, DC: American Psychological Association. 
Wiersma, E. C., \& Denton, A. (2013). From social network to safety net: Dementia-friendly communities in rural northern Ontario. Dementia, 15(1), 51-68.

World Health Organisation. (2007). Global age-friendly cities: A guide. Geneva: World Health Organisation.

World Health Organisation. (2015). First WHO ministerial conference on global action against dementia: Meeting report. Geneva: World Health Organization.

Wyman, M. F., Shiovitz-Ezra, S., \& Bengel, J. (2018). Ageism in the health care system: Providers, patients, and systems. In L. Ayalon \& C. Tesch-Römer (Eds.), Contemporary perspectives on ageism: Vol. 19. International perspectives on aging (pp. 193-213). Berlin: Springer.

Open Access This chapter is licensed under the terms of the Creative Commons Attribution 4.0 International License (http://creativecommons.org/licenses/by/4.0/), which permits use, sharing, adaptation, distribution and reproduction in any medium or format, as long as you give appropriate credit to the original author(s) and the source, provide a link to the Creative Commons license and indicate if changes were made.

The images or other third party material in this chapter are included in the chapter's Creative Commons license, unless indicated otherwise in a credit line to the material. If material is not included in the chapter's Creative Commons license and your intended use is not permitted by statutory regulation or exceeds the permitted use, you will need to obtain permission directly from the copyright holder. 


\title{
Chapter 17 \\ Ageism and Neuropsychological Tests
}

\author{
Boaz M. Ben-David, Gali Malkin, and Hadas Erel
}

\subsection{Introduction}

Increase in life expectancy is one of the core characteristics of the modern life (Schneider 1999). However, whereas medicine and technology enable relatively good health (Eggleston and Fuchs 2012), the apparent cognitive decline is still considered one of the most central aspects of ageing (for an overview see, Craik and Salthouse 1992; but for a steady age-related advantage in vocabulary, Ben-David et al. 2015; also see Evans 2018; Chap. 16, in this volume). It is one of the most feared aspects of growing old (Morley 2004). In this context, accurate measures of cognitive decline have become increasingly important. These typically involve the assessment of core cognitive skills, such as memory, language proficiency, intelligence and executive functions (for a review see, Monge and Madden 2016).

Older adults' performance on cognitive assessment tests has important implications both on the individual level and on the societal level. For individuals, performance is a marker for cognitive ability, influencing self-image and life choices. For society as a whole, performance sets the perspective (and expectations) on the capabilities of older people in general, contributing to ageism. Cognitive assessment tests are administered with two (dependent) implicit assumptions: (a) the tests are a

\footnotetext{
B. M. Ben-David ( $\square)$

Communication, Aging and Neuropsychology Laboratory (CANlab), Baruch Ivcher School of Psychology, Interdisciplinary Center (IDC), Herzliya, Herzliya, Israel

Faculty of Medicine, Department of Speech-Language Pathology, University of Toronto, Toronto, ON, Canada

Toronto Rehabilitation Institute - University Health Network, Toronto, ON, Canada e-mail: boaz.ben.david@idc.ac.il

G. Malkin $\cdot$ H. Erel

Communication, Aging and Neuropsychology Laboratory (CANlab), Baruch Ivcher School of Psychology, Interdisciplinary Center (IDC), Herzliya, Herzliya, Israel
}

L. Ayalon, C. Tesch-Römer (eds.), Contemporary Perspectives on Ageism, International Perspectives on Aging 19, https://doi.org/10.1007/978-3-319-73820-8_17 
valid gauge of performance in older adults and (b) cognitive abilities decline in older age. Because test performance is taken to provide a good estimate of abilities in older adults, reduced test performance is interpreted as reflecting an age-related cognitive decline. If one assumes an age-related cognitive decline, reduced performance in cognitive tests can be seen as further support for test validity. In the current chapter, we wish to challenge these assumptions, questioning the validity of cognitive tests as an unbiased gauge of older adults' abilities, and as a result, questioning the extent of age-related cognitive decline.

As a first step, we review evidence suggesting that performance on cognitive tests is affected by sensory decline. Currently, cognitive tests are not designed to take this factor into account. Specifically, sensory decline in ageing degrades the information processed, impairing cognitive processing (Schneider and PichoraFuller 2000). Indeed, age-related changes in cognitive performance (on several tests) can be minimized (or even effaced) when sensory decline is controlled for, or by changing the sensory context of the test (vision: Ben-David and Schneider 2009; auditory: Ben-David et al. 2011a).

In the second part of this chapter, we discuss evidence of the impact of age-based stereotype threat on test performance. Specifically, the predicament arising from negative ageing stereotypes on cognitive decline can be experienced as a selfevaluation threat (Steele and Aronson 1995), leading to decreased performance, thus fulfilling the ageist prophecy (Hess et al. 2003). Here, too, there is evidence to suggest that elevating stereotype threat may minimize age-related changes in performance (e.g., Mazerolle et al. 2017). Finally, notwithstanding age-related neurological changes (as frontal and hippocampal decline; West 1996), this chapter suggests that the common assumption on the extent of age-related decline in cognitive abilities may be exaggerated, and the respective role of the sensory and social contexts on performance is considerably ignored.

To understand the interplay between the implicit assumptions and the sensory and social contexts, consider the following example. A 75-year-old goes to a university lab to be tested for cognitive abilities, or to a clinic to be tested for cognitive impairment, when decline (or even dementia) is suspected. The mere presentation of the test may elicit the expectation to perform poorly, negatively affecting performance. Auditory and visual information, such as test material and instructions, present a greater sensory challenge due to age-related sensory decline, again negatively affecting performance. Reduced performance serves to further validate common stereotypes about the rate and extent of cognitive deterioration with ageing, as the test is taken as valid and unbiased. Simply put, performance on tests, which may be biased due to sensory and social aspects of ageing, confirms assumptions of reduced cognitive abilities in ageing.

In sum, our analysis of the literature focuses on the two main threats to the validity of neuropsychological assessment in ageing: the sensory context and the social context. These contexts not only describe the mechanisms underlying biases in evaluating cognitive performance in older age, but also offer insights that can improve the validity of such tests. Targeting the sensory and social context in 
neuropsychological assessment may assist in reducing age-bias (leading to ageism) in the scientific, medical and general community.

\subsection{Ageing and the Sensory Context of Neuropsychological Assessment}

\subsubsection{Age-Related Sensory Decline}

Ageing is commonly accompanied by a sensory decline (Crews and Campbell 2004), indicated by an increase in the use of sensory aids, such as hearing devices and glasses (Roberts and Allen 2016). To focus our discussion, we target auditory and visual age-related decline in healthy ageing. Auditory decline in healthy ageing is related to neural changes across different auditory areas in the brain, as well as cochlear changes in the ear (Gordon-Salant et al. 2010). Auditory changes lead to an increase in hearing thresholds, where one needs louder target sounds for correct detection (Roberts and Allen 2016), and supra-threshold changes (Glasberg and Moore 1992), such as distortion of the incoming stimuli (Grose and Mamo 2010). Ageing is also marked by less efficient auditory scene analysis (Bregman 1990), where both top-down and bottom-up processes impact difficulties in segregating the target speech from competing sound sources in the background (e.g., other people talking; Tun and Wingfield 1999). Visual changes in healthy ageing typically include retinal degeneration (Monge and Madden 2016), and presbyopia (Scialfa 2002). These changes degrade basic visual processes, such as near-term vision (Spear 1993), visual acuity (clarity of vision, Owsley 2011), contrast sensitivity (the ability to detect luminance differences to distinguish objects from background, Greene and Madden 1987) and colour perception (e.g., Nguyen-Tri et al. 2003).

Intelligence Tests The age-related sensory decline discussed above is likely to have an impact on cognitive processing, and therefore, on neuropsychological assessment (Roberts and Allen 2016; Schneider and Pichora-Fuller 2000). Perhaps the most striking evidence comes from a line of studies on age-related sensory decline and scores on different intelligence batteries (e.g., Anstey et al. 2001; Lindenberger and Baltes 1994). Findings show that visual and auditory acuity scores (near and far visual acuity, pure tone auditory acuity) could account for $93.1 \%$ of the age-related variance in intelligence scores (with 156 participants aged 70-103). These findings were later replicated and extended on a larger sample (687 participants), with a larger age range (25-103 years, Baltes and Lindenberger 1997) and to longitudinal data (Ghisletta and Lindenberger 2005). In sum, evidence suggests that sensory decline is closely related to a decline in performance on neuropsychological assessment. 


\subsubsection{Theories on the Interaction of Sensory and Cognitive Ageing}

How to explain this link between sensory and cognitive ageing? Four possible hypotheses have been discussed (Schneider and Pichora-Fuller 2000, see also Wayne and Johnsrude 2015): (1) Sensory deprivation hypothesis. Sensory decline, over time, leads to a cognitive decline due to social isolation and reduced use of the relevant cognitive functions (Lin et al. 2013); (2) Cognitive load hypothesis. Cognitive decline leads to a decline in perceptual processes (the interpretation of the sensory input). This is based on the idea that cognitive load can impair even simple sensory tasks (Li et al. 2001; Lindenberger et al. 2000) (3) Common cause hypothesis. Degeneration in the central nervous system causes a deterioration of both perception and cognition (Baltes and Lindenberger 1997). Indeed, cardiovascular risk factors have been associated with both hearing loss and cognitive decline (Roberts and Allen 2016); finally, (4) Information degradation hypothesis. Unclear and distorted perceptual information delivered to the cognitive system directly impairs cognitive performance, due to an increase in the resources required for the perception process and errors embedded in the input (Schneider and Pichora-Fuller 2000).

These hypotheses are not necessarily mutually exclusive. Clearly, the interaction of sensory and cognitive processing suggests that each factor can affect the other, with similar biological changes influencing both (Baltes and Lindenberger 1997). However, the information degradation hypothesis presents the framework for understanding the possible age biases in neuropsychological testing that may lead to ageism. If perception and cognition are taken to comprise one integrated system (Wingfield and Tun 2007), where both processes share the same pool of resources (Glisky 2007), then when perceptual processing requires more resources due to agerelated sensory decline, less resources are available for cognitive processing (Heinrich et al. 2008). Furthermore, cognitive processing demands more resources when it is based on degraded sensory information, tapping into the already reduced pool. This model suggests that sensory degradation (i.e., the reduced quality of sensory information) is an alternative explanation for age-related declines in performance. Thus, it directly challenges the two implicit assumptions underlying neuropsychological testing in ageing: test validity and the extent of age-related cognitive decline. The validity of this model can be tested very easily with simple experimental manipulations (see Monge and Madden 2016). This hypothesis also affords a possible remediation for neuropsychological assessments in older age. Mainly, ameliorating the sensory input (or removing them all together, Ben-David and Icht 2017), can minimize age-related differences.

In the next sections, we discuss the assessment of three main cognitive abilities, taken to represent age-related cognitive decline: inhibition, speech comprehension and memory. We offer evidence to suggest that the neuropsychological assessment can be drastically impacted by age-related sensory degradation in vision (inhibition), in hearing (comprehension) or both (memory). 


\subsubsection{Inhibition: An Example of the Effect of Visual Degradation on Neuropsychological Tests}

The need to inhibit irrelevant information is a central cognitive ability in daily activities. For example, when driving a car one must attend to the road, while ignoring irrelevant visual distractors, such as billboards. Similarly, when reading this text, one needs to ignore irrelevant dimensions, such as the size and shape of the page, and focus on the content of the words. One of the prominent theories on cognitive changes in ageing suggests that this specific process deteriorates in ageing (Hasher and Zacks 1988). The age-related decrease in the efficiency of inhibitory processes is a part of a general theory on a decrease in executive functions - a decrease in monitoring and control of behaviour (Baddeley 1996). This cognitive decline is generally attributed to selective prefrontal deterioration in ageing (Dempster 1992). However, recent studies suggest that visual sensory degradation can explain some of the age-related variance in performance (see a discussion in Ben-David et al. 2014a).

The 'gold standard' for evaluating inhibition in ageing is the colour-word Stroop test (Stroop 1935; see Melara and Algom 2003 for a relevant review). In this paradigm, participants are asked to name aloud the font colours of printed words, ignoring their content. For example, saying aloud "blue" when presented with the word RED printed in blue. The latency advantage for naming the font colour of a colourneutral word (e.g., TABLE printed in blue) over an incongruent colour-word (RED in blue) is termed Stroop interference. An age-related increase in Stroop interference has been shown repeatedly in the literature (for reviews, see Ben-David and Schneider 2009; McDowd and Shaw 2000). It is commonly interpreted as reflecting an age-related decrease in the efficiency in inhibition (e.g., Troyer et al. 2006).

In the past decade, a line of studies by Ben-David and colleagues suggest that variance in colour-vision (in people with clinically normal colour-vision) can mediate performance on the Stroop test in various populations: healthy ageing (Anstey et al. 2002; Ben-David and Schneider 2009), people with dementia (Ben-David et al. 2014b) and people with traumatic brain injury (Ben-David et al. 2011b, 2016). In a meta-analysis (Ben-David and Schneider 2009), an age-related increase in colour-naming latencies (naming the font colour of a colour-neutral word) was found to be significantly larger than an age-related increase in reading latencies (reading a word printed black on white). This increased difficulty in colour-vision processing was found to be a possible source for reduced performance on the Stroop test, beyond any changes in inhibition. In a follow-up study, to simulate an agerelated colour deficiency, the Stroop test was presented with desaturated colour-set for a group of younger adults. By reducing the amount of colour information available, Ben-David and Schneider (2010) were able to "age" younger adults, generating the age-related increase in Stroop interference. Somewhat similar results were obtained in other inhibition test. For example, Bertone et al. (2007) simulated agerelated visual acuity degradation by fitting younger adults with occlusion filter lenses to blur their vision (e.g., to 20/40), severely reducing performance on an inhibition test. 
In sum, mimicking an age-related decrease in colour perception in younger adults was sufficient to lead to Stroop interference that is similar to that found in older adults. Because the colour-word Stroop test is widely used in clinical, neuropsychological and experimental screening tests as a measure of inhibitory control in older participants, there is reason to question the validity of inhibition diagnosis and the extent to which the inhibitory process in ageing decreases.

\subsubsection{Comprehension: An Example of the Effect of Auditory Degradation on Neuropsychological Tests}

Age-related auditory degradation impairs speech perception on various levels: single-word identification, sentence comprehension, source localization and the ability to segregate the source speaker from a noisy background (Ben-David et al. 2012; Humes and Dubno 2009; Schneider et al. 2002). This is supported by a line of studies showing that when the listening situation is adjusted to match older and younger adults' auditory abilities, speech processing can be equated (for a review, see Schneider et al. 2010). For example, (Ben-David et al. 2011b) used an eyetracking paradigm to measure age-related effects on speech processing, as the spoken word unfolds in time. The study found equivalent online speech processing for older and younger adults, when speech was presented in quiet. When the noise level was tailored to compensate for age-related auditory changes (by setting different signal-to-noise ratios to equate single-word identification across age-groups), again, online speech processing was mostly not affected by ageing (for possible cognitive effects, see Hadar et al. 2016).

Age-related changes in speech perception, as presented above, can directly affect performance on neuropsychological tests. Generally, basic test instructions are spoken, presenting a possible source for misunderstanding. The additional effort for deciphering spoken instructions may also decrease available resources and induce stress (Schneider et al. 2010). Importantly, in many cognitive tests, test stimuli are spoken rather than printed, presenting further sources for biases. For example, Schneider et al. (2000) asked older and younger participants to listen to lectures (8-13 min) on a noisy background and to later answer questions concerning their content. When both age groups heard the lecture at the same sound level (mimicking conditions in the clinic), significant age-related differences were found. However, when auditory conditions were individually adjusted to compensate for sensory degradation, these differences were eliminated. In other words, older adults were able to perform as well as younger adults, even in a complex listening comprehension task, when sensory degradation was compensated for (for replication, see Lu et al. 2016). These results may be further supported by a recent study indicating that younger adults with hearing impairment show equal cognitive performance to older adults with similar sensory decline (Verhaegen et al. 2014). Noting that declines in comprehension are often interpreted as a direct indication of age-related 
cognitive decline and even pre-dementia (Schneider et al. 2005), these findings present implications for various neuropsychological assessment tools.

\subsubsection{Memory: An Example of the Effect of Auditory and Visual Degradation on Neuropsychological Tests}

As discussed in the second section of this chapter, memory deterioration is one of the most prominent stereotypes in ageing. Research presents abundant evidence suggesting an age-related decline in a variety of memory tasks (Craik and Jennings 1992; Zacks et al. 2000). Yet, like comprehension, memory was also shown to depend on the perception of the auditory stimuli (Peelle and Wingfield 2005). Consider studies of spoken word-pairs, where listeners are presented with a list of spoken word-pairs, and later asked to recall a target word when given its pair. In an early study (Murphy et al. 2000), memory performance of older adults listening in quiet was nearly equivalent to that of younger adults listening in noise. Later, Heinrich and Schneider (2011) adjusted signal-to-noise ratios to equate identification of a single spoken word across age-groups (i.e., louder background noise was presented to younger adults). In this condition, memory performance of older adults matched that of younger adults, when ample time was given.

Visual decline was also shown to impair performance on memory tests. For example, Dickinson and Rabbitt (1991) occluded younger adults' vision to mimic older adults' visual perception when asked to read aloud a passage for later recall. Memory performance was severely diminished, even though no errors were performed during reading. In other words, the additional toll on processing (generated by visual degradation) can affect non-perceptual, higher-order cognitive processes, even when visual processing is still intact. Finally, visual sensory degradation was also correlated with other visual memory tasks (Stevens et al. 1998).

Dementia Screening Tests Age-related sensory degradation was not only found to impact memory tests in healthy ageing, but also dementia assessment, with severe implications for false positive mistakes (e.g., Feldman et al. 2008). We focus on commonly used screening tests for dementia such as the Mini-Mental State Examination (MMSE; Folstein et al. 1975) and the Montreal Cognitive Assessment (MoCA: Nasreddine et al. 2005). These tests are considered accurate tools for identifying indicators for pre-dementia and mild cognitive impairment (MCI: Luis et al. 2009). Yet, there is a body of evidence in the literature to indicate that these tools can be affected by sensory degradation as well. For example, Dupuis et al. (2015) found that older adults with sensory loss (whose vision andlor hearing scores did not meet the criteria for healthy ageing) were twice as likely to score below the cutoff point for potential pre-dementia as older adults with clinically normal visual and auditory thresholds. Indeed, in a different study, one third of older adults with hearing loss, who were already diagnosed with dementia, were reclassified as having a lesser degree of dementia when the MMSE was administered using sound 
amplification (Weinstein and Amsel 1986). Similarly, significantly better MMSE scores were documented when older adults with hearing loss were using fitted hearing aids (Acar et al. 2011). Dementia measures are also affected by age-related sensory decline that is still within clinically normal boundaries. For example, tailoring stimuli contrast level for older participants to resemble contrast perception of younger adults was sufficient to erase all age-related differences in a digit cancellation task (another indicator for pre-dementia) with healthy adults. When the same manipulation was conducted with older adults diagnosed with dementia, it significantly minimized performance decline (Toner et al. 2012). In sum, age-related visual and auditory decline can lead to overestimation and false-positive diagnosis of dementia. Results call for a careful examination of test results in light of agerelated sensory decline.

\subsubsection{Clinical Implications: Compensating for Sensory Degradation}

Simple actions may overcome the sensory bias in neuropsychological testing. We recommend adjusting test stimuli and instructions to compensate for age-related sensory changes. These include sound amplification, reducing background noise and increasing target sound level (enhancing signal-to-noise ratio), enhancing stimuli visual contrast, using larger font size, increasing the amount of light in the room, careful choice of colours and so on. We also recommend assessing the visual and auditory abilities of older participants in all cases of neuropsychological assessments. It is imperative to ensure the use of corrective aids (visual or auditory) when these are needed, as hearing and visual loss can severely reduce performance. These sensory scores can also serve to statistically adjust neuropsychological assessment scores to better reflect abilities (e.g., the Stroop task, Ben-David and Schneider 2010). In sum, to avoid a false diagnosis of a clinical cognitive decline one must not ignore or underestimate sensory decline.

\subsubsection{Sensory Context: Summary}

In the first section of this chapter, we discussed evidence showing that physical aspects of the test material (and instructions) present a direct threat to the validity of neuropsychological testing in ageing. Namely, age-related decline in performance on assessment tools may reflect, at least in part, a sensory rather than a cognitive decline. When reduced performance is evident, it is likely to be attributed to lower cognitive ability of the older test taker, rather than transient sensory contextual factors. This ageist bias might serve to further validate negative ageing stereotypes, resulting ultimately in the negative portrayal of older adults across both scientific 
literature and every day cultural representations. In the following section, we discuss how such age-based stereotypes may have a negative impact on performance, suggesting that the social aspects of the test may also put into question the validity of neuropsychological testing in ageing.

\subsection{The Social Context of Neuropsychological Assessment in Ageing}

Stereotype threat, one of the most widely investigated topics in social psychology (Pennington et al. 2016) occurs when underachievement among stigmatized group members is rooted in the situation more than in the individual (Leyens et al. 2000). The existence of a negative stereotype about a person's group means that in situations where the stereotype is applicable, the person will be at risk of confirming it as self-characteristic (Aronson 2002). In the seminal work of Steele and Aronson (1995), African American participants were tested on a verbal reasoning task. When the task was presented as a diagnostic indicator of intellectual ability, the performance of African-Americans (a population that generally suffers from a stereotype on intellectual abilities) was significantly worse compared to that of their Caucasian peers. When the task was presented as non-diagnostic, these differences in performance were eliminated. Therefore, making the racial stereotype about intellectual ability relevant to test performance impaired African Americans' performance relative to Caucasian participants.

Stereotype threat effects have been studied across different stereotyped social groups including women (e.g., Spencer et al. 1999), individuals from low socioeconomic status (e.g. Spencer and Castano 2007), gay men (Bosson et al. 2004), and older adults, as we will review in the next sections.

\subsubsection{Age-Based Stereotype Threat}

Older adults face pervasive negative stereotypes portraying them as forgetful, incompetent, and cognitively inferior to younger adults (Hummert et al. 1994; Kite and Wagner 2002). These stereotypes were found to have a negative impact on older adults' performance across diverse domains, and on their general well-being. A recent meta-analysis of 32 studies, covering more than a decade of research (Lamont et al. 2015), suggests that age-related reduced performance on memory tests and other cognitive measures may be vulnerable to age-based stereotype threat (with a moderate effect size, $d=0.36$ - an effect size measures the strength of a phenomenon, Sawilowsky 2009). In the current section of the chapter, we focus on how older adults' negative beliefs about their memory and other cognitive abilities can impact their performance on assessment tools. 
Age-based stereotype threat is typically induced in the lab by manipulating the relevance of the stereotype to task performance. Most studies usually invoke agebased stereotype threat by presenting participants with fictitious information confirming that cognitive abilities decline with age, by emphasizing the task's evaluative nature, or by implying an age-based comparison. One of the pioneering investigations of age-based stereotype threat is a study by Hess et al. (2003). In this study, stereotype threat was manipulated by informing younger and older adults about research findings depicting either the negative impact of ageing on memory (threat condition), or describing that memory is maintained across the lifespan (no-threat condition). Participants were then given a free recall memory test. Consistent with the stereotype threat framework, no age-related differences were noted in the nothreat condition. However, in the threat condition, recall was higher for younger than for older adults. In sum, traditional findings on a significant age-related decrease in performance on memory tasks might be affected by the activation of pervasive negative ageing stereotypes.

Real-world testing situations, such as testing in the clinic or a research lab, may induce a stereotype threat by nature, without requiring any special manipulations (Spencer et al. 2016). Simply taking a test in a negatively stereotyped domain, in the context of performance evaluation in ageing, is enough to trigger stereotype threat. Consider again a memory test. The typical procedure for testing the memory abilities of older adults (Hughes et al. 2013) involves multiple stereotype threat cues. These include the testing location: a college campus where older adult participants are surrounded by younger adults, or a hospital clinic highlighting sickness and disability. Test instructions may also trigger stereotype threat as participants are informed that their memory will be tested, with the commonly implicit assumption that their performance will be compared to that of younger adults. In fact, recruiting participants based on their age, or merely asking them to indicate their age in a demographic questionnaire can serve as a cue (Kang and Chasteen 2009). All of these cues may potentially lead to performance decrement, ultimately resulting in an over-estimation of age-related memory decline.

\subsubsection{Clinical Implications of Age-Based Stereotype Threat}

Perhaps the most striking indication of the consequences of age-based stereotype threat on assessment arises from two seminal studies on dementia assessment. Mazerolle et al. (2017) used the most common brief neuropsychological assessment batteries in ageing, MMSE and MoCA (as discussed in the previous part of this chapter). Experimenters simply informed all participants that they would perform a memory task and that both younger and older adults are taking part in the study (threat condition). In the reduced-threat condition, participants were also informed that typically there are no age-related differences in this task. Results show that $40 \%$ of the sample of community-dwelling older adults met the screening criteria for predementia in the threat condition. However, only $10 \%$ of the participants in the 
reduced-threat condition met these criteria. This finding is further supported in a study by Haslam et al. (2012) investigating a commonly used measure for early dementia detection (ACE-R). When participants were self-categorized as old, and were also led to expect that age-related cognitive decline is all-encompassing (rather than limited to a specific domain), 70\% met the diagnostic criterion for dementia. By contrast, only $14 \%$ on average met this criterion in all other (lower-threat) conditions. In sum, stereotype threat may lead not only to overestimation of cognitive decline but also to the false-positive diagnosis of pre-dementia, suggesting potential severe implications in real life.

It is important to note that age-based stereotype threat does not begin and end in the testing situation alone. There is evidence that older adults perform worse on a memory test following negative, rather than positive, age-related subliminal primes. That is, when words associated with negative aspects of aging (e.g., DEMENTIA) were presented at a speed allowing perception but not awareness (i.e. subliminal presentation), performance on a subsequent memory test was worse than when a positive word (e.g., SAGE) was subliminally presented (e.g., Hess and Hinson 2006; Levy 1996; Levy and Leifheit-Limson 2009). These implicit stereotypes may generate expectations that act as self-fulfilling prophecies (Levy and LeifheitLimson 2009), which may be at the root of the motivation of the older adult to search for a neuropsychological evaluation in the first place (Régner et al. 2016). For example, when an older adult is placed in situations predominantly occupied by younger adults (i.e., stereotype threat), typical memory lapses may be interpreted as abnormal age-related decline. There is evidence that both younger and older adults attribute older adults' memory failures to internal, stable factors (Erber et al. 1990). Older adults may refer to a case of forgetfulness as their "senior moment" (Barber 2017). Interpreting every-day memory failures as a sign for a need for intervention (Erber et al. 1990) may lead the older person to search for clinical assessment. Because the clinical assessment is also negatively affected by stereotype threat, this person may perform below his/her abilities, with profound clinical, social and economic consequences. Moreover, even if the person does in fact suffer a probable cognitive impairment, the debilitating effects of stereotype threat may be especially prominent for him/her (Scholl and Sabat 2008). These effects may influence the choice of suitable treatment options, and the adherence to treatment, resulting in an entirely different course of disease.

Eliminating age based stereotype cues calls for a multi-faceted approach, as demonstrated by Sindi et al. (2013). The authors compared younger and older adults' salivary cortisol levels, as a measure for stress, and performance on a memory neuropsychological test. The focus of the study was a manipulation of the environments to be stressful (unfavourable condition) or not stressful (favourable condition) for each age group. The unfavourable condition for older adults included: (1) A testing location known to young adults but not to older adults (university campus); (2) Testing performed in the afternoon, a non-optimal time for testing older adults, but optimal for younger adults; (3) A younger adult research assistant; (4) A memory task with which older adults, as opposed to younger adults, were not familiar (word list recall); (5) Instructions emphasizing the memory component of the 
task, matching the negative stereotype for older, but not for younger adults. In contrast, the favourable condition for older adults included: (1) A testing location that was known to older adults, but not to young adults (an older adult community centre); (2) Testing performed in the morning, an optimal time for testing older adults, but not for younger adults; (3) An older adult research assistant; (4) A memory task that was developed based on learning capacities of older adults (a face-association memory task, as older adults perform better when asked to recall relevant information, rather than unrelated words); (5) Instructions excluding an explicit indication that the task is testing memory. As expected, higher cortisol levels and lower memory performance were found for older adults in the unfavourable as compared to the favourable conditions. However, younger adults were not affected by the testing conditions. Although it is impossible to identify the relative contributions of each of these situational factors, this study demonstrates that many facets in the testing environment may be experienced differently by older and younger adults.

\subsubsection{Understanding Stereotype Threat Effects}

Generally, stereotype threat may arise from any situational cue indicating that an individual is at risk of confirming the stereotype, reminding the individual of culturally held stereotypes (Spencer et al. 2016). The literature has identified multiple reasons for the effects of stereotype threat on performance among younger adults.

One of the first mechanisms offered to understand stereotype threat effects is Negative Affect (Steele and Aronson 1995). In particular, increased levels of anxiety have been offered to mediate the effects of stereotype threat on performance. However, results regarding this hypothesis have been mixed (see a review by Pennington et al. 2016), with several studies failing to establish this relationship (e.g., Spencer et al. 1999). Therefore, while anxiety may play a role in explaining stereotype threat effects (especially when assessed via indirect measures, Bosson et al. 2004), it is likely not the only or the key explanation.

Taking a cognitive resources perspective, the Process Model (Schmader et al. 2008) suggests that stereotype threat disrupts performance via three distinct, yet interrelated, mechanisms: (a) triggering physiological stress response; (b) triggering a tendency to actively monitor performance, aimed to detect self-relevant information and signs of failure; (c) triggering efforts to suppress negative thoughts and emotions. Each of these mechanisms consumes cognitive resources that are required for successful performance on a given task. Generally speaking, there is ample direct and indirect evidence consistent with cognitive resource depletion in stereotype threat (Pennington et al. 2016).

Focusing specifically on older adults, the mechanisms underlying age-based stereotype threat are not fully understood, and may not be generalized from studies conducted among younger adults. With regard to affective factors, similar to younger adults, little evidence has been found for anxiety mediating the effects of age-based stereotype threat on performance (Chasteen et al. 2005; Hess et al. 2003; but see 
Swift et al. 2013). Inconsistent support has also been noted for the cognitiveresources hypothesis in older adults (Brelet et al. 2016; Mazerolle et al. 2012 vs. Hess et al. 2009; Popham and Hess 2015).

Why is it so difficult to fully understand stereotype threat effects among older adults? The answer may lie in the treatment of stereotype threat as a unitary concept, tailored by younger adults' experiences and perspectives. For example, according to Barber (2017), the reason cognitive depletion does not necessarily explain stereotype-threat effects in older adults may relate to their favourable emotion regulation abilities. Namely, regulating the negative affective states (such as anxiety and stress) induced by stereotype threat is resource demanding for younger adults. However, for older adults, regulating aversive emotions is less resource demanding (Scheibe and Blanchard-Fields 2009), suggesting a smaller role for this mechanism.

If stereotype threat effects are not fully explained by cognitive-resources depletion or by negative affect, what can explain them? Current literature appears to support the regulatory fit hypothesis in explaining stereotype threat effects in older age. According to this view, stereotype threat may elicit a prevention focus (Seibt and Förster 2004), in which participants aim not to be their worst, as opposed to striving to be their best. As suggested by the regulatory focus theory (Higgins 1997, 1999), this prevention focus will result in more cautious, error-free and loss aversion strategies. Consistent with the idea of a prevention focus, older adults under stereotype threat have been found to be more risk-averse in their decision making compared to non-threatened older adults (Coudin and Alexopoulos 2010), and respond more slowly (Popham and Hess 2015). In addition, stereotype threat was found to reduce older adults' (veridical) recall and recognition, but improve memory accuracy (Barber and Mather 2013b; Wong and Gallo 2016).

The fact that stereotype threat may elicit a prevention focus does not necessarily mean that it will result in decreased performance. There is evidence that stereotype threat could even improve older adults' performance when the task is framed as relating to losses rather than gains. For example, Barber and Mather (2013a) tested older adults on a working memory task, after inducing an age-based stereotype threat. When the tests were focused on gains (i.e., money earned for correct responses), stereotype threat was found to impair performance. However, when the tests were focused on losses (i.e., money lost for incorrect responses) threat improved performance. These findings were replicated using other memory tasks (MMSE, Word List Memory; Barber et al. 2015). This line of findings can support the regulatory fit (Higgins 2000) framework. According to this view, when task demands match the person's regularity focus, performance will increase, while a mismatch will decrease it. In sum, the reported negative effects of stereotype threat on older adults' performance may stem from a mismatch between the task structure and the threat-induced prevention focus (Grimm et al. 2009). 


\subsubsection{Social Context: Summary}

Findings presented in this section suggest the pervasive negative impact of agebased stereotype threat on performance in neuropsychological assessment. Evidence in the literature also suggests that this effect can have severe consequences, as predementia may be falsely detected in healthy older adults in the presence of stereotype threat cues. These cues are not only the outcome of laboratory manipulations, but may be present in the daily testing of older adults in the clinic or a university lab. It is important to recognize these cues in order to shape testing environments that evince the accurate capacities of older adults.

Although the mechanisms underlying threat effects in older adults are yet to be fully understood, the possibility that in some cases, activating negative age-based stereotypes does not necessarily result in performance decrement, is another promising direction. Changing the reward structure of the task to be loss-based (for example by emphasizing accuracy and minimization of mistakes), may also have important clinical implications.

Speaking more broadly, while several critiques have questioned whether stereotype threat actually generalizes from the laboratory into real-world testing situations (e.g., Sackett et al. 2004), when focusing on older adults, we believe that stereotype threat is responsible for an over-estimation of age-based cognitive decline among both scholars and practitioners. In some cases, this may lead to crossing a clinical boundary from normal to abnormal impairment (Haslam et al. 2012). Indeed, :"it is hard to imagine a social psychological effect that could have greater clinical relevance" (p.782).

\subsection{General Discussion}

The goal of this chapter was to test the two implicit assumptions underlying neuropsychological testing in ageing: test validity and the generalized view of the extent of age-related decline in cognitive abilities. We presented evidence from the current literature on the negative effects of age-related sensory decline and age-based stereotype threat on test performance. Our findings challenge these two assumptions, suggesting that age-related changes may not be as severe as previously suggested. Namely, age-related sensory decline and stereotype threat were shown to influence the context of the neuropsychological assessment and lead to an inaccurate measure of cognitive performance. In extreme cases, their influence may cause false diagnosis of pre-dementia, i.e., crossing a clinical boundary from normal to abnormal impairment. These contextual factors are not only the outcome of laboratory manipulation, but may be present in daily testing of older adults in the clinic or a university lab. It is important to account for these factors in order to shape testing environments appropriate for older adults. 
The pair of implicit assumptions appears to be embedded in test administration and scoring in many of the available tools. Generally, test materials are not formatted to meet age-related sensory degradation, and administration protocols specify neither the sensory context (such as illumination and noise levels) nor the social context (how to minimize stereotype threat) of the test. In most tests, normative scores are adjusted separately for each age group to compensate for the expected age-related decline (e.g., Stroop, WAIS). Simply put, the same score on a neuropsychological assessment may reflect normative performance for 70 year olds, but flawed performance for 20 year olds, echoing the pair of assumptions. Thus, test results, coupled with these assumptions, may provide support for ageism, affecting both the scientific and medical community and the public at large.

The evidence presented in this chapter has implications outside of the clinic/lab. Consider the office environment. The lighting and the noise level may be challenging for older employees. Thus, employees may have more difficulties in processing the written information, and in taking an active part in conversations. The resources allocated for deciphering the sensory input are not available for further cognitive processing. As a result, it is more difficult for older employees to utilize the full potential of their cognitive abilities. In turn, both colleagues and managers may perceive reduced performance as reflecting internal factors (an attribution error) - i.e., an age-related cognitive decline - judging older employees more harshly. This will lead to an atmosphere engendering stereotype threat. Taken together, daily activities in the office may be perceived by older employees as a test for cognitive abilities, where they are expected to underperform, and where sensory conditions place them at a disadvantage. By considering the sensory and social contexts, employers can improve the quality of work of older employees, extending their participation in the labour market and improving their quality of life.

Finally, upon reading this chapter, one may be reminded of the seminal book by Guthrie, "Even the Rat Was White: A Historical View of Psychology" (Guthrie 1976). Guthrie exposed how racist views shaped by studies in the early twentieth century affected the implementation and analysis of intelligence assessment tools at that time. Those studies suggested that the tone of skin was directly related to a decline in cognitive performance, and were guided by implicit assumptions on (1) test validity and (2) a racially-based decline in cognitive performance. Guthrie demonstrates the devastating implications of such tests by citing the following conclusions of a study by Philips, 1914: "If the Binet tests are at all a gauge of mentality, it must follow that there is a difference in mentality between the coloured and the white children. And this raises the question, should the two groups be instructed under the same curriculum?" (as quoted in Guthrie 1976:55). We hope that we can avoid repeating history, making the same mistakes in the twenty-first century. If researchers and clinicians acknowledge the current sensory and social biases of cognitive testing in older adults, it will set us on a promising path towards the design of more accurate assessment tools. 


\section{References}

Acar, B., Yurekli, M. F., Babademez, M. A., Karabulut, H., \& Karasen, R. M. (2011). Effects of hearing aids on cognitive functions and depressive signs in elderly people. Archives of Gerontology and Geriatrics, 52, 250-252.

Anstey, K. J., Dain, S., Andrews, S., \& Drobny, J. (2002). Visual abilities in older adults explain age-differences in stroop and fluid intelligence but not face recognition: Implications for the vision-cognition connection. Aging, Neuropsychology, and Cognition, 9, 253-265.

Anstey, K. J., Luszcz, M. A., \& Sanchez, L. (2001). Two-year decline in vision but not hearing is associated with memory decline in very old adults in a population-based sample. Gerontology, 47, 289-293.

Aronson, J. (2002). Stereotype threat: Contending and coping with unnerving expectations. In J. Aronson (Ed.), Improving academic achievement: Impact of psychological factors on education (pp. 281-304). Oxford: Academic Press.

Baddeley, A. (1996). The fractionation of working memory. Proceedings of the National Academy of Sciences of the United States of America, 93, 13468-13472.

Baltes, P. B., \& Lindenberger, U. (1997). Emergence of a powerful connection between sensory and cognitive functions across the adult life span: A new window to the study of cognitive aging? Psychology and Aging, 12, 12-21.

Barber, S. J. (2017). An examination of age-based stereotype threat about cognitive decline: Implications for stereotype-threat research and theory development. Perspectives on Psychological Science, 12, 62-90.

Barber, S. J., \& Mather, M. (2013a). Stereotype threat can both enhance and impair older adults' memory. Psychological Science, 24, 2522-2529.

Barber, S. J., \& Mather, M. (2013b). Stereotype threat can reduce older adults' memory errors. The Quarterly Journal of Experimental Psychology, 66, 1888-1895.

Barber, S. J., Mather, M., \& Gatz, M. (2015). How stereotype threat affects healthy older adults' performance on clinical assessments of cognitive decline: The key role of regulatory fit. The Journals of Gerontology, Series B: Psychological Sciences \& Social Sciences, 70, 891-900.

Ben-David, B. M., Chambers, C. G., Daneman, M., Pichora-Fuller, M. K., Reingold, E. M., \& Schneider, B. A. (2011a). Effects of aging and noise on real-time spoken word recognition: Evidence from eye movements. Journal of Speech, Language, and Hearing Research, 54, 243-262.

Ben-David, B. M., Erel, H., Goy, H., \& Schneider, B. A. (2015). "Older is always better": Agerelated differences in vocabulary scores across 16 years. Psychology and Aging, 30, 856-862.

Ben-David, B. M., Nguyen, L. L., \& van Lieshout, P. H. (2011b). Stroop effects in persons with traumatic brain injury: Selective attention, speed of processing, or color-naming? A metaanalysis. Journal of the International Neuropsychological Society, 17, 354-363.

Ben-David, B. M., \& Schneider, B. A. (2009). A sensory origin for color-word Stroop effects in aging: A meta-analysis. Aging, Neuropsychology, and Cognition, 16, 505-534.

Ben-David, B. M., \& Schneider, B. A. (2010). A sensory origin for color-word Stroop effects in aging: Simulating age-related changes in color-vision mimics age-related changes in Stroop. Aging, Neuropsychology, and Cognition, 17, 730-746.

Ben-David, B. M., Eidels, A., \& Donkin, C. (2014a). Effects of aging and distractors on detection of redundant visual targets and capacity: Do older adults integrate visual targets differently than younger adults? PLoS ONE, 9(12), 1-29. https://doi.org/10.1371/journal.pone.0113551.

Ben-David, B. M., Tewari, A., Shakuf, V., \& Van Lieshout, P. H. (2014b). Stroop effects in alzheimer's disease: Selective attention speed of processing, or color-naming? A meta-analysis. Journal of Alzheimers Disease, 38, 923-938.

Ben-David, B. M., Tse, V. Y., \& Schneider, B. A. (2012). Does it take older adults longer than younger adults to perceptually segregate a speech target from a background masker? Hearing Research, 290, 55-63. 
Ben-David, B. M., van Lieshout, P. H., \& Shakuf, V. (2016). Sensory source for Stroop effects in persons after TBI: Support from fNIRS-based investigation. Brain Imaging and Behavior, 10, $1135-1136$.

Ben-David, B. M., \& Icht, M. (2017). Oral-diadochokinetic rates for Hebrew-speaking healthy aging population: Non-word vs. real-word repetition. International Journal of Language \& Communication Disorders, 52(3), 301-310.

Bertone, A., Bettinelli, L., \& Faubert, J. (2007). The impact of blurred vision on cognitive assessment. Journal of Clinical and Experimental Neuropsychology, 29, 467-476.

Bosson, J. K., Haymovitz, E. L., \& Pinel, E. C. (2004). When saying and doing diverge: The effects of stereotype threat on self-reported versus non-verbal anxiety. Journal of Experimental Social Psychology, 40, 247-255.

Bregman, A. S. (1990). Auditory scene analysis. Cambridge: MIT Press.

Brelet, L., Moták, L., Ginet, M., Huet, N., Izaute, M., \& Gabaude, C. (2016). Enhancing older drivers' safety: On effects induced by stereotype threat to older adults' driving performance, working memory and self regulation. Geriatrics, 1, 20.

Chasteen, A. L., Bhattacharyya, S., Horhota, M., Tam, R., \& Hasher, L. (2005). How feelings of stereotype threat influence older adults' memory performance. Experimental Aging Research, $31,235-260$.

Coudin, G., \& Alexopoulos, T. (2010). 'Help me! I'm old!' How negative aging stereotypes create dependency among older adults. Aging \& Mental Health, 14, 516-523.

Craik, F. I. M., \& Jennings, J. M. (1992). Human memory. In F. I. M. Craik \& T. A. Salthouse (Eds.), Handbook of aging and cognition (pp. 51-110). Hillsdale: Erlbaum.

Craik, E. I. M., \& Salthouse, T. A. (Eds.). (1992). The handbook of aging and cognition. Hillsdale: Erlbaum.

Crews, J. E., \& Campbell, V. A. (2004). Vision impairment and hearing loss among communitydwelling older Americans: Implications for health and functioning. American Journal of Public Health, 94, 823-829.

Dempster, F. N. (1992). The rise and fall of the inhibitory mechanism: Toward a unified theory of cognitive development and aging. Developmental Review, 12, 45-75.

Dickinson, C., \& Rabbitt, P. (1991). Simulated visual impairment: Effects on text comprehension and reading speed. Clinical Vision Sciences, 6, 301-308.

Dupuis, K., Pichora-Fuller, M. K., Chasteen, A. L., Marchuk, V., Singh, G., \& Smith, S. L. (2015). Effects of hearing and vision impairments on the Montreal Cognitive Assessment. Aging, Neuropsychology, and Cognition, 22, 413-437.

Eggleston, K. N., \& Fuchs, V. R. (2012). The new demographic transition: Most gains in life expectancy now realized late in life. The Journal of Economic Perspectives, 26, 137-156.

Erber, J. T., Szuchman, L. T., \& Rothberg, S. T. (1990). Everyday memory failure: Age differences in appraisal and attribution. Psychology and Aging, 5, 236.

Evans, S. C. (2018). Ageism and dementia. In L. Ayalon \& C. Tesch-Römer (Eds.), Contemporary perspectives on ageism: Vol. 19. International perspectives on aging (pp. 263-275). Berlin: Springer.

Feldman, H. H., Jacova, C., Robillard, A., Garcia, A., Chow, T., Borrie, M., .. Chertkow, H. (2008). Diagnosis and treatment of dementia: 2. Diagnosis. CMAJ : Canadian Medical Association Journal = Journal De l'Association Medicale Canadienne, 178, 825-836.

Folstein, M. F., Folstein, S. E., \& McHugh, P. R. (1975). "Mini-mental state": A practical method for grading the cognitive state of patients for the clinician. Journal of Psychiatric Research, 12, 189-198.

Ghisletta, P., \& Lindenberger, U. (2005). Exploring structural dynamics within and between sensory and intellectual functioning in old and very old age: Longitudinal evidence from the berlin aging study. Intelligence, 33, 555-587.

Glasberg, B. R., \& Moore, B. C. (1992). Effects of envelope fluctuations on gap detection. Hearing Research, 64, 81-92. 
Glisky, E. L. (2007). Changes in cognitive function in human aging. In D. R. Riddle (Ed.), Brain and aging: Models, methods, and mechanisms (pp. 3-20). Boca Raton: CRC Press.

Gordon-Salant, S., Frisina, D. R., Popper, A. N., \& Fay, R. R. (2010). The aging auditory system (Vol. 34). New York: Springer.

Greene, H. A., \& Madden, D. J. (1987). Adult age differences in visual acuity, stereopsis, and contrast sensitivity. Optometry \& Vision Science, 64, 749-753.

Grimm, L. R., Markman, A. B., Maddox, W. T., \& Baldwin, G. C. (2009). Stereotype threat reinterpreted as a regulatory mismatch. Journal of Personality and Social Psychology, 96, 288.

Grose, J. H., \& Mamo, S. K. (2010). Processing of temporal fine structure as a function of age. Ear and Hearing, 31, 755-760.

Guthrie, R. V. (1976). Even the rat was white. 2nd Edition (1997). New York: Harper and Row.

Hadar, B., Skrzypek, J. E., Wingfield, A., \& Ben-David, B. M. (2016). Working memory load affects processing time in spoken word recognition: Evidence from eye-movements. Frontiers in Neuroscience, 10, 221.

Hasher, L., \& Zacks, R. T. (1988). Working memory, comprehension, and aging: A review and a new view. Psychology of Learning and Motivation, 22, 193-225.

Haslam, C., Morton, T. A., Haslam, S. A., Varnes, L., Graham, R., \& Gamaz, L. (2012). "When the age is in, the wit is out": Age-related self-categorization and deficit expectations reduce performance on clinical tests used in dementia assessment. Psychology and Aging, 27, 778.

Heinrich, A., \& Schneider, B. A. (2011). Elucidating the effects of ageing on remembering perceptually distorted word pairs. The Quarterly Journal of Experimental Psychology, 64, 186-205.

Heinrich, A., Schneider, B. A., \& Craik, F. I. (2008). Investigating the influence of continuous babble on auditory short-term memory performance. The Quarterly Journal of Experimental Psychology, 61, 735-751.

Hess, T. M., Auman, C., Colcombe, S. J., \& Rahhal, T. A. (2003). The impact of stereotype threat on age differences in memory performance. The Journals of Gerontology Series B: Psychological Sciences and Social Sciences, 58, 3-11.

Hess, T. M., \& Hinson, J. T. (2006). Age-related variation in the influences of aging stereotypes on memory in adulthood. Psychology and Aging, 21, 621.

Hess, T. M., Hinson, J. T., \& Hodges, E. A. (2009). Moderators of and mechanisms underlying stereotype threat effects on older adults' memory performance. Experimental Aging Research, $35,153-177$.

Higgins, E. T. (1997). Beyond pleasure and pain. American Psychologist, 52, 1280-1300.

Higgins, E. T. (1999). Promotion and prevention as a motivational duality: Implications for evaluative processes. In S. Chaiken \& Y. Trope (Eds.), Dual-process theories in social psychology (pp. 503-525). New York: Guilford Press.

Higgins, E. T. (2000). Making a good decision: Value from fit. American Psychologist, 55, $1217-1230$.

Hughes, M. L., Geraci, L., \& De Forrest, R. L. (2013). Aging 5 years in 5 minutes: The effect of taking a memory test on older adults' subjective age. Psychological Science, 24, 2481-2488.

Humes, L. E., \& Dubno, J. R. (2009). Factors affecting speech understanding in older adults. In S. Gordon-Salant, R. D. Frisina, A. N. Popper, \& R. R. Fay (Eds.), The aging auditory system (pp. 211-258). New York: Springer.

Hummert, M. L., Garstka, T. A., Shaner, J. L., \& Strahm, S. (1994). Stereotypes of the elderly held by young, middle-aged, and elderly adults. Journal of Gerontology, 49, P240-P249.

Kang, S. K., \& Chasteen, A. L. (2009). The moderating role of age-group identification and perceived threat on stereotype threat among older adults. The International Journal of Aging and Human Development, 69, 201-220.

Kite, M. E., \& Wagner, L. S. (2002). Attitudes toward older adults. In T. D. Nelson (Ed.), Ageism: Stereotyping and prejudice against older persons (pp. 129-161). Cambridge: MIT Press.

Lamont, R. A., Swift, H. J., \& Abrams, D. (2015). A review and meta-analysis of age-based stereotype threat: Negative stereotypes, not facts, do the damage. Psychology and Aging, 30, 180-193. 
Levy, B. (1996). Improving memory in old age through implicit self-stereotyping. Journal of Personality and Social Psychology, 71, 1092-1107.

Levy, B. R., \& Leifheit-Limson, E. (2009). The stereotype-matching effect: Greater influence on functioning when age stereotypes correspond to outcomes. Psychology and Ageing, 24, 230-233.

Leyens, J. P., Désert, M., Croizet, J. C., \& Darcis, C. (2000). Stereotype threat: Are lower status and history of stigmatization preconditions of stereotype threat? Personality and Social Psychology Bulletin, 26, 1189-1199.

Li, S., Lindenberger, U., \& Sikström, S. (2001). Aging cognition: From neuromodulation to representation. Trends in Cognitive Sciences, 5, 479-486.

Lin, F. R., Yaffe, K., Xia, J., Xue, Q., Harris, T. B., Purchase-Helzner, E.,. .. Simonsick, E. M. (2013). Hearing loss and cognitive decline in older adults. JAMA Internal Medicine, 173, 293-299.

Lindenberger, U., \& Baltes, P. B. (1994). Sensory functioning and intelligence in old age: A strong connection. Psychology and Aging, 9, 339-355.

Lindenberger, U., Marsiske, M., \& Baltes, P. B. (2000). Memorizing while walking: Increase in dual-task costs from young adulthood to old age. Psychology and Aging, 15, 417-436.

Lu, Z., Daneman, M., \& Schneider, B. A. (2016). Does increasing the intelligibility of a competing sound source interfere more with speech comprehension in older adults than it does in younger adults? Attention, Perception, \& Psychophysics, 78, 2655-2677.

Luis, C. A., Keegan, A. P., \& Mullan, M. (2009). Cross validation of the Montreal Cognitive Assessment in community dwelling older adults residing in the southeastern US. International Journal of Geriatric Psychiatry, 24, 197-201.

Mazerolle, M., Régner, I., Barber, S. J., Paccalin, M., Miazola, A. C., Huguet, P., \& Rigalleau, F. (2017). Negative aging stereotypes impair performance on brief cognitive tests used to screen for predementia. The Journals of Gerontology Series B: Psychological Sciences and Social Sciences, 72(6), 932-936. https://doi.org/10.1093/geronb/gbw083.

Mazerolle, M., Régner, I., Morisset, P., Rigalleau, F., \& Huguet, P. (2012). Stereotype threat strengthens automatic recall and undermines controlled processes in older adults. Psychological Science, 23, 723-727.

McDowd, J. M., \& Shaw, R. J. (2000). Attention and aging: A functional perspective. In F. I. M. Craik \& T. A. Salthouse (Eds.), The handbook of aging and cognition (2nd ed., pp. 221292). Mahwah: Erlbaum.

Melara, R. D., \& Algom, D. (2003). Driven by information: A tectonic theory of stroop effects. Psychological Review, 110, 422-471.

Monge, Z. A., \& Madden, D. J. (2016). Linking cognitive and visual perceptual decline in healthy aging: The information degradation hypothesis. Neuroscience \& Biobehavioral Reviews, 69, 166-173.

Morley, J. E. (2004). The top 10 hot topics in aging. The Journals of Gerontology Series A, Biological Sciences and Medical Sciences, 59, 24-33.

Murphy, D. R., Craik, F. I., Li, K. Z., \& Schneider, B. A. (2000). Comparing the effects of aging and background noise of short-term memory performance. Psychology and Aging, 15, 323-334.

Nasreddine, Z. S., Phillips, N. A., Bédirian, V., Charbonneau, S., Whitehead, V., Collin, I.,. .. Chertkow, H. (2005). The Montreal Cognitive Assessment, MoCA: A brief screening tool for mild cognitive impairment. Journal of the American Geriatrics Society, 53, 695-699.

Nguyen-Tri, D., Overbury, O., \& Faubert, J. (2003). The role of lenticular senescence in agerelated color vision changes. Investigative Ophthalmology \& Visual Science, 44, 3698-3704.

Owsley, C. (2011). Aging and vision. Vision Research, 51, 1610-1622.

Peelle, J. E., \& Wingfield, A. (2005). Dissociations in perceptual learning revealed by adult age differences in adaptation to time-compressed speech. Journal of Experimental Psychology: Human Perception and Performance, 31, 1315-1330.

Pennington, C. R., Heim, D., Levy, A. R., \& Larkin, D. T. (2016). Twenty years of stereotype threat research: A review of psychological mediators. PLoS One, 11, e0146487. 
Popham, L. E., \& Hess, T. M. (2015). Age differences in the underlying mechanisms of stereotype threat effects. The Journals of Gerontology Series B: Psychological Sciences and Social Sciences, 70, 225-234.

Régner, I., Mazerolle, M., Alescio-Lautier, B., Clarys, D., Michel, B., Paccalin, M., Piolino, P., Rigalleau, F., Sambuchi, N., \& Huguet, P. (2016). Aging stereotypes must be taken into account for the diagnosis of prodromal and early Alzheimer disease. Alzheimer Disease \& Associated Disorders, 30, 77-79.

Roberts, K. L., \& Allen, H. A. (2016). Perception and cognition in the ageing brain: A brief review of the short-and long-term links between perceptual and cognitive decline. Frontiers in Aging Neuroscience, 8, 39.

Sackett, P. R., Hardison, C. M., \& Cullen, M. J. (2004). On interpreting stereotype threat as accounting for African American-white differences on cognitive tests. American Psychologist, $59,7-13$.

Sawilowsky, S. S. (2009). New effect size rules of thumb. Journal of Modern Applied Statistical Methods, 8, 597-599.

Scheibe, S., \& Blanchard-Fields, F. (2009). Effects of regulating emotions on cognitive performance: What is costly for young adults is not so costly for older adults. Psychology and Aging, $24,217$.

Schmader, T., Johns, M., \& Forbes, C. (2008). An integrated process model of stereotype threat effects on performance. Psychological Review, 115, 336-356.

Schneider, B. A., Daneman, M., \& Murphy, D. R. (2005). Speech comprehension difficulties in older adults: Cognitive slowing or age-related changes in hearing? Psychology and Aging, 20, 261-271.

Schneider, B. A., Daneman, M., Murphy, D. R., \& Kwang-See, S. (2000). Listening to discourse in distracting settings: The effects of aging. Psychology and Aging, 15, 110-125.

Schneider, B. A., Daneman, M., \& Pichora-Fuller, M. K. (2002). Listening in aging adults: From discourse comprehension to psychoacoustics. Canadian Journal of Experimental Psychology/ Revue Canadienne De Psychologie Expérimentale, 56, 139-152.

Schneider, B. A., \& Pichora-Fuller, M. K. (2000). Implications of perceptual deterioration for cognitive aging research. In F. I. M. Craik \& T. A. Salthouse (Eds.), Handbook of cognitive aging II (pp. 155-219). Mahwah: Erlabum.

Schneider, B., Pichora-Fuller, M. K., \& Daneman, M. (2010). Effects of senescent changes in audition and cognition on spoken language comprehension. In S. Gordon-Salant, D. R. Frisina, A. N. Popper, \& R. R. Fay (Eds.), Springer handbook of auditory research: The aging auditory system (Vol. 34). New York: Springer.

Schneider, E. L. (1999). Aging in the third millennium. Science, 283, 796-797.

Scialfa, C. T. (2002). The role of sensory factors in cognitive aging research. Canadian Journal of Experimental Psychology/Revue Canadienne De Psychologie Expérimentale, 56, 153-163.

Seibt, B., \& Förster, J. (2004). Stereotype threat and performance: How self-stereotypes influence processing by inducing regulatory foci. Journal of Personality and Social Psychology, 87, 38.

Scholl, J. M., \& Sabat, S. R. (2008). Stereotypes, stereotype threat and ageing: Implications for the understanding and treatment of people with Alzheimer's disease. Ageing and Society, 28, 103-130.

Sindi, S., Fiocco, A. J., Juster, R. P., Pruessner, J., \& Lupien, S. J. (2013). When we test, do we stress? Impact of the testing environment on cortisol secretion and memory performance in older adults. Psychoneuroendocrinology, 38, 1388-1396.

Spear, P. D. (1993). Neural bases of visual deficits during aging. Vision Research, 33, 2589-2609.

Spencer, B., \& Castano, E. (2007). Social class is dead. Long live social class! Stereotype threat among low socioeconomic status individuals. Social Justice Research, 20, 418-432.

Spencer, S. J., Logel, C., \& Davies, P. G. (2016). Stereotype threat. Annual Review of Psychology, $67,415-437$.

Spencer, S. J., Steele, C. M., \& Quinn, D. M. (1999). Stereotype threat and women's math performance. Journal of Experimental Social Psychology, 35, 4-28. 
Steele, C. M., \& Aronson, J. (1995). Stereotype threat and the intellectual test performance of African Americans. Journal of Personality and Social Psychology, 69, 797.

Stevens, J. C., Cruz, L. A., Marks, L. E., \& Lakatos, S. (1998). A multimodal assessment of sensory thresholds in aging. The Journals of Gerontology Series B: Psychological Sciences and Social Sciences, 53, 263-272.

Stroop, J. R. (1935). Studies of interference in serial verbal reactions. Journal of Experimental Psychology, 18, 643-662.

Swift, H. J., Abrams, D., \& Marques, S. (2013). Threat or boost? Social comparison affects older people's performance differently depending on task domain. The Journals of Gerontology Series B: Psychological Sciences and Social Sciences, 68, 23-30.

Toner, C. K., Reese, B. E., Neargarder, S., Riedel, T. M., Gilmore, G. C., \& Cronin-Golomb, A. (2012). Vision-fair neuropsychological assessment in normal aging, Parkinson's disease and Alzheimer's disease. Psychology and Aging, 27, 785-790.

Troyer, A. K., Leach, L., \& Strauss, E. (2006). Aging and response inhibition: Normative data for the victoria stroop test. Aging, Neuropsychology, and Cognition, 13, 20-35.

Tun, P. A., \& Wingfield, A. (1999). One voice too many: Adult age differences in language processing with different types of distracting sounds. The Journals of Gerontology Series B: Psychological Sciences and Social Sciences, 54, 317-327.

Verhaegen, C., Collette, F., \& Majerus, S. (2014). The impact of aging and hearing status on verbal short-term memory. Aging, Neuropsychology, and Cognition, 21, 464-482.

Wayne, R. V., \& Johnsrude, I. S. (2015). A review of causal mechanisms underlying the link between age-related hearing loss and cognitive decline. Ageing Research Reviews, 23, 154-166.

Weinstein, B., \& Amsel, L. (1986). The relationship between dementia and hearing impairment in the institutionalized elderly. Clinical Gerontologist, 4, 3-15.

West, R. L. (1996). An application of prefrontal cortex function theory to cognitive aging. Psychological Bulletin, 120, 272-292.

Wingfield, A., \& Tun, P. A. (2007). Cognitive supports and cognitive constraints on comprehension of spoken language. Journal of the American Academy of Audiology, 18, 548-558.

Wong, J. T., \& Gallo, D. A. (2016). Stereotype threat reduces false recognition when older adults are forewarned. Memory, 24, 650-658.

Zacks, R. T., Hasher, L., \& Li, K. Z. H. (2000). Human memory. In F. I. M. Craik \& T. A. Salthouse (Eds.), Handbook of aging and cognition (2nd ed., pp. 293-357). Mahwah: Erlbaum.

Open Access This chapter is licensed under the terms of the Creative Commons Attribution 4.0 International License (http://creativecommons.org/licenses/by/4.0/), which permits use, sharing, adaptation, distribution and reproduction in any medium or format, as long as you give appropriate credit to the original author(s) and the source, provide a link to the Creative Commons license and indicate if changes were made.

The images or other third party material in this chapter are included in the chapter's Creative Commons license, unless indicated otherwise in a credit line to the material. If material is not included in the chapter's Creative Commons license and your intended use is not permitted by statutory regulation or exceeds the permitted use, you will need to obtain permission directly from the copyright holder. 


\title{
Chapter 18 \\ Introduction to the Section: Against Ageism
}

\author{
Liat Ayalon and Clemens Tesch-Römer
}

So far, the chapters in this book have provided convincing evidence that ageism is bad for you." It is bad for the individual, as it potentially affects wellbeing, quality of life, social life, sexuality, and the type and quality of health and mental health services one receives. It is also bad for society at large, as it creates divisions between generations and potentially establishes power imbalances that can prevent older adults from realising their full potential (see Chapters 1-17 in this volume). It is not surprising, then, that in 2016, the World Health Organization received a mandate to combat ageism (Officer et al. 2016).

The present section contains five chapters on interventions against ageism. The first four chapters are focused on policy and legal interventions to target ageism, whereas the latter chapter is a case example of an educational intervention to fight ageism.

The chapter by Doron, Numhauser-Henning, Spanier, Georgantzi, and Mantovani (2018; Chap. 19) presents a legal framework for European law to fight ageism. The chapter starts by describing the slow progression of the field of elder law. The fact that elder law is a relatively new phenomenon presents an obstacle to protecting older adults' rights and fighting ageism. Old age is not mentioned as a potential basis for discrimination in the Universal Declaration of Human Rights, adopted by the United Nations General Assembly in 1948, nor in any other UN declaration since then. This hampers the ability of legal authorities to address issues associated with old age discrimination and the violation of older people's rights.

The chapter by Mikołajczyk (2018; Chap. 20) provides a specific overview of the Council of Europe's approach towards ageism. The author concludes that addressing the rights of older people through the Council of Europe is a relatively new and still under-developed phenomenon. Ageism is hardly ever recognized in

\footnotetext{
L. Ayalon $(\bowtie)$

Louis and Gabi Weisfeld School of Social Work, Bar Ilan University,

Ramat Gan 52900, Israel

e-mail: liat.ayalon@biu.ac.il

C. Tesch-Römer $(\varangle)$

German Centre of Gerontology, Berlin, Germany

(C) The Author(s) 2018

L. Ayalon, C. Tesch-Römer (eds.), Contemporary Perspectives on Ageism, International Perspectives on Aging 19, https://doi.org/10.1007/978-3-319-73820-8_18
} 
official documents of the Council of Europe. Like Doron et al. (2018), Mikołajczyk (2018) argues that the Council of Europe is just beginning its fight against ageism.

The chapter by Georgantzi (2018; Chap. 21) provides a complementary but less favourable view of ageism and law in Europe by focusing on the European Union's approach towards ageism. The author argues that although the EU advocates for a society for all ages, which is free of discrimination, age categorization remains a justifiable and acceptable form of inequality. Georgantzi implies that the EU is concerned with population ageing, but equates it with dependency, frailty, and burden, rather than focusing on the protection of the rights of older adults and ensuring their equal participation in society.

In contrast to chapters 19-21, which address the macro-level in Europe and point to the current inadequacy of the system, the chapter by Larsson and Jönsson (2018; Chap. 22) provides a more local outlook on the fight against ageism by drawing on Sweden as a case example. The authors propose that the equal rights framework in Sweden ensures that young people with disability are able to fully participate in society. Older people with disability, however, suffer from institutional ageism, which prevents them from obtaining similar rights. The authors argue that older adults in the third age, who represent the active ageing model, should serve as a typical group, against which older adults with disability could be compared in order to improve the long-term care provided to them.

The concluding chapter in this section, by Requena, Swift, Naegele, Zwamborn, Metz, Bosems, and Hoof (2018; Chap. 23), takes a completely different look at interventions to target ageism. Drawing from intergroup contact theory, the authors demonstrate the effectiveness of an educational intervention that brings young and old people together as members of the same community. The authors outline an intervention which addresses communication style between the generations as a way to potentially reduce ageism.

Overall, these five chapters demonstrate that we are only at the beginning of the journey to combat ageism. Whereas the negative consequences and manifestations of ageism are well-documented, much less is known about fighting ageism. Literature on psychological interventions, such as campaigns to raise awareness about ageism (Mendonça et al. 2016), or educational interventions to improve knowledge and attitudes about ageism, such as ("Combating Ageism: Change in Student Knowledge and Attitudes Regarding Aging," Cottle and Glover 2007) would be helpful complements to the chapters presented here.

The diversity of theoretical explanations used to account for ageism suggests that there are multiple pathways to combat ageism. For instance, terror management theory (Martens et al. 2005) might suggest that disassociating old age from death and disability could be a useful way to combat ageism. Alternatively, de-sensitizing people to death and disability could also be an effective tool in the fight against ageism. Because older adults can be seen as a symbolic or realistic threat to younger generations (North and Fiske 2012), emphasizing older adults' contribution to society could be another means to combat ageism.

It is important to note that there is still a need to fine-tune the messages delivered to potentially reduce ageism. Do we want to foster feelings of empathy and pity or would a message of admiration of older adults be more beneficial? Should we target knowledge about older adults or attitudes towards older adults? Should we focus on 
hard laws enforced by legal and political authorities, or should we strive for a bottom-up change in the way we view and behave towards older adults? To date, these questions have not been comprehensively addressed, but the chapters in this section introduce some compelling and fresh perspectives.

\section{References}

Cottle, N. R., \& Glover, R. J. (2007). Combating ageism: Change in student knowledge and attitudes regarding aging. Educational Gerontology, 33(6), 501-512. https://doi. org/10.1080/03601270701328318

Doron, I., Numhauser-Henning, A., Spanier, B., Georgantzi, N., \& Mantovani, E. (2018). Ageism and anti-ageism in the legal system: A review of key themes. In L. Ayalon \& C. Tesch-Römer (Eds.), Contemporary perspectives on ageism: Vol. 19. International perspectives on aging (pp. 303-320). Berlin: Springer.

Georgantzi, N. (2018). The European union's approach towards ageism. In L. Ayalon \& C. TeschRömer (Eds.), Contemporary perspectives on ageism: Vol. 19. International perspectives on aging (pp. 341-368). Berlin: Springer.

Larsson, A. T., \& Jönson, H. (2018). Ageism and the rights of older people. In L. Ayalon \& C. Tesch-Römer (Eds.), Contemporary perspectives on ageism: Vol. 19. International perspectives on aging (pp. 369-382). Berlin: Springer.

Martens, A., Goldenberg, J. L., \& Greenberg, J. (2005). A terror management perspective on ageism. Journal of Social Issues, 61(2), 223-239.

Mendonça, J., Mariano, J., \& Marques, S. (2016). Lisbon street campaign against ageism: A promising multi-stakeholder initiative. Journal of Intergenerational Relationships, 14(3), 258-265.

Mikołajczyk, B. (2018). The council of europe's approach towards ageism. In L. Ayalon \& C. Tesch-Römer (Eds.), Contemporary perspectives on ageism: Vol. 19. International perspectives on aging (pp. 321-339). Berlin: Springer.

North, M. S., \& Fiske, S. T. (2012). An inconvenienced youth? Ageism and its potential intergenerational roots. Psychological Bulletin, 138(5), 982.

Officer, A., Schneiders, M. L., Wu, D., Nash, P., Thiyagarajana, J. A., \& Bearda, J. R. (2016). Valuing older people: Time for a global campaign to combat ageism. Bulletin of the World Health Organization, 94(10), 710.

Requena, M. J., Swift, H., Naegele, L., Zwamborn, M., Metz, S., Bosems, W. P. H., \& Hoof, J. (2018). Educational methods using intergenerational interaction to fight ageism. In L. Ayalon \& C. Tesch-Römer (Eds.), Contemporary perspectives on ageism: Vol. 19. International perspectives on aging (pp. 383-402). Berlin: Springer.

Open Access This chapter is licensed under the terms of the Creative Commons Attribution 4.0 International License (http://creativecommons.org/licenses/by/4.0/), which permits use, sharing, adaptation, distribution and reproduction in any medium or format, as long as you give appropriate credit to the original author(s) and the source, provide a link to the Creative Commons license and indicate if changes were made.

The images or other third party material in this chapter are included in the chapter's Creative Commons license, unless indicated otherwise in a credit line to the material. If material is not included in the chapter's Creative Commons license and your intended use is not permitted by statutory regulation or exceeds the permitted use, you will need to obtain permission directly from the copyright holder.

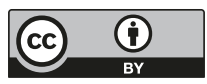




\title{
Chapter 19 \\ Ageism and Anti-Ageism in the Legal System: A Review of Key Themes
}

\author{
Israel (Issi) Doron, Ann Numhauser-Henning, Benny Spanier, \\ Nena Georgantzi, and Eugenio Mantovani
}

\subsection{Introduction}

This chapter provides an overview of legal frameworks relevant for addressing the social phenomenon of ageism in Europe. In writing this chapter, we have been interested in how sources ascribable to law and ageing in Europe can grasp ageism, "a process of systematic stereotyping and discrimination against people because they are old" (Butler 1975).

This chapter is one of three others included in this book that are differently related to legal institutions and legal frameworks which are relevant to ageism in Europe. The reason for including three different chapters stems from the need to accommodate the diverse legal regimes and constructions that are available under different European jurisdictions.

This chapter provides a general overview of the inter-relationships between law, ageing and ageism including the presentation of some illustrative examples. It places the overview in the European historical context and discusses specific the-

\section{Doron $(\varangle)$}

The Center for Research and Study of Aging, Department of Gerontology, University of Haifa, Haifa, Israel

e-mail: idoron@univ.haifa.ac.il

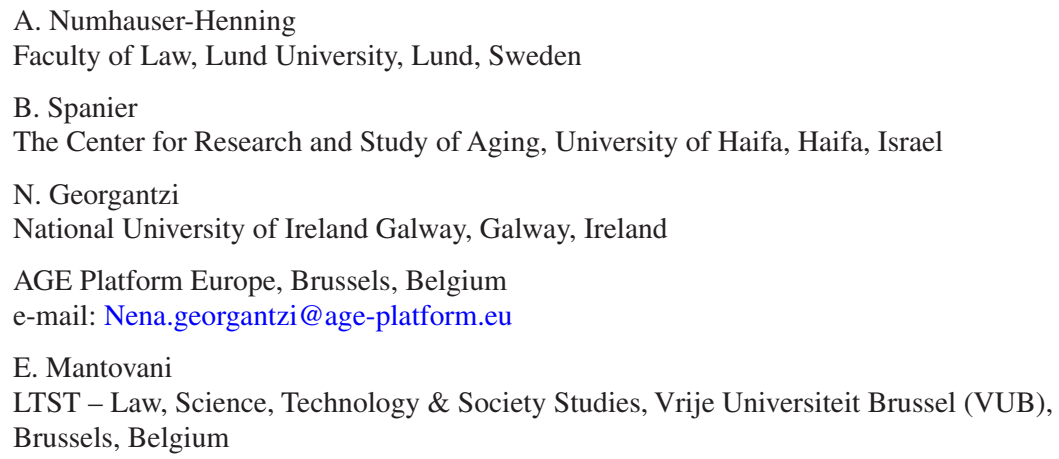


matic cases, such as compulsory retirement and empirical studies regarding the European Court of Human Rights and the Court of Justice of the European Union.

The second chapter (2018; Chap. 20) moves from the general to the specific, focusing on a central European institution, the Council of Europe. Founded in 1949, this regional organization promotes human rights in Europe. This chapter discusses law and ageism through the lens of the Council of Europe's instruments and bodies: the European Social Charter, the jurisprudence of the European Court of Human Rights, and the Council of Europe non-binding "soft-law" means.

The third chapter (2018; Chap. 21) focuses on the European Union. The European Union operates on a legal basis, the EU Treaty of the functioning of the European Union (TFEU), and structures that are autonomous and different from that of the Council of Europe. This chapter broaches ageism under the light of the EU Charter of Fundamental Rights, of the European Union's directives and policies on ageing, and of the case law of Court of Justice of the European Union.

By combining general and more specific legal perspectives, this triad of contributions provides, it is hoped, a resourceful and comprehensive source to understand how ageism and law interact within the European context.

The present chapter is structured as follows: Part One, describes the development of the field of "law and ageing" in Europe from a historic perspective. It detects in the equality provisions, as rooted in international and European human rights law, the main place for the (potential) emancipation of older persons from stereotypes and prejudices. Part Two provides a general overview of ageism and international human rights law. It describes the current tensions surrounding the debates around the need for a new specific international convention for the rights of older persons. Part Three provides specific "case-studies" of the inter-relations between law and ageism: one - focuses on EU law and compulsory retirement; two - focuses on a quantitative analysis of case-law from the European Court of Human Rights (ECoHR) and the Court of Justice of the European Union (CJEU); and three - draws the attention to existing studies regarding the relationships between law and ageism on the micro level, and in specific how law and ageism is perceived by lawyers and older clients.

\subsection{Part One - Law and Ageing: A Short History}

Before the early 1970s, the area of legal inquiry that is today referred to as "elder law" or "law and ageing" was virtually unknown in the field of law (Levine 1982; Bogutz 2008). Equally, the study of the relationships and interconnections between law, older persons and/or the ageing process was latent in the debates of social gerontologists (Doron 2009). This state of affairs changed dramatically with the emergence, almost 50 years ago, in the United States, of "law and ageing" as an autonomous field of legal scholarship and practice. The emergence of law and ageing as a field of legal studies and practice in the United States in the early 1970s can be ascribed to three factors: first, the demographic ageing of American population 
and the social changes that this wrought on all fields of life, demanding a social response; second, the awareness on the part of private bar and private lawyers that their clients were growingly older. This has pushed lawyers from different branches of law to "specialise" in the field of elder law. Third, and finally, the academia and the research community at large realised the opportunity and need to explore this new field of law. As an outcome of the combination of these three factors, the field of "elder law" has become recognised as a unique field and expertise in law, in the United States in particular, with its specific law journals, professional bodies, as well as new programs and classes have been established within law schools.

Unlike the United States, continental Europe has been much slower in developing and recognising elder law as a specific field of knowledge within the legal profession and academic circles (Evrard and Lacour 2012). One could argue - only in passing, as there is no place to hold this discussion here (Doron 2009) - that this is due to a combination of the history of the notion of citizenship in Europe, with the continental-law tradition of universalism which makes it difficult to justify the "separation" of the rights of older persons from the general law on human rights. However, from the beginning of the 1990s, a growing body of research has emerged on the rights of older persons (Doron 2009; Soden and Doron 2012). Today, the Norma Elder Law Research Environment, developed with the Norma Research Programme at Lund University, Sweden, is arguably the most well-established example of a legal laboratory in Europe that concentrates on the legal status and position of older persons within legal systems and in society (Norma Research Programme 1996).

Social gerontology was also slow in recognizing the importance of the interconnections between law and ageing. In short, social gerontologists became interested in elder law when they recongised that the law, for instance, on access to training, to health, is also part of our culture and understanding of social ageing experiences (Levine 1982). Since then, a growing body of inter-disciplinary projects has sought to bring together lawyers and social-gerontologists. These efforts have led to new approaches and outcomes, such as what is called "jurisprudential gerontology" or "geriatric jurisprudence" (Doron 2006). These outcomes, while reflecting a very much "work in progress" situation, testifies to the increasing consensus among scholars that, on the one hand, the law cannot ignore the ageing of human society and that, on the other hand, social gerontology, cannot ignore the legal impact and inter-connections associated with being old. This means that, when exploring and trying to better understand social phenomena such as ageism one should also look at and into the ways law incorporates, supports, or attempts to oppose it.

\subsection{Part Two Ageism and International Human Rights}

A key theme at the intersection of law, ageing, and ageism in Europe concerns the human rights status of older persons. The aim of this descriptive analysis is to gain a better understanding of how human rights law seizes ageism. A starting point for 
discussing ageism from a positive, international human rights law perspective is arguably the Universal Declaration of Human Rights (UDHR), adopted by the United Nations (UN) General Assembly in 1948. The Universal Declaration of Human Rights recognises that all humans are born free and equal in dignity and rights (art. 1). "Everyone", continues article 2, is entitled to all the rights and freedoms set forth in it, "without distinction of any kind, such as race, colour, sex, language, religion, political or other opinion, national or social origin, property, birth or other status." While arguably, being "old" can certainly be covered under "other status" - it is interesting to note that "age" does not specifically appear in this article.

Moreover, ageism can act as a barrier to the enjoyment of the inherent entitlement of all human beings to human rights, such as the right to adequate standard of living, to health, to access justice, to live free from violence and abuse (OHCHR 2012). The stereotyping and discriminating against individuals or groups on the basis of their age (Butler 1975) may be "under the skin" of social norms and prejudices, but lead to very concrete and overt age discrimination (Chung 2010, p.4; Herring 2009, p.12). Employers, for instance, who struggle with their own sense of ageing, may more easily make discriminatory choices in hiring older persons.

In the international human rights system, there is no general legal instrument to dispel prejudices against older people. However, starting from the 1990s and with increasing momentum in the last decade, human rights law actors have begun to study how human rights can combat ageism. In 1996, General Comment (n. 6) of the Committee supervising, the Covenant on Economic Social and Cultural rights (IESCR) had clarified that the list of forbidden grounds of discrimination contained in the core human rights treaties must be interpreted as including age (CESCR 1996); 13 years later, in 2009, the same committee recognised age as a "prohibited ground of discrimination in several contexts", e.g., against unemployed older persons in finding work, in access to training and retraining, and on discrimination in access to universal old age pension due to place of residence" (our italics, CESCR 2009). In 1989, a different UN body, the UN Human Rights Committee, the body that monitors and receives complaints under the 1966 International Covenant on Civil and Political Rights (ICCPR), clarified in General comment No. 18 that the non-discrimination clause extends to any pieces of legislation adopted by a State party. While not mentioning age, the comment indicates that states adopting laws providing, directly or indirectly, for distinctions on the basis of age can also come under scrutiny of nondiscrimination. Under other UN Conventions, the Committee supervising the convention on the Elimination of all forms of Discrimination against Women (CEDAW) recognized ageism as a human rights issue in its general recommendation no. 27 when it reminded that States 'have an obligation to eliminate negative stereotyping and modify social and cultural patterns of conduct that are prejudicial and harmful to older women' (CEDAW 2010, para 36). One year later, in 2011, the UN warned against the "ingrained stigma and discrimination- the ageism- which many older people are subjected to" in access to primary care and health prevention (Grover 2011; UN Human Rights Council 2011). The UN Independent Expert on the Enjoyment of All Human Rights by Older Persons was appointed in 2014. In her 2015 report, she pointed out how "Ageist attitudes still persist throughout the world, 
leading to discriminatory practices towards older persons, including in care settings. Age-based discrimination generates a lack of self-esteem and disempowerment, and undermines an older person's perception of autonomy" (Kornfeld-Matte 2015).

Arguments like these have been put forth, more recently, to advocate for a more affirmative specification of a human rights law (Mégret 2011; Doron and Apter 2010; De Hert and Mantovani 2011; Seanad Public Consultation Committee 2012). The failure of the existing mechanisms to adequately address ageism at the different levels and spheres of social life is one of the arguments of the proponents for a new Convention, which include primarily Latin American and Caribbean States (ECLAC 2007), more recently joined by African and Asian countries. In this debate European States have remained skeptical (Helpage International 2013).

\subsection{Part Three: The Real Context of Law and Ageism - Three Examples}

After providing a broad overview of elder law in general, and the international context of human rights law and its relevance to older persons, this part offers three specific examples which are representative of the diverse and complex ways in which law and ageism interact.

\subsubsection{Example 1: Ageism, Non-discrimination and Employment Law in the EU}

This section will present a more specific legal framework regarding age discrimination under the European Union law. From the legal science point of view there is a special and close connection between ageism and non-discrimination regulation. The reason for choosing the example of "discrimination" - or discriminatory behavior - is that it is an integral part of most definitions of ageism (Iversen et al. 2009). Moreover, non-discrimination regulations are important tools to come to terms with ageism.

In general, equal treatment and non-discrimination regulation play a central role in today's legislation. As noted earlier, there is yet no international convention proper on older persons' rights in general or against discrimination on the grounds of (old) age more specifically. However, the right not to be discriminated against on the grounds of age has been increasingly constitutionalized in the last decades (O'Cinneide 2015). O'Cinneide delineates how national apex courts, despite the uncertain status of age discrimination as such in constitutional and international human rights law, to a certain extent have been willing to review the degree to which age-based distinctions stand up to constitutional requirements regarding equal treatment and non-discrimination. Already in 1967, age joined sex and race as a ground 
for discrimination in the United States, and age as a prohibited ground has subsequently appeared in the constitutions of countries such as Canada, South Africa and Finland. In the EU, the Amsterdam Treaty of 1997 (now Article 19 of the Treaty on the Functioning of the European Union -TFEU) provided new competences for EU institutions to take measures against discrimination inter alia on the grounds of age. In its Article 2,1 the EU Charter of Fundamental Rights (which after the Lisbon Treaty became part of the primary EU law) contains a ban on discrimination concerning, among other grounds, age (Meenan 2007). To date, EU law prohibits discrimination on the ground of age only in the field of employment. Things may change as the Council of the EU, leveraging on article 21 of the Charter of Fundamental Rights and article 19 of the Treaty on the Functioning of the European Union, may adopt a directive on 'horizontal' age discrimination that will expand the age discrimination clause to new areas (European Commission proposal European Commission Proposal for a Council Directive 2008).

\subsubsection{Age Discrimination in Employment Under EU Law}

In the EU, after the Amsterdam Treaty of 1997, the Council adopted Directive 2000/78/EC, the Employment Equality Directive, a regulation which provoked interest in the topic of age discrimination in employment among European scholars (Fredman and Spencer 2003; Meenan 2007; Sargeant 2008; Schlachter 2010; Hendrickx 2013; Numhauser-Henning and Rönnmar 2015). The Directive includes a non-discrimination clause on the ground of age among other grounds but also admits - in its article 6 - the possibility to justify direct age discrimination. In contrast to the US, where the Age Discrimination in Employment Act (ADEA) of 1967 is purposefully targeting older workers, the Directive 2000/78/EC is not specific to old age, but it instead covers discrimination against all ages (Tobler 2015).

However, as the Directive targets the labour market, it is relevant for persons who are approaching their post-employment years or who are being just above 50 years of age and older (Julén Votinius 2016). As anticipated, a key provision is article 6, which provides that differences of treatment on the ground of age "shall not constitute discrimination, if, within the context of national law, they are objectively and reasonably justified by a legitimate aim, including legitimate employment policy, labour market, and vocational training objectives, and if the means of achieving that aim are appropriate and necessary.' In essence, the directive proscribes direct age discrimination which is not justified by a legitimate aim (article 6.1. provides a non-exhaustive list of examples) and which is attained by means that are disproportionate to the aim.

Being open to justification, one important theme in the literature is whether age discrimination in itself is more acceptable than other forms of discrimination. Agebased distinctions are not linked to historically embedded patterns of group subordination and thus, do not have a negative impact upon human dignity to the same degree as do distinctions based on archetypical non-discrimination grounds such as gender and race (O'Cinneide 2015, p 14). Dagmar Schiek, apart from the 'common 
rationale' of discrimination law related to 'ascribed otherness,' also distinguishes policy aims related to both the sustainability of future pension claims and the ban's dysfunctional nature in relation to hitherto established labour law (Schiek 2015). These rationales have also been discussed in terms of a 'double bind' associated with the age discrimination ban (Hendrickx 2013; Numhauser-Henning 2015; Schiek 2011). They include on the one hand, the 'collective' interest approach in terms of social and economic policy planning (such as compulsory retirement but also active ageing strategies); and on the other hand, the 'individual' interest approach such as the pursuit of freedom of choice and dignity at the individual level.

Macnicol draws attention to the application of Art. 6.1 as an accepted expression of statistical discrimination. On the one hand, writes Macnicol (Macnicol 2006, p.11), age as a proxy 'lumps together a wide range of abilities.' This, he suggests, is manifestly unfair, given the great heterogeneity that exists amongst older persons. On the other hand, 'age proxies can also be seen as cheap, convenient and quick methods of decision-making, based upon judgements about working capacity which are fundamentally correct in the aggregate, even if their use may involve individual cases of injustice' (Macnicol 2006, p.11).

This weaker format of the EU ban on age discrimination is an important reason why age discrimination has been the subject of so many Court of Justice of the European Union decisions. The balance to be struck between the individual approach and the collective approach is achieved precisely in the case law of the Court of Justice of the European Union and here is where the compatibility of age-based distinctions in national law has been brought to test. In the case Mangold (CJEU, C-144/04), the Court of Justice of the European Union ruled that 'the principle of non-discrimination on the grounds of age must be regarded as a general principle of Community law' (paragraph 75). The conceptualization of equality on the ground of age as a general principle of EU law has been qualified in subsequent decisions, such as Kücükdeveci (CJEU, C-555/07) and Prigge (CJEU, C-447/09).

Overall, it is possible to say that the Court has remained stable on the position taken in Mangold, acknowledging the existence of a general principle of nondiscrimination on grounds of age in European Union law. As for the content of the substance of the discrimination test, however, O'Cinneide's comment is that the court has been prone to apply 'a light rationality' test accepting justifications such as policy promoting intergenerational employment, whenever 'they can be shown to be rationally linked to the achievements of a legitimate aim' (O'Cinneide 2015, p 59). Similarly, Meenan concludes her analysis of the case law of the Court of Justice of the European Union on age discrimination suggesting that, in practice, age discrimination in itself has proven a more acceptable ground than other forms of discrimination (Meenan 2007). For others, the court has applied a lenient proportionality test in relation to issues such as compulsory retirement, and a somewhat stricter test in cases involving pension reforms and pension-related benefits (Schlachter 2011; Kilpatrick 2011). Fudge, who distinguishes three different sets of proportionality tests, argues that the strictest test applies to occupational requirements (Fudge 2016). 
A ban on age discrimination is thus per se an example of 'anti-ageist' legislation. What makes the EU ban double-edged is the scope for justification of direct discrimination. The 'anti-ageist' effect of the ban relies on the interpretation of this scope according to Article 6.1 in the Employment Equality Directive. At the domestic level, ageism in other fields (e.g. finances) has not been put to the test in case law to any greater extent, despite empirical studies revealing its existence (Meenan 2007, p 282). However, non-discrimination regulation is typically 'elitist' in character - meritocracy is generally speaking the hidden norm - and truly anti-ageist practices can be said to often require a working life adapted to older workers' special needs, such as flexible work arrangements and so on (Ilmarinen 2001; NumhauserHenning 2013). In contrast with disability discrimination, accommodation is not an integrated requirement concerning age discrimination. If and when positive action elements exist, these are often related to age as a traditional stratifier in labour law and standard employment contract perceptions - be it seniority rules in redundancy situations or seniority wage-setting (Foubert et al. 2013; Numhauser-Henning 2015). Age-related active measures are known to exist, however, by means of both legislation and collective bargaining (ter Haar and Rönnmar 2014; Rönnmar 2015).

\subsubsection{The Case of Compulsory Retirement}

One could ask how is it possible that what appears to be age discrimination in employment may be legitimate and proportional decision-making in matters of personnel management. An important example of the double bind conundrum is compulsory retirement.

Pension system sustainability is one of the great challenges in relation to an ageing population for EU Member States. Public standard pension schemes were mainly developed during the twentieth century as a response to standard employment and traditional labour law (Freedland 2013; Strauss 2013). In the case law of the European Union Court of Justice, e.g., Palacios de la Villa (CJEU, C-411/05), Age Concern England (CJEU, C-388/07), Rosenbladt (CJEU, C-45/09), and Hörnfeldt (CJEU, C-141/11), the question that arises is whether acceptance of continued compulsory retirement is justified under article 6.1 of the Employment Equality Directive or whether the age discrimination ban instead should be uphold. In the case Hörnfeldt, the Swedish government argued for yes, 'the 67-year rule [for compulsory retirement]', says Sweden 'seeks, firstly, to avoid termination of employment contracts in situations which are humiliating for workers by reason of their advanced age'. And added that 'the age-limit reflects the political and social consensus which has long prevailed between the social partners' (Hörnfeldt, paragraphs 26 and 27). The court limited itself to observe that 'automatic termination of the employment contracts of employees [...] has, for a long time, been a feature of employment law in many Member States and is widely used in employment relationships. It is a mechanism which is based on the balance to be struck between political, economic, social, demographic and/or budgetary considerations and the choice to be made between prolonging people's working lives or, conversely, providing for 
early retirement' (Hörnfeldt, paragraph 28 - citingthe Rosenbladt case [CJEU, C-45/09], paragraph 44) where it was first formulated).]

As indicated above, a good number of scholarly articles have concentrated on the proportionality test (i.e. a key legal principle which limits the Court's intervention) applied and its strictness in comparison with other cases. Another set of articles has concentrated on understanding the why (e.g. the reasons and rationale) of this continued practice of compulsory retirement (Schiek 2011; Suk 2012; NumhauserHenning 2015). The Court of Justice of the EU has accepted the following as legitimate aims: intergenerational fairness in terms of access to employment, prevention of humiliating forms of employment termination, and a reasonable balance between labour-market and budgetary concerns. The existence of a right to a pension has also played a significant role in the continued acceptance of compulsory retirement, though rather at a system level than in the individual case (CJEU, C-411/05 and C-141/11). The Court of Justice of the EU's acceptance on grounds of intergenerational fairness contrasts with economic research (of both a theoretical and empirical nature), which emphasizes the 'lump of labour fallacy,' and opposes propositions that compulsory (or premature) retirement schemes will help to combat youth unemployment or that older workers crowd younger workers out of the labour market (Dewhurst 2013). Behind the humiliation argument lies the fact that in upholding the ban against age discrimination, dismissal cases would be all about ability - or rather lack thereof. An extrapolation of this line of arguments is the risk of weakening European-style employment protection altogether - and, moreover, furthering flexible employment (Numhauser-Henning 2013, 2015). This line of argument can be said to be confirmed by the UK's experience after abolishing compulsory retirement as the general rule (Manfredi and Vickers 2016). In the UK, the continued opening for an 'Employer-justified Retirement Age' is an issue of concern - not least in a university context (Barnard and Deakin 2015; Dewhurst 2016). In an overall perspective - and despite the Court of Justice of the EU's acceptance hitherto - the practice of compulsory retirement is no doubt losing ground in the EU Member States.

\subsubsection{Example 2: Law, Ageism, and Courts}

Courts, and case-law, play an important role in the development of jurisprudence in the field of ageism and elder law. However, and despite the growing interest and awareness to ageing and ageism within the European legal system and within international human rights bodies, not much empirical research has been conducted in this field. While specific cases - as presented in the previous sections- serve as precedents of legal policy, questions still remain regarding the broader legal work done by courts when it comes to ageism or older persons. In this section, two empirical studies regarding case law and ageism will be presented: The first, from the European Court of Human Rights; and the second from the Court of Justice of the European Union. 
The importance of empirical studies of court rulings is underlined in legal theory, which sees courts as social institutions, playing an important role as a tool for social change. Both in North America and Europe, courts have been used as strategic tools by individuals or human rights organization in order to promote the rights of minority or excluded social groups. It is against this backdrop and from this symbolic perspective that both the European Court of Human Rights as well as the Court of Justice of the European Union are analysed in the following paragraphs.

\subsubsection{Empirical Study of the European Court of Human Rights}

The European Convention on Human Rights does not explicitly address the rights of older persons as such. This is in-and-by itself an interesting point: older persons, as a unique social group - are "invisible" in Europe's key human rights instrument. To the extent that older people are to enjoy human rights, they need to find "auspices" within the context of the convention's general articles. It is not surprising, then, that to date the sphere of elder rights has practically not been studied at all within the context of the European Court of Human Rights. Until recently, even the Court itself did not address elder rights as a unique legal subject. This changed only in the last years, when the Court published a document in which it reviewed, in an unsystematic manner, the main judgments dealing with the subject. ${ }^{1}$

A recent study by Spanier et al. (2013), on which the following lines are based, offers a general, descriptive investigation of the extent to which the rights of older persons are discussed in this Court. The methodology of the research included an empirical analysis of the case law of the European Court of Human Rights, retrieving varied background data about judgments involving older persons from the Court's website (HUDOC). ${ }^{2}$ Due to limited time and resources, a stratified random sampling of 226 judgments were analyzed for this study. In general, the number of judgments delivered to persons aged 60 or above, out of all judgments delivered by the Court in the same years, are represented in percentage in the following graph (Fig. 19.1).

The period of time under scrutiny corresponds to the years following the entry into force of protocol 11 (1998), which introduced a reinforced judicial mechanism, allowing any individual claiming to be the victim of a violation of the Convention to bring a complaint directly to the European Court of Human Rights. After an initial stage in which an increase in applications by older persons was registered, in line with the general increase that followed the entry into force of Protocol 11, the relative rate of older persons' applications stabilized; an average of $11.9 \%$ of judgments were delivered to older persons throughout the period 2000-2010.

\footnotetext{
${ }^{1}$ Elderly People and the European Convention on Human Rights, available at: http://www.echr. coe.int/Documents/FS_Elderly_ENG.pdf (Last visited November 2014).

${ }^{2}$ Available at:

http://www.hudoc.echr.coe.int/sites/eng/Pages/search.aspx\#\{ “documentcollectionid2":["GRA NDCHAMBER","CHAMBER"]\} (Last visited November 2014).
} 


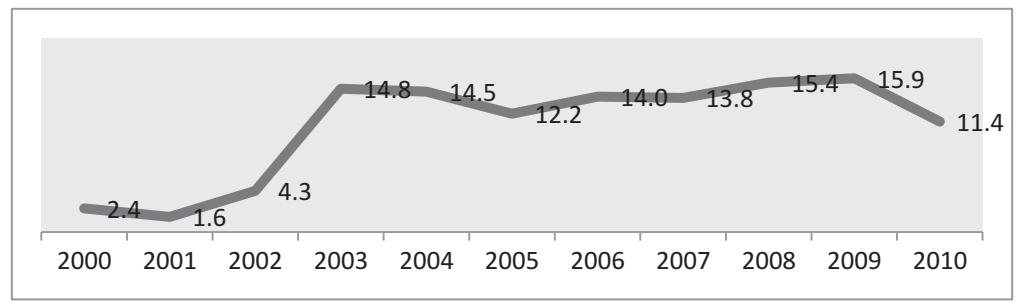

Source: Spanier, Doron, \& Milman-Sivan, 2013: pg. 411.

Fig. 19.1 Percentage of judgments given to older persons in relation to all the judgments made in each year (Source: Spanier et al. (2013): pg. 411)

These findings can be interpreted in different ways. Considering that older persons are relatively poor and potentially more disabled, accessibility to the legal systems is more complex for this than for other age groups. Hence, these data can be interpreted positively, in spite of difficulties, older persons do reach the European Court of Human Rights. On the other hand, one must recall that Europe has the largest older population in the world (160 million), about $20 \%$ of the entire population of Europe (approximately 800 million) (UN Secretary General 2009). Hence, the percentage of judgments dealing with older persons in Europe is still lower than the relative percentage of older adults in the population.

In a second phase, the study on older persons and the European Court of Human Rights looked beyond the mere number of applications into the substantial legal issues raised by older persons. For an application to be accepted to the Court, the applicant must prove that the act in question violates one (or more) of the articles of the Convention. In this study, we examined the main provisions mobilized in Court in older persons' applications. The provisions that were mostly mobilized in applications lodged by older persons were:

First Type of Cause: Article 6, Right to a Fair Trial The largest number of cases brought to the Court by older persons activate article 6 . The Court has heard under this article cases in which the reasonable time to obtain justice and redress, the accessibility to legal systems, and the failure to enforce judicial decisions were at stake. In the case of Romanika v. Poland of 2006 (ECtHR Application no. 53284/99), the applicant, aged 78, took Romania to the Strasbourg court after lamenting the excessive length of the civil proceeding he had been involved in: some 13 years, for the dissolution of a co-ownership. The Court, "having regard to the applicant's age," ruled that it could "not accept the Government's opinion that special diligence was not called for in the present case" (paragraph 62).

Second Type of Cause: Protocol 1, Article 1, Right to the Enjoyment of Possessions this category comprises cases dealing with claims of older persons regarding the right to the enjoyment of possessions. According to the Court's judgment, this is a comprehensive right, including not only property rights, but also the rights to a salary, welfare payments, pension rights (Harris et al. 2009). 


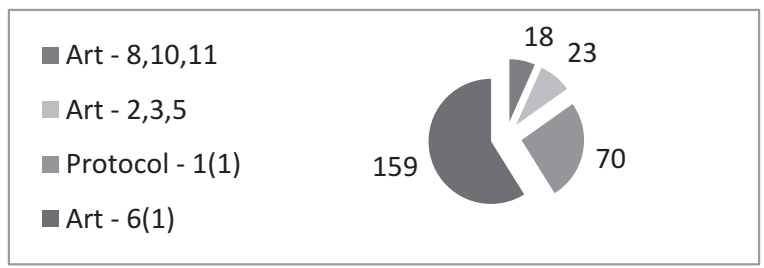

Source: Spanier, Doron, \& Milman-Sivan, 2013: pg. 413.

Fig. 19.2 Distribution of number of cases according to main articles (Source: Spanier et al. (2013): pg. 413) (In many cases, Section 6(1) is only part of the application. The applications join it onto other sections, which, they believe, were violated according to the Convention. It should be noted that, because some cases overlap, the number of judgments described in the table is larger than the sample number of 226 . Therefore, the numbers stands for the cases and not percentages)

Third Type of Cause: Articles 2, 3, 5, Breach of the Right to Life and Liberty The sections in this type of cause usually deal with loss of life (Frederic 2007), caused by the state (Gandaloyeva v. Russia (2008) ECtHR Application no. 14800/04), or by the police (Ramsahai and others v. The Netherlands (2007) ECtHR Application no. 52391/99). What emerges from this case law is that in some cases older persons are themselves victims of death or damage caused by poor hospital conditions and/or inappropriate treatment, involuntary transfer (article 2), inhuman or degrading punishment or treatment (article 3), deprivation of liberty or confinement (article 5) (Fig. 19.2).

\subsubsection{An Empirical Study of the Court of Justice of the European Union}

Similar to the previous study, the research on the Court of Justice of the European Union (CJEU) delves on cases drawn from the court's database, obtained by typing search keywords (e.g. elderly, senior, old etc.), and by screening for cases relevant for the rights of older persons (for a detailed description of the methodology see Doron 2013). As a result, 123 cases were analyzed, covering a period of time from 1994 to 2009.

Almost half the cases (58/47.2\%) pertained to "Social Policy" issues. e.g. calculation of the pension rights (39\%) and equal treatment for men and women (31.7\%, while the two other major legal areas were free movement of persons (29/23.6\%) and social security for migrant workers $(26 / 21.1 \%)$. Only very few elder rights cases involved issues like Competition ( 3 cases), or Principles of Community Law (1 case). The vast majority of cases involved pensions: either state funded pensions (61/49.6\%) or employer-based occupational pensions (36/29.3\%). The rest of the cases were mostly about age discrimination, mandatory retirement or attendance/home care (all of them 6 cases each). There were only 2 cases involving health care issues, and one case involving the regulation of nursing homes. Overall, a "typical" elder rights' case discussed under the Court of Justice of the EU is likely to be dealing with pensions' rights legal issues around its calculation or gender equality in pension treatment. 
On the escort of this statistics, one could suggest, on the one hand, that the amount of elder rights' cases brought before the Court of Justice of the EU is very low compared to the overall case load (more than 6000 throughout the relevant preiod). When they arrive at the Court of Justice of the EU, the focus is around economic issues (pensions) or discrimination in treatment on the ground of sex Major legal issues in the field of elder rights such as patients' rights, health-care, institutional or community-based long term care, housing or employment - are almost non-existent.

On the other hand, within these limited numbers of cases and narrow scope of legal decisions, the outcomes are encouraging. In the majority of the cases, the court rules in favor of older persons. It seems that there is significant awareness for the illegality of sex-discrimination in old age and of the illegality of governments' attempts to hinder the pension rights of older Europeans. In the context of specific countries, such as Germany or Belgium, there is a strong awareness and usage of local courts to the Court of Justice of the EU role.

\subsubsection{Example 3: Ageism, Lawyers and Older Clients}

Our final example is focused on empirical studies regarding the ageist (or antiageist) experiences of lawyers, judges, and older clients. In general, it could be stated that in Europe, there is a very small and limited body of direct empirical research on ageism within the legal system (e.g. lawyers, judges) or from the older persons' perspectives on the legal system. In Israel, several small scale studies have been conducted in these fields. One example can be found in a small scale quantitative study measuring ageism among lawyers (Untzik-Heilbrun and Or-Chen 2014). This study found that while their general knowledge on aging (using PFoAQ) was low, the level of ageist attitudes of lawyers in Israel (based on a convenience sample of 225 Israeli lawyers) was better (less-ageist) compared with Israeli professionals in the medical fields (e.g. nurses), but worse (more-ageist) compared with Israeli travel-agents.

Another example can be found in an Israeli case-study analysis regarding the narrative construction of old age in an Israeli case involving the legality of nursing home contract (Doron 2012). This study found that one can find in the rhetoric of the courts a combination of both stereotypical negative depiction of old age, as well as a non-ageist, an emancipatory and empowering picture of older persons as autonomous and independent agents. Finally, another small scale study in Israel looked into the experience and attitudes of older persons with regards to the legal system (Segal et al. 2014). This quantitative study (based on a convenience sample of 219 older Israeli - 60 years old and above) found that in general, the attitudes of older persons towards the Isreali legal system were negative. However, in a qualitative study regarding the accessibility of the courts to the older population in Israel, the participants described how judges gave them special respect once in the court room due to their old age (Ben-Eliezer and Doron 2011). 


\subsection{Concluding Remarks}

This chapter has provided an overview of the field of law, ageing and ageism; a general description of existing international norms in the field of ageism; and three specific examples on how law and ageism inter-relate. This chapter joins two other chapters in this book (2018, Chaps. 20-21) which together provide a descriptive analysis of how European legal frameworks are relevant for older persons in general, and how they can potentially assist in combating ageism in particular.

This general descriptive picture provides key considerations and recommendations for future research. It seems that overall there is relatively limited awareness to ageism and to "older persons" as a unique and distinguished social group within European jurisprudence. Therefore, there is a need for more research and debate on the impact that "elder-specific" mechanisms or initiatives, such as the complaints instigated by association and heard by the European Social Committee, could have on the perception of ageism and discrimination on the ground of age. Moreover, there is a lack of empirical research about how national courts of law respond to the problem of ageism. The methodology and the research offered in this chapter on the case law of the European Court of Human Rights could be replicated in the context of the Council of Europe's European Social Charter as well as national constitutional courts. Empirical research in the field of law, ageing and ageism could also be more targeted and, for instance, embrace real life experiences. In this connection, one notes an almost total a lack of empirical studies regarding the attitudes of lawyers towards older clients, and regarding experiences of older clients in their encounter with lawyers and with the legal system. More empirical research is needed in this field in order to better understand the inter-connection between law and ageism and to allow for the development of a theoretical framework that will explain this reality.

\section{References}

Barnard, C., \& Deakin, S. (2015). Age discrimination and labour law in the UK: Managing ageing. In A. Numhauser-Henning \& M. Rönnmar (Eds.), Age discrimination and labour law, Comparative and conceptual perspectives in the EU and beyond. Alphen aan den Rijn: Wolters Kluwer.

Ben-Eliezer, A., \& Doron, I. (2011). The meaning of accessibility to the courts by older persons. Gerontology, 38(1), 71-89 [Hebrew].

Bogutz, A. D. (2008). Elder law: A personal perspective. In I. Doron (Ed.), Theories on law and ageing. The jurisprudence of Elder Law (pp. 1-9). Berlin Heidelberg: Springer.

Butler, R. N. (1975). Why survive?: Being old in America. New York: Harper and Row.

Chung, C. (2010). The necessity of a human rights approach and effective United Nations mechanism for the human rights of the older person.

Committee on Economic, Social and Cultural Rights (CESCR). (1996). General Comment No. 6: The economic, social and cultural rights of older persons.

Committee on Economic, Social and Cultural Rights (CESCR). (2009). General Comment No. 20: Non-discrimination in economic, social and cultural rights. 
Committee on the Elimination of Discrimination Against Women (CEDAW). (2010). General recommendation No. 27 on older women and protection of their human rights.

De Hert, P., \& Mantovani, E. (2011). Specific human rights for older persons? European Human Rights Law Review, 4, 398-418.

Dewhurst, E. (2013). Intergenerational balance, mandatory retirement and age discrimination in Europe: How can the ECJ better support national courts in finding a balance between generations. Common Market Law Review, 50, 1333.

Dewhurst, E. (2016). Proportionality assessments of mandatory retirement measures: Uncovering guidance for national courts in age discrimination cases. Industrial Law Journal, 45(1), 60-88.

Doron, I. (2006). Elder law: Current issues and future frontiers. European Journal of Ageing, 3(1), $60-66$.

Doron, I. (2009). Theories on law and ageing. The jurisprudence of Elder Law. Berlin/Heidelberg: Springer.

Doron, I. (2012). A Judicial Rashomon: On ageism and narrative justice. Journal of Cross-Cultural Gerontology, 27(1), 17-28.

Doron, I. (2013). Older Europeans and the European Court of Justice. Age \& Ageing, 42, 604-608.

Doron, I., \& Apter, I. (2010). International rights of older persons: What difference would a new convention make to lives of older people? Marquette Elder's Advisor, 11(2).

European Commission Proposal for a Council Directive on implementing the principle of equal treatment between persons irrespective of religion or belief, disability, age or secual oientation, COM (2008) 426 final.

Evrard, A., \& Lacour, C. (2012). A European approach to developing the field of law and ageing. In A. Soden \& I. Doron (Eds.), Beyond Elder Law (pp. 149-173). New York: Springer.

Foubert, P., et al. (2013). An EU perspective on age as a distinguishing criterion for collective dismissal: The case of Belgium and the Netherlands. The International Journal of Comparative Labour Law and Industrial Relations, 29(4), 415-432.

Frederic, E. (2007). The length of civil and criminal proceedings in the case-law of the European Court of 525 Human Rights. Strasbourg: Council of Europe Publishing.

Fredman, S., \& Spencer, S. (2003). Age as an equality issue. Oxford: Hart Publishing.

Freedland, M. (2013). Burying Caesar: What was the standard employment contract? In K. Stone $\&$ H. Arthurs (Eds.), Tehtinking workplace regulation: Beyond the standard contract of employment. New York: Russell Sage Foundation.

Fudge, J. (2016). Dignity, disadvantage and age: Putting constitutional fundamental rights to work for older workers. In A. Numhauser-Hennning(Ed.), Elder law: Evolving European perspectives. Cheltenham: Elgar Publishing. (forthcoming).

Georgantzi, N. (2018). The European union's approach towards ageism. In L. Ayalon \& C. TeschRömer (Eds.), Contemporary perspectives on ageism: Vol. 19. International perspectives on aging (pp. 341-368). Berlin: Springer.

Grover, A. (2011). Thematic study on the realization of the right to health of older persons by the Special Rapporteur on the right of everyone to the enjoyment of the highest attainable standard of physical and mental health.

Harris D. J., O'Boyle M., Bates E. P., \& Buckley C. M.. 2009. Harris, O'Boyle \& Warbric Law of the European convention on human rights (2nd ed.).

Helpage International. (2013). Strengthening the rights of older people worldwide. Osnabrück: Building greater European support.

Hendrickx (Ed.). (2013). Active ageing and labour law, contributions in honour of Professor Roger Blanpain. Cambridge: Intersentia.

Herring, J. (2009). Older people in law and society. Oxford: Oxford University Press.

Ilmarinen, J. (2001). Ageing workers in the European Union - Status and promotion of work ability, employability and employment. Helsinki: Finnish Institute of Occupationalo health, Ministry of Scoial Affiars and Helath, Ministry of Labour.

Iversen, T. N., et al. (2009). A conceptual analysis of ageism. Nordic Psychology, 61(3), 4.

Julén Votinius, J. (2016). Intersectionality as a tool for analysing age and gender in labour law. In S. Manfredi \& L. Vickers (Eds.), Challenges of active ageing. London: Palgrave Macmillan. 
Kilpatrick, C. (2011, September). The court of justice and labour law in 2010: A new EU discrimination law architecture. Industrial Law Journal, 40(3), 280-301.

Kornfeld-Matte, R. (2015). Autonomy and care of older persons - Report of the independent expert on the enjoyment of all human rights by older persons.

Levine, M. L. (1982). Introduction: The frame of nature, gerontology, and law. Southern California Law Review, 56(1), 261-228.

Macnicol, J. (2006). Age discrimination, an historical and contemporary analysis. Cambridge: Cambridge University Press.

Manfredi, S., \& Vickers, L. (Eds.). (2016). Challenges of active ageing. London: Palgrave Macmillan.

Meenan, H. (2007). Reflecting on age discrimination and rights of the elderly in the European Union and the council of Europe. Maastricht Journal of European and Comparative Law, 14, 39.

Mégret, F. (2011). The human rights of older persons: A growing challenge. Human Rights Law Review, 11(1), 37.

Norma Research Programme. (1996). http://www.law.lu.se/\#!TheNormaResearchProgramme. Accessed 15 May 2016.

Mikołajczyk, B. (2018). The council of europe's approach towards ageism. In L. Ayalon \& C. Tesch-Römer (Eds.), Contemporary perspectives on ageism: Vol. 19. International perspectives on aging (pp. 321-339). Berlin: Springer.

Numhauser-Henning, A. (2013). Labour law in a greying labour market - In need of a reconceptualisation on work and pension norms. The position of older workers in labour law. European labour Law Journal, 4(2), 84.

Numhauser-Henning, A. (2015). Labour law, pension norms and the EU ban on age discrimination: Towards ultimate flexibilization? In A. Numhauser-Henning \& M. Rönnmar (Eds.), Age discrimination and labour law, Comparative and conceptual perspectives in the EU and beyond. Alphen aan den Rijn: Wolters Kluwer.

Numhauser-Henning, A., \& Rönnmar, M. (Eds.). (2015). Age discrimination and labour law, Comparative and conceptual perspectives in the EU and beyond. Alphen aan den Rijn: Wolters Kluwer.

O'Cinneide, C. (2015). Constitutional and fundamental rights aspects of age discrimination. In A. Numhauser-Henning \& M. Rönnmar (Eds.), Age discrimination and labour law, Comparative and conceptual perspectives in the EU and beyond. Alphen aan den Rijn: Wolters Kluwer.

Office of the High Commissioner for Human Rights (OHCHR). (2012). Normative standards in international human rights law in relation to older persons - Analytical outcome paper.

Rönnmar, M. (2015). Age discrimination and labour law: A comparative analysis. In R. NumhauerHenning (Ed.), Age discrimination and labour law, Comparative and conceptual perspectives in the EU and beyond. Alphen aan den Rijn: Wolters Kluwer.

Sargeant, M. (2008). The law on age discrimination in the EU. Alphen aan den Rijn: Kluwer Law International.

Schiek, D. (2011). Age discrimination before the ECJ - Conceptual and theoretical issues. Common Market Law Review, 48, 777.

Schiek, D. (2015). Proportionality in age discrimination cases - Towards a model suitable for socially embedded rights. In A. Numhauser-Henning \& M. Rönnmar (Eds.), Age discrimination and labour law, Comparative and conceptual perspectives in the EU and beyond. Alphen aan den Rijn: Wolters Kluwer.

Schlachter, M. (Ed.). (2010). The prohibition of age discrimiation in labour relations. Reports to the XVIIIth international congress of comparative law, Nomos.

Schlachter, M. (2011). Mandatory retirement and age discrimination under EU law. IJCLLIR, 27, 287-299.

Seanad Public Consultation Committee. (2012). Report on the rights of older people.

Segal, M., Mor, S., \& Hantman, S. (2014). The attitudes of older persons towards the law and courts in Israel: Accessibility, trust and ageism. Gerontology, 41(3), 51-70 [Hebrew]. 
Soden, A., \& Doron, I. (2012). Beyond elder law: New directions in law and aging. New York: Springer.

Spanier, B., Doron, I., \& Milman-Sivan, F. (2013). Older persons' use of the European court of human rights. Journal of Cross-Cultural Gerontology, 28, 407-420.

Strauss, K. (2013). Equality, faoir mutualisation and the socialisation of risk and reward in European pensions. In N. Countouris \& F. Mark (Eds.), Resocialising Europe in a time of crisis. Cambridge: Cambridge University Press.

Suk, J. (2012). From antidiscrimination to equality: Stereotypes and the life cycle in the United States and Europe. American Journal of Comparative Law, 60, 75.

ter Haar, B \& Rönnmar, M (2014). Intergenerational bargaining, EU age discrimination law and EU policies - An integrated analysis (Report for the project iNGenBar).

Tobler, C. (2015). EU age discrimination law and older and younger workers: Court of justice of the European Union case law developments. In A. Numhauser-Henning \& M. Rönnmar (Eds.), Age discrimination and labour law, Comparative and conceptual perspectives in the EU and beyond. Alphen aan den Rijn: Wolters Kluwer.

UN Economic Commission for Latin America and the Caribbean (ECLAC). (2007). Brasilia declaration.

UN Human Rights Committee. (1989). General Comment No. 18 - Non-discrimination.

UN Human Rights Council. (2011). Panel discussion on the realization of the right to health of older persons. Geneva.

UN Secretary General. (2009). Follow-up to the second world assembly on ageing (A/64/127).

Untzik-Heilbrun, I. Or-Chen, K. (2014). Lawyers' attitudes towards older clients in Israel. Gerontology, 41(3), 31-49 [Hebrew].

Open Access This chapter is licensed under the terms of the Creative Commons Attribution 4.0 International License (http://creativecommons.org/licenses/by/4.0/), which permits use, sharing, adaptation, distribution and reproduction in any medium or format, as long as you give appropriate credit to the original author(s) and the source, provide a link to the Creative Commons license and indicate if changes were made.

The images or other third party material in this chapter are included in the chapter's Creative Commons license, unless indicated otherwise in a credit line to the material. If material is not included in the chapter's Creative Commons license and your intended use is not permitted by statutory regulation or exceeds the permitted use, you will need to obtain permission directly from the copyright holder. 


\title{
Chapter 20 \\ The Council of Europe's Approach towards Ageism
}

\author{
Barbara Mikolajczyk
}

\subsection{Introduction}

Robert Butler coined the term ageism almost 50 years ago to describe symptoms and roots of unequal and degrading treatment of older persons (Butler 1975, 1969). Ageism in the twenty-first century continues to be a rampant and widespread phenomenon. Epidemic ageism (Palmore 2001, p. 574) is believed to affect more than 164 million seniors living in Europe (Age UK 2011), which means that a significantly higher proportion of Europeans are exposed to ageism than to sexism or racism (Grześkowiak 2012). Not surprisingly, ageism is becoming a question of common concern in European forums, including the Council of Europe-an intergovernmental organization of 47 European countries, including the 28 European Union member states.

According to Article 1 of the Statute of the Council of Europe, one of the main aims of the Council is "to achieve a greater unity between its members for the purpose of safeguarding and realising the ideals and principles [through] discussion of questions of common concern and by agreements and common action in ... the maintenance and further realisation of human rights and fundamental freedoms" (Council of Europe 1949). This provision clearly indicates that the Council of Europe is a forum for discussion in which democratic and human rights standards are worked out. While it does serve as a platform for discussion, the Council, unlike the European Union, does not have at its disposal any strict (financial) sanctions. It does, however, have some organizational sanctions, such as suspending the rights of representation stipulated in Article 8 of the Statute.

The substantial legal output of the Council of Europe bodies and the establishment of mechanisms controlling and monitoring the fulfilment of obligations arising

B. Mikołajczyk ( $\square)$

Faculty of Law and Administration, University of Silesia, Katowice, Poland

e-mail: barbara.mikolajczyk@us.edu.pl

L. Ayalon, C. Tesch-Römer (eds.), Contemporary Perspectives on Ageism, International Perspectives on Aging 19,

https://doi.org/10.1007/978-3-319-73820-8_20 
from human rights treaties makes it possible to speak of a Council of Europe "megasystem" of human rights protection (Madsen 2007, p. 154), covering over 820 million people in Europe, including older persons. For this reason, the Council of Europe appears to be a legitimate forum for taking up the issues of ageing, the status of older persons and, finally, ageism, because, as social challenges, they fully match the goals of this organization. Ageism is assuredly a very arduous matter for international lawmakers, more so even than racism and sexism. When working out standards for the protection of rights of older persons, the Council of Europe bodies should take into account not only cultural, economic, and social differences between groups living in member states, but also the various concepts, forms, and symptoms of ageism, which are quite often imperceptible at first glance.

In this chapter, I examine the degree of interest in ageism among Council of Europe members, and the degree of interest in its elimination through the Council of Europe forum. I also examine the interpretation of the concept of ageism by various Council of Europe institutions. Finally, I explore the Council's willingness and ability to eliminate or at least mitigate ageism effectively.

It may be assumed that the Council of Europe has appropriate instruments with which to fight ageism, but these tools appear to be scattered across its various bodies. That is why, in order to identify the Council's potential to fight ageism, it is first necessary to extract these tools and examine them separately. Second, taking into account the thousands of documents issued by the Council's many bodies, it is also necessary to single out relevant acts for examination. As a result, this chapter is divided into two parts. The first is a short description of the selected Council of Europe institutions and their competences. The second is dedicated to the Council of Europe's output on the subject of the rights of older persons, including treaties and not legally binding acts.

\subsection{Council of Europe Institutions Relevant to Ageism}

The rights of older persons and their protection from ageism is increasingly to become a subject of interest to various Council of Europe institutions. Generally, most of the Council of Europe bodies have the power to take on the problem of age discrimination, stereotypes of older persons, and ageism. However, this chapter focuses mainly on the current outputs of the Parliamentary Assembly and the Committee of Ministers, which are supported by their advisory committees (Bond 2010), and on the work of the main treaty bodies - the European Court of Human Rights and the European Social Committee.

The Parliamentary Assembly is a deliberative body consisting of representatives from national parliaments. The most important European human rights issues are discussed in the Parliamentary Assembly. According to Article 29 of the Statute, the Parliamentary Assembly is entitled to issue resolutions embodying recommendations and proposals for discussion to the Committee of Ministers. This happens quite often in response to current political and social issues. 
Composed of the foreign ministers of all the member states (in accordance with Articles 13-14 of the Statute), the Committee of Ministers is the main decisionmaking body. Its decisions are embodied in legally binding conventions or in the form of recommendations addressed to governments. The Committee of Ministers' recommendations are usually reactions to previous initiatives of the Assembly (Świtalski 2009). According to Article 15 of the Statute, at the recommendation of the Parliamentary Assembly or on its own initiative, the Committee of Ministers is competent to consider actions required in order to further the aim of the organization, including the conclusion of conventions or agreements, as well as the adoption of common policy. In addition, the conclusions issued by the Committee may take the form of recommendations to the governments of member states, and the Committee may monitor the member states' actions with regard to such recommendations.

The Council of Europe Commissioner for Human Rights is another institution relevant to the problem of ageism. The Commissioner is an independent body with the objective of promoting respect for human rights in the member states (Sivonen 2012). Among other initiatives, the Commissioner's awareness-raising activities are crucial to the fight against ageism. The situation of older adults, including agerelated aspects of issues such as housing, poverty, and institutional care, are within the scope of the Commissioner's interest. Thomas Hammarberg, who was Commissioner in 2006-2012, placed special attention on the situation of older adults in Council of Europe member states in the context of an information campaign against elder abuse and other symptoms of ageism. In his country reports and "Human Rights Comments" he referred to the dilemmas of "whistle-blowers" (Jones and Kelly 2014) and the adoption of relevant legislation to better protect personnel working in various types of institutions for older persons when reporting poor conditions or abuses (Council of Europe Commissioner for Human Rights 2011). He branded bad practices and harmful legislation and pointed out successful initiatives such as the Irish NGO programme, "Older \& Bolder", aimed at identifying negative stereotypes against older adults (Cantillon and Vasquez del Aguila 2011; Hammarberg 2012). The steps taken by the Commissioner for Human Rights, as well as the potential for future steps, contribute to shaping European awareness about the rights of older persons and the threats of ageism.

Another group of institutions are those established by virtue of treaties ratified by the Council of Europe member states. They are not the Council of Europe's organs as such, but they are firmly placed within the structure of the Council of Europe. First, the European Court of Human Rights, an international court established in 1959 , rules on applications by individuals or states with allegations of violations of the civil and political rights set out in the European Convention on the Protection of Human Rights and Fundamental Freedoms (European Convention on Human Rights). The Court's case-law makes the Convention a powerful living instrument for meeting new challenges in Europe.

Two other independent committees should be noted. The European Committee of Social Rights evaluates legal and practical steps taken by the state parties to the European Social Charters and their conformity with the provisions of these treaties. 
The Committee of Social Rights also adopts conclusions on national reports submitted by states. If a member state ratifies a particular protocol, the Committee is also able to consider collective complaints submitted by civil society organizations and to make decisions based on these complaints.

Finally, the main competence of the European Committee for the Prevention of Torture and Inhuman or Degrading Treatment or Punishment (the Committee for the Prevention of Torture) - a non-judicial mechanism existing alongside the judicial mechanism of the European Court of Human Rights - is to visit places of detention, such as prisons, police stations, psychiatric hospitals, and other closed institutions, to assess how individuals deprived of their liberty are treated. After each mission, the Committee sends a detailed report to the state concerned, containing the Committee's findings, recommendations, comments, and requests for information.

The institutions listed above were established on a variety of legal bases, and have different natures and competences. Regardless of these differences, they have a common goal of facilitating economic and social progress, achieving greater unity between Council of Europe members, ensuring the protection of human rights, and achieving the ideals and principles that constitute the common European heritage (Table 20.1).

\subsection{Treaty Law}

The main way to harmonize and unify human rights standards in Europe is for states to adopt treaties in the Council of Europe forum. Benoît-Rohmer and Klebes (2005) state that, "by creating a common legal area, they make the member states more cohesive-democratically, socially and culturally" (p. 85). As a result, over 200 treaties and additional protocols have been adopted through the Council of Europe forum. The treaties ideally help member states cooperate on many sensitive issues, including ageing and ageism. However, no convention referring to the elimination of ageism has been adopted at the Council of Europe forum, and no treaty has yet explicitly discussed the rights of older persons or referred to the fight against ageism.

\subsubsection{Treaties Protecting the First Generation of Human Rights}

The principal Council of Europe treaty, the previously mentioned 1950 European Convention on Human Rights (Council of Europe 1950), and its additional protocols, form what is known as the first generation of human rights, being essentially linked with dignity, liberty and participation in political life. Rights belonging to this generation are more of a civil and political nature and include, among other things, the right to life, a ban of torture and degrading treatment, equality before the 
Table 20.1 European institutions competent to take action against ageism

\begin{tabular}{|c|c|c|c|c|}
\hline Body & Legal basis & Status & Members & Selected competences \\
\hline $\begin{array}{l}\text { Parliamentary } \\
\text { Assembly }\end{array}$ & $\begin{array}{l}\text { Statute of the } \\
\text { Council of } \\
\text { Europe of } \\
1949\end{array}$ & $\begin{array}{l}\text { Statutory } \\
\text { organ }\end{array}$ & $\begin{array}{l}\text { Parliamentarians } \\
\text { from the member } \\
\text { states }\end{array}$ & $\begin{array}{l}\text { Serving as a platform } \\
\text { for discussion; issuing } \\
\text { resolutions; inspiring, } \\
\text { proposing, and helping } \\
\text { to shape new national } \\
\text { laws }\end{array}$ \\
\hline $\begin{array}{l}\text { Committee of } \\
\text { Ministers }\end{array}$ & $\begin{array}{l}\text { Statute of the } \\
\text { Council of } \\
\text { Europe of } \\
1949\end{array}$ & $\begin{array}{l}\text { Statutory } \\
\text { organ }\end{array}$ & $\begin{array}{l}\text { Foreign ministers } \\
\text { of the member } \\
\text { states or their } \\
\text { deputies }\end{array}$ & $\begin{array}{l}\text { Acting as a "guardian" } \\
\text { of the fundamental } \\
\text { values of the } \\
\text { organization; } \\
\text { monitoring member } \\
\text { states' compliance; } \\
\text { developing international } \\
\text { law through } \\
\text { conventions; adopting } \\
\text { recommendations and } \\
\text { resolutions; supervising } \\
\text { states' implementation } \\
\text { of the European Court } \\
\text { of Human Rights' } \\
\text { judgements }\end{array}$ \\
\hline $\begin{array}{l}\text { Commissioner } \\
\text { for Human } \\
\text { Rights }\end{array}$ & $\begin{array}{l}\text { Resolution } \\
\text { (99) } 50, \\
\text { adopted by the } \\
\text { Committee of } \\
\text { Ministers on } 7 \\
\text { May } 1999\end{array}$ & Independent & $\begin{array}{l}\text { "Eminent } \\
\text { personality of a } \\
\text { high moral } \\
\text { character having } \\
\text { recognised } \\
\text { expertise in the } \\
\text { field of human } \\
\text { rights" according to } \\
\text { Article } 10 \text { of the } \\
\text { Resolution (99)50 }\end{array}$ & $\begin{array}{l}\text { Fostering the effective } \\
\text { observance of human } \\
\text { rights; assisting member } \\
\text { states in implementing } \\
\text { human rights standards; } \\
\text { promoting education in } \\
\text { and awareness of human } \\
\text { rights; taking part in } \\
\text { proceedings before the } \\
\text { European Court of } \\
\text { Human Rights }\end{array}$ \\
\hline $\begin{array}{l}\text { European Court } \\
\text { of Human Rights }\end{array}$ & $\begin{array}{l}\text { European } \\
\text { Convention on } \\
\text { the Protection } \\
\text { of Human } \\
\text { Rights and } \\
\text { Fundamental } \\
\text { Freedoms of } \\
1950\end{array}$ & Treaty body & Independent judges & $\begin{array}{l}\text { Issuing judgements and } \\
\text { decisions in cases } \\
\text { submitted by individuals } \\
\text { against member states; } \\
\text { issuing judgements in } \\
\text { inter-state cases; } \\
\text { interpreting the } \\
\text { European Convention } \\
\text { on Human Rights }\end{array}$ \\
\hline
\end{tabular}


Table 20.1 (continued)

\begin{tabular}{|c|c|c|c|c|}
\hline Body & Legal basis & Status & Members & Selected competences \\
\hline \multirow[t]{2}{*}{$\begin{array}{l}\text { European } \\
\text { Committee of } \\
\text { Social Rights }\end{array}$} & $\begin{array}{l}\text { European } \\
\text { Social Charter } \\
1961\end{array}$ & \multirow[t]{2}{*}{ Treaty body } & \multirow[t]{2}{*}{$\begin{array}{l}\text { Independent } \\
\text { experts }\end{array}$} & \multirow{2}{*}{$\begin{array}{l}\text { Monitoring } \\
\text { implementation of the } \\
\text { 1961 European Social } \\
\text { Charter, its additional } \\
\text { protocols, and the } 1996 \\
\text { Revised European } \\
\text { Social Charter; } \\
\text { examining states' } \\
\text { reports and adopting } \\
\text { conclusions; considering } \\
\text { collective complaints } \\
\text { and issuing decisions }\end{array}$} \\
\hline & $\begin{array}{l}\text { Revised } \\
\text { European } \\
\text { Social Charter } \\
\text { of } 1996\end{array}$ & & & \\
\hline $\begin{array}{l}\text { European } \\
\text { Committee for } \\
\text { the Prevention of } \\
\text { Torture and } \\
\text { Inhuman or } \\
\text { Degrading } \\
\text { Treatment or } \\
\text { Punishment } \\
\text { (European } \\
\text { Committee for } \\
\text { the Prevention of } \\
\text { Torture) }\end{array}$ & $\begin{array}{l}\text { European } \\
\text { Convention for } \\
\text { the Prevention } \\
\text { of Torture and } \\
\text { Inhuman or } \\
\text { Degrading } \\
\text { Treatment or } \\
\text { Punishment of } \\
1987\end{array}$ & Treaty body & $\begin{array}{l}\text { Independent } \\
\text { experts }\end{array}$ & $\begin{array}{l}\text { Visiting member states } \\
\text { on a periodic basis to } \\
\text { assess how individuals } \\
\text { deprived of their liberty } \\
\text { are treated; making } \\
\text { observations, public } \\
\text { statements, and } \\
\text { recommendations; } \\
\text { preparing reports; } \\
\text { setting up standards }\end{array}$ \\
\hline
\end{tabular}

law, the right to fair trial, the prohibition of slavery, freedom of speech and religion, and voting rights (Vasak 1977). The Convention refers to the rights and freedoms of "everyone" and does not contain any specific reference to the rights of older persons, or even to age discrimination, which is inextricably linked to ageism.

Article 14 of the Convention on Human Rights, which prohibits discrimination, does not explicitly specify age for non-discrimination. It states: "The enjoyment of the rights and freedoms set forth in this Convention shall be secured without discrimination on any ground such as sex, race, colour, language, religion, political or other opinion, national or social origin, association with a national minority, property, birth or other status." However, the last premise of "other status" suggests that no-one shall be discriminated against on any other ground.

It is also easy to notice that this provision has a non-autonomous character, which means that it is tied only to the rights contained in the European Convention on Human Rights and its additional protocols. Unfortunately, ageism also affects people in spheres beyond the scope of the Convention-that is, in social areas not covered directly by this treaty. Protocol No. 12 to the Convention (Council of Europe 2000a) has removed this limitation and now it establishes a general standard of non-discriminatory treatment by public authorities (Martin et al. 2015), but it failed to expand the list of premises prohibiting discrimination. It was explained that further inclusion was considered unnecessary from a legal point of view, because the list of non-discrimination grounds is not exhaustive (Council of Europe 2000b, 
para. 20). It was also proved in the case Schwizgebel v. Switzerland considered by the Court (European Court of Human Rights 2010a). In this case, the author of the complaint was a 47-year-old single woman who, due to her age, had been refused permission to adopt a child. The Court, invoking the principle of the best interest of a child, did not find a violation of Article 14 in connection with Article 8 of the European Convention on Human Rights (respect for private and family life) but it finally considered age as a premise covered by Article 14. This case should be recognized as exceptional, because the European Court of Human Rights tends to be cautious about issuing judgements referring solely to age. When the Court does refer to an applicant's age, it is usually in combination with questions of health and conditions of detention, procedural safeguards, or gender discrimination (De Pauw 2014). The case of Schwizgebel v. Switzerland did not refer to ageism, but the recognition of age as a separate premise may be the first step toward a deeper consideration of age-related issues, including ageism, by the Court. It should be remembered that the European Court of Human Rights might, within the framework of its dynamic interpretation of the European Convention on Human Rights (Dzehtsiarou 2011), refer to ageism as a source of discrimination or as a unique or special form of discrimination. Nevertheless, in the Tyrer v. United Kingdom ruling the Court described the Convention as "a living instrument, which must be interpreted in the light of present-day conditions" (European Court of Human Rights 1978). Moreover, in the judgement of 13 June 1979, Marckx v. Belgium, the Court stated that member states are obliged to provide effective and reasonable possibilities to their citizens to benefit from the Convention (European Court of Human Rights 1979). The doctrines set out in these rulings allow the expectation that victims of ageism will not be excluded from the protection offered by the European Convention on Human Rights. However, it appears that currently compared to victims of racism and sexism, a person suffering from any form of ageism is put a disadvantage in asserting his or her rights (Wintemute 2004; Meenan 2007; Mikołajczyk 2013).

Because "age" is not listed among the premises, older Europeans are often not aware of the possibilities provided by the Convention. Despite quite a significant number of older (over 60) complainants submitting applications to the European Court of Human Rights, it is unclear whether they have submitted claims because they feel that their human rights were violated exclusively due to their age (Spanier et al. 2013; Mikołajczyk 2013). Moreover, the concepts of ageism and even age discrimination have never appeared in claims submitted to the Court in obviously "old age related" cases. These include the involuntary transfer of an older person from one care home to another, as in Watts v. the United Kingdom (European Court of Human Rights 2010b); forced placement in a nursing home, as in H. M. v. Switzerland (European Court of Human Rights 2002a); and the limitation of nighttime care in the case of McDonald v. the United Kingdom (European Court of Human Rights 2014). Other cases include the divestiture of individuals of their legal capacity, as in $X$ and $Y v$. Croatia (European Court of Human Rights 2011a); the insufficiency of old-age pensions to maintain an adequate standard of living, as in 
Larioshina v. Russia (European Court of Human Rights 2002b) and Budina v. Russia (European Court of Human Rights 2009); and poor hospital conditions, inappropriate treatment, or negligence by nursing home staff, as in Volintiru v. Italy (European Court of Human Rights 2008a) and Dodov v. Bulgaria (European Court of Human Rights 2008b).

However, this is not to say that the jurisprudence of the European Court of Human Rights does not contribute at all to limiting ageism in the Council of Europe member states. For example, in the case Heinisch v. Germany, the Court found a violation of Article 10 of the European Convention on Human Rights (freedom of speech) and argued in its judgement, among other things, that the information provided by the applicant (a nurse reporting on poor conditions in a geriatric nursing home where she had been employed) had been disseminated in the public interest, which ranked over the employer's interest (European Court of Human Rights 2011b). This case should be considered in the context of the protection of whistle-blowers, which was revealed by the Council of Europe Commissioner for Human Rights.

Obviously, this judgement is significant for the fight against elder abuse. It has also become an important element in the campaign to raise awareness of the situation of older persons and, as a result, is important to the anti-ageism campaign.

When discussing elder abuse, we should also take into consideration the European Convention for the Prevention of Torture and Inhuman or Degrading Treatment or Punishment of 1987 (Council of Europe 1987). Although this Convention does not refer directly to older persons, its essence is to protect people placed not only in prisons (some of whom might be older adults), but also in other institutions where people are de facto deprived of their liberty. As mentioned in the beginning of this chapter, the European Committee for the Prevention of Torture, established on the basis of Article 1 of this Convention, organizes visits to various places of detention in the member states, including hospitals, psychiatric hospitals, and care centres, in order to assess how individuals placed in such institutions are treated. To date, the notion of ageism has not appeared directly in reports, standards, or conclusions of this Committee. However, the Committee does take into account the situation of older prisoners and older patients of psychiatric establishments. For example, in the Committee's standards, revised in 2015 (European Committee for the Prevention of Torture and Inhuman or Degrading Treatment or Punishment 2015a), referring to involuntary placement in psychiatric establishments, the Committee stresses the patients' right to privacy and the needs of older patients in this sphere, especially in relation to personal hygiene. The Committee reproached many practices encountered during the country visits in relation to older persons, which might have been rooted in intentional or implicit ageism. For example, the Committee observed that the practice in "some psychiatric establishments of continuously dressing patients in pyjamas/nightgowns is not conducive to strengthening personal identity and self-esteem; individualisation of clothing should form part of the therapeutic process" (European Committee for the Prevention of Torture and Inhuman or Degrading Treatment or Punishment 1998, sec. 34).

It is also worth mentioning this Committee's questionnaire for visits to social care institutions (European Committee for the Prevention of Torture and Inhuman 
or Degrading Treatment or Punishment 2015b). The questionnaire does not have a legal, but rather a practical nature, containing a long list of questions that may contribute to the identification of ageism. The checklist includes such questions as: Is there ill-treatment by staff (physical and/or verbal)? Is there inter-resident violence? Do members of staff react and intervene promptly in case of incidents? Are measures taken to protect particularly vulnerable residents? Regarding the allocation of different groups of residents, are there placement policies? Regarding residents' privacy, are there individual wardrobes? Lockable space for personal belongings? Can residents keep personal belongings in their room? What types of restraint are used? Seclusion? Physical restraint? Mechanical restraint (straps, straitjacket, bed sides, net bed, etc.)? Chemical restraint? Other types? Are staff properly trained (including in non-physical de-escalation techniques)? Certainly, these questions may be very useful in detecting ageist behaviour/approaches of the staff in a given institution. However, the results of this procedure will also depend on the awareness and sensibility of the inspectors.

\subsubsection{The Council of Europe's Social Law}

Civil and political rights contained in the European Convention on Human Rights are complemented by social and economic rights set out in the European Social Charter adopted in 1961 (Council of Europe 1961) and amended by three protocols (Council of Europe 1988a, 1991, 1998) as well as in the Revised European Social Charter of 1996 (Council of Europe 1996a). They guarantee a broad range of everyday human rights related to employment, housing, health, education, social protection, and welfare. The European Social Charter of 1961 Articles 12-15 contain rights of significant importance for older persons: the right to social security, to social and medical assistance, to benefit from social welfare services, and the right of a disabled person to independence, social integration, and participation in the life of the community. However, it cannot be assumed that the authors of the Charter in the early 1960s intended to relate it in any way to ageism or similar phenomena, because at that time, this issue went beyond the sphere of interest of the international community, and age (including old age) was not considered as a separate premise of non-discrimination in human rights law. Some progress in this field can be observed in the case of Article 4 of the Additional Protocol of 1988 to the European Social Charter, which was subsequently copied in 1996 by Article 23 of the Revised European Social Charter. Article 23 provides for the right of older people to social protection. Parties are obliged to ensure the effective exercise of this right by adopting appropriate measures: "to enable elderly persons to remain full members of society for as long as possible, by means of: (a) adequate resources enabling them to lead a decent life and play an active part in public, social and cultural life; (b) provision of information about services and facilities available for elderly persons and their opportunities to make use of them"; "to enable elderly persons to choose their life-style freely and to lead independent lives in their 
familiar surroundings for as long as they wish and are able, by means of: (a) provision of housing suited to their needs and their state of health or of adequate support for adapting their housing; (b) the health care and the services necessitated by their state"; and "to guarantee elderly persons living in institutions appropriate support, while respecting their privacy, and participation in decisions concerning living conditions in the institution" (Council of Europe 1996a). Although the Protocol and the Revised European Social Charter do not explicitly mention ageism, all the itemized elements of social protection for older persons have tackled the most ageist, agesensitive situations. Furthermore, the Explanatory Report to the Protocol clarifies that "the expression 'full members' means that elderly persons must suffer no ostracism on account of their age" (Council of Europe 1988b, p. 7, para. 54). It could be assumed that ostracism may be construed here as one aspect of ageism, and therefore all the measures taken under Article 23 seem to be crucial for combating ageism as well.

It should also be mentioned that the Revised European Social Charter encompasses other rights that are connected with the situation of older persons in contemporary Europe. The first section of Article 26 touches upon the right to dignity at work, aiming to prevent sexual harassment in the workplace. However, the second section aims at awareness, information, and the prevention of recurrent reprehensible or distinctly negative and offensive actions directed against individual workers in the workplace or in relation to work. It also means that the states are obliged to take measures that encompass actions protecting older workers against ageist behaviours of employers and other employees.

The Revised Charter also contains an anti-discrimination clause-Article E, which is based on Article 14 of the European Convention of Human Rights (Council of Europe 1996b, para. 136), so as a result, the premise of age is not on the list.

Both Social Charters contain mandatory and non-mandatory provisions. A contracting party should elect to be bound by a specified number of non-mandatory provisions. However, Article 23-potentially the most anti-ageist provision in the Council of Europe social law-is not among the mandatory provisions of the Charter. As a result, member states tend not to be willing to be bound by these obligations, deeming them too demanding.

As stated above, not all 47 member states of the Council of Europe are parties to the charters. Only 27 are, and most of them also ratified the Revised European Social Charter, which is binding on 34 states. ${ }^{1}$ As parties to the Charters, the ratifying states had to accept the reporting mechanism, but only 15 of them agreed to collective complaints being submitted to the European Committee of Social Rights by social partner organizations and non-governmental organizations against a given state. However, in the Committee's conclusions in reference to Article 23, the notion of ageism was not touched upon. Neither was it discussed when the Committee examined collective complaints on the grounds of Article 23 in the cases related to old age submitted in International Federation of Human Rights Leagues (IFHR) $v$. Ireland, complaint 42/2007 (European Committee of Social Rights European

${ }^{1}$ July 2017. 
Committee of Social Rights 2008) and The Central Association of Carers in Finland v. Finland, complaint No.70/2011 (European Committee of Social Rights 2011).

\subsection{Beyond the Council of Europe Treaties-Soft Law}

Because ageism and anti-ageism norms do not appear explicitly in the Council of Europe treaties, it is reasonable to focus on the Council of Europe non-binding documents, which are often concerned with soft law covering a wide range of instruments of varying natures and goals. There are various concepts of soft law in the international law doctrine, and various acts issued by international bodies are classified as soft law. There are opinions contesting the existence of this kind of law, but opposing views recognize it as a new quasi-source of international law. Shelton (2000) defined these norms as "normative provisions contained in non-binding texts" (p. 292). There are also opinions that soft law, just as legal norms, is not binding, but that the norms might influence the development of international customary law which is, alongside treaties, the most important hard law source. Moreover, soft law still might be used by courts to interpret binding norms contained in treaties (Terpan 2015; Spanier et al. 2016).

Soft law may not only affect the interpretation of treaties by relevant bodies, but may also fill in the gaps or supplement the hard law instruments (Shelton 2003). This soft law function appears fundamental in the absence of a treaty dedicated to older adults. Finally, it might be observed that currently non-binding instruments have strong enforcement mechanisms, sometimes even stronger than treaties (Terpan 2015), so the differences between binding and non-binding acts may turn out to be "really blurred" (Shelton 2003, p. 8). It might be assumed that significant potential power is embedded in the Council of Europe's activity beyond the concluded treaties, especially in the resolutions and recommendations of the Parliamentary Assembly and the Committee of Ministers.

\subsubsection{A Piecemeal Approach}

The acts adopted by the Council of Europe organs can be divided into two groups of documents: those directly referring to older persons' issues of age in Europe; and those that are part of a wider issue, such as social cohesion, mental health, family policies, dependence, old age pensions, health care in prisons, and the full participation of people with disabilities in society. Although they do not refer to ageism explicitly, all the documents belonging to the latter group affect European opinion on the situation of vulnerable people, including older adults. Therefore, relevance to ageism should also be sought in documents dedicated specifically to ageing and older persons. 
As it happens, only a few resolutions and recommendations of the Committee of Ministers and the Parliamentary Assembly address ageism. Most of documents dedicated to ageing and senior citizens do not refer to ageism at all. Some of these acts indirectly, and just barely, tackle ageism, such as the "Guiding Principles to be Taken Into Account When Taking Measures Concerning Elderly People" enclosed in the Committee of Ministers Recommendation (94) 9 (Committee of Ministers 1994). These guidelines stressed the crucial role of the media, appropriate information, and education. According to this document, adequate steps taken should increase family and public sensitivity to issues of relevance to seniors, and in particular should enhance the positive perceptions of the role of older people in society.

In Recommendation 1428 (1999), Future of Senior Citizens: Protection, Participation, Promotion, the Assembly requested the Committee of Ministers to consider the possibilities of asking the member states to take relevant steps in the area of raising awareness and training of welfare and medical staff to detect mistreatment in any environment in which older people might be living, and to encourage states to create different, more positive images of older adults. Hancock (1999), the author of the Explanatory Memorandum to Recommendation 1428, clarified the background of the Recommendation by indicating that "the right to dignity would be clearly backed up by greater respect for older persons, particularly in public life and in terms of the image projected of them" (Council of Europe 1999, para. 40).

Parliamentary Assembly Resolution 1793 (2011), Promoting Active AgeingCapitalising on Older People's Working Potential, should also be recognized as an important document. For the first time, the Assembly used expressis verbis the term "ageism," confirming that, although it is less well known than racism or sexism, it is nevertheless "a harmful prejudice that results in widespread lack of respect for older people, whether through the media, which promote stereotypical and degrading images of older people, within society, where they are the victims of physical and financial abuse, in the workplace, where they are subject to unequal treatment, or in the health sector where they do not always receive appropriate medical care and services" (Parliamentary Assembly 2011, para. 1).

In the report that served as a basis for this Resolution, Jacquat (2011) noticed that differences in treatment between individuals or groups on the grounds of age are often based on generalized assumptions or casual stereotypes. Even if direct discrimination is forbidden by law, negative attitudes towards older workers are still deeply rooted in our contemporary work culture. Older workers have more limited chances of finding a new job and of accessing training and education. Quite often they are forced to give up work against their will. Because age discrimination and age-related harassment in the workplace demean older people's dignity and damage their self-esteem, the creation of a more positive approach among employers of older workers is a requisite. Hence, special emphasis should be placed on highlighting the positive aspects of employing older workers, and measures should be taken to ensure that the advantages of employing older workers are more widely acknowledged (Council of Europe 2011).

Finally, Parliamentary Assembly Resolution 1958 (2013), Combating Discrimination Against Older Persons on the Labour Market, is another document 
that explicitly addresses ageism. In this document, the Assembly identifies age discrimination, including discrimination in the field of recruitment and work relations, as one of the most widespread forms of discrimination, and indicates substantial differences between the Council of Europe member states in terms of awareness of the problem and the scale of efforts undertaken to combat it. What is more important, according to the Parliamentary Assembly, "age discrimination goes hand-inhand with the more general phenomenon of 'ageism', driven by a negative view of ageing in society" (Parliamentary Assembly 2013, para. 4). The Parliamentary Assembly is of the opinion that it is vital to strive to change beliefs and attitudes in order to eliminate stereotypes, as well as build a positive and true image of workers in all age groups. Therefore, the Assembly invited the Council of Europe member states to support information campaigns aimed at changing attitudes about ageing, to raise public awareness of the experiences of older workers, to encourage mentoring programmes, and to facilitate intergenerational dialogue. This Resolution was based on a report by Sahiba Gafarova (Council of Europe 2013) which contains more references to ageism. Gafarova defined age discrimination as "differential treatment and denial of rights or opportunities unjustified on any other grounds. This form of discrimination has become a sociological concept in its own right known as ageism. Like racism and sexism, ageism concerns prejudices on the part of one group against other groups" (Council of Europe 2013, B1. 2). ${ }^{2}$

Gafarova also observed that ageism in the area of employment is reflected in discriminatory language, attitudes, and practices based on age. It may be conscious or unconscious and is guided by various stereotypes. Moreover, providing arguments for the submission of the draft of Resolution 1958 (2013), she identified a number of prejudices affecting the ageing population, including: physical difficulties (being slow, requiring rest periods, physical inability to perform work duties); mental and cognitive difficulties (elderly workers deal poorly with emergency situations; they are not self-confident); proneness to mistakes and accidents (as a result, older workers are associated with extra costs); inability to concentrate; limited skills; lack of creativity or capacity for innovation; being too old for training; having difficulties in relations with young people; and being resistant to changes.

Finally, in May 2017 the Parliamentary Assembly issued the Resolution 2168 (2017) entitled Human Rights of Older Persons and Their Comprehensive Care dedicated to improvement of care for older persons and preventing their social exclusion. In this new Resolution the Assembly calls on the member states to take measures with a view to combating ageism. These measures should, inter alia, prohibit, in law, age discrimination in the provision of goods and services and promote a positive attitude to ageing through awareness-raising campaigns targeting the media (Parliamentary Assembly 2017). Thus, "ageism" is used for a third time in the text of the Assembly's resolution, indicating that ageism and its symptoms are becoming increasingly better identified within the Council of Europe.

\footnotetext{
${ }^{2}$ The author of the report confirmed that there are many types of ageism, which also affect young people, but the report and the drafted Resolution did not cover these.
} 


\subsubsection{A Holistic Approach}

The most crucial document relating to older persons is the Committee of Ministers Recommendation CM/Rec(2014)2 to Member States on the Promotion of Human Rights of Older Persons of 19 February, 2014 (Committee of Ministers 2014). It is a complex response to previous initiatives of the Parliamentary Assembly and applies a human rights-based approach to the situation of all older persons. The main assumption of this Recommendation is that older adults should enjoy their fundamental rights and freedom on an equal basis with other people. Its main goal is to eliminate barriers denying senior citizens their rights.

The Recommendation to Member States on the Promotion of Human Rights of Older Persons is of a new generation. It consists of two parts: a recommendation, and an appendix containing guidelines and good practices in the areas of nondiscrimination, autonomy, and participation, an older person's status before justice institutions, protection from violence and abuse, social protection, employment, and various aspects of care (including consent to medical care, palliative care, residential care, and institutional care). The Committee of Ministers recommends that member states ensure the implementation of the Recommendation's principles within national legislation and practice, that they consider providing examples of good practices, and that they evaluate the effectiveness of the measures taken. Aimed at raising awareness of the human rights and fundamental freedom of older persons, the Committee advises the wide dissemination of this document by the states among the relevant authorities and other stakeholders. The Recommendation provides that the Committee of Ministers will examine the implementation of its provisions within 5 years of its adoption. So, despite its non-binding character, the Recommendation is equipped with a follow-up mechanism, which might improve its chance of achieving long-term effects.

Surprisingly, the term "ageism" was not used in the text of the Recommendation. According to the Explanatory Memorandum interpreting this Recommendation, it merely "aims at promoting older persons' protection in societies where the ageism is rising or in situations where they may be vulnerable" (Council of Europe 2014, para. 30). The Memorandum does not explain the meaning of ageism, but it refers to the concept of ageism contained in Parliamentary Assembly Resolution 1793 (2011), Promoting Active Ageing-Capitalising on Older People's Working Potential.

Although the Recommendation does not use the term ageism, it tackles the principle of ageism directly and indirectly, through related issues such as age discrimination and awareness, by raising campaigns on older persons' rights, including the protection of whistle-blowers. The interpretation of the anti-discrimination clauses provided in the Memorandum to the Recommendation should be recognized as particularly important, because it may affect the future case law of the European Court of Human Rights and the European Committee of Social Rights. The Memorandum explains that the Recommendation reaffirms the principle of the full enjoyment of all human rights and freedoms of older persons without any discrimination in the 
meaning of Article 14 of the European Convention on Human Rights and Article E of the Revised European Social Charter. As mentioned above, "age" is not indicated among the premises stipulated in these anti-discrimination clauses, which, until the adoption of the Memorandum, created various controversies and ambiguities. Therefore, it is significant that the Memorandum provides extensive interpretation of these clauses by including age as a premise of "other status" (Council of Europe 2014, para. 31).

In the area of raising awareness, the Committee invites the member states to take appropriate measures to protect older persons from financial abuse, deception, and fraud. As to the situation of older persons who require assistance and care, the Committee places special attention on the implementation of sufficient measures aimed at raising awareness among medical staff, care workers, informal carers, and other individuals who provide services to older persons. The appendix to the Recommendation indicates German, Greek, Austrian, and Finnish good practices in this area as models to be followed by other member states. It also mentions the European project "Breaking the Taboo" (co-financed by the European Commission) aiming at drawing up a strategy for recognizing and counteracting violence against older women within families. At the same time, the Memorandum, referring to the European Court of Human Rights judgement in the Heinisch case, explains that one of the Recommendation's goals is to encourage member states to take legislative or other measures to protect anyone reporting abuse of older adults from dismissal or other reprisals. All such initiatives, if they are adopted by the states, might also contribute to the elimination of ageism, as the background of ill-treatment of older people.

\subsection{Conclusions}

Taking into account almost seven decades of the Council of Europe's activity in the field of human rights, addressing the rights of older persons is relatively new in this forum. Ageism has scarcely appeared in documents adopted in the last decade. It might also be stated that the threat of ageism and the need to take steps against it have only slowly been breaking through, with difficulties, in the agendas of the Council of Europe bodies, and have been introduced into very few Council of Europe official documents. However, it should be remembered that the Council of Europe is created by its member states and it reflects those member states' attitudes towards ageism and their political will to identify and eliminate it. Each document adopted by the Parliamentary Assembly and the Committee of Ministers is a result of a consensus achieved by the member states, which are not always aware of the existing problem, or are not interested in taking steps that require financial outlay, such as financing media campaigns or training caregivers and officials.

Currently, ageism is more often indicated in explanations to soft law documents, where it is understood as prejudice or stereotypes serving as grounds for discrimination, elder abuse, and other violations of older persons' human rights. It is confirmed 
that ageism is inextricably intertwined with discrimination, but both concepts are not used interchangeably. Only once has ageism been described as a special or unique form of discrimination and not as its source.

On the other hand, although ageism does not appear on the Council of Europe's agenda as often as sexism, racism, or homophobia, the Council of Europe has tangible tools at hand to take action against it. Potentially, each of the Council of Europe organs indicated at the beginning of this chapter is or might be competent to contribute to the elimination of ageism. This aim might be achieved thanks to the proper interpretation of the presently binding treaties, through calling on member states to take relevant measures and monitoring the implementation of these measures, and finally, through pointing out good and bad practices towards older persons. Certainly, the European Court of Human Rights, as a "hard" controlling mechanism, plays an extremely important role in this area. If it takes a position on ageism, or simply refers to relevant soft law documents, in its jurisprudence, it will be a quantum leap forward in the protection of older persons in Europe. If the fight against ageism is to be effective, other tools at the Council of Europe's disposal, such as monitoring and warning on violations of human rights, must also be mobilized. However, it seems that, at the present time, the Council of Europe is just at the beginning of this fight.

\section{References}

Age UK. (2011). Grey matters-A survey of ageism across Europe (EU Briefing and Policy Recommendations, 11). Retrieved from: http://www.ageuk.org.uk/Documents/EN-GB/Forprofessionals/ageism_across_europe_report.pdf?dtrk=true

Benoît-Rohmer, F., \& Klebes, H. (2005). Council of Europe law. Towards a pan-European legal area. Strasbourg: Council of Europe Publishing.

Bond, M. (2010). The Council of Europe and human rights. An introduction to the European Convention on Human Rights. Strasbourg: Council of Europe Publishing.

Butler, R. N. (1969). Age-ism: Another form of bigotry. Gerontologist, 4, 243-246.

Butler, R. N. (1975). Why survive?: Being old in America. New York: Harper and Row.

Cantillon, S., \& Vasquez del Aguila, E. (2011). Older people and age discrimination in the Irish labour market. Social Justice Series, 4, 28-48.

Committee of Ministers. (1994). Recommendation (94) 9 to Member States on Elderly People of 10 October 1994. Retrieved from https://search.coe.int/cm/Pages/result_details.aspx?ObjectId $=09000016804 \mathrm{c} 49 \mathrm{ec}$

Committee of Ministers. (2014). Recommendation CM/Rec(2014)2 to Member States on the Promotion of Human Rights of Older Persons of 19 February 2014. Retrieved from https:// search.coe.int $/ \mathrm{cm} /$ Pages/result_details.aspx?ObjectId=09000016805c649f

Council of Europe. (1949). Statute of the Council of Europe. Council of Europe, CETS (Council of Europe Teary Series, No. 1).

Council of Europe. (1950). Convention for the protection of human rights and fundamental freedoms (CETS No. 5).

Council of Europe. (1961). European social charter (CETS No. 35).

Council of Europe. (1987). European convention for the prevention of torture and inhuman or degrading treatment or punishment (ECAT) (CETS No.126). 
Council of Europe. (1988a). Additional protocol to the European social charter (CETS No. 128).

Council of Europe. (1988b). Explanatory report to the additional protocol to the European social charter. Retrieved from https://rm.coe.int

Council of Europe. (1991). Protocol amending the European social charter (CETS No. 142).

Council of Europe. (1996a). The revised European social charter (RESC) of 1996 (CETS No. 163).

Council of Europe. (1996b). Explanatory report to the European social charter (Revised). Retrieved from https://rm.coe.int

Council of Europe. (1998). Additional protocol to the European social charter providing for a system of collective complaints (CETS No. 158).

Council of Europe. (1999). Report of the f the Social, Health and Family Affairs Committee on future of senior citizens: Protection, participation, promotion (rapporteur: M. Hancock, Doc. 8461).

Council of Europe. (2000a). Protocol no 12 to the convention for the protection of human rights and fundamental freedoms (CETS No. 177)

Council of Europe. (2000b). Explanatory report on protocol 12 to the convention for the protection of human rights and fundamental freedoms. Retrieved from https://rm.coe.int/Council

Council of Europe. (2011). Report of the Social, Health and Family Affairs Committee, promoting active ageing - Capitalising on older people's working potential (rapporteur: D. Jacquat. Doc. 12431). Retrieved from http://www.assembly.coe.int/nw/xml/XRef/Xref-DocDetails-en. asp?FileID $=12862 \&$ lang=en

Council of Europe. (2013). Report of the committee on social affairs, health and sustainable development, combating discrimination against older persons on the labour market (rapporteur: S. Gafarova, Doc. 13292). Retrieved from http://www.assembly.coe.int/nw/xml/AssemblyList/ MP-Details-EN.asp?MemberID=6681

Council of Europe. (2014). Explanatory memorandum to the recommendation CM/Rec(2014)2 promotion of human rights of older persons adopted by the Committee of Ministers of the Council of Europe on 19 February 2014. Retrieved from https://search.coe.int/cm/Pages/ result_details.aspx?ObjectId=09000016805c6318

Council of Europe Commissioner for Human Rights. (2011). Report by Thomas Hammarberg, Commissioner for Human Rights of the Council of Europe, following his visit to Ireland from 1 to 2 June 2011 CommDH(2011)27. Retrieved from http://www.coe.int/en/web/commissioner

De Pauw, M. (2014). Interpreting the European Convention on Human Rights in light of emerging human rights issues: An older persons' perspective. Human Rights and International Legal Discourse, 8, 235-257.

Dzehtsiarou, K. (2011). European consensus and the evolutive interpretation of the European Convention on Human Rights. German Law Journal, 12(10), 1730-1745.

European Committee for the Prevention of Torture and Inhuman or Degrading Treatment or Punishment. (2015a). CPT Standards. CPT/Inf/E (2002) 1 - Rev. 2015. Retrieved from http:// www.cpt.coe.int/en/documents/eng-standards.pdf

European Committee for the Prevention of Torture and Inhuman or Degrading Treatment or Punishment. (2015b). Checklist for visits to social care institutions where persons may be deprived of their liberty by Jari Pirjola and Vytautas Raškauskas, Council of Europe CPT/Inf (2015) 23. Retrieved from http://www.cpt.coe.int/

European Committee of Social Rights. (2008). International Federation of Human Rights Leagues (IFHR) v. Ireland (Application No. 42/2007) Decision on merits of 3 June 2008. Retrieved from http://hudoc.esc.coe.int/en

European Committee of Social Rights. (2011). The Central Association of Carers in Finland $v$. Finland Complaint (Application No. 70/2011, decision of 4 December 2012). Retrieved from http://hudoc.esc.coe.int/en

European Court of Human Rights. (1978). Tyrer v. United Kingdom (Application 5856/72, judgement of 25 April 1978). Retrieved from http://hudoc.echr.coe.int/eng

European Court of Human Rights. (1979). Marckx v. Belgium (Application 6833/74, judgement of 13 June 1979). Retrieved from http://hudoc.echr.coe.int/eng 
European Court of Human Rights. (2002a). H.M. v. Switzerland (Application no. 39187/98, judgement 26 February 2002). Retrieved from http://hudoc.echr.coe.int/eng

European Court of Human Rights. (2002b). Larioshina v. Russia (Application no. 56869/00, decision as to the admissibility (inadmissible) of 23 April 2002). Retrieved from http://hudoc.echr. coe.int/eng

European Court of Human Rights. (2008a). Volintiru v. Italy (Application no. 8530/08, communicated case). Retrieved from http://hudoc.echr.coe.int/eng

European Court of Human Rights. (2008b). Dodov v. Bulgaria (Application no. 59548/00, judgement of 17 January 2008). Retrieved from http://hudoc.echr.coe.int/eng

European Court of Human Rights. (2009). Bina v. Russia (Application no. 45603/05, decision as to the admissibility (inadmissible) of 18 June 2009).

European Court of Human Rights. (2010a). Schwizgebel v. Switzerland (Application no. 25762/07, judgement 10 June 2010). Retrieved from http://hudoc.echr.coe.int/eng

European Court of Human Rights. (2010b). Watts v. the United Kingdom (Application no. $53586 / 09$, decision as to the admissibility (inadmissible) of 4 May 2010). Retrieved from http://hudoc.echr.coe.int/eng

European Court of Human Rights. (2011a). X and $Y$ v. Croatia (Application no. 5193/09, judgement 3 November 2011). Retrieved from http://hudoc.echr.coe.int/eng

European Court of Human Rights. (2011b). Heinisch v. Germany (Application no. 28274/08, judgement of 11 July 2011). Retrieved from http://hudoc.echr.coe.int/eng

European Court of Human Rights. (2014). McDonald v. the United Kingdom (Application no. 4241/12, judgement 20 May 2014). Retrieved from http://hudoc.echr.coe.int/eng

Grześkowiak, A. (2012). Analiza wybranych aspektów zjawiska ageizmu w Europie z wykorzystaniem wykresów typu biplot [Analysis of selected aspects of ageism in Europe with application of biplots]. Ekonometria, 3, 70-82.

Hammarberg, T. (2012). Discriminatory policies towards elderly people must stop (Human Rights Comment of 19 January 2012). Retrieved from http://www.coe.int/en/web/commissioner

Jones, A., \& Kelly, D. (2014). Whistle-blowing and workplace culture in older peoples' care: Qualitative insights from the healthcare and social care workforce. Sociology of Health \& Illness, 7, 986-1002. https://doi.org/10.1111/1467-9566.12137

Madsen, M. R. (2007). From Cold War Instrument to Supreme European Human Rights Court: The European Court of Human Rights at the Intersection of International and National Law and Politics. Law \& Social Inquiry, 1, 137-159.

Martin, C., Rodríguez-Pinzón, D., \& Brown, B. (2015). Human Rights of Older People: Universal and Regional Legal Perspectives. Series: Ius Gentium: Comparative Perspectives on Law and Justice, 45, 125-215.

Meenan, H. (2007). Reflecting on age discrimination and rights of the elderly in the European Union and the Council of Europe. Maastricht Journal of European \& Comparative Law, 1, 39-83.

Mikołajczyk, B. (2013). Is the European Convention on Human Rights ready for global ageing? The International Journal of Human Rights, 4, 511-529.

Palmore, E. (2001). The Ageism Survey: First findings. The Gerontologist, 5, 572-475.

Parliamentary Assembly. (1999). Recommendation 1428 (1999), Future of senior citizens: Protection, participation, promotion of 23 May 1999. Retrieved from http://website-pace.net/ en_GB/web/apce/documents

Parliamentary Assembly. (2011). Resolution 1793 (2011), Promoting active ageing_Capitalising on older people's working potential of 28 January 2011. Retrieved from http://website-pace. net/en_GB/web/apce/documents

Parliamentary Assembly. (2017). Resolution 2168 (2017) Human rights of older persons and their comprehensive care of 30 May 2017. Retrieved from http://website-pace.net/en_GB/web/apce/ documents 
Parliamentary Assembly Resolution 1958. (2013). Combating discrimination against older persons on the labour market of 4 October 2013. Retrieved from http://website-pace.net/en_GB/ web/apce/documents

Shelton, D. (2000). Commitment and compliance: The role of non-binding norms in the international legal system. Oxford: Oxford University Press.

Shelton, D. (2003). Law, non - law and the problem of 'soft law'. Introduction. In D. Shelton (Ed.), Commitment and compliance: The Role of non-binding norms in the international legal system (pp. 1-18). Oxford: Oxford University Press.

Sivonen, I. (2012). The Commissioner for Human Rights. In G. de Beco (Ed.), Human rights monitoring mechanism of the Council of Europe (pp. 1-18). London: Routledge.

Spanier, B., Doron, I., \& Milman-Sivan, F. (2013). Older persons' use of the European Court of Human Rights. Journal of Cross Cultural Gerontology, 4, 407-420.

Spanier, B., Doron, I., \& Milman-Sivan, F. (2016). In course of change? Soft law, elder rights, and the European Court of Human Rights. Law and Inequality, 1, 55-86.

Świtalski, P.A. (2009). Miejsce Rady Europy w europejskiej architekturze instytucjonalnej [Council of Europe in the European institutional architecture.] In H. Machińska (Ed.), 60 lat Rady Europy. Tworzenie i stosowanie standardów prawnych [60 years of the Council of Europe. Establishing and enforcement of legal standards] (pp. 9-34). Oficyna Prawa Polskiego Council of Europe.

Terpan, F. (2015). Soft law in the European Union - The changing nature of EU law. European Law Journal, 1, 68-96.

Vasak, K. (1977). Human rights: A thirty-year struggle: The sustained efforts to give force of law to the Universal Declaration of Human Rights. UNESCO Courier, 11, 28-32.

Wintemute, R. (2004). "Within the ambit": How big is the "gap" in article 14 European Convention on Human Rights? European Human Rights Law Review, 4, 366-382.

Open Access This chapter is licensed under the terms of the Creative Commons Attribution 4.0 International License (http://creativecommons.org/licenses/by/4.0/), which permits use, sharing, adaptation, distribution and reproduction in any medium or format, as long as you give appropriate credit to the original author(s) and the source, provide a link to the Creative Commons license and indicate if changes were made.

The images or other third party material in this chapter are included in the chapter's Creative Commons license, unless indicated otherwise in a credit line to the material. If material is not included in the chapter's Creative Commons license and your intended use is not permitted by statutory regulation or exceeds the permitted use, you will need to obtain permission directly from the copyright holder.

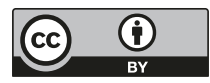




\title{
Chapter 21 \\ The European Union's Approach towards Ageism
}

\author{
Nena Georgantzi
}

\subsection{Introduction}

The European Union (EU) provides legal guidance and policy coordination for its member states and represents an additional layer in the political, economic, and social reality faced by older people. What started as a purely economic union has been transformed into an enhanced inter-state collaboration on an increasing number of policy areas. The EU is now expected to act not only in several fields that impact older people's lives, including non-discrimination and human rights, gender equality, patient safety, consumer protection, and passengers' rights, but also to engage in "soft cooperation" on aspects of social security, notably in the fields of pensions and healthcare. Studying ageism at the EU level can, therefore, help to unravel whether the multilateral legal, policy, and economic processes serve to disable or foster the various barriers and discrimination in old age.

This chapter does not discuss the case law of the Court of Justice of the European Union (CJEU), which is presented in another Chap. 19 Doron et al., 2018 of this volume, but instead makes a critique of the scope of the EU's agenda to tackle ageism. Focusing on the end of the life spectrum and based largely on experiential knowledge of the EU arena, I do not look into ageism as a theoretical construct but instead am interested in its policy application by the Union's bodies.

Under these considerations I critique the EU's narrow agenda, which fails to adequately address equality in old age. I also argue that the Union's conceptualization

N. Georgantzi $(\square)$

National University of Ireland Galway, Galway, Ireland

AGE Platform Europe, Brussels, Belgium

e-mail: Nena.georgantzi@age-platform.eu

(C) The Author(s) 2018

L. Ayalon, C. Tesch-Römer (eds.), Contemporary Perspectives on Ageism, International Perspectives on Aging 19,

https://doi.org/10.1007/978-3-319-73820-8_21 
of ageing and older people is susceptible to prejudice. To do this, the chapter first presents the sense of equality that guides the assessment of the EU's performance in tackling ageism (Part 21.2). Second, it discusses the EU's main achievements in the area of non-discrimination and ageing, as well as its shortcomings (Part 21.3). Third, it exposes examples of ageist discourse that create discrepancies between EU rhetoric and practice to promote equality for all ages (Part 21.4). And finally, it suggests how EU laws and policies can move towards a more substantive form of equality through a human rights-based approach (Part 21.5).

\subsection{Towards a Substantive Understanding of Equality in Old Age}

Ageism is not the same as discrimination as the latter involves a manifestation of ageist prejudice in the form of behaviour or treatment (Herring 2009, p. 12). According to its treaties, the EU has a duty to combat discrimination (Article $3 \S 3$, Treaty on the European Union 2012), but there is no language explicitly stipulating the need to fight ageism in all its forms or to address comprehensively the social construct of old age that is entrenched in European society. For this reason, in this chapter I understand the EU's efforts in the area of non-discrimination as contributing generally to an anti-ageist agenda. However, the lack of the use of the term and concept of ageism in EU discourse probably reveals a narrow understanding of structural inequalities in old age.

Equality and non-discrimination are not uncontroversial terms; they are attributed diverse meanings and goals (Fredman 2011, p. 40). Not all forms of unequal treatment qualify as wrongful discrimination, even more on the grounds of age where-according to international and European law-even direct discrimination, such as age limits, can be justified in the context of labour market policies, pension systems, and the allocation of scarce resources.

This chapter goes beyond a formal understanding of equality according to which likes should be treated alike. It adopts Fredman's (2003) definition of equality as "the facilitation of choice or autonomy, the protection of dignity and the enhancement of participative democracy or social inclusion" (p. 38). Accepting that structural barriers, such as ageist norms, may create disadvantages for older people, it asserts that positive action might be necessary to achieve equality of opportunities and prevent undignified treatment and marginalization of this population.

This broad understanding of equality is not merely theoretical but builds on the aspirations of the EU treaties and the Charter of Fundamental Rights (known as the Charter or the EU Charter). Thanks to Article 19 (previously Article 13) of the Treaty on the Functioning of the European Union (TFEU), the EU can take positive action, such as adopting dedicated legislative measures, to preclude discrimination. Moreover, Article 21 of the Charter of Fundamental Rights (European Union 2016), which became part of the EU's primary law after the Treaty of Lisbon in 2009 
(European Union 2007), prohibits discrimination on the grounds of age. This provision represents a novelty in human rights law, which lacks an explicit and clear protection from age discrimination. Nevertheless, the EU's primary law merely gives the possibility for the EU to take anti-discrimination measures, without imposing a duty to do so. In addition, positive action is possible only upon the unanimous agreement of all the member states of the European Council (Article 19\$1 TFEU), in compliance with the EU's existing array of competences and the principle of subsidiarity, ${ }^{1}$ as well as only within the remits of EU law (Article 51 of the EU Charter of Fundmantal Rights). These limitations give broad discretion to EU bodies and member states to decide whether and what type of positive action might be needed to tackle discrimination.

In the legal tradition older people are consistently problematized as subjects of social security and economic and social rights (Dabove 2015, p. 141). Legislative instruments preceding the EU Charter of Fundamental Rights, including the EU's 1989 Community Charter of Fundamental Social Rights of Workers (European Community 1989), which enshrined the right to adequate income in retirement, and the Revised European Social Charter of the Council of Europe (1996), which introduced the first legally binding reference to the "right of the elderly to social protection" under Article 23, only attributed social rights in old age, discounting aspects of equal treatment. Failing to enshrine a vision of equality in old age can send a discriminatory message and further reinforce stereotypes of older people as recipients of welfare and individuals with needs instead of rights.

The EU Charter of Fundamental Rights includes "the most reliable and definitive confirmation of the rights of the elderly ... within the EU" (Meenan 2007, p. 65). It recognizes in Article 25 "the rights of the elderly to lead a life of dignity and independence and to participate in social and cultural life." Unlike previous instruments, this provision is introduced in the Equality Chapter of the Charter and represents another remarkable legal innovation (EU Network of Independent Experts on Fundamental Rights 2006). Article 25 should be read as giving guidance on how equality in old age needs to be interpreted so that it becomes effective. What this Article tells us is that - as with other discrimination grounds- the EU aspires to an application of substantive equality that needs to be understood as an obligation not only to refrain from action that treats people less well because of their age but also to take into account the particular needs of older people through positive action (Duncan 2008; McLachlin 2013; Nikolaidis 2015). As a matter of fact, the EU legislature provides us with a clear benchmark on the basis of which we can measure the Union's performance in the pursuit of equality in old age. Dignity, independence, and participation are the bedrock of a human rights-based approach to equality in old age. These notions mirror Fredman's (2003) definition of substantive equality, which refers to dignity, choice, autonomy, participative democracy, and social inclusion (p. 38).

\footnotetext{
${ }^{1}$ According to the principle of subsidiarity, in areas where the EU does not have exclusive competence (including non-discrimination), action is in principle at the discretion of member states, and the EU can only take action if the objectives cannot be sufficiently achieved at the national level.
} 
Placing dignity at the centre of equality means that the EU should not diminish older people or perpetuate ageist treatment. Lumping people together in age categories can be a risk to their inherent dignity as it attributes certain characteristics (such as loss of ability, contribution, or value) to the individual and accepts stereotypical views of old age. In practice, a conception of equality that respects the dignity of the person should not result in undermining the moral and social status of older people. At the same time, equal respect for the dignity of people of different ages will on occasion require treating age groups differently (Duncan 2008). In addition, the distinct experiences of age discrimination faced by older persons justify tailored measures that take into account the specific challenges of old age (Mégret 2011; Seanad Public Consultation Committee 2012). For example, more needs to be done to cater for groups particularly at risk of discrimination, such as older women, who, in addition to suffering from gender and age discrimination in the labour market, are now struggling with increased difficulties to reconcile work and family care duties as a result of the reduction in social services to older persons.

When independence underpins equality agendas, policies are directed towards giving people of all ages choices to live independently. To reach this objective, not only are older people to be offered the same array of opportunities as everyone else, but they are also to be enabled to fulfil their choices (Fredman 2003, p. 44). This understanding implies going beyond an obligation to abstain from limiting older people's autonomy to taking steps, such as promoting adapted housing, adequate income, access to flexible working, care, and support so that older people can continue to live independently.

The notion of participation is broad, encompassing social and cultural life (which are included in the letter of Article 25) but also-according to the explanations to the Charter (Fundamental Rights Agency n.d.) - all other spheres of life. Age discrimination and age stereotyping underpin social exclusion, whether in relation to employment, health care, or the fair distribution of assets and resources (Stuckelberger et al. 2012). Including participation in the conceptualization of equality is not merely about avoiding interference but also about facilitating meaningful involvement, strengthening consultation, and combating social exclusion, for example through non-discrimination legislation, accessibility standards, and affirmative action for the integration of those in vulnerable situations, such as migrants and people with functional limitations. A substantive equality approach is not exclusionary, in that it aims to ensure equal participation in society and build the capacity of individuals to understand and claim their intrinsic rights.

In sum, the EU Charter aspires to more than consistent treatment to achieve equality across all ages. Yet the absence of a legal duty for the EU to adopt nondiscrimination legislation and promote equality, which applies to all grounds of discrimination based on Article $19 \S 1$ TFEU, is one of the reasons why, to date, "the scope of legal protection on grounds of age hardly goes beyond the employment sector" (Lassen et al. 2014, p. 106). Whilst acknowledging this normative restriction, this chapter investigates the potential for the EU to become a driver for a 
"society for all ages". It critically analyses EU law, policy, and discourse based on the three criteria set out in the Charter of Fundamental Rights-dignity, independence, and participation - to discuss the EU's record on promoting equality for older people and to suggest how future EU action can be framed so that it effectively meets the Charter's objectives.

\subsection{Key EU Milestones and Their Limitations}

\subsubsection{EU Anti-discrimination Legislation}

Arguably one of the key achievements in the EU's fight against ageism is the 2000 directive establishing a framework for equal treatment in employment and occupation, also known as the Employment Framework Directive (Council of the European Union 2000). This law has provided minimum standards throughout Europe and has led to positive reforms at the national level (Tymowski 2016). It has moreover helped to challenge structural inequalities in the labour market, such as upper age limits in job advertisements (European Commission 2014).

However, as explained in a previous chapter (2018; Chap. 20), Article 6 of the Employment Framework Directive allows member states to apply a wide range of exceptions to the rule of age equality in order to fulfil their social and employment objectives. For example, it is legitimate to offer professorships to younger people as a means of encouraging recruitment in higher education (see, for example, Vasil Ivanov Georgiev v. Tehnicheski universitet-Sofia, filial Plovdiv. Joined cases C-250/09 and C-268/09, 2010). For O'Dempsey and Beale (2011), direct discrimination on the basis of age does not appear to be exceptional, which "creates an inherent vulnerability at the heart of the prohibition of age discrimination, and means that a careful balance has to be struck in order to ensure that the prohibition is meaningful" (p. 5). This broad discretion afforded to national jurisdictions to set aside equal treatment in old age has led to diverging national practices and levels of protection against age discrimination across the EU (Tymowski 2016).

Another shortcoming of this legislation is that it fails to extend reasonable accommodation to older workers. The concept of reasonable accommodation creates a duty to make necessary adjustments so that individuals can gain access or perform tasks, which otherwise they would be unable to. This right, which, according to Nikolaidis (2015), is inextricably linked with equality, at the moment only exists for people with disabilities. Yet giving older people a right to flexible working, adjustment of the work environment, and arrangements to support informal care provision makes economic sense and also increases equality of opportunities for senior workers. However, to date, there is limited discussion on extending reasonable accommodation beyond disability and what discussion there is is only at 
a theoretical level. ${ }^{2}$ To move from theory to practice the EU would need to revise its legislation and should also ensure that future initiatives on work-life balance take due account of the interdependencies between the working population and retired people, with both sides occasionally providing financial support and care for the other age group.

Moreover, the EU law does not extend protection from age discrimination outside the field of employment. In 2008, the European Commission prepared a proposal for a Council Directive on implementing the principle of equal treatment between persons irrespective of religion or belief, disability, age, or sexual orientation (European Commission 2008b). If adopted, this piece of law would complete the EU framework by affording to the above discrimination grounds a similar level of protection as currently exists for race and gender under EU law (European Commission 2008a). However, 8 years after the initial proposal, the directive is still stuck in negotiations, due to strong resistance from a few member states and despite the promise of the current Commission that the so-called "horizontal directive" would be passed within a year of its election. Due to this lack of coverage of other areas it can be argued that there exists a "hierarchy of grounds", whereby EU law protects more comprehensively against discrimination on some grounds than on others (Fundamental Rights Agency 2012).

With regard to age discrimination, the draft directive includes an exception for financial services, for which age can be used as a proxy when it is a determining factor for the product or service in question (Article 2\$7, European Commission 2008b). In addition, there is a general clause allowing public and private actors to apply measures which discriminate on the ground of age as long as they can be justified by a legitimate aim. This draft provision (Article 2\$6), which is similar to Article 6 of the Employment Directive, allows for a broad range of measures to be objectively justified as non-discriminatory. Such measures include situations where appropriate age differences might be needed, as for instance children's toilets, children's airfares, or age limits for selling alcohol.

In 2015, the Latvian EU Presidency included a new exemption for preferential pricing in respect of specific age groups in the draft directive (Article $2 \S 6$ c, Council of the European Union 2015b). The proposed new text by the Latvian Presidency allows any preferential charges, fees, or rates in respect of persons in a specific age group not to constitute discrimination. This new clause creates open-ended opportunities for commercial actors to apply different prices for specific age groups. Although intended as a means for seniors or young people to benefit from special tariffs and services, it does not exclude purely commercially driven risk assessments. In the point of view of AGE Platform Europe, the representative network of older people at the EU level, this addition weakens the principle of age equality and practically excludes older people from the scope of the directive (AGE Platform Europe 2015a).

${ }^{2}$ For a notable exception, see Bribosia and Rorive (2013). 
At the very least, this long list of exceptions seems to be telling us more about when discrimination is acceptable than when it is not. Not only do these exceptions complicate the negotiations of the draft directive, but they also enhance the view that old age disadvantages are unavoidable and therefore acceptable (Calasanti et al. 2006). Failing to enshrine a universal protection from age discrimination, old age is perceived as a relevant criterion of social structures rather than as a source of systematic inequalities. In its report on the implementation of the Employment Directive, the European Commission underlined that concerted efforts are needed to remove prejudices and "clarify the circumstances in which difference of treatment based on age may be justified" (European Commission-Research and Innovation 2014, p. 49). Undoubtedly, the even more complex set of exemptions foreseen under the horizontal directive makes it even more difficult to clearly demarcate which treatment is justified and which is discriminatory.

In this section I have argued that the provisions of both the Employment Framework Directive and the draft horizontal directive are susceptible to abuse. They can be used to limit the opportunities of older people to access employment, goods, and services and therefore breach the principle of independence. By considering age limits and proxies as valid and widely acceptable they therefore reinforce stereotypes of older people as different from the rest of the population and disregard their individual capacities, which offends their human dignity and may lead to degrading treatment. They do not distinguish between policies that enable participation and measures that lead to exclusion of certain groups and therefore they also fail to promote equal participation.

Instead of endorsing and justifying blunt age limits, in order to comply with the Charter's objectives, EU legislation and its interpretation by the CJEU should build on the benchmarks of Article 25 to define whether a treatment is discriminatory or not. Article 25 requires us to ask whether differential treatment-be it in the form of "justified discrimination" or positive action-facilitates the participation of older people in public, economic, social, and cultural life or rather impedes their dignity and independence and therefore breaches their rights. This is a simple test but also a fundamental change in mindset that is necessary to deliver the promise of age equality and to challenge ageism with the same rigorousness as with other forms of discrimination. Indeed, it is not so long ago that distinctions on the basis of one's sex were also considered to be "objectively justified". For example, a 1961 case of the Italian Constitutional Court considered female adultery as more serious than male adultery and therefore approved the differential treatment of men and women on this matter (de Witte 2010). EU law has been instrumental in levying genderbased stereotypes and breaking down the barriers to the equal participation of women. To tackle injustice and prejudices based on age, the EU needs to abandon its conservative outlook on age-based distinctions and inspire an anti-ageist vision across its legal and policy framework. 


\subsubsection{EU Policy}

Policy action complements the Union's legislative competence and can provide useful guidance on how to address systemic forms of ageism. The EU addressed ageing for the first time in 1982 in the European Parliament Resolution "on the situation and the problems of the aged in the European Community" (European Parliament 1982). Seizing the momentum of the first World Assembly on Ageing that took place in the same year, this resolution underlined the EU's responsibility to take measures, including reallocating the budget, to help older citizens. It moreover reaffirmed older people as citizens with equal and full rights. Several age-related policy proposals followed. Notably, in 1990, the European Council adopted a Decision on "Community Actions for the Elderly" (Council of the European Communities 1990), which prescribed priority actions aiming at their integration and declared 1993 as the European Year of the Elderly and Solidarity Between Generations. These early policy directions provide a relatively comprehensive roadmap for promoting older people's participation and independence and view seniors as citizens with full rights.

Since then, EU legislation, funding, research, and policy coordination in the field of ageing has been well developed (European Commission 2012b). These activities range from adopting senior employment strategies and addressing the risk of elder abuse to promoting lifelong learning and funding research on new technologies that can, among other things, support older people's stay at home (AGE Platform Europe 2012). For example, the EU has set up a platform for exchange among private actors that have signed onto "diversity charters"- - voluntary commitments to fight discrimination, including on the grounds of age-in the workplace (European Commission 2015d). These policy tools have a potential to promote the three aspects of substantive equality, but they also entail some gaps.

The last time the Commission made explicit its commitment to fight against discrimination on age was in a communication that provided the baseline for the 2008 legislative proposal for a horizontal directive (European Commission 2008a). Moreover, the European Commission has not paid attention to the widespread age limits that exist across the region in access to health services; neither has it addressed age discrimination against older people with disabilities, despite the fact that it bound by the UN Convention on the Rights of Persons with Disabilities (UN CRPD) (United Nations General Assembly 2007) and complements member states' efforts to materialize the rights therein (AGE Platform Europe 2016).

Even without the adoption of the draft horizontal directive, the Commission has the possibility to address the (in)validity of age-related criteria in soft policy measures and in the implementation of existing mechanisms, such as its "Disability Strategy" (European Commission 2010). Tolerating age-based distinctions, failing to provide guidance for member states on how to apply equal treatment in all ages, and lacking a cohesive approach to the fight against age discrimination gives a message of older people as potentially being less deserving of health care, support in case of disability, and overall equal treatment. 
On the other hand, the European Commission financially supports NGOs, such as AGE Platform Europe, which brings together older people's associations from across the EU. Through its funding, the Commission indirectly empowers older people and facilitates their participation in decision-making. It also promotes a positive image of old age and supports older people to become active citizens. Nevertheless, the Commission does not consistently consult representatives of older people in dossiers of direct relevance to them, thus failing to attain their equal participation. For example, AGE Platform Europe has deplored the lack of involvement of older people in the implementation of the UN Convention on the Rights of Persons with Disabilities, despite the EU's rhetoric about the relevance and direct application of this treaty for a large part of the older population (AGE Platform Europe 2015b). The NGO has also stressed that older people are rarely consulted by the Council when the rights of older people are discussed.

EU-funded research can help to understand discrimination in old age and provide the evidence necessary for adopting or adjusting policy action. While EU research in the field of ageing is relatively developed, ${ }^{3}$ one still comes across age limits in data collection and/or the use of age categories that are too broad, such as "the 65+ population". For example the Fundamental Rights Agency (FRA), an EU advisory body, included age limits in a recent study on violence against women and failed to include older people in the sample of a project on the rights of people with disabilities (Fundamental Rights Agency 2014a, b). These generalizations treat older people as a homogeneous group and do not reflect the living realities and challenges in different stages of the lifespan. Associating "the old" with a fixed set of characteristics is demeaning and a violation of their human dignity.

On a positive note, in 2015, age discrimination and the rights of older people were included for the first time in the EU's Action Plan for Human Rights, which is a roadmap for the Union's relations with third countries (Council of the European Union 2015a). Under priority 16 the Action Plan mentions, "Increase awareness of the human rights and specific needs of older persons paying particular attention to age based discrimination." Unfortunately, this commitment is not mirrored in the EU's internal affairs, where "there is a lack of a coherent policy and legal framework to enhance the enjoyment of the rights of the elderly" (Lassen et al. 2014, p. 107).

To justify its inaction, the European Commission has argued that the primary duty to deliver age equality and fulfil the rights of older people falls within the competences of member states and limits its obligation to respecting the rights of older people - that is, to refrain from action that deliberately impacts the enjoyment of these rights (European Commission 2016c, p. 89). Although the same claim can be

\footnotetext{
${ }^{3}$ The creation of the European Equality Law Network, a group of legal experts on non-discrimination, which provides analysis on issues of equality across European states, is a positive example. Other examples include the funding of the Survey of Health, Ageing and Retirement in Europe (SHARE), the Active Ageing Index, and several studies on experiences of discrimination (Eurobarometer). Eurofound, the European Foundation for the Improvement of Living and Working Conditions, has compiled an impressive set of research on ageing, with a focus on work, retirement, and care.
} 
made for the rights of other groups at risk of discrimination, the EU has only used this argument for older people. As a matter of fact, the Union has an extensive policy framework for the protection of women: in 2010 the EU launched a "Strategy for the Equality Between Women and Men," which was recently extended to 2019 (European Commission 2015e). The European Commission also enshrined its priorities in the field of disability in the "Disability Strategy" (European Commission 2010) and adopted an "EU Agenda on the Rights of the Child" (European Commission 2011). Other equality initiatives include the "EU Framework for National Roma Integration Strategies" (Council of the European Union 2011), the "List of Actions by the Commission to Advance LGBTI ${ }^{4}$ Equality" (European Commission 2015c), and several soft and legal measures to promote the rights of children, racial, ethnic, religious, and linguistic minorities as well as to tackle intolerance (European Commission 2016c).

Overall, EU bodies prefer an ad hoc and opportunistic approach to ageing; while this can help to promote independence and participation in the labour market, at the same time it does not reflect the broad aspirations inscribed in the EU's early texts, which were based on equality and rights. Ageing policies are nowadays primarily driven by economic arguments and as a result the policy framework on active ageing and the silver economy ${ }^{5}$ is a lot more developed than actions to combat poverty, exclusion, elder abuse, and discrimination. References to the rights of older people in human rights reporting by the European Commission, the European Parliament, and the European Council are scarce and unsystematic (AGE Platform Europe 2013). At the same time, ageing and older people are not "mainstreamed" in other areas, such as disability, in the same way that, for instance, gender is.

Compared to other discrimination grounds, the EU has deprioritized age discrimination and older people's issues (AGE Platform Europe 2014b). This results in soft, incoherent policies, which fail to establish age discrimination as wrongful and to politicize the fight against ageism. To achieve the threefold objectives of substantive equality, the EU needs to open up a dialogue on how to extend and scale up its activities to fight age discrimination and how to ensure consistency and avoid gaps in its existing array of work.

\subsubsection{The Legacy of the European Year 2012}

An exception to the residual concern of the EU for older people was the European Year on Active Ageing and Solidarity Between Generations (EY2012). During this year, the Union put a spotlight on older people and aimed at, among other things, promoting activities "which will help to combat age discrimination, to overcome

\footnotetext{
${ }^{4}$ Lesbian, Gay, Bisexual, Transexual and Intersex.

${ }^{5}$ According to Eatock (2015), "The "Silver Economy" can be defined as the economic opportunities arising from the public and consumer expenditure related to population ageing and the specific needs of the population over 50" (Eatock 2015, p. 2).
} 
age-related stereotypes and to remove barriers" (European Parliament \& European Council 2011, art. 2). However, the expectations set out for the year were relatively low: EY2012 was intended as a framework for the mobilization of stakeholders to foster awareness raising, exchange good practices, and convey a more positive image of population ageing and did not aim at extending the scope of age discrimination at EU and national levels. Despite lacking a real potential for measurable impact on the ground, EY2012 offered funding opportunities for national authorities to develop comprehensive strategies on active ageing, which "are about changing attitudes and developing a more positive approach to tackling the challenges of ageing" (Zaidi 2015, p. 2). While it is out of the scope of this chapter to explore how EY2012 influenced action at a national level, it is certain that follow-up initiatives are needed to translate the political momentum into a "strong political legacy that delivers concrete results" in the long term (Council of the European Union 2012).

However, some tools developed during EY2012 may serve as building blocks for anti-ageist policies. "Guiding Principles on Active Ageing and Solidarity Between Generations" (Council of the European Union 2012) provides a roadmap for such action. This document, which was adopted by the Council in December 2012, makes specific reference to age discrimination, but only focuses on the labour market. Moreover, at the EU level, following EY2012, the active ageing agenda has been integrated into existing EU frameworks, in particular in "Europe 2020", which is the EU's strategy for "smart, sustainable and inclusive growth" and includes the "European Innovation Partnership on Active and Healthy Ageing" (European Commission 2012a). These initiatives have a strong focus on increasing the participation of older people in the labour market and ensuring the sustainability of health and social care systems through innovative mechanisms. Whilst these actions have the potential to support independent living in old age, they lag behind in effectively promoting dignity and participation beyond the economic sphere.

Almost 5 years after EY2012 we are witnessing the deficiency of EU policies in living up to the commitments made during the European Year. Despite its focus on active ageing, age discrimination in the labour market has not waned; older workers are still penalized despite research that shows that their productivity and expertise increase in old age (European Commission 2014, p. 49). Negotiations on the horizontal directive have not advanced, and the European Commission has not included older people's rights or age discrimination in its work priorities and "is concentrating its action on the rights of children, women, persons with disabilities" (Parent 2015, p. 3). In fact, the portfolio of the Commissioner for Justice, Consumers and Gender Equality does not include any reference to age discrimination, with the exception of the horizontal equal treatment directive (Juncker 2014a). EU policy initiatives on ageing thus seem to be consistently downgraded into actions that view older people as service users or consumers, and the actual impact of EY2012 remains questionable. As a result, the recently announced "European Pillar of Social Rights" will concentrate on work-related rights (European Commission 2016a).

Drawing attention to the older workforce and to financial gains reflects the hierarchy of the economic over the social in EU policymaking. The EU action on old age is characterized by an à la carte approach, which does not encompass all forms 
of exclusion and fails to recognize the multiple roles played by older people in society. Looking at old age only through the lens of employment and social protection assumes that older people are either active in the labour market or in need of care and protection. The following section explores whether the EU's discourse on ageing reflects the diversity of the group or rather ignores older people's equal rights as citizens and human beings.

\subsection{Ageist Discourse and the Diversity of Older People}

\subsubsection{The Elder Burden Narrative}

Although age-inclusive laws and policies can considerably improve the lives of older people, when institutions, structures, and behaviours are underpinned by ageist assumptions, older people face significant disadvantages in their participation in society. EU policy action aims at "confronting demographic change" (European Commission 2005), "dealing with the impact of an ageing population" (European Commission 2009) and the "dramatic changes in the age structure in the EU" (European Commission-Economic and Financial Affairs 2015, p. 1). It highlights the financial implications of demographic ageing, engaging in a discourse on dependency, and the so-called "elder burden". Yet it has been argued that this narrative of the burden of older people creates a new form of ageism, imposes various forms of societal barriers, and nourishes intergenerational conflict (Walker 2015).

An illustrative example of this prejudiced approach is the 2015 Ageing Report, which presents a mere macroeconomic analysis of the costs of ageing and consistently uses old age as a proxy for declining abilities and increasing needs (European Commission-Economic and Financial Affairs 2015). By contrast, the 2015 Youth Report presents a comprehensive account of the situation of young people, how the economic crisis influenced them, and what actions the EU should take to address them (European Commission-Youth 2015). The choice of authors of the two documents is indicative of the different lenses through which EU institutions view ageing and youth: the former is drafted by the European Commission's financial service unit, the latter by the Directorate General for Education and Culture, which is in charge of youth policies. Thus, ageing is considered at the macro level and in relation to the financial implications it brings, without considering aspects of individual ageing and older person's rights. On the other hand, youth benefits from a comprehensive approach that reflects on societal barriers to their active inclusion, as well as EU initiatives to promote it.

Certainly economic concerns linked with demographic ageing are not only inevitable but also to a large extent legitimate. However, the pursuit of socioeconomic objectives, such as ensuring the sustainability of social protection systems, promoting youth employment, and improving the capitalist function of the market, needs to be accompanied by a reflection of how older people can be empowered as citizens 
with full rights and responsibilities to participate in employment and education and contribute to social, political, cultural, and economic life.

Besides, the presentation of ageing as a profound social challenge resembling acute financial and economic crises is per se ageist, as it fosters a view of old age as a life stage of unmet needs rather than as a period of productivity, growth, and equal opportunities (Huenchuan and Rodríguez-Piñero 2011, p. 20; Thompson 2005). Framing ageing policies based on dependency ratios assumes that everyone 65 and over is not working or contributing in another capacity to the economy and to society. Not only are working lives across the EU gradually extending beyond this threshold, but also a large number of older people contribute in the informal sector, in particular, as volunteers and caregivers (Ehlers et al. 2011). In addition, the older generation represents unexploited social capital as mentors and socio-political actors in their communities. Sustaining a view of old age through a dependency lens diminishes older people's role, ignores their multiple contributions to society, and equates ageing with unproductivity, impairment, and leisure. It thus legitimizes and reinforces older people's marginalization, including by providing them with fewer and lower quality services (Fredvang and Biggs 2012).

Instead of merely focusing on old age as a bounty, policies need to equally address investments in ageing as an opportunity. The previous part of this chapter provided evidence of an asymmetric response to an ageing society. This policy thinking is worrisome from a social justice perspective, as it does not empower older people to use their accumulated knowledge and life experience for the benefit of society. This approach moreover, ignores how structural ageism, which is inherent in legal, social, and economic institutions, diminishes older people's life chances (Scrutton 1990, p.21, as cited in Duncan 2008; Macnicol 2006).

\subsubsection{Ageing as a Disability}

The EU shares the viewpoint that there is an important overlap between age and disability-related issues and suggests viewing older people's vulnerability from a disability angle (European Union 2011). This approach ignores the idea that "growing older should not be a disability in itself" (Morgan and David 2002, p. 436). It moreover disregards the diversity of the older age group, since although the prevalence of disability increases with age, approximately half of the $65+$ generation across the EU does not encounter disabilities (Grammenos 2013). It also impedes a due consideration of the distinct challenges of old age and the social factors that impact older people's lives.

Ageism is not the same as "disablism," although older people may be victims of both (Thompson 2005, p. 72). Old age is a period of systematic inequalities in distributions of power, roles, and resources, which unless acknowledged are likely to be seen as natural, and thus beyond dispute (Calasanti et al. 2006, pp. 17-18). It is these structural disadvantages and stereotypes that, in association with disability and other characteristics and experiences, such as gender and race, may lead to 
multiple discrimination. Using the disability legal and policy framework to provide adequate responses to specific issues that affect older people, such as access to formal and informal services, accessibility, and others, is an important tool for ageing advocates. However, equating old age with disability is an unwelcome stereotype, since it narrows the scope of old age needs, challenges, and contributions solely to those related to impairment.

\subsubsection{The Active Ageing Trap}

The "active ageing" paradigm has potential as an alternative to the idea of older people as dependent, disabled, or vulnerable. Drawing on the work of the World Health Organization (WHO) (World Health Organization 2002), for the EU "active ageing" involves releasing older people's potential by helping them "stay in charge of their own lives for as long as possible as they age and, where possible, to contribute to the economy and society" (European Commission-Employment Social Affairs and Inclusion n.d.).

According to Moulaert and Biggs (2012), however, the originally holistic active ageing narrative has been restricted through EU practice to a notion intrinsically linked with economic productivity. Although the EU framework has evolved since Moulaert and Biggs made the above remark-as shown in the previous part of this chapter - the EU maintains a utilitarian ageing agenda which largely focuses on people of good health who can contribute to its economic growth: its threefold approach includes increasing "senior employment"; investing in the silver economy; and improving the sustainability of social protection systems (European Commission 2015b; European Commission-Research and Innovation 2014).

Anti-ageist agendas that are driven by concerns about the economy and not about older people are likely to undermine their interests (Duncan 2008). In particular, the Silver Economy initiative (European Commission 2015b) adopts a consumerist approach targeting mainly older people with a secure income but also indirectly the families of those who need support and care and might benefit from innovative market-based solutions. Not only does this frame see older people merely as consumers and not as citizens with full rights and responsibilities, but it also risks forcing out of its remit all those who do not consume. As former UN Secretary-General, Kofi Annan, once said, "A society for all ages is one that does not caricature older persons as patients and pensioners. Instead, it sees them as both agents and beneficiaries of development ... it seeks a balance between supporting dependency and investing in lifelong development" (Annan 1998).

In addition, despite being at least to a certain extent helpful in providing an image of ageing which is powerful, positive, and dependency-free, active ageing strategies may exclude people who are very old, isolated, or suffering from severe impairments (Priestley 2003). Although extremely relevant as a preventive concept, 
this approach has its limits in addressing older people who may already be in a vulnerable situation. Just like consumerism, active ageing policies encourage individual responsibility to cope with the challenges of ageing and alleviate the societal burden. They are more concerned with what older people can do to avoid the collapse of the health and social security systems, rather than with what the state can do to serve older people and proactively confront demeaning attitudes about old age, as well as the intersection of old age with race, disability, and gender, among other factors. These intragenerational inequalities are often more widespread and pervasive than intergenerational inequities (Duncan 2008). Unless active ageing is understood to be more than economic participation or consumerism, policies cannot avoid the damaging and diminishing effects of social constructions of old age. Regardless of the intention to empower older people, active ageing strategies probably have little impact on those older people who assume different roles or purposes in later life, such as those oriented towards the community or self-growth, and those who struggle to live independently and be included in their communities.

Our societies tend not to make a distinction between active and inactive childhood, motherhood, or adulthood. However, active ageing is seen as the standard that older people need to achieve in order to benefit from state protection as full citizens. As long as active ageing agendas dictate what older people should and should not be doing, they may be perceived as patronizing but also as excluding those who deviate from the norm. Moulaert and Biggs (2012) suggest moving instead toward agendas of "desired ageing," which are flexible and respectful of older people's autonomy to live their lives as they wish.

On the one hand, active ageing and silver economy initiatives can help disentangle old age from the stigma of inevitable decline, burden, and worthlessness and thus may have a strong anti-ageist effect. On the other hand, by overstressing older people's economic contribution and individual responsibility, they fail to reflect the diverse experiences and wishes of older people and the societal disadvantages that they may face, such as poverty, social isolation, loneliness, role loss, discrimination, and abuse. Positive stereotypes of ageing can, therefore, also be ageist insofar as they "deny and downgrade their distinctive needs and actual and potential contributions, and question the legitimacy of old age per se, and they especially denigrate those who cannot conform" (Duncan 2008, p. 1152). Instead of normative labelling, we need a holistic approach to ageing, which includes all the good and bad things associated with old age, just like with all other parts of life. This is why active ageing strategies need to be accompanied by a rights-based political agenda outlining public responsibility to respect the autonomy of older people and support them in their diverse roles and expectations of old age. 


\subsection{The Potential of a Rights-Based Approach to Fight Ageism}

The two previous sections of this chapter argued (a) that the consistent downplay of older people's rights within the EU framework is emblematic of the injustice faced by this group, and (b) that current conceptions of older people by the EU-whether as burdensome, disabled, or active - have failed to address the diversity of the older population and inspire a society for all ages. Even outside times of economic and refugee crises older people have attracted little, if any, attention as subjects of rights. Discrimination against older people, although prevalent across all EU countries and extremely pervasive in its manifestation and effects on older people's personhood, autonomy, and security, has neither induced public outrage nor a body of standards to confront it. This last section explores how a human rights-based approach (HRBA) can be operationalized as the EU's antidote to ageism.

The HRBA is gaining traction worldwide as an effective way to address in a systematic and comprehensive manner the disadvantages and prejudices linked with old age (Bras Gomes 2011; Chung 2010; UN Department of Economic and Social Affairs 2009; Doron and Apter 2010; Duncan 2008; Fredvang and Biggs 2012; Hammarberg 2011; Mégret 2011; Pillay 2014; Quinn 2013; Stuckelberger et al. 2012; Tang and Lee 2006; Townsend 2006). An HRBA shifts the focus towards state obligations to remove social injustices faced by individuals in their jurisdiction. It creates a duty to promote equality and emphasizes seeing older people as holders of rights. The added value of this approach compared to the welfare or neoliberal models often reflected in EU policies is that, whereas the realization of human rights requires the organization of socio-economic policies, the HRBA goes beyond economic arguments as the raison d'être of such policies. It does not target only those who are privileged, healthy, or have money, nor does it aim only at action that is cost-efficient, but focuses on the full and equal realization of human rights for all. Hence, it has the potential to make the most positively impactful policy changes for older people and for society as a whole.

Counter arguments to this approach will necessarily reflect the economic costs of a comprehensive rights agenda. Although it is outside the scope of this paper to do a cost-benefit analysis, its thesis is that the current status quo is not only bad for older people, but for society as a whole, as ageism impedes older people from becoming full agents in their communities. Lifting age barriers in preventive screening can enhance the health and therefore the employability of older workers. Providing reasonable accommodation to informal caregivers will allow older people to stay longer in the labour market, while relieving the state from the obligation of formal assistance to those in need. Providing training without age limits breaks the cycle of long-term unemployment as older people can more easily re-enter the labour market. Better transport and services will not only improve older people's 
independence and participation but it will also allow them to travel, consume, and volunteer. Investments in health and accessibility lead to savings for the funding of long-term care. Economic objectives can only be partially achieved unless wider societal issues are tackled. As Fredman and Spencer (2003) suggest, "The real question then becomes not what is the cost of age equality, but how should the cost be equitably distributed among the three main possible cost bearers: employer, the state and the individual or the family" (p. 4).

The EU's current approach to ageing is full of paradoxes: on the one hand, it reproduces stereotypes of older people as burdensome and useless; on the other hand, its concentration on labour market participation assumes exactly the opposite. The tolerance of age limits across EU countries results in situations where people $65+$ in the same country are considered capable of working but too old to drive and to receive preventive treatment. Upper age limits in travel insurance also create barriers to intra-EU freedom of movement, damaging the targets of "senior tourism" and the silver economy. The EU promotes longer working lives while at the same time maintaining mandatory retirement ages. Obviously many of these cases do not make economic sense. As Blaikie (cited in Macnicol 2006) observed, "the reasons behind discrimination are frequently economic, but the capacity to maintain oppression is primarily psychological" (p. 11).

These considerations should encourage us not to jump to conclusions about the cost of an HRBA, at least not before considering the cost of the alternative. Instead of only proposing ambitious special measures for older people, an HRBA focuses on tangible actions, which require a shift in the mindset and some procedural aspects of EU institutions. Its premise is that while progress will be gradual and lengthy, as an immediate next step a lot can be accomplished just by equally factoring older people into EU decision-making.

The new Commission has appointed its first Vice-President in charge of "ensuring that every Commission proposal or initiative complies with the Charter of Fundamental Rights" (Juncker 2014b, p. 4). Vice-President Timmermans is expected to mainstream fundamental rights across all EU actions. The proposal for an integration of an HRBA across all EU policies is, therefore, timely and consistent with the EU's aspirations.

The following paragraphs explore how EU action can be reframed to comply with an HRBA, based on the framework developed by Amnesty International and the International Human Rights Network (2006). Their methodology embraces the following five principles: express application of the human rights framework, empowerment, participation, non-discrimination, and accountability (Amnesty International \& International Human Rights Network 2006). Each of these methods is analysed below, with suggestions for concrete ways in which they can be operationalized by the EU. 


\subsubsection{Express Application of the Human Rights Framework}

This chapter has provided anecdotal evidence of EU policy being driven by the needs of an older population. Using this criterion, instead of the fulfilment of rights that the EU adheres to in its founding treaties, makes the obligation to respect and promote these rights appear contingent and reversible.

Applying the first principle of the HRBA in EU policies on ageing and older people would entail first and foremost looking at how Articles 21 and 25 of the EU Charter of Fundamental Rights has shaped EU action, translating intentions into means. Secondly, an HRBA would rebalance the EU's action on ageing by covering areas unrelated to economic or utilitarian concerns. Thirdly, EU officials would be trained and encouraged to consistently consider the impact of their decisions and budget allocation in making assessments of the rights of older people.

Expressly referring to the rights of older people would tear down the barriers between different policy sectors and give visibility to older people as rights-holders. Without necessarily creating a branch of human rights specific to older people, this could act as a comprehensive and coordinated approach to older people's fundamental rights, which would ensure uniformity, policy coherence, and synergies between initiatives taken at different levels and by various services. It would strike a balance between the competing paradigms of dependency and active ageing that prevail across EU policy, based on the vision set forward by the EU Charter of Fundamental Rights, its founding treaties, and international human rights conventions ratified by the EU-in particular, the UN Convention on the Rights of Persons with Disabilities (UN CRPD) (United Nations General Assembly 2007). "Mainstreaming" would become an obligation for all EU bodies, who would have to look at old age through a human rights lens. As a result, the rights of this group would not be ignored or set aside but would be placed "at the heart of its activities" (European Union 2016, Preamble).

\subsubsection{Empowerment}

Empowerment means ensuring that policies allow older people to participate equally in society, not to be considered as "charity". The EU has a long history of social policies for older people, but it treats them as beneficiaries and not as rights holders (Martin et al. 2015). Applying this principle, the EU should move away from the dependency and burden paradigm. It should abandon the stereotypical portrayal of older people as senile, unproductive, and frail. Nor should it dictate to older people what they ought to do to remain active, but rather support them in making autonomous choices for their lives. It could also reject the dependency ratio as a measure of older people's value in order to reflect both the extended working lives of older people and their economic contribution as volunteers, informal carers, 
grandparents, and so on. ${ }^{6}$ It should engage in an empowering discourse that does not adopt old-age biases and perceptions of ageing as something negative that is to be avoided and fought against. This narrative needs to be reflected across all of the EU's action and funding, by scrutinizing new initiatives and research projects. For example, although the majority of EU-funded projects promote positive images of old age, the IMI SPRINTT project, which aims to prevent physical disability, claims that "the real challenge is to fight ageing" (AGE Platform Europe 2014a; SPRINTT Project 2014). Rather than seeing ageing as something to be fought against, old age should be acknowledged as a period full of resources and opportunities.

Moreover, efforts are to be made to ensure a common understanding of age equality and the rights of older people. By encouraging a welfare approach to old age, the EU puts an emphasis on servicing older people's needs rather than building their capacity to understand and claim their rights. Older people should be made aware of the existing legal framework and how it relates to their everyday lives and the policy developments at the national and EU level. They need to know their rights and responsibilities, the duties of state and private actors to respect, protect, and fulfil them, as well as the processes that are available for them to claim their rights and bring about positive reforms. This could be achieved through EU-wide awareness-raising campaigns and funding initiatives at local and national levels that aim at empowering older people to take up various roles in their communities. Overall policies should give older people the power and capacities to improve their lives, allow them to raise their voices, to contribute and to be heard by decisionmakers, without making them passive subjects.

\subsubsection{Participation}

The principle of participation is a call for policies that allow for a genuine participation of older people, including the most marginalized and minority groups. Participation in policy and legal processes can take the form of involvement of representative civil society organizations with anchors at grass-roots level. It presupposes timely and accessible information so that participation is constructive and meaningful.

AGE Platform Europe has deplored the inconsistent consultation of older people across EU policies and called for the inclusion of older people in all policies that concern them (AGE Platform Europe 2015b). There is certainly room for improvement by systematically including old age advocates in related bodies (such as the High Level Group on Disability and High Level Group on Non-Discrimination), processes (such as the European Innovation Partnership on Active and Healthy Ageing and the European Semester), and also by ensuring regular dialogues with institutions, such as the Directorate-General (DG) for Justice, Consumers and

\footnotetext{
${ }^{6}$ For an alternative, see Farrel 2016.
} 
Gender Equality (DG JUST) and the DG for Employment, Social Affairs and Inclusion (DG EMPL), as well as formations of the Council, including the Council Working Parties on Human Rights (COHOM), Fundamental Rights, Citizens' Rights and Free Movement of Persons (FREMP), and Social Questions. The EU could also consider setting up an inter-service group on old age-such as the one that exists on disability - that would inform and guide EU action, exchange information, and improve understanding of old age challenges and the EU's role to tackle them. Participation and inclusion of persons at risk of discrimination, such as older people, must also be supported by the EU Structural and Investment Funds. Such actions would ensure that involvement at the EU, national, regional, and local levels is accessible, transparent, and timely.

\subsubsection{Non-discrimination}

The HRBA seeks to end discrimination, paying due attention to causes and situations of accumulated disadvantages that may lead to multiple discrimination. Nondiscrimination on the grounds of age is considered to be a general principle of EU law but EU institutions have not applied it directly to guide policy, case law, or to combat ageism. As explained earlier in the chapter, in practice, EU law is narrowly focused on employment and on a formal definition of equality that includes a negative obligation not to interfere.

Non-discrimination on the grounds of age needs to become a matter of priority in all EU policies. The EU should establish where age limits and proxies are appropriate and which are the factors that accentuate discrimination also beyond the workplace. Mainstreaming non-discrimination includes a comprehensive and connected consideration of older people across all EU actions, in a similar way that the EU has taken gender into account in every policy decision (Fredman and Spencer 2003).

The EU should also gather data so that difference in opportunities can be assessed. Data should be disaggregated by age and gender, avoiding large age cohorts (for example, 50+), and as far as possible avoiding age limits. Age discrimination needs to be consistently addressed in surveys, such as the Survey of Health, Ageing and Retirement in Europe (SHARE), which to date does not include specific questions on age discrimination. Moreover, resources should be allocated for empirical studies on old age inequalities, including those at the intersection of racial, religious, gender, disability, and other forms of discrimination. The Fundamental Rights Agency, in particular, should initiate and foster projects that put a spotlight on the social injustices faced by the older group. 


\subsubsection{Accountability}

The allocation of equal rights to people of all ages represents an important element of fulfilling the EU's commitments (Economic Commission for Europe 2008). As we have seen in the first part of this chapter, the EU Charter does not provide for legally enforceable rights that individuals can claim from their governments and EU institutions. However, human rights are stripped of meaning unless they are accompanied by social and economic policies to support them. The principle of accountability is about identifying positive and negative obligations - for state and private actors and by extension for the EU-in order to move from commitments to tangible outcomes.

In concrete terms, the application of the principle of accountability requires a threefold effort. First, it calls for human rights impact assessments to identify the potential positive and negative impact of plans, budgets, and reform programmes, as well as the necessary policies to address it. However, the EU has not included the rights of older people in its country-specific recommendations in the area of equality (European Commission 2016b). Neither has the European Commission addressed the adverse impact of social reforms on healthy life expectancy, whereas there is evidence that while people are living longer, they live more years in ill health (AGE Platform Europe 2015c). In the future, austerity measures promoted by the EU should not disregard existing human rights standards but instead ensure that the structural disadvantages faced by older adults are taken into account in budgetary and macroeconomic reforms. Impact assessments are necessary to allow for planned reforms to address sustainability and deficit problems, without undermining the enjoyment of human rights.

Second, to respect the principle of accountability a set of specific, enforceable targets that can be used to measure the EU's performance internally and as a global actor in promoting age equality and confronting ageism could also be developed. To do so, the EU could take stock of existing international instruments, such as the Madrid International Plan of Action on Ageing (MIPAA) (United Nations 2002), which, although it is neither a bill of rights nor legally enforceable, includes a set of commonly agreed upon policy objectives. The EU could also promote the use of human rights indicators in order to monitor the progressive realization of economic and social rights under the ongoing reforms. In practical terms, this would mean that reforms should take into account the human rights implications of measures, as well as principles such as transparency, accountability, participation, and attention to the most vulnerable groups, including older persons.

Third, monitoring over time would ensure that there is a gradual improvement rather than deterioration of rights. However, the EU lacks an enforcement mechanism that reviews progress in mainstreaming age equality and the rights of older people. A service or dedicated body, including the Commission, civil society organizations, and representatives of the member states, might be needed to ensure 
policy integration and "to link ageing to other frameworks for social and economic development and human rights" (Annan 2002, p. 1). A consistent application of the principle of accountability along the above lines will ensure that older people are factored into laws, policies, and institutions, allowing for a prompt response to threats or violations of rights.

\subsection{Conclusion}

The EU has an impressive legal and policy framework in place when it comes to other grounds of discrimination, but it misses the mark for old age (Lassen et al. 2014). This chapter outlines the EU's narrow interpretation of its obligation to combat age discrimination and shows how it has not afforded ageism the visibility it deserves, bearing in mind that it is the most commonly experienced form of discrimination (European Commission 2015a). In fact, the EU's ongoing austerity measures inadvertently increase the risk of inequality and exclusion (Parent 2015). Despite some remarkable achievements, including the Employment Framework Directive and EY2012, the EU has generally had a patchy approach to ageism. Efforts to enshrine anti-ageist objectives in active ageing and social policy agendas are to be encouraged, without ignoring their limits in terms of scope and impact, both because they have not been part of a well-developed set of mainstreaming actions and because they fall into the trap of "essentializing" older people either as vulnerable or active. Active ageing strategies are certainly useful elements in an effective approach towards non-discrimination and equal opportunities; but, "for anti-ageist policies and practices to be taken seriously in their own right, they have to be given the profile they deserve" (Thompson 2005, p. 59).

Moreover, policy action will be deficient if ageism persists in beliefs and policy thinking (Herring 2009, p. 13). This chapter shows that the EU is deeply conscious of population ageing but is less concerned with individual ageing and the human rights challenges related to ageing. The Union's legal and policy framework have attributed social characteristics to chronological age, in particular, consolidating expectations about the relationship between work, retirement, and economic contribution. Old age has been defined as an indicator of incapacity, unproductivity, dependency, impairment, and burden. This vision of ageing not only sustains agebased stereotypes and categories but also legitimizes age discrimination and marginalization. The EU needs to set up more cohesive and effective mechanisms to rectify the structural inequalities and prejudicial disadvantages that serve to exclude older people. A human rights-based approach is particularly well suited to promoting equality and dignity in old age. It advances a vision of older people as rightsholders and guarantees an in-depth analysis of how EU law and policies affect the rights of older people and what further action is needed to materialize them, taking into account both individual and public responsibility. 
Acknowledgments Many thanks to Professor Eamon O'Shea from NUI Galway who reviewed an earlier draft of this chapter and helped me improve its overall structure. In addition, I would like to thank my colleagues at AGE Platform Europe, in particular Julia Wadoux and Ilenia Gheno, who provided comments and ideas for elaboration. I also acknowledge the contribution of Ann Leahy, $\mathrm{PhD}$ Candidate, Department of Sociology, Maynooth University, Kildare, who gave me the idea of discussing in detail how to apply a human rights-based approach to EU action, based on her work on how to apply HRBA to ageing policies in Ireland.

The opinions presented in this chapter are those of the author and do not necessarily reflect the official opinion of AGE Platform Europe or the National University of Ireland in Galway. Responsibility for the information and views set out in this chapter lies entirely with the author.

\section{References}

AGE Platform Europe. (2012). Active senior citizens: A guide to the EU. Retrieved from http://www. age-platform.eu/images/stories/EN/activesenior_citizens_for_europe-_a_guide_to_the_eu.pdf

AGE Platform Europe. (2013). AGE platform Europe support for UN independent expert on the rights of older persons and call for an EU-level multi-stakeholder dialogue group to discuss the rights of older persons. Retrieved from http://www.age-platform.eu/press-releases/ we-need-eu-multi-stakeholder-dialogue-group-older-people $\%$ E2\% $80 \% 99$ s-rights-supporteu\%E2\%80\%99s

AGE Platform Europe. (2014a). IMI SPRINTT project: Claiming that "the real challenge is to fight ageing" is a blatant form of ageism [Press release]. Retrieved from http://www.ageplatform.eu/press-releases/imi-sprintt-project-claiming-\%E2\%80\%9C-real-challenge-fightageing $\%$ E2\%80\%9D-blatant-form-ageism

AGE Platform Europe. (2014b). Informal exchange with the COHOM on the rights of older people. Retrieved from http://www.age-platform.eu/images/FINAL_handout_meeting_AGE_ COHOM_28_05_2014.pdf

AGE Platform Europe. (2015a). AGE newsflash 22/06/2015: Time to adopt an ambitious horizontal directive that protects equally against all grounds of discrimination!

AGE Platform Europe. (2015b). AGE platform Europe contribution for the review of the EU report by the committee on the rights of persons with disabilities. Retrieved from http://tbinternet. ohchr.org/Treaties/CRPD/Shared\%20Documents/EUR/INT_CRPD_CSS_EUR_21338_O.pdf

AGE Platform Europe. (2015c). European semester's country specific recommendations: More caution needed when reforming social protection systems to address loss in healthy life expectancy [Press release]. Retrieved from http://www.age-platform.eu/press-releases/ european-semesters-country-specific-recommendations-more-caution-needed-when

AGE Platform Europe. (2016). AGE platform Europe position on structural ageism. Retrieved from http://age-platform.eu/images/stories/Publications/papers/AGE_IntergenerationalSolidarity_ Position_on_Structural_Ageism.pdf

Amnesty International, \& International Human Rights Network. (2006). Our rights, our future human rights based approaches in Ireland: Principles, policies and practice. Retrieved from http://www.ihrnetwork.org/files/IHRN-AI\%20HRBA\%20Ireland\%20Sept05\%20FINAL.pdf

Annan, K. (1998). A 'society for all ages' honours traditional leadership role for elders, SecretaryGeneral says, opening international year of older persons [Press release]. Retrieved from http://www.un.org/press/en/1998/19981001.sgsm6728.html

Annan, K. (2002). Foreword to political declaration and Madrid international plan of action on ageing. United Nations. Retrieved from http://www.un.org/en/events/pastevents/pdfs/Madrid_ plan.pdf

Bras Gomes, V. (2011). Human rights of older persons: Policy or implementation gap? Paper presented at the 5th Warsaw Seminar on Human Rights, Warsaw. 
Bribosia, E. \& Rorive, I. (2013) Reasonable accommodation beyond disability in Europe? European Commission. Directorate-General for Justice. Retrieved from http://ec.europa.eu/ justice/discrimination/files/reasonable_accommodation_beyond_disability_in_europe_en.pdf

Calasanti, T., Slevin, K. F., \& King, N. (2006). Ageism and feminism: From "Et Cetera" to center. NWSA Journal, 18(1), 13-30.

Chung, C. (2010). The necessity of a human rights approach and effective United Nations mechanism for the human rights of the older person. Retrieved from http://www.ohchr.org/ EN/HRBodies/HRC/AdvisoryCommittee/Session4/Pages/Index.aspx. Council of Europe. European Social Charter (Revised) (1996).

Council Directive 2000/78/EC of 27 November 2000 establishing a general framework for equal treatment in employment and occupation (2000).

Council of the European Communities. (1990). Council decision of 26 November 1990 on community actions for the elderly.

Council of the European Union. (2011). An EU framework for national roma integration strategies up to 2020 - council conclusions. Retrieved from http://register.consilium.europa.eu/doc/ srv?l=EN\&f=ST\%2010658\%202011\%20INIT

Council of the European Union. (2012). Council declaration on the European year for active ageing and solidarity between generations (2012): The way forward. Retrieved from http:// register.consilium.europa.eu/doc/srv?l=EN\&f=ST\%2017468\%202012\%20INIT

Council of the European Union. (2015a). Council conclusions on the action plan on human rights and democracy 2015-2019. Retrieved from https://ec.europa.eu/anti-trafficking/sites/ antitrafficking/files/council_conclusions_on_the_action_plan_on_human_rights_and_democracy_2015_-_2019.pdf

Council of the European Union. (2015b). Proposal for a council directive on implementing the principle of equal treatment between persons irrespective of religion or belief, disability, age or sexual orientation, from presidency on 8 May 2015 to working party on social questions. Retrieved from http://data.consilium.europa.eu/doc/document/ST-8679-2015-INIT/en/pdf

Dabove, M. I. (2015). Elder law: A need that emerges in the course of life. Aging International, 40, 138-148.

Department of Economic and Social Affairs, U. N. (2009). Report of the expert group meeting 'rights of older persons'. Retrieved from http://www.un.org/esa/socdev/ageing/documents/ egm/bonn09/report.pdf

de Witte, B. (2010). From a "common principle of equality" to "European antidiscrimination law". American Behavioral Scientist, 53(12), 1715-1730.

Doron, I., \& Apter, I. (2010). International rights of older persons: What difference would a new convention make to lives of older people? Marquette Elder's Advisor, 11(2), Article 7.

Doron, I., Numhauser-Henning, A., Spanier, B., Georgantzi, N., \& Mantovani, E. (2018). Ageism and anti-ageism in the legal system: A review of key themes. In L. Ayalon \& C. Tesch-Römer (Eds.), Contemporary perspectives on ageism: Vol. 19. International perspectives on aging (pp. 303-320). Berlin: Springer.

Duncan, C. (2008). The dangers and limitations of equality agendas as means for tackling old-age prejudice. Ageing and Society, 28(8), 1133-1158.

Eatock, D. (2015). The silver economy - Opportunities from ageing. Retrieved from http://www. europarl.europa.eu/EPRS/EPRS-Briefing-565872-The-silver-economy-FINAL.pdf

Economic Commission for Europe, U. N. (2008). A society for all ages: Challenges and opportunities. Retrieved from http://www.unece.org/pau/pub/mipaa.html

Ehlers,A., Naegele, G., \& Reichert, M. (2011). Volunteering byolderpeople in the EU. Retrieved from https://www.eurofound.europa.eu/publications/report/2011/quality-of-life-social-policies/ volunteering-by-older-people-in-the-eu

EU Network of Independent Experts on Fundamental Rights. (2006). Commentary of the charter of fundamental rights of the European Union - Article 25. Droits des personnes âgées. Retrieved from European Commission. http://ec.europa.eu/justice/fundamental-rights/files/ networkcommentaryfinal_en.pdf 
European Commission. (2005). Communication from the commission - green paper "confronting demographic change: A new solidarity between the generations". Retrieved from http://eurlex.europa.eu/legal-content/EN/ALL/?uri=CELEX:52005DC0094

European Commission. (2008a). Communication from the Commission to the European Parliament, the Council, the European Economic and Social Committee and the Committee of the Regions - Non-discrimination and equal opportunities: A renewed commitment. Retrieved from http://eur-lex.europa.eu/legal-content/EN/TXT/?uri=URISERV\%3Adh0001

European Commission. (2008b). Proposal for a Council Directive on implementing the principle of equal treatment between persons irrespective of religion or belief, disability, age or sexual orientation. Retrieved from http://eur-lex.europa.eu/legal-content/en/ALL/?uri=CELEX:5200 $8 \mathrm{PC} 0426$

European Commission. (2009). Communication from the Commission to the European Parliament, the Council, the European Economic and Social Committee and the Committee of the Regions Dealing with the impact of an ageing population in the EU (2009 Ageing Report). Retrieved from http://eur-lex.europa.eu/legal-content/EN/ALL/?uri=CELEX:52009DC0180

European Commission. (2010). Communication from the Commission to the European Parliament, the Council, the European Economic and Social Committee and the Committee of the Regions, European Disability Strategy 2010-2020: A Renewed Commitment to a Barrier-Free Europe. Retrieved from http://eur-lex.europa.eu/legal-content/EN/TXT/?uri=celex:52010DC0636

European Commission. (2011). Communication from the Commission to the European Parliament, the Council, the European Economic and Social Committee and the Committee of the Regions, An EU Agenda for the Rights of the Child. Retrieved from http://ec.europa.eu/justice/policies/ children/docs/com_2011_60_en.pdf

European Commission. (2012a). Communication from the Commission to the European Parliament and to the Council Taking forward the Strategic Implementation Plan of the European Innovation Partnership on Active and Healthy Ageing. Retrieved from http://eur-lex.europa.eu/ legal-content/EN/ALL/?uri=CELEX:52012DC0083

European Commission. (2012b). The EU contribution to active ageing and solidarity between generations. Retrieved from http://ec.europa.eu/social/main.jsp?catId=738\&langId=en\&pubI $\mathrm{d}=6920$ \& visible $=1$

European Commission. (2014). Commission Staff Working Document, Annexes to the Joint Report on the application of the Racial Equality Directive (2000/43/EC) and the Employment Equality Directive (2000/78/EC) Accompanying the document Joint Report on the application of Council Directive 2000/43/EC of 29 June 2000 implementing the principle of equal treatment between persons irrespective of racial or ethnic origin ('Racial Equality Directive') and of Council directive 2000/78/EC of 27 November 2000 establishing the general framework for equal treatment in employment and occupation ('Employment Equality Directive'). Retrieved from http://eur-lex.europa.eu/legal-content/EN/TXT/PDF/?uri=CELEX:52014SC0005\&from $=$ en

European Commission. (2015a). Eurobarometer on Discrimination 2015. Retrieved from http://ec.europa.eu/justice/events/colloquium-fundamental-rights-2015/files/factsheets/ factsheet_eurobarometer_fundamental_rights_2015_en.pdf

European Commission. (2015b). Growing the European Silver Economy. Retrieved from http:// ec.europa.eu/research/innovation-union/pdf/active-healthy-ageing/silvereco.pdf

European Commission. (2015c). List of Actions by the Commission to advance LGBTI equality. Retrieved from http://ec.europa.eu/justice/discrimination/files/lgbti_actionlist_en.pdf

European Commission. (2015d). Practical guide to launch and implement a Diversity Charter. Retrieved from http://ec.europa.eu/justice/discrimination/files/emerging_charter_guide_en.pdf

European Commission. (2015e). Strategic Engagement for Gender Equality 2016-2019. Retrieved from http://ec.europa.eu/justice/gender-equality/document/files/strategic_engagement_en.pdf

European Commission. (2016a). Communication from the Commission to the European Parliament, the Council, the European Economic and Social Committee and the Committee of the Regions, Launching a consultation on a European Pillar of Social Rights. Retrieved from http://eur-lex. europa.eu/legal-content/EN/TXT/?uri=COM:2016:127:FIN\#document2 
European Commission. (2016b). Country-specific recommendations in the areas of Justice, Consumers and Equality policy. Retrieved from http://ec.europa.eu/justice/newsroom/ effective-justice/news/160518_en.htm

European Commission. (2016c). Staff Working Document on the Application of the EU Charter of Fundamental Rights in 2015 Accompanying the document Report from the Commission to the European Pariliament, the Council, the European Economic and Social Committee and the Committee of the Regions 2015 Report on the Application of the EU Charter of Fundamental Rights. Retrieved from http://ec.europa.eu/justice/fundamental-rights/files/ staff_working_doc_charter_2015_en.pdf

European Commission - Economic and Financial Affairs. (2015). The 2015 Ageing Report Economic and budgetary projections for the 28 EU Member States (2013-2060). Retrieved from http://ec.europa.eu/economy_finance/publications/european_economy/2015/pdf/ ee3_en.pdf

European Commission - Employment Social Affairs and Inclusion. (n.d.). Active ageing. Retrieved from http://ec.europa.eu/social/main.jsp?catId=1062

European Commission - Research and Innovation. (2014). Population Ageing in Europe - Facts, implications and policies. Retrieved from https://ec.europa.eu/research/social-sciences/pdf/ policy_reviews/kina26426enc.pdf

European Commission - Youth. (2015). EU Youth Report 2015. Retrieved from http://ec.europa. eu/youth/policy/implementation/report_en.htm

European Community. (1989). Community Charter of fundamental social rights of workers. European Economic and Social Committee. Retrieved from http://www.eesc.europa.eu/ resources/docs/community-charter--en.pdf

European Parliament. (1982). Resolution on the situation and the problems of the aged in the European Community.

European Parliament, \& European Council. (2011). DECISION No 940/2011/EU OF THE EUROPEAN PARLIAMENT AND OF THE COUNCIL of 14 September 2011 on the European Year for Active Ageing and Solidarity between Generations. Retrieved from http://eur-lex. europa.eu/legal-content/EN/TXT/?uri=URISERV\%3Aem0038

Council of Europe. European Social Charter (Revised) (1996).

European Union. (2007). Treaty of Lisbon amending the Treaty on European Union and the Treaty establishing the European Community. (2007/C 306/01). Retrieved from http://eur-lex.europa. eu/legal-content/en/TXT/?uri=CELEX\%3A12007L\%2FTXT

European Union. (2011). Opening statement by the European Union. Paper presented at the Open Ended Working Group on Ageing, Second session, New York.

European Union. (2012). Consolidated version of the Treaty on European Union. (2012/C 326/01). Retrieved from http://eur-lex.europa.eu/legal-content/en/TXT/?uri=CELEX\%3A12012M\%2F TXT

European Union. (2016). Charter of fundamental rights of the European Union. (2016/C 202/02). Retrieved from http://eur-lex.europa.eu/legal-content/EN/TXT/?qid=1476199840542\&uri=C ELEX:12016P/TXT

Farrel, C. (2016). Disproving beliefs about the economy and aging. New York Times. Retrieved from http://www.nytimes.com/2016/05/14/your-money/disproving-beliefs-about-the-economy-and-aging.html?_r=1

Fredman, S. (2003). The age of equality. In S. Fredman \& S. Spencer (Eds.), Age as an equality issue (pp. 21-69). Oxford/Portland: Hart Publishing.

Fredman, S. (2011). Discrimination law. Oxford: OUP.

Fredman, S., \& Spencer, S. (2003). Age as an equality issue: Legal and policy perspectives. Oxford/Portland: Hart Publishing.

Fredvang, M., \& Biggs, S. (2012). The rights of older persons - Protection and gaps under human rights law. In: Brotherhood of St Laurence Centre for Public Policy, University of Melbourne

Fundamental Rights Agency. (2012). Inequalities and multiple discrimination in access to and quality of healthcare. Retrieved from http://fra.europa.eu/sites/default/files/ inequalities-discrimination-healthcare_en.pdf 
Fundamental Rights Agency. (2014a). Political participation of persons with disabilities - Publications. Retrieved from http://fra.europa.eu/en/project/2013/ political-participation-persons-disabilities/publications

Fundamental Rights Agency. (2014b). Violence against women: An EU-wide survey. Main results report. Retrieved from http://fra.europa.eu/en/publication/2014/ violence-against-women-eu-wide-survey-main-results-report

Fundamental Rights Agency. (n.d.). Article 25 - The rights of the elderly. Retrieved from http://fra. europa.eu/en/charterpedia/article/25-rights-elderly

Grammenos, S. (2013). European comparative data on Europe 2020 \& People with disabilities. Retrieved from http://digitalcommons.ilr.cornell.edu/cgi/viewcontent.cgi?article=1569\&conte $\mathrm{xt}=$ gladnetcollect

Hammarberg, T. (2011). Keynote by Commissioner for Human Rights of the Council of Europe. Paper presented at the 5th Warsaw Seminar on Human Rights, Warsaw.

Herring, J. (2009). Older people in law and society. Oxford: Oxford University Press.

Huenchuan, S., \& Rodríguez-Piñero, L. (2011). Ageing and the protection of human rights: Current situation and outlook. Santiago: Economic Commission for Latin America and the Caribbean (ECLAC), United Nations.

Juncker, J.-C. (2014a). Mission Letter Commissioner for Justice, Consumers and Gender Equality [Press release]. Retrieved from http://ec.europa.eu/commission/sites/cwt/files/ commissioner_mission_letters/jourova_en.pdf

Juncker, J.-C. (2014b). Mission Letter Frans Timmermans First Vice-President, in charge of Better Regulation, Interinstitutional |Relations, the Rule of Law and the Charter of Fundamental Rights [Press release]. Retrieved from https://ec.europa.eu/commission/sites/cwt/files/ commissioner_mission_letters/timmermans_en.pdf

Lassen, E. M., Mayrhofer, M., Vedel Kessing, P., Sano, H.-O., Garcia San José, D., \& Frank Jørgensen, R. (2014). Report on factors which enable or hinder the protection of human rights. In Frame Fostering Human Rights Among Europian Policies (Ed.), Work Package No. 2.

Macnicol, J. (2006). Age discrimination, an historical and contemporary analysis. New York: Cambridge University Press.

Martin, C., Rodríguez-Pinzón, D., \& Brown, B. (2015). Human rights of older people-universal and regional perspectives (Vol. 45). New York: Springer.

McLachlin, B. (2013). Human dignity at any age: The law's response to an aging population. Journal of International Aging Law and Policy, 6(111).

Meenan, H. (2007). Reflecting on age discrimination and rights of the elderly in the European Union and the Council of Europe. Maastricht Journal of European and Comparative Law, 14, 39.

Mégret, F. (2011). The human rights of older persons: A growing challenge. Human Rights Law Review, 11(1).

Mikołajczyk, B. (2018). The council of europe's approach towards ageism. In L. Ayalon \& C. Tesch-Römer (Eds.), Contemporary perspectives on ageism: Vol. 19. International perspectives on aging (pp. 321-339). Berlin: Springer.

Morgan, R. E., \& David, S. (2002). Human rights: A new language for aging advocacy. The Gerontologist, 42(4), 436-442.

Moulaert, T., \& Biggs, S. (2012). International and European policy on work and retirement: Reinventing critical perspectives on active ageing and mature subjectivity. Human Relations, 66(1), 23-43.

Nikolaidis, C. (2015). The right to equality in European human rights law: The quest for substance in the jurisprudence of the european courts. Oxfordshire/New York: Routledge.

O'Dempsey, D., \& Beale, A. (2011). Age and employment. Retrieved from http://ec.europa.eu/ justice/discrimination/files/age_and_employment_en.pdf

Parent, A.-S. (2015). The impact of the European year 2012 on active ageing and solidarity between generations: A critical assessment. Geron, 1. Retrieved from https://mijn.bsl.nl/the-impact-ofthe-european-year-2012-on-active-ageing-and-solida/6648962?fulltextView=true

Pillay, N. (2014). Opening statement to the social forum. Retrieved from http://www.ohchr.org/ EN/NewsEvents/Pages/DisplayNews.aspx?NewsID=14483\&LangID=E 
Priestley, M. (2003). Disability: A life course approach. Cambridge: Polity.

Quinn, G. (2013). 'Human rights and older people in Ireland-Policy paper' Age: From human deficits to human rights - Reflections on a changing field.' Paper presented at the Launch Event 'Human Rights \& Older People Working Group', Dublin.

Scrutton, S. (1990). Ageism. In E. McEwen (Ed.), Age: The unrecognised discrimination (pp. 12-27). London: Age Concern England.

Seanad Public Consultation Committee. (2012). Report on the rights of older people. Retrieved from http://www.oireachtas.ie/parliament/media/committees/seanadpublicconsultationcommittee/reports/FinalReport.pdf

SPRINTT Project. (2014). SPRINTT Project:The first European collaborative research to fight ageing [Press release]. Retrieved from http://www.mysprintt.eu/sites/default/files/PRESS\%20 RELEASE_SPRINTT_APPROVED\%20(Salvataggio\%20automatico).pdf

Stuckelberger, A., Abrams, D., \& Chastonay, P. (2012). Age discrimination as a source of exclusion in Europe: The need for a human rights plan for older persons. In N. Keating \& T. Scharf (Eds.), From exclusion to inclusion in old age: A global challenge (pp. 125-144). Bristol: Policy Press.

Tang, K.-L., \& Lee, J.-J. (2006). Global social justice for older people: The case for an international convention on the rights of older people. British Journal of Social Work, 36, 1135-1150.

Thompson, S. (2005). Age discrimination. Lyme Regis: Russel House Publishing.

Townsend, P. (2006). Policies for the aged in the 21st century: More 'structured dependency' or the realization of human rights? Ageing and Society, 26(2), 161-179.

Tymowski, J. (2016). The employment equality directive - European implementation assessment. Retrieved from http://www.europarl.europa.eu/RegData/etudes/STUD/2016/536346/ EPRS_STU(2016)536346_EN.pdf

UN General Assembly. (2007). Convention on the rights of persons with disabilities: Resolution adopted by the General Assembly.

United Nations. (2002). Political declaration and Madrid international plan of action on ageing. Madrid: UN.

Vasil Ivanov Georgiev v Tehnicheski universitet - Sofia, filial Plovdiv Joined cases C-250/09 and C-268/09 (Second Chamber, European Court of Justice 2010).

Walker, A. (2015). Foreword. In K. Walsh, G. M. Carney, \& A. N. Leime (Eds.), Ageing through austerity: Critical perspectives from Ireland. Bristol: Policy Press.

World Health Organization. (2002). Active ageing: A policy framework. Retrieved from http:// apps.who.int/iris/bitstream/10665/67215/1/WHO_NMH_NPH_02.8.pdf

Zaidi, A. (2015). Active ageing index: A legacy of the European Year 2012 for active ageing and solidarity between generations. Retrieved from http://www.euro.centre.org/ data/1430842611_13456.pdf

Open Access This chapter is licensed under the terms of the Creative Commons Attribution 4.0 International License (http://creativecommons.org/licenses/by/4.0/), which permits use, sharing, adaptation, distribution and reproduction in any medium or format, as long as you give appropriate credit to the original author(s) and the source, provide a link to the Creative Commons license and indicate if changes were made.

The images or other third party material in this chapter are included in the chapter's Creative Commons license, unless indicated otherwise in a credit line to the material. If material is not included in the chapter's Creative Commons license and your intended use is not permitted by statutory regulation or exceeds the permitted use, you will need to obtain permission directly from the copyright holder.

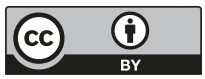




\title{
Chapter 22 \\ Ageism and the Rights of Older People
}

\author{
Annika Taghizadeh Larsson and Håkan Jönson
}

\subsection{Introduction}

Internationally, engagement in critical thinking on disability is still rare in official discussions on ageing policies as well as in gerontological research. Rather than focusing on environmental and societal failures to remove barriers to inclusion, activity restrictions and related problems encountered by people in later life are, in ageing discourse, even today, frequently viewed through the medical model lens. Ageing discourse largely continues to stress the incapacities and helplessness of older persons with care needs and impairments and tends to overlook the environmental and societal limitations that diminish a disabled person's opportunities to fully participate in society and enjoy life. Furthermore, attempts to counter ageism have tended to put healthy ageing and healthy seniors to the fore, and might therefore inadvertently contribute to further exclusion and discrimination of the less healthy and vital part of the older population. On the other hand, in actions against disability discrimination and in disability studies, there are few references to older people (Kennedy and Minkler 1998; Priestley 2003). Consequently, the scope for knowledge transfer from disability activism and research to the field of gerontology that could counter discrimination of older people with impairments and lead to changes and improvements in current systems of long-term care have so far largely been rendered invisible.

This chapter examines how, and if, the situation of older people in need of longterm care could be targeted by learning from disability policies. We base our

\footnotetext{
A. T. Larsson ( $\square)$

Division Ageing and Social Change, Linkoping University, Norrkoping, Sweden

e-mail: annika.t.larsson@liu.se

H. Jönson ( $\square)$

School of Social Work, Lund University, Lund, Sweden

e-mail: hakan.jonson@soch.lu.se

L. Ayalon, C. Tesch-Römer (eds.), Contemporary Perspectives on Ageism, International Perspectives on Aging 19,

https://doi.org/10.1007/978-3-319-73820-8_22
} 
elaboration on this issue on a number of works that we published between 2009 and 2016 (Jönson and Harnett 2016; Jönson and Taghizadeh Larsson 2009; Taghizadeh Larsson 2013, 2011), the most recent of which was co-authored with our colleague Tove Harnett. The chapter starts with a critical analysis of established attempts to counter ageism, highlighting how these attempts have failed to include the so-called fourth age, and might instead contribute to further stigmatization of older people with care needs. Drawing upon models from disability policies, we then introduce an equal rights framework and show how it could be used to combat discrimination and improve everyday conditions of older people in need of care. In the third section of the chapter, we use the equal rights framework to question existing cases of "institutional ageism" whereby older people with disabilities are excluded from government programs benefiting younger people. Cases where the support system of Sweden enables older people with impairments and need for support in tasks such as eating, dressing, and going to the toilet to participate in so-called third age activities (cf. Laslett 1989) are included to illustrate this possibility. We conclude with recommendations on how improvements in long-term care could be accomplished by learning from disability policies and critical thinking on disability.

In this chapter, we frequently refer to Sweden and, in particular, to Swedish disability policy. Given differences between welfare states, our argument is not that the Swedish model should be exported and used internationally. Instead, we consider Swedish policies and arguments presented in Swedish policy documents as useful in order to rethink and reframe long-term care.

\subsection{Advantages and Disadvantages of Countering Ageism Through the Concept of "Healthy Ageing"}

The most prevalent way to counter ageism so far can be summarized as dissociation between old age on the one hand and illness, impairment, and dependency on the other hand. As part of this approach, discourses and concepts of healthy ageing, third age, and successful ageing have helped to dispel myths about older people as a frail and dependent population. This approach has helped disseminate more accurate information about the fact that today most people over the age of 65 live healthy, active, and independent lives. This resonates with the tripartite model of attitudes that has been prominent in research on ageism, consisting of cognitive, emotional, and behavioural components, and draws upon theories on lagging images of old age that appear in the writings of scholars like Mathilda Riley and Erdman B. Palmore. In an article published in the Journal of Ageing Studies (Jönson and Taghizadeh Larsson 2009), we analysed this upgrading approach to ageism by referring to campaigns aimed at increasing participation in working life during the 1950s and 1960s, where activists claimed that older people had the same capacity to work as their younger workmates. What older workers lacked in speed and adaptability, they 
gained in experience, patience, and thoroughness (Wohlin 1960). Older people should therefore be valued and encouraged to keep working. Upgrading of older people by bringing healthy ageing and healthy seniors to the fore is also embedded in current campaigns in Europe to promote intergenerational solidarity. While enhanced solidarity between different age groups is launched as a strategy in itself to counter age discrimination on the AGE Platform Europe (2016) website, it is also described as a way to "help achieve the EU's goal of promoting active and healthy ageing." Furthermore, a short movie that "encapsulates the achievements of the European Year 2012 for active ageing and solidarity between generations" that can be downloaded on the website is crowded with seniors dancing, singing, laughing, demonstrating, working, and golfing in groups or together with children of all ages. In the movie, there is no sign of wheelchairs, sticks, or walkers, and no sign of nursing homes or other forms of long-term care.

Though obviously excluding older people with impairments and illnesses, it is easy to understand the occurrence of this upgrading approach from a historical perspective. Every new generation of seniors has become increasingly more vital and healthy, and the development of welfare states has enabled a larger proportion of older people to keep a decent standard of living, but images have lagged behind. Laslett's (1989) reference to a third age reflects these changes and was, unsurprisingly, introduced as an attempt to upgrade images of ageing on the basis of functional ability among third age seniors. For a long time, functional comparisons have been a trump card of anti-ageism, in the sense that "the truth" has proven that older people are more capable and similar to non-old people than is generally believed. For example, Wigdor (1995) wrote, "People confuse the $90 \%$ of older people who are able with the $10 \%$ that are not" (p. 103). Whereas the upgrading approach has great advantages, it is also "ableist" in its character as it communicates the message that societal status is gained through health and functional ability. This problem has been highlighted in critical gerontology, in relation to divisions between a third and fourth age and attempts to launch models of successful and healthy ageing by acknowledging that this might contribute to further stigmatization of older people with impairments and care needs.

Another, yet related, established attempt to counter ageism could be summarized as the age irrelevance approach. Critical gerontologists such as Bytheway (1995) have argued that the construction of old age as a distinct category acts to justify age discrimination. Using a similar argument, a Swedish government investigation of older people (SOU 2002:29, 2003:91) ten years ago suggested that "age" and "older" should become less relevant concepts. People would thus be freed from roles and limiting expectations that accompany the traditional division of the life course into separate stages, and working life could contain several careers and span well beyond the age of 65 . However, because our present society is not only oriented toward age but also toward function, attempts to de-age policies could result in problematic consequences for people with illnesses and impairments. Even if such attempts aim at replacing age grading with individual needs among all equal 
citizens, functional ability enters as a key factor when age becomes less important. This is what happened in Sweden during the 1950s and 1960s, when researchers hoped to arrange for a more flexible working life. The plan was to let company doctors decide when older workers were no longer fit to belong in the workforce rather than imposing a fixed retirement age (Jönson 2001). A suggestion made by Sweden's Committee on Older People also highlights the tendency to replace age with function: "Our claim is that political action must be directed towards the possibility of enabling new and more flexible patterns of the life course without further age divisions in society. Instead of dividing the life course further into chronologically defined blocks, possibilities must be increased to sandwich work, education, societal involvement, family life and free time from early youth until this is impossible due to illness or failing functional ability" (SOU 2003:91, p. 194). A chronologically graded life course with accompanying norms may be ageist, but it has the capacity to replace functional ability as a way of labelling citizens.

Upgrading and age irrelevance approaches have been developed as part of a laudable project to dissociate old age from a paradigm of decline and loss. However, the character or consequences of these prominent attempts to counter ageism tend to be ableist and to further stigmatize and marginalize older people with impairments and care needs by conveying and consolidating the message that high status and success in old age is related to health and functional ability. In both cases, and alongside the discrimination of older people, ableism is to some extent present in the very struggle against ageist norms. Thus, in order to combat discrimination and to improve everyday conditions of older people in long-term care there is a need for other approaches.

\subsection{Lessons from Disability Policies and Disability Research}

Already in 1980, Levin and Levin (1980) argued that a prominent feature of ageism is to regard problems of older people as caused by ageing. Following this line of thought, common strategies within anti-ageism have been to question age as an explanatory factor and organizing principle and to downplay physical, bodily consequences of the ageing process. This was also the logic followed by the Swedish Committee on Older People referred to above. Quite different approaches to function as well as to age have been launched by disability activists, policy makers, and researchers as part of an endeavour to improve the situation for (non-old) people with disabilities.

In Sweden, public care and support services for older people and people with disabilities are handled and discussed within two policy areas: policy for older people and disability policy. Although the objectives of these areas are in many ways similar, there are also obvious differences between the two (Erlandsson 2014), entailing government investigations and other documents within the realm of disability policy—an area with a strong connection to the disability movement- to 
display more of a clear-cut citizenship perspective. Consequently, there is a stronger emphasis on equal value and equal rights and on the need to close the gap between people with and without disabilities. Within disability policies, researchers and official policy makers have frequently taken a protagonist stance and emphasized the need to make people with disabilities equal citizens. Prominent members of the disability movement have also been key players in the process-most notably, Bengt Lindqvist, who was the minister responsible for disability policies in the Social Democratic government from 1985-1991, had previously been president of the Swedish Association of the Visually Impaired (1975-1985), and was one of the founders of the socialist association, Disabled People's International.

Below we present a model developed in disability policies that could be used to argue for improvements of long-term care for older people. The model refers to a recent paper published in The Gerontologist (Jönson and Harnett 2016). The strategy we suggest differs from both the upgrading and the age irrelevance approaches that have been adopted internationally within anti-ageism as well as within Swedish Policy for older people (SOU 2002:29, 2003:91). It aims to acknowledge age, while also looking past bodily shortcomings in later life, and focuses on the way society disables and discriminates older persons with care needs and impairments. In this model, we refer to the Scandinavian normalization principle that has been prominent in disability policies of the Nordic countries. In the Gerontologist paper, this principle is developed into an equal rights framework that may be used to identify discriminating practices and claim "equal rights" for older persons with long-term care needs.

The first outlines of the Scandinavian normalization principle appeared in Denmark and Sweden in the 1950s. A characteristic of the principle was that it used people in general - referred to as "ordinary citizens"-as the comparative reference group and identified persons with impairments as deprived relative to other members of society. The principle suggests that society should make available for persons with impairments living conditions that are the same as or similar to those of citizens in general. People with disabilities should be able to live like "others."

In 1970, the originator of this principle, Bengt Nirje, suggested eight normalizing rights for young people with developmental impairments (Nirje 1970):

1. A normal rhythm of the day

2. A normal weekly rhythm

3. A normal rhythm of the year

4. A normal development experience of the life cycle

5. Have choices, wishes, and desires respected

6. Live in a bisexual world (not in unisexual groups)

7. Apply normal economic standards

8. Access to physical facilities such as (apartment-like) housing, schools, workplaces, and hospitals that are the same as or similar to those provided for ordinary citizens 
Nirje (1970) formed his principle as a critique of contemporary disability policies at a time when large institutions were the dominant form of housing for persons with intellectual disabilities. Normality and justice for people with disabilities living in institutions was at the time based on comparisons to others living in institutions or having similar disabilities.

To question institutionalization and categorization according to medical models, Nirje (1970) used a number of references to comparative categories external to the institution and to the entire context of care and bodily and intellectual shortcomings. In accordance with the right to access physical facilities similar to those provided for ordinary citizens, Swedish disability policy has emphasized that housing for people with intellectual disabilities should be the same as or similar to ordinary housing. Daily activities should take place in arenas that are external to the context of care; that is, that schools and workplaces should be separate from housing (Tideman 2000).

In his original work, Nirje particularly commented on normal conditions in relation to life phases: childhood, youth (school age), adulthood, and old age. This construction of normality with reference to age has become central to Swedish disability policies and activism. Age-based activities have guided comparisons of lifestyles and rights, with the former being used to argue for the latter. For example, in the early 1990s, policy makers and disability activists argued with reference to age in a comprehensive government investigation (SOU 1990:19, 1991:46, 1992:52) preceding the introduction of a system of personal assistance that significantly improved conditions for younger people with disabilities. In the investigation, the Swedish Disability Committee (SOU 1991:46) explained how key concepts like accessibility, participation, influence, and equality should be measured: "We have seen it as important to present proposals which mean that people with significant impairments (children, youth and adults) have equal conditions as others of similar ages" (p. 143). In this perspective, it is in relation to their age peers that the conditions of people with disabilities should be compared. This is clearly expressed in writings about younger people with disabilities, where normalization is defined as a right to participate in activities typical of young people. A reference to the age norms of youth may be phrased like this: "He who is young should be able to live a life like other youngsters, to travel on an Interrail pass, take a language course, study abroad, party, and so on" (Peterson 2003, p. 217). The Disability Committee also mentioned specific roles, norms, and activities associated with childhood and youth, and discussed parenthood and participation in working life as roles for adults (SOU 1991:46). The possibility to compare ages may be regarded as the trump card of the disability movement, since such comparisons have the potential to identify welfare arrangements without focusing on diagnosis or characteristics associated with impairments. 


\subsection{The Equal Rights Framework and Institutional Ageism}

Is it possible to transfer the ideas of the normalization principle adopted by disability activists to long-term care for older people? Can society make available for older persons with impairments and illnesses living conditions that are as close as possible to those of "others of the same age"? Who are those "others of the same age" who could serve as comparative reference groups in demands for justice? What kind of comparable living conditions should policies aim to achieve?

Building on the Scandinavian normalization principle, Jönson and Harnett (2016) have developed an equal rights framework (Fig. 22.1) that could be used to analyse and propose changes in care for older persons. A typical internal reference is to argue that justice is achieved when residents at a care facility are treated equally, for instance having the possibility to go for a walk or having a shower twice every week like others at the facility. An external reference group for comparison might include people in general: for example, other men or women; other Muslims; other vegetarians; or other couples. Should older couples be deprived of possibilities to live together like other couples, just because they have support needs? If not, society should provide solutions that allow them to keep living together. Following the disability movement, a general aim should be to increase external comparisons when discussing the rights of older people who receive long-term care.

In order to explain the strengths of the equal rights framework to improve longterm care and living conditions for older people in the fourth age, we use the framework to question existing cases of "institutional ageism" whereby older people with impairments are excluded from government programs benefiting younger people with disabilities. The strategy proposed could also be used in attempts to improve

\begin{tabular}{|l|l|l|}
\hline Type of references & $\begin{array}{l}\text { Internally oriented - } \\
\text { care and impairment }\end{array}$ & $\begin{array}{l}\text { Externally oriented - } \\
\text { society in general }\end{array}$ \\
\hline Context-centred & $\begin{array}{l}\text { The contexts of care or } \\
\text { impairment }\end{array}$ & Other contexts invoked \\
as comparison
\end{tabular}

Fig. 22.1 An equal rights framework for persons in need of support and care (First published in The Gerontologist, Jönson and Harnett 2016; Reproduced from Jönson and Harnett 2016) 
long-term care in cases, and countries, where the situation in need of improvement is not as clearly and explicitly related to ageism.

Instead of acting as a normative reference group, as the ideal or individually correct standard that older persons may fail or manage to live up to, we suggest that it is possible, and relevant, to use the third age and older people without impairments and care needs as a comparative reference group. Furthermore, we argue that society should make available for older persons with impairments living conditions that are typical for members of this group of active, healthy seniors. Our point of departure is a qualitative interview study with people ageing with extensive physical disabilities that was conducted in Sweden some years ago. The study was previously published in English as an article in the Journal of Human Development, Disability, and Social Change (Taghizadeh Larsson 2011) and as a chapter in the book, Ageing With Disability: A Life Course Perspective (Taghizadeh Larsson 2013).

In disability policy, a prominent idea is that the right of people with extensive disabilities to live like others and to be self-determinant and autonomous can be realized through personal assistants that serve as the so-called assistance user's "arms and legs," while the user determines what should be done, and how. In Sweden, this idea was materialized in 1994 by the introduction of the system of personal assistance. This reform improved conditions for people below the age of 65 with lasting, long-term support requirements, in the sense that their opportunities to take control over their own lives were significantly improved (Szebehely and Trydegård 2007). In 2001, the right to keep assistance after 65 was introduced. However, the conditions still are that personal assistance has to have been granted before the age of 65, and the amount of assistance accorded may not be increased after the 65th birthday. This "institutional ageism" can be understood partly as the result of the above described and successful endeavour to provide disabled people of younger ages with rights that are typical of non-disabled citizens. In this struggle, what is just and equal has been defined in relation to citizens of similar ages: children, youth, and adults of "active ages". To some extent the exclusion of older people can then be understood as the inadvertent result of a struggle against other forms of prejudice; that is, as a struggle against ableism. It can also be seen as a struggle against the traditional inclusion of all people with needs into one group (Jönson and Taghizadeh Larsson 2009). For older people, there has been a lack of comparative reference groups and, as a result, comparisons in long-term care have tended to depart from the left-hand column of the framework: as internal to care and impairment.

How do we move comparisons to the right-hand column in the framework? We have already mentioned a number of categories that could be used creatively when claiming rights to live like "others". Our suggestion then is that the third age, associated with a number of activities and lifestyles - studies, travel, leisure, involvement in the family, and volunteer work - could be used as a comparative reference group for older persons in need of care. In other words, and building on lessons from disability policies and research, we suggest that it could be claimed that an older person who has aged into impairments should be able to live a life like others who are 
older, visiting relatives, traveling, studying, and participating in volunteer work. These activities should not be regarded as normative - they should not be standards to live up to- -but as typical, and thus possible to refer to when defining social rights.

Third Agers with Extensive Impairments The idea of using the third age as a comparative reference group for older persons with impairments does not depart from an imagined situation; it is empirically anchored in the life of some people who have aged with impairments. Based on qualitative interviews with 12 persons aged 65-72 with extensive physical disabilities belonging to the first, and small, cohort of Swedish citizens with the legal right to keep their personal assistance after 65 years of age, we illustrate the potential of the third age to become an important reference group for people with impairments and long-term care needs.

All 12 interviewees were dependent upon some form of mobility support (cane, walker, or wheelchair) more or less all the time; nine primarily used a wheelchair. The diagnoses reported were the following: polio (three); multiple sclerosis (MS) (five had at one time been diagnosed with MS, but two of these presented the diagnosis as uncertain or ambiguous); cerebral palsy (two); spinal injuries (one); stomach and intestinal diseases (one). What is of interest is that members of the population of older people who had impairments and extensive support needs before they turned 65 are provided with a type of help that other members of the category of older people are not entitled to have. Having had their impairments for a long time, they have to some extent also encountered and in some cases embraced the ideology and models that have been developed by the disability movement and as part of official policy.

When the 12 individuals talked about what they had been doing lately, what they were planning to do in the near future, and when they were asked to talk about an ordinary week and a normal day, an image of recreationally active, committed individuals emerged. The women and men in question described how they went to the theatre and concerts, were involved in artistic activities, took part in language studies, sports and gymnastics, and travelled both within and outside Sweden. Several took an active part in society through volunteer work at various levels (international, national, and municipal) and within various associations aimed at improving the living conditions of disabled people. Some were active in providing supervision for their personal assistants and in handling elements of the administration connected with their assistance. They appeared, in other words, as continually engaged in life in a way typical of a "third ager" (see Laslett 1989).

The current lifestyle of the participants largely seemed to be a matter of devoting their free time to activities that they to some extent had been previously engaged in, when they were still on early retirement pension or were working. As Margareta (aged 66), who left work when she was in her 50s, put it: "Much of what I thought was kind of hobby stuff before, I pursue in a somewhat different way now." Some commented that the activities that they were engaged in today were the kind that they probably would have devoted their careers to if the possibility had existed. Among those was Inger (aged 67), who was diagnosed with polio as a child. Inger 
had applied and been accepted to an art college when she was a young woman. At that time, however, the educational institution was located on the fourth floor of a building without a lift, which made it impossible for her, as a wheelchair user, to begin her studies. Today Inger, with the support of her personal assistants, devotes a good portion of her time to artistic activities of various forms. Likewise, other participants described how developments in technical aids had created an opportunity for them, despite increased impairment, to engage in sports in ways that were impossible when they were younger. Hence, the dimension of self-fulfilment that is characteristic of the third age (Laslett 1989) can also be part of being a senior with extensive impairments.

For those participants who had personal assistance, this support stood out as a critical element in effectively achieving an active, third-age-like lifestyle. They talked about personal assistance as "the best thing that ever happened" to them and as "heaven-sent". When life with personal assistance was compared to previous experiences of eldercare in the form of municipal home help services, participants highlighted flexibility, the possibility to influence the choice of assistants, and greater control over one's everyday life among the benefits. In line with arguments from disability scholars and activists that it is possible to be highly dependent on other people, yet perceive oneself as autonomous, some said that personal assistance makes it possible to "manage oneself."

A striking example of this is the story of Ann-Marie, aged 65, and diagnosed with MS at the age of 20. Ann-Marie was an active member of an international art association. Through a monthly scholarship, a more established artist supported her in her artistic development for a few hours every Wednesday. As Ann-Marie had lost the ability to move her arms and legs, she used her mouth when she painted. Aside from being one of the participants engaged in artistic activities and in gymnastics, she was an experienced traveller. At the time of the interview, she had recently visited Denmark, Spain, and Iceland. During the interview, Ann-Marie described her future travel plans:

On the topic of travelling, I probably won't travel abroad anymore. I've had enough of that. Although, sometimes I think I haven't explored all of Iceland yet. I should go to the northern part, too. But, no, I probably won't. I'll keep myself to Sweden from now on. And you know what? Recently I had this idea to adjust Lennart's car so we can adjust one of the seats to fit my wheelchair in there. That way we can go on shorter trips alone. So that's our small project right now.

Lennart, who is referred to in the interview extract, is one of Ann-Marie's personal assistants and has for many years assisted her with tasks from brushing away strands of hair from her face to personal hygiene, meals, and dressing. However, it is AnnMarie herself, through a specially designed computer, who administers the assistance and plans the assistants' schedules.

The participants in the study mentioned above managed to do something that both anti-ageists and disability activists so far have largely failed to do. Through their stories, they provided "updated" images of older people with extensive impairments living third-age-like lifestyles. By doing so, they also indicated that activity restrictions and problems that people encounter in later life could be countered in 
similar ways as in younger ages; that is, they indicated that they should have the right to live like others in the same (third) age-like older people without impairments and long-term care or support needs.

Adding to our argument that the third age could be considered as a relevant reference group for older people with long-term care needs, two recent case studies exploring the phenomenon of living with dementia with support from personal assistants (Hellström and Taghizadeh Larsson 2017) showed that older people who have acquired cognitive impairments as older adults may also live active lives "like others in the third age." The two persons who participated in the case studies both received their dementia diagnosis at a relatively young age and had extensive care needs when they reached the age of 65 . One of the case studies involved a 72-yearold man, diagnosed with frontotemporal dementia 13 years previously, his wife, and personal assistants. The other involved a woman aged 66, diagnosed with Alzheimer's disease 11 years previously, her husband, and personal assistants. Both the man and woman had lost their abilities to use spoken language and to walk. Their daily lives with dementia and personal assistance were studied by participant observations inside and outside the home of the participant, video recordings, and audio-recorded interviews with spouses and assistants. The study illustrates that an active and relatively independent life inside one's own home and in the local community, including for example daily trips with an adapted car to various destinations, such as cafés and tourist sights, may be an option even for people with late stage dementia if access to flexible and personalized support, such as personal assistance, is provided.

\subsection{Conclusions and Recommendations}

How should we respond to ageism? This question is at the heart of the chapters in this book that deal with interventions to reduce ageism. Our conclusion, based on the Swedish case, is that older people in need of long-term care/support are victims of institutionalized ageism in the sense that they receive less help than people of younger ages. The justifying idea behind this discrimination is that because the process of ageing is generally linked to more diseases, impairments, and ultimately results in death, it can be considered appropriate to regard impairments among members of the category of older people as normal, and hence a matter to adjust to and cope with. This ageist rationale is internalized in the form of low expectations among older people themselves. Kane and Kane (2005) suggested that part of the discrepancy between long-term care for young and old can be traced to differences in the goals and expectations held by these age cohorts. Whereas younger people with disabilities see themselves as prevented by circumstances from participating fully in life's activities and thus seek (or demand) services that will permit full participation, older people seem to be willing to settle for much less: "They seem to view decline as an inevitable consequence of aging that must be borne with equanimity. This propensity to accept less, and hence to demand less, is associated with 
greater life satisfaction-interpreted as some form of coping, but the propensity really reflects ageism" (Kane and Kane 2005, p. 52). People are educated to expect that impairments after the age of 65 are the result of normal ageing and that shrinking possibilities are consequences of the normal ageing process.

In relation to the equal rights framework, attempts to fight institutionalization have been expressed in claims that the person in long-term care should be able to keep preferred habits and appearances. However, as shown by Harnett and Jönson (2017) in a recent study of Swedish nursing homes, external comparisons to personhood were found to be difficult to uphold when the ageing process was perceived to change the needs of the person. As a result, references to personhood are moved to the left in the framework; normality and justice are then defined as the possibility to live like one usually lives within the context of care. The persons who are cited in this chapter as members of a category that have aged with impairments and with the type of support that older persons are usually not entitled to, show us that these "truths" may be challenged.

Responding to ageism as a general phenomenon, anti-ageist campaigners have attempted to establish differences and divisions within the category of older people that are based on the presence and absence of disease and impairments. A major approach has been to claim that a majority of older people are healthy and able and, for this reason, ageist images of older people as frail should be replaced by updated descriptions. Our argument is that ableism has become embedded in and/or might be the consequence of some of the most prominent approaches that are used to counter ageism. Our recommendation is to shift focus from the performance and capability of ageing individuals to the performance and capability of society, and investigate how society enables or disables older persons with impairments. Our main argument is that policies relating to long-term care for older people could be improved by learning from disability policy and critical thinking on disability promoted by scholars aiming to improve the living conditions for, particularly, younger people with impairments. The approach that has been suggested in this chapter means that the third age, which so far has been a normative reference group for older people, could serve as a comparative reference group when older persons with impairments and care needs, as well as researchers and activists, argue for improvements in long-term care.

\section{References}

AGE Platform Europe. (2016). European day of solidarity between generations 2015. http://www. age-platform.eu/news-press/coverage/special-briefings/439-special-briefing-en/2652-european-day-of-solidarity-between-generations-2015. Accessed 14 May 2016.

Bytheway, B. (1995). Ageism. Buckingham/Bristol: Open University Press. 
Erlandsson, S. (2014). Hjälp för att bevara eller förändra? Åldersrelaterade diskurser om omsorg, stöd och service [Help to maintain or to change? Age-related discourses on care, support and service] (Doctoral dissertation). Stockholm: Stockholm University.

Harnett, T., \& Jönson, H. (2017). "They are different now"-Biographical continuity and disruption in nursing home settings. Journal of Aging Studies, 42, 1-8.

Hellström, I., \& Taghizadeh Larsson, A. (2017). Dementia as chronic illness: Maintaining involvement in everyday life. In L.-C. Hydén \& E. Antelius (Eds.), Living with dementia. Relations, responses and agency in everyday life (pp. 136-148). London: Palgrave McMillan.

Jönson, H. (2001). Det moderna åldrandet: Pensionärsorganisationernas bilder av äldre 19411995 [Modern aging: Pensioners' organizations' images of the elderly 1941-1995] (Lund Studies in Social Work 2). Lund: Lund University.

Jönson, H., \& Harnett, T. (2016). Introducing an equal rights framework for older persons in residential care. The Gerontologist, 56(5), 800-806. https://doi.org/10.1093/geront/gnv039

Jönson, H., \& Taghizadeh Larsson, A. (2009). The exclusion of older people in disability activism and policies-A case of inadvertent ageism? Journal of Aging Studies, 23(1), 69-77.

Kane, R. L., \& Kane, R. A. (2005). Ageism in healthcare and long-term care. Generations, 29(3), 49-54.

Kennedy, J., \& Minkler, M. (1998). Disability theory and public policy: Implications for critical gerontology. International Journal of Health Services, 28(4), 757-776.

Laslett, P. (1989). A fresh map of life: The emergence of the third age. London: Weidenfeld and Nicolson.

Levin, J., \& Levin, W. C. (1980). Ageism: Prejudice and discrimination against the elderly. Belmont: Wadsworth.

Nirje, B. (1970). The normalisation principle-implications and comments. Journal of Mental Subnormality, 16, 62-70.

Peterson, G. (2003). Specifik och generell lagstiftning [Specific and general legislation]. In M. Tideman (Ed.), Perspektiv på funktionshinder och handikapp (pp. 208-224). Lund: Studentlitteratur.

Priestley, M. (2003). Disability: A life course approach. Malden: Polity.

SOU. (1990:19). Handikapp och välfärd? En lägesrapport [Handicap and welfare? A progress report]. Betänkande av 1989 års Handikapputredning. [Swedish official government reports].

SOU. (1991:46). Handikapp, välfärd, rättvisa [Handicap, welfare, justice]. Betänkande av 1989 års Handikapputredning. [Swedish official government reports].

SOU. (1992:52). Ett samhälle för alla [A society for everybody] Handikapputredningens slutbetänkande. Betänkande av 1989 års Handikapputredning. [Swedish official government reports].

SOU. (2002:29). Riv ålderstrappan! Livslopp i förändring [Down with the age ladder! Changing views of the life course]. Diskussionsbetänkande av den parlamentariska Äldreberedningen Senior 2005. [Swedish official government reports].

SOU. (2003:91). Äldrepolitik för framtiden. 100 steg till trygghet och utveckling med en åldrande befolkning [Future Policy for the Elderly in Sweden.100 steps to security and development for an aging population] Slutbetänkande av den parlamentariska Äldreberedningen Senior 2005. [Swedish official government reports].

Szebehely, M., \& Trydegård, G.-B. (2007). Omsorgstjänster för äldre och funktionshindrade: skilda villkor, skilda trender? Socialvetenskaplig tidskrift, 14(2-3), 197-220.

Taghizadeh Larsson, A. (2011). On the possibilities of "ageing successfully" with extensive physical impairments. Journal of Human Development, Disability, and Social Change, 19(2), 127-140.

Taghizadeh Larsson, A. (2013). Is it possible to "age successfully" with extensive physical impairments? In E. Jeppsson Grassman \& A. Whitaker (Eds.), Ageing with disability: A life course perspective (pp. 55-71). Bristol: Policy Press.

Tideman, M. (2000). Normalisering och kategorisering: Om handikappideologi och välfärdspolitik i teori och praktik för personer med utvecklingsstörning. Lund: Studentlitteratur. 
Wigdor, B. T. (1995). Public awareness of aging: Its impact. In C. Hummel \& C. J. Lalive D’Epinay (Eds.), Images of aging in western societies. Proceedings of the 2 nd "images of ageing" conference, Sierre, Centre for Interdisciplinary Gerontology. Geneva: University of Geneva.

Wohlin, M. (1960). Hela folket $i$ arbete! Arbetsförmedling och arbetsanskaffning för äldre [The entire population at work! Distributing and providing work for older people]. Stockholm: Möllerkommitten för åldringsfrågor.

Open Access This chapter is licensed under the terms of the Creative Commons Attribution 4.0 International License (http://creativecommons.org/licenses/by/4.0/), which permits use, sharing, adaptation, distribution and reproduction in any medium or format, as long as you give appropriate credit to the original author(s) and the source, provide a link to the Creative Commons license and indicate if changes were made.

The images or other third party material in this chapter are included in the chapter's Creative Commons license, unless indicated otherwise in a credit line to the material. If material is not included in the chapter's Creative Commons license and your intended use is not permitted by statutory regulation or exceeds the permitted use, you will need to obtain permission directly from the copyright holder. 


\title{
Chapter 23 \\ Educational Methods Using \\ Intergenerational Interaction to Fight \\ Ageism
}

\author{
María del Carmen Requena, Hannah J. Swift, Laura Naegele, \\ Marc Zwamborn, Susan Metz, Wilco P. H. Bosems, and Joost van Hoof
}

\subsection{Introduction}

The social phenomenon of ageing has deeply modified contemporary societies, making it possible that three or more generations live together within the same chronological environment. Even though this development can be viewed as a great achievement, it does not mean that societies have changed their often negative concept of older generations. This holds particularly true for younger generations, as they, for example, often view older persons as conservative, petulant and pessimistic (Requena and Gonzalez 2008). Studies that explain ageist behaviour tend to focus on the micro level (linking ageist attitudes with individual characteristics) or on the macro level, where ageist behaviour is attributed to shared cultural norms and attitudes that shape individual, organisational and societal behaviour regarding certain age cohorts (Shiu et al. 2015). As multigenerational societies become the norm,

M. del Carmen Requena ( $\triangle)$

Department of Psychology, Universidad de León, León, Spain

e-mail: c.requena@unileon.es

H. J. Swift

Centre for the Study of Group Processes, School of Psychology, Keynes College, University

of Kent, Canterbury, UK

e-mail: H.J.Swift@kent.ac.uk

L. Naegele

Institute of Gerontology (IfG), University of Vechta, Vechta, Germany

M. Zwamborn · S. Metz

Summa College, Summa Healthcare, Eindhoven, The Netherlands

W. P. H. Bosems · J. van Hoof

Centre for Healthcare and Technology, Fontys University of Applied Sciences,

Eindhoven, The Netherlands

L. Ayalon, C. Tesch-Römer (eds.), Contemporary Perspectives on Ageism,

International Perspectives on Aging 19,

https://doi.org/10.1007/978-3-319-73820-8_23 
rather than the exception in Europe, the question of how existing prejudices and age cohort related discrimination could be tackled arises.

Within this context education plays an important role. The sector of higher education, in particular, aims to form professionals in this new multigenerational landscape and it must be aware of its double role as a tool to combat demeaning stereotypes based on ageing and prevent ageist beliefs and attitudes. Ideally, higher education incorporates learning social competences and interpersonal abilities, and this perspective faces implicit stereotypes because it removes social conventionalisms and shared expectancies where ageist stereotypes are grounded.

Theoretical frames based on intergroup theories (Stephan and Mealy 2011) lay out how coexistence and participation in a common space favours personal knowledge and avoids explicit ageism (Hagestad and Uhlenberg 2005). Intergroup theories propose that positive intergenerational relations, which require personal involvement beyond the mere coexistence, can reduce implicit ageist attitudes and values. Intergenerational relations presuppose a double bond between persons: one is affective and another one is based on specific interaction rules within the community. Research has shown that affective bonds promoted by personal relationships are significantly related to the lack of implicit ageist stereotypes (Jost et al. 2004). This kind of intergenerational relations is present in family or labour contexts, but is underrepresented in formal educative environments, which are typically homogeneous regarding age. It is not usual to find older persons sharing the classroom with younger students, unless when intentionally prepared. It is also not usual to find young and older persons sharing leisure places unless some kind of emotional bond is present. Therefore, higher education institutions have the responsibility to promote educative intergenerational experiences both within the formal academic environment and beyond it in real life contexts. Students find the chance to put into practice not only the technical knowledges acquired in their studies, but develop affective bonds and prosocial abilities by means of intergenerational encounters.

A myriad of concrete examples illustrate these ideas. Consider how young European nursing students prefer not to work in the ageing sector, even if it is a major source of employment. For example, studies on the professional preferences among students of degrees such as medicine, social work or education show that they begin their studies preferring to work with children or young persons, while the practice with older persons is generally neglected to the last ordinal preference (Kalisch et al. 2013). This lack of interest is not only related to the emergence of negative memories and experiences but also to erroneous beliefs and myths about age and ageing (Requena and Gonzalez 2008). Such tenets are based on outdated socio-cultural patterns of interaction between generations especially among young persons and first year university students. In contrast, it has been confirmed that intergenerational groups linked by commercial or ephemeral bonds are less efficient in terms of prosocial interaction than affectively loaded intergenerational relations (Chonody and Wang 2014).

This chapter presents theoretical models, methodologies and a case-study, which exemplify and lay the foundation for an applied educative model based on the combination of scientific knowledge delivered in classrooms with experiential 
methodologies. In particular, the proposed approach combines technical instruction with person-centred education as a successful formula to fight implicit ageist stereotypes in higher education. The chapter starts out with outlining three theoretical frameworks (Intergroup Contact Theory, Intergenerational Contact Theory and the Concept of Generational Intelligence) and aims to explain in educational contexts how intergenerational contact can help to prevent discrimination based on age. Subsequently the illustration of concrete experiential methodologies in higher education that facilitate intergenerational contact are outlined, the chapter ends with the presentation of the case study "Senior in Class", conducted in the Netherlands, that can be considered as a 'good practice' example of intergenerational contact intervention to preventing ageism.

\subsection{Theoretical Frames}

\subsubsection{Intergroup Contact Theory}

Intergroup contact theory (Allport 1954) is a social psychological theory, which suggests that, under the right conditions, contact or interactions between members of opposing groups may improve attitudes and bring about a reduction in intergroup prejudice and stereotypes. The optimal conditions specified by Allport include equal status between group members, working towards a common aim or goal, providing an opportunity for intergroup cooperation and institutional support or support from an authority figure. Research has identified further conditions that facilitate the beneficial effects of intergroup contact. For instance, Cook (1962) highlighted the importance of intimacy within the interaction and suggests this underpins the potential to see the interaction partner as more than an 'acquaintance', which is likely to facilitate the development of a cross-group friendships (i.e., friendships between people who belong to different social groups). Indeed, cross-group friendships are a direct form of intergroup contact. Pettigrew's (1998) review found that individuals with friends from different social groups had significantly lower levels of in-group bias, and it is the most likely type of contact to result in positive outcomes, including, a reduction of prejudice and increase in sympathy towards, and admiration of, outgroup members (Pettigrew 1997; Davies et al. 2011).

Since Allport introduced intergroup contact theory as a means of prejudice reduction, there have been many studies exploring its effects, in various contexts, with a range of outgroup targets (predominately race and ethnicity, followed my mental or physical disability and sexual orientation). In 2006, Pettigrew and Tropp conducted an extensive review and meta-analysis of 515 of these studies, conducted between 1940 and 2000, that included more than 250,000 participants. The results showed that studies adhering to Allport's optimal conditions of contact tend to produce larger effects and are therefore, generally seen as more successful in reducing prejudice. However, studies that didn't adhere to these conditions tend to produce smaller effects, but were also considered successful at reducing prejudice. Therefore, the 
authors concluded that these conditions should be seen as facilitating factors, rather than essential conditions for prejudice reduction. In addition, research has shown that the prejudice reduction effects of intergroup contact are generalizable beyond the original contact partner (Pettigrew and Tropp 2006). In other words, contact interactions between people who belong to different social groups can reduce prejudice towards the contact partner's entire outgroup (as well as to the contact partner), resulting in changes in attitudes towards groups of people. The findings of the metaanalysis, in which $10 \%$ of the studies explored contact interactions between different age groups, has significant implications for intergenerational contact (i.e., contact between members of different age groups or generations), suggesting that it is viable prejudice reduction technique capable of reducing ageist attitudes towards contact partners, as well as prejudice towards older adults in general.

\subsubsection{Intergenerational Contact Theory}

The majority of intergenerational contact research tends to focus on the effects of intergenerational interactions that take place during day-to-day life, and reveals that positive intergroup contact is related to more positive outcomes, including a decrease in explicit and implicit negative attitudes towards older adults (see Drury et al. in press for review) and tend to lead to more positive behavioural intentions, such as intentions to donate to charities that support older people, and agreeing to spend more time with older adults (Bousfield and Hutchison 2010; Hutchison et al. 2010). This is particularly the case when young people's experiences were frequent and of good quality, in other words, considered to be positive interactions (Hutchison et al. 2010).

However, just like intergroup contact, there are different types of intergenerational contact, which can occur in a range of settings. For instance, cross-group friendships are a direct form of contact, but contact can also be indirect, such as extended contact and imagined contact. Extended contact works on the basis that a-friend-of-yours-is-a-friend-of-mine (Wright et al. 1997). For example, the knowledge that a same aged friend has a friend, who is an older adult, can reduce ageism. Imagined contact works simply by asking people to imagine having a positive encounter or interaction with someone (usually asked to imagine a stranger) from another social group. For example, in two studies, undergraduate students who imagined a positive interaction with an older adult stranger reported less prejudice and bias toward older adults compared to students, who imagined an outdoor scene (Turner et al. 2007). However, unfortunately it seems that opportunities for meaningful interactions between generations and opportunities to from cross-generational friendships between generations are rare. Evidence from the European Social Survey shows that $80 \%$ of respondents aged $15-24$ have no friends aged 70 and over (Abrams et al. 2011). There are often significant barriers and obstacles to the formation of cross-group friendships, particularly between people from different 
age groups. Therefore, intergenerational contact programmes, are often used to fill this void and provide opportunities to bring generations together with the aim of improving intergenerational relationships.

\subsubsection{Generational Intelligence}

The emerging model called "generational intelligence" offers a conceptual frame to interpret the complex and multidimensional issue of intergenerational relations. Against the backdrop of constantly shifting socio-demographics, the model takes the dual challenges of being placed in the situation of another generation, while simultaneously negotiating sustainable relationships amongst members of different generations (Biggs et al. 2011). Generational intelligence is defined as the capacity to reflect and act towards the comprehension of oneself and others as members of an age group, of a cohort, and of a family living in a present social and cultural context. Young and old coordinate common chronological time with roles, which can differ between generations. For example, in the past, the older persons were the holders of wisdom while currently young persons have a better access to knowledge. In the past, the social role determined by the pair education-work was significantly less dependent on chronological age. For example, work was distributed in terms of family needs, not in chronological terms when children had to leave school to work and help at home. Moreover, in contemporary societies there are manifold temporal contexts occupied by several generations sharing the same chronological time. An essential feature of generational intelligence is using education to encourage people to understand the temporal context of others. This model does not search for a neutral age and does not presuppose that age is irrelevant. Rather, the model focuses on creating spaces where age is distinctive from several generational points of view, and suggests this must be taken into account within a pragmatic negotiation process. The social classification of people according to age influences the expectations of the roles played by citizens at different ages: children play, young people study, adults work and the elderly rest. However, the real plurality of significant roles played by older persons (such as support for the family, caring for their grandchildren and support for the community through volunteering) goes beyond the tripartite social structure education-work-pension. There are severe discursive limitations on the expectancies of older persons because their identity and responsibility are impoverished (Biggs and Lowenstein 2013).

The National Council on Aging of the U.S.A. (Ventura-Merkel and Lidoff 1983), for instance, proposes the development of generational intelligence through activities that increase cooperation, interaction or exchange between two generations. The exchange is more than the mere fact of bringing together young and old, since it aims at the organised achievement of benefits for both generations. The copresence of older and young people should promote generational know-how 
together with the ability to use it as a key and non-decorative element of generational interventions. Decisions about the content of these programmes are made taking into account as a priority objective the generational educational exchange that, precisely because they are different from each other, can create a space for communication, dialogue, encounter and learning (McClusky 1990).

The presented frameworks stress the potential of reducing existing age-related stereotypes through direct interaction between different generations. Establishing ties between different generations is essential in order for members of different age cohorts to discuss differences between them as well as to express their need for each other (Manheimer 1997). Such ties include interactions that happen through the exchange of knowledge, such as young people introducing older people to the use of technologies, while older people contribute their vital life and work experience to younger generations. The idea of intergenerational knowledge exchange is rather common in the social sphere of work, for example, as part of mixed-age groups in general. However, this chapter aims to look at the higher educational sector and its potential for reducing ageism through intergenerational contact. It should be mentioned that programmes, aimed at fostering this intergenerational contact, are not exempt of unexpected results that can end in failure and therefore, careful planning and constant supervision are required (Sánchez and Kaplan 2014). The following chapter (2018; Chap. 24) introduces the method of "Experiential Service-Learning" as a vehicle for facilitating interaction amongst different cohort members and provides the methodical background for the case study presented in the closing of this chapter.

\subsection{Experiential Service-Learning}

Educational practices in ageing societies are constantly exploring new inclusive educational methodologies for all ages. According to the theoretical models previously proposed, it is necessary to balance the current curriculum based on the acquisition of an extensive body of theoretical knowledge with new experiential learning methodologies that favour not exclusively academic formation, but also communitybased learning. John Dewey (1916-1995) is acknowledged as the creator of the theoretical rationale for contemporary academic Service-Learning: "Experience is better than a ton of theory because it is only in experience that any theory has vital and verifiable experience" This author argued for the advantages of offering significant experiences with which students can acquire knowledge and develop abilities to solve real world problems. Dewey's proposal is to incorporate concrete experiences into the learning process with an ulterior critical reflection on the experience (Conway et al. 2009). The success of Service-Learning as a powerful strategy able to improve learning and foster an engaged citizenship against ageism is well documented (Basran et al. 2012). In fact, research showed that students taking part in Service-Learning Programmes obtain better academic records, increase their 
self-efficacy, enrich their personal identity, their social conscience and self-confidence and are more aware of their civic and ethical responsibilities towards the sociocultural context where they live.

The Service-Learning planning methodology requisites, established by the National Service-Learning Clearinghouse (NSLC) (Gallagher 2007), are the following:

- The production of knowledge departs from problems rather than from disciplines;

- Problems faced by Service-Learning strategies and their solutions are handled with academic tools and scientific rigour. The activities should foster social links to articulate Service-Learning within and without the classroom;

- Active participation of students in all phases of the Service-Learning field work, including diagnostic, planning, management, results, evaluation and reflection (see the project "Seniors in Class" below);

- The evaluation of solidary attitudes amongst different generations has the same weight as academic learning;

- Reflection on results. To achieve this requirement it is appropriate to use evaluation tools such as discussion groups and portfolio, described in the case study in the following section.

\subsubsection{Service-Learning in Higher Education}

Within the context of higher education (universities and colleges) Service-Learning methodology begins with the American Compact Campus in the 1990s. This campus is currently shared by more than 959 colleges, universities, public and private educational institutions in more than 30 states throughout the United States of America. The mission of these centres is to promote civic responsibility through knowledge transmission and community-based research. Europe also was influenced by Service-Learning methods. Among the first initiatives stands out the 2003 created European Service-Learning Association and the EU project CIVICUS, promoted by the Vytautas Magnus University in Lithuania, in which forms of cooperation between universities and companies were explored (Natalija and Deivida 2011). The Netherlands Centre for Social Development (Movisie) is one of the main entities disseminating Service-Learning (Lub et al. 2009), including special attention to older persons. The drop of voluntary work in society forced the government to rule that all students must work between 48 and $72 \mathrm{~h}$ in Service-Learning activities from September 2010 onwards. Service-Learning was introduced in the curriculum in 2007 and obtained compulsory status in 2011. Similar centres are created in Sweden and Switzerland. ${ }^{1}$ In the United Kingdom, Service-Learning practices are understood as citizenship education and they are organized by civic extra-academic

\footnotetext{
${ }^{1}$ www.servicelearning.ch
} 
institutions such as Community Service Volunteers. For example, outstanding intergenerational programmes incorporate old persons as mentors of difficult school children (Jerome 2012). Germany founded the network Lernen durch Engagement, ${ }^{2}$ which includes excellence and cooperative centres and is active in the publication of materials. In Spain, the network Red Estatal de Aprendizaje-servicio and in Barcelona the Red ApS-U organise Service-Learning activities promoted by a group of older persons and retired professionals, like the iaioflautas. ${ }^{3}$

\subsubsection{Reasons for the Service Learning Model in University Settings}

The university as an institution must articulate educational programmes, lines of research and civic missions that together reflect the key elements of the curriculum of students as future professionals. In particular, service learning methodologies in higher education settings: (1) are not a panacea (or new magic recipe) but an educational approach consistent with the intention to achieve meaningful learning experiences and create genuine theory/praxis interfaces, (2) mobilises teaching resources for new realities. The rejection and avoidance of patterns of social discrimination and stereotyped behaviour such as ageism are realistic curricular objectives of experiential methodologies (Brown et al. 2013). The European Higher Education Area has reformulated the concept of higher education with the incorporation of ethical education including values and attitude education, However, no curricular space have been granted to these aspects. Therefore, these learnings are to be acquired by extracurricular activities and a transversal approach to the curriculum (see the example offered in the "Seniors in Class" project case study). The difference between practical curricular activities and service learning is the compulsory character of the former. Curricular activities are obligatory in order to obtain an academic title, while service learning experiences must be conceived in a less rigid way, not as a bureaucratic requirement but as an experiential methodology valued beyond the academia. The following section describes the project of the third age class, cross-curricular approach based on the service learning methodology.

\subsection{Seniors in Class Project: A Case Study}

This section describes the different phases of an ongoing service learning experience, which follows the National Service-Learning Clearinghouse methodology (Fig. 23.1). The project 'Seniors in Class" (Dutch: 'Senioren in de Klas DOEN!') is

\footnotetext{
${ }^{2}$ www.servicelearning.de

${ }^{3}$ http://www.iaioflautas.org
} 
Fig. 23.1 Phases of the service-learning field work

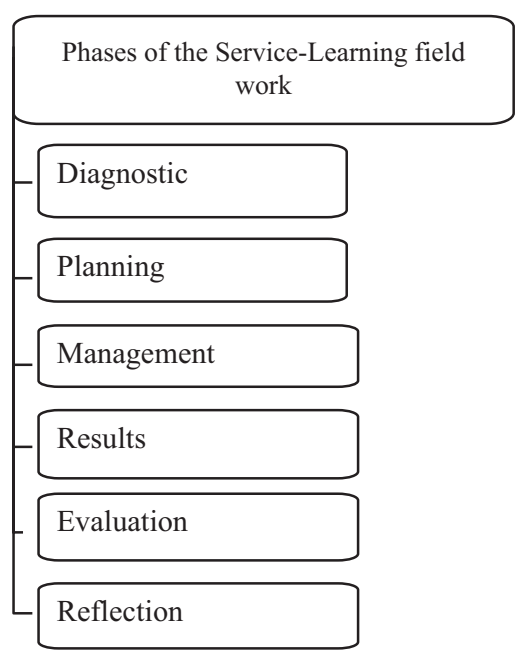

a project which concerns the improvement of the educational programme, involving the active participation of seniors in lectures and workshops, in this case, in the domain of healthcare and technology. This project is a joint project of Fontys University of Applied Sciences and Summa College in Eindhoven, The Netherlands (van Hoof et al. 2015b). Besides fostering the academic learning of the studentparticipants, this project also puts a focus on facilitating intergenerational contact and developing generational intelligence through inviting seniors to actively participate in class.

\subsubsection{Phases of the Service-Learning Field Work}

In the Netherlands, the provision of healthcare and welfare services for the older population is a topical subject in politics at national and local levels, and features heavily in the media. Older people are expected to age-in-place, thresholds for admission to long-term care facilities are growing ever higher, and existing nursing home capacity is being re-evaluated in terms of quantity and quality. Health care schemes that were once provided by the state are now being substituted by solutions and services at the local level, some of which include a wide array of healthcare and welfare technologies. The education programmes of universities of applied sciences and vocational colleges in the domains of healthcare and welfare are, therefore, continuously updated in terms of the inclusion of societal themes and new developments (van Hoof et al. 2015a). One of the projects which concerned the improvement of educational programmes involves the active participation of seniors in lectures and workshops, in this case, in the domain of healthcare and technology. 


\subsubsection{Planning}

The project aims to involve older adults (explicitly referred to as 'seniors' as requested by the participants of the project) with students in education related to the design and application of technology in healthcare in order to combat age stereotypes and ageism. In order to achieve this general objective, three goals were placed central in the project, which directly relate to some of the facilitating conditions for intergroup contact:

- First, the project wanted to present seniors as societal role models. A role model is not per se a successful businessman or a famous person. In this project, a role model is someone who is right in the middle of a certain societal problem or challenge, such as a senior who actively uses numerous means and solutions to keep functioning independently and maintain a social life. It is this group explicitly, that we wish to involve in our educational programme as 'old and gold', with a differentiation in terms of needs and interests for a certain type of educational method.

- Second, seniors work together during educational activities with students and lecturers (co-creation) in the field of design and evaluation of living environments and technologies. There is a mutual exchange of knowledge and skills, and design prototypes of students are being optimised.

- Third, by involving seniors in education, they indirectly receive didactical education and they participate more intensively in society. By giving attention in class to the topics that seniors are experts of, seniors have to prepare themselves in the context of a certain problem and the way the related knowledge can be transferred as optimally as possible. A lecturer has the task to support the senior in transferring this knowledge to the students.

In this project, the young participants were third and fourth year students of different educational programmes and a group of approximately 30 seniors between the age of 60 and 90 years old, who are no longer actively part of the work force. These seniors were willing to involve in the development and execution of new types of educational activities and methods in Summa College (educational programme of nursing and welfare) and Fontys University of Applied Sciences (educational programme of the minor healthcare and technology). The recruitment of the participants started out by contacting existing networks, such as organisations and associations for older people, and new networks to come into existence during the project itself. Some of the seniors knew of friends, acquaintances and other interested persons who joined the group of volunteers. Summa College had a large network of participating seniors who had an active engagement in the activities organised in the Lokaal+ initiative. Recruitment through a mailing to the association for retired workers of both educational organisations yielded more volunteers. The majority of participating seniors had higher education, had experience with educational methods, management, coaching of young persons and students, and presenting to groups. Only a few had a strong basis in the domain of healthcare and 


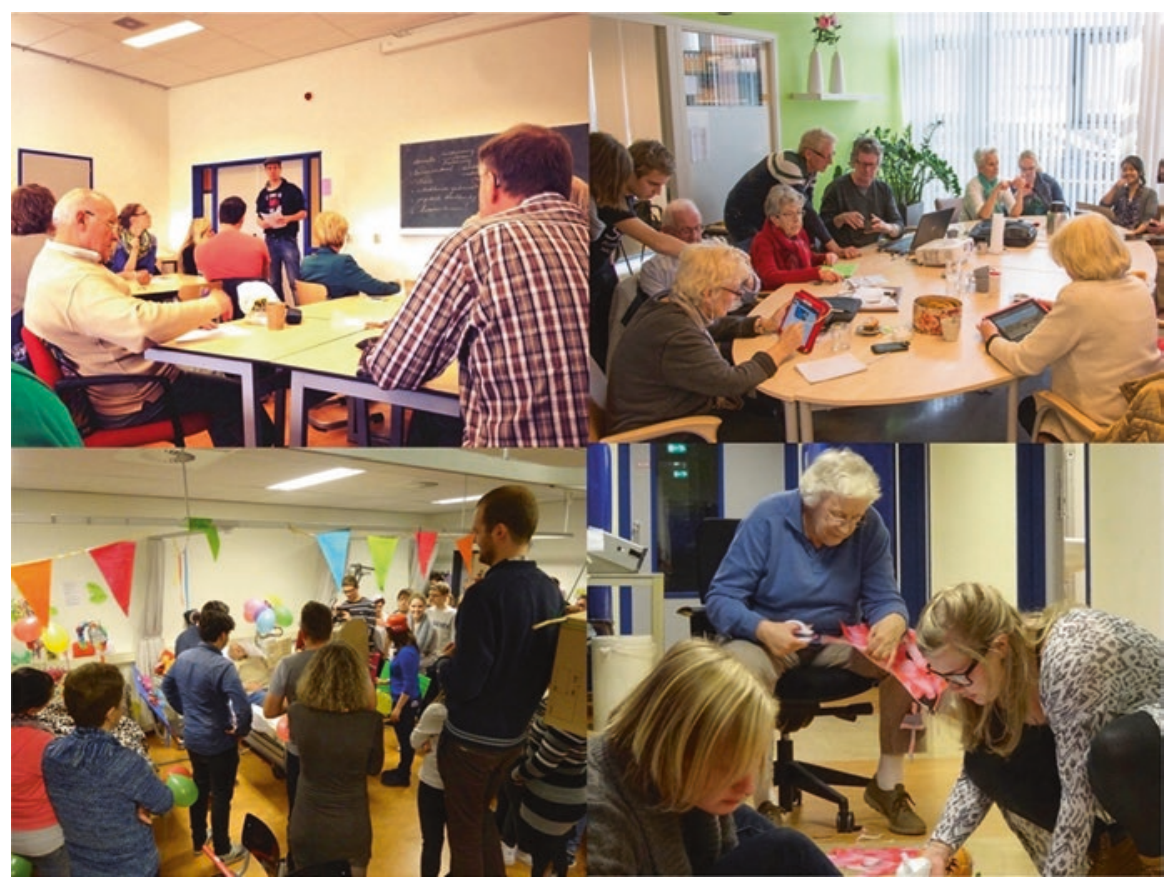

Fig. 23.2 Intergenerational cooperation during design classes, lectures and iPad instructions gatherings

technology. There were also some limitations that impacted the involvement of seniors, such as chronic back problems and impaired hearing.

\subsubsection{Management}

The project of the senior class was carried out at the Summa College and Fontys University of Applied Sciences worked together to arrange creative workshops for the project Nursing Home of the Future (van Hoof et al. 2014a, b, c, 2015c) and in the project Lokaal+ of Summa College. ${ }^{4}$ This project was financially supported by the Municipality of Eindhoven (Programma Leren in Eindhoven 2030).

In the first project, seniors were involved as active co-designers of technological solutions for bed-ridden residents of nursing homes (Fig. 23.2) (van Hoof et al. 2015c). Seniors, even those with mild dementia, can be excellent spokespersons for their own subgroup and contribute to design projects when receiving the right levels of support and instruction (Kort and van Hoof 2014). Together with students, seniors write scenarios for the interior design of nursing home rooms and improvements to

${ }^{4}$ http://www.summacollege.nl/over-summa-college/leuk-en-lekker/lokaal.html 
the direct surroundings of the bed itself, in order to support the self-care abilities of bed-ridden nursing home residents. In the second project, seniors learn how to use homecare technologies during training sessions by students from the nursing department. Lokaal+ is a meeting space, shaped as a small home, within the faculty building of Summa College, which is run by students who are supervised by lecturers. The Lokaal + initiative aims on community dwelling seniors, who live in the adjacent neighbourhoods, and who are welcome for a talk or activities, or to get a helping hand for small household tasks or societal support which is no longer provided for by the State of municipality. In a corner of the Lokaal+ facility, seniors can get acquainted in the VieDome Experience Centre with the possibilities of modern technologies (home automation systems) in the domain of smart homes and e-health. Students can provide assistance and instructions to seniors in the field of modern technologies, including the use of tablet computers and internet banking (Fig. 23.2), exploring the digital world which can pose problems in terms of accessibility and be ageist in its own way (Sourbati 2015). Both projects showed that the people involved (students, seniors and lecturers) gained insights from the interaction with each other, and that further research was needed as to how seniors could be involved in the educational programme in the most fitting and beneficial way.

\subsubsection{Procedure}

The seniors were informed that participating in the project provides a quality stimulus to the educational programmes. During their involvement, experiences and knowledge become available to the students. Through the project, seniors can exploit their value as life experts in an educational setting, and introduce students to the realm of aged care and implementation of technology to support the facilitation of care. Moreover, seniors serve as coaches and can share some of their life experiences. In the project, the participation of seniors means that they have again a tangible societal importance (as educators), have a chance to combat possible social isolation, gain new knowledge of technology and build a new social and semiprofessional network. The educational programmes, in turn, are being enriched by life experiences of seniors and expertise from outside of the universities and colleges. The involvement of seniors also provides opportunities to add a layer of depth in the curriculum, for instance, in relation to themes which require a certain degree of life experience, such as illness and pain, loss and mourning, euthanasia, and death. In addition, the seniors also made an appearance as simulation patients in practicing telecare (screen-to-screen e-health). With the students, the stereotyped image of a "grandmother or grandfather" was previously worked in front of the image of "old gold" that fine-tuned into a more subtle image that is a better presentation of a modern-day senior. The actual knowledge, skills and attitudes of the students become more realistic. This is an asset when making personas or fictional characters in design projects. 
The participation of seniors calls for creativity among the lecturers, as they have to come up with new ways to involve seniors in their educational programmes and methods. Seniors need to acquire a certain position in these lectures and workshops, in which their knowledge and skills can be exploited to the benefit of all. The large advantage of the involvement of seniors lies in the fact that students have direct access to the end-users of healthcare technology, whether these seniors are 'patients' using these technologies themselves, or as informal carers assisting a loved-one in need. The basis for the project is the creation of a win-win-situation.

Although the majority of seniors have skills to share with students, it does not automatically mean they wish to engage in the role of a lecturer and actively teach students. There was a general consensus in the project that the senior should not take over tasks from a lecturer and actually be a cheaper substitute for an existing lecturer on the pay roll of the school.

\subsubsection{Evaluation Tool}

The activities will be carried out through two cooperative methodologies: discussion groups and portfolio to be complicated as part of the evaluation, both during the process and at the end of it. The training sessions were conducted through the discussion group led by the project promoters in which the members of the project participated: seniors, students and teachers. As mentioned earlier, the discussion group not only provides information on the contents of an activity but also provides a space for interpersonal knowledge and offers opportunities to overcome emotional upheavals caused by erroneous beliefs about age stereotypes (Ferguson et al. 2013). In addition, the mutual support provided by the group improves the performance of activities (Wilson 1992). The portfolio is a collection of evidence that is considered pertinent, relevant and useful for the project: documents, cartoons, articles, publicity, stories, anecdotes, sound files and photographs. The portfolio is coordinated by the project leaders and built by the seniors, students and lectures participating in the project. The final part of the portfolio is a final reflection of the strengths, weaknesses and possible improvements.

\subsubsection{Results}

The majority of seniors said the instructions to participate in the project were clear and they indicated that they knew what was expected from them as a contribution to the achievement of the educational goals. Without any exception, seniors felt that they were treated with respect and that they had sufficient space and freedom for their own opinions and ideas. The participation turned out to be meaningful to the 
seniors, partly because of the valuable ideas they heard during discussions with students. Seniors stated that they learnt practical new things by participating in classes, such as getting acquainted with new technologies (tablet computers, e-health systems).

It became evident that seniors liked the fact that students were willing to share their own life experiences concerning illnesses and losses in open-hearted group discussions. During the sessions, seniors broke the ice and students soon followed. Because of the interaction a mutual understanding is developed, and insights are provided into each other's lives. The seniors and students learn to tune their communication skills to one another. This is another asset for students who pursue a career in the healthcare and welfare sectors. Seniors expressed a unanimous sense of joy from participating in the activities, and words as "collaboration", "listening", "mutual learning" were mentioned. Students were described by the seniors as "sincerely interested and involved."

Lectures and students valued the participation of seniors in the health and technology education programme as a "valuable contribution" because they acted as sounding board for the student, $\mathrm{t}$ as an experts who can help the student to sharpen ideas or to improve a design. In the words of one of the students, who was involved in the design of an interactive closet for dressing challenges in dementia:

\section{Brainstorming about our project together with seniors certainly gave use new insights. The seniors told us that it is important for care recipients to receive visual feedback. We started working on this feedback the same week. We have made $3 \mathrm{~d}$ prints of the handles in the shape of clothes. (student participate in the project)}

Finally, the participation of seniors in the project made it easier for them to see the friendly side of technologies. This fact contributes to alleviate the digital divide between generations that is behind some of the ageist beliefs.

\subsubsection{Evaluation}

The evaluation conducted through the discussion groups revealed the need to consider sociodemographic variability in future projects, in order to reflect the heterogeneity among seniors in Dutch society. Note that the group of major participants in this project belong to a group with a good educational level and a certain management of technologies. Considering the different typologies of seniors will not only have a greater efficiency in the resolution of technological projects, but also a greater respect and less ageist attitudes on the part of the majors, teachers and students. From a more content-based perspective, seniors valued working together with young people, for instance, having fruitful discussions with one another. Some of the reflections of the students make it clear: 
It was great fun to engage with actual seniors.

I though the lecture was nice and interesting, much nicer than the standard lectures because you can put theory into practice. I would like to have many more of such lessons.

I believe that these conversations and interactions make a deep impression on all students, and therefore stick to the collective mind. In addition, the seniors give us new insights because they were raised in a different time and also because they have more life experience. In short, I like to see more of it!

Finally, based on the information obtained in the discussion groups and portfolio, a large number of manuals were made for the interactive educational methods that are used for embedding the activities in the existing curricula. By doing so, the results become embedded in the routines of the educational programmes instead of an occasional activity. Currently, these manuals are being implemented in educational activities of other degrees such as the orthopaedic technology and applied gerontology classes.

\subsubsection{Reflection}

For future generational projects, prior training in intergenerational communication skills should be considered. One of the critical points identified in both discussion groups and in the portfolio were the difficulties in managing emotions and communication between participants. Regarding the turn of the word among the seniors, it was more complicated to solve because some seniors take on a more dominant role than others and this caused some irritation between them. On the other hand, the conversation between the students and seniors was overprotective or secondary talk of the baby, reflecting stereotypes attributed to seniors. Often, stereotyped behaviours are generally unconscious and accommodate the stereotype that is formed over the group with which it has to interact.

\subsection{Limitations of Educational Methodologies on Ageism}

There is still much to learn in higher education about potentially successful methodologies against ageism. Educational techniques such as experiential learning methodologies such as Service-Learning at a local, regional or international levels, concentrate in answering the how and the what for questions but lack a ripe theoretical body of knowledge sustaining them. Moreover, in this kind of educational experience several distinct institutions and entities are obliged to cooperate and share objectives, organisation and deployment of spaces, schedules, budgets and resources. Despite scattered academic university efforts to implement those programmes, such ventures often lack rigor or an ability to systematically measure their educational 
outcomes. Furthermore, professional education programmes in the scientific fields that may hold many of the solutions such as engineering, natural, social and health sciences find that their curricular schedules are too intensive to allow students to combine technical learning with programmes that serve the community. However, advanced societies require academic curricula that incorporate educative programmes contributing to generational and cultural coexistence in an increasingly aged and mobile world.

Faculty and institutions often find difficulties when it comes to the application of learning methodologies in the classroom. Students usually find that these methodologies require from them an additional work charge in their course. Sometimes they have problems with their own classmates and other team members, or consider they receive little help from their tutors. Also lecturers signal some difficulties regarding the amount of time they need to set up and manage their teaching out of classrooms. It is important to bear in mind that lecturers normally do not receive any support in the heavy administrative and organisational tasks derived from launching this type of programmes (Blakey et al. 2015). The institutions and entities fostering learning initiatives in the academic realm also face problems regarding the technical and personal inexperience of students in professional environments. Therefore, the new methodological initiatives require time investment in the adequate formation and supervision of students. Despite all these difficulties, methodologies such as story-telling and Service-Learning local, regional and international are steadily growing in all educative fields and the success in their application in general compensates the difficulties encountered (Blakey et al. 2015).

Regarding research designs and characteristics, experiential methodologies usually present specific limitations due to their educational origin. For example, studies are usually transversal and based on qualitative inquiries, diary data from students and self-evaluations. Samples are small and often not aleatory, comparison groups are not always present and participants are often self-selected. Answers are standardly recorded in the presence of the concerned professionals, and therefore student's answers can be systematically biased.

Not all experiential methodologies are successful, because some experiences may reinforce stereotypes or reflect a charitable conception of volunteering (doing for instead of doing with) (Egger 2008). Educating the next generation of professionals requires broad perspectives in the areas of social responsibility and global citizenship. Additionally, experiential methodologies rely on praxis-oriented theories which try to improve the participation and responsibility of students with respect to social life and global citizenship. Interdisciplinary methodologies out of the classrooms require from the docents high amounts of motivation and engagement. Experiential methodologies need not only an adequate academic niche, but also the support from financial and political decisions, in order to favour educational models based on generational intelligence and sensibility towards age idiosyncrasies. 


\subsection{Proposal for the Future}

Ageing brings unknown sceneries in which several generations and life styles meet during prolonged periods. We need to promote a theoretical model as "having an open mind while actively seeking to understand generational norms and expectations of others, and leveraging this gained knowledge to interact, communicate and work effectively in diverse environments" (Hunter et al. 2004).

The interconnected and accessible flat world in which we live gives us the chance to appreciate how all human cultures share a common interest in fostering inclusive societies for all ages. In order to develop generational intelligence, it is necessary to educate specific knowledge, skills, and attitudes, including maintaining openness to other generations and other cultures, withholding judgment, respecting and valuing differences and tolerating ambiguity (Songer and Breitkreuz 2014). Learners build on these attitudes by gaining knowledge of cultures, customs, beliefs, and by becoming generationally self-aware (Deardorff 2006). People with generational intelligence are able to observe, evaluate, analyse, interpret, and, finally, relate to others in variable generational and cultural keys (Deardorff 2006; Breitkreuz and Songer 2015).

Author Contributions $\mathrm{M}^{\mathrm{a}}$ del Carmen and J. van Hoof jointly planned and conceived the chapter. J. van Hoof, M. Zwamborn, S. Metz, W.P.H. Bosems contributed to the chapter through their case study of the Seniors in Class project. Hannah Swift wrote the theoretical frame and Laura Naegele brought together the different sections of the chapter.

\section{References}

Abrams, D., Russell, P. S., Vauclair, M., \& Swift, H. (2011). Ageism in Europe: Findings from the European social survey. London: Age UK.

Allport, G. W. (1954). The nature of prejudice. Cambridge, MA: Perseus Books.

Ayalon, L., \& Tesch-Römer, C. (2018). Researching ageism. In L. Ayalon \& C. Tesch-Römer (Eds.), Contemporary perspectives on ageism: Vol. 19. International perspectives on aging (pp. 403-406). Berlin: Springer.

Basran, J. F., Dal Bello-Haas, V., Walker, D., MacLeod, P., Allen, B., D’Eon, M., et al. (2012). The longitudinal elderly person shadowing program: Outcomes from an interprofessional senior partner mentoring program. Gerontology \& Geriatrics Education, 33(3), 302-323.

Biggs, S., \& Lowenstein, A. (2013). Generational intelligence: A critical approach to age relations. New York: Routledge.

Biggs, S., Haapala, I., \& Lowenstein, A. (2011). Exploring generational intelligence as a model for examining the process of intergenerational relationships. Ageing and Society, 31(7), $1107-1124$.

Blakey, J. M., Theriot, S., Cazzell, M., \& Sattler, M. (2015). Is service-learning worth it?: A mixedmethods study of faculty's service-learning experiences. The International Journal of Research on Service-Learning and Community Engagement, 3(1), 18 pages.

Bousfield, C., \& Hutchison, P. (2010). Contact, anxiety, and young people's attitudes and behavioral intentions towards the elderly. Educational Gerontology, 36, 451-466. https://doi. org/10.1080/03601270903324362 
Breitkreuz, K. R., \& Songer, T. D. (2015). The emerging 360 degree model for global citizenship education. The International Journal of Research on Service-Learning and Community Engagement, 3(1).

Brown, G. A., Bull, J., \& Pendlebury, M. (2013). Assessing student learning in higher education. New York: Routledge.

Chonody, J. M., \& Wang, D. (2014). Predicting social work students' interest in gerontology: Results from an international sample. Journal of Gerontological Social Work, 57(8), 773-789.

Conway, J. M., Amel, E. L., \& Gerwien, D. P. (2009). Teaching and learning in the social context: A meta-analysis of service learning's effects on academic, personal, social, and citizenship outcomes. Teaching of Psychology, 36(4), 233-245.

Cook, S. W. (1962). The systematic analysis of socially significant events. Journal of Social Issues, $18,66-84$.

Davies, K., Tropp, L. R., Aron, A., Pettigrew, T. F., \& Wright, S. C. (2011). Cross-group friendships and intergroup attitudes: A meta-analytic review. Personality and Social Psychology Review, 15(4), 332-351.

Deardorff, D. K. (2006). Identification and assessment of intercultural competence as a student outcome of internationalization. Journal of Studies in International Education, 10(3), 241-266.

Drury, L., Abrams, D., \& Swift, H. J. (in press). Making intergenerational connections: An evidence review. London: Age UK.

Egger, J. B. (2008). No service to learning: "Service-learning" reappraised. Academic Questions, 21(2), 183-194.

Ferguson, S. M., Phillips, P. E., Roth, B. L., Wess, J., \& Neumaier, J. F. (2013). Direct-pathway striatal neurons regulate the retention of decision-making strategies. Journal of Neuroscience, 33(28), 11668-11676.

Gallagher, S. H. (2007). A qualitative research study of service learning in three undergraduate business courses. Lowell: University of Massachusetts.

Hagestad, G. O., \& Uhlenberg, P. (2005). The social separation of old and young: A root of ageism. Journal of Social Issues, 61(2), 343-360.

Hutchison, P., Fox, E., Laas, A., Matharu, J., \& Urzi, S. (2010). Anxiety, outcome expectancies, and young people's willingness to engage in contact with the elderly. Educational Gerontology, 36, 1008-1021. https://doi.org/10.1080/03601271003723586

Hunter, L. M., Hatch, A., \& Johnson, A. (2004). Cross-national gender variation in environmental behaviors. Social Science Quarterly, 85(3), 677-694.

Jerome, L. (2012). Service learning and active citizenship education in England. Education, Citizenship and Social Justice, 7(1), 59-70.

Jost, J. T., Banaji, M. R., \& Nosek, B. A. (2004). A decade of system justification theory: Accumulated evidence of conscious and unconscious bolstering of the status quo. Political Psychology, 25(6), 881-919.

Kalisch, H. R., Coughlin, D. R., Ballard, S. M., \& Lamson, A. (2013). Old age is a part of living: Student reflections on intergenerational service-learning. Gerontology \& Geriatrics Education, 34(1), 99-113.

Kort, H. S. M., \& van Hoof, J. (2014). Design of a website for home modifications for older persons with dementia. Technology and Disability, 26(1), 1-10.

Lub, V., Van Arum, S., \& Sprinkhuizen, A. (2009). Voor het verval. Belemmeringen en voorwaarden voor vroegsignalering en bewonersparticipatie. Journal of Social Intervention: Theory and Practice, 18(4), 62-82. (in Dutch).

Manheimer, R. J. (1997). Generations learning together. Journal of Gerontological Social Work, 28(1-2), 79-91.

McClusky, H. Y. (1990). The community of generations: A goal and a context for the education of persons in the later years. InIntroduction to educational gerontology (pp. 59-83). Washington, DC: Hemisphere. 
Natalija, M., \& Deivida, V. (2011). Service-learning in Lithuania: Escape from narrow professionalism. Образование через всю жизнь: непрерывное образование в интересах устойчивого развития, (9), 141-144 (in Russian).

Pettigrew, T. F. (1997). Generalized intergroup contact effects on prejudice. Personality and Social Psychology Bulletin, 23, 173-185.

Pettigrew, T. F. (1998). Intergroup contact theory. Annual Review of Psychology, 49(1), 65-85.

Pettigrew, T. F., \& Tropp, L. R. (2006). A meta-analytic test of intergroup contact theory. Journal of Personality and Social Psychology, 90(5), 751-783.

Requena, C., \& Gonzalez, M. (2008). Effects of intergenerational interaction on aging. Educational Gerontology, 34(4), 292-305. https://doi.org/10.1080/03601270701883908

Sánchez, M., \& Kaplan, M. (2014). Intergenerational learning in higher education: Making the case for multigenerational classrooms. Educational Gerontology, 40(7), 473-485.

Shiu, E., Hassan, L. M., \& Parry, S. (2015). The moderating effects of national age stereotyping on the relationships between job satisfaction and its determinants: A study of older workers across 26 countries. British Journal of Management, 26(2), S. 255-S. 272. https://doi. org/10.1111/1467-8551.12091

Songer, A. D., \& Breitkreuz, K. R. (2014). Interdisciplinary, collaborative international service learning: Developing engineering students as global citizens. International Journal for Service Learning in Engineering, Humanitarian Engineering and Social Entrepreneurship, 9(2), $157-170$.

Sourbati, M. (2015). Age(ism) in digital information provision: The case of online public services for older adults. InInternational conference on human aspects of IT for the aged population (pp. 376-386). New York: Springer.

Stephan, W. G., \& Mealy, M. D. (2011). Intergroup threat theory. InThe encyclopedia of peace psychology. Hoboken: Wiley.

Turner, R. N., Crisp, R. J., \& Lambert, E. (2007). Imagining intergroup contact can improve intergroup attitudes. Group Processes \& Intergroup Relations, 10, 427-441. https://doi. org/10.1177/1368430207081533

van Hoof, J., Dooremalen, A. M. C., Wetzels, M. H., Weffers, H. T. G., \& Wouters, E. J. M. (2014a). Exploring technological and architectural solutions for nursing home residents, care professionals and technical staff: Focus groups with professional stakeholders. International Journal for Innovative Research in Science and Technology, 1(3), 90-105.

van Hoof, J., Wetzels, M. H., Dooremalen, A. M. C., Nieboer, M. E., van Gorkom, P., Eyck, A. M. E., Zwerts-Verhelst, E. L. M., Peek, S. T. M., van der Voort, C. S., Moonen, M. J., van Dijck-Heinen, C. J. M. L., Weffers, H. T. G., Overdiep, R. A., Aarts, S., Vissers-Luijcks, C., \& Wouters, E. J. M. (2014b). The essential elements for a nursing home according to stakeholders from healthcare and technology: Perspectives from multiple simultaneous monodisciplinary workshops. Journal of Housing for the Elderly, 28(4), 329-356.

van Hoof, J., Wetzels, M. H., Dooremalen, A. M. C., Wouters, E. J. M., Nieboer, M. E., Sponselee, A. A. M., et al. (2014c). Technological and architectural solutions for Dutch nursing homes: Results of a multidisciplinary mind mapping session with professional stakeholders. Technology in Society, 36, 1-12.

van Hoof, J., Wetzels, M. H., Dooremalen, A. M. C., Overdiep, R. A., Nieboer, M. E., Eyck, A. M. E., van Gorkom, P. J. L. M., Zwerts-Verhelst, E. L. M., Aarts, S., Vissers-Luijcks, C., van der Voort, C. S., Moonen, M. J. G. A., van de Vrande, H. A., van Dijck-Heinen, C. J. M. L., \& Wouters, E. J. M. (2015a). Exploring innovative solutions for quality of life and care of bedridden nursing home residents through co-design sessions. Journal of Aging Research, 2015, Article ID 185054.

van Hoof, J., Zwerts-Verhelst, E. L. M., Nieboer, M. E., \& Wouters, E. J. M. (2015b). Innovations in multidisciplinary education in healthcare and technology. Perspectives on Medical Education, 4(3), 146-148. 
van Hoof, J., Zwamborn, M., Metz, S., \& Bosems, W. (2015c). Senioren in de klas als verrijking van het onderwijs. Onderwijs en Gezondheidszorg, 40(2), 22-25. (in Dutch).

Ventura-Merkel, C., \& Lidoff, L. (1983). Program innovation in aging: Vol. 8, Community planning for intergenerational programming. Washington, DC: National Council on Aging.

Wilson, B. (1992). Memory therapy in practice. In Clinical management of memory problems (pp. 120-153). Boston: Springer.

Wright, S. C., Aron, A., McLaughlin-Volpe, T., \& Ropp, S. A. (1997). The extended contact effect: Knowledge of cross-group friendships and prejudice. Journal of Personality and Social Psychology, 73, 73-90.

Open Access This chapter is licensed under the terms of the Creative Commons Attribution 4.0 International License (http://creativecommons.org/licenses/by/4.0/), which permits use, sharing, adaptation, distribution and reproduction in any medium or format, as long as you give appropriate credit to the original author(s) and the source, provide a link to the Creative Commons license and indicate if changes were made.

The images or other third party material in this chapter are included in the chapter's Creative Commons license, unless indicated otherwise in a credit line to the material. If material is not included in the chapter's Creative Commons license and your intended use is not permitted by statutory regulation or exceeds the permitted use, you will need to obtain permission directly from the copyright holder. 


\title{
Chapter 24 \\ Introduction to the Section: Researching Ageism
}

\author{
Liat Ayalon and Clemens Tesch-Römer
}

Research is critical to assess the prevalence, origins, and consequences of ageism as well as the potential effectiveness of various interventions to fight ageism. A major challenge associated with the assessment of ageism is the fact that being seen as ageist is generally considered to be negative. Most people do not wish to be seen as ageist (Cherry et al. 2015) and so will respond to questions about ageism with caution. Moreover, ageism is highly prevalent and often unnoticed, because it is so ingrained in our lives (Perdue and Gurtman 1990). This is why implicit measures of ageism are recommended to supplement explicit measures (Shiovitz-Ezra et al. 2016).

Another challenge associated with the assessment of ageism concerns its subjective nature (Ayalon 2016; Voss et al. 2017). In order to acknowledge an event as ageist, one has to notice the event, interpret it as ageist, and then cite ageism as the cause of the event. Any of these three processes can impact one's willingness to acknowledge ageism. The social context plays an important role, as society clearly defines events as ageist or non-ageist based on current norms and expectations. For instance, whereas asking a job applicant his or her age is the norm in some countries, in other countries asking such a question is not considered acceptable. Hence, the subjective nature of ageism should be acknowledged (Ayalon 2016; Kornadt et al. 2015).

In the first chapter of this section (2018; Chap. 25), Snellman argues that most research on ageism to date has focused on empirical data. Less attention has been paid to aspects such as the normative value applied to ageism and theoretical or

\footnotetext{
L. Ayalon $(\bowtie)$

Louis and Gabi Weisfeld School of Social Work, Bar Ilan University,

Ramat Gan 52900, Israel

e-mail: liat.ayalon@biu.ac.il

C. Tesch-Römer

German Centre of Gerontology, Berlin, Germany

e-mail: clemens.tesch-roemer@dza.de

L. Ayalon, C. Tesch-Römer (eds.), Contemporary Perspectives on Ageism, International Perspectives on Aging 19, https://doi.org/10.1007/978-3-319-73820-8_24
} 
interpretive considerations. Snellman argues that the research training of the investigators, rather than the research questions, often guides the selection of the approach. He further suggests that more attention to the selection of a particular research approach would be beneficial and enriching for research in general and for research in the field of ageism in particular.

As international researchers, Wilińska, de Hontheim, and Anbäcken (2018; Chap. 26) give a reflexive personal account of conducting research on ageism in different countries and cultures. They argue that being physically away from your own culture is an opportunity to re-examine common assumptions about age and ageing and develop a more critical understanding of these issues in light of their varied manifestations in different cultures. To some degree, this chapter corresponds with Snellman's chapter (2018; Chap. 25), as it indicates ways to broaden normative understandings of ageism through exposure to views and perspectives that do not represent the majority view in one's own culture.

The chapter by Swift et al. (2018; Chap. 27) is an empirical account of ageism in Europe as assessed via the European Social Survey (ESS). The chapter highlights the ESS data as a means to understand ageism. It draws from social psychology theories to demonstrate the contribution of the findings to theory and empirical knowledge. In addition, the authors discuss the importance of multi-level analysis to account for the individual and country levels simultaneously. Given the fact that ageism has both micro- and macro-level origins and manifestations, the ESS provides a unique opportunity to enhance understanding of the intersections between the two levels.

Buttigieg, Ilinca, Sao Jose, and Taghizadeh Larsson (2018; Chap. 29) present a comprehensive overview of how ageism is defined and measured in health and longterm care. Like Snellman, these authors call for a division between empirical research and theoretical research, as most research in the field of health and longterm care is empirical and atheoretical in nature. The authors further call for the use of mixed research methods and perspectives in order to provide a more complete account of ageism in health and long-term care.

Abuladze and Perek-Bialas (2018; Chap. 28) similarly encourage the use of publicly available datasets to measure ageism. Their chapter focuses on the use of measures to assess ageism in the workforce. They use an empiricist approach (as defined by Snellman in this section) to classify measures according to five possible aspects of ageism in the labour market: recruitment/retention, performance, training, interaction with older colleagues, and structural ageism. This chapter, as well as the chapter by Swift et al. (2018; Chap. 27), provides an excellent resource for readers who wish to become familiar with the use of publicly available datasets.

Also in this section, Mendonça, Marques, and Abrams (2018; Chap. 30) outline the results of a review of measures to assess ageism in children. Research has consistently shown that ageism is common among young children and youth and not only among older adults. This supports claims about the automaticity of age categorization (Perdue and Gurtman 1990) and potentially about the evolutionary nature of ageism (Burnstein et al. 1994). Nevertheless, children have different language and test-taking skills that may require somewhat different measures. The authors 
suggest a classification of measures according to the tripartite model of attitudes (behavioural, cognitive, emotional) and their placement along a continuum of explicit versus implicit measures.

The last chapter in this section is by Phelan (2018; Chap. 31), who uses discourse analysis to demonstrate how ageism is constructed and deconstructed in everyday life. The chapter demonstrates how individuals can position and construct older people in an ageist or non-ageist framework. Using Snellman's definitions, this chapter takes an interpretive approach, as it examines ageism from a more philosophical/theoretical stand.

These chapters provide potentially useful tools to assess ageism. The chapters by Snellman (2018; Chap. 25), Wilińska et al. (2018; Chap. 26), and Phelan (2018; Chap. 31) are more theoretical in nature. They suggest new ways to think about the phenomenon of ageism, which could potentially affect the ways we study it. The chapters by Swift et al. (2018; Chap. 27), Buttigieg et al. (2018; Chap. 29), Abuladze and Perek-Bialas (2018; Chap. 28), and Mendonça et al. (2018; Chap. 30), on the other hand, provide practical tools for the assessment of ageism in various settings (general society, health and long-term care, and the labour force) and among different target populations (older adults, professionals, adult children, family members, and young children). Swift et al. (2018), Abuladze and Perek-Bialas (2018), and Mendonça et al. (2018) take into account cross-cultural and national considerations. This is particularly important given the fact that ageism is a social phenomenon that does not only occur at the individual level, but rather is affected by socio-cultural aspects (Cuddy et al. 2005; Vauclair et al. 2016).

Although it is not specifically focused on in the chapters of this section, an additional aspect of ageism research is the assessment of ageism at the macro-level (Ayalon and Rothermund 2017). There are multiple macro-level indicators of inequality, such as the Gini coefficient and the coefficient of variation (Allison 1978). With regard to specific characteristics, there are measures of gender inequality such as the Gender Inequality Index and the Gender-Related Development Index (Dijkstra and Hanmer 2000; Gaye et al. 2010) that could potentially be applied to ageism. Consistently, the Active Ageing Index and the Age Watch Index both represent attempts to assess the conditions of older adults in society (AgeWatch 2015; Zaidi et al. 2013). Although informative, these studies evaluate the absolute status of older adults in society and do not provide a comparative analysis of the status of old versus young people in society, as was recently proposed by Ayalon and Rothermund (2017). Nonetheless, these studies indicate a macro-level direction, which is much needed given the manifestation of ageism at the individual level as well as at the social/structural/institutional level.

There has been great progress in researching ageism and there are multiple possibilities for future research. Research should take into account not only ageism at the individual level but also at societal and institutional levels, as ageism often cooccurs at both levels. The availability of public datasets on ageism provides a substantial resource for researchers wishing to explore the topic and develop cross-national comparisons. The limited theoretical grounding of a substantial portion of the research on ageism should be seen as an opportunity for researchers, 
who could potentially contribute to an emerging and growing field not only through the production of empirical data, but also through the construction and development of theoretical understandings of the phenomenon of ageism.

\section{References}

Abuladze, L., \& Perek-Białas, J. (2018). Measures of ageism in the labour market in international social studies. In L. Ayalon \& C. Tesch-Römer (Eds.), Contemporary perspectives on ageism: Vol. 19. International perspectives on aging (pp. 459-489). Berlin: Springer.

AgeWatch, G. (2015). Global AgeWatch Index 2013: Help Age International. www.helpage.org/ global-agewatch

Allison, P. D. (1978). Measures of inequality. American Sociological Review, 43(6), 865-880.

Ayalon, L. (2016). Perceived age discrimination: A precipitator or a consequence of depressive symptoms? The Journals of Gerontology Series B: Psychological Sciences and Social Sciences, gbw101. https://doi.org/10.1093/geronb/gbw101.

Ayalon, L., \& Rothermund, K. (2017). Examining the utility of national indicators of relative age disadvantage in Europe. European Journal of Ageing. https://doi.org/10.1007/ s10433-017-0435-2.

Burnstein, E., Crandall, C., \& Kitayama, S. (1994). Some neo-Darwinian decision rules for altruism: Weighing cues for inclusive fitness as a function of the biological importance of the decision. Journal of Personality and Social Psychology, 67(5), 773.

Buttigieg, S., Ilinca, S., Jose, M. S., \& Larsson, A. T. (2018). Researching ageism in health-care and long term care. In L. Ayalon \& C. Tesch-Römer (Eds.), Contemporary perspectives on ageism: Vol. 19. International perspectives on aging (pp. 491-513). Berlin: Springer.

Cherry, K. E., Allen, P. D., Denver, J. Y., \& Holland, K. R. (2015). Contributions of social desirability to self-reported ageism. Journal of Applied Gerontology, 34(6), 712-733.

Cuddy, A. J., Norton, M. I., \& Fiske, S. T. (2005). This old stereotype: The pervasiveness and persistence of the elderly stereotype. Journal of Social Issues, 61(2), 267-285.

Dijkstra, A. G., \& Hanmer, L. C. (2000). Measuring socio-economic gender inequality: Toward an alternative to the UNDP gender-related development index. Feminist Economics, 6(2), 41-75.

Gaye, A., Klugman, J., Kovacevic, M., Twigg, S., \& Zambrano, E. (2010). Measuring key disparities in human development: The gender inequality index. Human Development Research Paper, $46,41$.

Kornadt, A. E., Voss, P., \& Rothermund, K. (2015). Age stereotypes and self-views revisited: Patterns of internalization and projection processes across the life span. The Journals of Gerontology Series B: Psychological Sciences and Social Sciences, 72(4), 582-592.

Mendonça, J., Marques, S., \& Abrams, D. (2018). Children's attitudes toward older people: Current and future directions. In L. Ayalon \& C. Tesch-Römer (Eds.), Contemporary perspectives on ageism: Vol. 19. International perspectives on aging (pp. 515-546). Berlin: Springer.

Perdue, C. W., \& Gurtman, M. B. (1990). Evidence for the automaticity of ageism. Journal of Experimental Social Psychology, 26(3), 199-216.

Phelan, A. (2018). Researching ageism through discourse. In L. Ayalon \& C. Tesch-Römer (Eds.), Contemporary perspectives on ageism: Vol. 19. International perspectives on aging (pp. 547562). Berlin: Springer.

Snellman, F. (2018). Normative, empiricist, and interpretive considerations in the ageism research process. In L. Ayalon \& C. Tesch-Römer (Eds.), Contemporary perspectives on ageism: Vol. 19. International perspectives on aging (pp. 407-422). Berlin: Springer.

Swift, H., Abrams, D., Marques, S., Vauclair, C. M., Bratt, C \& Lima, M. L. (2018). Agisem in the European region: Finding from the European social survey. In L. Ayalon \& C. Tesch-Römer 
(Eds.), Contemporary perspectives on ageism: Vol. 19. International perspectives on aging (pp. 439-457). Berlin: Springer.

Shiovitz-Ezra, S., Ayalon, L., Brodsky, J., \& Doron, I. I. (2016). Measuring ageism based on knowledge, attitudes and behavior: Findings from an Israeli pilot study. Ageing International, 41(3), 298-310.

Vauclair, C.-M., Marques, S., Lima, M. L., Abrams, D., Swift, H., \& Bratt, C. (2016). How does income inequality get under the skin? The mediating role of perceived age discrimination in the inequality-health nexus for older and younger people. Available online: http://www.iaccp.org/ sites/default/files/reims_pdf/U2SbP2/Vauclair.pdf

Voss, P., Kornadt, A. E., \& Rothermund, K. (2017). Getting what you expect? Future self-views predict the valence of life events. Developmental Psychology, 53(3), 567.

Wilińska, M., de Hontheim, A., \& Anbäcken, E. M. (2018). Ageism in a cross-cultural perspective: Reflections from the research field. In L. Ayalon \& C. Tesch-Römer (Eds.), Contemporary perspectives on ageism: Vol. 19. International perspectives on aging (pp. 423-438). Berlin: Springer.

Zaidi, A., Gasior, K., Hofmarcher, M. M., Lelkes, O., Marin, B., Rodrigues, R., et al. (2013). Active ageing index 2012 concept, methodology and final results. Vienna: European Centre for Social Welfare Policy and Research.

Open Access This chapter is licensed under the terms of the Creative Commons Attribution 4.0 International License (http://creativecommons.org/licenses/by/4.0/), which permits use, sharing, adaptation, distribution and reproduction in any medium or format, as long as you give appropriate credit to the original author(s) and the source, provide a link to the Creative Commons license and indicate if changes were made.

The images or other third party material in this chapter are included in the chapter's Creative Commons license, unless indicated otherwise in a credit line to the material. If material is not included in the chapter's Creative Commons license and your intended use is not permitted by statutory regulation or exceeds the permitted use, you will need to obtain permission directly from the copyright holder. 


\title{
Chapter 25 \\ Normative, Empiricist, and Interpretive \\ Considerations in the Ageism Research \\ Process
}

\author{
Fredrik Snellman
}

\subsection{Introduction}

This chapter reflects on the normative, empiricist, and interpretive considerations researchers are facing in the process of researching ageism. The starting point of this study was a doctoral dissertation that, by triangulating data, methods, and theory, explored how ageism is manifested in the lives of older people (Snellman 2009). Such a research endeavour is warranted by system justification theory, arguing that support for an ageist structure of society is sometimes strongest among individuals who are most harmed by it (Jost et al. 2004). A large and increasing number of ageism studies report on empirical data; however, these studies are rarely explicitly related to epistemological and ontological questions. Little attention has previously been devoted to the philosophy of science aspects of ageism and therefore there is a gap in what we know about the wider scope of challenges in researching ageism and how we view and understand ageism in our world.

One way to devote attention to the philosophy of science aspects of ageism is to focus on the normative, empiricist, and interpretive (Howarth 2000) considerations and choices we as researchers are forced to make during the research process. In short, these considerations enable researchers to (a) take a standpoint against and strive to change negative ageist consequences in society (normative); (b) observe accurately and show how ageist elements are related in a narrow context (empiricist); and (c) observe, show, understand, and reflect critically on how ageist elements are related in a wider context (interpretive).

Among the myriad of choices to be made is the choice of what definition of ageism to use in any given case. This chapter demonstrates different types of ageism definitions. These are influenced by normative, empiricist, and interpretive

F. Snellman $(\bowtie)$

Department of Social Work, Umeå University, Umeå, Sweden

e-mail: fredrik.snellman@umu.se 
considerations, each of which is crucial to how the research process will play out and what claims will be able to be made, and not made, about ageism. To make one choice of definition automatically prevents the analytical possibilities coupled to the choice of other alternatives. The chapter provides examples of ageism studies, which are influenced by normative, empiricist, or interpretive considerations. These examples should not be understood as strict representations of normative, empiricist, or interpretive types of study. Rather, these types of considerations have led to specific outcomes, and reveal the choices made during the research process. It is not reasonable to claim that any study on ageism is strictly coupled only to one of these considerations and simultaneously uncoupled from all of the others. Fragments of all considerations, to a varying degree, are present in any ageism research process and in any definition of ageism. Inspired by Howarth's (2000) reasoning on discourse theory and normative, empiricist, and interpretive types of science, I draw here on the experiences made in trying to triangulate data, methods, and theory to show how ageism is manifested and sustained in older people (Snellman 2009).

\subsection{Triangulating Data, Methods, and Theory to Explore Ageism in Older People}

My starting point for this discussion of ageism research process considerations was my doctoral dissertation, "Old Folks" [gammfolket]. On Life Experiences and Everyday Ageism (Snellman 2009). The dissertation consisted of three empirical studies and an analytical summary that investigated the connections between them. Gammfolket is a dialect form commonly used in the northern inland of Sweden, roughly translating to "old folks". It has positive connotations inasmuch as it signals a group of people we should in some way admire, treasure, and protect. It can also have negative connotations: it can be used ironically to describe older people who are no longer able to do something or are lagging behind in current trends or knowledge, such as new communication technologies. These meanings are not exhaustive-others could be added—but, in essence, the word gammfolket captures different nuances of how we use often ambiguous, ageist language in society.

The research process leading to Gammfolket started with an interest in older people's experiences of age discrimination, which eventually led me to something quite different. The first study (Snellman 2005) demonstrated that there were similarities in narrative elements in the ways the older people sampled in the study talked about their lives-for instance, that there were clear boundaries between different life stages (childhood, war-time experiences, working life, and retired life) and similar types of narrated experiences within those life stages. When the older people in the study summarized their lives it tended to be done in a meaning-making manner that ended in a rich and positive view of life. This rich view of life emerged independently of how many traumas the informants had experienced during their lives, and how severe those traumas were. Deeply unsettling life experiences and 
traumas (of which encounters with discriminatory practices were not even a small part) were woven into a meaningful narrative of life.

The design of the first study included two significant challenges. First, it was not appropriate to ask people directly about age discrimination, because people often do not eagerly admit to being a member of a disadvantaged group in society. Second, in 2002, when the study was conducted, Butlers' (1969) definition of ageism did not turn out to be useful for analysing how ageism was manifested and sustained in the life stories of older people. Ageism, as well as its Swedish equivalent ålderism, was not a familiar word to Finno-Swedish older people living in the Western coastal regions of Finland. Consequently, empirical questions containing "ageism" were not possible to use. General theories in social gerontology that were available at the time (Bengtson et al. 1999) also did not provide explicit guidance on how to research age discrimination in older people. An alternative study design was decided upon, which was considered novel at the time. The choice was made to collect life stories from 16 people ( 9 women and 7 men in their late 70s and early 80s), with the expectation that this would allow people to freely share their lifetime experiences of age discrimination. This expectation turned out to be naïve. Despite my sense that the informants did talk about age discrimination during the interviews, it was disappointing and frustrating to listen to the recordings and read the transcribed text, because not once during the many hours of life story interviewing did the informants mention the word "discrimination". Additionally, the word "age" was explicitly mentioned by only one informant on one occasion. The word "age" was ostensibly not used at all in the narration of these life stories.

When the life-story study was being finalized, an opportunity emerged to design and include survey questions within Interreg's Gerontological Regional Database (GERDA) project funded by the European Regional Development Fund. Coming on the heels of the difficulties I had demonstrating how age discrimination is manifested and sustained in older people by using life stories, explicit survey questions on age discrimination and attitudes towards older people within different domains of society were included in the GERDA survey in 2005. This study found a high proportion of individuals who reported negative attitudes towards older people within the labour market $(70.1 \%)$, and a smaller number of people who reported negative attitudes towards older people when visiting shops or banks (12.3\%) as a customer. A theoretically informed structural equation model suggested that the reported attitudes were latent factors of structural, cultural, and individual levels of ageism in society (Snellman 2009). As opposed to not being able to make any explicit claims about age discrimination by utilizing life-story data, the GERDA survey data allowed for making explicit conclusions about both age discrimination and ageism.

In this second study, however, there was uncertainty as to whether the designed items were valid and reliable. During the research process there was a lot of discussion on aspects of language and about what the informants actually had in mind when they responded to the questions. In addition, even though I had intended this empirical study to deliver the data that would finalize the dissertation, there was no obvious way to relate the outcomes to the first study that used life stories. The two 
simply did not add up. They seemed to be of two totally separate scientific worlds, and, frankly, did not contribute as much as I had hoped to exploring how ageism is manifested and sustained in older people.

A third empirical study (Snellman et al. 2012) and research process was therefore designed in parallel. This study design returned to the advantages of having the informants speak freely about their experiences. When I thought about my role as a researcher I realized the importance of how to introduce the topic in the first instance and that the way questions are posed to informants is crucial. This led to a focus group design. Six focus groups (three in Sweden and three in Finland) were carried out with the novel idea of allowing different types of birthday cards to guide the participants' discussion of age and ageing. Six cards in total were presented to participants: one was a humorous card on the topic of sexual activity, another merely had the number 75 printed on it, and so on. This design required extremely little involvement from me as a researcher. The focus group interviews more or less guided themselves and the informants participated very eagerly in the discussion, asking and answering questions amongst themselves. The focus group design created a sort of miniature version of society and allowed for a kind of demonstration of how ageism is negotiated. It enabled us to see the complexity of meaning that was triggered by the birthday cards, and it highlighted the infeasibility of providing a simple explanation of ageism. For instance, it was made obvious that the positive views some respondents had of one type of birthday card did not hold true for other respondents. This was also the case for cards that were initially judged as conveying negative views.

By listening to the recordings and reading the transcripts it became apparent that silence and changing the subject were tactics used to negotiate ageism. The informants talked about age discrimination. For example, when one of the informants said, "I think he wants us to talk about discrimination," they did talk about discrimination for a short while (the role of age and gender among women active in municipal politics), but eventually changed the subject and continued discussing age-related aspects of life that they were more interested in. Although previous research has suggested that birthday cards convey negative views of older people, none of the six focus groups was in unanimous agreement that the cards they were shown were negative or inappropriate and should be prohibited. The focus group design made it evident that older people themselves are co-creators of ageist language and culture.

After having completed the three empirical studies of ageism in older people, I returned my attention to the overarching aspects of what connected the different studies. During the process it became clear that the focus group study and the study that drew on survey data were explicitly related to ageism. The study that drew on life stories, however, was still a loose end: it did not seem to relate to ageism or age discrimination in any explicit way. Guided by discourse theory and by themes that were identified in the focus group study, the life stories were revisited. With a modified understanding of ageism as much more complex and as something continuously negotiated, a pattern that had not been evident before revealed itself in the life stories, perhaps because it was too simple and familiar. The life-story data contained 
a very high number of words such as "old," "older," "young," "younger," "time," "year," "month," and so on. The number of these signifiers of everyday ageism (Snellman 2009) suggested that they held meaning for the narrators of the life stories. These signifiers, and the meanings coupled to them, seemed both to mask and to mark ageism in society.

To summarize, identifying how ageism is manifested and sustained in older people, in a societal context in which there was no linguistic awareness of ageism, posed a significant ontological challenge. This challenge was addressed by triangulating different types of data, methods, and theories. An inductive starting point in older people's life stories utilized deconstruction and theories of social gerontology; descriptive statistics, structural equation modelling, and explicit ageism theories were applied to survey data; and focus group interview data analysed with thematic content analysis and informed by discourse theory and the theory of age coding enabled the discovery of ageism signifiers such as "older" and "younger". In other words, there was no easy answer to the question of how ageism is manifested and sustained in the lives of older people. It was a long process: the findings did not appear overnight, and the process required multiple data sets, methods, and theories. Researching ageism in older people required its own theoretical and conceptual customization, which was derived from normative, empiricist, and interpretive considerations and decisions during the research process.

\subsection{Normative Considerations}

Taking into account normative considerations in the ageism research process mainly implies two things. First, normative considerations require taking a standpoint (without necessarily making theoretically informed interpretations) that ageism per se is negative. Second, the phenomenon of ageism concerns a certain target group of people, commonly referred to as "older people" or "the elderly". Normative considerations are often accompanied by an automatic and unquestioned assumption that the problem, whatever it might be, is a problem of discrimination - that is, that it is negative by definition. Ageist discrimination or negative treatment is invoked instead of analysed (Cruikshank 2003), without a substantial understanding of what is behind a certain kind of behaviour or practice.

Normative considerations imply reactiveness against things that are perceived as inappropriate in society. These considerations are commonly brought to the fore when we are observing troubling issues for the very first time or at an early stage of acquaintance. For instance, this was my un-reflected position when I was first attempting to demonstrate how ageism is manifested and sustained in older people by collecting and analysing life-story data. In my own case, the drive to use life stories was inspired by my own previous discriminatory actions toward my paternal grandmother, who suffered a period of severe mental illness and who attempted suicide twice. I felt that I had not respected my grandmother's fullness as a person when, for example, I went with her to a doctor's appointment and accused her of 
lying. As a result of my actions, I considered it important to allow older people to speak their minds freely about what matters to them, without allowing anyone else to define their reality. I was doing normative consideration, which, according to Howarth (2000), "seek[s] to advocate and justify the key principles around which society [should be] structured" (p. 130). Awareness and the observation of unjust age-related phenomena can be imperative for an early stage conceptualization of ageism and more generally how society should be structured, by allowing us to consider more insightfully our common sense views of what is acceptable and not acceptable in an age-friendly society.

Normative considerations are evident in the way ageism was first defined by psychiatrist and gerontologist Robert Butler (1969) as

the systematic stereotyping of and discrimination against people because they are old, just as racism and sexism accomplish this with skin color and gender. Old people are categorized as senile, rigid in thought and manner, old fashioned in morality and skills ... [A] geism allows the younger generation to see older people as different from themselves; thus they subtly cease to identify with their elders as human beings. (p. 243)

Considering that this was the first definition of ageism it is not surprising that it is normative, as it arose in reaction to something perceived as unjust. As a definition it categorizes older people as a group; it is difficult to view as anything other than targeting the negative; and it arose reactively from Butler's identification of issues with unsatisfactory housing for older people. Several years later, Butler continued the conceptualization process by adding other considerations to what he had first discovered and defined. In his article, "Dispelling Ageism: The Cross-Cutting Intervention", Butler (1989) added that he was just as concerned with older people's negativism towards younger people. Butler's work shows the importance of renewed and continued consideration and reasoning that goes beyond the normative by practising bold self-criticism. Butler's 1969 article is very often cited in publications focusing on ageism, whereas the article from 1989 is hardly ever mentioned. This alone calls for critical reflection on the homogenizing normative power that early conceptions and definitions can have. It also highlights the need to question habitual categories initially created during research training and to continue training the "capacity to break old mental habits and create new ones" (Swedberg 2012, p. 19).

Normative considerations are justifiable as long as they are understood not to be the only possible approach to studying ageism, and as long as they are not allowed to define and delimit the broader field. In fact, normative considerations can be viewed as critical in the first stages of a research process or as a first step in changing society. For instance, legislation is needed to secure fair treatment of older and younger workers within the labour market; but legislation would not be needed unless it addressed something we collectively agree is unjust. Regardless of what has been scientifically demonstrated, we have agreed, as a society, that something is needed to prevent discrimination within the labour market. Legislation on age discrimination has been introduced across all European countries partly as a result of the EU council directive on equal treatment in employment and occupation (2000/78/EC). The directive forced EU member states to introduce legislation 
against age discrimination and is an example of an applied supranational, reactive, normative consideration, that indicates how societies should be structured, viewed from an EU perspective. However, previous research has shown that the directive was received differently in member states (Nygård and Snellman 2014). Legislation on age discrimination was quite automatically adopted in Finland, whereas there was more debate, resistance, and negotiated exceptions in Sweden. This shows how early normative initiatives are interpreted in different ways and that these initiatives might not automatically fit all societies, unless they are adapted in order to correspond better with the norms and values that already exist in a specific societal context.

It is not explicitly stated in scientific publications that normativity is applied, which in itself is not surprising. We tend to avoid the idea of applied normativity because we think science should not be affected by mores. Smith (1995), however, writes "all self-images [of disciplines] reflect normative concerns" (p. 30), which begs the question whether any of the considerations used in studying ageism or in published studies on ageism can be considered non-normative.

The use of normative considerations is key in intervention studies when researchers set out to demonstrate whether it is possible to improve an unjust or negative outcome. The starting point of any intervention study must be that some aspect in a group of people's lives is negative and that it can possibly be improved by intervening in an appropriate way. An example of using normative considerations within a randomized controlled trial context is a study by Jacobson (2006) entitled, "Overcoming 'Ageism' Bias in the Treatment of Hypercholesterolaemia". The term ageism is mentioned four times in the article, but the inclusion of it in the title puts ageism in the spotlight and discloses its significance. Ageism in the title has been assigned quotation marks, which signals something that is not explicitly communicated. The review article showed that statins are more often prescribed to younger patients than to older patients, who are thereby denied the benefits of the intervention. The clinical findings demonstrated that statins are safe and well tolerated when prescribed to older patients, and that there is no obvious reason not to prescribe statins to those with the highest cardiovascular risk. The article shows that, even when appropriate methodological rigour is used, there can be a glide into applying normative arguments, without including scholarly sources on ageism research. The argument against ageist practice is accomplished without an explicit theoretical foundation at any stage of the research process. In some cases this makes sense, for instance when all other alternative explanations have been overthrown. It is, in other words, possible to invoke ageism in a reactive manner, even though it has not been empirically analysed. This conveys a normative message about how society should be organized.

Another example of a study that addresses negative views of older people is Kane's (2004) "Ageism and Intervention: What Social Work Students Believe About Treating People Differently Because of Age". Kane investigated whether social work students' perceptions, needs assessments, and recommendations varied as a function of the age of people diagnosed with severe cancer as described in a vignette. This study found that social work students were more likely to think that older 
people should be allowed to commit suicide (which was ethically problematic) and that younger people had a greater chance of recovery (which was not true). The findings have obvious relevance for social work practice, but did not provide evidence on how social workers would actually make decisions in practice. This study pinpoints a pattern of reasoning that people might not necessarily be aware of. Like Jacobson's study (2006), Kane's study (2004) examined the normative foundation the work of a certain group relies on and how and why this foundation should be changed. In other words, it showed that there are other key principles around which professions and society should be structured.

Other studies within the field of social work have shown that substance users' age affects professionals' perceptions of substance use severity (Samuelsson and Wallander 2014) and treatment recommendations (Wallander and Blomqvist 2009). These studies, however, did not explicitly use the term ageism, but nonetheless serve as examples of applying normative considerations and attempting to raise awareness of age-related perceptions in social work practice. There are a large number of scientific publications, on a range of topics, that demonstrate the significance of age, but that are not explicitly coupled to theories of ageism.

\subsection{Empiricist Considerations}

Traditional forms of (logical) empiricism emphasize the utmost accuracy in making empirical observations and represents a nomothetic (generalizing) notion of an ideal form of knowledge. As a starting point for knowledge, empiricism generally opposes speculation, intuition, feelings, and other sources that are difficult, if not impossible, to quantify (Andersen 2001). It is not possible to categorically avoid empiricist considerations in any given research process. However, there can be some variation in the degree to which empiricist considerations find their way into the actual practice of collecting data. The goal for social sciences is to explain social phenomena (Elster 2007). The explanation needs to be grounded in reality, and on observations and empirical data about this reality. So we have to decide how to observe reality based on ontological views we have about how ageism exists. Whether or not we consider ourselves to be empiricist researchers, we always struggle to identify the most appropriate methods for obtaining data at some point in the research process. In every single research process, we strive to design our investigation in a way that enables us to observe ageist reality in the most accurate manner. Observations we make of the ageist reality are theory-dependent (Føllesdal et al. 2001), and the emphasis on accurate observations which characterizes empiricism presumes a theoretical foundation at an earlier stage in the research process. This simultaneously sets constraints on what observation-based interpretations it is possible to make.

Collecting data with surveys, carrying out experiments, and using existing data registers are examples of methods that at the design stage are more clearly influenced by empiricist considerations. However, it would not be accurate to think that 
quantitative data is the only type of data that is influenced by empiricist considerations. Qualitative data collection is also influenced by empiricist considerations. Empiricist decisions can be seen to be made when we arrive at a point in the research process where we know with greater certainty what we want to assess and how. For instance, the focus group study collecting qualitative data on ageism in birthday cards can be seen as more influenced by empiricist considerations than the survey that collected quantitative data by asking direct questions about age discrimination. When I asked direct questions in survey form, I had only a vague notion of what I wanted to observe. But in the focus group study, I had a much clearer sense of how and what I wanted to observe, based on an empiricist understanding.

Empiricist considerations are also evident in definitions of ageism as a prejudice, a method of stereotyping, and discrimination (e.g., Wilkinson and Ferraro 2002; Iversen et al. 2009). Empiricist considerations in the ageism research process can be seen in efforts to accurately assess individual-level components of ageism (stereotype, prejudice, discrimination) (Thompson 2006; Palmore 1999, 2005) using explicit and implicit measures of ageism (for an overview of such measures, see Lassonde et al. 2012, pp. 175-176). Lassonde et al. (2012) developed an implicit way of assessing ageism using the so-called contradiction paradigm "to measure age-related stereotypes in passages describing older adults" (p. 174). They found that people read sentences more slowly when the content portrayed behaviours that were inconsistent with age-related stereotypes as compared to content that was consistent with age-related stereotypes. Their results were not related to explicit ways of assessing ageism, which, according to the authors, confirmed that the contradiction paradigm can be used to assess age-related stereotypes. The researchers acknowledged that the scale is not an alternative for assessing affective (prejudice) and behavioural (discrimination) components of ageism. Lassonde et al.'s method of assessing stereotypes is an important theoretical contribution, and a result of systematic empiricist consideration. Their study demonstrates robust empirical results, a transparent description of the study design and decisions made during the research process, and a highly effective way of instantiating what prejudice, stereotyping, and discrimination corresponds to in real life situations.

North and Fiske's (2013) development of an intergenerational-tension ageism scale illustrates an explicit way of assessing ageism in an empirical study. In this study, North and Fiske did not depart from a definition of ageism, but from existing ageism scales, which they felt focused mainly on descriptive stereotypes and what older people are. Instead, they empirically tested a three-factor model of prescriptive ageism. These factors were described as "active, envied resource succession, symbolic identity avoidance, and passive, shared resource consumption (SIC)" (North and Fiske 2013, p. 706). The SIC-scale fulfilled the requirements for internal validity, i.e., statistical explanations of the data were identified that qualified the results as a scale.

Lassonde et al. (2012) and North and Fiske (2013) focused on stereotypes and prejudice and did not engage in discussion about what the scales are linked to in terms of outcomes. Both contributions end in a suggestion that the scales can be 
used for purposes of investigating how ageism relates to behaviour, which is a very challenging task. Tornstam (2006), in a study of age-related attitudes and discrimination, demonstrated that even if we are predisposed to behave in a certain way (for example, by embodying negative attitudes), we do not necessarily do so. Other studies using empiricist considerations have, however, investigated ageism and beliefs related to different outcomes.

Becca Levy has made significant contributions to empirical studies of ageism. She proposes that ageism and self-stereotypes have an effect on memory performance in old age (Levy 1996), on handwriting (Levy 2000), on the will to live (Levy et al. 1999), hearing decline (Levy et al. 2006a), myocardial infarction (Levy et al. 2006b), cardiovascular events in later life (Levy et al. 2009), and longevity (Levy et al. 2002). These studies make important contributions because they provide statistical explanations related to outcomes most people can comprehend. Many people would agree that ageism — even if they do not necessarily recognize the term —at least in principle is important. It is not, however, until we start linking it with potential challenges in our own bodies that people really understand its impact on life and society. Measuring ageism accurately and demonstrating its relation to outcomes requires empiricist considerations at an early, theory dependent, stage of the research process.

\subsection{Interpretive Considerations}

Interpretive considerations in the ageism research process concern designing studies for activities of interpretation, understanding, and meaning-making of a complex ageist reality. Interpretive considerations originated with scholars such as Wilhelm Dilthey, Max Weber, and Hans-Georg Gadamer. Interpretive design considerations are brought to the fore in the research process when we want to explore the uniqueness of situations in an ageist reality and when the study focus is of a type that does not repeat itself in a regular manner (i.e., when ageism is considered too complicated to explain by making generalizations). These occasions require that ideographic notions-notions that describe the uniqueness of individual situations - are utilized. The dependency on interpretive theory (Føllesdal et al. 2001) is more present in later stages of the research process.

Interpretation is viewed as necessary in situations in which we do not understand the complexity of what is being studied (Føllesdal et al. 2001). This type of dilemma presents itself in unique, previously unexplored cases in which we do not have a clear idea of how to accurately observe ageism. Without interpretation in these cases, there is no way of understanding ageism, no way of making sense of or identifying the meaning of how and why ageism takes place in our world. For instance, the unintentional discovery of and labelling of ageism signifiers in the life stories study (Snellman 2009) was the result of an extensive process of triangulating empirical data, analytical methods, and a variety of theories to interpret and understand 
the unique and challenging phenomenon of how ageism is manifested and sustained in older people. This discovery was enabled by critically scrutinizing empirical data collected at different points in time during the research process. In the process, words such as "older" and "younger" were observed, but, without combining different types of data, methods, and theories, I would not have been able to label those words signifiers of ageism. The fragments of a complex ageist reality that surfaced in the later stages of the research process required interpretive considerations to bring them to the fore.

There are other distinctive features to interpretive considerations. One feature is the two-way direction between the overall structure of society on the one hand and individuals living and making choices in society on the other. This has been called the "dialectical confluence of ageism" (Wilkinson and Ferraro 2002), and is perhaps the main reason why empirical data needs to be interpreted with the use of theory in the later stages of the research process. A second feature is that actors in the role of researchers are co-creators (meaning makers) of society's ageist structure (Bytheway and Johnson 1990; Føllesdal et al. 2001; Snellman 2016). A third feature is awareness, which is needed to understand, among other things, (a) the uniqueness of situations and the broader consequences of ageism, (b) what comprises the ageist structure of society, and (c) how the ageist structure is sustained.

Interpretive considerations can be identified in definitions describing ageism in terms of practices (Bytheway et al. 2007; Snellman 2016). There are other useful conceptualizations of (ageist) practices that use other terms than ageism, such as "age-relations" (Calasanti 2003) and "age coding" (Krekula 2009). Elsewhere I have suggested an interpretive (constitutive) working definition of ageism as

constitutive practices which are permeated with our experiences of the chronological, social, biological and psychological life course. We utilize age-or some other adjacent terminology that signifies age-in a myriad of different ways to organize our own and other people's lives and to make our social worlds intelligible. (Snellman 2016, p. 149)

This working definition of ageism was enabled by the triangulation of empirical data, methods, and theory that I arrived at during an extended research process. In addition to the word "practices", the word "constitutive" in the working definition has important implications for continued interpretive considerations. Constitutive is generically described as "having the power to enact or establish" (Merriam-Webster n.d.). Constitutive means that structure-in the meaning of established societal practices-influences (not determines) individual behaviour (is constituted by) and individual behaviour establishes (constitutes) the structure in the meaning-making practices of society. In other words, this is the "dialectical confluence of ageism" as described by Wilkinson and Ferraro (2002). This, in turn, implies that if structure is not complete, decisively finished, it can potentially be changed. So, interpretive considerations in the research process are sometimes more about reflecting on who has the power to define and label an ageist reality. Interpretive considerations allow for an understanding of how people themselves can become aware of and master 
their life-world (Freire 1996). Higher levels of awareness spill over into enhanced possibilities of exercising power over one's own situation. Departing from definitions of ageism as practices enables a more open form of investigation that allows for the discovery of aspects that could not even be anticipated in the early stages of the research process. Interpretive considerations in the ageism research process also bring us closer to exploring the intersectional complexity of situations and society (Wilińska et al. 2018; Chap. 26, in this volume). In simple terms, intersectionality means that we try to observe and analyse several uniquely socially organizing principles simultaneously; for example, how aspects of age, gender, ethnicity, and class overlap in a given situation.

Interpretive considerations in the ageism research process include other ways of collecting data than carrying out experiments, collecting survey data, and using existing registers. For instance, Bytheway et al. (2007) used diaries to examine people's accounts of discrimination, exclusion, and rejection. They were able to show that everyday events, such as going to the hairdresser, were perceived as discriminating when individuals were not given the haircut they wanted. This type of study design was needed to capture unique, ageist events that often occur in everyday life but still in some countries are considered too trivial to qualify as discrimination in, for example, a legal sense.

\subsection{Discussion}

In this chapter, I reflect on how normative, empiricist, and interpretive considerations have influenced the ageism research process and definitions of ageism. Normative considerations in the research process are characterized by taking a stand against something perceived as immoral or negative in society and wanting to change something which is viewed as problematic. A normative research process is not dependent on ageism theory or theorizing at any stage of the process. Rather, it is characterized by taking a stand, making a claim, and invoking ageism (Cruikshank 2003) as a means to explain practices when other explanations have been precluded. Reliance on normative considerations can be depicted as the initial step in theorizing ageism and as a way to suggest new testable hypotheses and novel research questions. Normativity on the structural level of society enables common sense decision making about what the morally correct thing to do is in a variety of situations. As human beings, we are quite often, but not always, good at common sense decision making. However, acting on normativity, always to some degree, leads us into a biased dead-end. Normative characteristics in ageism definitions show most evidently in the description of the phenomenon as something negative and as a way to distinguish older people (for example) as a target for intervention. Normative considerations guide us towards designing research (perhaps even without intention) in a way that allows us to express opinions about and strive to change negative consequences of ageism for a variety of target groups in society. 
Empiricist considerations in the ageism research process are characterized by making as accurate as possible assessments of ageism. This requires having a clear idea of what and how to assess, which, in turn, presupposes a foundation in theory at an early stage in the research process. Empiricist considerations are theory dependent at early stages of the research process. This is for instance accomplished by assessing prejudice, stereotypes, and discrimination. These three elements are the most obvious empiricist characteristics in ageism definitions. Accuracy resulting from empiricist considerations has provided the research field with validated scales to assess ageism (e.g., Lassonde et al. 2012; North and Fiske 2013) and demonstrated how stereotypes affect a range of different outcomes. Empiricist considerations allow us to assess ageism in as valid, reliable, and accurate a manner as possible. Empiricist considerations in early stages of the research process help guide research towards accurate observation and allow us to show how ageist elements are manifested in specific contexts.

Interpretive considerations in the research process are brought to the fore when the phenomena being studied are unique and extensively complex, that is, when complexity surpasses the possibilities of accurate assessment. In this chapter, for example, the discussion involves the complex challenge of demonstrating how ageism is manifested in and sustained among older people. Our notions of a complex ageist reality are often present in a variety of ways, but uncertainties about how to make sense of a complex reality often prevents us from proceeding. Addressing situations of great complexity regarding ageism requires a process in which we observe reality, collect rich data about age-related aspects of everyday life, and link those data to more abstract types of theories in later stages of the research process. Interpretive considerations in the research process are distinctively characterized by theory dependency in its later stages. In order to make sense of complex situations, it is of the essence that the choice of ageism definition is of a type that allows an interpretive kind of process. Such definitions of ageism include those that identify it in terms of practices. Unique, complex situations can be explored by using a definition of ageism that includes "practices", as this enables a wider contextual conceptualization not circumscribed by narrower alternatives, such as stereotypes. Interpretive considerations in later stages of the research process guide our investigation towards meaning making and understanding of a complex ageist reality, and towards reflecting critically on how ageist elements are related in a wider context.

Normative, empiricist, and interpretive considerations can be seen as being active in different stages of the research process, and are differently theory dependent. The purely normative is not theory dependent at any stage; the empiricist is theory dependent at an early stage; and the interpretive is theory dependent at a later stage of the research process. Depending on the degree of complexity and what we hope to accomplish in researching ageism, normative, empiricist, and interpretive considerations guide our choices and influence our notions of what the most useful forms of knowledge are. As researchers, we are often inclined to make one-sided choices about whether a normative, empiricist, or interpretive design is the most 
appropriate solution. This depends largely on what kind of research training we have. Research training, rather than the research problem, tends to guide what we eventually use. In this chapter, I have argued that a customization of normative, empiricist, and interpretive considerations - in other words, a triangulation of data, methods, and theories in an extended research process - can be a fruitful and creative way to pursue ageism research. Hopefully, the merits of customized triangulation have been demonstrated in a way that will inspire creative identification of novel research questions that will continue to help raise awareness of ageism and identify ways to intervene against the elements of ageist reality that we do not want and retain the elements of ageist reality that we still need.

\section{References}

Andersen, H. (2001). Empirism. In T. Brante, H. Andersen, \& O. Korsnes (Eds.), Sociologiskt lexikon. [Sociological dictionary]. Stockholm: Natur och Kultur.

Bengtson, V. L., Rice, C. J., \& Johnson, M. L. (1999). Are theories of aging important? Models and explanations in gerontology at the turn of the century. In V. L. Bengtson \& K. W. Schaie (Eds.), Handbook of theories of aging (pp. 3-30). New York: Springer.

Butler, R. N. (1969). Age-ism: Another form of bigotry. The Gerontologist, 9, 243-246.

Butler, R. N. (1989). Dispelling ageism: The cross-cutting intervention. The Annals of the American Academy of Political and Social Science, 503, 138-147.

Bytheway, B., \& Johnson, J. (1990). On defining ageism. Critical Social Policy, 10, 27-39.

Bytheway, B., Ward, R., Holland, C., \& Peace, S. (2007). Too old: Older people's accounts of discrimination, exclusion and rejection. London: Help the Aged.

Calasanti, T. M. (2003). Theorizing age relations. In S. Biggs, A. Lowenstein, \& J. Hendricks (Eds.), The need for theory. Critical approaches to social gerontology (pp. 199-218). New York: Baywood.

Constitutive. (n.d.). In Merriam-Webster online. Retrieved from https://www.merriam-webster. com/dictionary/constitutive

Cruikshank, M. (2003). Learning to be old. Gender, culture and aging. Lanham: Rowan \& Littlefield.

Elster, J. (2007). Explaining social behaviour. More nuts and bolts for the social sciences. Cambridge: Cambridge University Press.

Føllesdal, D., Walløe, L., \& Elster, J. (2001). Argumentationsteori, språk och vetenskaps filosofi [Argumentation theory, language and philosophy of science]. Stockholm: Thales.

Freire, P. (1996). Pedagogy of the oppressed. Harmondsworth: Penguin Books.

Howarth, D. (2000). Discourse. Concepts in the social sciences. Buckingham: Open University Press.

Iversen, T. H., Larsen, L., \& Solem, P. E. (2009). A conceptual analysis of ageism. Nordic Psychology, 61(3), 4-22. https://doi.org/10.1027/1901-2276.61.3.4

Jacobson, T. A. (2006). Overcoming 'ageism' bias in the treatment of hypercholesterolaemia. Drug Safety, 29(5), 421-448. https://doi.org/10.2165/00002018-200629050-00005

Jost, J. T., Banaji, M. R., \& Nosek, B. A. (2004). A decade of system justification theory: Accumulated evidence of conscious and unconscious bolstering of the status quo. Political Psychology, 26(6), 881-919. https://doi.org/10.1111/j.1467-9221.2004.00402.x

Kane, M. N. (2004). Ageism and intervention: What social work students believe about treating people differently because of age. Educational Gerontology, 30, 767-784. https://doi. org/10.1080/03601270490498098 
Krekula, C. (2009). Age coding - On age-based practices of distinction. International Journal of Ageing and Later Life, 4(2), 7-31. https://doi.org/10.3384/ijal.1652-8670.09472.

Lassonde, K. A., Surla, C., Buchanan, J. A., \& O'Brien, E. J. (2012). Using the contradiction paradigm to assess ageism. Journal of Aging Studies, 26, 174-181. https://doi.org/10.1016/j. jaging.2011.12.002

Levy, B. R. (1996). Improving memory in old age through implicit self-stereotyping. Journal of Personality and Social Psychology, 71, 1092-1107.

Levy, B. R. (2000). Handwriting as a reflection of aging self-stereotypes. Journal of Geriatric Psychiatry, 33, 81-94.

Levy, B. R., Ashman, O., \& Dror, I. (1999). To be or not to be: The effects of aging stereotypes on the will to live. Omega, 40, 409-420.

Levy, B. R., Slade, M. D., Kunkel, S. R., \& Kasl, S. V. (2002). Longevity increased by positive self-perceptions of aging. Journal of Personality and Social Psychology, 83, 261-270.

Levy, B. R., Slade, M. D., \& Gill, T. M. (2006a). Hearing decline predicted by elders' stereotypes. Journal of Gerontology: Series B, Psychological Sciences and Social Sciences, 61, 82-87.

Levy, B. R., Slade, M. D., May, J., \& Caracciolo, E. A. (2006b). Physical recovery after acute myocardial infarction: Positive age self-stereotypes as a resource. International Journal of Aging and Human Development, 62, 285-301.

Levy, B. R., Zonderman, A. B., Slade, M. D., \& Ferrucci, L. (2009). Age stereotypes held earlier in life predict cardiovascular events in later life. Psychological Science, 20, 296-298.

North, M. S., \& Fiske, S. T. (2013). A prescriptive intergenerational-tension ageism scale: Succession, identity, and consumption (SIC). Psychological Assessment, 25(3), 706-713. https://doi.org/10.1037/a0032367

Nygård, M., \& Snellman, F. (2014). The (non)politicisation of age discrimination in Finland and Sweden. International Journal of Sociology and Social Policy, 34(9/10), 694-709. https://doi. org/10.1108/IJSSP-06-2013-0066

Palmore, E. B. (1999). Ageism. Negative and positive. New York: Springer.

Palmore, E. B. (2005). Typologies. In E. B. Palmore, L. Branch, \& D. K. Harris (Eds.), Encyclopedia of ageism (pp. 332-335). New York: Haworth.

Samuelsson, E., \& Wallander, L. (2014). Disentangling practioners' perceptions of substance use severity: A factorial survey. Addiction Research and Theory, 22(4), 348-360. https://doi.org/1 $0.3109 / 16066359.2013 .856887$

Smith, S. (1995). The self-images of a discipline: A genealogy of international relations theory. In K. Booth \& S. Smith (Eds.), International relations theory today (pp. 1-37). Cambridge: Polity Press.

Snellman, F. (2005). "Det beror på hur man tar det”. Kollektiva livsuttryck, individuella livslopp och meningskonstruerande processer i äldres livsberättelser ["It depends on how you take it". Collective life-forms, individual life-span and processes of meaning making in the life-stories of older people] (Unpublished licentiate thesis). Turku: Åbo Akademi University.

Snellman, F. (2009). "Gammfolket". Om livserfarenheter och vardagens ålderism [Old folks. On life experiences and everyday ageism] (Doctoral dissertation). Retrieved from Umeå University database DIVA (No. 60).

Snellman, F. (2016). Whose ageism? The reinvigoration and definitions of an elusive concept. Nordic Psychology, 68(3), 148-159. https://doi.org/10.1080/19012276.2015.1125301

Snellman, F., Johansson, S., \& Kalman, H. (2012). A pilot study of birthday cards as vignettes: Methodological reflections on the elusive everyday ageism. International Journal of Humanities and Social Sciences, 2(7), 21-33.

Swedberg, R. (2012). Theorizing in sociology and social science: Turning to the context of discovery. Theory and Society, 41, 1-40. https://doi.org/10.1007/s11186-011-9161-5

Thompson, N. (2006). Anti-discriminatory practice (4th ed.). New York: Palgrave Macmillan.

Tornstam, L. (2006). The complexity of ageism. A proposed typology. International Journal of Ageing and Later Life, 1(1), 43-68. https://doi.org/10.3384/ijal.1652-8670.06114. 
Wallander, L., \& Blomqvist, J. (2009). Modelling ideal treatment recommendations: A factorial survey of Swedish social workers' ideal recommendations of inpatient or outpatient treatment for problem substance users. Journal of Social Service Research, 35, 47-64. https://doi. org/10.1080/01488370802477436

Wilińska, M., de Hontheim, A., \& Anbäcken, E. M. (2018). Ageism in a cross-cultural perspective: Reflections from the research field. In L. Ayalon \& C. Tesch-Römer (Eds.), Contemporary perspectives on ageism: Vol. 19. International perspectives on aging (pp. 423-438). Berlin: Springer.

Wilkinson, J. A., \& Ferraro, K. F. (2002). Thirty years of ageism research. In T. D. Nelson (Ed.), Ageism. Stereotyping and prejudice against older persons (pp. 339-358). Cambridge, MA: MIT.

Open Access This chapter is licensed under the terms of the Creative Commons Attribution 4.0 International License (http://creativecommons.org/licenses/by/4.0/), which permits use, sharing, adaptation, distribution and reproduction in any medium or format, as long as you give appropriate credit to the original author(s) and the source, provide a link to the Creative Commons license and indicate if changes were made.

The images or other third party material in this chapter are included in the chapter's Creative Commons license, unless indicated otherwise in a credit line to the material. If material is not included in the chapter's Creative Commons license and your intended use is not permitted by statutory regulation or exceeds the permitted use, you will need to obtain permission directly from the copyright holder. 


\title{
Chapter 26 \\ Ageism in a Cross-Cultural Perspective: Reflections from the Research Field
}

\author{
Monika Wilińska, Astrid de Hontheim, and Els-Marie Anbäcken
}

\subsection{Introduction}

There has been a long-standing interest in researching ageing from a cross-cultural perspective. The recognition of the societal and cultural dimensions of ageing has spurred interest in research that explicitly focuses on highlighting the meaning of context for the process and experience of ageing. Moreover, the acknowledgment of previously limited views of ageing has opened new directions in ageing research. In 1986, when the Journal of Cross-Cultural Gerontology was established, its editors stipulated that research on non-Western settings would be favoured in the journal, which corresponded with "a need for a scholarly journal devoted to worldwide variation in the aging experience" (Beall et al. 1986).

This trend has also been visible in studies that aim to define and measure ageism in objective ways in different parts of the world. For example, in North America, measurement scales that assess the scope and prevalence of ageism in everyday life include the Ageism Survey (see McGuire et al. 2008; Palmore 2004) and the Relating to Older People Evaluation questionnaire (see Allen et al. 2008; Cherry and Palmore 2008). In Europe, the European Social Survey (ESS) has been widely applied to investigate ageist attitudes, the prevalence of age discrimination at national levels, and to offer cross-country comparisons (see Swift et al. 2018;

\author{
M. Wilińska $(\bowtie)$ \\ Jönköping University, Jönköping, Sweden \\ e-mail: monika.wilinska@ju.se \\ A. de Hontheim \\ Université libre de Bruxelles, Brussels, Belgium \\ e-mail: asdehont@ulb.ac.be \\ E.-M. Anbäcken \\ Mälardalen University, Västerås, Sweden \\ e-mail: els-marie.anbacken@mdh.se
}


Chap. 27, in this volume). Accordingly, there is growing recognition that ageism needs to be understood in relation to the various spaces in which it occurs (McHugh 2003). For example, different welfare and cultural norms tend to affect the ways in which people relate to this phenomenon (Radl 2012; Trusinová 2014; van den Heuvel and van Santvoort 2011).

Schoenberg and Lewis (2005) discussed the phenomenon of cross-cultural ageism to emphasize that a cross-national perspective in the study of ageism makes an important contribution to understanding the ways in which local contexts shape and influence ageism. Such a perspective, however, does not need to entail an essentialist view of culture; rather, it encourages reflection upon various norms, practices, and meaning-making processes embedded in particular socio-cultural settings and their influence on ageism and ageist practices. In this chapter, we follow this line of argument and develop it further by discussing the complexity of exploring diverse ageist practices as performed in different parts of the world and reflecting at the same time upon the researchers' socio-cultural backgrounds, through which their experiences of fieldwork and research on various enactments of ageism are filtered. The key tenet of our argument is that these two dimensions interact during the fieldwork to create unique frameworks that researchers apply in their studies and which in effect lead to various understandings of ageism.

\subsection{Ageism-From Global to Local Phenomena and Back}

"Every age is problematic, or rather, having an age is a danger" (Gullette 2004, p. 181). This statement, made by renowned cultural critic Margaret Gullette, accentuates the prevalence of age ideology in current socio-economic and cultural contexts. Ageism is a multidimensional phenomenon that goes beyond discriminatory practices or events. It is predicated upon the understanding of age as an important signifier of classes of people (Bytheway 1995) that effectively creates ranks of more and less desired ages. It is a form of social oppression and inequality that often goes unnoticed when people are involved in their business as usual. As emphasized in the chapter on gendered ageism, ageism is also a form of social practice that is used to achieve not only age-specific goals, such as favouring some age groups at the expense of other groups, but also to accomplish other important objectives, such as fulfilling organizational visions or work-related tasks (Llewellyn 2015; Wilińska and Henning 2011). Because of this, ageism becomes a difficult phenomenon to research. Like any other form of social inequality, ageism not only exists in direct discriminatory and exclusionary actions, but, more often, it can be found in numerous taken for granted meanings and practices that are ordinarily considered natural. The popularity and social acceptance of widely used anti-ageing products (Vincent 2006, 2007) and age-related jokes on birthday cards (Ellis and Morrison 2005) are only two examples of practices that very often receive little if any recognition as harmful and demeaning to particular age groups. 


\subsection{Ageism in West and East}

Ageism as a societal structure that is enacted in social relationships and practices has been mainly associated with Western cultures that have been extensively criticized for their overarching focus on and desire for everlasting youth which devalues ageing and old age (Gullette 2004). Studies that explicitly aim at comparing enactments of ageism in Western and Eastern cultures usually employ either attitudes surveys or media analysis.

In an overview of quantitative studies examining differences in attitudes towards older people in Western and Eastern countries, North and Fiske (2015) demonstrated that their results contradict many common assumptions about East and West. For example, the most commonly held assumption about those differences is that Eastern countries and cultures are more respectful of older people. North and Fiske (2015) challenged this claim by establishing a link between level of ageism and population ageing rate and suggesting that many Eastern countries experience high rates of population ageing and, therefore, increasing levels of ageism. They emphasized a need for more context-sensitive research that is also conducted within similar cultures and geographical regions.

Ageism may be a worldwide phenomenon but its particularities attest to the importance of recognizing the interaction between situational contexts and ageist practices. For example, methodological reflections on the ways in which the ESS is used in Europe to study ageism confirms that levels of sensitivity to the experience of ageism vary from country to country making it difficult to reach rigorous conclusions (Trusinová 2014). There seems to be a clear difference in the experience of direct age discrimination between Northwest and Southeast Europe, which, among other things, can be related to the differences in social arrangement systems following diverse welfare state traditions (van den Heuvel and van Santvoort 2011).

Research results from studies examining ageism in the media also confirm the importance of context when discussing this phenomenon. For example, a comparative study of TV advertisements in Taiwan and the UK has shown that although ageism is widely spread in both countries, its forms and contents differ due to various cultural and traditional norms (Chen 2015). Whereas in the UK ageism is mostly visible in unrealistic images of active and healthy older people, in Taiwan the same phenomenon is reflected in advertisements that mainly focus on ill health and the vulnerability of older people. Lien et al. (2009) and Raman et al. (2008) further demonstrated that, although the underrepresentation of older people in the media is widely spread around the world, the particularities of marginalization and stigmatization of older people in the media need to be contextualized. 


\subsection{Cross-Cultural Research Approaches to Ageism}

Very often, cross-cultural comparisons of ageism are conducted from the perspective of difference (idiographic) and it is difference that is actively searched for. In contrast, Anbäcken and Nitta (2008) discussed the position of "similarities in differences and differences in similarities" (p. 172) as a more fruitful response to the challenges posed by cross-country comparisons. This position rejects the static view of culture and instead brings to the fore sensitivity to the context and the interlinked relations between particularities and universalities. It is a position that, for example, has enabled researchers to demonstrate that the perception of daily life among older people whose spouses were institutionalized in the Japanese and the Swedish contexts are similar. Moreover, it might be useful to highlight in-group varieties rather than only to delineate differences between countries (Anbäcken and Nitta 2008; Johansson et al. 2008). Such a position has the potential to creatively combine a search for differences and unique characteristics (idiographic perspective) with a search for similarities and discovering overarching patterns (nomothetic perspective) by demonstrating that differences and similarities can co-exist.

Not only does the perspective used to compare various contexts make a difference, but researchers themselves matter. Japanese gerontologist Koyano (1989) contended that many myths regarding ageing in Japan had been constructed by Western scholars who entered the country without fully understanding the particularities of everyday life and the ways in which older people would and would not interact with foreign researchers. For example, he found that rituals of respect which were praised by Western scholars very often concealed negative attitudes towards old age that were very difficult to discern, even by natives (Koyano 1989). This only strengthens the point about the complexity of revealing ageist practices, which, enmeshed in everyday doings, often go unnoticed. This difficulty not only exposes the conflict between insider (emic) and outsider (etic) perspectives that may substantially impinge on comparative research efforts in the field of ageing (TeschRömer and von Kondratowitz 2006), but also highlights the fact that regardless of the perspective, knowledge is hardly objective. On the contrary, it reveals its interdependency on the social reality in which it is produced (McCarthy 1996; Longino 1990).

Research on ageism conducted in unfamiliar socio-cultural settings is also challenging simply from the practical perspective of researchers travelling, living, and working abroad. The prospect of encountering new, unexpected scenes typical of all research fieldwork can be much higher in such situations. Furthermore, the process of negotiating one's own position in the field can be very demanding because even off-field negotiations are conducted outside the familiar context (Ortbals and Rincker 2009). These, combined with a range of theoretical and methodological perspectives, may be perceived as diverse "voices" pulling the researcher in different directions (Mallozzi 2009). This hidden or "shadow" side of fieldwork (Corin 2008) simultaneously influences our perception and is contingent upon our own stories and experiences in the fieldwork. 


\subsection{Researchers Entering the Field of Ageism}

In this chapter, we reflect upon examples of qualitative studies to highlight an important but often neglected dimension of research on ageism: the researchers themselves. We work from the perspective of knowledge as culture, where culture does not only entail a system of shared meanings, but rather emphasizes a range of cultural practices that form our reality (McCarthy 1996). We explore the position of researchers who, on the one hand, apply the privileged perspective of strangers to their fieldwork, and on the other hand, are deeply embedded in their own sociocultural backgrounds, which affect their way of approaching later life and ageism (e.g., Anbäcken 2004; Anbäcken and Kinoshita 2008; Wilińska 2014).

The fieldwork situations analysed in the subsequent parts of this chapter are based on the three distinct voices of the researchers who authored this chapter. All excerpts are based on fieldnotes the authors took while conducting thier studies. We discuss the presented fieldwork situations to highlight two issues: first, the complexity and variety of ageist practices; second, the active role researchers have in making sense of the social world. This means that in addition to analysing the empirical material, we critically look at the ways in which we approached that material in the past and the ways in which we could approach it currently. Following Mason's (2013) reasoning about "re-using" qualitative data, we reflexively engage with the empirical material from both a close and a far away perspective. In this way, we contextualize and recontexualize our data and ourselves to apply perspectives of time and space not only to ageism as a social phenomenon but also to research on ageism.

The three authors are women of different ages. We were born and brought up in different countries: Astrid is from Belgium; Els-Marie is from Sweden and Japan; and Monika is from Poland. We embarked on our academic journey researching ageism in different ways, although we all have an academic connection with Asia; Els-Marie also has a private connection to Japan. All three of us are qualitative researchers, although from different disciplinary positions. Our thinking and writing about ageism is affected by the various "voices" we hear during periods of fieldwork and while conducting interviews. We combined our experiences to offer a shared reflection on conducting cross-cultural research on ageism. The situations presented below attest to how our various backgrounds impacted our work, and emphasize the need to understand ageism as a socially, culturally, and politically embedded phenomenon that reveals itself variously, depending on the context.

\subsection{The Pervasiveness of Ageism}

Monika I see myself as an inequality researcher. The focus on ageism is important in my work, but I also work on wider issues to understand patterns of inequality and their persistence over time and space. My own life is also an important site of such 
inquiries mainly due to my status as an Eastern European immigrant woman living in Western Europe. My thinking about inequalities always begins with a simple yet profound principle of sociological imagination as outlined by Mills (1959/2000), which aims at linking individual biographies with societal histories. As challenging as it is, this statement gains a whole new meaning in the context of cross-cultural research.

A few years after migrating to Sweden from Poland, I travelled back to my home country to conduct fieldwork at one of the many Universities of the Third Age (U3A). I was rather excited about the visit and its purpose. I recalled times when I was a student and could see U3A students coming for their afternoon sessions, which started just after our sessions ended. We not only shared the building but also the teaching staff. I had thought of the visit as a possibility to shed a positive light on old age and to demonstrate an example of activist initiative that goes against widely accepted ageist stereotypes.

During my visits, I was always treated in a very positive and friendly manner and I could feel that my visit and prospective study were welcome. I was also excited about conducting research in a familiar setting, in a well-known country. I was, however, considered a kind of hybrid person who was "one of us" in some sense and yet also "the other." People often said to me, "You know how it is here," but I also felt I was approached with caution and that little was revealed about the organization. It was within this context that I was told that if I wanted to learn more about old age, I should "walk the streets" rather than spend my time with the U3A, "because, although ageing does happen, it does not happen here."

\subsection{The Easiness of Ageism}

Els-Marie My studies on ageing and care in Japan began in the early 1990s but did not specifically focus on ageism. To look at previous studies in the rear-view mirror through an ageism lens is not only a thrilling task, but it also provides methodologically unorthodox ways of studying a phenomenon that originally was not intended to be studied. The text below serves as a good example of both ageism and how the researcher as a tool is influenced by perhaps hidden ageist preconceptions.

After a few days of participant observations at a Japanese municipal "home for the aged," which at that time were for older persons with social rather than health care needs, I attended a meeting of the karaoke club. I was seated at the large rectangular table with ladies and gentlemen mostly dressed in brown and grey, with solemn faces, singing love songs: "You and I are Osaka sparrows... how far will we fly tonight?" It not only shook my image of older people, but evoked in me a strong feeling of existential closeness. I realized that they had once been my age, and the places they were singing of were "my" places too, as I was born in Japan and in the Osaka region (Anbäcken 1997, p. 1).

While my focus had been on the residents as a category of older people with certain care needs in a specific socio-cultural setting, they revealed themselves 
behind their institutional identity as individuals of a particular time in Japanese history and with their own history. Those love songs were part of their life course. In retrospect, I feel that, with my preconceptions about ageing in Japan, I was the one with unconscious ageist views. My preconceptions, formed by an image of filial duty, had made me see older people as a category of care recipients, where care needs and care relations defined their life. Moreover, I risked making simplified "culturalist" assumptions in my field of study. This could possibly have blurred my views, colouring my analysis with unquestioned ageist views hidden within cultural explanations.

\subsection{Ageism as Inequality Practices-Analytical Reflections}

When Monika visited the University of the Third Age (U3A), she was in her early 30s. She assumed that the U3A members, people in their 60s, 70s, and 80s, would be sharing their stories of ageing and old age with her. It took time for her to understand that the U3A was, in fact, used by its members as a shield to protect them from negative images of old age and older people. The phrase, "There is no ageing here," was, on the one hand, an enactment of ageism; on the other, it offered protection from the socio-cultural context that associated ageing with a time of decline, and withdrawal from public and social spaces. Els-Marie similarly began her studies with a search for differences. Her surprise at discovering similarities instead revealed to her that she had been seeing older people as a "category" with defined features, rather than as individuals.

When conducting research on ageism, we need to start hearing stories about researchers' preconceived ideas about older people and ageing and how they might lead to discrimination. The examples above demonstrate that inequalities are perpetuated by every one of us. We as researchers might also be contributing to fuelling the inequality systems. Inequalities are not only about direct and obvious discriminatory acts, but also about "small things" that we do daily without thinking (Schwalbe 2008). In this context, it is possible to see how tempting and comfortable it can be to think about oneself as an exception, as one who can move beyond stereotypes and draw on the privileged position of a stranger. Neither researchers nor people in later life are immune to preconceptions. Cross-cultural studies only magnify this process.

Unfamiliar settings and people can help reveal hidden stereotypes and images that we use to make sense of situations, events, and processes. These stereotypes and images become anchors that we easily drop but struggle to pull up due to the comfort of illusory understanding they create. For example, it is much easier to accept that an older person of American origin living in Japan does not like sushi because she or he is not Japanese rather than to actively look for alternative explanations, such as that the person has a food allergy or is a vegetarian. In the field of ageing, this form of cultural determinism is often built on the understanding of cultures as static and older people as mere victims of their national cultures (Wilińska and Anbäcken 2013). 


\subsection{Ageism and Socio-political Structures}

Els-Marie "What generates changes in policies for older people, and what conserves them?" was a question I posed in an attempt to write a policy ethnography study on how policies and institutional care pamphlets constructed the image of older persons and their families in Japan and Sweden (Anbäcken 2013, p. 256).

With regard to policies, it was clear (albeit from a very small sample) that both Japanese and Swedish texts from the early 21 th century showed similar patterns of belittling older people in need of care and describing them as a social problem. This problematic view of old age is related to an image of older people ceasing to be productive - in both cases in industrialized countries where experience and wisdom are not much valued anymore. Even the traditional image of wisdom in older age in Japan was challenged after WWII when the welfare regime adopted a productivist view, emphasizing economic development over social distribution (Makita 2010, p. 82).

By the mid-20th century, Sweden had already developed a pension system, and old age homes were gradually being transformed in the direction of "home-like care and care at home" (Anbäcken 2013). The social democratic view slowly changed ageist views of "old people's homes," but the view that "those who have built our nation should be cared for" continued to bear hidden ageist views, as the message was that they (the elderly) were to be taken care of. The Japanese old-age care pamphlets depicted "cute," smiling, animation-style grannies, often in three-generation settings. The Swedish pamphlets had realistic drawings of an elderly couple followed by a text describing care options. Could the Swedish pamphlet be described as less ageist than the Japanese, because it simply provided information on available services and how to obtain them? The Japanese brochures seemed to put forward a consumerist perspective by providing information about room sizes, number of staff, and frequency of baths. In contrast, the Swedish brochures tended to emphasize the care relation between older people and staff members; they were filled with images of affection and communication between the care home residents and care home staff.

Looking back, I made a new discovery: that what I had earlier found to be positive about the kindness described in the Swedish brochures and negative about the seemingly materialistic view in the Japanese ones could itself be problematic. While the former used an idealized image of benevolent staff, the latter offered a more concrete description of the physical environment and daily routines that one could expect. The process of re-reading the empirical material through the lens of ageism led not only to new understandings but also to a greater awareness of my own assumptions. 


\subsection{Socio-political Embeddedness of Ageism-Analytical Reflections}

Welfare and social policy discourses have been identified as important sites of ageism (Biggs 2001), clearly contributing to, if not shaping, intergenerational conflicts (Estes and Phillipson 2002), and invoking irrational fear of the ageing population (Vincent 1996). However, the reading of such policies and interpreting them in a cross-cultural context is far from easy. The example above demonstrates the way in which researchers' own backgrounds and socio-cultural reference points can interact with the analysed material, leading to interpretations that may be biased.

The use of animation in the eyes of Western culture is often perceived as childish, and, when applied to other than child-like situations, is read as patronizing and discriminatory. However, in Japan, with its long-standing tradition of manga, the reading of animation is different and does not always imply childish content. On the contrary, the art of manga has been used for centuries to narrate complex stories by engaging multimodal reading skills, and it remains one of the key hallmarks of Japanese culture (Ito 2005). Els-Marie's reflections on her interpretation of policy texts from two different countries demonstrate the continual homage we pay to our own socio-cultural background when researching ageism. In fact, on many occasions, we wish we could go beyond our socio-cultural background in order to be able to transcend taken for granted understandings that continually affect our research results and the concepts we selectively use to justify them.

The socio-political context gives meaning to social practices and it is via this context that some practices can be interpreted as ageist. For example, the use of manga itself cannot be seen as a sign of ageism in the example described above, but the focus on material aspects of care could be, as it indirectly implies that the material is what older people are interested in. Such an image reduces the view of care to the provision of goods rather than social relations-a reduction that is made more problematic by occurring in an environment that values the collective self over the individual self. Similarly, at the outset, the Swedish brochures seemed far from ageist. Yet given the cultural focus on the individual that characterizes the welfare state in Sweden, the predominance of staff in the images of care homes can also be seen as potentially ageist. In Sweden, a direct relationship between the individual and the state has traditionally been a unique characteristic of the welfare contract (Bergren and Trägårdh 2006), and by emphasizing the role of a mediator (care staff), the brochure imagery can be seen as implying a weakened position of older people. 


\subsection{Ageism Across the Life-Course}

Astrid My interest in ageism began when I was working on a book I dedicated to my older students, which aimed to strengthen their confidence in the success of their studies and help them overcome stereotypes related to ageism (de Hontheim 2014). In addition to that, several of my research topics have focused on radical sociocultural changes, such as pioneer evangelization in West Papua. When traditions are profoundly shaken, society seeks ways to mobilize creativity to build new references with the help of those who are considered knowledgeable and culturally wise. In West Papua, older people are traditionally designated to lead communities through times of change.

\subsection{Honouring Older People and Discriminating Against Younger People}

In West Papua, population movements are mostly caused by massive transmigration from overcrowded Indonesian islands such as Java and Sumatra, pushing the Asmat to the edge of their former territories. The Indonesian administration has been struggling with this cultural group, which they classify as "the least economically active in the country." The majority of the 70,000 Asmat are hunter-gatherers and tradition constitutes the core of their daily life.

In the ritual house (jeuw), the centre for the community and political decision making, the only people authorized to speak are the elders, who are considered to be the tradition-holders or cultural specialists. They have the right to sit in the physical centre of the house, where the ancestors are thought to dwell. Guided or inspired by the ancestors, these cultural specialist elders protect the traditions and ensure that norms are respected, with an emphasis on appropriate social and ritual relationships.

A major part of traditional knowledge is transmitted through initiation, which is still intimately connected to headhunting, although it is symbolic nowadays. The elders' responsibilities are of paramount importance, from training the young to giving gifts that signify young people's entry into the community. In a society that imposes silence on the younger generation, control by older adults is the norm. Young people are considered to be foolish and are deprived of the right to speak. In this culture, young people are at the service of others. They always follow behind older people, for example during meal times or when strolling through the village. Older people have the right to use physical force in the teaching of the young.

In this context, human sciences researchers must manage deeply ingrained ageist structures directed against younger people. In this culture, young people are not considered to deserve the right to participate in research or to express their opinions. 


\subsection{Ageism as a Total Social Fact-Analytical Reflections}

Although ageism may refer to any age group, the most common understanding is that it mainly affects older people. Astrid's example reemphasizes the point that the direction of ageism is context-bound. For the Asmat, it is old age that is privileged and carries numerous benefits in social position and status. Consequently, European researchers may find themselves reproducing Asmat adults' deeply ingrained ageism that affects young people in that society. Ageism as a social practice based on the differentiation of people according to their age may not only be expressed in a variety of ways, but may also refer to different age groups. To study ageism in diverse societies requires attentive observation of various age practices and their consequences for different groups within each society rather than for just one age group.

Astrid's fieldwork example demonstrates some of the most direct and visible forms of discrimination that can affect different age groups. Lack of a voice, lack of respect, and lack of one's own place are typical among the underprivileged in structures that privilege some groups over others and effectively discriminate to the point of symbolic and physical abuse. What is more, such practices are seen as necessary to maintaining and reproducing the social reality. Ageism could thus be considered a total social fact (Mauss 1923) _ an expression of social mechanisms most essential to the perpetuation and reproduction of society. The division of society into age classes not only determines the social positions of people belonging to different age groups, but importantly it creates age-based systems of rights, obligations, and moral conduct.

\subsection{Ageism in the Eye of the Beholder?}

Monika I travelled to Japan with the aim of researching care and the everyday life of older people in several Japanese towns and cities. It was an amazing journey that allowed me to get a glimpse into the social and cultural norms guiding everyday life in Japan. I lived and worked with Japanese colleagues, I read books written by Japanese authors, and I learned the basics of the Japanese language. This helped me make sense of what I observed and heard about old age. A number of study visits helped me learn about the various ways in which older people lived and were cared for. I had the privilege of speaking with several older women and learning about their everyday lives.

I began to understand the significant role of technology in people's lives and learned about a number of innovative solutions that were designed with the purpose of increasing the safety and security of older people. During one of the visits in an assisted living facility for older people, I was introduced to a woman who proudly walked me through her apartment showing off her life story through pictures, objects, and various certificates. Prompted by the visit organizer, she also 
demonstrated a number of safety alarms and technological devices that the apartment was equipped with. While we were taking another tour of the apartment, the visit organizer noticed an unopened box with a wearable alarm device that was to be used by residents at all times for the purpose of alerting staff to sudden weakness, illness, and so on. When asked why she was not using it, the woman said that she was not that old yet.

\subsection{Is It Ageism or Not?-Analytical Reflections}

Initially, the situation above seems far from exemplifying ageism. In Els-Marie's view, the alarm system was a sign of safety, a service from the welfare system that at a minimum level allowed this seemingly independent older woman to keep her autonomy and control when to call for help. Els-Marie interpreted the woman's choice as a sign of being autonomous and exercising the right to decide about her own life. Els-Marie situated that understanding of the situation in a research context which was rooted in the continuous study of change processes regarding ageing, care, and the welfare system in Japan (Anbäcken 1997, 2004, 2008).

According to Monika, with her understanding of social inequalities as accomplishments - as something that "doesn't just happen ... it happens because of how people think and act" (Schwalbe 2008, p. 38; see also Tilly 1999)—-the situation revealed several dimensions that are relevant for researching ageism. First, there is the context of social policy, with its focus on improving the wellbeing of older people, which produces a certain image of the needs and wishes that an older person may have. Second, there is the reaction of an older person to a supposedly helpful device that in her eyes symbolizes old age-something negative that she does not want to identify herself with. Third, there is a researcher born in the early 1980s in Poland and brought up in the context of a deeply ingrained mistrust in things that come from the state, who interprets the situation as a clash between the overpowering state and a vulnerable individual.

Haraway (1991, p. 190) argued that "only partial perspective promises objective vision," suggesting that the situated nature of our knowledge rather than being limiting is liberating. In their highly informative argument about the value of and need for comparative research on ageism, Tesch-Römer and von Kondratowitz (2006) privilege the role of theory in assuring a high quality of endeavours that could effectively push the field of ageing studies forward. However, to use a theory is to look at a phenomenon from a certain position, and that position has been developed in a certain context. There is a risk of transposing theories and concepts born in one setting to another. In the context of North-South power relations, this aspect of crosscultural research on ageism becomes even more pronounced. As discussed above, Els-Marie and Monika each looked at the same situation and offered two different interpretations that were grounded in their personal histories as well as in the theoretical frames they chose. 


\subsection{Discussion: Establishing a "Sense of Touch" with the Field}

Ageism is a global, socio-cultural practice that is deeply embedded in local contexts that not only filter its meaning but also give rise to unique enactments of ageism. In this chapter, our objective was to spotlight the active role of researchers, who become tools for transporting various meanings and enactments of ageism. This chapter is an attempt to tease out various entanglements of ageism, context, and researcher to accentuate the role of researchers in cross-cultural studies of ageism and to offer some "how to" recommendations in studies that research ageism from a cross-cultural perspective.

We began this chapter with a reference to the opening statement of the Journal of Cross-Cultural Gerontology. We agree with the importance of demonstrating "worldwide variation in the aging experience" (Beall et al. 1986). Ageism is a diverse phenomenon including a large variety of practices that are deeply embedded in socio-cultural and political contexts. This means that cross-cultural research on ageism should aim at broadening and complicating our perspective on ageism rather than arriving at a unified picture. Longino (1990) contends that "[s]cientific inquiry is unlike portrait painting in two very important ways: it is social and it is complex, consisting of many activities carried out by different persons" (p. 19). The examples used in this chapter are not straightforward and are prone to a variety of interpretations. We purposefully selected them to demonstrate the complexity and sociality involved in researching ageism from a cross-cultural perspective. In many respects, what we propose here is a type of reflexive methodology (Alvesson and Sköldberg 2009) that is needed in research on ageism to constantly remind ourselves of the relationship between the knower, the (un)known, and the context of knowing. This, in turn, may help us to rethink various theories and concepts that we apply in our studies. Globally practiced ageing research is often based on standards and theories born in Western countries (Aboderin and Hoffman 2015). The example of the Asmat and their understanding of old age as a time of increased social and political engagement reveals the extent to which such theories are ill-fitted to account for worldwide variations of ageing experiences and, by extension, ageism.

Our discussion is based on examples from qualitative studies that by their nature focus on situated meaning making. We find this dimension important not only for revealing the various enactments of ageism in everyday life, but also for highlighting the voices of people who confront ageism by interpreting and acting upon its meaning. However, the points we raise in the chapter are not limited to qualitative research. The active role of researchers who colour their research with their own understanding of age and ageism is visible in all types of studies. Further, as Jylhä (2007) contends, ethnographic comparisons may fruitfully inspire larger quantitative studies of ageing and ageism. For example, the idea that ageism is not only perpetrated against older people is just one such inspiration. This means that rather than locating our studies within specific age groups, we can move beyond 
chronologically oriented studies to explore the ways in which a variety of age norms affect and/or are enacted among various groups (Bytheway 2005; Gullette 2004).

In the context of their discussion of a "joint participation model," Kinoshita (Anbäcken and Kinoshita 2008, p. 8) emphasizes the necessity of establishing "a sense of touch in the field" that involves researchers visiting each other's empirical fields and learning about the research contexts to create a common ground for forthcoming interpretations. Acknowledging the importance of such exchanges that merge emic and etic perspectives, in this chapter we extend the discussion by claiming that the "sense of touch" in cross-cultural research on ageism should not only be established within the socio-cultural context, but also in researchers' own preconceptions and reasons for selecting certain concepts, theories, and methodologies. This constant dialogue is necessary to fully appreciate and benefit from the great privilege of participating in cross-cultural studies of ageing and ageism. Importantly, this dialogue needs to be firmly based on spatial and temporal considerations. It is not only about the question of where but also about the question of when. It is the socially, spatially, and temporally created contexts that make a difference to ageist practices and the research that examines them.

\section{References}

Aboderin, I., \& Hoffman, J. (2015). Families, intergenerational bonds, and aging in Sub-Saharan Africa. Canadian Journal on Aging/La Revue canadienne du vieillissement, 34(3), 282-289.

Allen, P. D., Cherry, K. E., \& Palmore, E. (2008). Self-reported ageism in social work practitioners and students. Journal of Gerontological Social Work, 52, 124-134.

Alvesson, M., \& Sköldberg, K. (2009). Reflexive methodology: New vistas for qualitative research. London: Sage.

Anbäcken, E. (1997). Who cares? Culture, structure and agency in caring for the elderly in Japan (Unpublished doctoral dissertation), Stockholm University, Sweden.

Anbäcken, E. (2004). Researching home help services for the elderly: How cultural concepts affect the research design. In E. Olsson, A.-L. Närvänen, E. Näsman, \& B.-M. Öberg (Eds.), Changing worlds and the ageing subject (pp. 96-114). Aldershot: Ashgate.

Anbäcken, E. (2013). Policy language in the care for the aged in Japan and Sweden: Does it reflect or steer ideology? In E. Cedersund \& E. Brunnberg (Eds.), New tools in welfare research (pp. 255-293). Uppsala: NSU Press.

Anbäcken, E., \& Kinoshita, Y. (2008). Older people in an international local context: The cases of Japan and Sweden (Vårdal Report Series, 2008/1). Stockholm: Vårdalstiftelsen.

Anbäcken E., \& Nitta, M. (2008). "Until death do us part?" Experienced institutionalization: Couples' experiences in a spouse's placement process in Sweden and Japan. In E.-M. Anbäcken, \& Y. Kinoshita (Eds.), Older people in an international local context: The cases of Japan and Sweden (pp. 165-213). Stockholm: Vårdal Report Series, 2008/1.

Beall, C. M., Eckert, J. K., \& Goldstein, M. C. (1986). Editorial. Journal of Cross-Cultural Gerontology, 1(1), 1-3.

Berggren, H., \& Trägårdh, L. (2006). Är svensken människa?: Gemenskap och oberoende i det moderna Sverige. Stockholm: Norstedts.

Biggs, S. (2001). Toward critical narrativity. Stories of aging in contemporary social policy. Journal of Aging Studies, 15, 303-316.

Bytheway, B. (1995). Ageism. Buckingham: Open University Press. 
Bytheway, B. (2005). Ageism and age categorization. Journal of Social Issues, 61(2), 361-374.

Chen, C. H. (2015). Advertising representations of older people in the United Kingdom and Taiwan: A comparative analysis. The International Journal of Aging and Human Development, 80(2), 140-183.

Cherry, K. E., \& Palmore, E. (2008). Relating to older people evaluation (ROPE): A measure of self-reported ageism. Educational Gerontology, 34, 849-861.

Corin, E. (2008). Personal travels through otherness. In A. McLean \& A. Leibing (Eds.), The shadow side of fieldwork. Exploring the blurred borders between ethnography and life (pp. 239-261). Malden: Blackwell.

de Hontheim, A. (2014). Trop vieux pour apprendre? Petit manuel de l'adulte en proie au doute. Saint-Pierre-de-l'Isle: EdiMaât.

Ellis, R. S., \& Morrison, T. G. (2005). Stereotypes of ageing: Messages promoted by age-specific paper birthday cards available in Canada. International Journal of Ageing and Human Development, 61(1), 57-73.

Estes, C., \& Phillipson, C. (2002). The globalization of capital, the welfare state, and old age policy. International Journal of Health Services, 32(2), 279-297.

Gullette, M. M. (2004). Aged by culture. Chicago: The University of Chicago Press.

Haraway, D. J. (1991). Simians, cyborgs, and women. The reinvention of nature. New York: Routledge.

Ito, K. (2005). A history of manga in the context of Japanese culture and society. The Journal of Popular Culture, 38(3), 456-475.

Johansson, I., Anbäcken, E., Nitta, M., Karp, H., \& Kinoshita, K. (2008). Daily life as seen from the perspectives of older people in Sweden and Japan. In E.-M. Anbäcken \& Y. Kinoshita (Eds.), Older people in an international local context: The cases of Japan and Sweden (pp. 130-164). Stockholm: Vårdal Report Series 2008/1.

Jylhä, M. (2007). Comparisons, cultures, contexts. European Journal of Ageing, 4(2), 101-102.

Koyano, W. (1989). Japanese attitudes towards the elderly: A review of research findings. Journal of Cross-Cultural Gerontology, 4, 335-345.

Lien, S. C., Zhang, Y. B., \& Hummert, M. L. (2009). Older adults in prime-time television dramas in Taiwan: Prevalence, portrayal, and communication interaction. Journal of Cross-Cultural Gerontology, 24(4), 355-372.

Llewellyn, N. (2015). 'He probably thought we were students': Age norms and the exercise of visual judgement in service work. Organization Studies, 36(2), 153-173.

Longino, H. E. (1990). Science as social knowledge: Values and objectivity in scientific inquiry. Princeton: Princeton University Press.

Makita, M. (2010). Gender roles and social policy in an ageing society. The case of Japan. International Journal of Ageing and Later Life, 5(1), 77-106.

Mallozzi, C. A. (2009). Voicing the interview: A researcher's exploration on a platform of empathy. Qualitative Inquiry, 15(6), 1042-1060.

Mason, J. (2013). Re-using' qualitative data: On the merits of investigative epistemology. Sociological Research Online, 12(3), 3.

Mauss, M. (1923). Sociologie et anthropologie. Paris: Quadrige.

McCarthy, E. D. (1996). Knowledge as culture: The new sociology of knowledge. London: Routledge.

McGuire, L., Klein, D. A., \& Chen, S.-L. (2008). Ageism revisited: A study measuring ageism in East Tennessee, USA. Nursing \& Health Sciences, 10, 11-16.

McHugh, K. E. (2003). Three faces of ageism: Society, image and place. Ageing \& Society, 23, 165-185.

Mills, C. W. (1959/2000). The sociological imagination. Oxford: Oxford University Press.

North, M. S., \& Fiske, S. T. (2015). Modern attitudes toward older adults in the aging world: A cross-cultural meta-analysis. Psychological Bulletin, 141(5), 993-1021.

Ortbals, C. D., \& Rincker, M. E. (2009). Fieldwork, identities, and intersectionality: Negotiating gender, race, class, religion, nationality, and age in the research field abroad. Political Science \& Politics, 42(2), 287-290. 
Palmore, E. B. (2004). Research note: Ageism in Canada and the United States. Journal of CrossCultural Gerontology, 19, 41-46.

Radl, J. (2012). Too old to work, or too young to retire? The pervasiveness of age norms in Western Europe. Work, Employment \& Society, 26(5), 755-771.

Raman, P., Harwood, J., Weis, D., Anderson, J. L., \& Miller, G. (2008). Portrayals of older adults in U.S. and Indian magazine advertisements: A cross-cultural comparison. Howard Journal of Communications, 19(3), 221-240.

Schoenberg, N. E., \& Lewis, D. C. (2005). Cross-cultural ageism. In E. B. Palmore, L. G. Branch, \& D. K. Harris (Eds.), Encyclopedia of ageism (pp. 87-92). New York: The Haworth Pastoral Press.

Schwalbe, M. (2008). Rigging the game. How inequality is reproduced in everyday life. New York: Oxford University Press.

Swift, H., Abrams, D., Marques, S., Vauclair, C. M., Bratt, C., \& Lima, M. L. (2018). Agisem in the European region: Finding from the European social survey. In L. Ayalon \& C. Tesch-Römer (Eds.), Contemporary perspectives on ageism: Vol. 19. International perspectives on aging (pp. 439-457). Berlin: Springer.

Tesch-Römer, C., \& von Kondratowitz, H. J. (2006). Comparative ageing research: A flourishing field in need of theoretical cultivation. European Journal of Ageing, 3, 155-167.

Tilly, C. (1999). Durable inequality. Berkley: University of Chicago Press.

Trusinová, R. (2014). No two ageisms are the same: Testing measurement invariance in ageism experience across Europe. International Journal of Social Research Methodology, 17(6), 659-675.

van den Heuvel, W. J., \& van Santvoort, M. M. (2011). Experienced discrimination amongst European old citizens. European Journal of Ageing, 8(4), 291-299.

Vincent, J. A. (1996). Who is afraid of an ageing population? Critical Social Policy, 16, 3-27.

Vincent, J. A. (2006). Ageing contested: Anti-ageing science and the cultural construction of old age. Sociology, 40(4), 681-698.

Vincent, J. A. (2007). Science and imagery in the 'war on old age'. Ageing \& Society, 27, 941-961.

Wilińska, M. (2014). Shame on me ... emotions in the fieldwork on old age in Japan. Qualitative Social Work, 15(5), 602-618.

Wilińska, M., \& Anbäcken, E. M. (2013). In search of the everyday life of older people in Japan: Reflections based on scholarly literature. Journal of Cross-Cultural Gerontology, 28(4), 435-451.

Wilińska, M., \& Henning, C. (2011). Old age identity in social welfare practices. Qualitative Social Work, 10(3), 346-363.

Open Access This chapter is licensed under the terms of the Creative Commons Attribution 4.0 International License (http://creativecommons.org/licenses/by/4.0/), which permits use, sharing, adaptation, distribution and reproduction in any medium or format, as long as you give appropriate credit to the original author(s) and the source, provide a link to the Creative Commons license and indicate if changes were made.

The images or other third party material in this chapter are included in the chapter's Creative Commons license, unless indicated otherwise in a credit line to the material. If material is not included in the chapter's Creative Commons license and your intended use is not permitted by statutory regulation or exceeds the permitted use, you will need to obtain permission directly from the copyright holder.

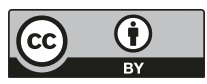




\title{
Chapter 27 \\ Agisem in the European Region: Finding from the European Social Survey
}

\author{
Hannah J. Swift, Dominic Abrams, Sibila Marques, \\ Christin-Melanie Vauclair, Christopher Bratt, and Maria-Luisa Lima
}

\subsection{Introduction}

It's been almost 50 years since the term 'ageism' was first introduced in recognition of prejudicial attitudes held towards people because of their age. Since then, research in Europe has consistently shown that more people report experiencing age prejudice and discrimination followed by prejudice based on gender, and then race or ethnic background (Abrams et al. 2011a; Abrams and Houston 2006). This trend is found in most countries in the European region with the exception of Israel and Latvia (Ayalon 2014). On average 35\% of people who took part in the European Social Survey (ESS) said they had experienced 'unfair' treatment because of their age, but these experiences of ageism differ across Europe, from 54\% in the Czech Republic to $17 \%$ in Portugal and Cyrus (Abrams et al. 2011a). Despite its relatively high prevalence, ageism is still under researched (Abrams et al. 2015) and remains a relatively accepted form of prejudice, deemed to be an inevitable part of the ageing process (Nelson 2005; Nelson 2017). Differences between countries in the prevalence of experienced ageism could be related to various contextual differences that exist for these countries. Across Europe rates of population ageing, fertility, immigration and emigration differ and are leading to changing patterns of demography (Creighton 2014). Although Europe as a whole must adapt to population ageing, changing demographic patterns across Europe, coupled with substantial socioeconomic, cultural and political differences, are likely to impact on people's experiences of ageing, and could also explain why people in some countries are more or

H. J. Swift $(\bowtie) \cdot$ D. Abrams · C. Bratt

Centre for the Study of Group Processes, School of Psychology, Keynes College, University

of Kent, Canterbury, UK

e-mail: H.J.Swift@kent.ac.uk

S. Marques · C.-M. Vauclair · M.-L. Lima

Instituto Universitário de Lisboa (ISCTE-IUL), CIS-IUL, Lisbon, Portugal

(C) The Author(s) 2018

L. Ayalon, C. Tesch-Römer (eds.), Contemporary Perspectives on Ageism,

International Perspectives on Aging 19,

https://doi.org/10.1007/978-3-319-73820-8_27 
less likely to experience ageism. Cross-national data, such as the ESS, have allowed researchers to identify some of the psychological and sociological factors associated with people's experiences of ageism.

In this chapter, we review the existing social psychological framework used to explore ageism which informed the design of the Experiences and Expressions of Ageism Module fielded in the 2008/2009 ESS. We also review the subsequent published findings and studies that have utilized the ESS data to explore how the availability of cross-national data has advanced theory and understanding of ageism across Europe. Much of this evidence uses a multilevel approach. Thus, we also explore the benefits and limitations of such an approach for understanding ageism across Europe.

\subsection{The European Social Survey}

The European Social Survey (ESS) is an academically driven cross-national survey conducted every 2 years across the European region since 2001. The survey measures attitudes, beliefs and behavior patterns in (up to) 30 nations. Each survey consists of a fixed module and two or three rotating modules. Round 4 of the survey fielded in 2008 and 2009 included a rotating module on Experiences and Expressions of Ageism (herein referred to as the Ageism Module). The module was designed by members of the EURAGE group (European Research group on Attitudes to Age) lead by Prof. Dominic Abrams (University of Kent), Prof. Luisa Lima (CIS-IUL at ISCTE-IUL) and Prof. Genevieve Coudin (University of Paris). It contains 55 items which were developed and pilot tested extensively within a framework that was subject to detailed scrutiny, peer review and evaluation by experts in the ESS Central Coordinating Team. The Ageism module provides representative samples from 29 countries and over 55,000 individuals. It uses computer-based personal interviews with national samples between 1215 and 2576 people aged 15 and over. The questions in the module reflect seven key domains including how age boundaries are defined, age identification, the content of age-based stereotypes, perceived social status, perceived threat, experiences of discrimination and the extent of intergenerational relations. The items within these domains are guided by theoretical models from social psychology theories of prejudice, including social identity and self-categorisation theory (Tajfel 1981), stereotype content model (Fiske et al. 2002), intergroup threat theory (Stephan and Stephan 2000) and intergroup contact theory (Pettigrew 1998).

This chapter introduces each of these domains and reviews key findings from published research that has used the Ageism module. The search for published research was conducted using Google Scholar in 2017. First, key search terms 'Ageism' and 'European Social Survey' were entered. The search, which was restricted to publications after 2008, resulted in 391 hits. Each article (conference proceedings, presentations were excluded) was read to make an initial judgement about its relevance. We were only interested in academic or grey literature (i.e. research published in academic journals or by government or non-government 
organizations) that used, analyzed or reported findings from the Ageism Module. We stopped the search at the point when all of the articles listed were irrelevant (page 20 of Google Scholar search). This resulted in 36 articles for review which were then categorized according to the primary or most relevant domain. Before we review the findings it important to note that many of the publications adopt a multilevel approach to analyzing ESS data.

\subsubsection{Multilevel Modelling}

The ESS data constitute individual responses that are grouped or clustered by the country they are from. This hierarchical structure (i.e. individuals grouped within countries) is conducive to multilevel modelling. Multilevel modelling is a statistical regression approach that accommodates the context in which individuals are living (Raudenbush and Bryk 2002), thus allowing for the simultaneous examination of phenomenon at both the societal (e.g. country)- and individual-level. In order to explain differences between countries, country-level (also known as macro-level) variables are used as predictors of individuals' attitudes and experiences. These can be socio-cultural, but also socio-structural contexts. The first refers to collective social phenomena such as widely shared social representations, for example, about older people's social status in society, or societal meta-perceptions (see Vauclair et al. 2016). The latter refers to structural aspects of society such as economic and political systems of the country, for instance a country's gross domestic product (GDP), level of inequality (as indicated by the GINI index) or a country's average retirement age. All of which can have an effect on different aspects of expression of prejudice and experiences of ageing.

The benefit of the multilevel approach is the examination of psychological phenomena of expressions of ageism (e.g. age stereotypes, perceived threat, perceived social status of older people) which do not emerge in social vacuum. It is known that groups and whole societies recognize and tend to share similar stereotypes and prejudices (Schaller et al. 2002) which constitute a collective reality that has an impact on older people in terms of their ageing experiences. Thus, the ESS allows for research to be conducted at two levels of analysis and therefore can independently explore effects at the individual and country-level, as well as provide insight into what kind of the combination of these factors are most likely to ameliorate or exacerbate ageism. Some of the factors might be difficult to change (e.g., a country's affluence), however, other factors might be more malleable. For instance, employment of older people may be raised through 'age quotas'. Cultural beliefs may also (slowly) change through targeted information, because culture is after all dynamic. Interventions can be targeted by taking into account the different layers of effects that produce negative age stereotyping. Furthermore, country-level findings (e.g., the effect of unemployment rates or the age ratio) can be translated to the regionallevel within countries which will be of great interest for policy-makers within 
countries in Europe. The following sections summarise the empirical studies that were identified as relevant in our review.

\subsection{Ageism in Europe}

\subsubsection{Age Categorisation}

In order to understand who is vulnerable to age discrimination it is important to understand how people define age groups. Age categorisation is the process of classifying people as belonging to a certain age group, and by implication, not belonging to other age groups. Age categorisation is highly relevant to the issue of age-based discrimination because ageism can arise in relation to specific age points, for example, the age of retirement or particular age ranges (e.g. the over 50's), but also in terms of general category labels such as 'young' or 'old' (Bytheway 2005).

Once categorisation has occurred, stereotypes associated with the category label might then be erroneously applied to the individual. This can result in discrimination, but also put individuals (particularly older adults) in a situation where they fear being 'judged' negatively in terms of their age (cf. stereotype threat, Lamont et al. 2015). Socially and psychologically the use of age categorisation can be highly problematic because it may cause people to restrict what is deemed acceptable for particular age groups based on their own or others' ageist assumptions. For example, people may be judged or they may see themselves as 'too young' or 'too old' to pursue particular activities or roles. For this reason, the very act of categorising others into different age groups and the way people define those groups has significant implications for people's choices and actions (see The Risks of Ageism Model, Swift et al. 2017).

However, understanding the process of age categorisation can be tricky. Unlike other forms of prejudice, such as racism and sexism, which are directed at fixed social categories, the boundaries that define 'old' and 'young' age groups are fluid (Bytheway 2005). In the Ageism module respondents were asked to estimate the age at which people stop being described as 'young' and to estimate the age at which people start being described as 'old'. On average, across the 29 countries, respondents perceived youth to end at 40 years and old age to begin at 62 , this may mean that people below 40 years and over 62 years are more vulnerable to age prejudice and discrimination due to their perceived 'young' or 'old' age, respectively. However, the placement of these age boundaries varies by respondent's own age, the self-categorization of their age, gender and the country in which they live (Abrams et al. 2011a; Ayalon et al. 2014; Basleven 2010), such that both perceptions of the end of youth and onset of old age increase with respondents' age. In addition, respondents who self-categorized themselves as belonging to a younger age group (relative to those who are the same chronological age) also perceived old age to start later (Basleven 2010). Women perceived the end of youth and onset of old age to be later than did men, and the end of youth was viewed as early as 34 in 


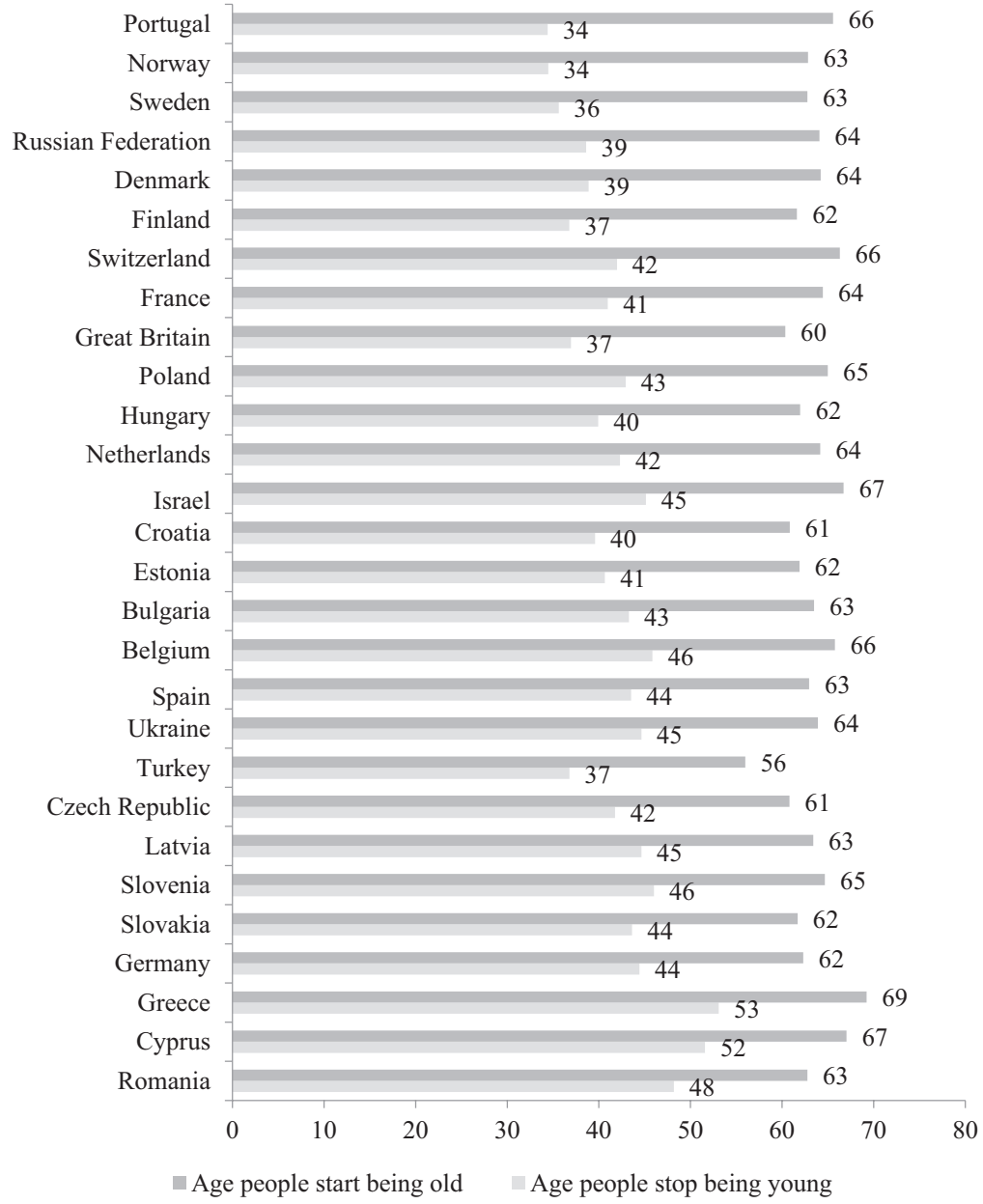

Fig. 27.1 Estimated end of youth and onset of old age

Norway, but as late as 52 in Greece, while old age was viewed as starting at 65 in Greece, but 55 in Turkey (Abrams et al. 2011a) (Fig. 27.1).

Analysis by Ayalon et al. (2014) using the full ESS data confirmed that $14 \%$ of the total variance in the perceived end of youth was associated with differences between countries, while only $5.7 \%$ of the total variance in the perceived onset of old age was associated with differences between countries. In addition to the previous study, the authors found that having better subjective health and living with a spouse or partner was also associated with perceiving the end of youth to be later, while higher levels of education, better subjective health, higher life satisfaction and sharing a residence with a spouse or partner were all associated with perceiving old age to be later. Taking a multilevel approach, Ayalon et al. (2014) also examined 
how contextual factors, such as country-level differences in life expectancy or inequality, are associated with each age-boundary. The study revealed that respondents in countries with a higher life expectancy, higher levels of inequality and a higher percentage of individuals between the ages of 15-64 were more likely to perceive the end of youth to be later. Whereas, respondents in countries with higher education and higher levels of inequality, were more likely to perceive old age to be later. However, official retirement age and fertility rates were not associated with either age boundary.

Together, this research suggests that people have different constructions of age depending on their vantage point, depending on personal, shared and interdependent social contexts of the individual, but also on some culturally shared social contexts (e.g. education, life expectancy and inequality). Understanding how age boundaries are socially constructed within societies is important because they can shape individual's social construction of what age is, and what it means to belong to a particular age group. In this way, age categorisations can impact on individuals via their own behaviours and life choices, but also by constructing attitudes towards various age groups (Swift et al. 2017).

\subsubsection{Age Identification}

One factor that is likely to influence the salience of age in social contexts, and therefore the likelihood of age categorisation processes and the subsequent application of stereotypes is age identification. Age identification is the extent to which people identify with an age category and can be an important measure of the extent to which age, and belonging to an age group informs social identity and who we are (Tajfel and Turner 1979; Tajfel 1981). Social Identity Theory states that individuals are motivated to gain positive distinctiveness for their ingroups by comparing them favourably with other groups, which can result in holding prejudice views against outgroup members. Shared age identity is assumed to denote an awareness of similarities, a feeling of solidarity towards others in the same position but this, by implication can also be a potential antagonist against those who are different. Therefore, age identity could also be an important factor in shaping generational conflict, for instance, over the distribution of resources.

The meaning of age identification can be ambiguous unless it clarifies what age people identify with. For instance, research conducted with individuals aged 65 and over revealed that those with more positive perceptions of ageing (measured by selfratings of cognitive and physical functioning tasks) typically have a more youthful age identity, i.e. participants felt younger. These individuals also had a higher level of satisfaction with their current age, perceived the onset of old-age to be later and showed more willingness to live to 100 years of age (Uotinen et al. 2003). Therefore, it cannot be assumed that age identification measures identification to chronological age, as this research demonstrates individuals can identify with their subjective age - the age they feel, which might be different from their chronological age. 
Accordingly, in the ESS, respondents were first asked to 'self-categorize' themselves by picking a box from a card with nine possible options laid out horizontally. The first three boxes (A, B and C) were described as 'young', the next three (D, E and F) as 'middle' and the final three ( $\mathrm{G}, \mathrm{H}$, and J) as 'old'. Respondents were asked 'which box best describes the age group you see yourself as belonging to? If you see yourself as very young, pick the first box. If you see yourself as very old, pick the last box. Otherwise pick one of the boxes in between. Fitzgerald et al. (2010) analysis of this item (for UK only) revealed that the oldest 'young' category and the two younger 'middle-aged' categories were most popular accounting for half of the responses from respondents aged 18 to 59. Interestingly, around half of those in their 40s (49\%) and 50s (52\%) chose the mid-point of the "middle" category on the scale (E). Perhaps this reflects a desire to be perceived as precisely in mid-life, aware that 'young' is no longer an option but not ready yet to accept being labelled 'old'. Most notably, 25\% of respondents aged 70 and over defined themselves as 'middle aged' and only a small minority (14\%) choose the highest "old" label (J). Importantly, the analysis by Fitzgerald et al. (2010) suggests two things; (1) people of the same age do not necessarily identity with the same age group, and (2) many people chose to identify with an age group that is 'younger' than what might be assigned according to chronological age.

In the ESS, respondents were then asked whether they had a weak or strong sense of belonging to the age group they had chosen, using a scale from 0 ("very weak sense of belonging') to 10 ('very strong sense of belonging'). Analysis of this item, has tended to find the relationship between age, self-categorized age and age identification to be a curvilinear ' $U$ ' shape, with younger and older age groups showing stronger identification to their respective age groups (Abrams et al. 2011a, b; Fitzgerald et al. 2010; Marques et al. 2014a). This suggests that age identification is more important for younger and older age groups, or that age identity is more salient for these age groups, perhaps due to transitional changes occurring around them (e.g. becoming a young adult or moving into retirement). It could also suggest that these age groups are more likely to be motivated to maintain a positive distinction and therefore, more likely to hold ageist attitudes against one another, which in turn means people belonging to these age-groups may be more vulnerable to agediscrimination from other age groups.

However, social identity also can have important positive consequences for selfesteem, health and wellbeing (Whitbourne and Sneed 2002; Marques et al. 2014a) and the literature thus far, has mostly been concerned with exploring how older adults are able to maintain a high level of age identification, self-esteem and wellbeing in later life, despite the existence of ageism and other negative perceptions associated with ageing (e.g. paradox of wellbeing, Swift et al. 2013; Whitbourne and Sneed 2002). Research suggests a positive age-identity is one mechanism by which older adults are able to maintain positive self-esteem, sense of self and wellbeing. The other mechanisms include having a developed set of coping mechanisms, having the ability to select emotionally rewarding social partners (see socio-emotional selectivity theory, Carstensen 1992) and being able to shift goals and standards to what is achievable in later life (e.g. accommodation; Whitbourne and Sneed 2002). 
Research exploring the associations of age identity on older people has been mixed. For instance, older individuals who perceived themselves as "old" also rated their health as poorer than older individuals who perceived themselves as younger (Stephan et al. 2012). But, in a study of 60 people aged 64 and over, Garstka et al. (2004) showed that when older people are faced with age discrimination, increasing their identification with their age group may be an important "fighting" strategy to increase well-being. However, the impact of social identification on self-esteem, health and wellbeing is dependent particularly on the perception of the social status associated with the group (Ellemers 1993; Ellemers et al. 1988; Tajfel and Turner 1979). In line with this, research using the ESS data suggests that these mixed effects of age identification are because age identity can confer a positive or negative image of ageing, depending on the perceived social status of older people (Marques et al. 2014a).

\subsubsection{Social Status}

The status of a group is determined by its relative place or position in society (Parsons 1951). In the ESS, social status refers to prestige, social standing or position ascribed to individuals that mark their position in a given social system. Evidence form the ESS demonstrates that people in their 40s are perceived to have the highest status, followed by people in their 20s and people over 70 are perceived to have the lowest status (Abrams et al. 2011a). Understanding social status is important because ageism is partly driven by societal representations of older people as being inferior to middle-aged people in terms of power and social status, wealth, respect and influence (Garstka et al. 2004). These perceptions determine how we deal and interact with members of these groups, and how we feel and identify with our own social groups.

In our recent paper, we argue that in order to understand the impact of age identification on older people's self-reported health, we have to understand the role played by the perceived social status of old age group in society (Tajfel and Turner 1986; Marques et al. 2014a). For instance, older people's subjective evaluation of their social status is negatively associated with their self-rated health, depression and long-standing illness (Demakakos et al. 2008; cf. Hu et al. 2005). According to Wilkinson (1996) the perceptions of one's place in the social hierarchy are linked with negative emotions (i.e., feeling of shame) and may influence fundamental health outcomes via neuroendocrine mechanisms. Belonging to a subordinate category potentially confers a negative social identity which can have negative conse-

quences for self-esteem and well-being. On the other hand, belonging to a high-status category creates feelings of pride and positive outcomes for one's self-esteem. Therefore, the effects of age identity on self-esteem and subjective-health (i.e. selfrated perception of health) are very much dependent on the social standing or posi- 
tion of that group in society. Our analysis of a subsample of respondents aged 70 and over revealed that perceived status moderates the negative effect of age identification on older people's subjective health. Firstly, if age identification is high, there is a greater impact of social status on subjective health. Secondly, age identification is negatively related to subjective health in countries where older people are perceived to have lower status (Marques et al. 2014a). In countries where old age is perceived as signifying low status, just acknowledging that one is old is likely to present real risks to one's health, a possibility that is rarely considered in health policy but should be considered by public policy addressing health issues (WHO 2002). The research provides an important theoretical contribution by demonstrating that the perceived social status of people over 70 is an important determinant of the extent to which age identification has negative consequences on older people's subjective health and clarifies some previously mixed evidence concerning the effects of age identification.

Although, across ESS countries there is a general consensus that people aged 70 and over are considered to have lower social status, there are considerable differences depending upon the perceivers' age and also between European countries. For instance, the perceived social status of people aged 70 and over increases with respondents age (Abrams et al. 2011b; Marques et al. 2014a), which is likely to be due to increasing motivation to gain positive distinctiveness for the next age group they will belong to. There are also considerable cross-country differences in the amount of status afforded to older people. For instance, in the ESS $16.27 \%$ of the total variance in the perceived social status of people over 70 was associated with differences between countries (Vauclair et al. 2014b). Our research findings also show that societal perceptions of older people's status are positively related to crosscountry differences in Gross Domestic Product (GDP), state pension age, the societal emphasis on autonomy values and levels of social inequality indicated by the GINI index (Abrams et al. 2011b). Furthermore, a separate analysis revealed that both societal modernisation (a sociological construct referring to profound economic, social and cultural transition from 'pre-modern', 'traditional' societies to 'modern' societies, indicated by the Human Development Index) and levels of employment of people aged 65 and over are positively associated to the perceived status of people over 70. However, these two factors also interact with each other. The perception of older people's status is boosted in less modern societies if there is a relatively high employment rate of people aged 65 and over indicating that their active contribution to the economy is credited with more positive representations (Vauclair et al. 2014b). The finding suggests that maintaining the employment of older people may be an important factor determining their personal living standards and providing more positive representations of the status of older people across society. Moreover, low social status of people over 70 can be particularly problematic for older people who identify with their age, as this can have a stronger negative effect on health. 


\subsubsection{Age Stereotypes}

Research suggests that there are multiple representations and stereotypes of ageing, which vary in the extent to which they are negative and positive. For instance, research from the US, UK and across Europe has continued to suggest that older people are stereotyped as frail, ill, dependent and incompetent (Levy 2009; Marques et al. 2014b, Coudin and Alexopoulos 2010), but also wise, experienced and more moral than younger adults (Levy 1996; Swift et al. 2013; Abrams et al. 2011a). Several studies have explored age-related stereotypes across age and cultural groups. Many of the negative and positive representations of ageing can be captured within the stereotype content model, which has been supported by over 10 years of national and international research. It proposes that younger and older age groups can be evaluated along two basic dimensions of competence and warmth (otherwise referred to as friendliness; Fiske et al. 2002; Cuddy et al. 2005). Work conducted in the UK and across Europe, (e.g., Abrams et al. 2009, 2011a; Vauclair et al. 2010) has shown repeatedly that older people are stereotyped with a mixed representation of high warmth (positive), but low competence (negative). This mixed representation results in feeling pity for older people, thus society holds 'benevolent' or patronising 'doddery but dear' views of older people (Cuddy et al. 2005) -older people are liked but often patronised and not given power or voice because of their perceived low status and declining competence. In contrast, younger targets are characterised by high competence, but relatively low warmth. This is also a mixed perception, but results in feelings of envy and underpins a more hostile form of prejudice (Fiske et al. 2002). Thus, the stereotype content model does provide a framework that proposes that different societal representations of younger and older adults informs the expressions of prejudices and types of discrimination they are likely to experience. In the ESS, the stereotype content items were presented as meta-perceptions, i.e. they asked 'to what extent do you think other people think people over 70 are viewed as...competent, friendly'. Therefore, they represent a view and perspective that is thought to be widely shared by others.

The literature search found three papers that explored the role of stereotypes. The first described here, explored the extent to which competence and warmth moderate determinants of job satisfaction. Using data from Round 4 and 5 of the ESS, the research conducted by Shiu et al. (2015) was primarily interested in exploring how extrinsic rewards (e.g. job security and opportunity for career advancement) and intrinsic rewards (e.g. task discretion and work pressure) relate to job satisfaction. It also hypothesized that each of these relationships should be moderated by societal views of older people's competence, such that in countries where there is a shared meta-perception that older adults are less competent, there would be a stronger effect of job security on job satisfaction, a stronger negative effect of work pressure on job satisfaction and a weaker effect of opportunity for advancement on job satisfaction. It also hypothesized that societal views of older people as warm and friendly should moderate the relationship between work pressure and job satisfaction, such that the negative relationship between work pressure and job satisfaction should be 
stronger for older workers in countries where people over 70 are perceived as more warm and friendly. Based on Gouldner's (1960) norm of reciprocity, the authors suggest meta-perceptions of older people to be warm and friendly places expectations and work pressures on older workers to be more sociable, leading to lower job satisfaction. The multilevel analysis revealed that country-level competence and warmth (aggregated ESS data from Round 4) moderated the effect of work pressure on job satisfaction in the predicted direction, but also found that the relationship between opportunity for advancement and job satisfaction is stronger in countries where older people are perceived as less warm. No other hypotheses were confirmed and there was no support for moderating effects of competence on job security, opportunity for advancement or task discretion.

However, relatedly, the second paper found that perceptions of people aged 70 and over as competent are significantly predicted by participation of older people in paid and volunteer work (Bowen and Skirbekk 2013). The final paper explored the extent to which personal meta-perceptions predict experiences of ageism, using data from respondents aged 70 and over. It revealed that personal meta-perceptions of negative age stereotypes and specific intergroup emotions (pity, envy, contempt) are associated with higher perceived age discrimination. However, at the country-level, only paternalistic meta-perceptions (i.e. warmth and pity) were consistently associated with greater perceived age discrimination (Vauclair et al. 2016).

In sum, given the theoretical connection between stereotypes, prejudice and discrimination, it is important to establish the role of personal and societal metaperceptions (i.e. those perceptions and views held by individuals and those aggregated to the country-level). The research reveals the importance of countering age-stereotypes at each of these levels, thus effective counter-ageism strategies need to be directed towards and change individual's perceptions but also collective societal perceptions (Vauclair et al. 2016).

\subsubsection{Feelings of Prejudice}

The ESS includes both direct and indirect measures of prejudice. Two direct measures ask respondents to rank on a 0-10 scale "how negative or positive you feel towards people in their 20s / 70s". In general, respondents reported positive feelings towards older and younger age groups, however, these feelings do vary across Europe, with respondents in Turkey reporting the most negative feelings towards people in their 70s and respondents from Latvia and Finland reporting the most positive feelings. A difference score created by Ayalon (2013) indicated in general more positive feelings towards older than younger adults, with only three countries reporting more positive feelings towards younger (Turkey, Greece and Croatia), but an intraclass correlation coefficient of $2.3 \%$ revealed little cross-country variability. On the surface, this finding is inconsistent with the common assumption in the literature that older people are the foremost targets of ageism (see Nelson 2017). 
Usefully, the ESS data allows us to make comparisons between the degree to which people hold age-prejudices with the reported experiences of discrimination (i.e. the degree to which people are targeted by discriminatory behaviors or practices because of age), and reveals a discrepancy; despite widely shared positive feelings towards younger and older people, there is a relatively high prevalence of age discrimination. However, direct measures of prejudice should be interpreted with some caution as people may not be willing to admit having feelings of prejudice towards older or younger people (Abrams 2010). To overcome this, the ESS also included two indirect measures of prejudice by assessing the extent to which people are internally and externally motivated to be unprejudiced (Plant and Devine 1998).

In an extensive exploration of how individual meta-perceptions, societal metaperceptions and norms of intolerance predict older people's experiences of ageism, Vauclair et al. (2016) revealed that in countries in which people think that it is important to be unprejudiced towards other age groups, older people reported experiencing less age discrimination. Moreover, social norms of intolerance of age prejudice had a larger statistical effect on perceptions of age discrimination compared to other societal meta-perceptions, including the perceived status, warmth and competence of people aged 70 and over. The analysis suggests that social norms that promote intolerance to prejudice are an important factor to improve older people's experiences of ageing.

\subsubsection{Experiences of Discrimination}

In order to understand the extant and prevalence of ageism it is important to ask people whether they have experienced age discrimination. The Ageism module contains three items to explore this issue, one of these measures can be compared to reported experiences based on gender or ethnicity. The other two items allow us to understand experiences of specific forms of discrimination, such as blatant discriminatory acts (e.g. bad treatment) and more subtle behaviours (e.g. patronizing behaviour or neglect). Importantly, these items coupled with advances in statistical analysis, allow us to explore experienced of age discrimination across countries (Trusinova 2014) and age (Bratt et al. 2018). A recent study used these three items to (1) investigate measurement invariance for perceived age discrimination across countries and across age and (2) to investigate levels of perceived age discrimination across age (Bratt et al. 2018). The study concluded that the three items have sufficient measurement invariance across countries and across age to merit conclusions about levels of perceived age discrimination. The analysis uncovered substantial perceived age discrimination not only among older people, but even more so among younger people. The consistency and international scope of the evidence from the ESS strongly challenges the conventional wisdom that ageism is primarily a problem for the old. Rather, it affects all ages and the relationship between them. The study concluded that more research is required to understand ageism toward 
younger people and to consider developmental differences and changes over the lifespan.

Using a stepwise linear regression approach Van den Heuvel and van Santvoort (2011) revealed that gender, education, income, belonging to an ethnic minority, life satisfaction, subjective health status, trust in other people and the perceived seriousness of age discrimination in the country, are all related to experiences of age discrimination in a subsample of ESS respondents aged 62 years and over. Interestingly, using ESS data from Round 4, Meeusen and Kern (2016) investigated the generalizability of five types of prejudice (prejudice directed towards immigrants, homosexuality, age-groups, unemployed, and gender) and revealed they were positively related, such that if an individual holds negative attitudes towards one target group, they are also likely to hold prejudicial attitudes towards other target groups as well. This could indicate that any counter-prejudice and discrimination interventions are likely to have spill-over effects for reducing prejudicial attitudes towards other social groups not specifically targeted by an intervention.

\subsubsection{Perceived Threat}

Some theories of prejudice also contend that negative attitudes towards social groups are associated with the perception that these groups pose various types of threat (e.g. Intergroup Threat Theory, ITT Stephan and Stephan 2000; Riek et al. 2006). These include symbolic threat, the threat to people's values, culture and way of life and economic threat, the extent to which economic outcomes of one group might be burdened or dependent on those of a different group. Evidence from the ESS demonstrates that older age groups pose greater threats to the economy by being a burden on health care and welfare resources by being perceived to contribute little to the economy (Abrams et al. 2009, 2011a).

Perceptions of threat change with age. Younger people are more likely to perceive older adults as being a threat to the economy (Abrams et al. 2011a, b). However, older people themselves perceive other older people as being a burden on health care resources. Perceptions of threat also depend on the cultural context. Higher state pension age is associated with lower perceived threat to health care resources, GDP, autonomy values and inequality are associated with reduced perception of economic threat (Abrams et al. 2011b).

Perceived threat in the form of the economic contribution of older people has been associated with older people's participation in entrepreneurship and innovation. Using a subsample of the Eurobarometer of respondents aged between 50 and 74 , Kautonen (2012) found that the perceived economic contribution of people over 70 (a macro-level contextual variable derived by aggregating the ESS data) was significantly, negatively related to the probability of an individual thinking about becoming an entrepreneur. In other words, people over 50 seem to be inclined towards considering entrepreneurship in countries where older people are perceived to contribute less to the economy. Kautonen (2012) suggests that a positive 
perception of the economic contribution of people aged 70 and over in a country may lead to reduced ageism in the workplace and, therefore, a higher demand of the services of older workers in the labour market, both of which decrease the relative attraction of starting a business.

\subsubsection{Intergenerational Relations}

An important indicator of social inequality and prejudice is the degree to which social groups share the same goals and values and the degree to which they understand each other. The 'Common ingroup identity' model (Gaertner and Dovidio 2000) shows that prejudice can be reduced when people perceive they belong to one common group, or belong to different groups that share an overarching community. ESS respondents were asked how they saw people in their 20s and people over 70 . On average, across the European Region, respondents were more likely to view people in their 20 s and 70 s as two separate groups within the same community (49\%), 29\% thought that people in their 20s and 70s should be seen as individuals, $10 \%$ though they belonged to one group, while $12 \%$ thought people in their 20 s and 70 s belonged to two separate groups who were not part of the same community.

A large number of studies in social psychology (see Pettigrew 1998) have shown that experiences of positive contact between members of different groups lead to positive inter-group attitudes and relations. Specifically, the theories about intergroup contact suggest that positive personal relationships, especially friendship with members of other groups, are important determinants for reducing prejudice between different groups. Thus, the degree and type of contact are relevant indicators of exclusion and discrimination of different age groups in a given society (c.f. Schneider 2004). To get a sense of whether respondents have meaningful voluntary interactions with people from different age groups, ESS respondents were asked how many friends, other than family members, they had under the age of 30 and over the age of 70 - age boundaries which most people would regard as clearly distinguishing between young and old. Across the ESS 52\% of respondents said they did not have a friend over the age of 70 , compared to $31 \%$ who said they did not have a friend under the age of 30 . The number of respondents who reported having friendships with people under 30 and people over 70 varied by respondents' age group. Those aged between 15 and 24 were more likely to have other friends under $30,80 \%$ stated they had no friends over the age of 70 . People over the age of 70 were more likely to have friendships with those also over the age of 70 , but over half of these respondents $(70 \%)$ said they had no friends under the age of 30 (Abrams et al. 2011a).

Dykstra and Fleischmann (2016a) explored predictors of cross-age friendships. As predicted by the 'meeting principle', individuals who operate in settings where there are opportunities for meaningful interactions with people belonging to a different age group, (e.g. age-diverse work places, religious communities and having close 
ties with different generational family members) are more likely to have cross-age friendships. In addition, individuals with more favourable attitudes towards other age groups are more likely to have cross-age friendships, which supports intergroup contact theory. In a separate analysis Dykstra and Fleischmann (2016b) contend that having greater capacity to 'actively age' i.e. greater independence, health, security, might create greater opportunities for meaningful intergenerational interactions. However, the active ageing index, developed by Zaidi et al. (2013) which assesses experiences and potential for active ageing across four domains of employment, social participations, independent living and capacity for active ageing (as a countrylevel predictor) was not found to be associated with the development of intergenerational friendships (Dykstra and Fleischmann 2016a). This suggests that to improve contact between generations interventions should focus on proving opportunities to interact within people's immediate environments.

\subsection{Conclusions}

The ESS data on ageism provide a framework for understanding people's attitudes to age, and their experiences of age discrimination. The data provide evidence based indicators that can inform policy on issues surrounding age equality and antidiscriminatory legislation for individual countries but also at the European region level. They also provide an insight into avenues for tackling some of the issues that affect older people and all of us as we age, such as negative attitudes to age, isolation and exclusion. There is great value in cross-national data such as the ESS. Thus far, the ESS data have been important for (a) understanding people's experiences of growing older, (b) understanding processes that contribute to age discrimination, such as how age groups are perceived throughout the life course and (c) understanding how people's experiences influence their perceptions of age, or how their perceptions of age influence their experiences. Moreover, multilevel approaches to the analysis of ESS data have made significant theoretical and practical contributions to disciplines concerned about ageism and issues associated with ageing, such as, social psychology, sociology, social gerontology, social policy and business studies.

\section{References}

Abrams, D., Eilola, T., \& Swift, H. (2009). Attitudes to age in Britain 2004-08 (Department of Work and Pensions, Research Report No. 599). Crown 2009.

Abrams, D., \& Houston, D. (2006). Equality, diversity and prejudice in Britain: Results from the 2005 survey. Report to the cabinet office equalities review, Centre for the Study of Group Processes. Canterbury: University of Kent.

Abrams, D., Russell, P. S., Vauclair, C.-M., \& Swift, H. (2011a). Ageism in Europe: Findings from the European Social Survey. London: Age UK. 
Abrams, D., Swift, H. J., Lamont, R. A., \& Drury, L. (2015). The barriers to and enablers of positive attitudes to ageing and older people, at the societal and individual level. Foresight government Office for Science. Retrieved from https://www.gov.uk/government/uploads/system/ uploads/attachment_data/file/454735/gs-15-15-future-ageing-attitudes-barriers-enablers-er06. pdf

Abrams, D., Vauclair, C.-M., \& Swift, H. (2011b). Predictors of attitudes to age in Europe (Department of Work and Pensions, Research Report No. 735). Crown 2011.

Abrams, D. (2010). Processes of prejudice: Theory, evidence and intervention (Research Report 56). London: Equality and Human Rights Commission.

Ayalon, L. (2013). Feeling towards older vs. younger adults: Results from the European Social Survey. Educational Gerontology, 39, 888-901. https://doi.org/10.1080/03601277.2013.7676 20

Ayalon, L. (2014). Perceived age, gender, and racial/ethnic discrimination in Europe: Results from the European social survey. Educational Gerontology, 40, 499-517. https://doi.org/10.1080/0 3601277.2013.845490

Ayalon, L., Doron, I., Bodner, E., \& Inbar, N. (2014). Macro-and micro-level predictors of age categorization: Results from the European social survey. European Journal of Ageing, 11, 5-18. https://doi.org/10.1007/s10433-013-0282-8

Basleven, C. (2010). Self-perceived age categorisation as a determinant of the old age boundary. Economic Bulletin, 30, 1994-2001. Available online https://core.ac.uk/download/pdf/6251064. pdf

Bowen, C. E., \& Skirbekk, V. (2013). National stereotypes of older people's competence are related to older adults' participation in paid and volunteer work. The Journals of Gerontology Series B: Psychological Sciences and Social Sciences, 68, 974-983. https://doi.org/10.1093/ gerontb/gbt10

Bytheway, B. (2005). Ageism and age categorization. Journal of Social Issues, 61, 361-374. https://doi.org/10.1111/j.1540-4560.2005.00410.x

Bratt, C., Abrams, D., Swift, H. J., Vauclair, C.-M., \& Marques, S. (2018). Perceived age discrimination across age in Europe: From an ageing society to a society for all ages. Developmental Psychology, 54(1), 167-180.

Carstensen, L. L. (1992). Social and emotional patterns in adulthood: Support for socioemotional selectivity theory. Psychology and Aging, 7, 331-338. https://doi. org/10.1037/0882-7974.7.3.331

Coudin, G., \& Alexopoulos, T. (2010). 'Help me! I'm old!' how negative aging stereotypes create dependency among older adults. Aging \& Mental Health, 14, 516-523. https://doi. org/10.1080/13607861003713182

Creighton, H. (2014). Europe's ageing demography (ILC-UK 2014 EU Factpack). London: International Longevity Centre- UK.

Cuddy, A. J. C., Norton, M. I., \& Fiske, S. T. (2005). This old stereotype: The pervasiveness and persistence of the elderly stereotype. Journal of Social Issues, 61, 267-285. https://doi. org/10.1111/j.1540-4560.2005.00405.x

Demakakos, P., Nazroo, J., Breeze, E., \& Marmot, M. (2008). Socioeconomic status and health: The role of subjective social status. Social Science \& Medicine, 67, 330-340.

Dykstra, P. A., \& Fleischmann, M. (2016a). Cross-age friendship in 25 European countries. Studi di Sociologia, LIV(2), 107-125. Retrieved from http://hdl.handle.net/1765/93004

Dykstra, P. A., \& Fleischmann, M. (2016b). Are societies with a high value on the active ageing index more age-integrated? In A. Zaidi, S. Harper, K. Howse, G. Lamura, \& J. Perek-Biala (Eds.), Building evidence for active ageing policies: Active ageing index and its potential. London: Palgrave Macmillan.

Ellemers, N. (1993). The influence of socio-structural variables on identity management strategies. In W. Stroebe \& M. Hewstone (Eds.), European review of social psychology (Vol. 4, pp. 27-58). New York: Wiley. 
Ellemers, N., Van Knippenberg, A., De Vries, N., \& Wilke, H. (1988). Social identification and permeability of group boundaries. European Journal of Social Psychology, 18, 497-513.

ESS Round 4: European Social Survey Round 4 Data. (2008). Data file edition 3.0. Norwegian social science data services, Norway - Data archive and distributor of ESS data.

Fiske, S. T., Cuddy, A. J. C., Glick, P., \& Xu, J. (2002). A model of (often mixed) stereotype content: Competence and warmth respectively follow from perceived status and competition. Journal of Personality and Social Psychology, 82, 878-902. https://doi.org/10.1037//0022-3514.82.6.878

Fitzgerald, R., Harrison, E., \& Steinmaier, F. (2010). Chapter 8. Age identity and conflict: Myths and realities. In British social attitudes survey, 2011. London: Sage.

Gaertner, S. L., \& Dovidio, J. F. (2000). Reducing intergroup bias: The common in-group identity model. New York/London: Routledge/Taylor \& Francis Group.

Garstka, T. A., Schmitt, M. T., Branscombe, N. R., \& Hummert, M. L. (2004). How young and older adults differ in their responses to perceived age discrimination. Psychology and Aging, 19, 326-335. https://doi.org/10.1037/0882-7974.19.2.326

Gouldner, A. W. (1960). The norm of reciprocity: A preliminary statement. American Sociological Review, 25, 161-178.

Hu, P., Adler, N. E., Goldman, N., Weinstein, M., \& Seeman, T. E. (2005). Relationship between subjective social status and measures of health in older Taiwanese persons. Journal of the American Geriatrics Society, 53, 483-488. https://doi.org/10.1111/j.1532-5415.2005.53169.x

Kautonen, T. (2012). Do age-related social expectations influence entrepreneurial activity in later life? Entrepreneurship and Innovation, 13, 179-187. https://doi.org/10.5367/ijei.2012.0083

Lamont, R. A., Swift, H. J., \& Abrams, D. (2015). A review and meta-analysis of age-based stereotype threat: Negative stereotypes, not facts, do the damage. Psychology \& Aging, 30, 180. https://doi.org/10.1037/a0038586

Levy, B. (1996). Improving memory in old age through implicit self-stereotyping. Journal of PersonalityandSocialPsychology, 71,1092-1107.https://doi.org/10.1037/0022-3514.71.6.1092

Levy, B. (2009). Stereotype embodiment. Current Directions in Psychological Science, 18, 332336. https://doi.org/10.1111/j.1467-8721.2009.01662.x

Marques, S., Swift, H. J., Vauclair, C.-M., Lima, M.-L., Bratt, D., \& Abrams, D. (2014a). Being old and ill' across different countries: Social status, age identification and older people's subjective health. Psychology and Health, 30, 699. https://doi.org/10.1080/08870446.2014.938742

Marques, S., Lima, M. L., Abrams, D., \& Swift, H. (2014b). Will to live in older people's medical decisions: Immediate and delayed effects of aging stereotypes. Journal of Applied Social Psychology, 44, 399-408. https://doi.org/10.1111/jasp.12231

Meeusen, C., \& Kern, A. (2016). The relation between societal factors and different forms of prejudice: A cross-national approach on target-specific and generalized prejudice. Social Science Research, 55, 1-15. https://doi.org/10.1016/j.ssresearch.2015.09.009

Nelson, T. D. (2005). Ageism: Prejudice against our feared future self. Journal of Social Issues, 61, 207-221. https://doi.org/10.1111/j.1540-4560.2005.00402.x

Nelson, T. (Ed.). (2017). Ageism: Stereotyping and prejudice against older persons. Cambridge, MA: Massachusetts Institute of Technology.

Parsons, T. (1951). The social system. New York: Free Press.

Pettigrew, T. (1998). Intergroup contact theory. Annual Review of Psychology, 49, 65-85. https:// doi.org/10.1146/annurev.psych.49.1.65

Plant, E., \& Devine, P. (1998). Internal and external motivation to respond without prejudice. Journal of Personality and Social Psychology, 75, 811-832.

Raudenbush, S. W., \& Bryk, A. S. (2002). Hierarchical linear models. Thousand Oaks: Sage.

Riek, B. M., Mania, E. W., \& Gaertner, S. L. (2006). Intergroup threat and outgroup attitudes: A meta-analytic review. Personality and Social Psychology Review, 10, 336-353. https://doi. org/10.1207/s15327957pspr1004_4

Schaller, M., Conway, L. G., III, \& Tanchuk, T. L. (2002). Selective pressures on the once and future contents of ethnic stereotypes: Effects of the communicability of traits. Journal of Personality and Social Psychology, 82, 861-877. https://doi.org/10.1037/0022- 
Schneider, D. J. (2004). The psychology of stereotyping. New York: Guilford Press.

Shiu, E., Hassan, L. M., \& Parry, S. (2015). The moderating effects of national age stereotyping on the relationships between job satisfaction and its determinants: A study of older workers across 26 countries. British Journal of Management, 26, 255-272. https://doi. org/10.1111/1467-8551.12091

Stephan, Y., Demulier, V., \& Terracciano, A. (2012). Personality, self-rated health, and subjective age in a life-span sample: The moderating role of chronological age. Psychology and Aging, 27, 875. https://doi.org/10.1037/a0028301

Stephan, W. G., \& Stephan, C. W. (2000). An integrated threat theory of prejudice. In S. Oskamp (Ed.), Reducing prejudice and discrimination. Mahwah: Lawrence Erlbaum Associates.

Swift, H. J., Abrams, D., Lamont, R. A., \& Drury, L. (2017). The risks of ageism model: How ageism and negative attitudes toward age can be a barrier to active aging. Social Issues Policy Review, 11, 195-231. https://doi.org/10.1111/sipr.12031

Swift, H. J., Abrams, D., \& Marques, S. (2013). Threat or boost? Social comparison affects older people's performance differently depending on task domain. Journal of Gerontology Series B Psychological Sciences and Social Sciences, 68, 23-30. https://doi.org/10.1093/geronb/gbs044

Tajfel, H. (1981). Human groups and social categories. Cambridge: Cambridge University Press.

Tajfel, H., \& Turner, J. C. (1979). An integrative theory of intergroup conflict. In W. G. Austin \& S. Worchel (Eds.), The social psychology of intergroup relations (pp. 33-47). Monterey: Brooks/Cole.

Tajfel, H., \& Turner, J. C. (1986). The social identity theory of intergroup behavior. In S. Worchel \& W. Austin (Eds.), Psychology of intergroup relations (pp. 33-48). Chicago: Nelson-Hall.

Trusinova, R. (2014). No two ageism are the same: Testing measurement invariance in ageism experience across Europe. International Journal of Social Research Methodology, 17, 659675. https://doi.org/10.1080/13645579.3013.823003

Uotinen, V., Suutama, T., \& Ruoppila, I. (2003). Age identification in the framework of successful ageing. A study of older Finnish people. International Journal of Ageing and Human Development, 56, 173-195. https://doi.org/10.2190/6939-6W88-P2XX-GUQW

Van den Heuvel, W. J. A., \& van Santvoort, M. M. (2011). Experienced discrimination amongst European old citizens. European Journal of Ageing, 8, 291-299. https://doi.org/10.1007/ s10433-011-0206-4

Vauclair, C. M., Abrams, D., \& Bratt, C. (2010). Measuring attitudes to age in Britain: Reliability and validity of the indicators (Working paper 90). Department for Work and Pensions. Crown, London. Retrieved from https://core.ac.uk/download/pdf/10635076.pdf?repositoryId=57

Vauclair, C.-M., Marques, S., Lima, M.-L., Abrams, D., Swift, H., \& Bratt, C. (2014a). Perceived age discrimination as a mediator of the association between income inequality and older people's self-rated health in the European region. The Journals of Gerontology Series B: Psychological Sciences and Social Sciences, 70, 901. https://doi.org/10.1093/geronb/gbu066

Vauclair, C.-M., Marques, S., Lima, M.-L., Bratt, C., Swift, H. J., \& Abrams, D. (2014b). Subjective social status of older people across countries: The role of modernization and employment. The Journals of Gerontology Series B: Psychological Sciences and Social Sciences, 70, 650. https:// doi.org/10.1093/geronb/gbu074

Vauclair, C.-M., Lima, M.-L., Abrams, D., Swift, H. J., \& Bratt, C. (2016). What do older people think what others think of them and does it matter? The role of meta-perceptions, metaaccuracy and societal norms in the prediction of experiences of age discrimination. Psychology \& Aging, 31, 699-710. https://doi.org/10.1037/pag0000125

Whitbourne, S. K., \& Sneed, J. R. (2002). The paradox of well-being, identity processes, and stereotype threat: Ageism and its potential relationships to the self in later life. In T. Nelson (Ed.), Ageism: Stereotyping and prejudice against older persons (pp. 247-273). Cambridge, MA: MIT Press.

Wilkinson, R. G. (1996). Unhealthy societies. The afflictions of inequality. London/New York: Routledge. 
World Health Organization. (2002). Active ageing: A policy framework. Geneva: World Health Organization.

Zaidi, A., Gasior, K., Hofmarcher, M.M., Lelkes, O., Marin, B., Rodrigues, R., Schmidt, A., Vanhuysse, P., \& Zolyomi, E. (2013, March). Active ageing index 2012: Concept methodology and final results (EC/UNECE, Active Ageing Index Project, UNECE Grant ECE/ GC/2012/003). European Centre for Social Welfare Policy and Research, Vienna. Retrieved from http://www.euro.centre.org/data/1453740620_84975.pdf

Open Access This chapter is licensed under the terms of the Creative Commons Attribution 4.0 International License (http://creativecommons.org/licenses/by/4.0/), which permits use, sharing, adaptation, distribution and reproduction in any medium or format, as long as you give appropriate credit to the original author(s) and the source, provide a link to the Creative Commons license and indicate if changes were made.

The images or other third party material in this chapter are included in the chapter's Creative Commons license, unless indicated otherwise in a credit line to the material. If material is not included in the chapter's Creative Commons license and your intended use is not permitted by statutory regulation or exceeds the permitted use, you will need to obtain permission directly from the copyright holder. 


\title{
Chapter 28 \\ Measures of Ageism in the Labour Market in International Social Studies
}

\author{
Liili Abuladze and Jolanta Perek-Białas
}

\subsection{Introduction}

Because the population is ageing, the workforce is also ageing, and ageism in the workplace has become increasingly evident. Measuring and analysing ageist attitudes, values, and perceptions among the general population is a more common practice than researching ageism in the workplace or in the labour market (e.g., Ayalon 2013). However, there are some good examples of research on ageism in the labour market (for some general studies see Phillipson 2004; Taylor and Walker 1998).

It is important to acknowledge that the lives of older adults and their ageing experiences are not fixed but fluid, dialectical, contextual, and changeable through human actions (Calasanti 1996). This is especially important in the labour market context, because of the tendency of ascribing fixed or inherent characteristics to older working people that may hinder working. A more detailed picture of older workers and retirement will help lead to a better understanding of many facets of ageism. Combining research on ageism in general and research on ageism in the labour market could help inspire new theoretical frameworks on these issues.

In the current chapter, ageism is firstly seen in prejudiced attitudes towards older people and their participation in the labour force. Ageism can be encountered in job seeking and hiring practices (Karpińska et al. 2011), in the workplace (Duncan 2003), in retention of workforce (Perek-Białas and Turek 2012), and in retirement

\footnotetext{
L. Abuladze $(\bowtie)$

Estonian Institute for Population Studies, Tallinn University, Tallinn, Estonia

e-mail: liili@tlu.ee

J. Perek-Białas

Jagiellonian University, Krakow, Poland

Warsaw School of Economics, Warsaw, Poland

(C) The Author(s) 2018

L. Ayalon, C. Tesch-Römer (eds.), Contemporary Perspectives on Ageism, International Perspectives on Aging 19,

https://doi.org/10.1007/978-3-319-73820-8_28
} 
practices (McNair 2006). Ageism in the labour market participation phase can manifest in cases when older people are not re-trained for or considered for jobs that require new types of skill sets in specific economic sectors, such as the high-tech or IT industries.

Much of the debate about older people in the labour market context centres on their productivity decline (Skirbekk 2004). Employers usually value the loyalty and experience of older workers, but often have doubts about their adaptability and learning capability (Solem 2015; Turek and Perek-Białas 2013). Specifically, managers often see older workers as resistant to innovation (Conen et al. 2011a; Henkens 2005). Such prejudices become even more of a concern given the technological advancements and emergence of the digital market in Europe, and may hold older adults back from acquiring new skills and knowledge necessary for new types of tasks. In addition to hindering renewal of skills at current workplaces or making training opportunities less accessible for older people, this could also result in difficulties to find a job (which is related to hiring practices). More communication and frequent contact with older workers, especially at the leadership or managerial level of the workplace, have been shown to help dissolve managers' negative stereotypes of older workers (Henkens 2005; Solem 2015).

Another form of ageism in the labour market, which may be country-specific, is structural ageism, stemming from fixed or in some cases even mandatory ${ }^{1}$ retirement ages that prohibit or make it difficult for people to continue working after a certain age (O'Dempsey and Beale 2011). These are situations where statutory retirement age is coupled with mandatory retirement - that is, a country's policies or legislations do not allow a person to work and receive a pension at the same time (OECD 2013; Sonnet et al. 2014). Some tax and benefit arrangements were identified previously as incentives for early retirement in most of the so-called industrialised countries - these operated as a way to allow younger generations to enter the labour market (Duval 2003; Blöndal and Scarpetta 1997). However, several countries have declared these incentives and practices unsustainable, and are reviewing and reforming these arrangements, for example by rising retirement ages. Although retirement age should usually correspond to population health developments and availability of national resources, it can be considered a form of ageism when it creates a barrier to employment. Moreover, such retirement age limits might be partly creating ageist attitudes in people, reinforcing the view of older people as fragile and non-capable after a certain age.

Ageism in the labour market can be intertwined with other discriminatory attitudes towards gender, ethnicity or race, and class (Crenshaw 1991; Jyrkinen and Mckie 2012). Additionally, differences in countries' workplace ageism depend on contextual and historical backgrounds that impact people's attitudes and values, and consequently the results of surveys that are taken in those countries. We explore

\footnotetext{
${ }^{1}$ Mandatory retirement age is a specific age at which the employee must retire. Several EU countries have mandatory retirement ages for specific sectors (O'Dempsey and Beale 2011). Fixed retirement age is defined for the purpose of this paper as simply being fixed at some level in a country as opposed to having a flexible retirement age system, such as in Sweden.
} 
international surveys that could be used for studying ageism in the labour market, and discuss their main attributes in the evaluation of measures, keeping in mind the target population, definition of old age, and a variety of country contexts. An international comparison of measures allows for a detailed evaluation of the performance of indicators across cultures, and international comparisons of measures of ageism in the labour market may provide insights into whether a country's position is an outlier or part of a regional pattern.

The following section gives an overview of the surveys chosen for our chapter. The third section presents descriptive results of country positions on five aspects of ageism in the labour market. This is followed by a discussion of the findings. Finally, the last section provides recommendations for researching ageism in the labour market using existing tools (measures as well as surveys).

\subsection{Comparative Surveys}

We look at how ageism in the labour market as a stereotype, attitude, or experience has been measured in international (mostly European) cross-country social surveys in order to evaluate available research tools. We searched all measures that reflected aspects of job seeking or hiring, workplace experiences or attitudes, retention of workers, retirement practices, skill renewal, and the qualities or characteristics ascribed to older workers.

The surveys were chosen based on the following criteria:

- They had information on individuals' (in some cases employers' or managers') self-reported experiences or attitudes regarding age in labour-market related issues;

- They were international/European cross-country surveys of the general population;

- Or they were international/European surveys that focused on the labour market or workplace context.

We examined the following surveys:

- The European Social Survey

- The World Values Survey

- Eurobarometer

- The Generations and Gender Survey

- The Survey of Health, Ageing and Retirement in Europe

- The European Union Labour Force Survey

- The European Company Survey

- The European Working Conditions Survey

- The Activating Senior Potential in Ageing Europe

These surveys were targeted at individuals or employers. All of the surveys were carried out in several countries which makes international comparisons and 
measures of ageism in the labour market possible. Also, most of these surveys have been established as regular data collecting infrastructures, and some of them specialise in studying the labour market context. These surveys are usually representative of the total population, thus making it possible to compare different population group experiences with ageism. More information on the sampling procedures and questionnaire methodologies of each survey can be found on their websites or in relevant publications.

Two surveys - the European Social Survey and the World Values Survey-are specifically aimed at charting the development of attitudes and values. Correspondingly, we found a large number of indicators in these surveys that measure ageist attitudes in the labour market. These indicators were mapped in special ageism modules: in round 4 of the European Social Survey (2008) and in round 6 of the World Values Survey (2010-2014). Similarly, Eurobarometer maps public opinion on various issues, including age-related attitudes in working environments. Discrimination-related questions were asked in 2006, 2009, 2012, and 2015. This survey regularly asks the opinion of around 1000 people aged 15 and above in each EU member state and EU candidate country.

The Generations and Gender Survey aims to study family relations and dynamics by interviewing people aged 18-79. It contained two indicators of ageism in the labour market that could be included in the analysis (from waves 1 and 2). Overall, 18 European countries and Australia have been part of the Generations and Gender Survey, a panel study that is carried out every 3 years in most of the participating countries. The fieldwork in different countries was carried out between 2002 and 2013.

The Survey of Health, Ageing and Retirement in Europe is a longitudinal survey of European countries interviewing people aged 50 and older every 2 years since 2004 on a wide range of topics, including work and retirement. The number of countries has varied, but steadily increased over the years, and the whole European Union is covered from the seventh survey round (since 2017). This survey is an offspring of the Health and Retirement Study that was started in the US.

The European Union Labour Force Survey is an annual survey of the European Union working-age population (15-74 year olds) carried out in all European Union countries. We mention this survey because we found one question from the questionnaire of the Estonian Labour Force Survey (2009-2014) that addressed ageist hiring practices. $^{2}$

There are also a number of surveys mapping employers' perspectives or employees' working environments, such as the European Company Survey, the European Working Conditions Survey (both carried out by Eurofound), and Activating Senior Potential in Ageing Europe, funded under the Seventh EU Framework Programme (Conen et al. 2011a).

\footnotetext{
${ }^{2}$ Unfortunately, we did not find similar questions in the surveys of other countries. Therefore, at the time of writing this paper, it was not possible to make a comparative analysis based on this indicator.
} 
The first European Company Survey was carried out in 2004-2005 and included 21 countries: 15 'old' European Union Member States, as well as Cyprus, the Czech Republic, Hungary, Latvia, Poland, and Slovenia. The second European Company Survey was carried out in 2009 and included 30 countries: the $27 \mathrm{EU}$ member states, Croatia, the Former Yugoslav Republic of Macedonia, and Turkey. The third time the survey was carried out was in 2013 and it included companies from 32 countries - the 27 European Union member states and Croatia, the former Yugoslav Republic of Macedonia, Iceland, Montenegro, and Turkey. The European Working Conditions Survey, which has been running since 1991, maps the working conditions and work environments of employees and self-employed people in Europe. The sixth wave was conducted in 2015 and included the 28 European Union countries, as well as Norway, Switzerland, Albania, the former Yugoslav Republic of Macedonia, Montenegro, Serbia, and Turkey.

The Activating Senior Potential in Ageing Europe project aimed at mapping employers' views and practices regarding older workers (ages 50-70) in ageing societies, and whether employers' views and organisational policies correspond to governments' policies (Conen et al. 2011a), providing a valuable source of studying ageism in the labour market. In total, more than 6800 employers were interviewed in Denmark, Germany, France, Italy, Poland, the Netherlands, the United Kingdom, and Sweden in this survey. We selected two questions from Activating Senior Potential in Ageing Europe to present here. These questions can be used as examples of measuring direct ageist attitudes of employers.

We calculated the prevalence of ageism per measure for each country and the mean of each indicator. The choice for a cut-off point indicating when a relatively large proportion of people could be identified as engaging in ageist behaviour or having ageist attitudes according to a specific measure in each country was based on the standard deviation of the mean. The results indicate ageism towards older people. Other potential indicators for which we could not present findings, but which could be valuable for research on ageism in the labour market are discussed in a separate section (Sect. 28.3.6). The overview and list of measures in Sect. 28.3 is followed by an evaluation of the observed measures (Sect. 28.4) and recommendations for researching ageism in the labour market (Sect. 28.5). The evaluation of findings led us to develop a taxonomy of measures, which we follow in outlining our recommendations for future research of ageism in the labour market.

\subsection{Measures of Ageism in the Labour Market}

We identified 18 of the most relevant measures from seven international (mostly European) large-scale population surveys and from one employers' survey that included eight European countries. All measures were self-reported. Seventeen indicators measured ageist attitudes and perceptions in the labour market (either from the employees' or the employers' perspective) or attitudes and perceptions about ageism in the labour market. One indicator measured the experience of 
structural ageism in the labour market (see Table 28.1). We chose these measures based on their explicit mention of an age-related word in the question in relation to any aspect of the labour market (contribution to the economy in general, labour market entry or exit, retaining workforce, workplace, colleagues, etc.). The most common age-related word was either a specific age number (e.g., 30, 70, 20s, 40s) or a relative indication of age, such as "young" or "old." The measures were grouped into five broad categories based on their focus:

- Workforce recruitment and/or retention,

- Performance,

- Training,

- Interaction with older colleagues,

- Structural ageism.

Most of the measures fell into the first two categories.

This chapter presents the results of international descriptive comparisons of the 18 measures grouped into five themes. Countries that had ageist attitudes or practices were chosen based on their results reaching above or below the standard deviation of the mean. This was true with the exception of one indicator from the Activating Senior Potential in Ageing Europe survey ("At what age would you say a person is too old to be working $20 \mathrm{~h}$ or more per week?"), as well as for the Eurobarometer indicator ("Regardless of whether you are actually working or not, please tell me, using a scale from 1 to 10 , how comfortable you would feel if one of your colleagues at work belonged to each of the following groups: a person over 60 years; a person under 25 years"). In case of the Activating Senior Potential in Ageing Europe indicator, the cut-off point was chosen to be age 65 . In the case of the Eurobarometer indicator, the difference between responses regarding younger and older age groups was calculated. We focus on ageism towards older age groups, hence, even if some questions were asking about younger age groups, we present the results that indicate ageism towards older adults.

\subsubsection{Recruitment and/or Retention of the Workforce}

One question from the European Social Survey used a specific age range to ask about people's concerns about employers' age-related preferences ("How worried are you that employers prefer people in 20 s rather than in their 40 s or above?"), and could be used as an indicator of perceived ageism of employers when recruiting or retaining workforce. A question from the Generations and Gender Survey that also specifically contrasted younger and older members of the workforce could also be used as a measure of general views of the employability of older people and is thus grouped under the category of recruitment and/or retention of workforce ("When jobs are scarce, younger people should have more right to a job than older people"). An important distinction between these two questions is that the latter reflects ageist views of the respondents themselves, not their experience or perception of ageist 


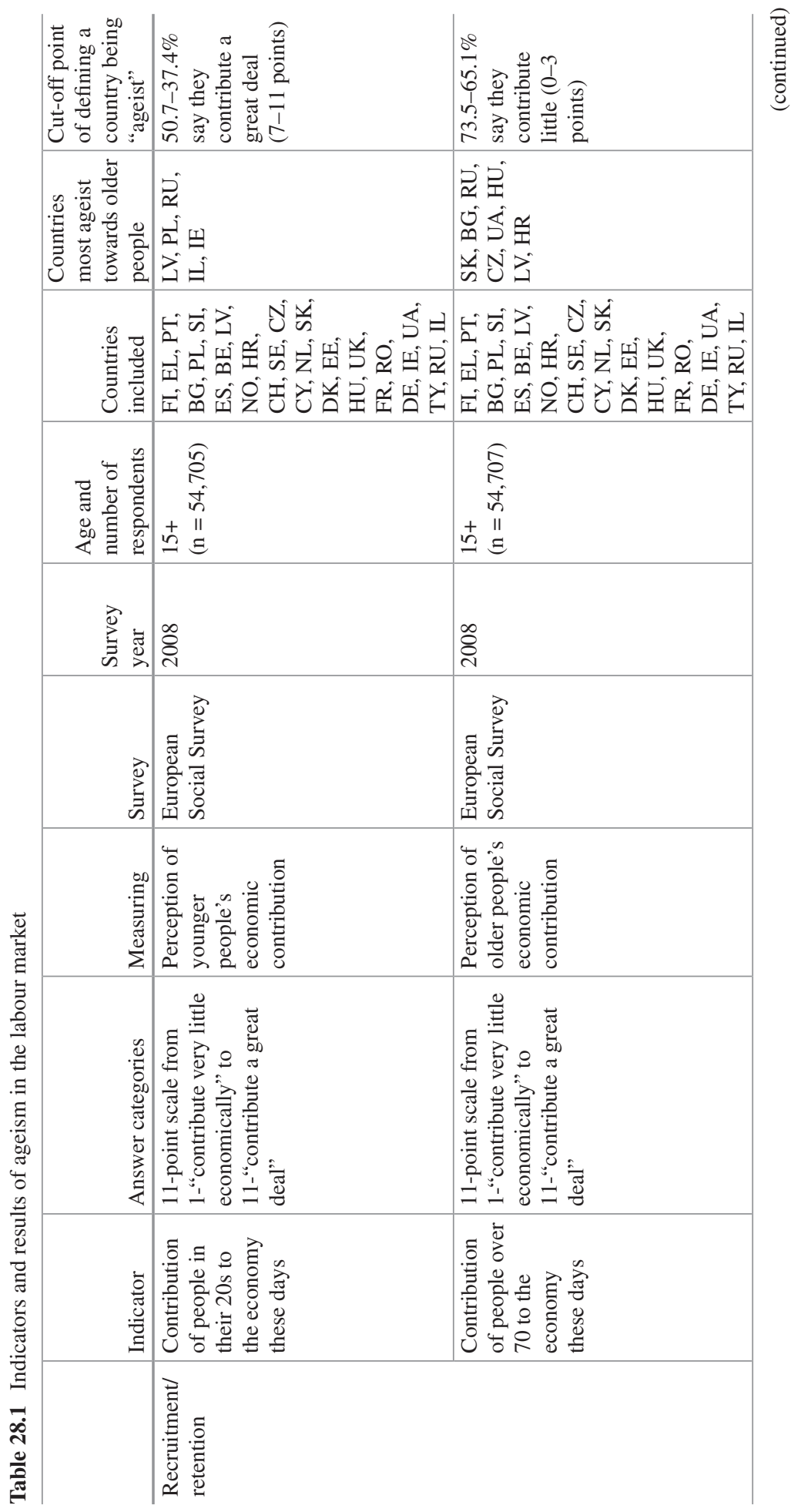




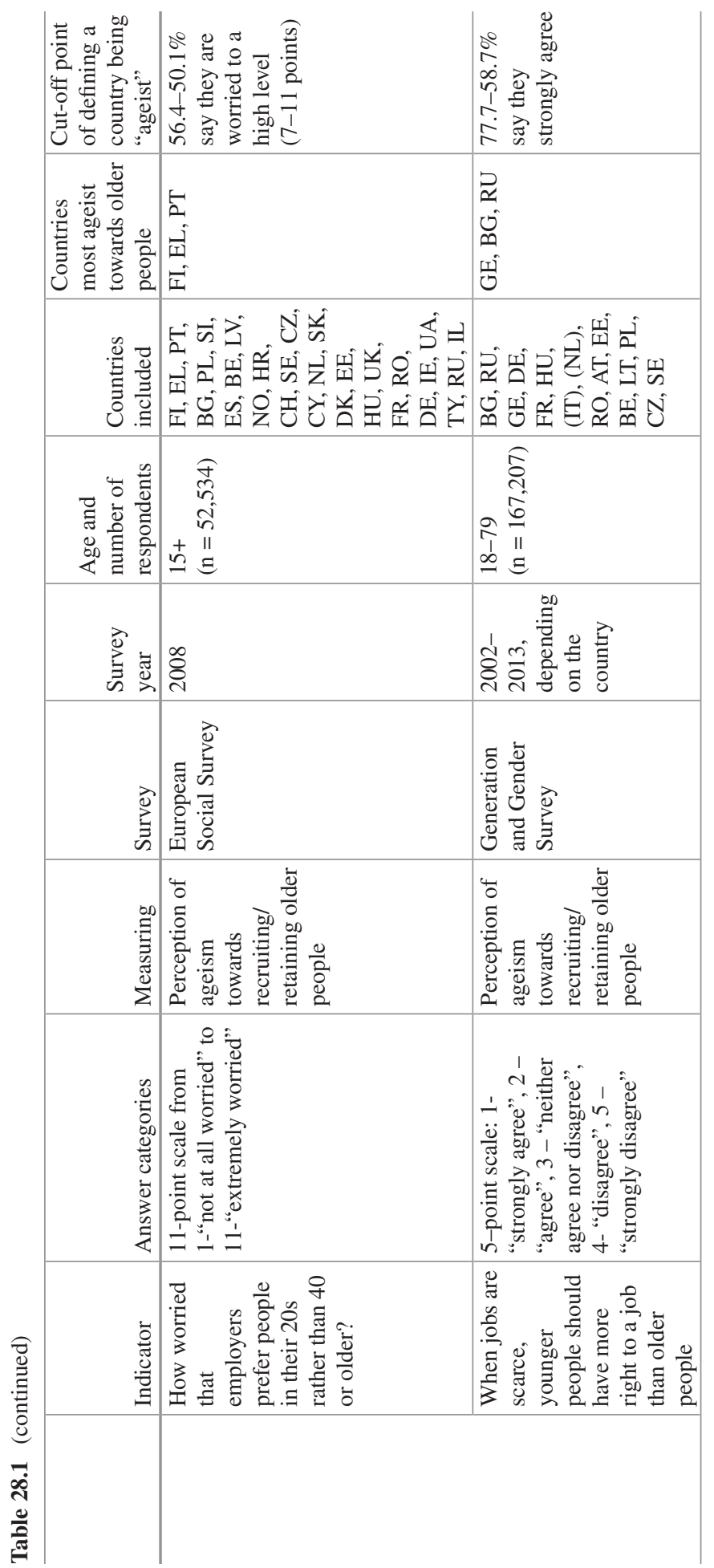




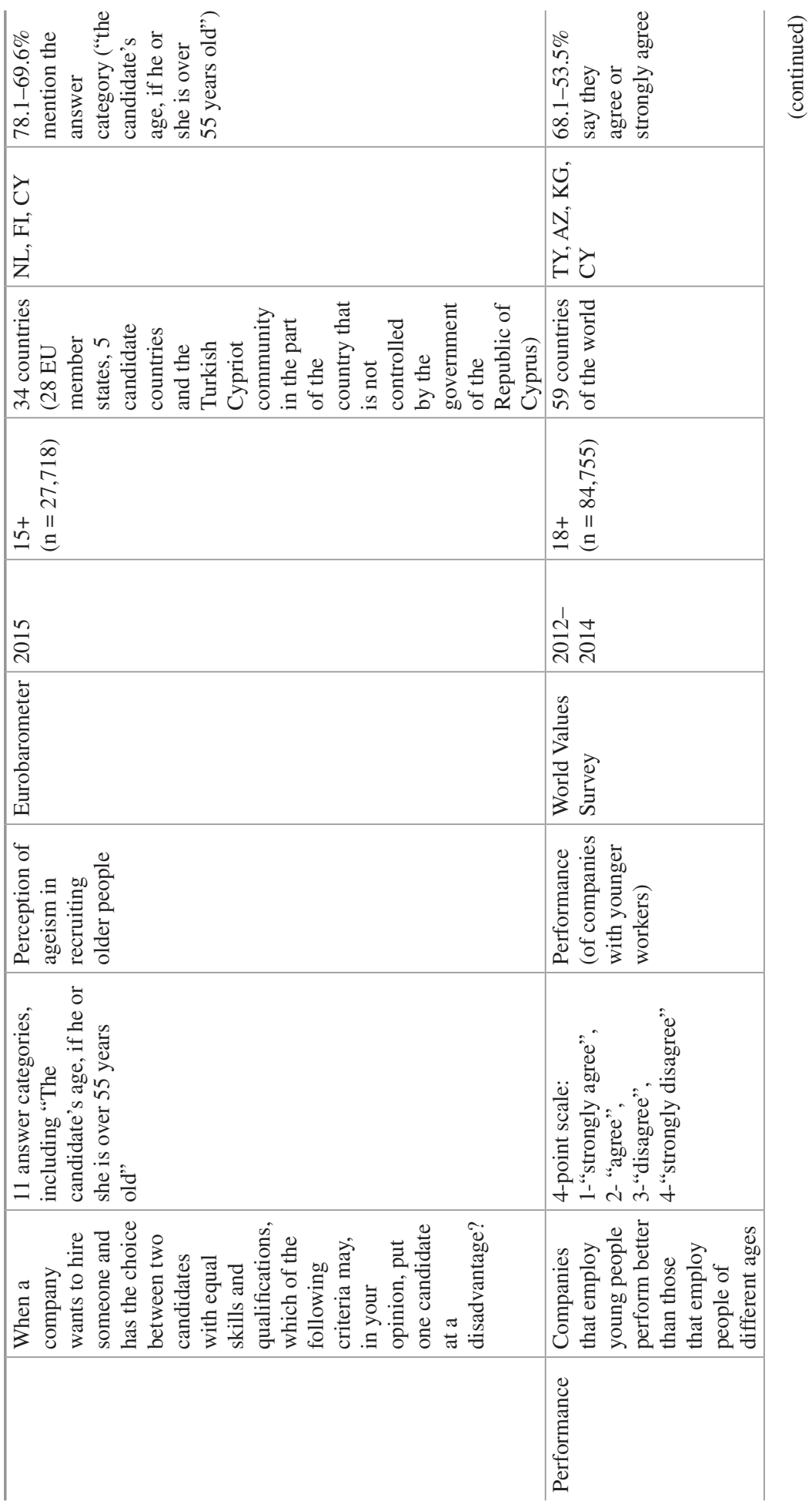




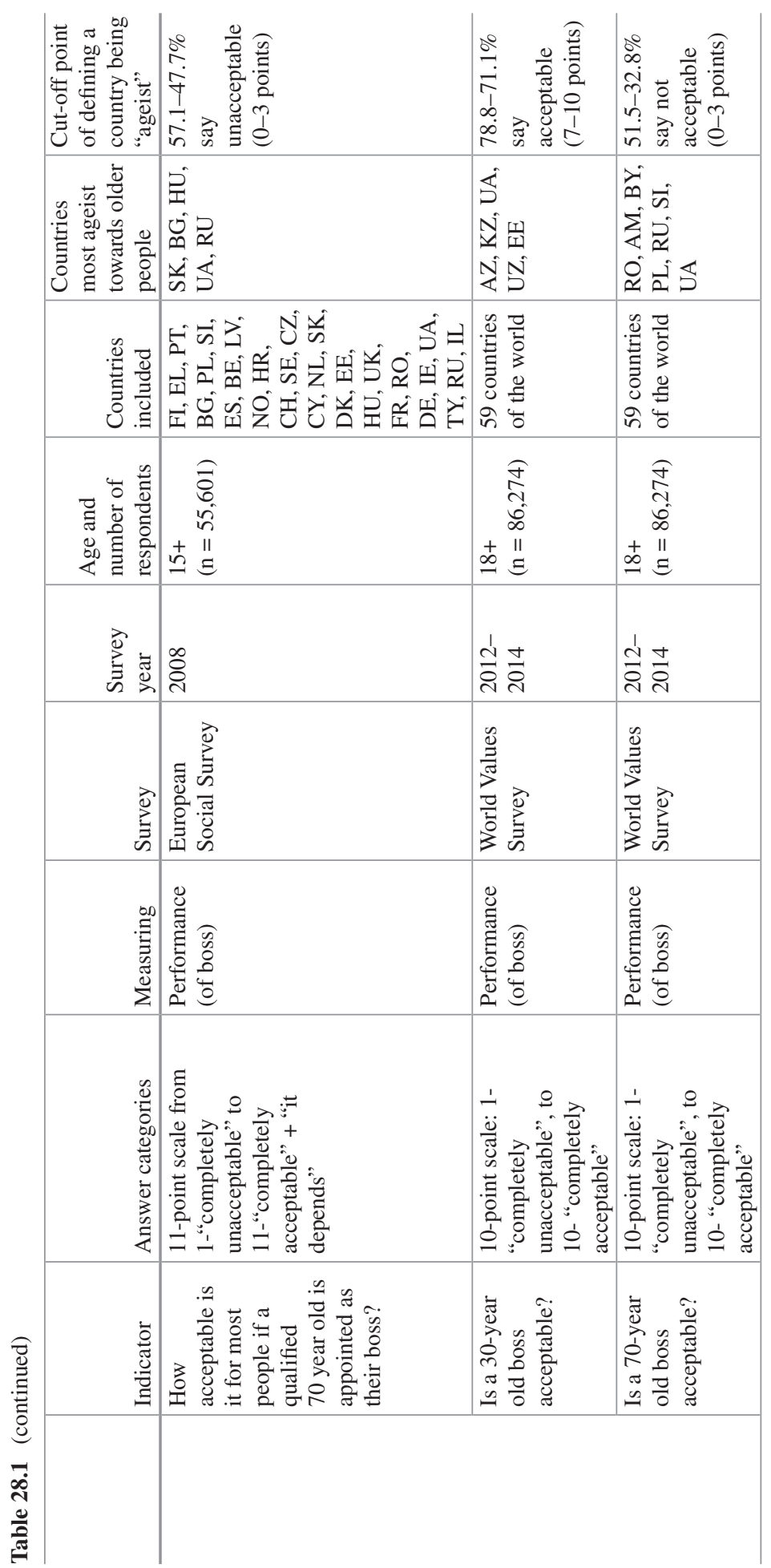




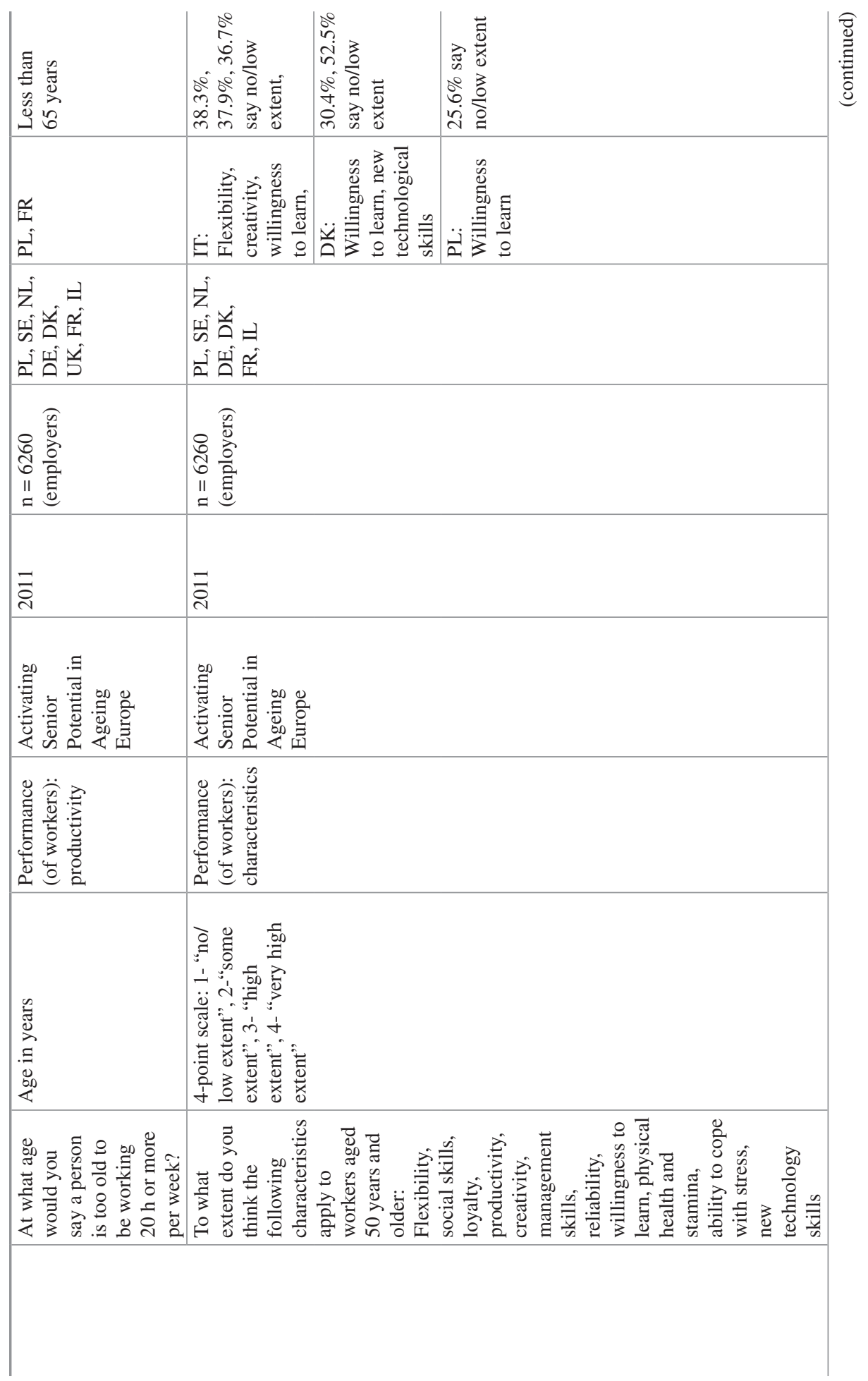




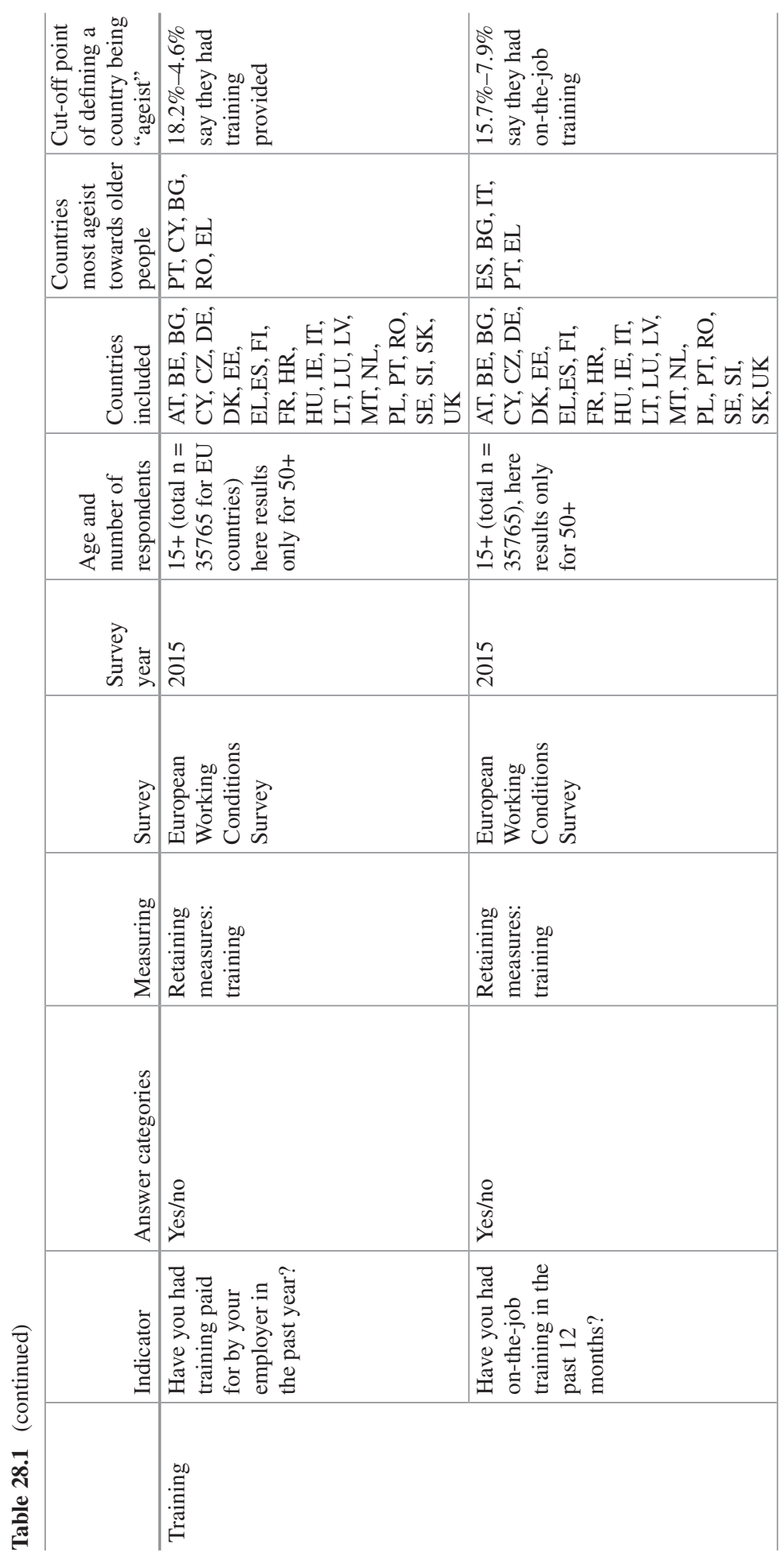




\begin{tabular}{|c|c|}
\hline 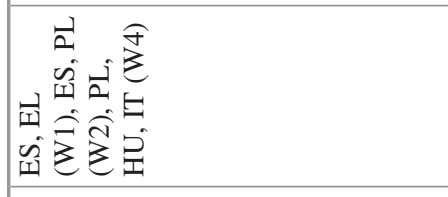 & 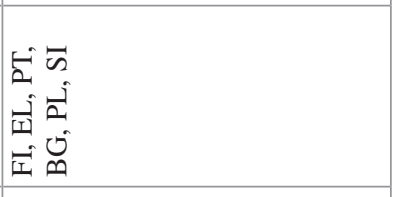 \\
\hline 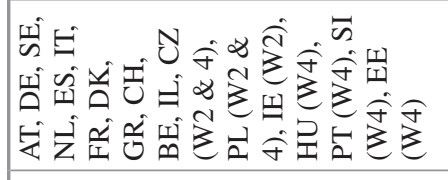 & 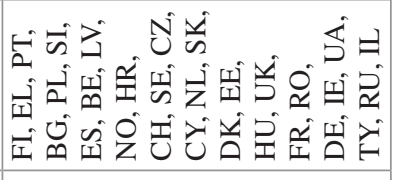 \\
\hline 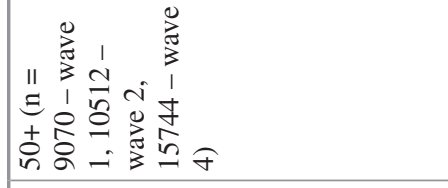 & 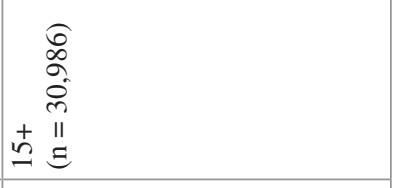 \\
\hline 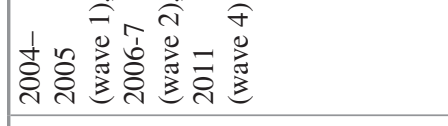 & 离 \\
\hline 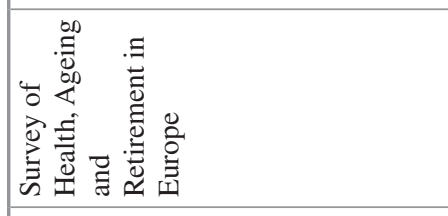 & 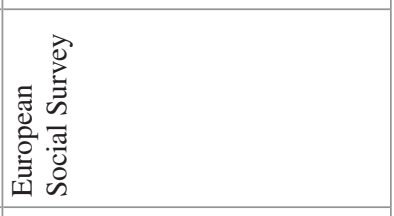 \\
\hline 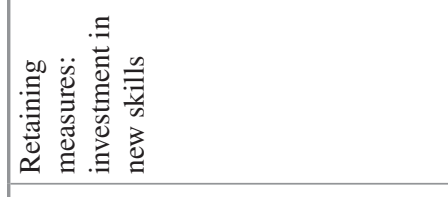 & 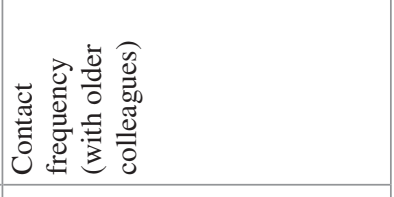 \\
\hline 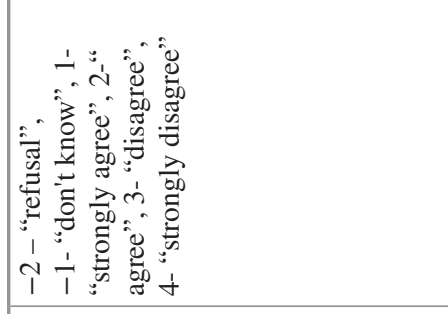 & 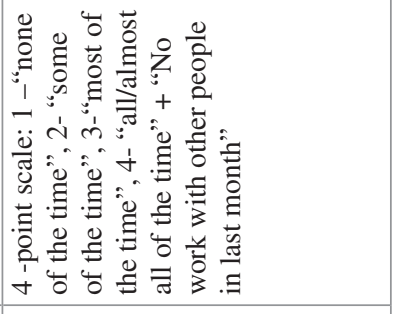 \\
\hline 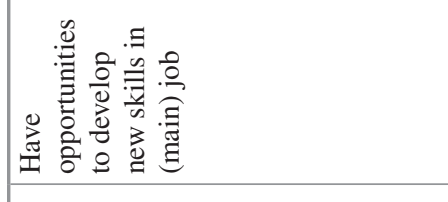 & 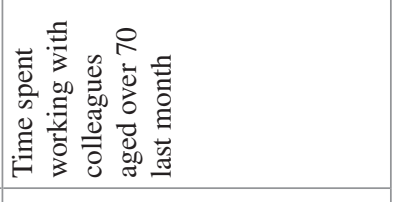 \\
\hline & 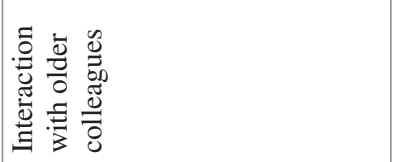 \\
\hline
\end{tabular}




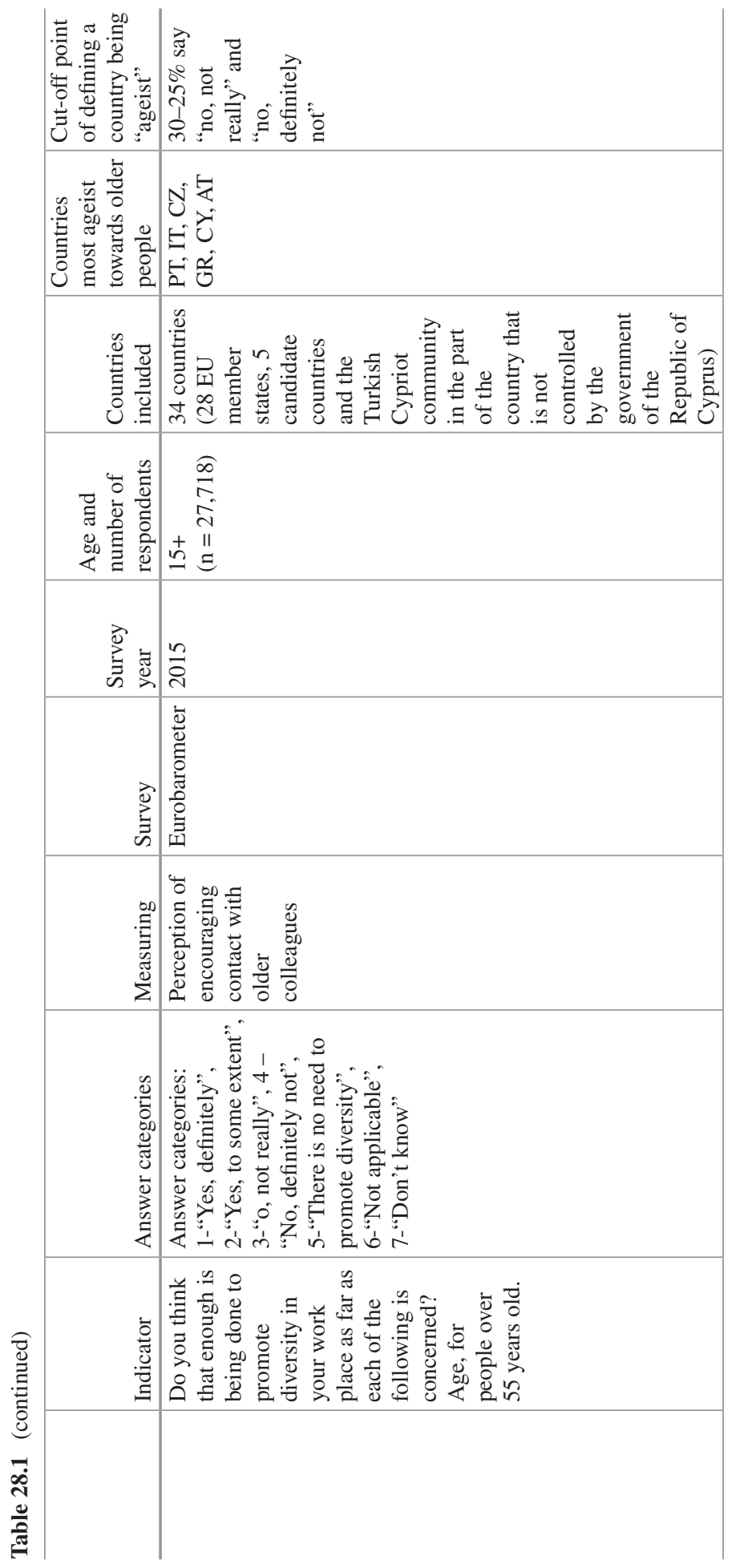




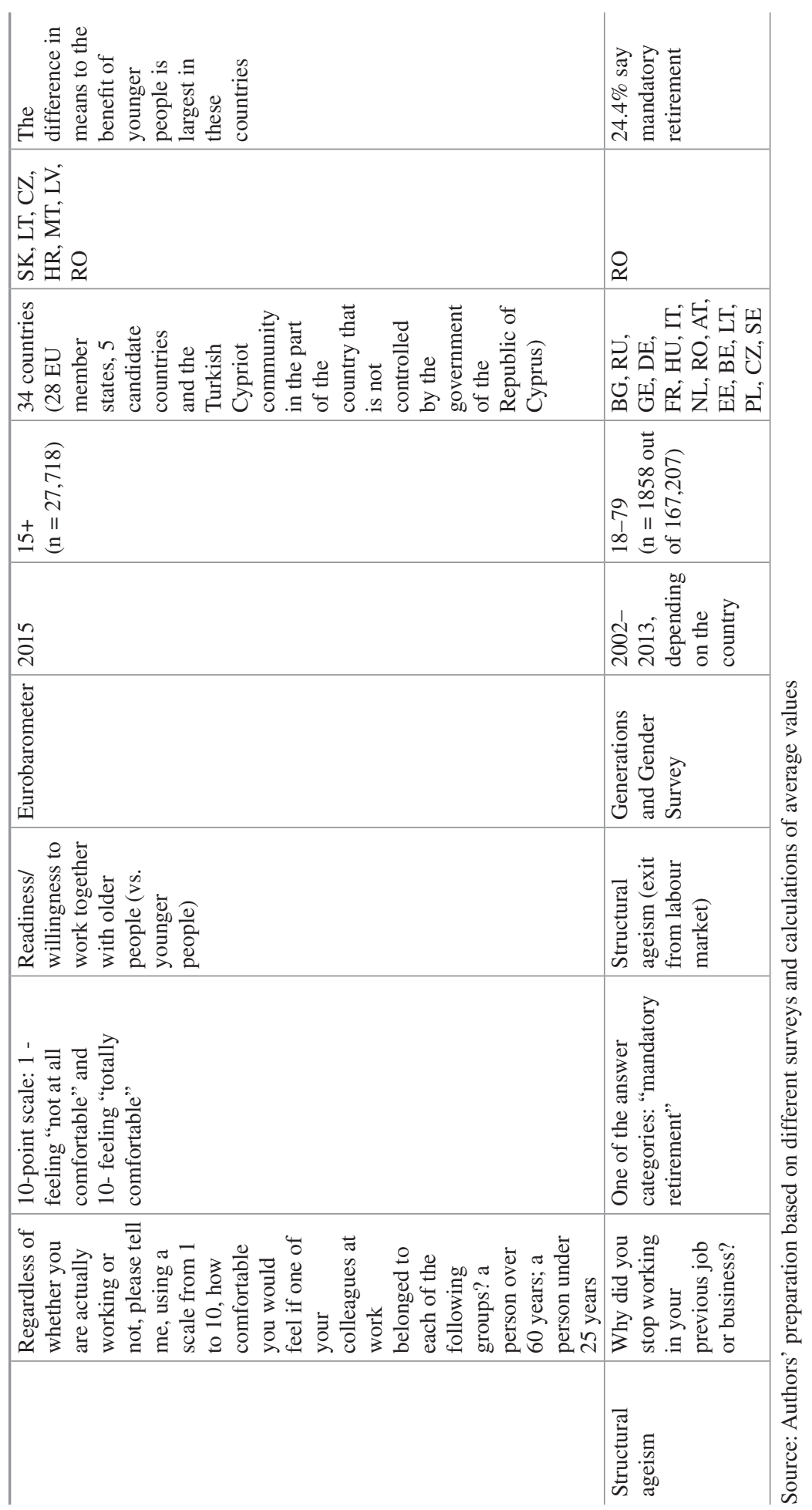


behaviour or attitudes in others. Hence, differences in the results might partly be related to this nuance. In the question that asked about people's perceptions of employers' ageist behaviours, Finland, Greece, and Portugal were shown to be the countries that were most concerned about employers preferring people in their $20 \mathrm{~s}$ over people in their 40s. The question that asked about a person's own ageist views showed that Georgia, Bulgaria, and Russia were the most ageist.

The indicator that we used from Eurobarometer ("In ([name of country], when a company wants to hire someone and has the choice between two candidates with equal skills and qualifications, which of the following criteria may, in your opinion, put one candidate at a disadvantage? The candidate's age, if he or she is over 55 years old?"- which was one of the possible answer categories) can be used as a measure of attitudes towards hiring older people. The highest percentage of people reporting this criterion was found in the Netherlands, Finland, and Cyprus. On the other end were Great Britain, Italy, Croatia, Poland, and Ireland. This indicator may have measured awareness of disadvantage by age rather than actual perceptions, attitudes, or experiences of ageism in the labour market.

Two questions from the European Social Survey that are categorised under recruitment/retention can be indicators of how people of different generations are perceived from an economic perspective. These questions ask about the contribution of younger (20s) and older (70s) people to the economy, but in two separate questions, thus not explicitly opposing young and old within a single indicator. However, when we compared the results from the two questions, we were able to identify countries in which respondents demonstrated ageist attitudes as those that had a high percentage of people who thought that people in their 20s contribute to the economy a great deal and a high percentage of people who thought that people in their 70s contribute little. The countries that scored high on both indicators were Russia and Latvia.

\subsubsection{Performance}

One question in the European Social Survey and one question in the World Values Survey asked about the acceptability of having a 70-year-old boss. The World Values Survey question was accompanied by a note indicating that countries may change the wording from " 70 " to "over 60 " if the $70+$ population is small. (The list of countries that changed the wording can be found from additional survey methodology or metadata documentation). The results of both surveys show that Slovakia, Bulgaria, Hungary, Ukraine, Russia, Slovenia, Romania, and Armenia were the least accepting of this situation. Finland also scored quite high in terms of being less accepting of having an older boss, although they remained within the margins of the standard deviation of the mean. In the Finnish case, it is possible that the fixed retirement age of 68 and mandatory retirement age of 67 for some public service occupations (O'Dempsey and Beale 2011) have some influence on the answers. Azerbaijan and Ukraine (followed by Kazakhstan, Uzbekistan, Estonia, Belarus, 
Romania, Russia, and Georgia within the standard deviation margin) showed correspondingly the highest proportions of people accepting a 30-year-old boss. Some non-European countries, such as Colombia, Egypt, Mexico, Qatar, Brazil, and Peru have reported values of the same magnitude.

One question from the World Values Survey measured attitudes about people's performance ("Companies that employ young people perform better than those that employ people of different ages"), and can be used as one of the measures of productivity expectations or prejudice. It is important to bear in mind that this question, similar to the Eurobarometer question about age being a potential disadvantage in recruitment/retention, addressed the ageist views of the respondents themselves, not their experiences or perceptions of ageism in others. Respondents from Azerbaijan, Kyrgyzstan, and Cyprus reported the most ageist attitudes in this indicator, following, on a global level, Ghana, Egypt, India, Turkey, and South Korea. Also, this was the only indicator among performance measures that opposes "young people" and "people of different ages." However, due to its ambiguous wording the question might measure attitudes of opposing performance of "young people" and "people of all ages", and not so distinctively "young people" and "old people".

Two questions from the Activating Senior Potential in Ageing Europe survey (Conen et al. 2011b) measured employers' ageist perceptions or attitudes. One of them was an indicator of attitudes about older adults' productivity or work ability ("At what age is a person too old to be working $20 \mathrm{~h}$ or more per week?"). This question was different from other indicators as it did not pre-define an age, but rather let the respondent (employer) define it. Polish and French employers reported the most ageist attitudes according to this indicator, as the mean value of answers was the lowest for respondents in these countries, i.e., below 65. The second item mapped a number of characteristics that are attributed to older workers (aged 50 or above): "To what extent do you think the following characteristics apply to workers aged 50 years and older (1 - " no/low extent", 2 - "some extent", 3 - "high extent", 4 - "very high extent"): flexibility, social skills, loyalty, productivity, creativity, management skills, reliability, willingness to learn, physical health and stamina, ability to cope with stress, new technology skills". Employers in Italy reported the most ageist attitudes: a larger share of these employers thought that flexibility, creativity, and willingness to learn did not apply to workers aged 50+. In Denmark and Poland more employers felt that older workers have no motivation to learn, and that they lack new technological skills.

\subsubsection{Training}

A number of questions addressed the workplace training of older adults. These questions can be used as sub-indicators for both retention and performance. Investing in older workers' training and skill renewal can improve their performance, which is especially important in societies where the general population as well as the workforce is ageing. These indicators could be used as measures of 
ageism regarding older people's performance enhancement at work. However, they could also be used as indicators of retaining practices. Through training that improves the performance of the existing workforce in an organisation, the retention of the workforce should also improve.

Two questions targeting employees and self-employed people from the European Working Conditions Survey showed that in Cyprus, Bulgaria, Romania, Bulgaria, Spain, Greece, Italy, and Portugal, a fairly small number (approximately 15\%) of workers aged 50 and above reported having received paid or on-the-job training.

The Survey of Health, Ageing and Retirement in Europe ${ }^{3}$ included a self-reported indicator of opportunities of training on the job of currently employed people. This was identified as a measure of investing in older workers'(aged 50+) performance as well as of workforce retention. According to this indicator, over $40 \%$ of employed people above the age 50 in Spain (in 2004 and 2006), Greece (in 2004), Poland and Hungary (both in 2011), and over 50\% in Poland in 2006 reported not having had training opportunities.

\subsubsection{Interaction with Older Colleagues}

Three indicators were classified as measures of interaction with older colleagues. The Eurobarometer survey (2015) asked the following question: "Do you think that enough is being done to promote diversity in your work place as far as each of the following is concerned?" Options included, "Age, for people over 55 years old". Portugal, Italy, the Czech Republic, Greece, Cyprus, and Austria had the highest percentage of people reporting that diversity was not being promoted in terms of having people 55 and older in the workplace. The option, "There is no need to promote diversity," was not included in the calculation of these outcomes, because the interpretation of this option includes ambiguity, and might therefore go beyond ageism towards older people only. However, we see that it could be considered as an answer category indicating ageism as well. If that option was to be taken into account, the countries with the highest percentage indicating ageism in that measure would include Bulgaria, Italy, Portugal, Poland, Greece, and the Czech Republic. In addition to interaction with older colleagues, this indicator might be used as a measure of ageism in hiring practices, but more specific information is needed to complement this.

We included a second question from the Eurobarometer survey: "Regardless of whether you are actually working or not, please tell me, using a scale from 1 to 10 , how comfortable you would feel if one of your colleagues at work belonged to each of the following groups: a person over 60 years; a person under 25 years." This question can be used as an indicator of readiness or willingness to work with older

\footnotetext{
${ }^{3}$ Data from wave 1 (2004-5), 2 (2006-7) and 4 (2011) were included in this overview. Data from the most recently available wave 5 (2013) yielded numbers of cases that were too low to be analysed by each country.
} 
people (vs. younger people). In general, the means for both age groups were quite high, but some countries indicated a lower mean of comfort for working with people aged below 25 years. We decided to calculate the difference in means between these indicators of different age groups to get a better idea of which countries had the largest split in acceptance of older and younger colleagues. The following countries showed the largest difference, indicating a greater comfort with younger than with older colleagues: Slovakia, Lithuania, the Czech Republic, Croatia, Malta, Latvia, and Romania. Interestingly, the means for being comfortable with younger and older colleagues were the same both in Denmark and Spain, indicating that egalitarian attitudes are more common in these two countries.

The European Social Survey asked how much time respondents had spent working with someone over 70 in the month prior to the interview. This indicator is a good measure of contact frequency between different age groups. Contact with older colleagues is an important factor in improving attitudes towards older people (Henkens 2005). Most people in all the countries surveyed did not have contact with colleagues over 70 in the workplace, probably as a result of most people retiring before that age. The largest proportion of people not having spent any time with colleagues over 70 were found in Finland, Greece, Portugal, Bulgaria, Poland, and Slovenia. The highest proportion of people having spent at least some time with colleagues over 70 were in Israel, Ireland, and France. Israel actually had the largest proportion of respondents saying they had spent most of their time $(6.7 \%)$ or all/ almost all of their time (5\%) working with colleagues aged 70 and over. In addition to ageist attitudes, the results are probably related to other factors, such as state policy (fixed retirement age), distribution of the population by fields of economic activity within countries, and life expectancy. Further analysis could deconstruct the exact conditions and causes shaping interaction with older colleagues: how much can be attributed to the ageist attitudes of employees, employers, and policymakers, and how much can be attributed to other factors, such as policies of mandatory retirement.

\subsubsection{Structural Ageism}

The mandatory retirement indicator is an explicit measure of structural ageism that might be a barrier for people to continue working. According to this self-reported measure from the Generations and Gender Survey, Romania has a large proportion $(24.4 \%)$ of people leaving their job due to mandatory retirement. It would be useful in future surveys to ask whether people would have continued working if mandatory retirement did not exist or if they had the chance to work past retirement age. Hence, a combination of willingness to continue working and the actual exit age would give a more informative idea of the extent of ageism. Otherwise, the single self-reported measure in its current form might just reflect the existence of an official retirement age, where causality might in fact run the other way, with the official retirement age impacting people's attitudes. 
Table 28.1 presents the most relevant survey questions. We decided to group the measures by the topic or theme they cover, for a total of five groups. Many of the questions capture attitudes, opinions, and perceptions with a scale measurement, such as a 4-point or 11-point Likert scale. However, even variations in the wording of similar measurements can lead to variations in output in terms of the countries' ranking on ageism in the labour market. Thus, results may reflect cultural differences in understanding and interpreting ageism. The importance of cultural contexts is discussed below.

\subsubsection{Other Potential Indicators of Ageism in the Labour Market}

The Survey of Health, Ageing and Retirement in Europe has several indicators that could be used as measures of ageism in the labour market (e.g., having a short-term or permanent contract, opportunities to develop new skills, and evaluation of prospects for job development). However, the most recently available wave of this survey (wave 5, 2013) had a low number of cases for most of these indicators. Coupled with a longitudinal methodology that maps each individual's various spheres of life events and characteristics every 2 years, the survey could potentially be a valuable source for studying ageist attitudes and experiences at the individual level. However, the ageing and attrition of the sample in longitudinal surveys often leads to a decrease in the number of cases (in this case employed older adults) available for analysis after a few waves.

In the European Union Labour Force Survey, one indicator was spotted that could be used as a measure of ageism in recruitment. The question, "Why did you not take the job when offered?", was followed by a number of options, including, "The employer wanted someone younger." This question was in the Estonian LFS questionnaires from 2009-2014 (question H24).

The European Company Survey included two potential indicators, one of which is an indicator of ageism in hiring practices: "Could you please tell me, for this establishment, the number or percentage of employees who... are older than 50 years of age?" The second question, which could be used as an indicator of attitudes regarding older employees' training practices or of an ageist behaviour ("Please tell me for each of the following groups of employees whether or not their needs for further training are systematically checked at regular intervals"), included "Older employees" as one of the potential answers (question MM562, Management Questionnaire, 2009).

The European Working Conditions Survey had indicators of potential ageist experiences at the workplace, such as: "Over the past 12 months at work, have you been subjected to any of the following?", followed by a number of options, including "Age discrimination" (Q65/72 in the 2010 and 2015 questionnaires); and "Since you started your main paid job, have you been subjected at work to any of the 
following?" (Q72 in the 2010 questionnaire only), also followed by a range of options, including "Age discrimination".

Activating Senior Potential in Ageing Europe had a number of potential indicators of ageism in the labour market, two of which we mention here: "At what age would you say a person is generally too young to retire permanently?", as an indicator of ageism towards younger ages; and "To what extent do you think the following characteristics apply to workers aged less than 35 years: flexibility, social skills, loyalty, productivity, creativity, management skills, reliability, willingness to learn, physical health and stamina, ability to cope with stress, new technology skills?", which could be used as an indirect indicator or as a validation of ageism towards older people because it does not use a specific term for older people in the wording.

\subsection{Evaluation of the Findings}

This paper identified measures of ageism in the labour market and tested their performance in cross-country comparisons. The comparative analysis was done with descriptive methods only, so the conclusions on country differences should be tested in the future with more rigorous analyses. Our discussion in the current section focuses on the topics or themes of measures, the target population of indicators and surveys, the wording of questions (especially with regard to the definition of old age), and each survey's usefulness for researching ageism in the labour market.

The measures identified in international cross-country surveys cover a broad scope of aspects of ageism in the labour market. Some measures indicated acceptance of older people as colleagues or as bosses, asking about frequency or availability of contact with older colleagues, about perceptions of employers' preferences in recruitment or performance of older adults, about qualities attributed to older people, and also about practices to improve older people's performance, training, and retention. There was also one indicator addressing the experience of structural ageism. In general, we divided the indicators into five broad groups based on which aspect of ageism in the labour market they measured:

- Recruitment and/or retention of older people,

- Performance of older workers,

- Training,

- Interaction with older colleagues,

- Structural ageism.

The recruitment/retention and performance indicators were the most widespread.

The target populations of the indicators and surveys examined in this chapter are generally defined by the survey sampling, not by a specific question. However, it is possible that some survey questions targeted specific respondents through routing. One question in the Eurobarometer survey specified that all survey respondents should reply regardless of the employment situation of the respondent. The 
Eurobarometer survey, the European Social Survey, the World Values Survey and the Generations and Gender Survey target the general adult population, with only the Generations and Gender Survey having an upper age limit (79). Some surveys specifically focus on older people (50+ in the Survey of Health, Ageing and Retirement in Europe), and some more generally on the working age population or working environment of employees and self-employed people (Labour Force Survey, European Working Conditions Survey). Company and employer surveys (European Company Survey, Activating Senior Potential in Ageing Europe) can be very valuable sources for studying employers' perspectives, attitudes, and practices because these are positions where ageist practices are often implemented.

There are variations in how "old age" is defined in the measures. Some use specific age indicators (e.g., 20s, 30s, 40s, 50 or above, 70) whereas other indicators are more general (e.g., "young," "old," "different ages"). However, most of these measures do not give information about what the respondents themselves consider "old," and therefore the results may be a reflection of a combination of factors. Only one question in the Activating Senior Potential in Ageing Europe survey asked employers to define the age at which an employee would be considered too old to work $20 \mathrm{~h}$ or more per week. In some cases, for example in the World Values Survey, differences in demographic structure are taken into account and countries have the option to change the wording of the question (from "70" to "over 60") if there are too few people in the older age groups. This is a good example of taking into account demographic trends and country context in measuring age discrimination, as well as of the perception of when old age starts (possibly often associated with eligible retirement age). This is also something for researchers to take into account when comparing different countries. In some cases, such as in the Eurobarometer interaction indicator, it is possible to combine different age groups for comparison.

It is not clear to what extent questions that specify a certain age or age group measure purely ageist attitudes. The results may reflect various aspects of the labour market, such as participation levels, qualification requirements, economic circumstances, health and life expectancy, and so on. In general, based on our descriptive overview, several Eastern and Central European countries emerge as most ageist based on the studied indicators-especially Russia, Poland, and Slovenia, followed by Bulgaria, Romania, and Ukraine. Some of these countries had a relatively low retirement age (60 for men and 55 for women) in the 1990s and in some cases even into the early twenty-first century (De Castello 1998; Puur 2000). Rapid population ageing and the transition from a planned economy to a market economy have occurred in these societies within a relatively short period. The economic restructuring during the transition period resulted in job losses that particularly impacted the older population, as new types of knowledge and experience were suddenly required (Puur 2000; Nugin et al. 2016). Therefore, several Eastern and Central European countries might have had less time to develop positive age-related attitudes, or in some cases might have placed a higher value on young people in the workforce that still holds today. Consequently, older people's potential, including in terms of loyalty, reliability, and experience, in the labour market may not yet be valued in a 
similar way as in some Nordic or Western countries. When comparing countries, contextual and historical backgrounds play an important role, especially the significant societal transformations that have occurred in several Eastern European countries since the 1990s.

Western and Northern European societies also have some ageist manifestations. Finland in particular emerged as a somewhat ageist country. This might indicate structural problems in the labour market, but it can also signify a high awareness of ageism in this country. Israel seems to be a competitive country where older people need to or want to work beyond the retirement age (or a very heterogeneous country with different attitudes and practices regarding older workers in different communities), but did not appear necessarily to be ageist based on our findings. A large proportion of people in Israel were concerned that people in their 20s were preferred by employers over those in their 40s. At the same time, a large proportion of people said that young people actually contribute to the country's economy a great deal. Also, Israel had the largest proportion of people who said they had spent time working with colleagues aged 70 or over, indicating a high frequency of contact between different age groups in the workplace. Israel's retirement age of 67 is relatively high compared to most other countries, which might influence the possibility of spending time with older colleagues in the workplace.

The Activating Senior Potential in Ageing Europe survey proved to be very useful in our study of ageist attitudes in that it pointed to potential problems with employers' attitudes in some Western and Nordic countries. We found that Italy had the largest proportion of employers who hold negative views about the characteristics of older adults. However, the Activating Senior Potential in Ageing Europe survey only included eight European countries, one of which was in Eastern Europe (Poland). Also, this survey was only carried out once, which does not allow for the assessment of changes in attitude over time. The results from the European Working Conditions Survey showed that a fairly small number of workers aged 50 and older have received training in Southern European countries such Portugal, Cyprus and Greece, but also including Bulgaria and Romania.

Questions in which the wording opposed different age groups in a single question-for example, "How worried that employers prefer people in their 20s rather than 40 or older?" seemed to work in a similar way to separate questions that asked about different age groups (for example, "Is a 30 -year old boss acceptable?" and "Is a 70-year old boss acceptable?"). However, from the indicators observed in this paper, the questions that asked specifically about respondents' preferences of one age group over another seemed to create an explicit outcome of ageism. This might be because the wording of these questions presented an inevitable opposition that was necessarily reflected in the answer. Respondents' perceptions of their employers' attitudes might also lead to some confusion in the results because the answers may be dependent on overall satisfaction with the working environment (GarcíaMainar et al. 2015) or overall satisfaction with colleagues (Hombrados-Mendieta and Cosano-Rivas 2013). Therefore, it might be more accurate to rely on employers' self-reports of their attitudes. One question's wording can be understood or interpreted ambiguously by respondents ("Companies that employ young people 
perform better than those that employ people of different ages"). Therefore the performance of this indicator as a measure of ageism specifically towards older people requires additional validation.

The European Social Survey and the World Values Survey are both general attitudinal surveys. Unfortunately, they have not included questions about ageist attitudes in the labour market context on a regular basis. Data on ageist attitudes gathered at one point in time do not give any information on the dynamics of the attitudes, how they change, improve, or worsen over time. Ideally, these dynamics could be measured longitudinally, as they are in the Generations and Gender Survey. In the Generations and Gender Survey, the relevant measures were included in waves 1 and 2. In a number of countries, many of the same people were interviewed in both waves. Therefore, using longitudinal methodology would give the best picture of change in attitudes over time.

Even though we identified some possible indicators of ageism in the labour market from the Survey of Health, Ageing and Retirement in Europe, most of these indicators did not have enough cases per country for generalisation. This is because some of the specific questions of the survey only targeted employed individuals, which means that the number of employed people per country included in the Survey of Health, Ageing and Retirement was too low to provide representative information pertaining to ageism in the labour market (at least in wave 5). This may be reflective of low labour force participation levels among the 50+ population in several countries, and thus itself may be a manifestation of ageism in the labour market. Alternatively, the problem may lie in attrition of people over time in panel studies.

The Generations and Gender Survey could be a useful source for studying ageism in the labour market, especially as it had one indicator of structural ageism. However, to be able to evaluate the effect of mandatory retirement as ageist, more measures need to be added to the analysis, such as willingness to work above the mandatory retirement age, which is highly dependent on job type, education, and broader cultural values on the individual level. One of the downsides of using the Generations and Gender Survey is that the fieldwork has been carried out over a long period of time (2002-2013). Hence, period effects, such as changes in political, legislative, and economic settings that may shape ageist attitudes or practices in the labour market may not be captured well.

\subsection{Taxonomy and Recommendations for Researching Ageism in the Labour Market}

This chapter examined indicators that asked about ageism-related beliefs, attitudes, and perceptions regarding the labour market. We disregarded more general ageist behaviours, attitudes, and feelings that were not related to the labour market. The 
Table 28.2 Taxonomy of measures of ageism in the labour market

\begin{tabular}{l|l|l|l}
\hline Topic/theme & Perspective & Defining (old) age & $\begin{array}{l}\text { Target population of surveys or } \\
\text { questions }\end{array}$ \\
\hline Recruitment/retention & View & $\begin{array}{l}\text { Opposing different age } \\
\text { groups }\end{array}$ & $\begin{array}{l}\text { General population vs. targeted } \\
\text { population }\end{array}$ \\
\hline Performance & Value & Specific age & Age limit \\
\hline Training & Attitude & Asking to define age & \\
\hline $\begin{array}{l}\text { Interaction with } \\
\text { colleagues }\end{array}$ & Perception & & \\
\hline Structural ageism & Experience & & \\
\hline
\end{tabular}

Source: Authors' preparation based on the overview done for this chapter

purpose was to map indicators of ageism in the labour market from existing largescale social surveys that are representative of countries' total populations, and that were carried out using internationally comparable methodologies. Table 28.2 presents a taxonomy of the studied measures (see Table 28.2). The measures, the taxonomy, and the surveys included in this analysis should not be taken as an exhaustive list. All of the surveys included here are carried out in several countries. Most of the observed indicators were measured only at one point in time, so change over time from an international perspective is not addressed in Table 28.2, but it is discussed in the text.

\subsection{Age: What Is Old?}

The age limits included in some survey questions were very broad. As a general rule, the definition of "old" depends on the country's cultural, social, and historical background. Some surveys or questions pre-defined "old", for example by limiting the age of the population that responds to the specific survey or question. Only one question, from the Activating Senior Potential in Ageing Europe survey, asked employers to specifically define old age ("At what age would you say a person is too old to be working 20 hours or more per week? "). Some outcomes of these measures may have multiple interpretation options in addition to indicating ageism towards older people in the labour market. For example, in the indicator that asked respondents specifically about people in their 20s and people in their 40s, the outcome may reflect a variety of situations, experiences, and policies relating to the educational system, labour market rigidity, occupation, and economic sector specificities of people from different age groups. To help mitigate this confusion, the definition of "old" should be very transparent or should be made very specific when ageism measures are being developed as well as when data is analysed. In surveys that allow for country-specific variations (as in the case of the World Values Survey), researchers should use additional documentation to research country information and should report such differences in measurements in their own research reports and articles. 
When surveys include separate questions with different age groups specified in the questions (for example: "Is a 30-year old boss acceptable?" and "Is a 70-year old boss acceptable?"), such indicators should be both used and compared in analyses.

\subsection{Target Population}

It is important to differentiate between the perspective of employees and employers when studying ageism in the labour market. When using surveys, the occupation of the respondent and the sector in which he or she is employed should be among the controlling factors. As employers are largely responsible for shaping organisational cultures and practices through communication (Henkens 2005; Solem 2015), specific surveys that target employers and would be conducted regularly might be especially useful. Some indicators not specifying a target population may be more suitable for assessing public opinion on ageism in the workplace.

\subsection{Development over Time}

All the indicators included in this study were measured only at one point in time. Regular measurements are needed to assess changes in attitude over time, the influence on attitudes of younger people entering the labour force, and the impact of policy or organisational reforms on attitudes. Longitudinal studies might provide the best opportunity to assess changes in ageist attitudes at the individual level, which might be influenced by personal or policy factors. The same might apply to employers' surveys.

\subsection{Context Matters}

Large international social surveys provide an opportunity to combine information from different spheres in a person's life; therefore, researchers of ageism indicators should make maximum use of existing surveys and the rich information within them. In addition to including indicators of overtly ageist attitudes, other more or less related events and characteristics should be controlled for, such as occupation, work history, and other related perceptions and attitudes. Specifically, satisfaction with life, satisfaction with the work environment, and satisfaction with colleagues can be seen as general proxies for subjective well-being (Muffels and Headey 2013), as well as subjective well-being in the labour market context (Tay and Harter 2013). 
Therefore, including these measures in research of ageism in the labour market may help explain ageist experiences of employees to an important extent. Studies should be able to address causality issues and to deconstruct the effects of attitudes, perceptions, organisational practices, employers' financial resources, structural barriers, and other factors influencing older adults' labour force participation and experiences.

Countries' contextual and historical backgrounds should be elaborated on in analyses of ageism in the labour market. As mentioned above, this may help to supplement information on demographic development (for example, regarding population ageing), how older people are seen in general in society, the context for developing certain attitudes, and how institutional settings have changed over time to accommodate these developments. Our descriptive analysis is only the first step in mapping ageism in the labour market on an international level. Future studies could aim to disentangle the relationship between measures and country contexts with regard to ageism in the labour market. With population ageing and transformations in the way work is done, ageism is an increasingly important topic for researchers and policymakers to address.

\subsection{Limitations}

This overview only mapped self-report measures that were mostly about attitudes, perceptions, and experiences of ageism in the labour market from quantitative social surveys. We acknowledge that some of the outcomes or country rankings might be explained by other factors, such as occupation or economic sector, the working environment, individual countries' policies and legislation, countries' historical and social contexts, and so on. For example, the measure we list under structural ageism (mandatory retirement as a reason for stopping work") can be seen to measure several things at the same time: the country's mandatory retirement age, respondents' willingness or unwillingness to work, and other factors. Therefore, future analysis should not only examine a single indicator. In addition, it would be useful to map "real-life data" or "hard data"- that is, measures of non-perception aspects of ageism in the labour market. These measures could include actual number of older workers in an organisation, number of trainings provided for older workers in comparison to younger people and their correspondence to the needs of people, contract and salary comparisons, and so on.

Another limitation of our study is that we have not included data with actual companies as the unit of analysis, capturing their hiring practices and promotion and retirement strategies. Including this data could give additional insights into the behaviour of employers. Even though such data have been collected, they are not currently publicly available. It was therefore not possible to include the results of these datasets in this overview. Finally, we carried out a descriptive analysis of 
available data, presenting an overview of measures from existing social surveys for the first time. This paper focused on identifying quantitative measures of ageism in the labour market and bringing out some basic descriptive results of country comparisons based on these measures. We recommend using these findings and measures from several surveys at the same time with more advanced statistical analyses to draw in-depth conclusions about ageism in the labour market.

Additionally, qualitative studies on ageism can provide in-depth information on the conceptualisation of age discrimination in employment (e.g., Roscigno et al. 2007) and the identification of practices that older individuals use, such as altering resumes, physical appearance, and language in order to increase their chances of being employed (Berger 2009). A number of studies offer insight into how to reexamine the hiring practices of employers or the retention of older workers (see, for example, Karpińska et al. 2011, 2013; Lazazzara et al. 2013). Data from qualitative studies on ageism in the labour market could be used to improve measures and surveys on this topic as well.

\subsection{Outlook}

There is an extensive collection of research tools for studying ageism in the labour market. Having data infrastructures in the form of international large-scale surveys makes it possible to conduct international comparative analyses of ageism in the labour market. Despite differences in the target population and in the wording of the questions, the existing surveys and measures provide a good opportunity to map attitudes and perceptions of ageism in the labour market with regard to recruitment, retention, performance, training of the workforce, and interaction with older colleagues. There are also ample opportunities for conducting rigorous internal validity tests of the indicators mentioned in this chapter.

The surveys examined in this overview allow information to be combined on several aspects of people's lives and their characteristics, which is highly advantageous. Cross-sectional analyses can be completed to assess change over time once the corresponding data become available.

\section{Appendix: List of Surveys}

Estonian Labour Force Survey (2009). Personal questionnaire. http://www.gesis.org/missy/files/ documents/EU-LFS/EE\%20LFS\%202009\%20Quest\%20Ind\%20Eng.pdf. Accessed 13 May 2016.

European Company Survey (2009). Management questionnaire. http://www.eurofound.europa.eu/ sites/default/files/ef_files/docs/surveys/ecs2009/questionnairemm.pdf. Accessed 13 May 2016. 
European Social Survey (2008). Round 4 Questionnaire. http://www.europeansocialsurvey.org/ docs/round4/fieldwork/source/ESS4_source_main_questionnaire.pdf. Accessed 16 May 2016.

European Working Conditions Survey, 6th survey (2010). Questionnaire. http://www.eurofound. europa.eu/sites/default/files/ef_files/surveys/ewcs/2010/documents/masterquestionnaire.pdf. Accessed 13 May 2016.

European Working Conditions Survey, 6th survey (2015). Questionnaire. http://www.eurofound. europa.eu/sites/default/files/page/field_ef_documents/uk_questionnaire.pdf. Accessed 13 May 2016.

Generations and Gender Survey (2003). Generations and Gender Survey Core Questionnaire for Wave 1. http://www.ggp-i.org/sites/default/files/questionnaires/GGP_QuestW1Core.pdf. Accessed 16 May 2016.

Generations and Gender Survey (2012). Generations and Gender Survey Core Questionnaire for Wave 2. http://www.ggp-i.org/sites/default/files/questionnaires/GGS_Wave2_ Questionnaire_V.2.0.pdf. Accessed 16 May 2016.

SHARE (2013). Wave 5 English generic main questionnaire. http://www.share-project.org/fileadmin/pdf_questionnaire_wave_5/SHARE_paperversion_5_4_10_en_GB.pdf. Accessed 16 May 2016.

World Values Survey (2012). Round 6 Questionnaire. http://www.worldvaluessurvey.org/ WVSDocumentationWV6.jsp. Accessed 16 May 2016.

\section{References}

Ayalon, L. (2013). Feelings towards older vs. younger adults: Results from the European Social Survey. Educational Gerontology, 39, 888-901. https://doi.org/10.1080/03601277.2013.7676 20

Berger, E. D. (2009). Managing age discrimination: An examination of the techniques used when seeking employment. The Gerontologist, 49(3), 317-332. https://doi.org/10.1093/geront/ gnp031

Blöndal, S., \& Scarpetta, S. (1997). Early retirement in OECD countries: The role of social security systems. OECD economic studies, No. 29, 1997/ II. http://www.oecd.org/eco/ growth/18378516.pdf. Accessed 19 July 2017.

Calasanti, T. M. (1996). Incorporating diversity: Meaning, levels of research, and implications for theory. The Gerontologist, 36(2), 147-156.

Conen, W., van Dalen, H., Henkens, K., \& Schippers, J. (2011a). Activating senior potential in ageing Europe: An employers' perspective (ASPA). Deliverable 12: Integrative international report on organisational surveys. The Hague: Netherlands Interdisciplinary Demographic Institute. http://www.aspa-eu.com/aspa_deliverables.htm. Accessed 13 May 2016.

Conen, W., van Dalen, H., \& Henkens, K. (2011b). Activating senior potential in ageing Europe: An employers' perspective (ASPA). Deliverable 1.1. Survey: Short report. The Hague: Netherlands Interdisciplinary Demographic Institute. http://www.aspa-eu.com/aspa_deliverables.htm. Accessed 13 May 2016.

Crenshaw, K. (1991). Mapping the margins: Intersectionality, identity politics, and violence against women of color. Stanford Law Review, 43(6), 1241-1299. https://doi.org/10.2307/1229039

De Castello Branco, M. (1998). Pension reform in the Baltics, Russia, and other countries of the former Soviet Union (BRO). Working Paper of the International Monetary Fund WP/98/11. http://www.imf.org/external/pubs/ft/wp/wp9811.pdf. Accessed 15 May 2016.

Duncan, C. (2003). Assessing anti-ageism routes to older worker re-engagement. Work, Employment \& Society, 17(1), 101-120. 
Duval, R. (2003). Retirement behaviour in OECD countries: Impact of old-age pension schemes and other social transfer programmes. OECD economic studies, no. 37, 2003//2. http://www. oecd.org/eco/growth/34561950.pdf. Accessed 19 July 2017.

García-Mainar, I., Montuenga, V. M., \& Navarro-Paniagua, M. (2015). Workplace environmental conditions and life satisfaction in Spain. Ecological Economics, 119, 136-146.

Henkens, K. (2005). Stereotyping older workers and retirement: The managers' point of view. Canadian Journal on Aging, 24(4), 353-366.

Hombrados-Mendieta, I., \& Cosano-Rivas, F. (2013). Burnout, workplace support, job satisfaction and life satisfaction among social workers in Spain: A structural equation model. International Social Work, 56(2), 228-246.

Jyrkinen, M., \& Mckie, L. (2012). Gender, age and ageism: Experiences of women managers in Finland and Scotland. Work, Employment and Society, 26(1), 61-77. https://doi. org/10.1177/0950017011426313

Karpińska, K., Henkens, K., \& Schippers, J. (2011). The recruitment of early retirees: A vignette study of the factors that affect managers' decisions. Ageing and Society, 31(04), 570-589.

Karpińska, K., Henkens, K., \& Schippers, J. (2013). Retention of older workers: Impact of managers' age norms and stereotypes. European Sociological Review, 29(6), 1323-1335.

Lazazzara, A., Karpińska, K., \& Henkens, K. (2013). What factors influence training opportunities for older workers? Three factorial surveys exploring the attitudes of HR professionals. The International Journal of Human Resource Management, 24(11), 2154-2172.

McNair, S. (2006). How different is the older labour market? Attitudes to work and retirement among older people in Britain. Social Policy and Society, 5(04), 485-494.

Muffels, R., \& Headey, B. (2013). Capabilities and choices: Do they make Sen'se for understanding objective and subjective well-being? An empirical test of Sen's capability framework on German and British panel data. Social Indicators Research, 110(3), 1159-1185.

Nugin, R., Kannike, A., \& Raudsepp, M. (2016). Generations in Estonia: Contemporary perspectives on turbulent times. Approaches to culture theory (Vol. 5). Tartu: University of Tartu Press.

O'Dempsey M., \& Beale A. (2011). Age and employment. European network of legal experts in the non-discrimination field. Supervised by Mark Freedland. European Commission Directorate General for Justice. http://ec.europa.eu/justice/discrimination/files/age_and_employment_ en.pdf. Accessed 19 July 2017.

OECD. (2013). Pensions at a glance 2013: OECD and G20 indicators. Paris: OECD Publishing. https://doi.org/10.1787/pension_glance-2013-en

Perek-Białas, J., \& Turek, K. (2012). Organisation level policy towards older workers in Poland. International Journal of Social Welfare, 21(s1), S101-S116.

Phillipson, C. (2004). Older workers and retirement: Critical perspectives on the research literature and policy implications. Social Policy and Society, 3(02), 189-195.

Puur, A. (2000). Changes in economic status of older population: The case of Estonia in the 1990s. Estonian Interuniversity Population Research Centre, RU series B no 42, Tallinn.

Roscigno, V. J., Mong, S., Byron, R., \& Tester, G. (2007). Age discrimination, social closure and employment. Social Forces, 86(1), 313-334.

Skirbekk, V. (2004). Age and individual productivity: A literature survey. Vienna Yearbook of Population Research, 2, 133-153.

Solem, P. E. (2015). Ageism and age discrimination in working life. Nordic Psychology, 68(3), 160-175. https://doi.org/10.1080/19012276.2015.1095650

Sonnet, A., Olsen, H., \& Manfredi, T. (2014). Towards more inclusive ageing and employment policies: The lessons from France, The Netherlands, Norway and Switzerland. De Economist, 162, 315-339. https://doi.org/10.1007/s10645-014-9240-x

Tay, L., \& Harter, J. K. (2013). Economic and labor market forces matter for worker well-being. Applied Psychology: Health and Well-Being, 5(2), 193-208. 
Taylor, P., \& Walker, A. (1998). Policies and practices towards older workers: A framework for comparative research. Human Resource Management Journal, 8(3), 61-76.

Turek, K., \& Perek-Białas, J. (2013). The role of employers opinions about skills and productivity of older workers: Example of Poland. Employee Relations, 35(6), 648-664.

Open Access This chapter is licensed under the terms of the Creative Commons Attribution 4.0 International License (http://creativecommons.org/licenses/by/4.0/), which permits use, sharing, adaptation, distribution and reproduction in any medium or format, as long as you give appropriate credit to the original author(s) and the source, provide a link to the Creative Commons license and indicate if changes were made.

The images or other third party material in this chapter are included in the chapter's Creative Commons license, unless indicated otherwise in a credit line to the material. If material is not included in the chapter's Creative Commons license and your intended use is not permitted by statutory regulation or exceeds the permitted use, you will need to obtain permission directly from the copyright holder. 


\title{
Chapter 29 \\ Researching Ageism in Health-Care and Long Term Care
}

\author{
Sandra C. Buttigieg, Stefania Ilinca, José M. S. de Sao Jose, \\ and Annika Taghizadeh Larsson
}

\subsection{Introduction}

Even as the literature documenting the numerous negative consequences of ageism for the experiences of older people is constantly growing (Minichiello et al. 2000; Dionigi 2015; Chrisler et al. 2016), ageism remains an elusive concept, interchangeably used to cover a wide range of phenomena. Research on ageism across contexts reveals the equivocal manner in which it is defined. Existing definitions of ageism cover intolerant knowledge, values, attitudes and behaviors towards older people or more generally, people of a certain age. Commonly, ageism is distinguished from age discrimination, the latter often defined as only one of many possible manifestations of ageism, and used in the context of labor market research to describe the manifest preference for younger employees. It is important to recognize that there is a spectrum of concepts related to ageism depending more often than not on the context in which it is studied. In this chapter, we aim to provide an overview of how

\footnotetext{
S. C. Buttigieg $(\bowtie)$

Department of Health Services Management, Faculty of Health Sciences, University of Malta, Msida, Malta

e-mail: sandra.buttigieg@um.edu.mt

S. Ilinca

European Centre for Social Welfare Policy and Research, Vienna, Austria e-mail: ilinca@euro.centre.org

J. M. S. de Sao Jose

Faculty of Economics, University of Algarve, Faro, Portugal

e-mail: jsjose@ualg.pt
}

\author{
A. T. Larsson \\ Division Ageing and Social Change, Linkoping University, Norrkoping, Sweden \\ e-mail: annika.t.larsson@liu.se
}


ageism is defined, measured and assessed in research on healthcare and long-term care, and use some of the emerging research evidence for the existence of ageism in these two contexts in order to exemplify. Focusing on ageism (focusing, for the purpose of this chapter on its relation to old age) we aim to critically analyze the conceptualization and measurement/assessment of ageism in existing empirical literature covering the wide spectrum of care from emergency and acute care to chronic and long-term care of older adults in order to make recommendations for future research. In so doing, we aim to provide insights into the various theoretical/ conceptual and methodological approaches that researchers can employ for measuring and assessing ageism. As part of the Memorandum of Understanding for the implementation of a European Concerted Research Action, designated as 'COST Action IS1402: Ageism - a multi-national, interdisciplinary perspective', of which the authors form part, five methodological aspects related to ageism were selected as relevant. These are assessment; spatial design; prevalence, antecedents and consequences; intervention; conceptualization and theory.

In this chapter, we focus on two of the aforementioned aspects, namely 'assessment' and 'conceptualization and theory' and aim to answer the following questions:

(i). Why is it important to know how ageism in healthcare and long-term care has been empirically studied? (Sect. 29.1)

(ii). What evidence for the existence of ageism among key stakeholders (e.g. health care professionals and long-term care workers, family members and older adults) is reported in empirical research covering these two contexts? (Sect. 29.2)

(iii). Which are the conceptual and methodological approaches used to measure and assess ageism involving these key stakeholders in the two contexts? (Sects. 29.3 and 29.4)

\subsection{Why Is It Important to Know How Ageism in Healthcare and Long-Term Care Has Been Empirically Studied?}

Health and long-term care represent important settings in relation to old age and ageism as they cover the full pathway of delivery of care related to health and illness that older adults often need to access. As populations are ageing, in particular in developed countries, increasing numbers of older adults pass through the wide spectrum of care from emergency and acute care to chronic and long-term care on a daily basis. The spectrum of care includes community and public health, primary care, emergency medicine, acute care, care of chronic illness and long term care - both institutionalized, as well as home/community-based. Health care and long-term care are complimentary yet diverse in the services offered, acuity of care, characteristics of health care professionals caring for older people, as well as in 
terms of proportion and age of older persons cared for. In particular, long-term care tends to have a higher percentage of vulnerable oldest old. Additionally, length of stay is longer in these settings, thereby potentially increasing the possibilities for discriminatory situations to arise. Furthermore, the level of education and training of care-workers in long-term settings may be very different from that of health care professionals in acute settings.

Our focus on ageism in health and long-term care is further motivated by huge gaps in the literature with regard to the real needs of care for this age group, a situation that may be interpreted as ageist and specifically deficient in focus when it comes to delivery of care for older people. This is most probably due to the fact that the younger age groups have more often than not attracted attention from health policy makers, as well as from hospital and primary care administrators and providers (Robb et al. 2003; American Diabetes Association 2015). Gatz and Pearson (1988) labeled the attitudes shown toward older adults, namely the specific treatment biases that are based on negative misconceptions, as a problem and defined it as "professional ageism." Specifically, Hunold et al. (2016) remarked that emergency departments (ED) are progressively becoming a critical site of care for older adults, but there is still minimal knowledge regarding the priorities of care delivery for this population. The same authors identified accuracy and efficiency of the medical evaluation as the most common but lacking priorities among older adults in the ED. Similarly, Aminzadeh and Dalziel (2002) argued that the currently practiced disease-oriented and discontinuous models of emergency care are not sufficient to match the multidimensional needs of frail older patients, who have divergent patterns in terms of care needs, as well as service use (Scott et al. 2007). This situation calls for further research to assess the effectiveness of triage and intervention strategies pursuing vulnerable older ED patients. With regard to acute care, particularly inpatient services, the major users are older people - a contribution of the ageing population but also a reflection of the evolving patterns of disease, i.e. chronic with acute complications, multiple comorbidities and functional consequences (Koch et al. 2009). Indeed, most health care systems are adapting to this change in users/patients age groups by redesigning and shifting care for younger adults to the community, primary care and day care where possible (Koch et al. 2009). However, one still questions the persistently reported fragmented care of older adults and urgently calls for an older patient priority-directed and holistic decision-making process that addresses the needs of older adults with multiple chronic conditions (Tinetti et al. 2016).

Fried and Ferrucci (2016) highlight the fact that the contribution of aging to chronic diseases can no longer be toned down. Geriatricians and gerontologists have approached this problem through the conceptualization of frailty as a diagnosable clinical syndrome characterized by marked susceptibility to stress, underlying loss of resiliency and diminished functional reserve. In health services, which cater for the care of chronic diseases, as well as in long-term settings, there is the tendency for professionals who may have internalized ageist attitudes during their formative years to use patronizing talk to older people, which Nelson (2005) considers as self-fulfilling prophecies that can translate ageist stereotypes into actual behavior and eventually into lower levels of older persons' empowerment of their care. 
Furthermore, Coleman (2003) and Boockvar et al. (2004) identify transitioning of care from health to long-term care facilities as commonplace for older adults, who are often somewhat 'lost' or 'sidelined' in terms of clinicians' priorities particularly when long lengths of stay in acute settings are mainly due to lack of space in long-term institutions. Indeed, older patients in acute settings are often considered a burden on the health system and are labelled as 'social cases' (Cohen et al. 2014) or 'bed-blockers' (Hawkes 2016). Perhaps more distressing is that at the far end of the spectrum of care, Condelius and Andersson (2015) state that there are gaps in the literature as to what care older people access throughout the last stages of their life, as well as which factors enable access to care in this group.

Statistics from the United Nations predict that by 2030, older persons are expected to account for more than $25 \%$ of the populations in Europe and in Northern America, 20\% in Oceania, 17\% in Asia and in Latin America and the Caribbean, and 6\% in Africa (United Nations World Populations Ageing 2015). Therefore, it is more likely that in the foreseeable future, the need for services in health and longterm care will continue to increase as will the risk that older people are not looked upon and treated as full citizens in these settings.

From such accounts it becomes evident that a structured analysis of ageism in health and long-term care is both timely and pertinent. However, without a comprehensive conceptualization and operationalization of ageism efforts to measure and assess the multiple manifestations of ageism in these two contexts are bound to fail. Consequently, we are not able to fully tackle ageism in practice. It is therefore important to evaluate the state of empirical research concerning ageism in both health and long-term care in terms of, identifying the definitions used, and the conceptual and methodological approaches applied. Only by so doing can we uncover the strengths and weaknesses of research in this field and help guide future research efforts towards the areas most in need of being addressed.

Finally, we hope that our results can contribute to the development of what we consider that acceptable quality of care for older adults should embrace; that is, the holistic bio-psychosocial model delivered by interdisciplinary teams of health care professionals, who are competent in the care of older people and that steers away from fragmented, chaotic and ageist delivery of care. This model of care is becoming even more relevant in view of emerging evidence that the integration of attitudes, values, standards and opinions referred to as internalization of ageist stereotypes is related to memory failures, physical frailty and risk of cardiovascular events (Levy 2009).

\subsection{Evidence for the Existence of Ageism in Health and Long-Term Care}

This section is organized in two subsections, one focused on health care and the other one on long-term care. In both sections we consider the evidence in relation to three groups of research participants, namely care professionals, family members and 
older people. In providing an overview of the evidence of ageism and ageist practices in health and long-term care, we consider each sector separately. Our choice reflects the clear separation in the specialized literature between analyses in health or in longterm care settings, with virtually no overlap or joint consideration in extant studies. It is also important to draw attention to the fact that each subsection considers evidence of ageism in relation to three stakeholder groups, namely health and long-term care professionals, family members and older people. This stands in recognition of their separate but equally important roles in the process of care.

\subsection{Ageism in Health Care}

Existing empirical research on ageism in health care mainly involves health care professionals across different disciplines (São José et al. 2017). Examples include doctors in primary health care, where ageism is related to clinical decision-making (Adams et al. 2006; Arber et al. 2006), physicians in hospital in their recommendations for physical activity among individuals with arthritis (Austin et al. 2013), unfair judging by Florida physicians of older adults simply because of their advanced age (Gunderson et al. 2005). Other examples are physicians deciding on access to critical care that is influenced by age against older people (Hubbard et al. 2003), and significant differences in access to treatment, depending on the patients' chronological age and prescribing chemotherapy less frequently as the patients' chronological age increase (Protiere et al. 2010).

There are also studies focusing on ageism in research in health care, involving researchers in diabetes. Here, evidence of ageism is related to "the extent of exclusion of older individuals from ongoing clinical trials regarding type 2 diabetes mellitus" (Cruz-Jentoft et al. 2013; p. 734) and "(...)"whether exclusion of older people was prevalent in research proposals submitted to Dublin teaching hospitals" (Briggs et al. 2012, p.311).

Another group of health professionals involved in the body of research on ageism in healthcare is nurses, such as nurses caring for individuals with spinal cord injury (Furlan et al. 2009, p. 674). In one of these studies (Gething et al. 2002), evidence of ageism is related to patterns of stereotyping among nurses in Australia and the United Kingdom. Furthermore, Kydd et al. (2014) described attitudes of nurses and nursing students in Scotland, Sweden and the US towards working with older people. Moreover, Holroyd et al. (2009) reported that negative biases and ageist attitudes among caregivers, and particularly nurses, toward older people in acute care settings, are among the more notable expressions in the health care system.

Some studies report on evidence of ageism in distinct areas of specialization, namely psychiatry (Bouman and Arcelus 2001) in the sense of taking a sexual history far more frequently of middle-aged men and of neglecting to do so in older male patients, and oncology (Kearney et al. 2000), whereby healthcare professionals (physicians, nurses and radiographers) may discriminate against older people. 
There are also studies that provide evidence of ageism involving older adults themselves. Chambaere et al. (2012) reported that the level of involvement of patients in decision making to intensify pain alleviation decreases with increasing age. Additionally, Koch and Webb (1996) described the 'conveyor belt' way of organizing care in wards, whereby patients dominated by the demands of the work timetable, powerless to have any influence on their own care and unable to express their individual needs. These authors also reported segregation in that providers label older adults as "old". Furthermore, Makris et al. (2015) reported that ageism emerged as a result of dismissing or minimizing comments by providers that can serve to inform or reinforce older adults' beliefs that back pain is directly related to old age, or perhaps, that providers have nothing more to offer.

\subsection{Ageism in Long-Term Care}

Existing empirical research on ageism in long-term care contrasts with that in healthcare in that the studies more often involved older adults and family members and less frequently care professionals as participants. This may be due to the fact that the subjects are more easily accessible in long-term care.

Most studies on ageism in long-term care involve residents in long-term institutions (Ayalon 2015; Bodner et al. 2011; Dobbs et al. 2008; Doyle 2014; Gamliel 2000; Lagace et al. 2011, 2012; Macdonald and Butler 2007; Roth et al. 2012, 2015; Taverna et al. 2014; Zimmerman et al. 2014). Ayalon (2015) reported a prominent general view of old age as a sign of decline and decay. This negative view of old age was stated as prominent among adult children, as well as their older parents. Zimmerman et al. (2014) also report evidence of ageism, namely physical environment (environmental press [ex.: not repairing a bathroom nearby because of budget restrictions]; not using social space for engagement [ex.: sticking all the older people in the front and leave them there]); using labels to describe different types of residents; multi-level settings (not minimizing "us" versus "them" [ex.: older people who are relatively autonomous and older people who are dependent]); independence (not supporting autonomy [e.g.: discouraging older people from doing certain tasks]); respect (not valuing the resident [ex.: feeling like a prisoner]); privacy (not providing privacy); care provision (not taking the focus off of decline [e.g.: reinforcing dependence and decay]; constant supervision).

Several studies on ageism in long-term care involved health care professionals, care workers and administrators of long-term institutions (Band-Winterstein 2015; Billings 2006; Dobbs et al. 2008; Dunworth and Kirwan 2012; Lagace et al. 2011; Reyna et al. 2007; Roth et al. 2012, 2015; Taverna et al. 2014; Wells et al. 2004; Zimmerman et al. 2014). For example, Band-Winterstein (2015) reported ageism as neglect in the everyday routine of care with the following emerging themes (being transparent; being invisible; being forgotten; perceiving older patients as no longer human; being treated as an object, in an automated fashion; lack of accurate medical diagnosis; using ageist language; using less expensive materials on older patients, 
because money is not wisely spent on older persons; older persons lose their sexuality, which justifies mixed communal and social participation of older people); and avoidance (attitudes and behaviour regarding social contact with older people). Billings (2006) reported evidence of ageism in professionals from health care and social care in terms of insensitive treatment in relation to communication and attitude; excluding older people from conversations, sensitive or otherwise; shouting at older people; being patronising; little assessment of the preferred way that older people like to be addressed; not giving an older person enough privacy when helping them with activities such as toileting, washing or dressing; letting older people have a limited choice in things such as when and what they eat, when they go to bed or have a bath; older people are given too many tablets which are not reviewed often enough; and that there are assumptions that older people are not sexually active.

There are also a few studies in this body of research that involved family members as subjects (Ayalon 2015; Condelius and Andersson 2015; Dobbs et al. 2008; Roth et al. 2012, 2015; Zimmerman et al. 2014). In particular, Condelius and Andersson (2015) reported ageism among the next of kin, "in that they perceive some conditions and complaints as a natural part of ageing with further examinations or treatments being regarded as "pointless" or even "wasted" (p. 11).

To sum up, existing empirical research in the contexts of health and long-term care provides an interesting continuum and diversity in terms of the evidence of ageism provided and the stakeholder groups that are surveyed.

\subsection{Theoretical and Conceptual Approaches in the Study of Ageism}

On an overall level, what appear as most striking in relation to theoretical and conceptual approaches in the empirical study of ageism in health and long-term care is that most studies in both of these areas do not, at least explicitly, apply any theory, and that very few studies use theories of ageism. Thus, the literature on ageism in health and long-term care appears as under-theorized. Particularly striking is the relative absence of theories of ageism. While the vast majority of the literature is occupied with studying the causes, the consequences and possible preventive strategies of ageism, scant attention has been paid to its conceptualization (Iversen et al. 2009). As many, non-harmonized definitions coexist in the field, the formulation of a general theory on the causes and effects of ageism, which can help ground empirical research in a coherent fashion, is rendered impossible (Iversen et al. 2009). In fact, our survey of the empirical literature on ageism in health and long-term care yielded a majority of studies that altogether lack any references to a theoretical framework and that are underpinned by definitions and conceptualizations of ageism, often only implicitly defined.

Interestingly, even when established theoretical frameworks are included, they are rarely theories specifically focused on ageism of ageism. The literature on ageism 
in health care is affected by the disconnect between empirical work and theoretical thinking on ageism. While a minority of studies is grounded in the conceptual works of Butler (1969), Butler and Lewis (1973), Bytheway and Johnson (2001), Levy et al. (2006), the vast majority fail to mention any theoretical framework or to interpret their results within a broader theoretical context. Other theoretical frameworks not specific to ageism, but employed in selected studies on ageism in health care include psychological models of clinical decision-making, the Behavioral Model of Health Services Utilization, The social ecological perspective (Moos 1979; Stokols 1992; Parke \& Chappell, 2010) and Allport's intergroup contact theory (Ajzen 2005). Theories that are normally used to study/discuss ageism in long-term care (São José et al. 2017) are as diverse as Goffman's perspectives on stigma and depersonalization in institutions are applied, Age Stratification Theories, Foucault's perspectives on power, and Normative Ethical Theories are employed by authors, while Terror Management Theory (Solomon et al. 1991) or Social Identity Theory (Turner and Reynolds 2010), that explicitly refers to the concept and phenomenon of ageism, if at all mentioned, are relegated to the discussion sections.

To date, the most comprehensive conceptualization attempt for ageism is offered by Iversen et al. (2009) in their seminal paper on the conceptual analysis of ageism. Starting from an in-depth review of existing definitions and theoretical works, they structured the core aspects of ageism along four dimensions and proposed and enriched, multi-dimensional conceptualization: "Ageism is defined as negative or positive stereotypes, prejudice and/or discrimination against (or to the advantage of) older people on the basis of their chronological age or on the basis of a perception of them as being 'old' or 'elderly'. Ageism can be implicit or explicit and can be expressed on a micro-, meso- or macro-level".

As identified by the authors, the key dimensions in the ageism concept are the three classical components (cognitive-stereotypes, affective-prejudice, behaviouraldiscrimination); the positive/negative aspect (positive ageism, negative ageism), the conscious/unconscious aspect (explicit ageism, implicit ageism); and the levels at which ageism can manifest (micro-level ageism, meso-level ageism, macro-level ageism) (Iversen et al. 2009). To these dimensions, Sao Jose and Amado (2017) add the self-directed/other-directed aspect of ageism, manifesting exclusively at the micro-level, in recognition of the prevalence of negative stereotypes towards people of one's own age or towards oneself, a phenomenon aptly described by Bodner et al. (2011) as 'self-ageism'.

Mapping existing empirical literature on ageism in health and long term-care over the main components of ageism, a spectrum of 32 possible variants of ageism emerges at their intersection (see Table 29.1). Not surprisingly, no studies in the empirical literature on ageism in health and long-term care recognize and account for the complexity of the ageism concept along all five dimensions (see Table 29.1 for a visual depiction of the different variants of ageism and an overlayed mapping of the empirical literature on ageism in the two settings). In fact, as numerous contributions rely on Butler's classical definition of ageism (1975) they recognize only five of the 32 components, namely: cognitive, behavioural, other-directed, explicit and negative ageism. Even more recent definitions of ageism that have been 
Table 29.1 Variants of ageism and literature mapping

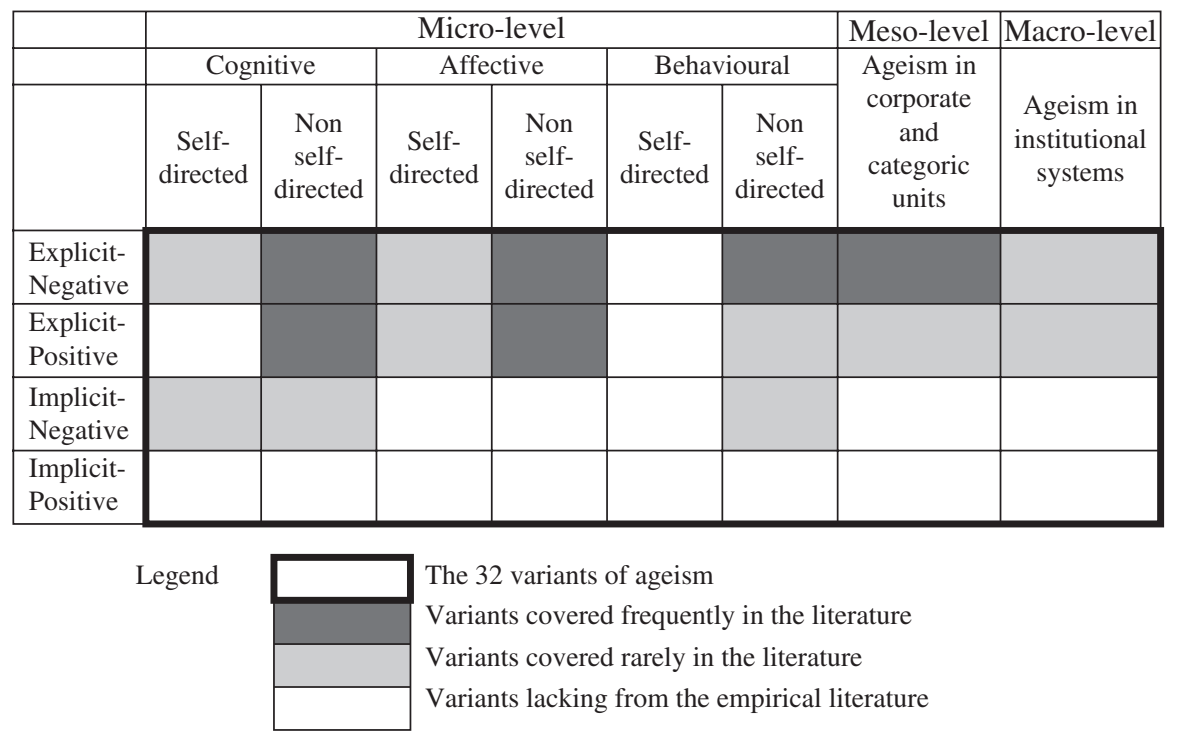

Source: Adapted from Iverson et al. (2009) and Sao Jose and Amado (2017)

employed in the empirical literature, as those proposed by Cuddy et al. (2005), Greenberg et al. (2002), Levy and Banaji (2002) and others, while generally more comprehensive in their scope, cover at most 10 components.

\subsection{Comparison of Research on Ageism in Health and Long-Term Care}

Concerning differences between the empirical literature on ageism in health and long-term care, among the three classical components of ageism, discrimination against people of a certain age, that is the behavioral components, is by a large margin most represented in the empirical literature on ageism in health care. The majority of studies concern themselves with identifying forms of discrimination in diagnosis (Adams et al. 2006, Arber et al. 2006, Rudd et al. 2007, Bond et al. 2003), discrimination in treatment and management (Koch and Webb 1996; Chambaere et al. 2012; Pedersen and Mehlsen 2011; Grant et al. 2000; Gnavi et al. 2007; Austin et al. 2013), discrimination in access to research and clinical trials (Cruz-Jentoft et al. 2013; Briggs et al. 2012) and differences in survival rates (Peake et al. 2003; Grant et al. 2000). The cognitive component, mainly addressed in qualitative studies, is generally reflected in research on the stereotypes and assumption about older patients not belonging in specific care institutions (Parke and Chappell 2010), about symptoms that are "normal" at more advanced ages (Iliffe et al. 2005; Makris et al. 2015) and about expected responses to treatment (Skirbekk and Nortvedt 2014). 
Finally, analyses of the affective component are all but absent in the literature on health care, with only one, recent study discussing prejudice towards older people, ageing and old age (Kydd et al. 2014) identified in our literature survey. The literature on ageism in long-term care, on the other hand, presents a more balanced division of interest between the three components. Negative stereotypes about the condition and abilities of older individuals (Band-Winterstein 2013; Billings 2006; Condelius and Andersson 2015) and about old age in general (Ayalon 2015; Gamliel 2000; Petersen and Warburton 2012; Roth et al. 2012) as well as negative reactions and prejudices towards older people (Dobbs et al. 2008; Roth et al. 2012; Natan et al. 2013; Wells et al. 2004) are well mapped in empirical studies. Finally, studies of discrimination against older adults in long-term care include such diverse topics as controlling the interaction and using inappropriate and diminishing language with older individuals (Band-Winterstein 2013; Lagacé et al. 2011; Doyle 2014), limiting older individuals' privacy (Billings 2006), providing sub-standard care (Band-Winterstein 2013; Doyle 2014) and segregating residents in long-term care facilities within age groups (Roth et al. 2012).

The representation of other ageism dimensions in the empirical literature is also highly skewed. We were able to identify only one study focusing on ageism in health care that explicitly considers positive stereotypes about ageing (Gunderson et al. 2005). Research on long term care more often recognizes the positive aspect of ageism (Lagacé et al. 2011; Natan et al. 2013; Wells et al. 2004) although it rarely takes a central place in the analysis. A noteworthy exception is the study of Taverna et al. (2014) who link the desire on the part of long-term care staff to respect residents' independence and autonomy due to their age (positive discrimination) to improper oral hygiene (a negative health outcome). This imbalance towards negative aspects of ageism is likely driven by a desire among researchers to identify those attitudes and behaviors that are likely to harm older individuals and lower the quality of the care they receive, in order to find ways to curtail them. However, the study of Taverna et al. (2014) is a case in point that all ageist attitudes and discrimination, even positive ones, can have negative effects, albeit unintended ones, and should therefore be considered in research more often.

Further differences between research on ageism in health and long-term care are that empirical studies on ageism in health care exclusively address the non self-directed aspect. This situation likely stems from the nature of interactions between older patients and their health care professionals, characterized by large information and control imbalances, shorter care spells and a focus on symptoms and disease. In long-term care, however, where older individuals interact both with caregivers and other residents for longer periods of time and with a more general goal of addressing both physical and psychological wellbeing of the care recipients, issues related to self-directed ageism are more salient. The empirical research on ageism in long-term care includes studies on ageist attitudes among older individuals themselves (Ayalon 2015) and discriminatory behaviors towards other older aged groups (Roth et al. 2012), as well as how these attitudes and behaviors are shaped by the specificities of the community or residential care environment (Gamliel 2000; Bodner et al. 2011). 
Concerning similarities between research on ageism in health and long term care, due to obvious difficulties in their systematic study, implicit stereotypes, prejudices and discrimination are rarely acknowledged in both bodies of the empirical literature and are addressed almost exclusively in qualitative studies. They address the existence of stereotypes and assumptions about older patients and residents that care professional hold, without being consciously aware of their presence or harboring any ill intention. Nonetheless, such attitudes can lead to improper care (Skirbekk and Nortvedt 2014) or delayed diagnosis, assessment (Pedersen and Mehlsen 2011) and treatment (Iliffe et al. 2005; Makris et al. 2015) with clear risks for negative health outcomes. Research on ageism in long-term care has also almost exclusively focused on explicit ageism, although a series of recent studies carried out in Canada (Lagace et al. 2011, 2012) on communication patterns between older adults and their caregivers in residential environments had uncovered that ageist language and attitudes are often employed by caregivers.

\subsection{Methodological Approaches in the Study of Ageism}

From our review of the literature, it is immediately apparent that ageism in health care is prevalent but immensely vague as a concept. It is important to consider the balance between older patients' experiences demands, real needs and ethical considerations when analyzing contexts, settings and case studies. This renders measurement even more difficult to achieve. Similarly, in long-term care, Sao Jose and Amado (2017) argue that despite the fact that ageism is "pervasive", it is difficult to define, identify, measure and most important of all to fight. Indeed, they call for research strategies that are capable of detecting, measuring and understanding the multidimensionality/complexity of ageism.

As should by now be apparent, the empirical literature on ageism in health and long-term care addresses a wide variety of forms and manifestations of ageism in these specific settings, which reflect into the diversity of study designs and tools employed by authors. As measurement is both difficult and essential in this field of research, in this section we turn our attention to methodological aspects. In very broad terms, we can talk of two main categories of studies: (i) those attempting to identify or capture ageism and that avail of qualitative methodological approaches and (ii) those that strive to measure or quantify manifest ageism and that rely on quantitative methodological approaches. Each is further described below, with a view of comparing and contrasting the bodies of research in health and in long-term care. In both fields, mixed methods studies are conspicuously rare. We identified only a couple of studies on ageism in health care (Adams et al. 2006; Arber et al. 2006), and only two contributions in long-term care focused research (Lagace et al. 2011; Taverna et al. 2014). As a consequence, we do not treat them as a separate category. This is an unfortunate gap in existing research, as mixed methods approaches offer researchers the opportunity to triangulate and more convincingly validate findings via different methodologies. 


\subsection{Comparison of Research on Ageism in Health and Long-Term Care}

\subsubsection{Qualitative Approaches}

Qualitative studies of ageism in both health and long-term care rely predominantly on interviews for data collection. Researchers generally choose a semi-structured format for interviews, although structured, open and in-depth interviews are also common, and often complement them with other data collection methods. Focus groups and participant observation are also commonly employed methods, in conjunction with interview based data collection (Makris et al. 2005; Skirbekk and Nortvedt 2014; Billings 2006; Gamliel 2000; Lagace et al. 2011) but also as the principle data collection method (Iliffe et al. 2005). Less prevalent in the empirical literature is the use of document analysis (Petersen and Warburton 2012). While many studies do not specifically identify the data analysis methods employed, thematic analysis, content analysis, discourse analysis and ethnographic analysis are commonly cited by authors.

While studies from both categories stated above have addressed ageism both in health and in long-term care settings, imbalances between the frequencies of application of qualitative versus quantitative approaches are apparent in both fields. Namely, qualitative approaches predominate in research on ageism in long-term care, whereas the vast majority of studies of ageism in health care belong to the second category. A systematic review of the literature on ageism in long-term care (Sao Jose and Amado 2017). reveals that qualitative studies are overrepresented in this field and more than twice as numerous as a quantitative approach. Therefore, the variety of qualitative methods employed is higher in the empirical long-term care literature with respect to that focused on health care.

Interestingly, qualitative studies in long-term care seem to favour the selection of older individuals themselves as study participants (Bodner et al. 2011; Doyle 2014; Lagace et al. 2012), in the slight detriment of care professionals (Band-Winterstein 2013; Billings 2006) and family members (Ayalon 2015; Condelius and Andersson 2015). Conversely, in health care based studies, care professionals are relatively more likely to be the subjects of qualitative studies (Skirbekk and Nortvedt 2014; Iliffe et al. 2005), although older adults are also often interviewed with regard to their in-patient and general care experiences (Koch and Webb 1996; Parke and Chappell 2010). We stress that a majority of qualitative studies focus exclusively on one participant group and fail to acknowledge the perspectives of other key actors. As the results cannot be cross-checked and compared, this lack of triangulation in participant selection can lead to one-sided accounts and paint only partial pictures of the contexts the studies attempt to describe. It is however, worth noting that a lack of diversity in participant selection is a problem that affects more severely the literature on ageism in health care. By comparison, qualitative studies in long-term care more routinely include two or all key stakeholders -i.e. older adults, family members and care professional (Dobbs et al. 2008; Lagace et al. 2011; Roth et al. 2015). 
Concerning similarities between the two fields of research, we note a disproportionate preference for studies based in residential care settings, both in the health care and the long-term care literature. When studying the experience of older adults in the health care system, researchers predominantly select in-patient settings and only rarely interview older adults outside the hospital setting (Makris et al. 2015). Similarly, ageism in long-term care is overwhelmingly studied in residential facilities, be they nursing/care homes, assisted living facilities or retirement communities. Only one study selected participants living in their own homes to analyze their experiences in receiving community based formal care (Doyle 2014). Equally rare are research efforts that span care settings. Most noteworthy, Billings (2006) finds evidence of ageist attitudes and discrimination against older people among professionals in health and social care services, working both in the community and in residential and medical care settings. The lack of diversity in the selection of the study setting is a significant shortcoming of empirical research on ageism in both health and long term care, as it fails to reflect the experiences of a wide majority of older individuals, who reside in the community and whose interaction with care professionals is only episodic. While it is understandable that this bias arises as an expression of convenience in participant selection and data collection, it constitutes one of the most significant remaining gaps in qualitative research on ageism.

\subsubsection{Quantitative Approaches}

While outnumbered by qualitative studies in the literature on ageism in long-term care, quantitative studies represent an overwhelming majority of research contributions on ageism in health care settings in our survey. The preferred data collection method, by a wide margin, is the administration of questionnaire based surveys to a selected population of interest. Common methods of survey administration include telephone-based (Austin et al. 2013; Jerant et al. 2004), mail-based (Kearney et al. 2000; Protiere et al. 2010) and direct distribution to participants (Kydd et al. 2014). Virtually all quantitative studies on ageism in long-term care rely on validated scales of ageism for data collection, while in the literature focused on health care a mix of ad-hoc survey instruments (Bouman and Arcelus 2001; Gunderson et al. 2005) and validated instruments is used (please refer to the next section for an overview of the main scales used to measure ageism). While sample sizes and response rates vary widely, in relation to the specific participant population targeted, numerous studies draw on small samples (less than 100 respondents), pointing to a necessity to replicate and reconfirm these findings in other settings and on larger groups in order to establish to what extent their results are generalizable.

While entirely absent from the long-term care literature, studies with randomized experimental designs eliciting the assessment of care professionals for patient/ case vignettes or video clips are not uncommon in health care focused research (Adams et al. 2006; Arber et al. 2006). Similarly, in the health care setting, studies of ageism are also based on registry data (Cruz-Jentoft et al. 2013), on analysis of 
case documentation and files (Bond et al. 2003; Peake et al. 2003), on auditing of clinical research proposals (Briggs et al. 2012), on the analysis of death certificates (Chambaere et al. 2013) and of hospital and other regional medical databases (Gnavi et al. 2007; Grant et al. 2000; Rudd et al. 2007). Due to the lack of coordinated data collection efforts, among other constraints, such studies are rendered virtually impossible and in fact, lack completely, from the empirical literature on ageism in long-term care. Not surprisingly, the range of data analysis methods employed parallels the diversity of methodological approaches to data collection. The most prevalent forms of statistical analysis used include descriptive statistics, analysis of variance and analysis of covariance techniques, factor analysis and regression analysis, but other approaches, driven by the particularities of the collected data can also be identified.

Quantitative studies of ageism using surveys for data collection are almost exclusively directed at care professionals, rather than care users (i.e. older people) both in health and in long-term care. Studies like Bodner et al.' (2011), using self-completion questionnaires to examine differences in ageist attitudes and perceived quality of life among older persons living in residential facilities and in the community, are exceedingly rare in the literature on long term care and, to the best of our knowledge, no similar studies exist in the health care focused literature. Noticeable is also the lack of quantitative studies on ageism that include family members among participants, both in health and long-term care. It is therefore evident that quantitative research has, to date, failed to recognize and appropriately map all relevant actor groups, leaving the perspective and experiences of relatives and close family circles covered exclusively by qualitative research efforts.

The problem of under-representation of diverse settings in studies of ageism in long-term care described above carries fully to the quantitative research literature. Virtually all studies collect data from only one care setting, overwhelmingly a residential care facility (Dunworth and Kirwan 2012). To the best of our knowledge, only Bodner et al. (2011) use a multi-setting data collection approach including individuals living in the community and in sheltered housing arrangements. In studies focusing on ageism in health care a similar imbalance is evident with regard to the over representation of specialist and high intensity care services, in the detriment of primary care based studies (Adams et al. 2006; Arber et al. 2006; Gunderson et al. 2005). Most commonly, the study focus is further narrowed with reference to a specific disease or pathology: diabetes mellitus (Cruz-Jentoft et al. 2013), arthritis (Austin et al. 2013), cardiovascular disease (Bond et al. 2003), spinal cord injury (Furlan et al. 2009), ischemic heart disease (Gnavi et al. 2007), colorectal cancer (Jerant et al. 2004), psychosis (Mitford et al. 2010), lung cancer (Peake et al. 2003), brain injury (Pedersen and Mehlsen 2011), breast cancer (Protiere et al. 2010), stroke (Rudd et al. 2007). This high degree of fragmentation of research results, by clinical specialty and disease group, raises questions about their transferability and generalizability and renders a comprehensive discussion about ageism in health care extremely difficult. 


\subsection{Specific Measurement Tools: Scales of Ageism}

As already hinted above, the majority of quantitative studies on ageism in health and long term care rely on already established instruments, generally described as scales of ageism. While the present review is not exhaustive, we briefly describe those most widely accepted and most commonly used in the health and long-term care literature, listed here in the chronological order of their development.

The Attitudes Towards Older People Scale proposed by Kogan (1961) is composed by 34 statements in a Likert scale format, with item values ranging between 1 (disagree strongly) to 7 (agree strongly) where higher scores indicate more positive attitudes. An attitude index can be computed as the mean of all 34 items. The Attitudes Towards Older People Scale is a uni-dimensional tool that does not recognize any dimensions or factors. It covers the affective and cognitive, other-directed, explicit, positive and negative components of ageism. This scale has been used both in long-term care based (Natan et al. 2013) and in health care based (Furlan et al. 2009; Gallagher et al. 2006; Kearney et al. 2000; Lui and Wong 2009; Topaz and Doron 2013) quantitative studies.

The Aging Semantic Differential Scale (Rosencranz and McNevin 1969) is a multidimensional tool designed to measure attitudes towards older people. It is organized along three factors: (i) level of effective goal orientation, adaptability and energy output of older people, (ii) level of dependency upon others and personal autonomy and (iii) level of social interaction. The tool consists of 32 polar adjectives (e.g. exciting/dull, progressive/old-fashioned, independent/dependent) in a 7-point Likert scale format, where lower values indicate more positive views. It covers the cognitive, other-directed, explicit positive and negative components of ageism. The Aging Semantic Differential Scale covers exclusively the cognitive component of ageism and the explicit and non self-directed aspects. In the empirical literature on ageism in health and long-term care it has been used, among others, by Gething et al. (2002) and Reyna et al. (2007).

The Facts on Aging Quiz was designed and further developed by Palmore (1977, 1998) as a tool for measuring basic knowledge about old age and aging as well as common misconceptions related to it. The proposed scale is uni-dimensional and consists of 50 statements in a true-false format. While it recognizes both positive and negative components of ageism, it covers only the cognitive, other-directed and the explicit component. Applications to the study of ageism in health care include works by Topaz and Doron (2013) and Gethering and colleagues (2002), while in the long-term care settings it has been used by Wells et al. (2004).

Developed in 1990 by Maryann Fraboni and colleagues, the Fraboni Scale of Ageism (Fraboni et al. 1990) was designed to measure attitudes and prejudices towards older people via 29 statements in a Likert scale format. It recognizes three distinct dimensions/factors: antilocution (referring mainly to stereotypes, positive 
and negative, about older people), discrimination (referring to attitudes, positive and negative, towards social rights and social participation of older people) and avoidance (referring to affective attitudes and behavior, positive and negative, with respect to social contact with older people). The scale covers all three classical components and both the positive and negative aspects of ageism, but it focuses exclusively on explicit and non self-direct variants of ageism. Examples of applications to the study of ageism in health and long-term care include Leung et al. (2011) and respectively Bodner et al. (2011) and Lagace et al. (2011).

The Reactions on Ageing Questionnaire (Gething 1994) is an instrument developed to gauge attitudes toward personal aging, a measure that correlates highly with attitudes towards other older people. The scale comprises 27 items in a 6-point Likert scale format, each represented by a statement on expectations regarding old age and is structured along three dimensions: fear of frailty, tedium in later life and losses in later life. It covers the affective and cognitive, other-directed, explicit, positive and negative components of ageism. Although the instrument was developed and primarily used in Australia, subsequent research confirmed its validity in cross-country studies (Gething et al. 2004). Among the studies using the reactions on Ageing Questionnaire, we note Gething et al. (2002), Wells et al. (2004) and Williams et al. (2007).

It is worth noting that all the scales presented above are not specific to health and long-term care research and are broad enough in their scope to be applicable to the analysis of ageism in various other research fields. In fact, the classic scales of ageism have been applied widely in fields as diverse as marketing, media, educational studies, business and organizational theory. This lack of context-specificity can be seen as a limitation, as respondents are requested to think about older people in general and not about older people receiving health and long-term care when answering these scales. Results might differ if the instruments were contextualized.

\subsection{Current Advantages and Shortcomings in Research on Ageism in Health and Long-Term Care}

The empirical literature on ageism in health and long-term care, as it emerges from our analysis of conceptualizations and methodological approaches, is very broad in its scope and touches on a wide range of topics. Although not represented with the same frequency, in depth analyses of ageist attitudes, prejudices and behaviors have been carried out both in long-term care and in health care settings, in a variety of contexts. We note however, a propensity for studies overwhelmingly representing Western cultures. It is therefore, of great importance that the breadth of the field continues to develop in future years, and that further studies are carried out in other geographical areas and in more varied cultural contexts. 
Such expectations do not appear overly optimistic, in light of the considerable development of the field in the last decade. While ageism has been recognized and discussed in the scientific literature for over 50 years, our review has uncovered a proliferation of empirical studies of ageism in health and long-term care over the last 10 years. This is especially true for long-term care based research, where a systematic review of the literature on ageism (Sao Jose and Amado 2017) uncovered that all selected studies were published after the year 2000, more than half of which had appeared between 2011 and 2015. Increased research interest in ageism in health and long-term care no doubt reflects growing awareness on the side of policy makers and the general public of the relevance of the phenomenon in these specific settings. At the same time as more research results become available and are disseminated issues related to ageism are better and more widely understood and hopefully, more easily addressed at the individual, organizational and institutional levels.

On the backdrop of this rapid and positive progression, a series of remaining gaps need to be acknowledged. As a result of persistent theoretical fragmentation and the co-existence of complementary but not entirely over-lapping definitions of the ageism concept, the empirical literature does not reflect the complexities of theoretical thinking on the topic. The mobilization of theories specifically focused on ageism is rare. Furthermore, when mapped against the most comprehensive conceptualization of ageism (Iversen et al. 2009; Sao Jose and Amado 2017), empirical results cluster around few components while entirely failing to acknowledge more refined aspects of ageism. The variants of ageism related to self-directed and to implicit ageism are particularly under-covered.

In a similar vein, we argue the field must strive towards higher complexity and flexibility in data collection and methodological approaches. Mixed methods studies that can integrate insights from both qualitative and quantitative data are all but lacking in the literature.

Finally, while considerable progress is being made in the development of reliable and validated measurement tools, we call attention to persistent shortcomings in the available instruments. Studies often rely on overly general terms and imprecise tools that use abstract terminology. A case in point is the pervasive use of the syntagma "older people" without any qualification on what is to be considered old. Reliance on such homogenizing expressions can mask the considerable diversity characteristic of older populations, confounding the obtained results.

\subsection{Recommendations for Future Research}

Based on the evidence we surveyed in our analysis and building on the gaps and shortcomings identified above, we propose a series of recommendations for future research. We believe development in these areas can help push the field forward and a coordinated research effort to address them is timely and would prove most fruitful. 
As our analysis uncovered a common weakness in underpinning empirical research into theoretical thinking, we recommend that existing theories of ageism should be mobilized more frequently. Such theories can prove extremely helpful for the formulation of research questions but also for intervention and study design and the interpretation of findings.

In fact, a stronger theoretical grounding, that recognizes the inherent complexities of the phenomenon of ageism should go hand in hand with the application of a more comprehensive and ideally, unified definition of ageism that can reflect the multiplicity and complexity of its manifestations. For example, by applying a comprehensive definition of ageism, we uncovered a gap in empirical research and strongly recommend the development of tools and research strategies to measure and assess self-directed ageism and implicit ageism. As long as this is not done, we will continue to have an incomplete picture of the prevalence of ageism in healthcare and long-term care. Furthermore, a unified definition would allow for the comparison of results between studies and across fields, enhancing the validity of the evidence.

Turning to the methodological aspects of research on ageism, we believe future studies should more frequently employ mixed research methods. By drawing on both quantitative and qualitative methodologies, studies can gain both in breadth and depth of understanding, while safeguarding against the shortcoming inherent in using each approach in isolation. Triangulation between data sources and methods can greatly improve the accuracy and reliability of research results and shed light on the finer aspects of the phenomenon of ageism. Furthermore, researchers should strive to enhance triangulation also with respect to participant selection (i.e. include staff members, as well as older people and family members as study subjects) and study setting (i.e. including non-residential settings in the research design) and ensure that all relevant perspectives and the whole gamut of situations and living conditions confronted by older people today are well represented in academic research in health care and long term care.

The quality of available evidence is also likely to improve if future research would rely on a combination of self-reporting techniques with non-self-reporting techniques, such as, participant observation and experimental designs, by helping minimize the impact of reporting biases. Similarly, the adaptation of an existing tool to the specificities of the health and long-term care contexts could help to improve accuracy. We recommend specifically that efforts should be directed to the development of scales and tools that are designed for and sensitive to idiosyncrasies in the care setting. A welcomed improvement on existing scales would also be the elimination of labels such as "old", "elderly", etc. As such scales should also be able to capture "subtyping ageism", a better strategy would be to formulate questions with reference to specific age groups (e.g. 65-75) rather than homogenizing labels.

In conclusion, we wish to acknowledge the great strides that research on ageism in health and long-term care has made over the last decades. This chapter aimed to summarize the wealth of knowledge already existing in the field as well as to provide 
more clarity into the conceptualization and measurement/assessment of ageism in healthcare and long-term care. In so doing, we uncovered great achievements but also "blind spots" in the literature and have, hopefully, charted the way ahead, in an attempt to support researchers, policy makers and practitioners alike in their efforts to address ageism in a variety of contexts.

\section{References}

Adams, A., Buckingham, C. D., Arber, S., McKinlay, J. B., Marceau, L., \& Link, C. (2006). The influence of patient's age on clinical decision-making about coronary heart disease in the USA and the UK. Ageing and Society, 26(02), 303-321.

Ajzen, I. (2005). Attitudes, Personality, and Behavior. New York: McGraw-Hill Education (UK).

American Diabetes Association. (2015). Standards of medical care in diabetes - 2015 abridged for primary care providers. Clinical Diabetes, 33(2), 97-111.

Aminzadeh, F., \& Dalziel, W. B. (2002). Older adults in the emergency department: A systematic review of patterns of use, adverse outcomes, and effectiveness of interventions. Annals of Emergency Medicine, 39(3), 238-247.

Arber, S., McKinlay, J., Adams, A., Marceau, L., Link, C., \& O’Donnell, A. (2006). Patient characteristics and inequalities in doctors' diagnostic and management strategies relating to CHD: A video-simulation experiment. Social Science \& Medicine, 62(1), 103-115.

Austin, S., Qu, H., \& Shewchuk, R. M. (2013). Age bias in physicians' recommendations for physical activity: A behavioral model of health care utilization for adults with arthritis. Journal of Physical Activity \& Health, 10(2), 222-231.

Ayalon, L. (2015). Perceptions of old age and aging in the continuing care retirement community. International Psychogeriatrics, 27(4), 611-6620.

Band-Winterstein, T. (2013). Health care provision for older persons: the interplay between ageism and elder neglect. Journal of Applied Gerontology, 34, 1-15. https://doi. org/10.1177/0733464812475308.

Band-Winterstein, T. (2015). Health care provision for older persons: The interplay between ageism and elder neglect. Journal of Applied Gerontology, 34(3), NP113-NP127.

Billings, J. (2006). Staff perceptions of ageist practice in the clinical setting: Practice development project. Quality in Ageing and Older Adults, 7(2), 33-45.

Bodner, E., Cohen-Fridel, S., \& Yaretzky, A. (2011). Sheltered housing or community dwelling: Quality of life and ageism among elderly people. International Psychogeriatrics, 23(8), 1197-1204.

Bond, M., Bowling, A., McKee, D., Kennelly, M., Banning, A. P., Dudley, N., Elder, A., \& Martin, A. (2003). Does ageism affect the management of ischaemic heart disease? Journal of Health Services Research \& Policy, 8(1), 40.

Boockvar, K., Fishman, E., Kyriacou, C. K., Monias, A., Gavi, S., \& Cortes, T. (2004). Adverse events due to discontinuations in drug use and dose changes in patients transferred between acute and long-term care facilities. Archives of Internal Medicine, 164(5), 545-550.

Bouman, W. P., \& Arcelus, J. (2001). Are psychiatrists guilty of 'ageism' when it comes to taking a sexual history? International Journal of Geriatric Psychiatry, 16(1), $27-31$.

Briggs, R., Robinson, S., \& O’Neill, D. (2012). Ageism and clinical research. Irish Medical Journal, 105(9), 311-312.

Butler, R. N. (1969). Age-ism: Another form of bigotry. The Gerontologist, 9, 243-246.

Butler, R. N. (1975). Why survive? Being old in America. New York: Harper and Row.

Butler, R., \& Lewis, M. (1973). Aging and mental health. St. Louis: C. V. Mosby Co.

Bytheway, B., \& Johnson, J. (2001). An evaluation of the use of diaries in a study of medication in later life. Internaional Journal of Social Research Methodology, 4(3), 183-204. 
Chambaere, K., Rietjens, J. A., Smets, T., Bilsen, J., Deschepper, R., Pasman, H. R. W., \& Deliens, L. (2012). Age-based disparities in end-of-life decisions in Belgium: A population-based death certificate survey. BMC Public Health, 12(1), 1.

Chambaere, K., Rietjens, J. A., Cohen, J., Pardon, K., Deschepper, R., Pasman, H. R. W., \& Deliens, L. (2013). Is educational attainment related to end-of-life decision-making? A large post-mortem survey in Belgium. BMC Public Health, 13(1), 1055.

Chrisler, J. C., Barney, A., \& Palatino, B. (2016). Ageism can be hazardous to women's health: Ageism, sexism, and stereotypes of older women in the healthcare system. Journal of Social Issues, 72(1), 86-104.

Cohen, A., Assyag, P., \& Boutron, I. (2014). Regarding the acute care of the elderly model. JAMA, 174(1), 40-48.

Coleman, E. A. (2003). Falling through the cracks: Challenges and opportunities for improving transitional care for persons with continuous complex care needs. Journal of the American Geriatrics Society, 51(4), 549-555.

Condelius, A., \& Andersson, M. (2015). Exploring access to care among older people in the last phase of life using the behavioural model of health services use: A qualitative study from the perspective of the next of kin of older persons who had died in a nursing home. BMC Geriatrics, 15, 138.

Cruz-Jentoft, A. J., Carpena-Ruiz, M., Montero-Errasquín, B., Sánchez-Castellano, C., \& SánchezGarcía, E. (2013). Exclusion of older adults from ongoing clinical trials about type 2 diabetes mellitus. Journal of the American Geriatrics Society, 61(5), 734-738.

Cuddy, A. J., Norton, M. I., \& Fiske, S. T. (2005). This old stereotype: The pervasiveness and persistence of the elderly stereotype. Journal of Social Issues, 61(2), 267-285.

Dionigi, R. A. (2015). Stereotypes of aging: Their effects on the health of older adults. Journal of Geriatrics, 2015, 1-9.

Dobbs, D., Eckert, J. K., et al. (2008). An ethnographic study of stigma and ageism in residential care or assisted living. The Gerontologist, 48(4), 517-526.

Doyle, S. (2014). The impact of power differentials on the care experiences of older people. Journal of Elder Abuse \& Neglect, 26(3), 319-332.

Dunworth, M., \& Kirwan, P. (2012). Do nurses and social workers have different values? An exploratory study of the care for older people. Journal of Interprofessional Care, Early Online: $1-6$.

Fraboni, M., Saltstone, R., \& Hughes, S. (1990). The Fraboni scale of ageism (FSA): An attempt at a more precise measure of ageism. Canadian Journal on Aging, 9(1), 55-56.

Fried, L. P., \& Ferrucci, L. (2016). Etiological role of aging in chronic diseases: From epidemiological evidence to the new geroscience. In Advances in Geroscience (pp. 37-51). Cham: Springer International Publishing.

Furlan, J. C., Craven, B. C., Ritchie, R., Coukos, L., \& Fehlings, M. G. (2009). Attitudes towards the older patients with spinal cord injury among registered nurses: A cross-sectional observational study. Spinal Cord, 47(9), 674-680.

Gallagher, S., Bennett, K. M., \& Halford, J. C. (2006). A comparison of acute and long-term health-care personnel's attitudes towards older adults. International Journal of Nursing Practice, 12(5), 273-279.

Gamliel, T. (2000). The lobby as an arena in the confrontation between acceptance and denial of old age. Journal of Aging Studies, 14(3), 251-271.

Gatz, M., \& Pearson, C. G. (1988). Ageism revised and the provision of psychological services. American Psychologist, 43(3), 184.

Gething, L. (1994). Health professionals' attitudes towards ageing and older people: Preliminary report of the reactions to ageing questionnaire. Australian Journal on Ageing, 13(2), 77-81.

Gething, L., Fethney, J., McKee, K., Goff, M., Churchward, M., \& Matthews, S. (2002). Knowledge, stereotyping and attitudes towards self ageing. Australasian Journal on Ageing, 21, 74-79.

Gething, L., Fethney, J., McKee, K., Persson, L. O., Goff, M., Churchward, M., Matthews, S., Halvarsson, M., \& Johannsson, I. (2004). Validation of the reactions to ageing questionnaire: 
Assessing similarities across several countries. Journal of Gerontological Nursing, 30(9), 47-54.

Gnavi, R., Migliardi, A., Demaria, M., Petrelli, A., Caprioglio, A., \& Costa, G. (2007). Statins prescribing for the secondary prevention of ischaemic heart disease in Torino, Italy. A case of ageism and social inequalities. The European Journal of Public Health, 17(5), 492-496.

Grant, P. T., Henry, J. M., \& McNaughton, G. W. (2000). The management of elderly blunt trauma victims in Scotland: Evidence of ageism? Injury, 31(7), 519-528.

Greenberg, J., Schimel, J., \& Martens, A. (2002). Ageism: Denying the face of the future. In T. D. Nelson (Ed.). Cambridge, MA: MIT Press.

Gunderson, A., Tomkowiak, J., Menachemi, N., \& Brooks, R. (2005). Rural physicians' attitudes toward the elderly: Evidence of ageism? Quality Management in Healthcare, 14(3), 167-176.

Hawkes, N. (2016). Sixty seconds on... bed blockers. BMJ, 352, i935.

Holroyd, A., Dahlke, S., Fehr, C., Jung, P., \& Hunter, A. (2009). Attitudes toward aging: Implications for a caring profession. Journal of Nursing Education, 48(7), 374-380.

Hubbard, R. E., Lyons, R. A., Woodhouse, K. W., Hillier, S. L., Wareham, K., Ferguson, B., \& Major, E. (2003). Absence of ageism in access to critical care: A cross-sectional study. Age and Ageing, 32(4), 382-387.

Hunold, K. M., Pereira, G. F., Jones, C. W., Isaacs, C. G., Braz, V. A., Gadi, S., \& Platts-Mills, T. F. (2016). Priorities of care among older adults in the emergency department: A cross-sectional study. Academic Emergency Medicine, 23, 362-365.

Iliffe, S., De Lepeleire, J., Van Hout, H., Kenny, G., Lewis, A., Vernooij-Dassen, M. J. F. J., \& The Diadem Group. (2005). Understanding obstacles to the recognition of and response to dementia in different European countries: A modified focus group approach using multinational, multi-disciplinary expert groups. Aging \& Mental Health, 9(1), 1-6.

Iversen, T. N., Larsen, L., \& Solem, P. E. (2009). A conceptual analysis of ageism. Nordic Psychology, 61(3), 4-22.

Jerant, A. F., Franks, P., Jackson, J. E., \& Doescher, M. P. (2004). Age-related disparities in cancer screening: Analysis of 2001 behavioral risk factor surveillance system data. The Annals of Family Medicine, 2(5), 481-487.

Kearney, N., Miller, M., Paul, J., \& Smith, K. (2000). Oncology healthcare professionals' attitudes toward elderly people. Annals of Oncology, 11(5), 599-601.

Koch, T., \& Webb, C. (1996). The biomedical construction of ageing: Implications for nursing care of older people. Journal of Advanced Nursing, 23(5), 954-958.

Koch, S., Hunter, P., \& Nair, K. (2009). Older people in acute care. Older people: Issues and innovafions in care (3rd ed.pp. 153-167). Sydney: Churchill Livingstone.

Kogan, N. (1961). Attitudes towards old people: The development of a scale and examination of correlates. Journal of Abnormal and Social Psychology, 62, 44-54.

Kydd, A., Touhy, T., Newman, D., Fagerberg, I., \& Engstrom, G. (2014). Attitudes towards caring for older people in Scotland, Sweden and the United States: Angela.

Lagacé, M., Medouar, F., Loock, J., \& Davignon, A. (2011). À mots couverts: le regard des aînés et des soignants sur la communication quotidienne et ses manifestations d'âgisme implicite. Canadian Journal of Aging/La Revue canadienne du vieillissement, 30, 185-196.

Lagacé, M., Tanguay, A., Lavallée, M., et al. (2012). The silent impact of ageist communication in long term care facilities: Elders' perspectives on quality of life and coping strategies. Journal of Aging Studies, 26, 335-342.

Leung, S., LoGiudice, D., Schwarz, J., \& Brand, C. (2011). Hospital doctors' attitudes towards older people. Internal Medicine Journal, 41(4), 308-314.

Levy, B. (2009). Stereotype embodiment a psychosocial approach to aging. Current Directions in Psychological Science, 18(6), 332-336.

Levy, B. R., \& Banaji, M. R. (2002). Implicit ageism. In T. D. Nelson (Ed.), Ageism stereotyping and prejudice against older persons (pp. 49-75). Cambridge, MA: MIT Press. 
Levy, B. R., Slade, M. D., \& Gill, T. M. (2006). Hearing decline predicted by elders' stereotypes. The Journals of Gerontology. Series B, Psychological Sciences and Social Sciences, 61(2), $82-87$.

Lui, N. L., \& Wong, C. H. (2009). Junior doctors' attitudes towards older adults and its correlates in a tertiary-care public hospital. Annals Academy of Medicine Singapore, 38(2), 125.

MacDonald, C., \& Butler, L. (2007, January). Silent no more: Elderly women's stories of living with urinary incontinence in long-term care. Journal of Gerontological Nursing, 14(20), 14-20.

Makris, U. E., Higashi, R. T., Marks, E. G., Fraenkel, L., Sale, J. E., Gill, T. M., \& Reid, M. C. (2015). Ageism, negative attitudes, and competing co-morbidities-why older adults may not seek care for restricting back pain: A qualitative study. BMC Geriatrics, 15(1), 1.

Maxim Topaz, R. N. M. A., \& Israel Issi Doron, L. L. B. (2013). Nurses' attitudes toward older patients in acute care in Israel. Online Journal of Issues in Nursing, 18(1), 61.

Minichiello, V., Browne, J., \& Kendig, H. (2000). Perceptions and consequences of ageism: Views of older people. Ageing and Society, 20(03), 253-278.

Mitford, E., Reay, R., McCabe, K., Paxton, R., \& Turkington, D. (2010). Ageism in first episode psychosis. International Journal of Geriatric Psychiatry, 25(11), 1112-1118.

Moos, R. H. (1979). Social ecological perspectives on health. In G. C. Stone, F. Cohen, \& N. E. Adler (Eds.), Health psychology: A handbook (pp. 523-547). San Francisco: Jossey-Bass.

Natan, M. B., Ataneli, M., Admenko, A., \& Noy, R. H. (2013). Nurse assessment of residents' pain in a long-term care facility. International Nursing Review, 60, 251-257.

Nelson, T. D. (2005). Ageism: Prejudice against our feared future self. Journal of Social Issues, 61(2), 207-221.

Palmore, E. B. (1977). Facts on aging: A short quiz. Gerontologist, 17, 315-320.

Palmore, E. B. (1998). The facts on aging quiz. New York: Springer.

Parke, B., \& Chappell, N. L. (2010). Transactions between older people and the hospital environment: A social ecological analysis. Journal of Aging Studies, 24(2), 115-124.

Peake, M. D., Thompson, S., Lowe, D., \& Pearson, M. G. (2003). Ageism in the management of lung cancer. Age and Ageing, 32(2), 171-177.

Pedersen, A. D., \& Mehlsen, M. (2011). Age-bias in staff appraisals of brain injury service provision? Nordic Psychology, 63(3), 25.

Petersen, M., \& Warburton, J. (2012). Residential complexes in Queensland, Australia: A space of segregation and ageism? Ageing and Society, 32(01), 60-84.

Protière, C., Viens, P., Rousseau, F., \& Moatti, J. P. (2010). Prescribers' attitudes toward elderly breast cancer patients. Discrimination or empathy? Critical Reviews in Oncology/Hematology, $75(2), 138-150$.

Reyna, C., Goodwin, E. J., \& Ferrari, J. R. (2007). Older adult stereotypes among care providers in residential care facilities. Journal of Gerontological Nursing, 33(2), 50-55.

Robb, C., Haley, W. E., Becker, M. A., Polivka, L. A., \& Chwa, H. J. (2003). Attitudes towards mental health care in younger and older adults: Similarities and differences. Aging \& Mental Health, 7(2), 142-152.

Rosencranz, H. A., \& McNevin, T. E. (1969). A factor analysis of attitudes toward the aged. Gerontologist, 9(1), 55-59.

Roth, E. G., Keimig, L., Rubinstein, R. L., Morgan, L., Eckert, J. K., Goldman, S., \& Peeples, A. D. (2012).

Roth, E. G., Eckert, J. K., \& Morgan, L. A. (2015). Stigma and discontinuity in multilevel senior housing's continuum of care. Gerontologist, $00(00), 1-10$.

Rudd, A. G., Hoffman, A., Down, C., Pearson, M., \& Lowe, D. (2007). Access to stroke care in England, Wales and Northern Ireland: The effect of age, gender and weekend admission. Age and Ageing, 36(3), 247-255.

São José, J., \& Amado, C. (2017). On studying ageism in long-term care: A systematic review of the literature. International Psychogeriatrics, 29(3), 373-387.

São José, J., Amado, C., Ilinca, S., Buttigieg, S., \& Taghizadeh Lars-son, A. (2017). Ageism in health care: A systematic review of operational definitions and inductive conceptualizations. The Gerontologist. https://doi.org/10.1093/geront/gnx020 
Scott, V., Votova, K., Scanlan, A., \& Close, J. (2007). Multifactorial and functional mobility assessment tools for fall risk among older adults in community, home-support, long-term and acute care settings. Age and Ageing, 36(2), 130-139.

Skirbekk, H., \& Nortvedt, P. (2014). Inadequate treatment for elderly patients: Professional norms and tight budgets could cause "ageism" in hospitals. Health Care Analysis, 22(2), 192-201.

Solomon, S., Greenberg, J., \& Pyszczynski, T. (1991). A terror management theory of social behavior: The psychological functions of self-esteem and cultural worldviews. Advances in Experimental Social Psychology, 24, 93-159.

Stokols, D. (1992). Establishing and maintaining healthy environments: Toward a social ecology of health promotion. American Psychologist, 47(1), 6.

Taverna, M. V., Nguyen, C., Wright, R., et al. (2014). Iatro-compliance: An unintended consequence of excessive autonomy in long term care facilities. Journal of Dental Hygiene, 88(1), 53-60.

Tinetti, M. E., Esterson, J., Ferris, R., Posner, P., \& Blaum, C. S. (2016). Patient priority-directed decision making and care for older adults with multiple chronic conditions. Clinics in Geriatric Medicine, 32(2), 261-275.

Turner, J. C., \& Reynolds, K. J. (2010). The story of social identity. In T. Postmes \& N. Branscombe (Eds.), Rediscovering social identity: Core sources. New York: Psychology Press.

United Nations, Department of Economic and Social Affairs, Population Division. (2015). World population ageing 2015 (ST/ESA/SER.A/390). http://www.un.org/en/development/desa/population/publications/pdf/ageing/WPA2015_Report.pdf. Accessed 15 Apr 2016.

Wells, Y., Foreman, P., Gething, L., \& Petralia, W. (2004). Nurses' attitudes toward aging and older adults - Examining attitudes and practices among health services providers in Australia. Journal of Gerontological Nursing, 30(9), 5-13.

Williams, B., Anderson, M. C., \& Day, R. (2007). Undergraduate nursing students' knowledge of and attitudes toward aging: Comparison of context-based learning and a traditional program. Journal of Nursing Education, 46(3), 115-120.

Zimmerman, S., Dobbs, D., Roth, E. G., Goldman, S., Peeples, A. D., \& Wallace, B. (2014). Promoting and protecting against stigma in assisted living and nursing homes. Gerontologist, $56,535-547$.

Open Access This chapter is licensed under the terms of the Creative Commons Attribution 4.0 International License (http://creativecommons.org/licenses/by/4.0/), which permits use, sharing, adaptation, distribution and reproduction in any medium or format, as long as you give appropriate credit to the original author(s) and the source, provide a link to the Creative Commons license and indicate if changes were made.

The images or other third party material in this chapter are included in the chapter's Creative Commons license, unless indicated otherwise in a credit line to the material. If material is not included in the chapter's Creative Commons license and your intended use is not permitted by statutory regulation or exceeds the permitted use, you will need to obtain permission directly from the copyright holder.

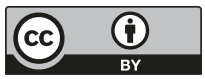




\title{
Chapter 30 \\ Children's Attitudes toward Older People: Current and Future Directions
}

\author{
Joana Mendonça, Sibila Marques, and Dominic Abrams
}

\subsection{Why and How Study Ageism in Children?}

Being old is to lose memory, to have wrinkles and also white hair" ("Maria", 6 years old). "I think that when we became old we can and we know a lot of things to teach to the future generation of the family ("Pedro", 11 years old).

Age is a fundamental dimension along which children organize their perceptions of people in their social world (Lewis and Brooks-Gunnn 1979). According to Levy (2009), stereotypes about the ageing process and, more specifically, about older people, become internalized across the life span in two fundamental ways: topdown (from society to individuals) and over time (from childhood to old age). As people age, stereotypes internalized during childhood and adulthood tend to eventually become self-stereotypes leading to often negative outcomes for older people (Levy 1996, 2003). Four main stereotypes against older people seem to be prevalent in society: (1) older people are generally depressed and lonely lacking family and close friends and having mood disorders; (2) older people constitute a homogeneous group and ageing is perceived as a unidimensional and unidirectional process; (3) older people are frail, sick and dependent on others; and (4) older people are seen as having cognitive and psychological limitations (Whitbourne and Sneed 2002). Several studies have shown that the mere exposure to negative stereotypical traits of old age (e.g., ill, dying, forgetful) has severe negative effects on older persons in multiple domains such as memory performance, stress levels and the

\footnotetext{
J. Mendonça $(\bowtie) \cdot$ S. Marques

Instituto Universitário de Lisboa (ISCTE-IUL), CIS-IUL, Lisbon, Portugal

e-mail: Joana_Mendonca@iscte-iul.pt; sibila.marques@ iscte.pt

D. Abrams

Centre for the Study of Group Processes, School of Psychology, Keynes College,

University of Kent, Canterbury, UK

e-mail: D.Abrams@kent.ac.uk
} 
will-to-live (e.g., Levy 1996, 2003; Marques et al. 2014a). These negative views are both expressed at the individual and institutional levels because there is also much evidence of negative treatment of older people across many areas such as the media, healthcare and organizational settings (Marques 2011; Mendonça et al. 2016; Swift et al. 2016; see similar chapters in this volume, e.g., Loos and Ivan (2018; Chap. 11), Wyman, Shiovitz-Ezra, and Bengel (2018; Chap. 13), Stypinska and Nikander (2018; Chap. 6)). Hence, understanding how representations of older people develop from an early age is of crucial importance in order to better understand and intervene in this domain.

At present, the literature in this field has still not yielded clear findings and it is therefore inconclusive regarding children's views of different age groups and, in particular, of older people. In fact, the two quotes at the beginning of the present chapter illustrate well the sort of contradictory evidence that currently exists regarding the representations of older people among young children. On the one hand, several studies show that children's perceptions of older adults tend to be mostly negative. For instance children as young as 3 years old (e.g. Middlecamp and Gross 2002), have been found to have negative ideas about older adults, children prefer younger to older adults (Isaacs and Bearison 1986) and they may refer to older people in a negative manner, associating this age group with traits such as helpless, stubbornness and senility (Pinquart et al. 2000). On the other hand, there are other studies that show no significant differences in attitudes regarding younger and older targets and some even report positive perceptions of older people. For example, in a study using the drawing test methodology, children expressed a generally positive image of older people, depicting an older family member who was happy, healthy and active (Robinson et al. 2014).

These contradictory sources of evidence suggest the need to explore this issue in more detail. In this chapter, our goal is to explore and systematize the main evidence gathered so far regarding children's attitudes towards older people, in order to gain a better understanding of how these attitudes develop in childhood. Therefore, the goals of this chapter are: (1) to present a literature review of the main body of studies assessing children's attitudes toward older people; (2) to classify the available measures according to fundamental criteria of prejudice development in childhood: their level of automaticity (explicit vs. implicit measures) and the dimensions covered (cognitive, affective or behavioral); and (3) to explore the pattern of development of children's attitudes toward older people in children. We believe that this represents a very important and meaningful contribution to this literature.

In the present analysis, we adopt the definition of attitudes based on the tri-partite model (Eagly and Chaiken 1993). According to this theory, an attitude is composed of three dimensions: affective (represented by prejudicial feelings), cognitive (represented by beliefs and stereotypes) and behavioral (expressed through behavior or behavioral intentions). These three dimensions of attitudes can express a positive or negative evaluation regarding the object (Eagly and Chaiken 2007). Hence, we are interested in exploring studies addressing these different dimensions of children's attitudes towards older people. In accordance with this definition, ageism represents the specific case when there is a negative attitude towards older people (either in affective, cognitive or behavioral terms). 


\subsection{What Do We Know About the Development of Prejudice in Childhood? Implications for the Study of Ageism}

There are numerous theories regarding the development of prejudice among children. We follow Levy and Hughe's (2009) suggested framework to organize the main theoretical approaches. For example, the Social Learning Theory (Allport 1954 ) is based on the assumption that children learn prejudice through the observation and imitation of relevant role models, namely their parents or peers. According to this theory, as children age and learn the expected behavior, their prejudice would also tend to increase or match the levels of their parents.

A different approach is presented by the Cognitive-Developmental Theory originally developed by Piaget and Weil (1951) and applied to the prejudice field by Aboud (1988), Bigler and Liben (2006) among others. According to this theory, prejudice is derived from children's limited cognitive abilities which undermines their capacity to see people as individuals, leading to overgeneralizations. With age, children's cognitive abilities such as multiple classification ability become more flexible, allowing them to recognize similarities across groups and differences within the same group.

Along with this cognitive maturation, children's expression of prejudice toward out-group members varies across different stages in childhood. In this regard, almost everything infants do is implicit in the sense that they are unlikely to be consciously considering and controlling any of their attitudes (Olson and Dunham 2010). Children's attitudes become increasingly explicit as they grow older: as toddlers, as preschoolers and, especially, as elementary school students. In this last developmental stage, children (especially from the age of 8 - e.g., Rutland et al. 2005; Abrams 2011) are able to manage the expression of their attitudes according to their goals and social constraints. The gradual developmental of the "explicit system" allows children to exert an increasing level of strategic control over previously automatic processes (Olson and Dunham 2010).

Another set of theories known as Social-Cognitive Developmental Theories, are based on both social and cognitive approaches, considering both personal factors (e.g. age, cognitive skills) and also characteristics of the social environment. For example, the Social Identity Development Theory (SIDT - Nesdale 1999), postulates that intergroup bias can take different forms among both adults and children, namely the preference for the in-group (in-group bias) and dislike for the outgroup (e.g. race prejudice) (Rodrigues 2011). This theory is derived from the Social Identity Theory (Tajfel and Turner 1979) which is based on the assumption that individuals are highly motivated to achieve and maintain a positive self-esteem within an intergroup context. Consequently, in-group favoritism reflects an individual's motivation to favor and positively distinguish the social groups he or she identify with from other relevant out-groups.

The Social Identity Development Theory has been currently used as a framework to explain the development of prejudice among children, mainly with regard to 
racism. According to this theory, racism is derived from a process, which involves four sequential phases across childhood: (1) The Undifferentiated Phase: children aged around 2-3 years old cannot categorize people based on their racial cues. Consequently, they are not able to express any kind of intergroup bias; (2) The Ethnic Awareness Phase: children of around 3-4 years old begin to be aware of the existence of social categories that are most salient (e.g. age, gender and race). In this phase, children develop the ability of self-identification and the sense of belonging to social groups; (3) The Ethnic Preference Phase: children aged around 5-6 years old, focus on positive in-group evaluation rather than on out-group derrogation. In this phase, children begin to show an in-group preference (e.g. a preference for people from their race); (4) The Ethnic Prejudice Phase: by the age of 7-8 years old children intergroup evaluations are focused both on in-group and out-group. Children hold negative out-group stereotypes and discriminate out-group members when socially permissible.

In an elaboration of Cognitive Developmental Theory (CDT), Brown and Bigler (2005) proposed a developmental framework for understanding children's perceptions of discrimination directed toward themselves and others. This model is based on the assumption that children's perceptions of discrimination are influenced by different factors: cognitive development (e.g. classification and social comparison skills), situational contexts (e.g. salience of one's group identity), and individual differences. More specifically, this model proposed that by the age of six, children acquire the basic cultural and social-cognitive skills required to perceive discrimination. Along with the cognitive maturation during the elementary school years, children may become more skilled to make attributions to discrimination in different contexts. At the end of elementary school (by age ten), children's perceptions of discrimination are more complex and similar to that of adults. However, at this age, children may not be able to perceive societal or more complex forms of institutional discrimination (e.g., subtle images portrayed in the media or hidden negative practices in some organizations). Finally, during adolescence, youth is expected to be able to identify discrimination at both societal and institutional levels.

Rutland et al. (2010), proposed a new socio-cognitive developmental perspective on prejudice that is drawn from two complementary theories: the social domain theory (Turiel 1998) and the social identity theory (SIT; Tajfel and Turner 1986). According to this perspective, the development of prejudice involves the interplay between moral reasoning (beliefs about fairness and justice) and group identity (influence of group norms). This means that children consider both moral beliefs and group identity when reasoning and developing judgments about groups and individuals. Overall, this perspective highlights the need to consider both socialcognitive abilities (emergence of moral beliefs) and intergroup context variables (social context and relationships with others).

Finally, in a further extension of the Social Identity Approach, the Developmental Model of Subjective Group Dynamics (Abrams et al. 2007; Abrams et al. 2009) holds that between the ages of 5 and 11 children develop a lay theory of group processes, which enables them to calibrate their expression of bias according to which groups are judged by the audience and by their own level of identity. 
The evolutionary perspective, considers that prejudice and discrimination are inevitable and, consequently, very difficult to change. For example, Fishbein (1996) argues that humans are predisposed to prefer individuals who are more genetically similar to themselves. The development of prejudice is therefore associated with the development of a group identity at early ages (3/4 years old).

Beyond race, research on the development of prejudice has often focused on sexism or gender-related prejudice - "prejudice attitudes (...) based on gender-related categorization of people" (Glick and Hilt 2000, p.7). According to these authors, gender-related prejudice develops and is expressed differently according to a developmental sequence - Between early childhood (2-3 years old) and puberty (around the age of 11), children prefer to play with same-sex peers, showing hostile feelings and beliefs toward out-group members. This hostile prejudice is expressed through overall negative emotional evaluations of the other sex and is based on a simple cognitive reasoning. A different pattern is found among adolescents whose greater cognitive abilities, emotions and sexual attraction to other-sex individuals results in a more ambivalent form of gender-related prejudice, which is characterized by paternalistic beliefs: woman are viewed as romantic objects who are also weak and need men's protection. These two different kinds of prejudice - hostile and benevolent - may coexist during adulthood, creating ambivalent attitudes and influencing adult cross-sex interactions. The important point, however, is that prejudice should become more multi-faceted with age.

Regarding the specific case of ageism, studies are scarcer but an important review of this field (Montepare and Zebrowitz 2002) presented some evidence. Some studies (e.g. McCall and Kennedy 1980) suggest that children are influenced by salient age cues at a very early age. In fact, children as young as 4 months differentially look at pictorial representations of faces of people of different age groups. In this chapter, Montepare and Zebrowitz (2002) advanced a hypothesis regarding the expected development of ageist beliefs in children based on a social-developmental perspective. According to this theory, children's social perceptions require the categorization of people on the basis of their age-related physical characteristics (height, face and voice cues) that are used to distinguish and classify people. Later in development, children's attitudes are reflected in three types of outcomes: prejudice (children's feelings toward older adults), stereotypes (children's beliefs and knowledge about older persons) and discrimination (children's intended or actual behaviors toward older persons). These different dimensions may involve different developmental paths. In early childhood, attitudes are mostly expressed through (negative) affective reactions toward older people. Meanwhile, children develop systematic behavioral stereotypes that become more complex as a function of their cognitive development. In middle childhood, children's attitudes toward older people become more positive and differentiated and this continues throughout adolescence and adulthood.

Montepare and Zebrowitz (2002) do not elaborate much on these initial propositions. Hence, much more attention needs to be devoted to evidence and theory. For instance, although some insights may be gained from previous studies on racism and sexism, we would be cautious about generalizing across domains. In fact, 
evidence so far, seems to suggest that different patterns of development and processes occur in different types of prejudice. For example, there are different theories specifically regarding the development of racism (e.g. Olson and Dunham 2010) and sexism (e.g. Glick and Hilt 2000). In the case of racism, research has focused on the role of the anti-racism norm and its influence on implicit and explicit prejudice in different stages of childhood. Studies suggest that the explicit expression of racism decreases as children get older, mainly due to conformity to a strong social anti-racism norm (Olson and Dunham 2010; Rutland et al. 2010). On the other hand, theories about the development of sexism are based on the assumption that gender-related prejudice exists throughout life assuming different forms according to the developmental stages (hostile vs. benevolent sexism) (Abrams 1989; Glick and Hilt 2000). These observations highlight the need to consider the distinctive features of each type of prejudice. However, we also assume the existence of core developmental processes. In this regard, Olson and Dunham (2010) suggest that the distinction between more implicit or explicit forms of prejudice is fundamental to understanding the patterns of development across childhood. Hence, similarly to what had been done in the case of racism, it would be important to understand how these two different modes of ageism operate across different age groups and to address the role of social-environmental factors such as the anti-ageism norms. Studies such as these would represent a very important contribute to this field of research.

We therefore aim to progress the field by reviewing the existing literature and providing a framework for systematic evidence from relevant studies in the literature. We present a classification of the main measures of ageism in children based on two main criteria: (i) the dimensions covered - cognitive, affective and behavioral (tripartite model of attitudes) and (ii) the four aspects of automaticity (consciousness, controllability, intentionality and efficacy). Together these allowed classifying measures into three categories: explicit/implicit and blend of explicit and implicit measures. We hope that this classification contributes to our knowledge regarding the development of attitudes towards older people.

\subsection{Goals and Method of the Present Study}

A literature review was undertaken using four databases (PsycARTICLES, PsycINFO, ERIC and Psychology and Behavioral Sciences Collection) and a combination of two groups of keywords - children AND ageism $(\mathrm{n}=135)$; children AND attitudes AND ageing $(\mathrm{n}=1257)$. Studies were considered in this review if they comply with the following inclusion criteria: (1) reported the use of measures to assess children's or adolescents' (under 18 years old) attitudes toward older people and/or the ageing process. (2) measured children's attitudes without any previous manipulation. Our goal was to explore studies measuring attitudes in their original form. Therefore, we excluded studies that employed interventions or experimental manipulations. 
Of the 1392 articles identified, 171 were duplicated and were therefore excluded. This search allowed us to identify 10 articles that focused specifically on the assessment of children's attitudes regarding older people and that met the inclusion and exclusion criteria. Subsequently, the reference lists from the identified studies were also consulted allowing us to locate 6 additional articles. Therefore, a total of 16 articles were subjected to a deeper analysis. These included both quantitative, qualitative or mixed methods.

\subsection{What Is Being Measured}

\subsubsection{Cognitive, Affective and Behavioral Measures}

We analyzed the available measures to assess children's attitudes based on the tripartite model (Eagly and Chaiken 2007), therefore considering their beliefs, feelings and behavior regarding older people and/or the ageing process. The cognitive dimension was mostly assessed through four scales: "Kogan's Attitude Toward Old People Scale" (Ivester and King 1977); "Social Attitude Scale of Ageist Prejudice" (SASAP - Isaacs and Bearison 1986); "Tuckman-Lorge Old People Scale (OP _ Harris and Fiedler 1988); and the "Child Adolescent Facts in Ageing Quiz" (CAFAQ - Haught et al. 1999). This quantitative approach is based on the assumption that through the use of scales with different methodological characteristics (e.g. Likert-type; dichotomous response) one can assess children's knowledge, beliefs and stereotypes associated with older people and the ageing process. For example, the "Kogan's Attitude Toward Old People Scale" (Ivester and King 1977) is a Likert-type instrument (34 items) for assessing adolescent's attitudes toward old people with respect to both norms and individual differences (e.g. "Most old people get set in their ways and are unable to change."). Stereotypes and misconceptions about different areas of older people's lives (e.g. personality characteristics; social adjustment) were also assessed through the use of the Tuckman-Lorge Old People Scale (OP - Harris and Fiedler 1988), in which participants were asked to circle "yes" or "no" for each of the 137 statements about old people (e.g. "They are unproductive."). A very similar method was used in the "Child Adolescent Facts on Ageing Quiz" (CAFAQ - Haught et al. 1999). However, in this case, children's and adolescent's attitudes were assessed through 16 items using a true/false format (e.g. "Most older workers do not work as well as younger workers"). All these instruments have in common the idea that children's attitudes are best assessed by asking children about their representations regarding specific stereotypic traits of older people.

A different approach was used in the "Social Attitude Scale of Ageist Prejudice" (SASAP - Isaacs and Bearison 1986) in which the categories of young and old were visually represented by photographs of a middle-aged person (35-50 years old) and of an aged person (70-85 years old). Children were then asked to select the picture 
of the person that they regard as the recipient of either positive (e.g. "One of these people is always invited to all parties because everyone likes him. Which person does everyone like?") or negative social events ("These two men are arguing. One of them is nasty and always yells at people. Which one is nasty?") (46 items). Beliefs and stereotypes regarding older people and the ageing process have also been assessed using a sentence completion task (Lichtenstein et al. 2003), by asking children to write responses to five prompts (e.g. "Old people..."; "When I am old I...").

The affective dimension has been mostly assessed through indirect measures, particularly the drawing test. This technique is based on the assumption that through drawing, children share their internal world of experiences (Lichtenstein et al. 2005). In the studies using this approach, different methodologies have been adopted. In some studies children were asked to draw a typical older person in a setting (e.g. Lichtenstein et al. 2005). Other studies specified that the drawn person should be an old person that children know from real life (Robinson et al. 2014), making the task more self-relevant to the children. Still other studies asked children to simply draw human figures of different ages (young/old from both genders) (e.g. Villar and Fabà 2012).

In some of this research (e.g. Lichtenstein et al. 2005), interviews were used as a complementary methodology in order to elicit oral or written responses to obtain more detailed information regarding the pictures drawn (e.g. person's age, activities, feelings, thoughts, possible relation to the child, person's characteristics that differ from those of the child). All the studies identified using this methodology aimed to cover both the cognitive and affective dimensions of children's attitudes regarding older people based on the analysis of several dimensions: height of the drawings, physical characteristics (e.g. wrinkles), activity level (e.g. wheelchairs), health status (e.g. hearing aids), personality, roles, settings, facial expression, emotions and also on children's responses on the interview.

Children's knowledge and feelings toward older people and the ageing process were also assessed through the use of two qualitative methods: a word association task (brainstorm about words associated with the concept of "young" and "old) and an attitude toward-ageing interview (e.g. "What do most old people spend their time doing?") (Laney et al. 1999).

A very different approach has been used to assess the behavioral dimension of children's attitudes. We found two studies measuring children's behavior toward older people, both sharing similar methodology. These are based on personal interactions between children and older people. For example, in order to explore whether children as young as $4-8$ years old already express negative stereotypes about older people, Isaacs and Bearison (1986) developed a behavioral measure based on a puzzle activity task $(\mathrm{n}=144)$ : in the experimental condition, each child worked individually with an older person (approximately 75 years) and in the control group the puzzle activity was performed by dyads of a child and a non-aged person (approximately 35 years). Children's attitudes regarding older people were assessed based on the scores on behavioral measures: proxemics distance (the distance between the confederate's chair and the child's placement of his or her chair); productivity (number of puzzles pieces placed); eye-contact initiation (number of times 
children directed their gaze toward the confederate); verbal interaction (e.g. number of words spoken by the child). In the other study using a behavioral methodology (Kwong See et al. 2012), the Piagetian number conservation task was modified to assess young children's age stereotyping. This was done by manipulating the perceived age of the experimenter (younger and older) asking the second question. This task was based on the assumption that children held different beliefs about the motivations of the two experimenters for asking the second question.

Finally, very few studies have assessed all three dimensions of children's attitudes (cognitive, affective and behavioral). As far as we know, only two instruments attempted to achieve this goal: "The Children's Attitudes toward the Elderly Scale" (CATE) (Jantz et al. 1977) and the "Children's View on Aging" (CVOA) (Marks et al. 1985). The CATE (Jantz et al. 1977) is composed by three sub-scales: (1) word association questions regarding the affective (e.g. "How do you feel about getting old?"), behavioral (e.g. "What do you do with that person?" - referred to the older person the child knew) and knowledge (e.g. "What can you tell me about older people?") dimensions of attitudes; (2) semantic differential composed by ten items on a five-point bipolar scale rating the two concepts "young people" and "old people" (e.g. "friendly-unfriendly"); (3) picture series: four drawings representing men at four stages of life were presented to children to elicit responses about their knowledge and feelings regarding older people and the ageing process (e.g. "Can you put these pictures in order from the youngest to the oldest?").

The CVOA (Marks et al. 1985) includes four sections with open-ended questions: (1) children are asked to think about becoming an old person and to answer nine open-ended questions covering the three dimensions of their perceptions of the ageing process: cognitive ("How can you tell when people are growing old?"); affective ("How will you feel when you are old?") and behavioral ("What will you do when you are old?"). These questions were followed by a close-ended question: "Do you think this is: (a) a good thing to happen?; (b) a bad thing to happen?; (c) neither a good or bad?"; (2) children are asked for information regarding the frequency and quality of contact with their grandparents; (3) children are asked about having an older person in the classroom (e.g. "Would you like having an old person in your classroom as a helper?"); (4) using a semantic differential scale composed by twelve bipolar word pairs children are asked to indicate what characteristics they attribute to older people (e.g. "pleasant-unpleasant").

Despite the useful effort to cover the three dimensions of children's attitudes, both scales (CATE and CVOA) share a common limitation - they represent an overlap of two different attitudinal objects: children's attitudes about older people and about the ageing process. The attempt to measure two different constructs simultaneously should be taken into consideration when analyzing the results obtained to assess ageism among children. Moreover, both scales are also limited in their measurement of the behavioral dimension of ageism in the sense that they only evaluate the behavioral intentions of children regarding older people and not their actual behaviors as it was done in other measures such as the puzzle (Isaacs and Bearison 1986) and the Piagetian adapted task (Kwong See et al. 2012). These aspects limit the value of the results obtained by the use of these measures. 


\subsubsection{Explicit vs. Implicit Measures}

In order to organize the literature regarding children's attitudes towards older people, we propose an alternative way to look at the measures and evidence. As far as we know, this is the first time such a classification has been proposed in order to classify children's attitudes in the case of age. Based on the definition of measure as an "outcome of a measurement procedure" (De Houwer 2006), and following previous approaches in other domains (Maass et al. 2000), we present a framework for classifying children's attitudes measures into three categories: explicit measures, both explicit and implicit measures and implicit measures.

Intergroup attitudes have been mainly measured through self-report questionnaires to assess participant's attitudes regarding their in-group and out-groups members. However, there are some concerns regarding the validity of these measures because people can easily control their explicit responses and act in order to comply with social norms, making prejudice less likely. Consequently, implicit measures have been increasingly used in order to reduce participant control over responses (Maass et al. 2000). This is based on the assumption that participants cannot strategically control the outcome of the implicit measurement procedure (De Houwer 2006).

The classification of the measures into the three categories mentioned above (Fig. 30.1) was based on the following four automaticity features: (1) intentionality

$\begin{array}{ll}\text { Intentional } & \text { Unintentional } \\ \text { Conscious } & \text { Unconscious } \\ \text { Non efficient } & \text { Efficient } \\ \text { Controlled } & \text { Uncontrolled }\end{array}$

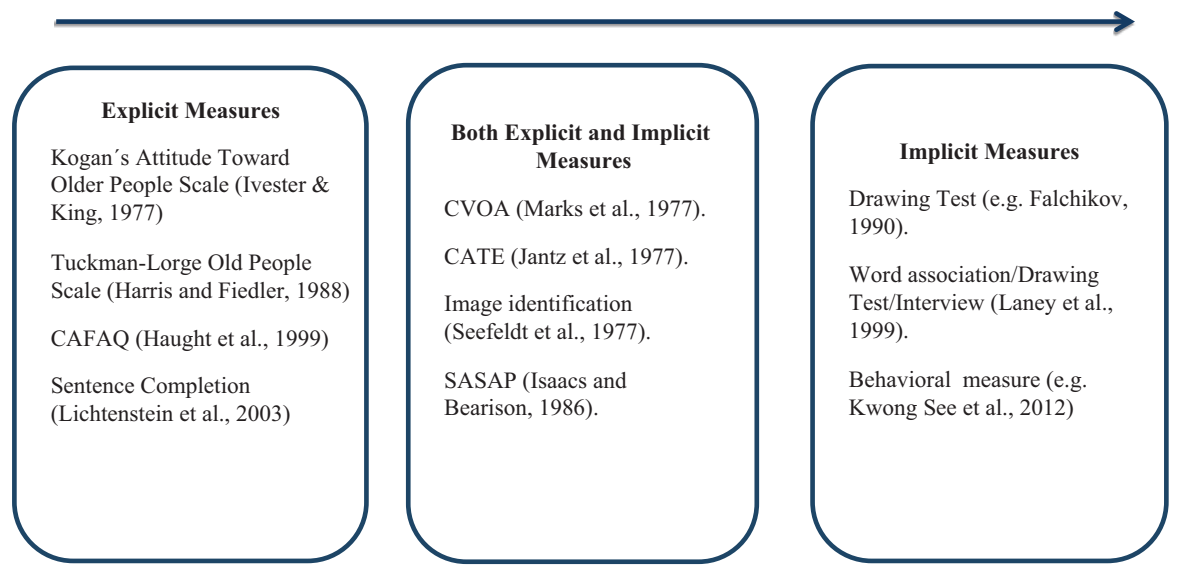

Fig. 30.1 Categorization of measures to assess children's attitudes regarding older people according to the automaticity features 
(whether one is in control over the instigation or "start-up" of processes); (2) awareness (one person can be aware of a stimulus event but also of its potential influence on subsequent experience and judgments); (3) efficiency (effects that are relatively effortless) and (4) controllability (one's ability to stifle or stop a process once started) (Bargh 1994). These automatic features do not necessarily occur together in the sense that automatic processing is not unitary. In fact, they are independent qualities that may appear in various combinations.

Explicit measures are more deliberative, mindful, and easily controlled (Maass et al. 2000). An example of an explicit scale is the Tuckman-Lorge Old People Scale (OP) (Harris and Fiedler 1988), in which participants were asked to circle "yes" or "no" for each item regarding misconceptions and stereotypes about old people (e.g. "They are unproductive".."). In this case, the process is intentional because participants have the goal of engaging in a process, are aware of the stimulus (older persons), the process itself is nonefficient (it requires attentional capacity and time to answer the 137 items) and controllable in the sense that participants can stop the process at any time.

By contrast, implicit measures are automatic because they are more unintentional, efficient, non-conscious and uncontrolled (Bargh 1994). An example of an implicit measure is the puzzle activity task described above (Isaacs and Bearison 1986). Behavioral measures aim to create experimental situations that parallel contexts of daily life and to observe participant's interpersonal behavior (Maass et al. 2000). In the case of the puzzle activity, children in the experimental setting were not aware of what was being measured (their behavior toward older confederates) and, consequently, had little or no control of their own thoughts and behaviors. Moreover, the process is efficient in the sense that it requires minimal attentional capacity and is not time consuming.

The third category includes measures that are a blend of both explicit and implicit questions. An example is the CATE scale (described above) which is constituted by more explicit sub-scales (word association questions and semantic differential) and more implicit ones (picture series based on drawings representing men at four stages of life).

The classification of the measures into these three categories facilitates the interpretation of the complex pattern of results that emerged from the use of different instruments to measure children's attitudes regarding older people.

\subsection{Analyses of Children's Attitudes Through Different Measures and Across Different Stages of Childhood}

\subsubsection{Explicit and Mixed Measures}

Studies using explicit measures or a combination of both explicit and implicit measures revealed more positive or mixed children's views of older people in comparison with those adopting an implicit approach. Explicit measures have predominantly 
assessed the cognitive dimension of children's attitudes. Despite some variability, the most positive results were found in studies assessing children's attitudes in late childhood (8-10 years old) (e.g. CVOA) and in the adolescence period (13-19 years old) (e.g. Kogan's Attitude toward Older People Scale; Ivester and King 1977). For example, in a study using the "Child-Adolescent Facts on Ageing Quiz" (CAFAQ Haught et al. 1999), children's knowledge and beliefs regarding older people were assessed through sentences on basic physical, mental and social facts about ageing. Adolescents (grade 12) showed positive attitudes whereas younger children (grade 3) showed a negative bias toward this age group. Younger children's misconceptions about older people were mainly focused on two dimensions: competence (not working as well as younger people) and social skills (being nice to other people).

The application of two scales that blended both explicit and implicit measures the "Children's Attitudes Toward the Elderly Scale" (CATE - Jantz et al. 1977) and the "Children's View on Aging (CVOA - Marks et al. 1985) revealed a more complex pattern of results. More specifically, the CATE was applied to children aged between three and 11 years old and revealed that children's attitudes toward older people were mixed. In affective terms, their descriptions of older people tend to be positive (e.g. "they are nice"; "friendly"; "wonderful"). However, the inverse pattern was observed regarding attributes of older people's physical (e.g. "ugly") and behavioral characteristics (e.g. "they can't really walk very fast"). Moreover, children's attitudes regarding their own ageing process tended to be negative (e.g. "I don't want to get old"), ascribing negative feelings to old age (e.g. "sad"; "depressed"). Nevertheless, older children (fifth and sixth graders) were the most positive about their future as older persons.

Some of these results are in line with those obtained through the application of the "Children's Views of Ageing" (CVOA - Marks et al. 1985), namely the negative perception children hold regarding their own ageing process ("you are sad"; nobody cares"). Responses in the semantic differential scale highlighted the positivity attributed to older people in the affective dimension, while young people were evaluated more positively based on the cognitive domain. In this study, children attributed negative characteristics to older people at both physical and psychological levels (e.g "lonely"; "scary"; "people no longer care about you"). However, children also showed positive behavioral intentions expressing motivation to interact with old people in their classrooms. It is nevertheless important to emphasize that children tested in this study were already 8-10 years old.

Taken together, these results suggest that, although some evidence shows that views of ageing tend to become more positive as children grow older, at least based on more explicit measures (e.g. Haught et al. 1999) a mixed and complex pattern of results still occurs depending on the dimension being assessed. Overall, it seems that children are more positive when we assess explicitly affective and behavioral aspects instead of cognitive representations of older people. Children also seem to be more negative when they are considering their own ageing process as opposed to making judgments about older people. However, the most important finding to emerge is the fact that these sort of explicit measures do not yield a significant and consistent pattern of results. One possibility is that, similar to what happens in other 
domains such as, for instance, racism, older children are able to control their answers and show ageistic intentions in a more strategic manner depending on task domain, thus limiting our ability to measure their more intrinsic attitudes (Olson and Dunham 2010). Given this complex pattern of results, attention to the type of procedure used and the dimensions covered in the measurement of children's attitudes should be given wider attention than has been so far.

\subsubsection{Implicit Measures}

Ageism among children has been consistently found in studies using implicit measures. For example, in a puzzle activity task (Isaacs and Bearison 1986), four-, sixand eight-year old participants distinguished aged from nonaged individuals and responded differently to them. More specifically, participants in the experimental condition (those working individually with an older person) initiated less eye contact, spoke less to confederates, initiated less conversations with them and required less appeals for assistance or verification. Interestingly, results showed an increase in ageism between the ages of 4 to $6 / 8$ years, with a decrease in the amount of eye contact in the aged confederate experimental condition, thus contradicting the pattern found with more explicit measures.

In another study, Kwong See et al. (2012) used a modified Piagetian number conservation task in order to assess interpersonal relationships between children and older people. In its original form, a child is asked if two aligned rows of objects have the same number of objects or if one of the rows has more. After the child agrees regarding the equality of the lines, the experimenter makes one of the lines longer and the child is then asked a second time if the two rows have the same number of objects or if one of the rows has more. According to the Piagetian theory, the second time asked, preoperational aged children (with an age between 4 and 7 years old) usually answer that the rows are different in the sense that they cannot conserve number. However, a different interpretation is provided by the conversational account for conservation errors according to which asking the same question twice is usually interpreted as a request for new or different information. Based on this assumption, Kwong See et al. (2012) hypothesized that when an adult experimenter asks if the two rows are the same a second time, a child infers that the experimenter wants to know if he/she is aware of the perceptual modification that has occurred. In this case, children are expected to consider that the experimenter is more cognitive capable by virtue of being an adult and therefore must know that the transformation did not change the number of objects in the line and is asking about something else. An opposite pattern of response is expected to occur when the experimenter is an older person: in this case, age stereotyping (e.g. poor vision or memory, cognitive impairments) is expected to become associated with the question asked by the experimenter. Thus, children might infer that the older experimenter is asking the second question because he needs to clarify if the number of objects in the rows is truly the same. As predicted 
by the authors, children held different beliefs about the motivations of the two experimenters and gave different answers according to these beliefs. When the experimenter was a younger adult, the majority of children gave an answer focused on length rather than number. The opposite pattern was found in the older adult experimenter condition, therefore highlighting the similarity of the rows. These results showed that children as young as 5 years old have already internalized age stereotypes believing that ageing is associated with decline. Unfortunately, this study did not include older children so we can not reach any conclusions regarding this aspect.

In another study using three qualitative and implicit methods - word association task, projective drawings and an attitude toward-ageing interview -first and second grade-students showed negative attitudes toward older people and the ageing process (Laney et al. 1999). More specifically, in the word association task, the words associated with "old" were mostly negative at different dimensions: psychologically (e.g. "weak"), mentally (e.g. "bored"), and low levels of activity (e.g. "retired"). The opposite pattern was found regarding young people who were characterized in a positive way (e.g. "happy"; "active"). Children's drawings depicted older persons performing sedentary and passive leisure activities (e.g. "watching out window; "watching $T V$ "). In addition, drawings revealed the physical characteristics attributed to older people (e.g. "gray hair"; "wrinkles"). This negative view of older people was also evident in children's responses to the interview: they considered that older persons perform passive activities (e.g. lying in bed") and need help from young people because they are physically disabled and/or sick. In addition, children expressed negative attitudes regarding the ageing process (e.g. "the body quits working") associating ageing with the "imminence of death".

Older children's (ages between 10.5 and 11.5 years) attitudes regarding older people were assessed through a comparative analysis of children's four drawings: a young man, an old man, a young woman and an old woman (Falchikov 1990). Results revealed that pictures of old people were more negative in content than those of young people, revealing a clear association between old age and a lack of human contact and loneliness. Drawings of old people frequently included characters such as glasses, wrinkles, canes or wheelchairs, hearing aids and slippers. Moreover, these pictures were significantly smaller than those of young people.

From the analyses of the literature, the only case in which the use of implicit measures yielded more positive views of ageing by children was when they were asked to draw older people in greater detail (e.g., within different scenarios). Specifically, in a study where students from two middle schools were asked to draw a typical older person in a setting (Lichtenstein et al. 2005), the drawings demonstrated the great variability of children's attitudes regarding older people, including both positive and negative traits. The most positive drawings were those depicting someone relevant to the students, namely a grandparent. The relevance of asking children to draw someone they knew was also shown in a study where children between the ages of eight and 12 were asked to produce a drawing of an old person they see in real life (in a setting) (Robinson et al. 2014). Overall, the drawings portrayed an older person (namely, a family member) who was "happy, healthy, active 
and with positive physical characteristics". Hence, these results suggest that children have a more positive view of older people that they know in their daily lives such as their grandparents. The target used to assess ageism against older people should be then carefully chosen.

Given their more consistent pattern of results, implicit measures seem like an interesting avenue to pursue in the study of children's attitudes regarding older people. In this sense, it would be extremely important to understand how more implicit and explicit attitudes develop throughout childhood and what are the main factors influencing these different aspects of ageism. A more complete and valid assessment of ageism during childhood would have many important implications to promote more meaningful prevention efforts against the wide negative representations of older people in our societies.

\subsubsection{Limitations of Available Measures}

We identified a range of measures that have been employed to assess children's attitudes regarding older people (summarized in Table 30.1). Although there is a reasonably large volume of work produced in this domain, it is nevertheless difficult to reach a firm conclusion of the developmental trajectory of ageism in children. In fact, a more thorough analysis of the measures used clarifies that they have important limitations that need to be overcome in the future.

The first limitation is the lack of psychometric consistency that is particularly relevant in the case of some studies (e.g., Harris and Fiedler (1988); Haught et al. (1999)). The lack of information about psychometric indicators (e.g. validity, reliability) jeopardizes the possibility of reaching conclusions about the meaning of these measures. Secondly, there is frequently an ambiguity or inconsistency in the attitudinal object that is measured. In some measures, there is an overlap of two different attitudinal objects: children's attitudes about older people (e.g., "what do you think about older people?") and the actual ageing process (e.g., "how do you perceive your own ageing will be?") (e.g. Jantz et al. 1977). This makes it difficult to compare the results obtained across the different studies. Third, most of the measures only provide a partial assessment of children's attitudes. As we have seen, several of the measures identified covered only the cognitive dimension of children's attitudes (their knowledge and beliefs regarding older people and/or the ageing process) (e.g. Issacs and Bearison (1986)), disregarding with few exceptions the affective and behavioral dimensions of attitudes. Given the fact that older children are more able to control their answers to these sorts of measures (Olson and Dunham 2010), it is important to diversify the methodologies used.

Further important limitation of integrating evidence from measures are attributed to the poor and incomplete description of the participants in the studies (i.e., age and grade level), the considerable variability of age range and low sample sizes (e.g. Falchikov 1990; Lichtenstein et al. 2005). This lack of transparency in the methodological affects the quality of the conclusions that may be drawn from such studies. 


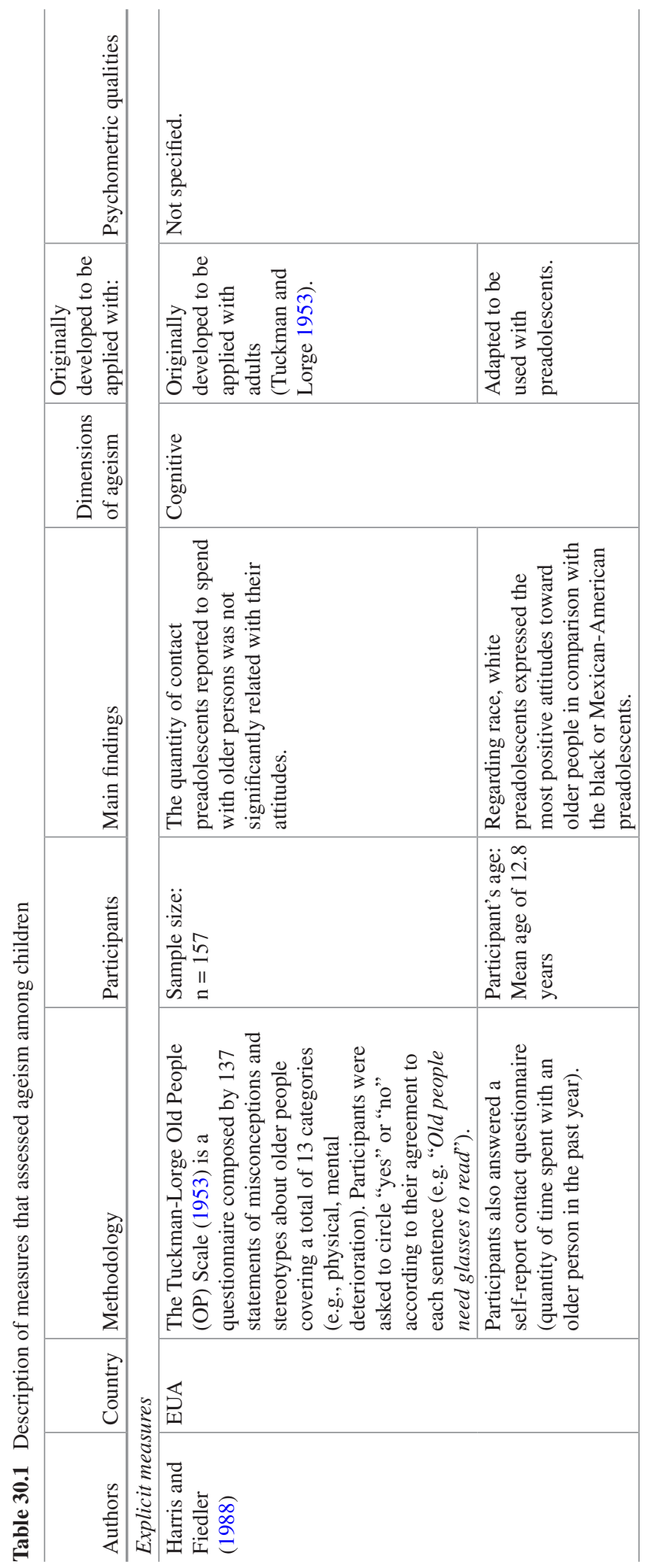




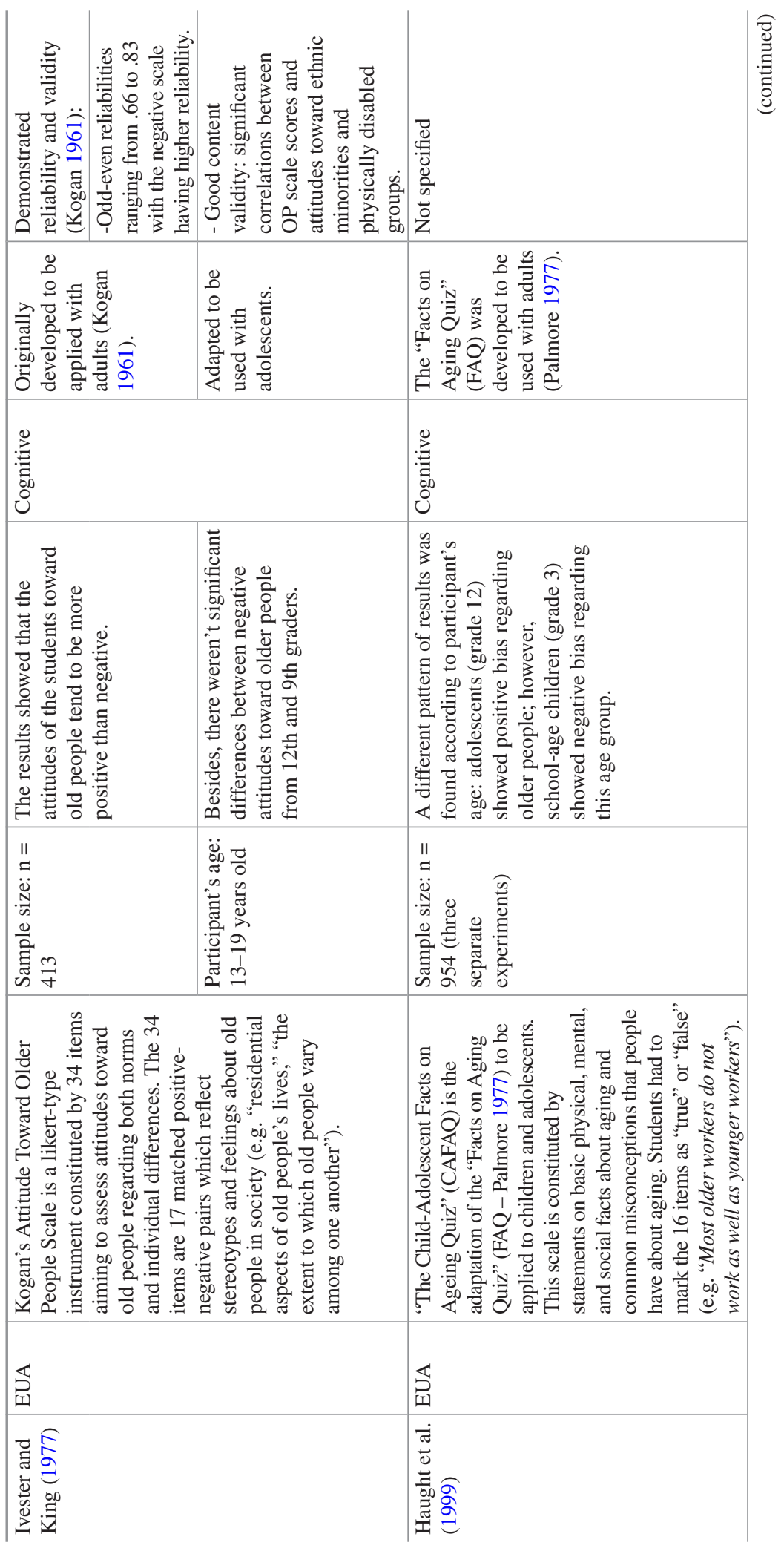




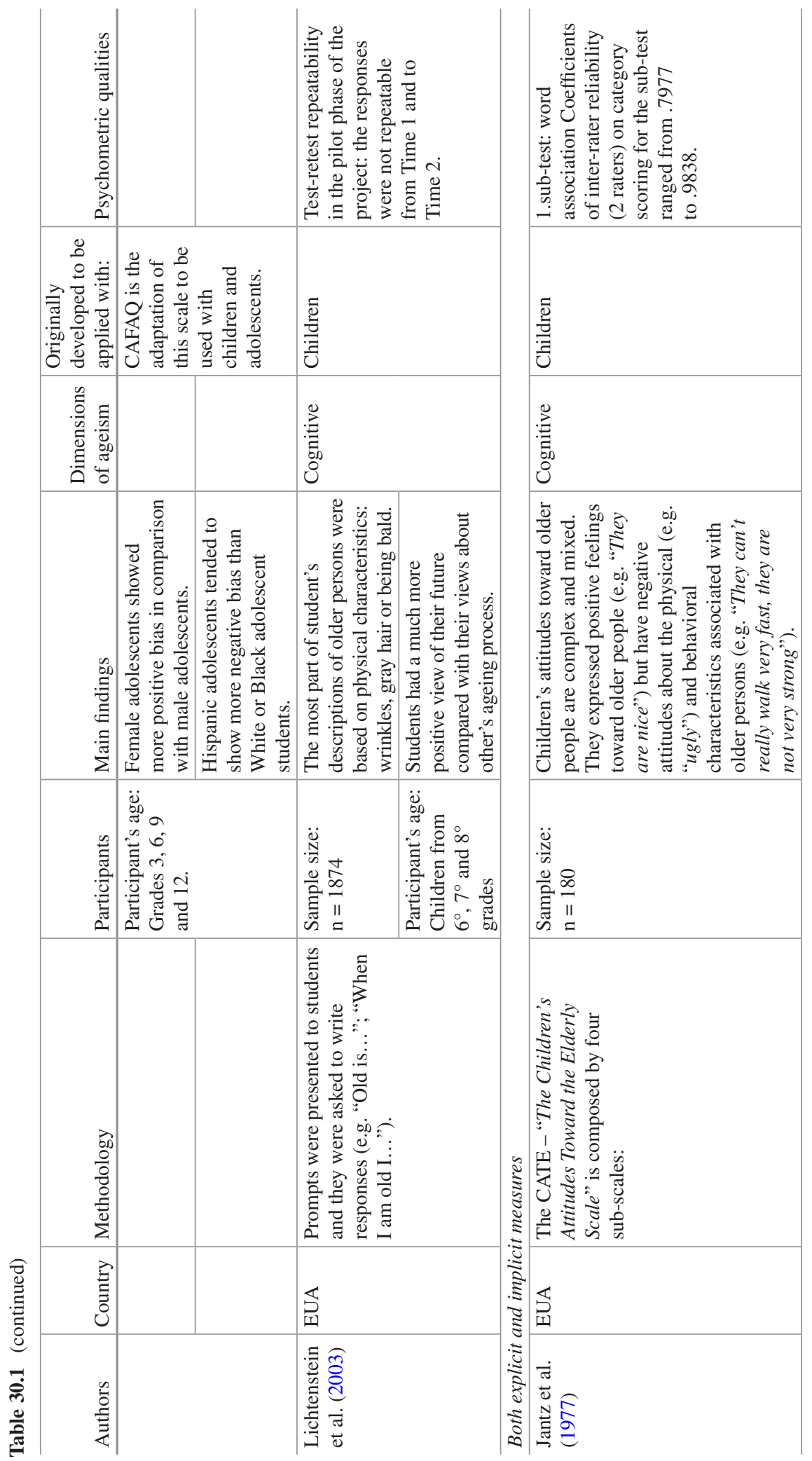




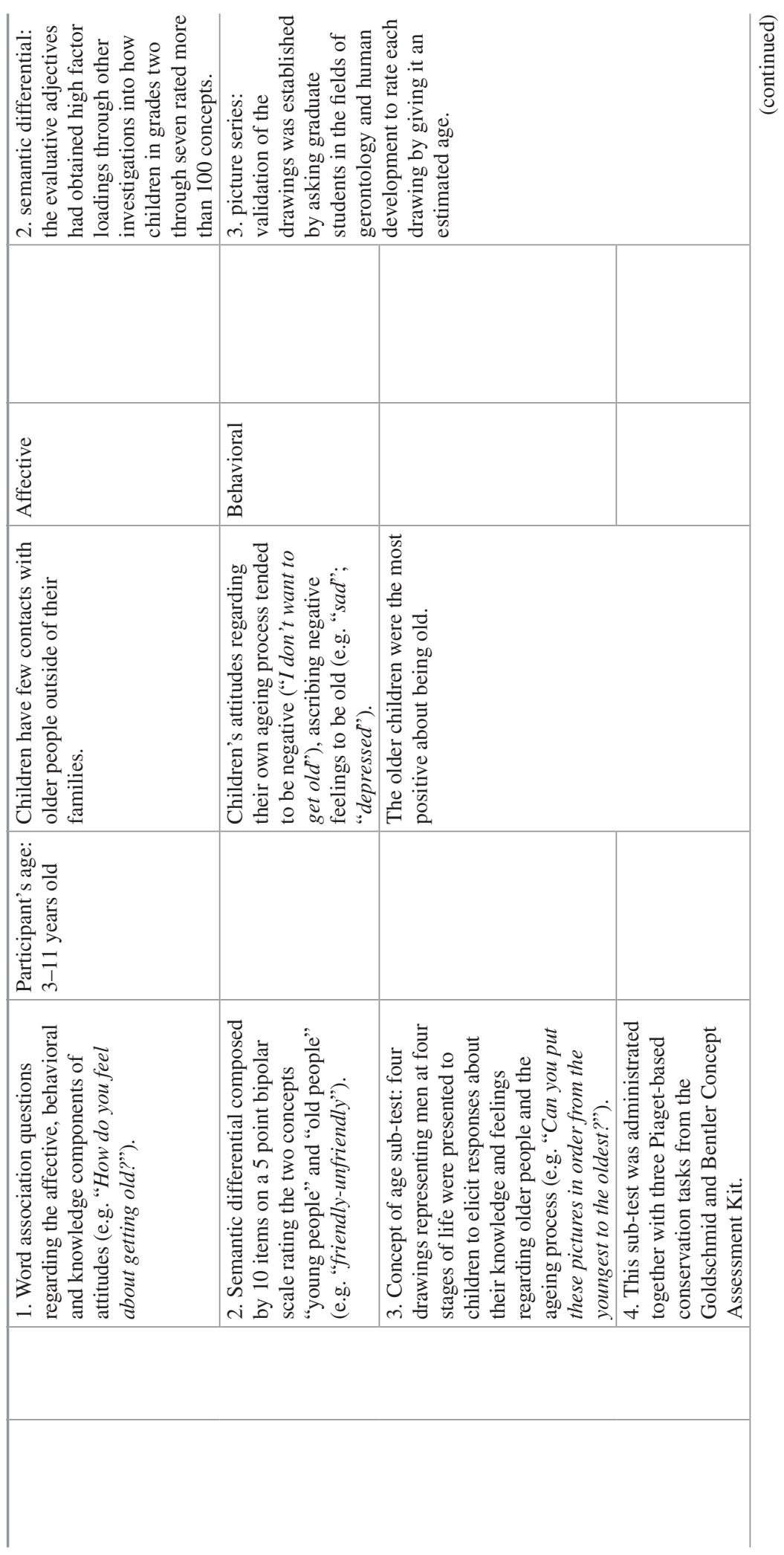




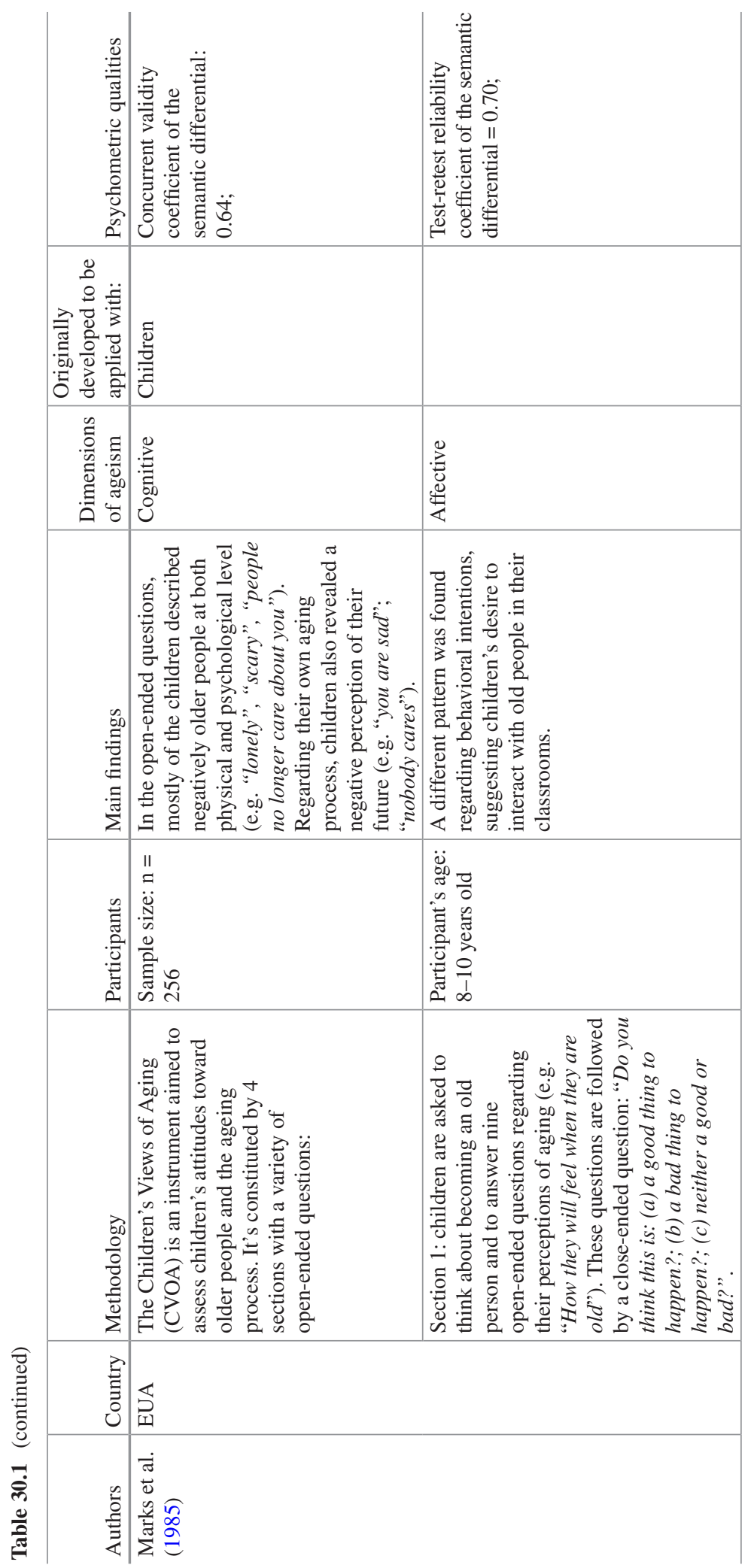




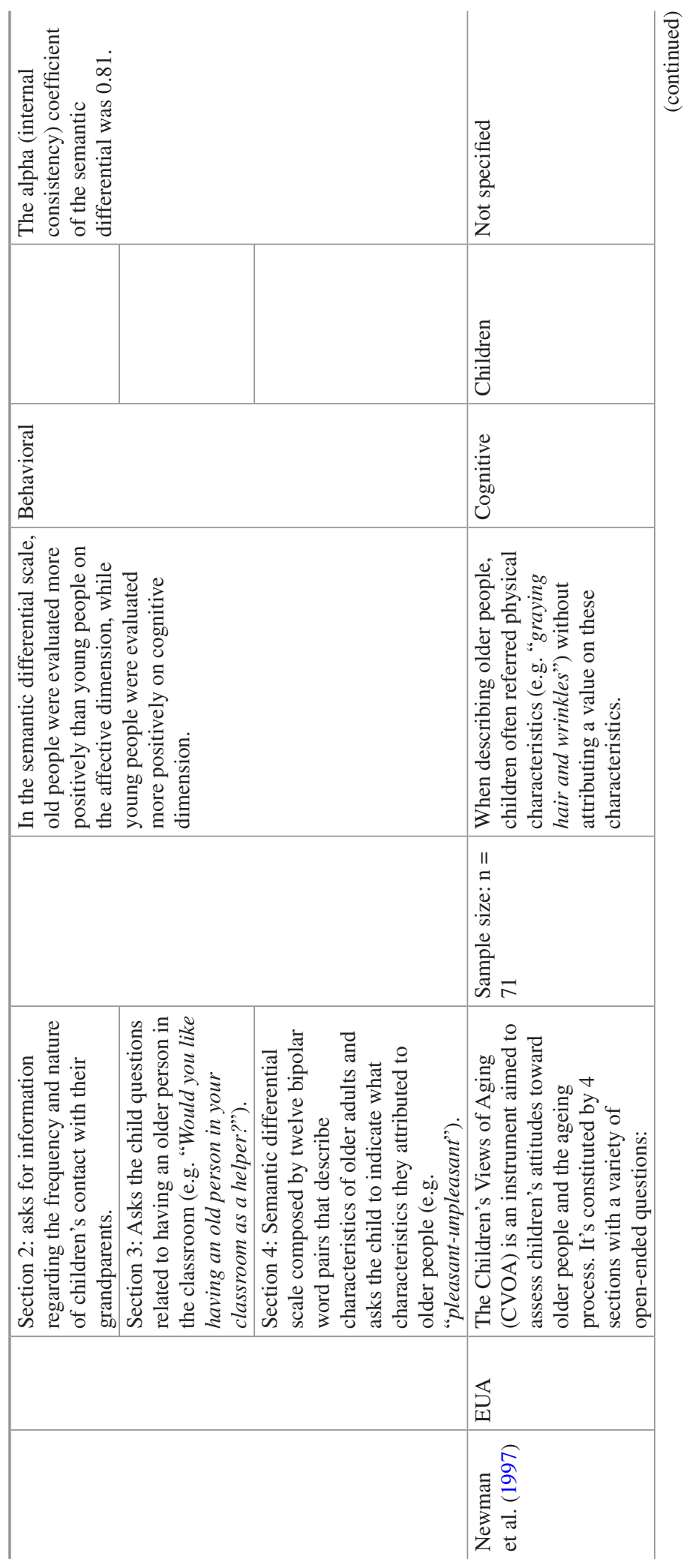




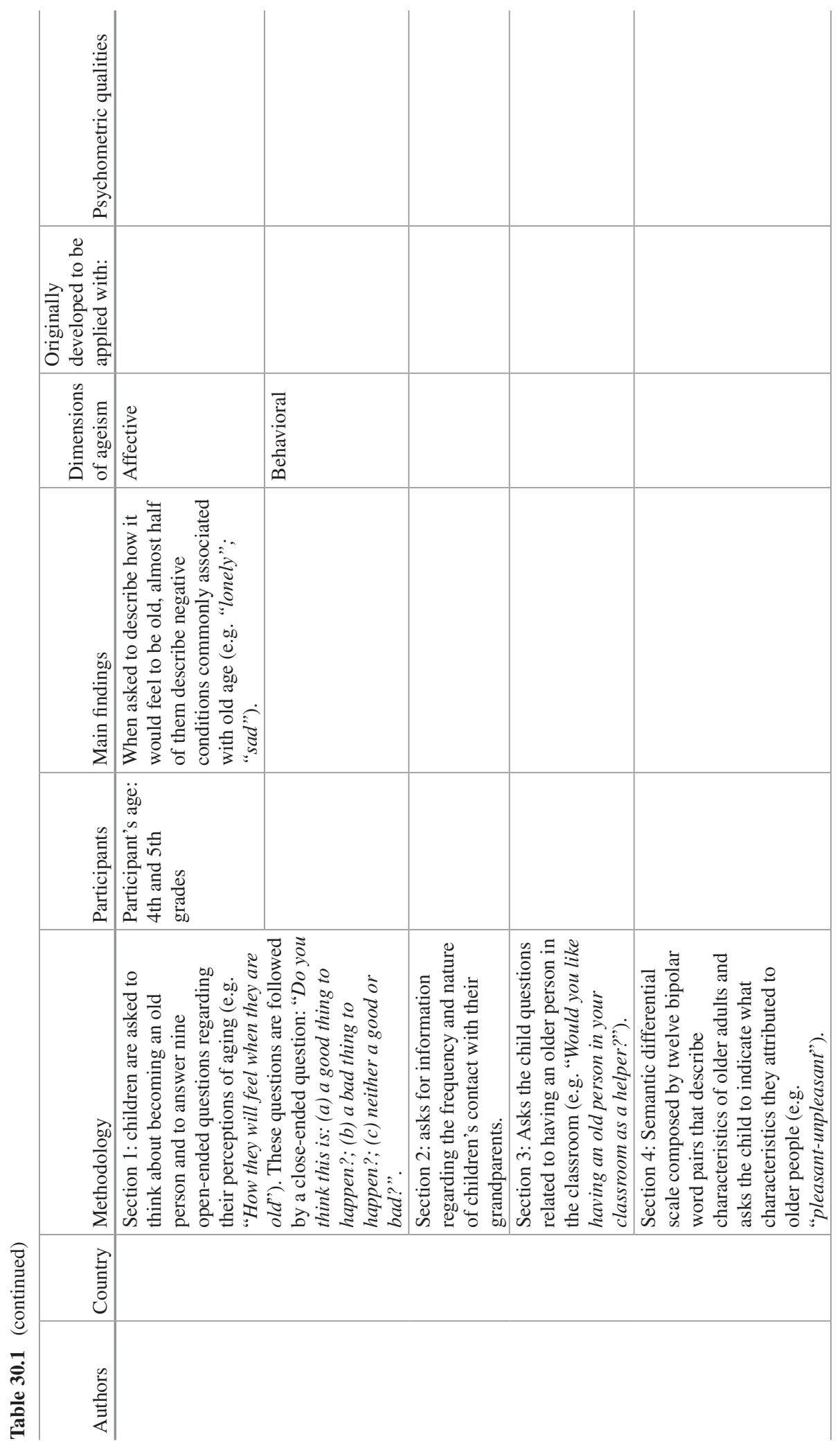




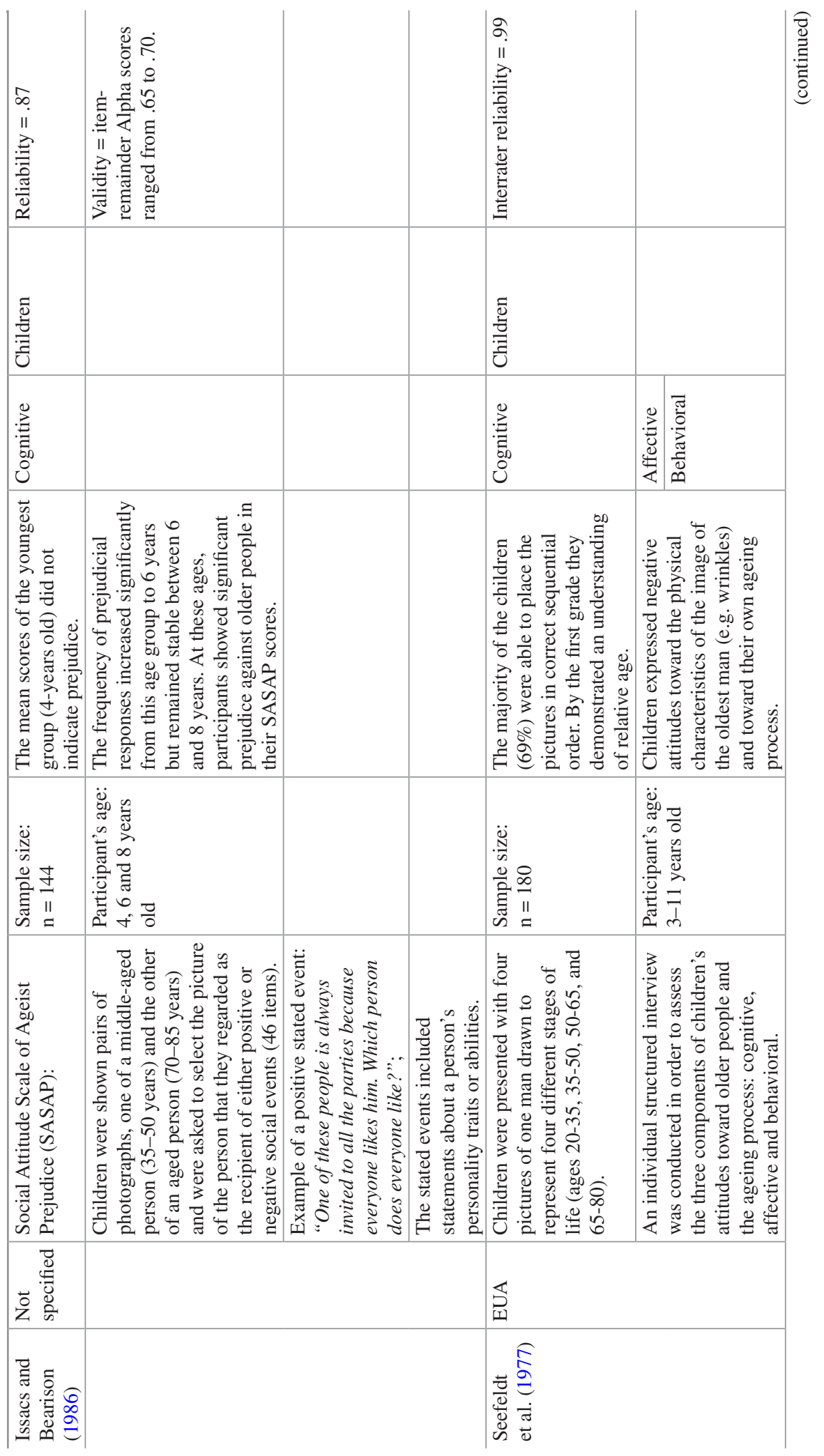




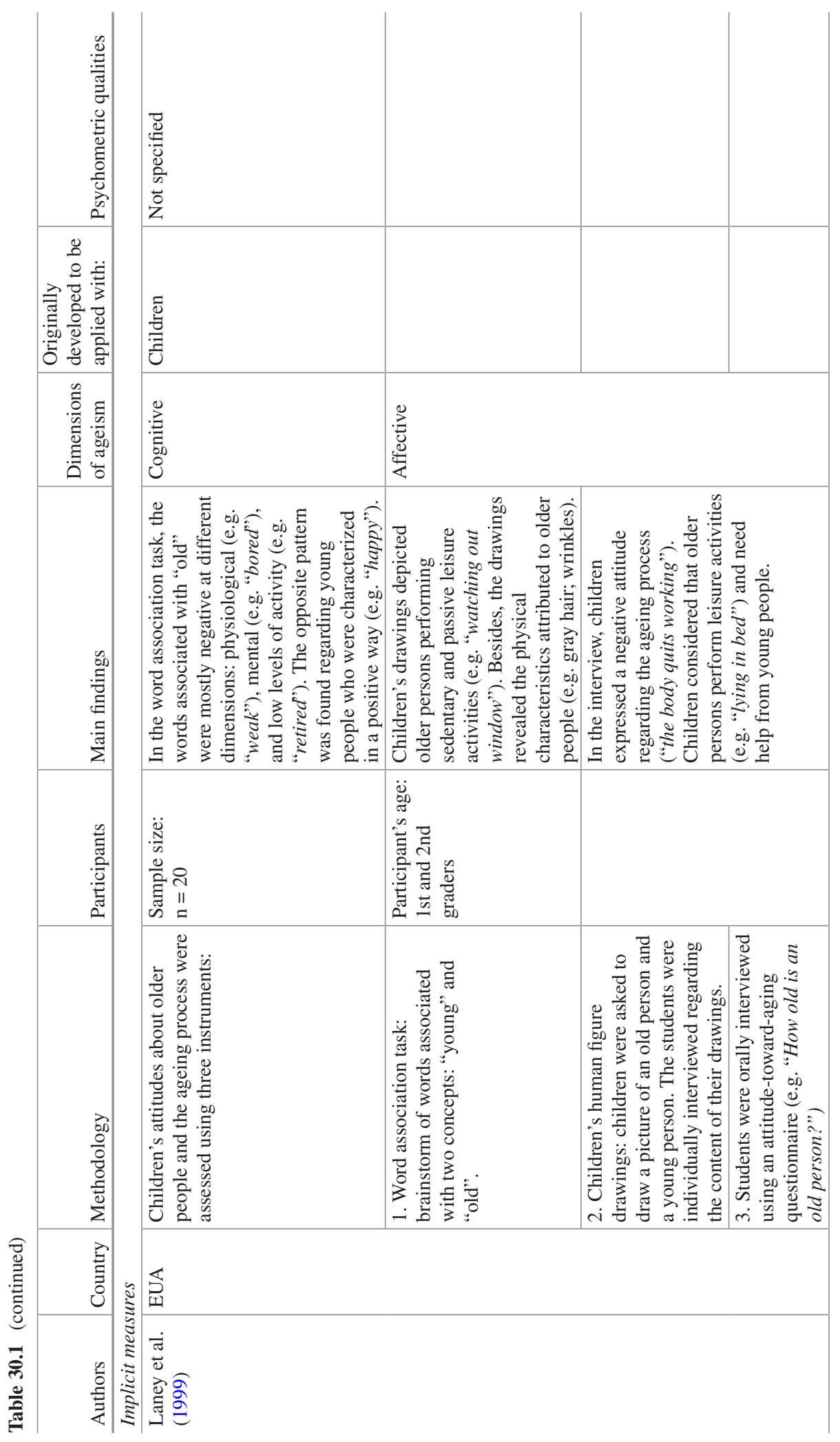




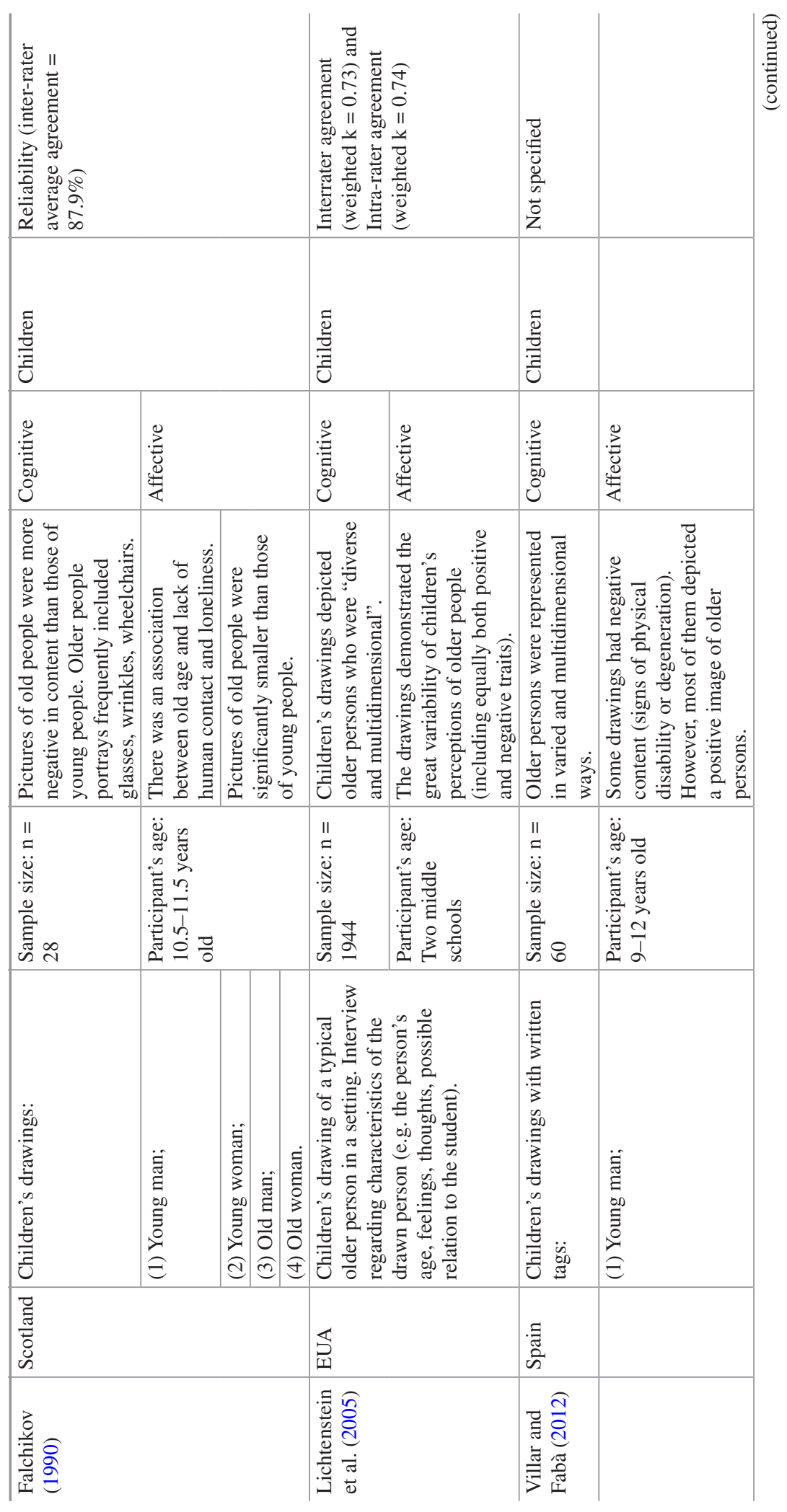




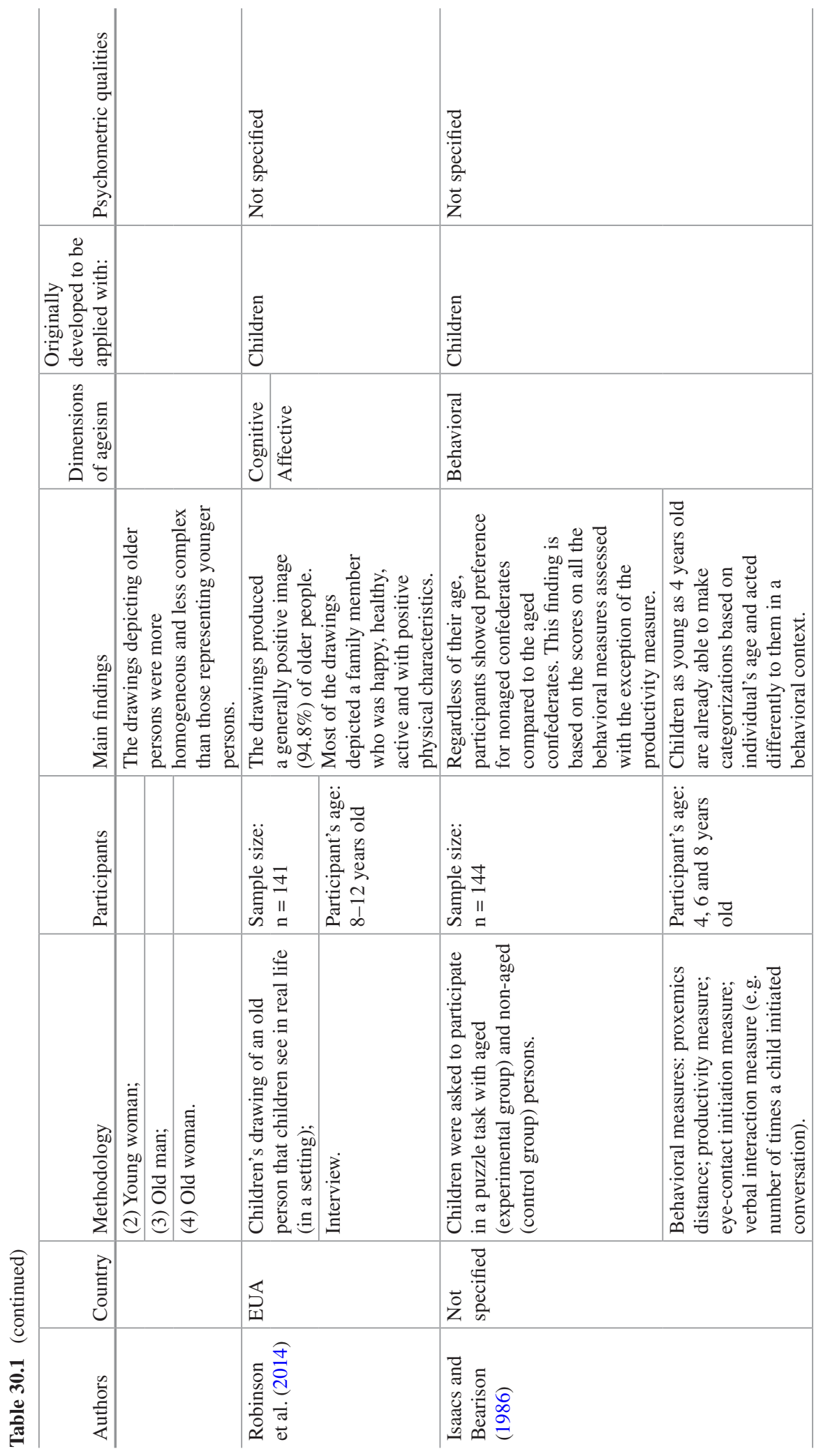




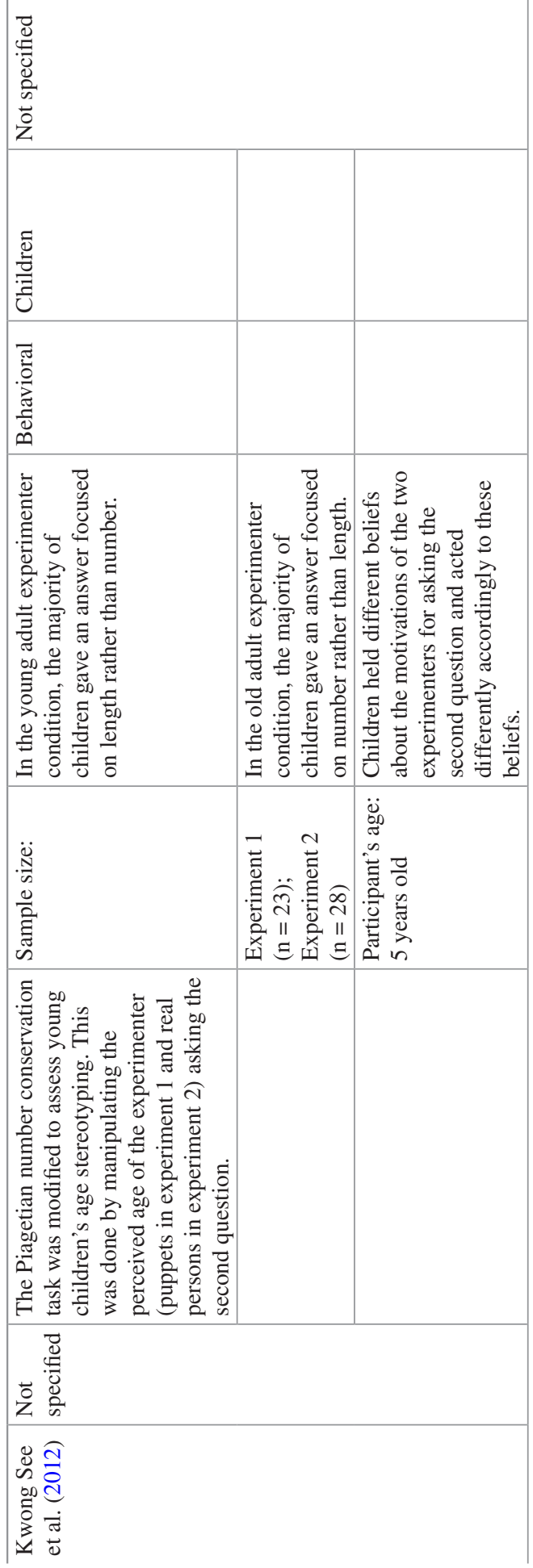


Another limitation is that the procedures used in the testing are not well described and appear very time consuming. For instance, the replicability of the studies using the behavioral methodology seems difficult in the sense that it requires the participation of older persons (for example, in a classroom context) in order to engage in interpersonal activities with younger participants (e.g. Isaacs and Bearison 1986). Another issue that requires further attention is that studies may use measures, such as scales, which may not be sensitive enough to capture the presence of ageism in very young children (e.g. Isaacs and Bearison 1986). This is particularly relevant in cases where scales were originally applied to adults, and have been used with children or adolescents with little or no adaptation (e.g. the "Tuckman -Lorge Old People Scale" - Harris and Fiedler 1988; "Kogan's Attitude toward Older People Scale" - Ivester and King 1977).

Finally, other aspects that have not been taken into consideration in these sort of studies are the need to control for important factors that may have an association with attitudes to age in children. For instance, in some studies, the prior contact between children and older people, namely their grandparents, was not assessed either in terms of quantity (Robinson et al. 2014) or quality (e.g. Harris and Fiedler 1988). This constitutes an important limitation in the sense that children's relationships with relevant older persons could reasonably serve as an important evidence for their cognitive, affective and behavioral overviews towards older people.

The recognition of these limitations is crucial for the refinement of currently available measures and for the development of more complex techniques in the future. New measures should be adapted and created that overcome some of the major limitations identified in this field.

\subsection{Future Directions \& Recommendations.}

Children's attitudes regarding older people represent a multidimensional construct (e.g. Lichtenstein et al. 2005) and, consequently, can be fully explored only if the three dimensions of attitudes (cognitive, affective and behavioral) are taken into account. Future studies aiming to explore children's attitudes regarding older people and/or the ageing process also should be based on a triangulation of both explicit and implicit measures. At the very least, research should be clear about the focus and type of measurement when formulating hypotheses. This will allow for a better evidence base to develop new theories on how implicit and explicit attitudes towards age and older people emerge and develop in childhood. More specifically, the use of this framework will help to establish a more systematic account on how ageism develops across childhood and how it is expressed by children of different age groups. For instance, if there is a social norm to not discriminate someone based on his or her age, one can hypothesize that older children will show less explicit ageism but, probably, their implicit ageism level will remain the same as happens, for instance, in racism (Rutland et al. 2005). This complex pattern of prejudice development across childhood should also be considered in studies on the development of 
ageism. Thus, a possible avenue to pursue is to explore the existence of an antidiscrimination norm based on people's age in children and adults. This will allow to address important topics in the field of ageism such as: the early origins of ageism, the development of self-presentation concerns and executive control and the ability to inhibit prejudicial responses (Olson and Dunham 2010).

Future measures of ageism in childhood should also have better psychometric qualities (i.e, test-retest reliability, concurrent validity, predictive validity, construct validity and content validity) and better sampling procedures. It is fundamental that specific information regarding participant's demographic characteristics be provided, e.g., their age. The measurement of other related factors such as prior relationships with grandparents or other significant older people is also of paramount importance in this domain and should be further considered as a necessity (Robinson et al. 2014).

Finally, we believe that it would also be important to conduct subsequent literature reviews, namely meta-analyses in this field. Although we tried to be as inclusive as possible, and we present the main studies in this domain, it would be important to consider other databases (e.g., Scopus, Web of Science) not included in this study. This would allow further exploration of the field, through a systematic procedure.

The improvement of measures of children's attitudes regarding older people is crucial and urgent. One important route will be to explore the instruments that have been used in other types of prejudicial attitudes (e.g., racism and sexism) and see how they can be applied to the case of ageism. It will allow further understanding of how ageism develops in childhood and the development of effective intervention programs (Marques et al. 2014b) to reduce ageism at an early age. In an ageing society, understanding how children think, feel and behave regarding older people is fundamental for preparing a better and more inclusive future for all age groups.

\section{References}

Aboud, F. E. (1988). Children and prejudice. New York: Basil Blackwell.

Abrams, D. (1989). Differential association: Social developments in gender identification during adolescence. In S. Skevington \& D. Baker (Eds.), The social identity of women (pp. 59-83). London: Sage.

Abrams, D. (2011). Wherein lies children's intergroup bias? Egocentrism, social understanding and social projection. Child Development, 82, 1579-1593. https://doi. org/10.1111/j.1467-8624.2011.01617.x.

Abrams, D., Rutland, A., Cameron, L., \& Ferrell, J. (2007). Older but wilier: In-group accountability and the development of subjective group dynamics. Developmental psychology, 43(1), 134. https://doi.org/10.1037/0012-1649.43.1.134

Abrams, D., Rutland, A., Pelletier, J., \& Ferrell, J. M. (2009). Children's group nous: Understanding and applying peer exclusion within and between groups. Child development, 80(1), 224-243. https://doi.org/10.1111/j.1467-8624.2008.01256.x

Allport, G. W. (1954). The nature of prejudice. Reading: Addison-Wesley. 
Bargh, J. A. (1994). The four horsemen of automaticity: Awareness, intention, efficiency, and control in social cognition. In R. J. Wyer, T. K. Srull, R. J. Wyer, \& T. K. Srull (Eds.), Handbook of social cognition, Vol. 1: Basic processes; Vol. 2: Applications (2nd ed., pp. 1-40). Hillsdale: Lawrence Erlbaum Associates, Inc.

Bigler, R. S., \& Liben, L. S. (2006). A developmental intergroup theory of social stereotypes and prejudice. Advances in child development and behavior, 34, 39-89. https://doi.org/10.1016/ S0065-2407(06)80004-2

Brown, C. S., \& Bigler, R. S. (2005). Children's perceptions of discrimination: A developmental model. Child Development, 76(3), 533-553. https://doi.org/10.1111/j.1467-8624.2005.00862.x.

De Houwer, J. (2006). What are implicit measures and why are we using them? In R. W. Wiers, A. W. Stacy, R. W. Wiers, \& A. W. Stacy (Eds.), Handbook of implicit cognition and addiction (pp. 11-28). Thousand Oaks: Sage. https://doi.org/10.4135/9781412976237.n2

Eagly, A. H., \& Chaiken, S. (1993). The psychology of attitudes. Fort Worth: Harcourt Brace.

Eagly, A. H., \& Chaiken, S. (2007). The advantages of an inclusive definition of attitude. Social Cognition, 25(5), 582-602. https://doi.org/10.1521/soco.2007.25.5.582

Falchikov, N. (1990). Youthful ideas about old age: An analysis of children's drawings. International Journal of Aging and Human Development, 31(2), 79-99. https://doi.org/10.2190/ Q28U-2QAW-24AM-6XA3.

Fishbein, H. D. (1996). Peer prejudice and discrimination: Evolutionary, cultural, and developmental dynamics. Boulder: Westview.

Glick, P., \& Hilt, L. (2000). Combative children to ambivalent adults: The development of gender prejudice. In T. Eckes, H. M. Trautner, T. Eckes, \& H. M. Trautner (Eds.), The developmental social psychology of gender (pp. 243-272). Mahwah: Lawrence Erlbaum Associates Publishers.

Harris, J., \& Fiedler, C. M. (1988). Preadolescent attitudes toward the elderly: An analysis of race, gender and contact variables. Adolescence, 23(90), 335-340.

Haught, P. A., Walls, R. T., Laney, J. D., Leavell, A., \& Stuzen, S. (1999). Child and adolescent knowledge and attitudes about older adults across time and states. Educational Gerontology, 25(6), 501-517. https://doi.org/10.1080/036012799267585.

Isaacs, L. W., \& Bearison, D. J. (1986). The development of children's prejudice against the aged. International Journal of Ageing and Human Development, 23, 175-195. https://doi. org/10.2190/8GVR-XJQY-LFTH-E0A1

Ivester, C., \& King, K. (1977). Attitudes of adolescents toward the aged. Gerontologist, 17, 85-89. https://doi.org/10.1093/geront/17.1.85

Jantz, R. K., Seefeldt, C., Galper, A., \& Serlock, K. (1977). Children's attitudes toward the elderly. Social Education, 41, 518-523.

Kogan, N. (1961). Attitudes toward old people: The development of a scale and an examination of correlates. Journal of Abnormal and Social Psychology, 62, 44-54.

Kwong See, S. T., Rasmussen, C., \& Pertman, S. Q. (2012). Measuring children's age stereotyping using a modified piagetian conservation task. Educational Gerontology, 38(3), 149-165. https://doi.org/10.1080/03601277.2010.515891

Laney, J. D., Wimsatt, T. J., Moseley, P. A., \& Laney, J. L. (1999). Children's ideas about aging before and after an integrated unit of instruction. Educational Gerontology, 25(6), 531-547. https://doi.org/10.1080/036012799267602

Levy, B. (1996). Improving memory in old age through implicit self-stereotyping. Journal of Personality and Social Psychology, 71(6), 1092. https://doi.org/10.1037/0022-3514.71.6.1092

Levy, B. R. (2003). Mind matters: Cognitive and physical effects of aging self-stereotypes. The Journals Of Gerontology: Series B: Psychological Sciences And Social Sciences, 58B(4), P203-P211. https://doi.org/10.1093/geronb/58.4.P203

Levy, B. (2009). Stereotype embodiment: A psychosocial approach to aging. Current Directions in Psychological Science, 18(6), 332-336. https://doi.org/10.1111/j.1467-8721.2009.01662.x.

Levy, S. R., \& Hughes, J. M. (2009). Development of racial and ethnic prejudice among children. In T. D. Nelson \& T. D. Nelson (Eds.), Handbook of prejudice, stereotyping, and discrimination (pp. 23-42). New York: Psychology Press. 
Lewis, M., \& Brooks-Gunn, J. (1979). Toward a theory of social cognitive development of self. New Directions for Child and Adolescent Development, 4, 1-20.

Lichtenstein, M. J., Pruski, L. A., Marshall, C. E., Blalock, C. L., Lee, S., \& Plaetke, R. (2003). Sentence completion to assess children's views about aging. The Gerontologist, 43(6), 839848. https://doi.org/10.1093/geront/43.6.839

Lichtenstein, M. J., Pruski, L. A., Marshall, C. E., Blalock, C. L., Liu, Y., \& Plaetke, R. (2005). Do middle school students really have fixed images of elders? The Journals of Gerontology: Series B: Psychological Sciences and Social Sciences, 60B(1), S37-S47. https://doi.org/10.1093/ geronb/60.1.S37.

Loos, E., \& Ivan, L. (2018). Visual ageism in the media. In L. Ayalon \& C. Tesch-Römer (Eds.), Contemporary perspectives on ageism: Vol. 19. International perspectives on aging (pp. 163176). Berlin: Springer.

Maass, A., Castelli, L., \& Arcuri, L. (2000). Measuring prejudice: Implicit versus explicit techniques. In D. Capozza, R. Brown, D. Capozza, \& R. Brown (Eds.), Social identity processes: Trends in theory and research (pp. 96-116). Thousand Oaks: Sage Publications Ltd..

Marks, R., Newman, S., \& Onawola, R. (1985). Latency-aged children's views of aging. Educational Gerontology, 11, 89-99. https://doi.org/10.1080/0380127850110202

Marques, S. (2011). A discriminação social das pessoas idosas. Colecção de Ensaios da Fundação Francisco Manuel dos Santos. Lisboa: Relógio D’Água Editores.

Marques, S., Lima, M. L., Abrams, D., \& Swift, H. (2014a). Will to live in older people's medical decisions: Immediate and delayed effects of aging stereotypes. Journal of Applied Social Psychology, 44(6), 399-408. https://doi.org/10.1111/jasp.12231

Marques, S., Vauclair, C. M., Rodrigues, R., Mendonça, J., Gerardo, F., Cunha, F., Sena, C., \& Leitão, E. (2014b). imAGES: intervention program to prevent ageism in children. Lisboa: Santa Casa da Misericórdia de Lisboa \& LEYA.

McCall, R. B., \& Kennedy, C. B. (1980). Attention of 4-month infants to discrepancy and babyishness. Journal of Experimental Child Psychology, 29, 189-201. https://doi. org/10.1016/0022-0965(80)90015-6

Mendonça, J., Mariano, J., \& Marques, S. (2016). Lisbon street campaign against ageism: A promising multi-stakeholder initiative. Journal of Intergenerational Relationships, 14(3), 258-265. https://doi.org/10.1080/15350770.2016.1195216

Middlecamp, M., \& Gross, D. (2002). Intergenerational daycare and preschooler's attitudes about aging. Educational Gerontology, 28, 271-288. https://doi.org/10.1080/036012702753590398

Montepare, J. M., \& Zebrowitz, L. A. (2002). A social-developmental view of ageism. In T. D. Nelson (Ed.), Ageism: Stereotyping and prejudice against older persons (pp. 77-125). Cambridge, MA: The MIT Press.

Nesdale, D. (1999). Developmental changes in children's ethnic preferences and social cognitions. Journal of Applied Developmental Psychology, 20, 501-519. https://doi.org/10.1016/ S0193-3973(99)00012-X.

Newman, S., Faux, R., \& Larimer, B. (1997). Children's view on aging: Their attitudes and values. The Gerontologist, 37(3), 412-417. https://doi.org/10.1093/geront/37.3.412

Olson, K. R., \& Dunham, Y. (2010). The development of implicit social cognition. In B. Gawronski, B. K. Payne, B. Gawronski, \& B. K. Payne (Eds.), Handbook of implicit social cognition: Measurement, theory, and applications (pp. 241-254). New York: Guilford Press.

Palmore, E. (1977). Facts on aging: A short quiz. The Gerontologist, 17(4), 315-320.

Piaget, J., \& Weil, A. M. (1951). The development in children of the idea of the homeland and of relations to other countries. International Social Science Journal, 3, 561-578.

Pinquart, M., Wenzel, S., \& Sörensen, S. (2000). Changes in attitudes among children and elderly adults in intergenerational group work. Educational Gerontology, 26(6), 523-540. https://doi. org/10.1080/03601270050133883

Robinson, T., Zurcher, J., \& Callahan, C. (2014). Youthful ideals of older adults: Ananalysis of children's drawings. Educational Gerontology, 41(6), 440-450. https://doi.org/10.1080/0360 1277.2014.983372 
Rodrigues, R. B. (2011). Conflicting social norms and white children's expressions of intergroup racial attitudes: a socio-normative developmental model (Doctoral dissertation). ISCTE Lisbon University Institute, Lisbon, Portugal.

Rutland, A., Cameron, L., Milne, A., \& McGeorge, P. (2005). Social norms and self-presentation: Children's implicit and explicit intergroup attitudes. Child development, 76(2), 451-466. https://doi.org/10.1111/j.1467-8624.2005.00856.x

Rutland, A., Killen, M., \& Abrams, D. (2010). A new social-cognitive developmental perspective on prejudice: The interplay between morality and group identity. Perspectives on Psychological Science, 5(3), 279-291. https://doi.org/10.1177/1745691610369468

Seefeldt, C., Jantz, R. K., Galper, A., \& Serock, K. (1977). Using pictures to explore children's attitudes toward the elderly. The Gerontologist, 17(6), 506-512. https://doi.org/10.1093/ geront/17.6.506

Stypińska, J., \& Nikander, P. (2018). Ageism and age discrimination in the labour market: A macrostructural perspective. In L. Ayalon \& C. Tesch-Römer (Eds.), Contemporary perspectives on ageism: Vol. 19. International perspectives on aging (pp. 73-90). Berlin: Springer.

Swift, H. J., Abrams, D., Drury, L., \& Lamont, R. A. (2016). The perception of ageing and age discrimination. Growing older in the UK. London: British Medical Association. Retrieved from http://www.bgs.org.uk/pdfs/2016bma_growing_older_in_uk.pdf

Tajfel, H., \& Turner, J. C. (1979). An integrative theory of intergroup conflict. The Social Psychology of Intergroup Relations, 33(47), 74.

Tajfel, H., \& Turner, J. C. (1986). The social identity theory of intergroup behavior. In S. Worchel \& W. Austin (Eds.), Psychology of Intergroup Relations (pp. 7-24). Chicago: Nelson Hall.

Tuckman, J., \& Lorge, I. (1953). Attitudes toward old people. Journal of Social Psychology, 37, 249-260.

Turiel, E. (1998). The development of morality. In W. Damon \& N. Eisenberg (Eds.), Handbook of child psychology: Vol. 3. Social, emotional and personality development (5th ed., pp. 863932). New York: Wiley.

Villar, F., \& Fabà, J. (2012). Draw a young and an older person: Schoolchildren's images of older people. Educational Gerontology, 38(12), 827-840. https://doi.org/10.1080/03601277.2011.6 45445

Whitbourne, S. K., \& Sneed, J. R. (2002). The paradox of well-being, identity processes, and stereotype threat: Ageism and its potential relationships to the self in later life. In T. D. Nelson (Ed.), Ageism: Stereotyping and prejudice against older persons (pp. 247-273). Cambridge, MA: The MIT Press.

Wyman, M. F., Shiovitz-Ezra, S., \& Bengel, J. (2018). Ageism in the health care system: Providers, patients, and systems. In L. Ayalon \& C. Tesch-Römer (Eds.), Contemporary perspectives on ageism: Vol. 19. International perspectives on aging (pp. 193-213). Berlin: Springer.

Open Access This chapter is licensed under the terms of the Creative Commons Attribution 4.0 International License (http://creativecommons.org/licenses/by/4.0/), which permits use, sharing, adaptation, distribution and reproduction in any medium or format, as long as you give appropriate credit to the original author(s) and the source, provide a link to the Creative Commons license and indicate if changes were made.

The images or other third party material in this chapter are included in the chapter's Creative Commons license, unless indicated otherwise in a credit line to the material. If material is not included in the chapter's Creative Commons license and your intended use is not permitted by statutory regulation or exceeds the permitted use, you will need to obtain permission directly from the copyright holder.

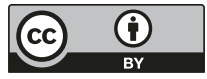




\title{
Chapter 31 \\ Researching Ageism through Discourse
}

\author{
Amanda Phelan
}

\subsection{Introduction}

The way we see the world is inevitably shaped by a number of factors such as culture, experience, language and values. Culture may be described as the customs, beliefs and values generally developed over time and experience, within a particular people or within a society. Language is one vehicle of cultural expression (Macionis and Gerber 2013). We understand the world by co-creating and co-constituting meaning and reality. The chapter begins with a brief presentation of the idea of social constructionism and ageism and then presents how one method of social construction, discourse, influences and mediates how we think, act and understand older people and how narratives can promote and privilege particular identities and consequently construct and reproduce ageism in society. Specific methodologies of discourse analysis are then introduced (Foucauldian discourse analysis and discursive psychology) to underpin the examination of data from research interviews of health care professionals (Phelan 2010), older people and their children (Ayalon 2015). Critical discourse analysis, such as Foucauldian discourse analysis, focuses on the examination of how political and social inequalities are constructed, sustained and reproduced in texts, which includes speech and written text and consequently discourse is seen as a site of power relations (Wooffitt 2005). In contrast, discursive psychology, another form of examining narrative, is concerned with a fine-grained analysis of the action orientation of language in constructing 'reality' (Potter 1996, 2003). Such constructions in discourse have consequences in that they legitimate public attitudes, perspectives and behaviors towards older people and can

\footnotetext{
A. Phelan $(\bowtie)$ e-mail: amanda.phelan@ucd.ie

L. Ayalon, C. Tesch-Römer (eds.), Contemporary Perspectives on Ageism, International Perspectives on Aging 19, https://doi.org/10.1007/978-3-319-73820-8_31
}

School of Nursing, Midwifery \& Health Systems, University College Dublin, Dublin, Ireland 
contribute to policy and legislation directions (Fealy and McNamara 2009). The combination of both approaches to examining discourse enables both a review of language as a general 'system of representation' (Hall 2001:72) as well as how language is used within social practices which create and stabilizes versions of reality (Potter 2003).

\subsection{Social Constructionism}

Social constructionism is a way of seeing the world. It emanates from the field of sociology. The way we see 'reality' is impacted by many factors. For example, we have many taken for granted 'truths', such as gender, the meaning of childhood or what constitutes an older person. These truths are not neutral in the world but evolve from meanings we subscribe to and also relate to how we position those meanings. For instance, in the case of gender, we could, instead, classify humans according to height, the colour of eyes or hair, however, an accepted, dominant classification of human beings is through anatomical characteristics. So as Searle (1997) suggests, objective facts, such as gender, are only objective through human agreement. However, such understandings and meanings are fluid in the sense that they can vary over time and within cultural assumptions.

Burr (1995) argues that social constructionism involves a number of assumptions. Firstly, there is a critical approach to how we perceive the world, which should make us question the basis of 'truth'. Secondly, understanding and knowledge are culturally and historically located. For instance, think of the idea of human rights. These are commonly accepted canons, yet historically and culturally, they vary in the context of equality of human beings. Yet, for some cultures, human rights can be socially constructed in alternative yet oppositional ways. For example, Ignatieff (2001: 102) notes that 'Since 1945, human rights language has become a source of power and authority. Inevidably, power invites challenge. Human rights doctrine is now so powerful, but also unthinkingly imperialist in its claim to universality, that it has exposed itself to serious intellectual attack'. Thus, Ignatieff (2001:102) continues to pose the question whether this constitutes an example of 'Western moral imperialism', which denies alternatives such as cultures where the rights of the collective can legitimately supersede the rights of the individual. Thirdly, Burr (1995) argues that knowledge is sustained by social processes. This is particularly important in discussing ageism and discourse, as discourse constructs shared understandings and promotes ways of thinking about the world. Age is a significant cultural aspect of society (Roscigno et al. 2007) which, as a chronological phenomena, can be taken as 'a fundamental and organising principle' (Spedale et al. 2014:1586) which shapes the very meaning of being old (Cruikshank 2013). Thus, the way we talk about older people and how we position them discursively has consequences not only in our perception of this population group, but also in their treatment within policy (Wilisńka and Cedersund 2010), legislation, health and social care practice and older people's subsequent experience of the world. 


\subsection{Ageism}

The 'discovery' of ageism is generally attributed to Robert Butler (1969) who identified how older people were constructed in stereotypical and discriminatory ways and this phenomena can be aligned to similar prejudicial perspectives such as racism and sexism. Hockey and James (2003) argue that discourses produce particular social identities for particular age groups. In terms of older adults, ageism can be either systematic or casual and can target either individuals or groups. Although Butler (1969) identified negative aspects of ageism, proponents such as Palmore (1999) argued that ageism also had positive aspects such as older people being more reliable workers or engaged in volunteerism. However, negative aspects of ageism are generally constituted by de-individualising and devaluing the older person through particular attitudes, practices and cultures. Ageism, within a negative lens, is considered enmeshed overtly and covertly in society and promotes a perspective of older people as holding homogeneous traits which are predominantly undesirable, such as having poor health, being unattractive, being senile, dependent, unemployable and inactive, asexual, and generally inflexible (Lyons 2009).

Bytheway (1995) argues that ageism, as an ideology, promotes particular views, usually from a dominant group, which justifies the way older people can be treated. Such perspectives are supported by Rowe and Kahn (1998:12) who argue that ageism is 'a negative view of a group divorced from reality'. The consequences of negative ageism are clear: inequality, inequity, a higher risk of maltreatment and disempowerment (Biggs et al. 1995; Minichiello et al. 2000; Phelan 2008; Malmedal et al. 2009). Indeed, Spedale et al. (2014) points to the cultural irony within the perspective that to successfully age is to appear 'ageless'. In contrast, youthfulness is highly prized which creates a 'culturally endemic paranoia' of ageing (Schwaiger 2006:14) demonstrating a mind (wanting to be youthful)-body (aging body) split (Biggs 1997). Even within the ageing process, the exclusion from particular roles can be seen as age increases. For example, older parenthood ( $>35$ years) can be considered a taboo and even harmful to a child (Wilisńka and Cedersund 2010).

Generally accepted societal norms can be identified as ageist. For instance, in employment, mandatory retirement has been argued as inherently ageist (Angus and Reeves 2006), as it implies those over a particular age are incapable of doing the job. Paradoxically, a lack of labour contribution has been seen as negative due to dependency related fiscal costs on nations (Wilisńka 2013). Moreover, ageism can be found within institutions such as health, social care, community participation and organisational practice (Spedale et al. 2014). In addition, stereotype embodiment theory suggests that older people themselves can internalise ageist assumptions and, within the context of self-fulfilling prophecies, position themselves accordingly (Minichiello et al. 2000; Calasanti 2015; Chrisler et al. 2016), through further reproducing and validating negative ageist traits. Such perspectives, also have consequences within health as older people may be excluded (or indeed self-exclude) from ameliorative treatments. However, there are some examples of older people separating themselves from the taken for granted concept of old age. In Wilisńka's 
(2013) consideration of members' experience of the University of Third Age, old age identities were rejected, yet, there was a separateness or otherness observed by the University of Third Age members (who were generally over retirement age or unemployed younger people) from older people outside this group.

Within media forms, discourse can perpetuate particular stereotypical identities for older people, for instance, within newspapers (Phelan 2009; Fealy and McNamara 2009; Wilisńka 2013; Weicht 2013; Chen 2015), television (Spedale et al. 2014; Chen 2016a, b), holiday brochures (Ylänne-McEwen 2000) and social media (Levy et al. 2014). Such public and authoritative forums are particularly influential in forming and perpetuating societal identities of older people by shaping public opinions through creating particular representations and relations (Harwood 2008, Wilisńka 2015).

\subsection{Discourse Analysis in Research Related to the Topic of Ageism}

Potter (2003:73) describes discourse analysis as a way of analysing how 'talk and text are used to preform actions' which enables making sense of social order (Howarth 2000) and creates identities and ideologies. In recent years, the use of discourse analysis has contributed to revealing how talk and texts construct older people in certain ways. In particular, examining discourses in old age is useful in determining how the ageing body becomes socially significant (Wilisńka 2013). In exploring 'silver market' holiday brochures using discourse analysis (YlänneMcEwen 2000), both positive and negative identities are presented. Activities which promote youthful pursuits and adventure are advertised, but the brochures also regress to a dependency discourse where the older holidaymaker has the security of home like destinations, afternoon teas and familiar comforts (Ylänne-McEwen 2000). Similarly, Coupland (2003) points to the portrayal of old age in anti-aging advertisements, which serve to fuel a fear of aging and that the aging skin is undesirable and in need of assistance as it is in decline and in need of repair.

In relation to policy formation, Weicht (2013) used discourse analysis to examine how older people, as subjects of policy, were constructed in Austrian newspapers and how particular interventions were legitimised based on such subject positions. Although findings demonstrated positive constructions of older people in terms of being active members of society, negative images dominated in the context of a lack of voice and agency of older people within reportage. Older people were deindividualised and assumed to be vulnerable and reliant on others (generally family) to determine their lives. Moreover, older person self-determination was diminished and while achievement was acknowledged, it was constructed as a past identity. In Weicht's study, chronological age was not an identifier, rather particular older 
groups with particular characteristics which were constructed as a 'demographic time-bomb' (Weicht 2013:190). Thus, policy was framed around dependency with care provided for older people at home with some state support. Equally, in the review of social policy documents from Poland and Sweden, Wilisńka (2013) revealed old age as being constructed as a problem of dependency related to both a lack of labor contribution (Poland) or poor health status (Sweden), both posing a financial burden on the states. Wilisńka (2013) argues that these perspectives are limiting and reductionalist.

Ageist constructions can also be located in media forms. For example, commenting on older people's construction within Irish newspapers, Fealy et al. (2012) point to the dominance of dependency subject positions where older people are constructed as others, separate from independent younger age groups and thus marginalized. Wilisńka (2013) used a multi-data discourse analysis approach to examine welfare cultures. Newspapers in Poland were used to analyse the welfare culture and three constructions of older people were identified in relation to family, market and society. Findings pointed to acceptable and unacceptable identity locations related to age, which could also be gender aligned. Chen (2015), using a discourse analysis approach, found that Taiwanese newspapers placed older people in a position of dependency. Similarly, in an analysis of television advertisements for life insurance products using discourse analysis, Chen $(2016 \mathrm{a}, \mathrm{b})$ also demonstrated how Taiwanese people over 50 years of age are positioned with findings pointing to patronizing communicative conventions which reinforced negative stereotyping and stigmatisation of old age. When Ylänne-McEwen (2000) examined how holidays were advertised with a target audience of older consumers, there was evidence of a juxtaposition of counter identities of aging. Positive accounts of 'golden agers' were the exception while the de-individualised older person as a receiver of resources was a more common identity (Ylänne-McEwen 2000).

\subsection{Discourse Analysis}

There are a number of philosophical and analytic approaches within discourse analysis. However, in this chapter, we will focus on two methods to examine discourse in research interviews: Foucauldian discourse analysis and discursive psychology. The chapter is specifically structured to demonstrate exemplars of various data types under the separate methodologies. Both methodological approaches complement each other and show how discourse works on both a macro level (Foucault) and a micro level (discursive psychology). Thus, the macro level enables a consideration of looking at how power relations in society work to construct and position older people through language and at the micro level how individuals actively construct subject positions in their interactive narratives. 


\subsection{Foucauldian Discourse Analysis}

Foucauldian discourse analysis is an approach within critical discourse analysis. In critical discourse analysis, language becomes much more than a system of representation. As Wodak and Meyer (2009: 2) state, 'CDA [Critical discourse analysis] is not interested in investigating a linguistic unit per se but in studying social phenomena which are necessarily complex...'. Thus, discourse has social implications and can produce, sustain and reproduce inequalities in power relations (Wodak and Fairclough 1997, Wooffitt 2005). Discourses are, therefore, a way of being in the world.

In the case of ageism, discourse has enabled the systematic stereotyping of older people and empowered perspectives which value youthfulness (Harbison 1999). Coupland and Coupland (1999) identify two ageist perspectives in relation to discourse. Firstly, ageist discourse describes the forms of talk and meaning to which an ageist perspective is applied at a local level, for example when talking, perceiving or constructing older people. Secondly, discourses of ageism refer to ageist practices related to particular consequences such as human rights breeches and the lack of opportunities afforded older people. Discourse can, therefore, produce inappropriate and derogatory ways of speaking of older people that can be discriminatory (Wilisńka 2015). As Gee (1990:143) argues:

A Discourse is a socially accepted association among ways of using language, of thinking, feeling, believing, valuing, and of acting that can be used to identify oneself as a member of a socially meaningful group or 'social network', or to signal (that one is playing) a socially meaningful 'role'.

Equally, discourse can serve to identify one as outside the socially meaningful group or deny the prospect of a socially meaningful role.

Michel Foucault developed particular understandings discourse and its operation in the legitimization of knowledge. In his numerous publications (Foucault 1975, 1989, 2002, 2003), discourse is constructed as a system of representation and knowledge. Thus, in using a Foucauldian approach as an analytic lens, ageist perspectives are seen to be produced through particular discourses related to the conditions of knowledge possibility within the context of what can be spoken of at a particular time. Accordingly, discourses produce subject positions of the older person. In this context, subject positioning means the location and identify afforded older people and as Davis and Harre (1990) note:

Once having taken up a particular position as one's own, a person inevitably sees the world from the vantage point of that position and in terms of the particular images, metaphors, storylines and concepts which are made relevant with the particular discursive practice in which they are positioned (Davis and Harre 1990:46)

Subject positions then create ideologies, which are simply commonly held beliefs of older people.

There are two main components in Foucauldian discourse analysis: archaeology and genealogy. Archeology traces a topic or idea related to how it appeared within 
the context of culture and history and discursive possibility at a given point of time. In the context of ageism, this means an understanding of how ageism emerged as a social product. In contrast, genealogy considers the propositions upon which the topics or ideas are founded or, in this context, how ageist stereotypes can regulate how older people are seen and treated. In this chapter, the review of narratives within the interview data from Phelan (2010) and Ayalon (2015) will predominantly draw on the latter perspective of genealogy. Genealogy enables an examination of the constitution of and relationship between discourse-knowledge-power interrelationships in the world. Thus, powerful discourses work within a complex network of relations which produce knowledge and sanction legitimate ways of positioning older adults and consequently speaking of, seeing and treating older adults. This power relationship, which Foucault terms bio-power, permeates all aspects of life and essentially underpins the visibility of ageism in discourse and practice and the subsequent legitimisation of 'truth' about older adults. Such 'truths' are not only constructed in discourses but can be internalised by older people, who may assume the prevailing subject positions, such as being frail, dependent, asexual or less valuable to society.

Foucauldian discourse analysis, allows a focus on discourse as constituting reality (Hepburn 2003, Phelan 2010) and discourse is seen as constructing legitimate knowledge in the social world, which influences behaviours, practices and identity (Jäger 2001). Thus, the point is that discourse is not neutral; it follows particular conventions and functions to serve a purpose such as constructing our ideas. Discourse can establish dichotomies such as positive and negative, 'them' and 'us' or whose voice is privileged and whose voice is silenced. Importantly, discourses become agents of power, constructing 'valid' knowledge and discourse can be considered as constituting ways of social influence (Coupland and Coupland 1999). Discourse, therefore, allows us to know about the world in 'context specific frameworks for making sense of things' (Van Leeuwen 2009:144). Thus, it is of little surprise that 'truths' are established through discourse as once we speak of a topic, it becomes known and familiar and may assume a taken for granted, unchallenged stance. Consequently, age categories promote particular identities and establish power relationships between each other (Calasanti 2015).

\subsection{Discursive Psychology}

Although the Foucauldian perspective critically examines issues related to discourseknowledge-power relationships, it neglects the individual active and subjective construction of narratives by people. Discursive psychology (Potter and Wetherell 1987, Edwards and Potter 1992, Wetherell 2001, Potter 2003) addresses this. Emerging from the fields of ethnomethodology and conversation analysis, discursive psychology centres on three main principles. Firstly, discourse is action orientated; it functions to some end, such as answering a question or describing an experience. Secondly, discourse is sequentially organised, for example, asking a question 
generally elicits an expected response. Thus, there are mutually understood conventions in discourse. Within this context, Edwards and Potter (1992) describe discourse being situated rhetorically, meaning that discourse is constructed to present particular valid arguments and to counteract alternative viewpoints.

Within the topic of ageist narratives, discursive psychology illuminates how apparently incoherent statements are contextually related and function in a particular way. Thus, the speaker's accountability is established through the justification, sense making and rational of the narrative, particularly related to how the speaker positions themselves or others they are referring to. Finally, in discursive psychology, discourse is both constructed and constructive. It is constructed by using tools such as words, ideas, beliefs and referential terms which build up the validity of what is being said (Wetherell 2001). Discourse is constructive in that the information given is interpreted and represents the individual in a particular way such as being neutral in the issue being discussed or demonstrating their stake and interest regarding the subject of conversation.

\subsection{Using Both Methods of Discourse Analysis as Lenses into Ageist Discourse}

While Foucauldian approaches allow the examination of the macro structure of discourses at a particular time and also interrogates the knowledge-power-discourse relationships, discursive psychology allows an examination of the micro processes of how an individual uses language as a social performance. In other words, while Foucault can offer a way to look at available knowledge at a particular time, discursive psychology enables a review of how individuals actively orientate discourse focusing on the individual's cognitive processes and the role of accountability and stake in speech acts (Potter 2003, Willig 2003).

This chapter section draws on published data from two studies to examine how ageism is constructed and reproduced in discourses within transcripts from semistructured interviews (Phelan 2010, Ayalon 2015). The participants are Irish community nurses (Phelan 2010) (interviewed in 2007-2008) and Israeli older adults and their children (Ayalon 2015) (interviewed 2010-2014).

\subsection{Using Foucault to Examine Discourses of Ageism}

Within the context of the interviews, there is what Foucault would consider the knowing self (Besley 2005). Applying a Foucauldian lens allows us to see how the individual speaker draws on both implicit and explicit common discourses of ageism in society, while discursive psychology enables a deconstruction of how such narratives are orientated to promote the speaker's individual stake and accountability. 
Foucault argues that what we speak of deductively draws on common and available and accepted macro discourses in circulation at a particular time. In a study using semi-structured interviews (Phelan 2010) with community nurses in the North East and East region of Ireland, participants constructed what their view was on older adults in Irish society, what constituted elder abuse and how they managed such cases. All community nurses constructed the older adults in society and those they cared from within negative ageist frameworks. When asked specifically about older adults in Irish society (i.e., not only those the nurses delivered care to), two participants initially commenced their narratives by stating the value of older people, however this was transient and all 18 participants drew on ageist discourses of dependency. This compares to findings in other studies where the value of older adults was attributed to past contributions (Weicht 2013). In the excerpt below, it is clear that older adults, as a population group, are constructed in a way that promotes a biomedical discourse of physical dependency and homogeneous characteristics. In addition, there is a discrete categorisation of older adults as different:

Alice:...but from 70 [years] onwards, I think hmm...they [older adults] deteriorate in health and in the general elderly population and vulnerability...

Dependency is unilaterally related to functional decline, as older people require external assistance to help them in daily life:

Ann: And then I suppose you know...inability to do things as well from themselves... what is the word I am looking for? God what's the word I'm looking for... activities of daily living... you know they [older adults] they need assistance with things in daily living.

In particular, medical dependency was related to both physical and cognitive decline and was spoken of by all participants who constructed older adults in general Irish society as being 'in need'. Drawing on the macro-discourse of ageism, risk and biomedicine, the participants all presented their narratives as undisputed truths.

Similarly in a study of continuing care retirement communities (CCRC) in Israel, Ayalon (2015) interviewed 34 dyads of older adults who had recently entered CCRC and their adult children to explore perceptions of old age and ageing. One of the prominent findings in this study was the dominance of negative views of ageing which were related to loss of function. For example, in the excerpt below, the biomedical view of decline is also apparent as the older adult's son used chronology as a basis for discontinuing driving:

Son: 'Up until now she was still driving, recently I stopped her, because her age is a little problematic'

Thus, like mandatory retirement ages, age not ability, is the standard for participation in activities.

Again, the decline of the body is continued in the nurses' discourses of older adults within their care (Phelan 2010) as the participant asserts her informed (and disciplinary powerful) opinion which promoted paternalism and denied the older person privacy and self-determination. Consequently, the subject position and identity of the older person is framed as helpless, dependent and vulnerable, again promoting a discourse of ageism: 
Deirdre: I suppose in my...just cross covering in my colleagues area just last weekend, there was a lady with Alzheimer's [disease]...total nursing care who had home help and who really needed 24 hour care but the family would have left in the afternoon from 2.00 4.00 or $2.00-5.00$ and left her unattended. Now she was immobile and... and that but it was the vulnerability of somebody who really required 24 hour care and the family not having the insight that really somebody should be there...

Examining the power-knowledge-discourse relationships in the excerpts demonstrates that these nurses heavily and unproblematically drew on ageist and stereotypical views of older adults. In particular, both functional and cognitive deterioration was a prominent feature of their narratives which emanated from powerful discourses of medical reductionalism related to biological decline. In essence, positive and diverse constructions of older adults in society and those who care was delivered to were predominantly absent.

Ageism was also constructed within an economic reliance of older adults who depended on old age pensions and other benefits, denying the ability to be economically productive. Thus, fiscal dependency is equated to chronological age rather than ability, denoting ageist perceptions:

Karen:...they [older people] don't have a lot of money...that their pension mightn't cover what their needs are...

Economic dependency further reinforces the older person's sense of vulnerability and denies alternative constructions of older people having sufficient funds. This can be related to the macro discourse of older adults related to pension 'burdens' within political statements as opposed to having independent means and financial stability.

Thus, age becomes a powerful justification for the limitation of an activity and is tacitly accepted through a self-internalisation of such reasoning as detailed in the older person's consideration of this. In the excerpt below, we can also see how society's social practices on driving influenced the older person. By not renewing the license, driving is prohibited as this is regulated through discourses on legislation. Furthermore, the association of age as a 'burden', is common in ageist discourses, and is also sustained by the older person. In the excerpt below, the inevitability of physical decline is not challenged by the older person, who did not pursue the possibility of amelioration of her visual deficits, and was influenced by her children's perspectives on her continued driving potential.

Older Person: 'Simply I did not renew the license. And the kids influenced me.... "If I need them," I told them, "I will be a burden on you. You will have to drive me. To take me to places"...

I also needed to go to an eye exam (to renew the driving license). I was afraid that they would tell me that I needed to do a cataract operation. I just decided to take this off my shoulders'

In addition, as detailed in the excerpt, the older person was fearful of being medically forced to withdraw from driving due to sight problems, thus, giving dominance to the medicalised view that her possible condition of cataracts which would preclude driving. Yet, the position of recovery from the treatment of cataracts was not 
presented, indicating ageist self-determination; that treatment is considered not to be an option due to age or that the cataract might be a catalyst to a medicalised argument to discontinue driving based on sight and the possible identification of other health decline. Accordingly, the older person's construction of the power of medical knowledge has a direct impact on her decision to discontinue driving, which is justified by not having legal permission to do so. Consequently, such perspectives demonstrate how prevailing discourses open up or deny subject positions and identities older people can assume. As one ages, dependency on others increases as a social reliance is created in the context of transport dependency.

\subsection{Using Discursive Psychology to Examine Discourses of Ageism}

As discussed previously, discursive psychology is concerned with the person's indicative construction of the narrative and, in particular, how that narrative is actively and individually orientated to produce a particular 'version' of reality which accounts for self and others in terms of stake and accountability. The context of ageism can be downplayed in narratives, yet, a careful review of the text can reveal the action orientation of neutralizing contentious issues to mitigate the speaker's stake and accountability.

In Ayalon's (2015) study, when asked about the move to CCRC from home, an older resident comments on how older people are preyed upon and are positioned as vulnerable.

Older person: I think that sense of security is unstable. As you hear, they attack an elderly here and rob an elderly there. Knocked on the door, presented themselves as... I don't know who and then attacked people, I think that here (CCRC) I am protected...

A careful examination of the text reveals a more complex repertoire. The older person positions herself and 'elderly' as a vulnerable population by stating 'I think that here (CCRC) I am protected'. The attribution of 'I think' (i.e., the conditional tense) functions in a way to counteract any future unsafe experiences (i.e., in the event she was wrong in asserting being safe in the CCRC) and concedes to the possible limitation of her knowledge of being secure. For example, others might think differently of living in CCRC, so the use of the conditional tense addresses accountability in the narrative. The veracity of the narrative of vulnerability is supported through a careful description (attack and rob) which characterises such attacks as normalised. The script is also constructed to logically justify the need for protection of and safety for older adults. In the script formulation, there is also a careful juxtaposition of telling a story where the facts are not clear (As you hear...they...I don't know who), yet this is contrasted and counter positioned with a more authoritative, credible and subjective evaluation of the personal experience of safety. The way the narrative is presented also puts the older person in a positive subject position as her own accountability is seen as a responsible person who took appropriate measures 
to protect herself by entering the CCRC as opposed to other older adults who choose to remain vulnerable in other settings. However, even within the narrative, it is evident that the need for protection of older adults is necessary due to vulnerability ascribed to older adults.

Equally, it can be seen that the community nurse in Phelan's (2010) study constructed abuse of older people in a particular way. When asked about why abuse might happen, the excerpt below shows an ageist framing of older adults:

Interviewer: Can you tell me what your perspective is on older people in Irish society...just in general?

Joan: Well, they are vulnerable aren't they? That's a big issue hmm...some people do it... if they are vulnerable they [perpetrators of abuse] do it because they can do it...I don't really know you see...

Yet the use of the 'aren't they?' question functions in a way to engender agreement from the listener and to counteract any impression that Joan could be wrong. There is a clear dichotomy established between vulnerable older people and powerful perpetrators ('... because they can do it'). The participant positioned the statement 'I don't' really know you see...' to attend to her own character and counter any negative impression of her perspective. This is achieved by playing down the motivation of her narrative in the context of overtly blaming the older person for being vulnerable. Thus, the implicit thrust of the text is ageist, yet, efforts are made to mask this through the use of the evaluative expression 'really', which portrayed her own character in a positive way.

Thus, even within the fine grained analysis of how people structure their version of reality, it can be seen that, although there are tacit linguistic strategies to neutralise the impact of ageist text, a critical examination of an individual's construction of their narrative reveals what the speaker is doing in the text and precisely how ageism is tacitly imparted through discourse.

\subsection{Discussion and Conclusion}

Lynam (2007:540) asks 'does discourse matter?' The answer is yes. Discourse itself constructs reality, producing 'valid' and legitimate knowledge and influencing behaviour (Jäger 2001). Thus, an examination of discourse is a particularly important component in understanding the complexity of ageism as a system of representation of older adults (Hall 2001) which denotes 'otherness'. This is apparent in the terms and nouns used, the imagery drawn up and defining older adults as both a separate group and as different from other groups (Fealy and McNamara 2009). Within this chapter, particular methods of critical discourse analysis have illuminated ways of deconstructing texts using multiple methodological approaches. The various text and sub-textual sources presented primarily reveal older adults as dependent, vulnerable, helpless and frail and although it is noted in each of the studies that there are counter positive ageing subject positions presented, the dominant 
discourse is aligned with the stereotypical negative constructions of ageism. The objective of such deconstruction of texts is to see language as a social practice and a social performance (Fairclough and Wodak 1997, Willig 2003). Language is a powerful vehicle of constructing reality and can both implicitly and explicitly establish, perpetuate and reproduce values, stereotypes and ways of seeing the world. Thus, as Fairclough and Wodak (1997) observe, there are ideological consequences which produce and reproduce inequalities, such as ageism. Such discourses can deny the construction of age as related to individual personhood and heterogeneity (Fealy and McNamara 2009). However, ideology is not the prime focus for critical discourse analysis, but rather it is the concealed and taken for granted views within discourse that are challenged (Wodak and Meyer 2009). Thus, in everyday discourse, there are power relations that exist and which appear neutral, tacit and unproblematic but promote inequalities.

Critical discourse analysis reveals particular subject positioning and identities afforded older adults and how particular discourses legitimate the dominance of populist views and ways of seeing the world. Ageism is generally concerned with power relations between societal groups and critical discourse analysis allows an interrogation of such power relations in society (Fairclough 1989). In navigating different approaches and different text representations, this chapter has provided an insight into how ageism is constructed and legitimised in relation to its condition of possibility in discourse; how an individual produces versions of reality and how newspapers mediate the social production of valid knowledge. Furthermore, discourse has consequences; it does not occur in an ideological vacuum but permeates societal attitudes, professional practice, policy and legislation and thus, is fundamental to the perpetuation of hegemonic interests.

Critical discourse analysis enables such ageist perspectives to be laid bare, which can be a self-fulfilling prophesy in older person's self-identity and in its consequential experiences for older adults in everyday life. A final question remains- Is it possible to have non-ageist discourse? Is it possible to remove age as a factor and only speak of people as individual heterogeneous human beings with an individualized personhood? The answer is yes. We see it in, for example, legislation as a criminal act. This is because a criminal act is defined as such regardless of age, in the Human Rights Declaration (UN 1948) and conversations of citizenship (Marshall 1949). Thus, the assumption of attributes of an aged population diminishes and instead discourse focuses on the individual regardless of chronology and articulates diversity rather than homogeneity. However, for this to become a reality poses a significant challenge. As Coupland (253) notes 'Ageist discourse is prevalent but discourses of ageism (and anti-ageism) are not'. Therefore, society needs to address the way discourse can often be constructed to represent older adults as stereotypical 'others', who are often associated with a homogenous biological decline. Only in recognizing this, can we be liberated from an ageist frame of reference when speaking of older adults. 


\section{References}

Angus, J., \& Reeve, P. (2006). Ageism: A threat to 'aging well' in the 21st century. Journal of Applied Gerontology, 25, 137-152. https://doi.org/10.1177/0733464805285745

Ayalon, L. (2015). Perceptions of old age and ageing in the continuing care retirement community. International Psychogeriatrics, 27(4), 611-620. https://doi.org/10.1017/S1041610214002415

Besley, T. (2005). Foucault, truth telling and technologies of the self in schools. Journal of Educational Enquiry, 6(1), 76-89.

Biggs, S. (1997). Choosing not to be old? Masks, bodies and identity management in later life. Ageing and Society, 17, 553-570.

Biggs, S., Phillipson, C., \& Kingston, P. (1995). Elder abuse in perspective. Buckingham: Open University Press.

Burr, V. (1995). An introduction to social constructionism. London: Routledge.

Butler, R. (1969). Ageism: Another form of bigotry. The Gerontologist, 9, 243-246. https://doi. org/10.1093/geront/9.4_Part_1.243

Bytheway, B. (1995). Ageism. Milton Keynes: Open University Press.

Calasanti, T. (2015). Combating ageism: How successful is successful aging? Gerontologist, 56, 1093-1101. https://doi.org/10.1093/geront/gnv076

Chen, C.-H. (2015). Advertising representations of older people in the United Kingdom and Taiwan. The International Journal of Aging and Human Development, 80(2), 140-183

Chen, C. H. (2016a). Older adults as discursively constructed in Taiwanese newspapers: A critical discourse analysis. International Journal of Society, Culture \& Language, 3(2), 72-84.

Chen C. H. (2016b). Marketing discourses of aging: Critical discourse analysis of TV advertising for over- 50s life insurance in Taiwan. Language Discourse and Society, 4,1(7), 7-30.

Chrisler, J. C., Barney, A., \& Palatino, B. (2016). Ageism can be hazardous to women's health: Ageism, sexism, and stereotypes of older women in the healthcare system. Journal of Social Issues, 72(1), 86-104. https://doi.org/10.1111/josi.12157

Coupland, J. (2003). Ageist ideology and discourse of control in skin care product marketing. In J. Coupland \& R. Gwyn (Eds.), Discourse, the body and identity (pp. 127-150). London: Macmillian Palgrave.

Coupland, N., \& Coupland, J. (1999). Ageing, ageism and antiageism: Moral stance in geriatric medical discourse. In H. E. Hamilton (Ed.), Language and communication in old age: Multidisciplinary perspectives (pp. 177-208). Routledge: London.

Cruikshank, M. (2013). Learning to be old: Gender, culture and aging (3rd ed.). Maryland: Rowman \& Littlefield Publishers.

Davis, B., \& Harre, R. (1990). Positioning: The discursive production of selves. Journal for the Theory of Social Behaviour, 20(1), 43-63. https://doi.org/10.1111/j.1468-5914.1990.tb00174.x

Edwards, D., \& Potter, M. (1992). Discursive psychology. London: Sage.

Fairclough, N. (1989). Language \& power. London: Longman.

Fairclough, N., \& Wodak, R. (1997). Critical discourse analysis. In T. Van Dijk (Ed.), Discourse as social interaction: Discourse studies-a multidisciplinary introduction (pp. 258-284). London: Sage.

Fealy, G., \& McNamara, M. (2009). Constructing ageing and age identity: A case study of newspaper discourses. Dublin: NCPOP.

Fealy, G., McNamara, M., Treacy, M. P., \& Lyons, I. (2012). Constructing ageing and age identities: A case study of newspaper discourses. Ageing \& Society, 32(1), 85-102. https://doi. org/10.1017/S0144686X11000092

Foucault, M. (1975). Discipline and punish. London: Allen Lane.

Foucault, M. (1989). The order of things. London: Routledge.

Foucault, M. (2002). The archeology of knowledge. London: Routledge.

Foucault, M. (2003). The birth of the clinic. London: Routledge Classics.

Gee, J. P. (1990). Social linguistics and literacies: Ideology in discourses, critical perspectives on literacy and education. London: Routledge. 
Hall, S. (2001). Foucault and discourse. In C. Seale (Ed.), Social research methods (pp. 345-349). London: Routledge.

Harbison, J. (1999). Models for intervention for 'elder abuse and neglect': A Canadian perspective on ageism, participation and empowerment. Journal of Elder Abuse and Neglect, 10(3/4), 1-17. https://doi.org/10.1300/J084v10n03_01

Harwood, J. (2008). Age identity and communication. In W. Donsbach (Ed.), The international encyclopedia of communication (Vol. 1). Massachusetts: Wiley Blackwell. https://doi. org/10.1111/b.9781118789308.2015.x

Hepburn, A. (2003). An introduction to critical social psychology. Los Angeles: Sage.

Hockey, J., \& James, A. (2003). Social identities across the lifecourse. Basingstoke: Palgrave.

Howarth, D. (2000). Discourse. Buckingham: Open University Press.

Ignatieff, M. (2001). The attack on human rights. Foreign Affairs, 80(6), 102-116.

Jäger, S. (2001). Discourse and knowledge: Theoretical and methodological aspects of a critical discourse and dispositive analysis. In R. Wodak \& M. Meyer (Eds.), Methods of critical discourse analsysis (pp. 32-62). London: Sage.

Levy, B. R., Chung, P. H., Bedford, T., \& Navrazhina, K. (2014). Facebook as a site for negative age stereotypes. Gerontologist, 54(2), 172-176. https://doi.org/10.1093/geront/gns194

Lynam, M. J. (2007). Does discourse matter? Using critical inquiry to engage knowledge development for practice. Primary Healthcare Research and Development, 8, 54-67. https://doi. org/10.1017/S1463423607000072

Lyons, I. (2009). Public perceptions of older people and ageing. Dublin: NCPOP.

Macionis, J. J., \& Gerber, L. M. (2013). Sociology. Toronto: Pearson.

Malmedal, W., Ingebrigsten, O., \& Saveman, B. (2009). Inadequate care in Norwegian nursing homes-as reported by nursing staff. Scandinavian Journal of Caring Sciences, 23(2), 231-242. https://doi.org/10.1111/j.1471-6712.2008.00611.x

Marshall, T. H. (1949). Citizenship and social class. Cambridge: Cambridge University Press.

Minichiello, V., Browne, J., \& Kendig, H. (2000). Perceptions and consequences of ageism: Views of older people. Ageing and Society, 20, 253-278.

Palmore, E. (1999). Ageism: Negative and positive (2nd ed.). New York: Springer.

Phelan, A. (2008). Elder abuse, ageism, human rights and citizenship: Implications for nursing discourse. Nursing Inquiry, 15(4), 320-329. https://doi.org/10.1111/j.1440-1800.2008.00423.x

Phelan, A. (2009). Examining newspaper reports of care in an Irish nursing home: A discursive analysis. Dublin: NCPOP.

Phelan, A. (2010). Discursive constructions of elder abuse: Community nurses accounts. Unpublished PhD. Dublin: UCD.

Potter, J. (1996). Representing reality: Discourse, rhetoric and social construction. London: Sage.

Potter, J. (2003). Discursive psychology: Between mind and paradigm. Discourse and Society, 14(6), 783-794.

Potter, J., \& Wetherell, M. (1987). Discourse \& social psychology: Beyond attitudes and behavior. London: Sage.

Roscigno, V. J., Mong, S., Byron, R., \& Tester, G. (2007). Age discrimination, social closure and employment. Social Forces, 86(1), 313-334.

Rowe, J. W., \& Kahn, R. L. (1998). Successful aging. New York: Random House.

Schwaiger, L. (2006). To be forever young? Towards reframing corporeal subjectivity in maturity. International Journal of Ageing and Later Life, 1(1), 11-41. https://doi.org/10.3384/ ijal.1652-8670.061111

Searle, J. R. (1997). The construction of social reality. New York: The Free Press.

Spedale, S., Coupland, C., \& Tempest, S. (2014). Gendered ageism and organizational routines at work: The case of day-parting in television broadcasting. Organisational Studies, 35(11), 1585-1604. https://doi.org/10.1177/0170840614550733

United Nations. (1948). Universal declaration of human rights. Paris: UN. 
Van Leeuwen, T. (2009). Discourse as the recontextualisation of social practice: A guide. In R. Wodak \& M. Meyer (Eds.), Methods of critical discourse analysis (2nd ed., pp. 144-161). London: Sage.

Weicht, B. (2013). The making of 'the elderly': Constructing the subject of care. Journal of Aging Studies, 27, 188-197. https://doi.org/10.1016/j.jaging.2013.03.001

Wetherell, M. (2001). Introduction. In M. Wetherell, S. Taylor, \& S. J. Yates (Eds.), Discourse theory and practice: A reader (pp. 1-8). London: Sage.

Wilisńka, M. (2013). Welfare spaces of (non)ageing-A discourse perspective. Contributions to Humanities, 12(1), 25-39.

Wilisńka, M. (2015). An older person and new media in public discourses: Impossible encounters? In J. Zhou \& G. Salvendy (Eds.), Human aspects of IT for the aged population: Design for aging (pp. 405-414). New York: Springer.

Wilisńka, M., \& Cedersund, E. (2010). "Classic ageism" or "brutal economy"? Old age and older people in the Polish media. Journal of Aging Studies, 24, 335-343.

Willig, C. (2003). Discourse analysis. In J. A. Smith (Ed.), Qualitative psychology-a practical guide to research methods (pp. 159-183). London: Sage.

Wodak, R., \& Fairclough, N. (1997). Critical discourse analysis. In T. A. van Dijk (Ed.), Discourse as social interaction (pp. 258-284). London: Sage.

Wodak, R., \& Meyer, M. (2009). Critical discourse analysis: History agenda and theory. In R. Wodak \& M. Meyer (Eds.), Methods of critical discourse analysis (2nd ed., pp. 1-33). London: Sage.

Wooffitt, R. (2005). Conversation analysis and discourse analysis: A critical and comparative introduction. London: Sage.

Ylänne-McEwen, V. (2000). Golden times for golden agers, selling holidays as lifestyle for the over 50s. Journal of Communication, 50(3), 83-99. https://doi.org/10.1111/j.1460-2466.2000. tb02854.x

Open Access This chapter is licensed under the terms of the Creative Commons Attribution 4.0 International License (http://creativecommons.org/licenses/by/4.0/), which permits use, sharing, adaptation, distribution and reproduction in any medium or format, as long as you give appropriate credit to the original author(s) and the source, provide a link to the Creative Commons license and indicate if changes were made.

The images or other third party material in this chapter are included in the chapter's Creative Commons license, unless indicated otherwise in a credit line to the material. If material is not included in the chapter's Creative Commons license and your intended use is not permitted by statutory regulation or exceeds the permitted use, you will need to obtain permission directly from the copyright holder.

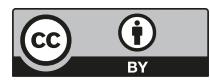




\title{
Erratum to: Contemporary Perspectives on Ageism
}

\author{
Liat Ayalon and Clemens Tesch-Römer
}

\section{Erratum to:}

\section{Ayalon, C. Tesch-Römer (eds.), Contemporary Perspectives on Ageism, International Perspectives on Aging 19, https://doi.org/10.1007/978-3-319-73820-8}

The original version of the book front matter was revised. The following acknowledgement has been added to the copyright page of this book.
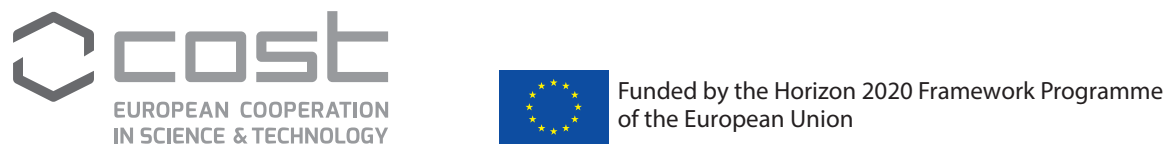

This publication is based upon work from COST Action IS1402, supported by COST (European Cooperation in Science and Technology).

COST is a funding agency for research and innovation networks. Our Actions help connect research initiatives across Europe and enable scientists to grow their ideas by sharing them with their peers. This boosts their research, career and innovation. www.cost.eu

The updated online version of the book can be found at https://doi.org/10.1007/978-3-319-73820-8 